\title{
BACTERIAL COMMUNITY STRUCTURE, FUnCTION AND DIVERSITY IN Antarctic Sea ICE
}

Rebecca Olivia MacLennan Cowie

\section{A thesis}

submitted to Victoria University of Wellington in fulfillment of the requirement for the degree of Doctor of Philosophy in Ecology \& Biodiversity

Victoria University of Wellington

Te Whare Wananga o te Upoko o te Ika a Maui 2011 
"I make no apologies for putting microorganisms on a pedestal above all other living things. For if the last blue whale choked to death on the last panda, it would be disastrous but not the end of the world. But if we accidentally poisoned the last two species of ammonia-oxidisers, that would be another matter. It could be happening now and we wouldn't even know..."

Tom Curtis (July 2006) 


\section{ACKNOWLEDGEMENTS}

I would first like to thank my supervisors, Ken Ryan and Els Maas, for without them this thesis would not have been possible. Ken, thank you for everything! Thanks for giving me the opportunity to carry out research as part of the K043 team in Antarctica. I am grateful for the wealth of time you had for me whenever I came knocking on your door. I appreciate for your support, time and effort throughout the last three years and especially during the write-up. Els, thank you for giving so much of your time and energy towards my research. Your knowledge and advice has been invaluable.

To my friends, fellow students and office mates who helped me along the way both scientifically and recreationally I thank Bionda Morelissen, Alejandra Perea Blazquez, Charles Lee, David Weller, Abi Powell, Mareike Sudek, Ingrid Knapp and Jade Berman.

For those who contributed in my research, I would like to thank the biotech group at NIWA for their guidance and interest in my research and to help pass the time in the laboratory. I would especially like to thank Matt Voyles for his time and patience. Thank you also to Kylie Price, Sarah Bury and Caoimhghin Ó Maolagáin.

For the amazing Antarctica adventure, a once-in-a-lifetime experience I managed to do twice I thank Eileen Koh, Andrew Martin, Stuart Donachie, Mike Hudson, Schannel van Dijken, Marti Anderson, Russell Babcock, Mark Heath, Lisa Bryant, Ana Aguilar-Islas, Simon Davy and Chris Thorn.

For funding, I thank the Foundation of Research Science and Technology, the Antarctic Research Center (VUW) Endowed Development Fund, the Faculty of Science Research Committee, the Royal Society of New Zealand and the Charles Flemming Fund. For logistical support I acknowledge Antarctica New Zealand, in particular Shulamit Gordon (LGP manager) and Brian Staite (LGP camp manager).

Lastly, I would like to thank my family for their support. Thanks especially to my dad who sparked my interest in biology from a young age by spending hours with me at the beach looking in rock pools. Finally, to Gareth. I thank you for your unconditional love and support and your belief in me. Without you this $\mathrm{PhD}$ from start through to finish would not have been possible.

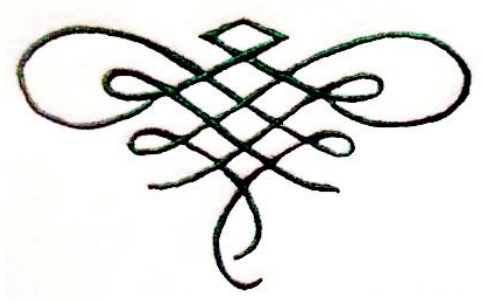




\begin{abstract}
Antarctic sea ice is an important feature of the southern ocean where at its maximum it can cover $8 \%$ of the Southern Hemisphere. It provides a stable environment for the colonisation of diverse and highly specialised microbes which play a central role in the assimilation and regulation of energy through the Antarctic food web. Polar environments are sensitive to changes in the environment. Small changes in temperature can have large effects on sea ice thickness and extent and Antarctic sea ice cover is expected to shrink by $25 \%$ over the next century. It is unknown how the sea ice microbiota will respond.
\end{abstract}

In order to understand the effects of climate change on the sea ice ecosystem it is necessary to obtain information about the community structure, function and diversity and their reactions with the environment. Studies have focused on algal diversity and physiology in Antarctic sea ice and in comparison studies on the prokaryotic community are few. Although prokaryotic diversity has been investigated using clone libraries and culture based methods, it is likely that certain species have still not been described. Almost nothing is known about the Antarctic sea ice bacterial community spatial and temporal dynamics under changing abiotic and biotic conditions or their role in biogeochemical cycles.

This is the first study linking Antarctic bacterial communities to function by using statistics to investigate the relationships between environmental variables and community structure. Bacterial community structure was investigated by extracting both the DNA and RNA from the environment to understand both the metabolically active (RNA) and total (DNA) bacterial community. The thickness of the sea ice and nutrient concentrations were key factors regulating bacterial community composition in Antarctic sea ice. Sea ice thickness is likely to have an effect on the physiological responses of algae leading to changes in photosynthate concentrations and composition of dissolved organic matter (DOM). Further investigations into the relationships between enzymatic activity and community structure revealed that the composition of the DOM drove variation between bacterial communities. 
There was no relationship between bacterial abundance and chlorophyll- $a$ (as a measure of algal biomass), suggesting a un-coupling of the microbial loop. However bacteria were actively involved in the hydrolysis of polymers throughout the sea ice core. Investigations using quantitative PCR (qPCR) found that the functional genes involved in denitrification and light energy utilisation were in low abundance therefore these processes are minor in Antarctic sea ice. These results confirm that sea ice bacteria are predominantly heterotrophs and have a major role in the cycling of carbon and nitrogen through the microbial loop.

This is the first study to document archaea, one of the three domains of life, in Antarctic sea ice. Their diversity was investigated using clone library methods and the majority grouped with the recently described phylum Thaumarchaeota and the rest with the Euryarchaeota. One group closely clustered with the ammonia-oxidising "Candidatus Nitrosopumilus maritimus". The abundance of archaea was investigated using $\mathrm{qPCR}$ and at most sites they comprised $<7 \%$ of the total prokaryotic community. However, they were occasionally in high abundance which suggests that they may be able to utilise available ammonia via nitrification.

The prokaryotic diversity was further investigated using culture-based methods and 454 sequencing. Bacterial OTUs were defined at $97 \%$ sequence identity and some were identified using both methods. However, many OTUs were identified using one or the other method suggesting that a greater amount of diversity could be gathered using both methods. This trend was also seen when comparing the 454 sequences from the DNA and RNA - based communities; therefore both the DNA and RNA should be extracted from the environment to investigate bacterial diversity.

The rarefaction curves suggested that the community diversity had been fully sampled. However, the presence of some species in the culture-based database and not in the 454 sequences showed that some bacterial groups were not extracted from samples. These groups included Gram positive bacteria which have a thicker cell wall that is more difficult to rupture during extraction from the environment. The number of bacterial OTUs in Antarctic sea ice appears to be $\sim 3 \times 10^{3}$, which is towards the lower end of species diversity estimates. Many of the abundant OTUs were cosmopolitan at all sites but in contrast, the rarer OTUs were endemic. Bacterial 
communities also showed a taxa-area relationship where communities that were collected closer together were more similar than those collected further apart. However, the environment rather than biogeography appeared to be controlling community change. These results suggest that the more abundant taxa may indeed be everywhere. These groups are likely to be more generalist species and able to survive dispersal. Rare taxa may be specialist species that become more abundant when the environment turns favourable. Bacterial groups belonging to the class Mollicutes and the phylum Planctomycetes were rare at the bottom of the sea ice core but became more dominant at the top of the ice core where DOM and nutrient concentrations are lower and irradiance is higher. These groups may be better adapted to a nutrient poor environment. My results show that although 'everything is NOT everywhere' however, 'the environment selects'. Climate change leading to decreased ice thickness and extent will influence microbial community structure and function which will have an impact on the Antarctic sea ice ecosystem. This thesis provides baseline information that will be useful for further long term monitoring of these communities. 


\section{TABLE OF CONTENTS}

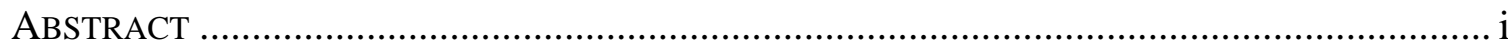

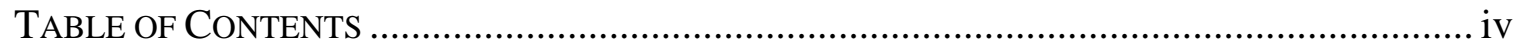

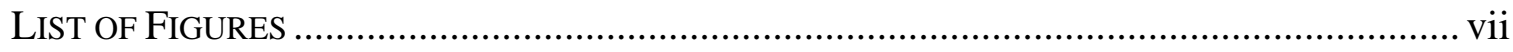

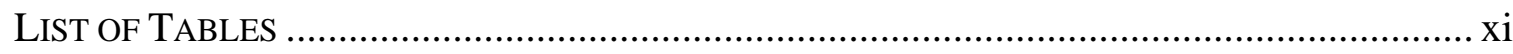

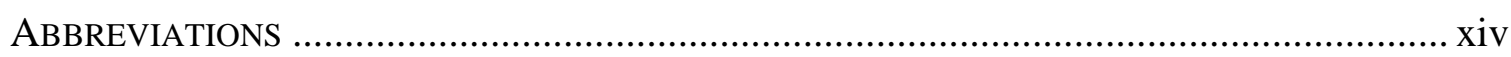

CHAPTER 1: General Introduction .................................................................. 1

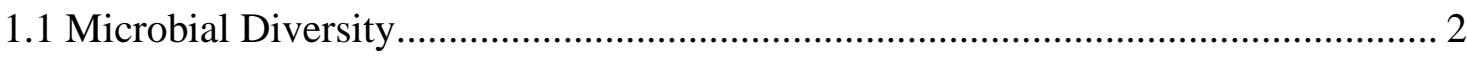

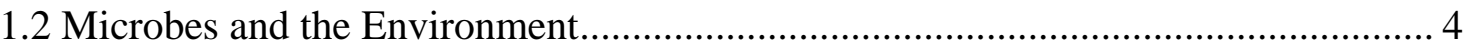

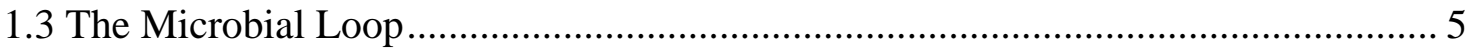

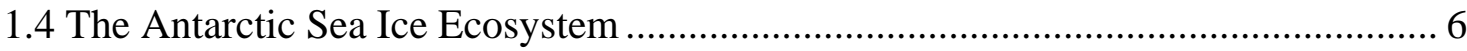

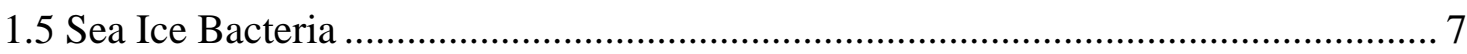

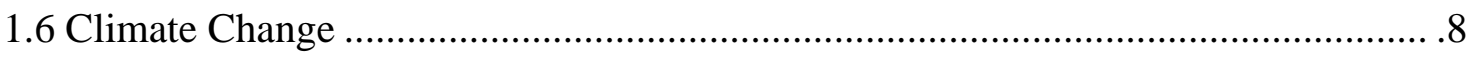

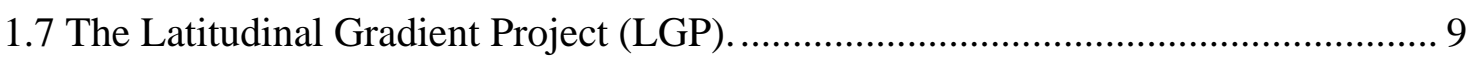

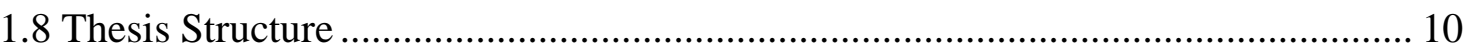

CHAPTER 2: Method Development ...................................................................... 13

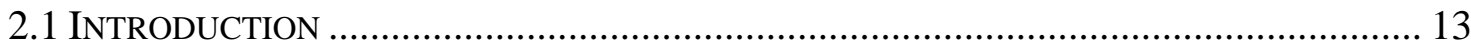

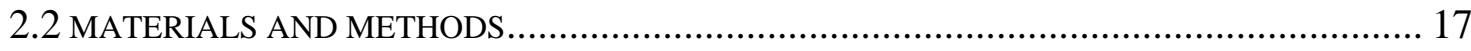

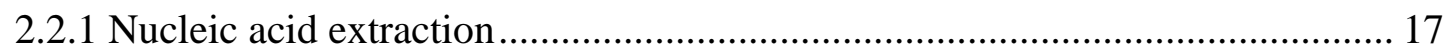

2.2.2 Collection of RNA from sea ice ................................................................ 25

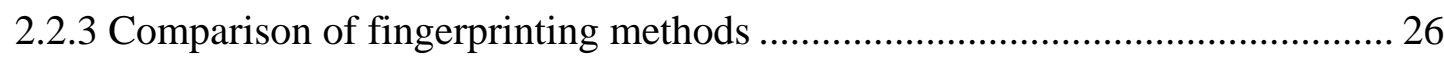

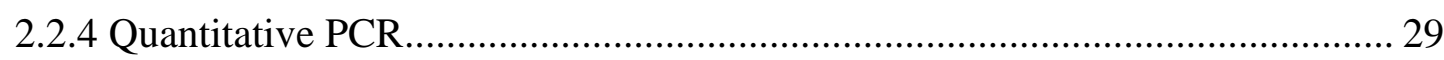

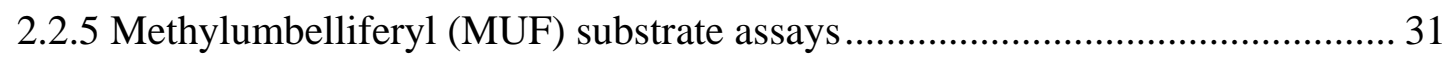

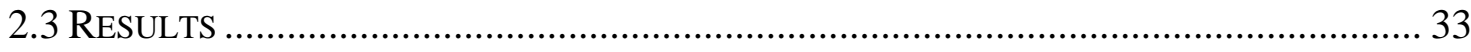

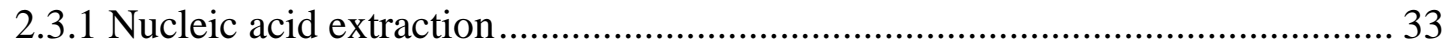

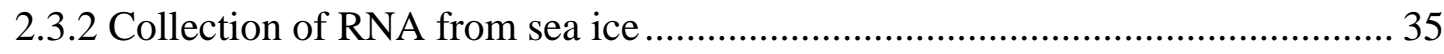

2.3.3 Comparisons between fingerprinting methods ............................................. 35

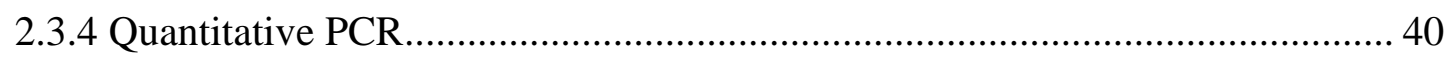

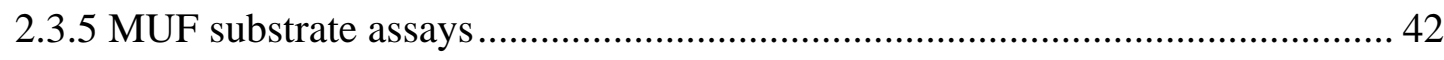

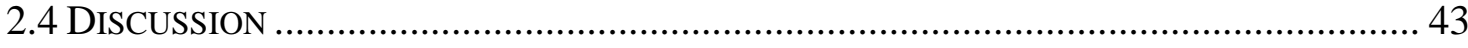


CHAPTER 3: Bacterial Community Structure and Relationships with the

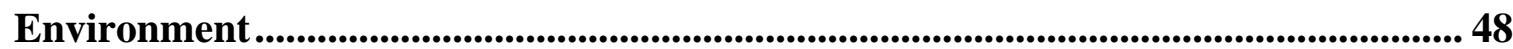

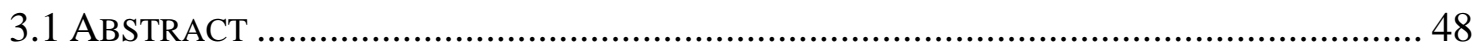

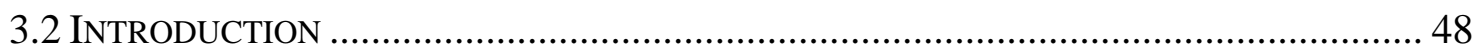

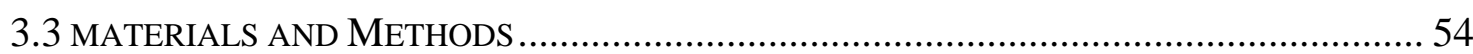

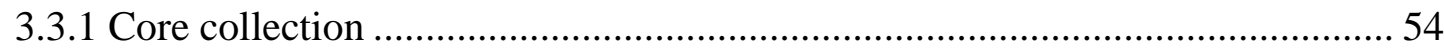

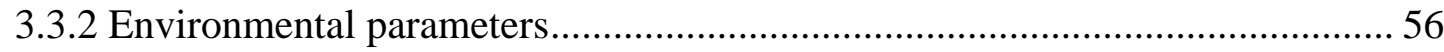

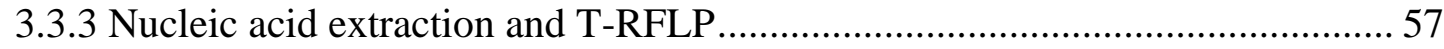

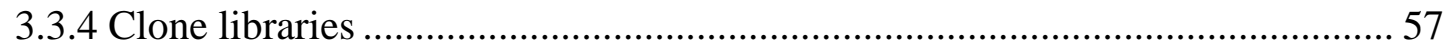

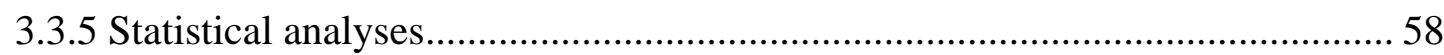

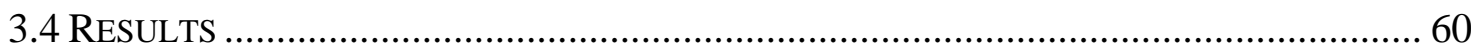

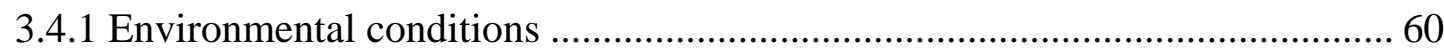

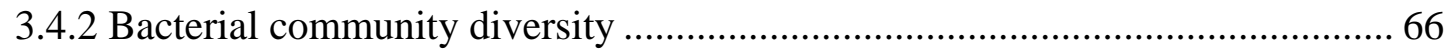

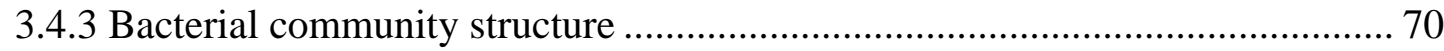

3.4.4 Relationships between the community and the environment.......................... 85

3.4.5 Inferring phylogeny from T-RFLP profiles .................................................... 87

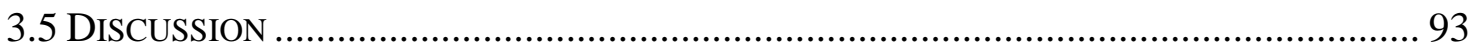

CHAPTER 4: Bacterial Community Function ...................................................... 105

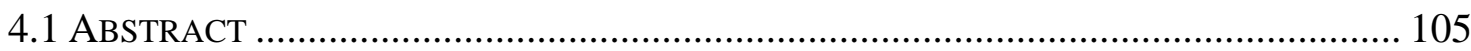

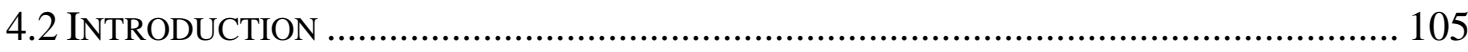

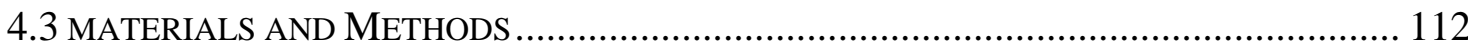

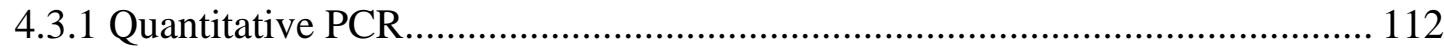

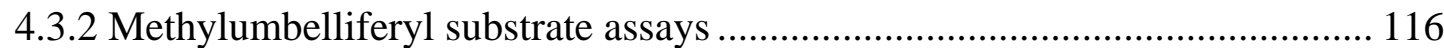

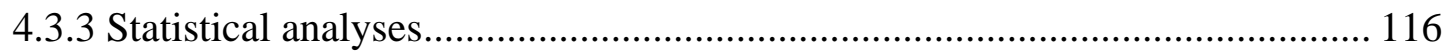

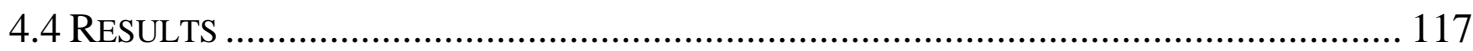

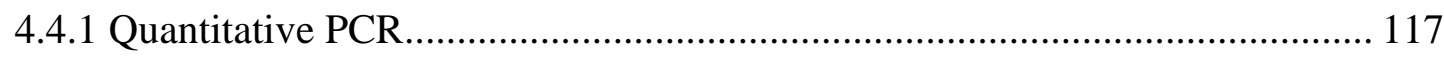

4.4.2 Methylumbelliferyl substrate assays ......................................................... 125

4.4.3 Similarities between bacterial community and enzymatic activity ................ 128

4.4.4 Relationships between the environment and MUF activity .......................... 129

4.4.5 Relationships between bacterial community structure

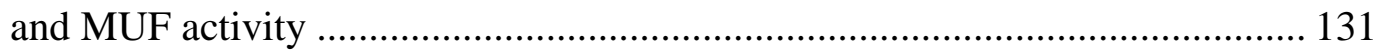

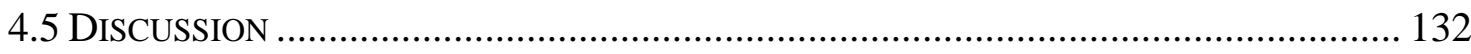


CHAPTER 5: Archaeal Diversity......................................................................................... 142

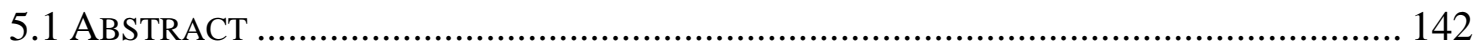

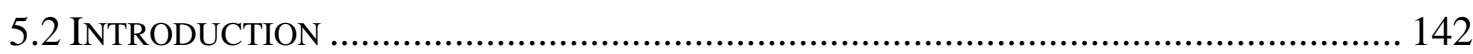

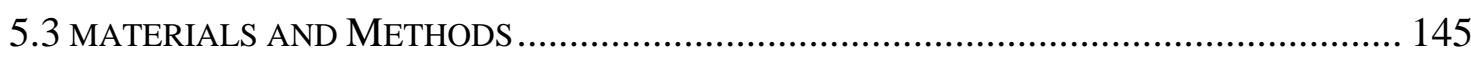

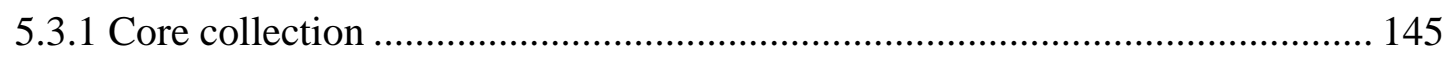

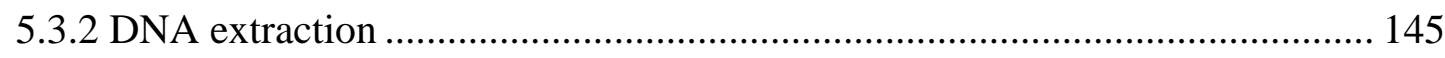

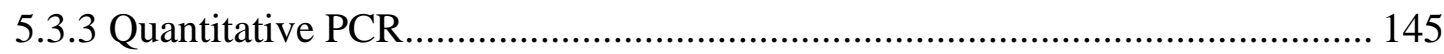

5.3.4 PCR conditions and clone library construction................................................. 146

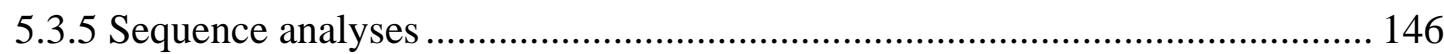

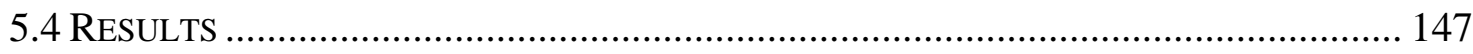

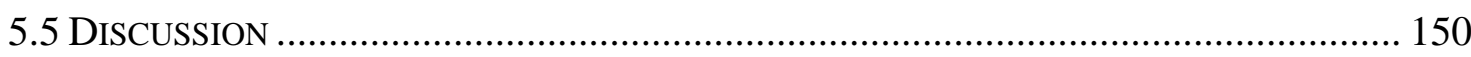

CHAPTER 6: Bacterial Diversity using Culture and Molecular Methods ............... 153

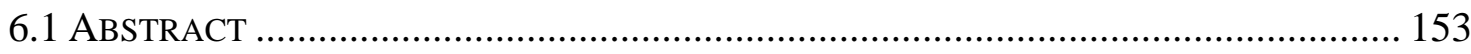

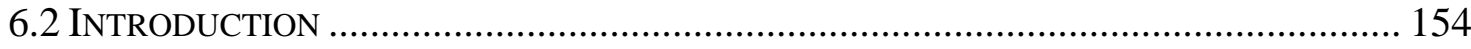

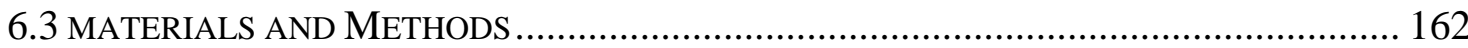

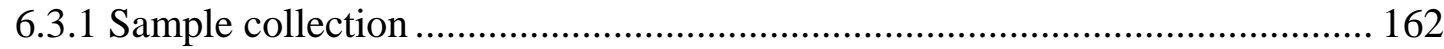

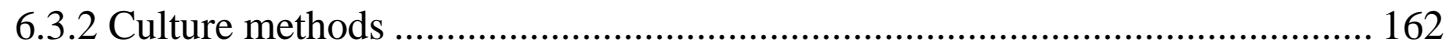

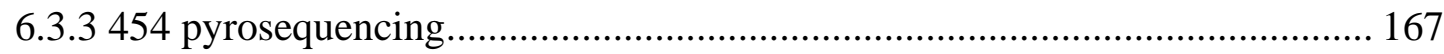

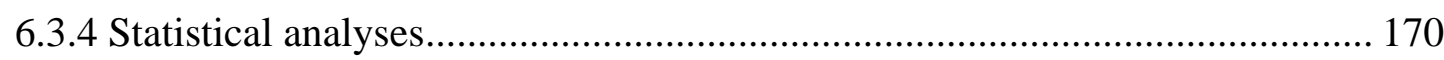

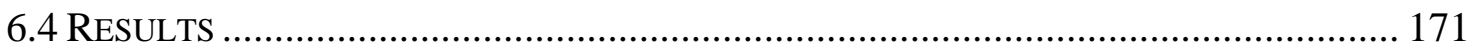

6.4.1 Culture-dependent bacterial diversity ........................................................... 171

6.4.2 Culture-independent bacterial diversity …………………………………..... 188

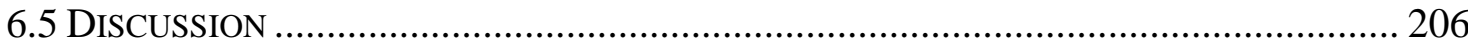

CHAPTER 7: General Discussion ........................................................................................ 217

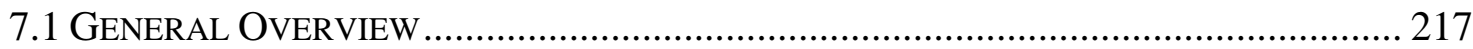

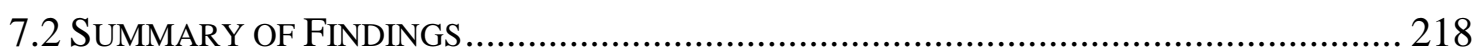

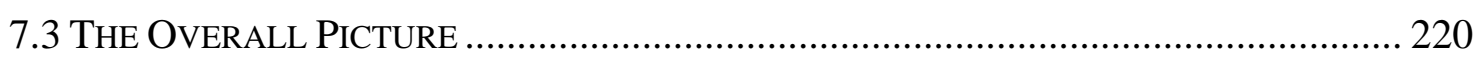

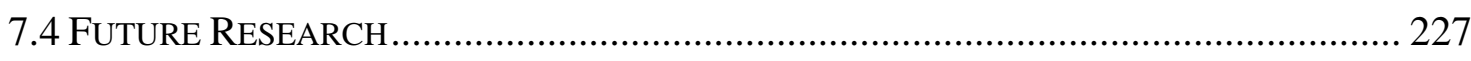

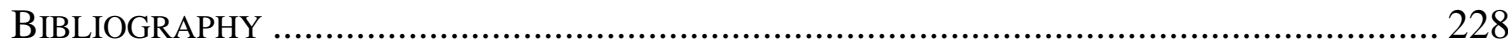

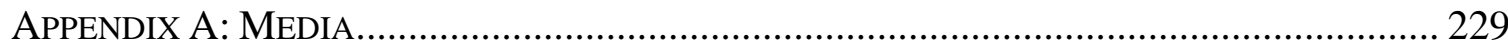

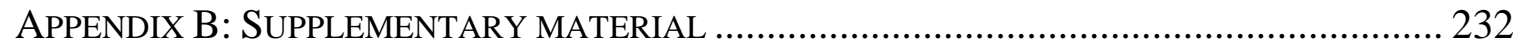

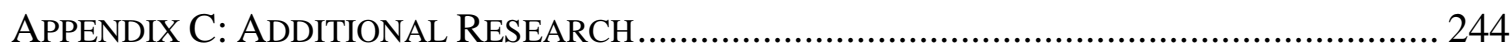




\section{LIST OF FIGURES}

\section{CHAPTER 1}

1.1 Integrated approaches to investigate bacterial diversity, functional roles and

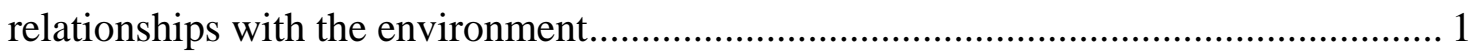

1.2 The potential temperature change of sea water down to $200 \mathrm{~m}$ in depth. ................ 9

1.3 Map showing the five sites of the Latitudinal gradient ..................................... 10

\section{CHAPTER 2}

2.1 Diagram showing the set up of the 96 well plate to measure MUF fluorescence from Antarctic sea ice samples.

2.2 Agarose gel showing the 16S rRNA gene amplified from DNA from the different extraction methods 34

2.3 Gel showing the 16S rRNA gene amplified from different RNA collection methods 35

2.4 DGGE gels of three samples run on different gradients ....................................... 36

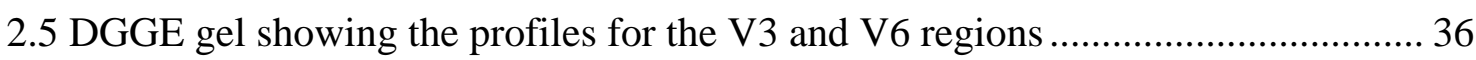

2.6 DGGE gel of bacterial communities in sea ice ................................................... 37

2.7 Electropherograms taken repeated samples to compare reproducibility ................. 39

2.8 Dendrogram of DGGE and T-RFLP profiles from bacterial sea ice communities.. 40

2.9 Temperature gradients for ten different functional genes .................................... 41

2.10 Agarose gel showing the pufM, PR and Chit genes .......................................... 41

2.11 Metabolic activity of bacteria using methylumbelliferyl substrates ..................... 43

\section{CHAPTER 3}

3.1 A simplified food web diagram, showing dominant roles of the 'microbial loop' 50

3.2 A simplified diagram of factors that may control bacterial community structure in Antarctic sea ice. 51

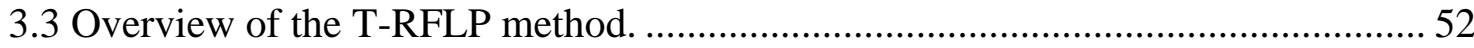

3.4 Map of the Ross Sea region, Antarctica, showing the site locations .......................55

3.5 Linear regression of bacterial cell counts against environmental variables............. 61

3.6 Significant relationships between Chl- $a$ and phosphate concentrations with increased latitudinal gradient 
3.7 Nutrient concentrations at the bottom of the ice core 63

3.8 Nutrient concentrations through the ice core 65

3.9 Number of DNA and RNA RFLs at the bottom of the ice core against the latitudinal gradient 66

3.10 Number of DNA and RNA RFLs against vertical position in sea ice 67

3.11 Diversity indices at the bottom of the sea ice core 69

3.12 Raw T-RFLP profiles from selected DNA bottom-ice samples 71

3.13 Raw T-RFLP profiles from selected RNA bottom-ice samples 72

3.14 Canonical analysis of principle components plots showing the PERMANOVA data of rDNA and rRNA communities from bottom ice samples taken in 2008 74

3.15 Canonical analysis of principle components plots showing the PERMANOVA data of rDNA and rRNA communities from bottom ice samples taken in 2008 against 2009

3.16 Raw T-RFLP profiles from the rDNA communities at the top, middle and bottom of the sea ice core at Cape Evans 2009

3.17 Raw T-RFLP profiles from the rRNA communities at the top, middle and bottom of the sea ice core at Cape Evans 2009 77

3.18 Raw T-RFLP profiles from the rDNA communities at the top, middle and bottom of the sea ice core at Granite Harbour2009 78

3.19 Raw T-RFLP profiles from the rRNA communities at the top, middle and bottom of the sea ice core at Granite Harbour2009. 78

3.20 Raw T-RFLP profiles from the rDNA communities from the water column in 2009

3.21 Raw T-RFLP profiles from the rRNA communities from the water column in 2009.

3.22 Canonical analysis of principle components plots showing the PERMANOVA data of rDNA and rRNA communities through the sea ice core in 2009 82

3.23 MDS plot on the T-RFLP profiles of rDNA and rRNA sea water communities... 85 3.24 CAP bi-plots showing those RFLs most responsible for driving separation between rDNA and rRNA bottom sea ice communities in 2008 88

3.25 CAP bi-plots showing those RFLs most responsible for driving separation between rDNA and rRNA bottom sea ice communities in 2009 89

3.25 CAP bi-plots showing those RFLs most responsible for driving separation between rDNA and rRNA through the sea ice core in 2009 90 


\section{CHAPTER 4}

4.1 Reactions of the microbial nitrogen cycle and examples of genes that are involved in these reactions. 107

4.2 Plate layout showing 24 cDNA samples for qPCR analysis................................ 114

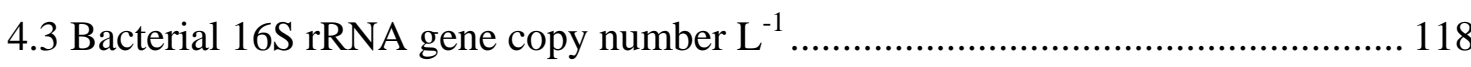

4.4 Archaeal 16S rRNA gene copy number $\mathrm{L}^{-1}$ and relative abundance $(\%)$ of

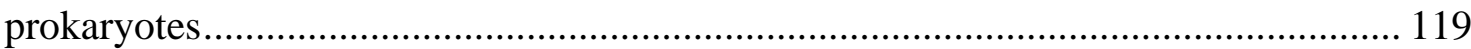

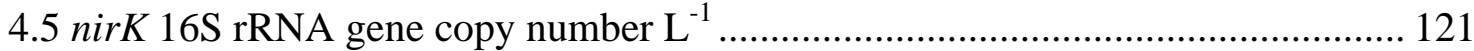

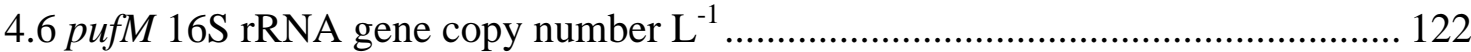

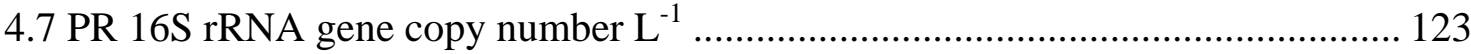

4.8 Relative abundance (\%) of nirK, pufM and PR genes ...................................... 124

4.9 Bacterial enzymatic activity in bottom sea ice from different sites in 2008 and

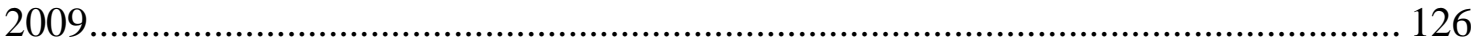

4.10 Bacterial enzymatic activity through the sea ice core in 2009 ........................... 127

4.11 Dendrogram showing similarities in MUF activity between different bacterial communities.

4.12 Significant relationships between nutrient concentrations in the environment and MUF bacterial activity.

4.13 Distance based redundancy (dbRDA) plot visualising the similarity in communities and associated changes in MUF activity

\section{CHAPTER 5}

5.1 Dendrogram showing the phylogenetic relationships between Archaeal 16S rRNA gene sequences from Antarctic sea ice

\section{CHAPTER 6}

6.1 Biochemical tests used to identify gram negative bacterial groups from the marine environment.

6.2 Biochemical tests used to identify gram positive bacterial groups from the marine environment 156

6.3 Culture dependent vs. culture independent methods.

6.4 Rank abundance indicating which proportions of the diversity can be detected with different methods

6.5 An overview of the 454 sequencing technology. 169 
6.6 Glucose oxidation and fermentation tests of isolates.

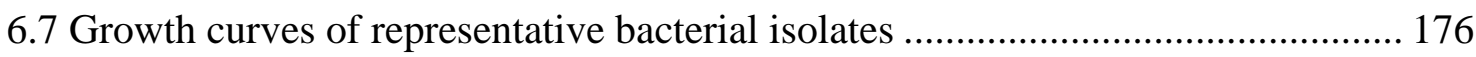

6.8 Representative RFLP profiles of the 16S rRNA gene ....................................... 178

6.9 Dendrogram showing the estimated phylogenetic relationships of isolates from

Gammaproteobacteria

6.10 Dendrogram showing the estimated phylogenetic relationships of isolates from

Alphaproteobacteria

6.11 Dendrogram showing the estimated phylogenetic relationships of isolates from Actinobacteria.

6.12 Dendrogram showing the estimated phylogenetic relationships of isolates from

Bacteriodetes.

6.13 Dendrogram showing the estimated phylogenetic relationships of isolates from

Firmicutes

6.14 Rarefaction curves at $0,3,5$ and $10 \%$ sequence dissimilarity 188

6.15 The main groups found in Antarctic sea ice using 454 sequencing. 189

6.16 Identification of OTUs to genera within the Actinobacteria 190

6.17 Identification of OTUs to genera within the Alphaproteobacteria and

Betaproteobacteria subgroups of the proteobacteria 191

6.18 Identification of OTUs to genera within the Gammaproteobacteria. 192

6.19 Identification of OTUs to genera within the Firmicutes. 193

6.20 Identification of OTUs to genera within the Bacteriodetes

6.21 Identification of OTUs to genera within the archaea.

6.22 Heat map showing the relative abundance (RA \%) of genera from 454

pyrosequencing among sites.

6.23 Heat map showing the relative abundance (RA \%) of genera from 454

pyrosequencing between DNA and RNA

6.24 Cluster analysis showing similarities of bacterial diversity among sites by 454 sequencing 


\section{LIST OF TABLES}

\section{CHAPTER 2}

2.1 DNA / RNA extraction kits trialled. 17

2.2 Overview of DNA extraction methods 20

2.3 Overview of RNA extraction methods 23

2.4 RNA collection methods from Antarctic sea ice. 26

2.5 DNA and RNA yields from the different simultaneous extraction kits in $n g \mathrm{l}^{-1} \ldots 33$

2.6 DNA quantity from the different simultaneous extraction kits in $\mathrm{ng} \mu \mathrm{l}^{-1} \ldots \ldots \ldots \ldots . . . . .33$

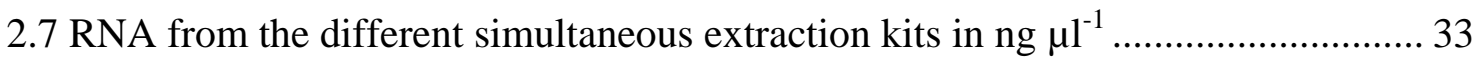

2.8 DNA yield ( $\mathrm{ng} \mu \mathrm{l}^{-1}$ ) when amplified with different concentrations of DNA and

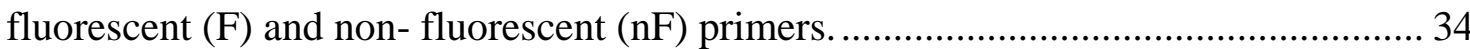

2.9 DNA yield of PCR products after amplification with various taq polymerase....... 38

2.10 The expected band sizes of functional genes, whether they were amplified and the closest sequence after BLAST.

2.11 The five genes targeted for qPCR showing the optimised annealing temperature.

\section{CHAPTER 3}

3.1 Permutational multivariate analysis of variance (PERMANOVA) of comparing DNA and rRNA bacterial communities at each site

3.2 Permutational multivariate analysis of variance (PERMANOVA) of bacterial communities from bottom ice cores in 2008

3.3 Permutational multivariate analysis of variance (PERMANOVA) of bacterial communities at CE and GH 2008 and 2009.

3.4 Permutational multivariate analysis of variance (PERMANOVA) of comparing rDNA and rRNA bacterial communities at each site

3.5 Permutational multivariate analysis of variance (PERMANOVA) of bacterial communities from bottom, middle and top of the sea ice cores in 2009.

3.6 Permutational multivariate analysis of variance (PERMANOVA) of bacterial communities at CE and GH 2009 at the bottom, middle and top of the ice core and from GH 2009 seawater (SW). 
3.7 Associations between bottom ice bacterial communities against environmental variables using a distance-based permutational multiple regression analysis

3.8 Associations between bacterial communities in the top, middle and bottom of the ice core against environmental variables using a distance-based permutational multiple regression analysis (DISTLM).

3.9 RFLs identified from rDNA and rRNA communities and their shifts from seawater through the ice core 91

3.10 Sequences associated with T-RFLP RFLs from the clone library 92

\section{CHAPTER 4}

4.1 Primers used in this study to target the five different genes and their optimal annealing temperatures $\left({ }^{\circ} \mathrm{C}\right)$.

4.2 Associations between bacterial communities and enzyme activity using a distance-based permutational multiple regression analysis (DISTLM).

\section{CHAPTER 5}

5.1 Archaeal and bacterial 16S rRNA gene copy numbers and relative proportions in Antarctic sea ice samples as determined by qPCR. 148

\section{CHAPTER 6}

6.1 Agars prepared for growth of Antarctic sea ice bacteria. 163

6.2 Number of bacteria grown on different media at different sites in 2008 172

6.3 Number of bacteria grown on different media through the ice core in 2009 173

6.4 Growth of isolates on 11 different sole carbon sources. 174

6.5 Lag phase and mean generation time (MGT) in hours from the isolates

6.6 16S rRNA sequence analysis showing the groups the isolates cluster within and the similarity with their nearest neighbor $(\%)$

6.7 16S rRNA gene sequences showing the \% similarity and \% divergence between the bacterial isolates

6.8 The 10 most abundant groups to genus level as determined by their percentage of relative abundance at the different sites 198

6.9 The 10 most abundant groups to genus level as determined by their percentage of relative abundance between the DNA and RNA populations 
6.10 The most abundant groups as determined by their percentage of relative abundance (RA \%) from 454 pyrosequencing though the sea ice core.

6.11 The most abundant genera as determined by their percentage of relative abundance (RA \%) from 454 pyrosequencing through the sea ice core.

6.12 Diversity indices, N1 and N2 (Hill numbers) and N21' (modified Hill's ratio) at each site.

6.13 A comparison between the bacterial groups identified by culture dependant methods with those found through pyrosequencing. 


\section{AbBreviations}

\begin{tabular}{|c|c|}
\hline AAnP & Aerobic Anoxygenic Phototroph \\
\hline Amp & Ampicillin \\
\hline Bchl- $a$ & Bacteriochlorophyll- $a$ \\
\hline BLAST & Basic Local Alignment Search Tool \\
\hline bp & Base pairs \\
\hline cDNA & Complementary DNA \\
\hline $\mathrm{CE}$ & Cape Evans \\
\hline Chl- $a$ & Chlorophyll- $a$ \\
\hline $\mathrm{CR}$ & Cape Roberts \\
\hline DEPC & Diethylpyrocarbonate \\
\hline $\mathrm{dH}_{2} \mathrm{O}$ & Double distilled water \\
\hline DNA & Deoxyribonucleic acid \\
\hline DOM & Dissolved organic matter \\
\hline dNTPs & Di-nucleotide tri-phosphates \\
\hline FISH & Fluorescent in situ hybridisation \\
\hline E. coli & Escherichia coli \\
\hline $\mathrm{EtBr}$ & Ethidium bromide \\
\hline gDNA & Genomic DNA \\
\hline $\mathrm{GH}$ & Granite Harbour \\
\hline IPTG & Isopropyl-beta-D-thiogalactopyranoside \\
\hline LB & Luria Burtani \\
\hline LGP & Latitudinal Gradient Project \\
\hline $\mathrm{MCM}$ & McMurdo Sound \\
\hline $\mathrm{MgCl}_{2}$ & Magnesium chloride \\
\hline mRNA & Messenger RNA \\
\hline $\min$ & Minutes \\
\hline PBS & Phosphate buffered saline \\
\hline PCR & Polymerase chain reaction \\
\hline PR & Proteorhodopsin \\
\hline rDNA & Ribosomal DNA \\
\hline
\end{tabular}




$\begin{array}{ll}\text { RNA } & \text { Ribonucleic acid } \\ \text { rRNA } & \text { Ribosomal RNA } \\ \text { RE } & \text { Restriction enzyme } \\ \text { rpm } & \text { Revolutions per minute } \\ \text { s } & \text { Seconds } \\ \text { SIMCO } & \text { Sea ice microbial communities } \\ \text { T-RFLP } & \text { Terminal restriction fragment length polymorphism } \\ \text { TNB } & \text { Terra Nova Bay } \\ \text { UV } & \text { Ultraviolet } \\ \text { X-Gal } & \text { 5-Bromo-4-chloro-3-indoxyl-beta D-galactopyranoside }\end{array}$




\section{Erapter One}

\section{General Introduction}

Bacteria are ubiquitous, occupying every imaginable habitat from hot thermal springs (Stout et al. 2009) to deep Mariana Trench sediments (Pathom-Aree et al. 2004). They are among the most abundant organisms on Earth. For example, one $\mathrm{mL}$ of surface seawater contains $>10^{5}$ cells and therefore it has been predicted that the oceans harbour $3.6 \times 10^{29}$ bacterial cells (Whitman et al. 1998). Their numerical dominance suggests that bacteria play a major role in biogeochemical cycles and can contribute significantly to ecosystem processes (Fuhrman et al. 1989; Azam and Worden 2004). The relationships between bacterial species, their function and environmental influences are complex but require an integrated approach (Figure 1.1).

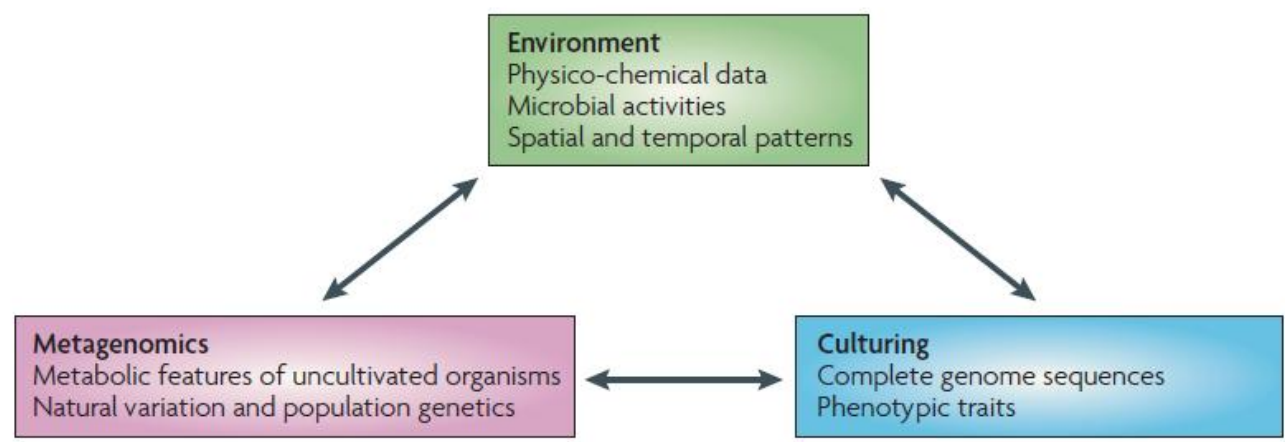

Figure 1.1 Integrated approaches to investigate bacterial diversity, functional roles and relationships with the environment in order to predict community response to environmental change. From Giovannoni and Stingl (2007).

Linking community structure with ecological function is important and can be investigated by looking at relationships between changes in bacterial community patterns, activity and the environment. Furthermore, particular functions can be linked to particular organisms by investigating bacterial functional genes using molecular 
methods. The combination of bacterial cultures and information about natural genetic variation provided by metagenomics gives greater insight into bacterial diversity.

\subsection{MICROBIAL DIVERSITY}

The global microbial community is extremely diverse and estimates for the number of bacterial species on Earth range from $10^{3}$ to $10^{9}$ (Pedrós-Alió 2006). The range of this estimate is due to two schools of thought. Firstly, the number of different microbes is low $\left(10^{3}-10^{4}\right)$ because microbes are small and easily dispersed, are involved in gene transfer and are not affected by geographical barriers (Finlay 2002; Fenchel and Finlay 2004). One problem in this is that geographical isolation is not necessarily required for speciation. Bacteria may evolve through sympatric speciation, and it has been shown that pure cultures of bacteria can evolve quickly. Therefore, microbial diversity may in fact be higher. Fenchel and Finlay (2004) however argued that microbial diversity may be overestimated as newly found sequences may belong to already described organisms, and that molecular diversity may not reflect "true" species as it does not give information about bacterial phenotypes. At the other end of the spectrum, high estimates of bacterial diversity are based on taxon-abundance or rarefaction curves (Curtis et al. 2002). Bacterial abundance is extrapolated from the total number of individuals and the most abundant taxa. Rarely do these curves reach an asymptote, signifying that the bacterial community diversity has not been fully sampled.

Microbial diversity characterises a variety of microorganisms at the genetic, species, and ecosystem levels. It also covers microbial distributions and functions. Thus, microbial diversity comprises aspects of species richness, evenness, composition, and function. The differentiation between bacterial species is somewhat arbitrary compared with higher organisms as bacteria are highly promiscuous in taking up genetic material from outside sources. The $16 \mathrm{~S}$ rRNA gene is the most common gene used to classify bacteria as it can discriminate between bacteria due to its highly conserved and variable regions and it also does not take part in horizontal gene transfer. Despite this, some bacteria cannot be demarcated using the 16S rRNA gene solely, and a combined approach requiring culture-based methods using phenotypic 
traits is required. Diversity can, however, be calculated with other units than that of species (Stackebrandt et al. 2002). Operational taxonomic units (OTUs) cluster individuals into non-overlapping classes according to a consistent criterion which is generally at a 16S rRNA gene sequence similarity of 97\% (Stackebrandt and Goebel 1994).

Bacterial diversity can be investigated using an array of techniques which can give varying information about the bacterial community. Before the discovery of molecular methods, bacteria were identified using culture methods and classified depending on their phenotypic characteristics. Although a large proportion of bacteria are difficult to culture, still many OTUs were classified and information could be gathered about both the abundant and rare organisms in the environment. However, the development of molecular methods revealed a wealth of bacteria that could not be cultured. Molecular techniques investigate microbial diversity generally by extracting DNA from the whole community. In comparison, few studies have investigated the RNA proportion of the bacterial community (i.e. Nogales et al. 2001; Moeseneder et al. 2005). DNA-based methods give insights into general biodiversity, genetic potential or abundant members of whole communities. On the other hand, as RNA is rapidly degraded, RNA-based technologies will only obtain information about the active (living) community. Comparison of both the 16S rDNA and rRNA can provide an expanded view of bacterial diversity and identify those bacteria that are responsible for the overall activity and productivity of the community. The bacterial community structure can be investigated using whole-community fingerprinting methods such as terminal restriction fragment-length polymorphism (TRFLP, Liu et al. 1997), denaturing gradient gel electrophoresis (DGGE, Muyzer et al. 1993) or automated ribosomal intergenic spacer analysis (ARISA, Fisher and Triplett 1999). While these methods give information about community structure, they provide less information about individual organisms in the community and fail to detect the rare taxa. Information about the individuals in a population can be collected from clone libraries and sequencing, but rare taxa sometimes still fall underneath the detection level. The recent development of high-throughput sequencing technologies has enabled the "rare biosphere" to be sampled and microbial diversity can now be explored to a greater depth (Sogin et al. 2006). 


\subsection{Microbes AND THE ENVIRONMENT}

It has long been of interest whether microbial communities are ubiquitously distributed or display spatial and/or temporal biogeographical patterns. W. Beijerinck speculated that bacteria are cosmopolitan, occurring anywhere on Earth's surface, as long as their environmental requirements are met and thus lead to Baas-Becking's statement "everything is everywhere, but the environment selects" (see O'Malley, 2007 and citations within). Finlay (2002) stated that "there is no biogeography for anything less than $1 \mathrm{~mm}$ ". Bacteria may indeed be cosmopolitan, as unlike macroorganisms they are not restricted by geography. This is due to their abundance, high dispersal, flexibility in habitat requirements, physiological flexibility and can obtain traits necessary for survival through horizontal gene transfer. However, other studies have suggested that most microorganisms are not cosmopolitan and have biogeographical patterns (Staley and Gosink 1999; Cho and Tiedje 2000; Oda et al. 2003). Pommier et al. (2007) collected samples from nine widespread locations using clone libraries and found that $69 \%$ of the OTUs were endemic, $17 \%$ were at two locations, $6 \%$ at three locations, and only $0.4 \%$ were found at all locations. A new theory perhaps is that bacterial species conform to the power-law relationship, where the number of species in an area is positively correlated with an increase in the size of that area. This relationship has been observed repeatedly in plant and animal communities over the last century (Rosenzweig 1995), but has only recently been applied to bacteria (Horner-Devine et al. 2004). If bacteria are easily dispersed and are ecologically redundant, no taxa-area relationships would be seen. However, HornerDevine et al. (2004) showed that the number of bacterial groups increased with greater area and that communities that were located close together were more similar in community composition than communities located farther apart. Their study also found that changes in microbial communities were driven by environmental changes rather than geographical distance suggesting that the environment rather that biogeography determines bacterial community patterns.

Many physical and biological factors control bacterial population growth and it is likely that no single factor dominates; therefore many environmental variables must be measured. Bacterial communities can be influenced by biotic and abiotic 
environmental variables (Fuhrman et al. 2006). With changes in environmental conditions, we expect bacteria to respond by i) migration into a more favourable area, ii) adaptation by a shift in phenotype and iii) extinction of certain species. As an individual species response to the environment is determined by its competitors, the impact of the environment must be analysed on the community as a whole. Bacterial communities may respond by changing both community richness and evenness, and this may occur at the individual or community level (Sigler et al. 2002). Environmental changes could therefore cause a loss or gain of certain OTUs, or a change in their distribution; therefore quantitative data are very important (Rappé et al. 1997).

\subsection{Microbial LOOP}

Microbes play key roles in biogeochemical processes, sustaining almost every other form of life on Earth. Originally, energy transfer in the 'classic' food chain was thought to flow from large phytoplankton such as diatoms and dinoflagellates through to higher trophic levels. However, this food web was incomplete and too simple which led to the realization of the significance of the 'microbial loop' (Azam et al. 1983). Their main finding was the significant amount of primary production that was thought to be lost to the environment as dissolved organic matter was instead utilised by heterotrophic bacteria. Bacteria are in turn consumed by Protozoa leading to carbon flow to higher trophic levels, or lysed by viruses thus recycling dissolved organic matter (DOM) (Middleboe et al. 2001). Bacteria also mineralise the DOM back to inorganic starting materials such as nitrate and phosphate which can then be utilized by algae to promote growth. Another important energy input into the microbial loop is from light harvesting bacteria. In marine systems, cyanobacteria play a substantial role as primary producers through photosynthesis (Fenchel 2008). A recent discovery is that of photoheterotrophic bacteria which are able to generate energy as ATP from light (Beja et al. 2002), suggesting that microbial loop dynamics are more complex than originally thought. 


\subsection{The Antarctic Sea Ice Ecosystem}

Annually, Antarctic pack ice expands to cover as much as 20 million $\mathrm{km}^{2}$ of the Southern Ocean (Maykut 1985). Ice formation generally begins in the autumn where ice crystals coagulate into 'grease ice' that forms a thin layer on the surface of the water. The ice will eventually form thicker nilas and pancake ice (Ackley and Sullivan 1994), and with additional growth a closed ice cover will establish. Sea ice thickens by ice crystal growth extending downwards into the water column and can reach a thickness of $>1$ meter in a matter of a few months before melting away as summer develops. During ice formation, the salts are expelled and brine channels of high salinity form throughout the ice matrix. The surface area of the brine channels can range from $0.6-4.0 \mathrm{~m}^{-2} \mathrm{~kg}^{-1}$ of ice and $6-41 \%$ of it is colonised by microbes (Krembs et al. 2000).

As sea ice forms, planktonic microbes are incorporated from the water column and become incorporated into the semi-solid matrix (Mock and Thomas 2005). These planktonic microbes are exposed to a large shift in environmental conditions, from living in seawater at $\sim 1.8^{\circ} \mathrm{C}$ to surviving in a completely enclosed ice matrix that has steep gradients of salinity, light, temperature and nutrient concentration (Arrigo and Sullivan 1992).

The survival and growth of organisms in this extreme environment has long been of interest. Antarctic sea ice diatoms were first described by Hooker (1847) and studies have since discovered macroalgae, ciliates, flagellates, protists, bacteria and viruses throughout the sea ice core (Sullivan and Palmisano 1984). Algal diversity and physiology have been the most extensively studied, perhaps, as algae are the most obvious organisms in sea ice microbial communities (SIMCO, for reviews see Lizotte et al. 2003, Thomas and Dieckman 2002). Typically, bacteria make up a small proportion of the SIMCO; however it has also been shown that bacteria can dominate within sea ice habitats (Kottmier and Sullivan 1987). The greatest biomass of organisms occurs at the bottom few centimeters of sea ice close to the seawater interface (McMinn et al. 2007). Here in the bottom $20 \mathrm{~cm}$ of ice, the environment is stable and favourable for growth where salinity is $35 \%$, temperature is $-1.8^{\circ} \mathrm{C}$ and 
there is a constant flux of nutrients from the water below (Arrigo and Sullivan 1992, Arrigo and Thomas 2004, Mock and Thomas 2005).

Sea ice is a major driver of polar marine ecosystems where for 9 months of the year, most of the primary production occurs not in the water column but in the sea ice (Arrigo and Thomas 2004). The sea ice microbial community (SIMCO) provides an enormous source of energy to Antarctic marine ecosystems and contributes up to 25 $\%$ of the total Southern Ocean production (Gross 2005). Organisms such as juvenile krill depend on this food supply for survival. Krill are a keystone species in the Antarctic food web and are a vital food source for higher trophic levels (Arrigo and Thomas 2004). The assimilation of carbon is based on an active sea ice microbial loop which has been shown as a positive relationship between microalgae (or proxies such as chlorophyll $a$ ) and estimates of bacterial abundance or production (Stewart and Fritsen 2004).

\subsection{SEA ICE BACTERIA}

The study of Antarctic sea ice bacterial diversity is still in its infancy and it is estimated that many bacteria in Antarctic sea ice are still un-described (Delille et al. 1992; Bowman et al. 1997; Staley and Gosink 1999; Brown and Bowman 2001). There has been research to suggest that many of the bacterial groups found in Antarctic sea waters are also found in the sea ice, and are found in Antarctic and Arctic zones (Brown and Bowman 2001; Junge et al. 2002; Brinkmeyer et al. 2003). However, the sea ice bacterial community is comprised of mainly psychrophilic species suggesting a shift in the abundances of bacterial groups to those better adapted to the sea ice environment (Staley and Gosink 1999; Junge et al. 2004). There have been no studies investigating changes in bacterial community structure at different sites in Antarctic sea ice. Although studies have, to some extent, demonstrated the activity of bacteria in sea ice microbial communities (Junge et al. 2004; Martin et al. 2009), virtually no information exists on what bacterial species contribute to overall productivity and the specific functions that they exhibit in sea ice. Bacteria have to survive the initial transition from the water to the ice core and could be assisted by gas vacuoles, cysts and spores (Staley and Gosink 1999). Gas vacuoles assist in buoyancy, 
which may i) bring bacteria into close association with algae, and thus a carbon source for bacterial growth, ii) aid in dispersal or iii) initiate incorporation into the ice core. Some bacteria produce special spores or cysts that are particularly resistant to desiccation and extreme temperatures (Staley and Gosink 1999). Once trapped in the matrix, sea ice bacteria appear to be adapted to the environment, producing antifreeze proteins (Gilbert et al. 2004), cold tolerant enzymes (Pomeroy and Weibe 2000) and polyunsaturated fatty acids (PUFA, Nichols et al. 1999b). Studies investigating sea ice bacterial sequences have found genes that are involved in denitrification (Staley and Gosink 1999) and light energy harvesting (Koh et al. 2010) suggesting that the bacteria may be involved in assimilation of DOM and light utilisation. Photorhodopsin sequences were relatively more common close to the surface of the ice core, although still rare, suggesting selection for these bacterial groups at high irradiances. Although bacteria have been identified in Antarctic sea ice, information about their ecology, their distribution and role in the sea ice ecosystem is still lacking.

\subsection{Climate change}

The intergovernmental panel on Climate Change (IPCC) has recently reported that "warming of the climate system is unequivocal, as is now evident from observations of increases in global average air and ocean temperatures, widespread melting of snow and ice, and rising global sea level" (Solomon et al. 2007). Global warming is expected to increase the temperature of the poles more so than the tropics. The poles are particularly sensitive to small increases in temperature where ice melting reduces reflection and allows more heat transfer from the ocean to the surface which accelerates the warming (Murray and Gryzmski 2007). If there is an increase in atmospheric carbon by $1 \%$ / yr over the next 100 years (Meehl et al. 2000), surface water temperature around Antarctica is expected to increase up to $3{ }^{\circ} \mathrm{C}$ (Figure 1.2) and sea ice extent and thickness are expected to be reduced by $25 \%$. This decrease in sea ice extent is likely to cause a shift in the relative sizes of the permanently open ocean zone (POOZ), the marginal ice zone (MIZ), and the sea ice zone (SIZ) (Arrigo and Thomas 2004). 


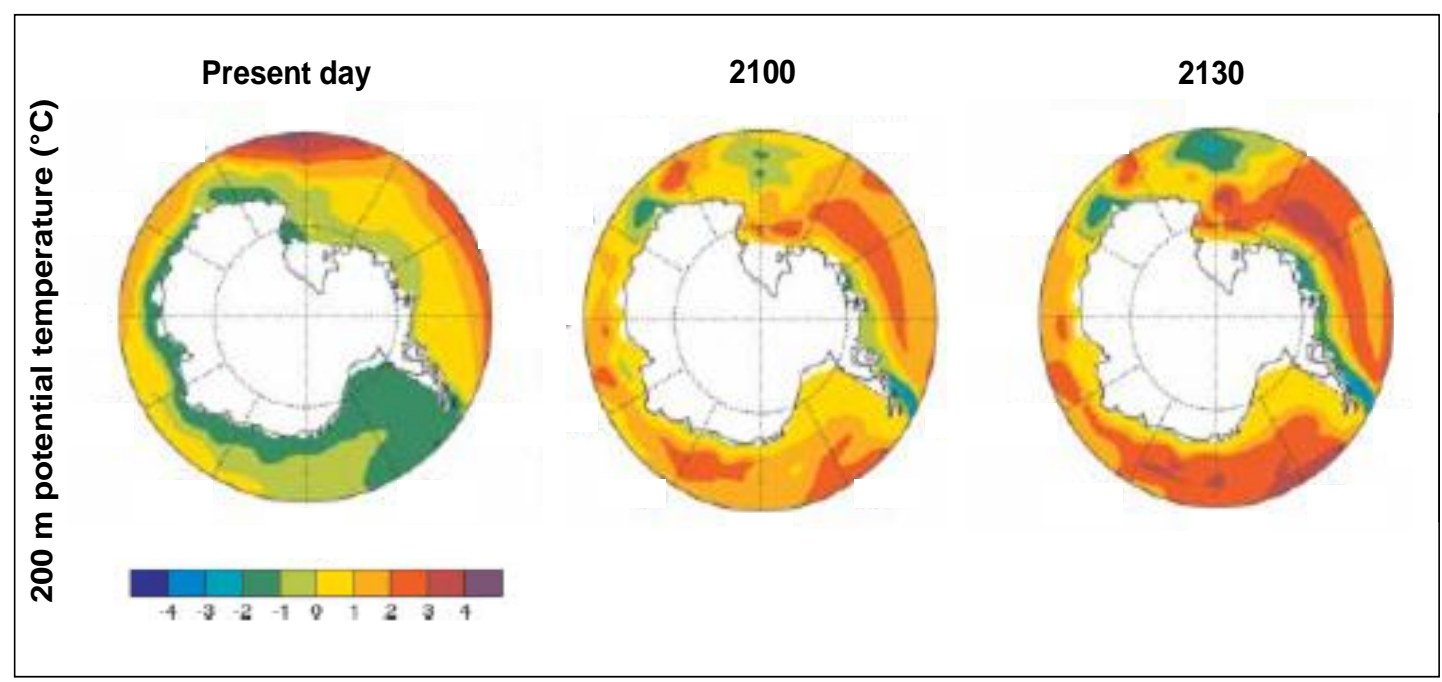

Figure 1.2 The potential temperature change of seawater down to $200 \mathrm{~m}$ in depth. Temperature is likely to increase by up to $3^{\circ} \mathrm{C}$ around most of Antarctica by year 2130 (Overpeck et al. 2006)

This receding sea ice associated with climate change highlights the need to develop a predictive understanding of how marine ecosystems will change with changes in sea ice distribution and thickness (Clarke and Harris 2003), and it is unknown how the SIMCO will respond. It is likely that there will be a change in microbial distribution and primary productivity that could have major implications for the Antarctic food web.

\subsection{Latitudinal Gradient Project (LGP)}

The Latitudinal Gradient Project (LGP) has been established to set up multi-nation and multidisciplinary research programs in the quest to address complex questions on climate change and variation (Howard-Williams et al. 2006). The LGP aims to understand the ecosystems along the Victoria Land coastline, Antarctica and the effects of environmental change on these ecosystems. This latitudinal gradient spans $14^{\circ}$ of latitude from $72^{\circ} \mathrm{S}$ at Cape Adare to $86^{\circ} \mathrm{S}$ at the southern end of the Ross Ice Shelf. Five sites along this gradient will be used as study sites: Cape Hallett, Terra Nova Bay, Granite Harbour, Darwin Glacier and the Beardmore Glacier (Figure 1.3). The latitudinal gradient varies in temperature, irradiance and sea ice parameters therefore this gradient can be used as a proxy for climate change. Latitudinal gradients have been used elsewhere in the past to measure such parameters as adaptive radiation 
of plants (Chapin 1974), invertebrate richness in streams (Castella et al. 2001) and vole dynamics (Turchin and Hanski 1997). As part of the LGP, microbial diversity and community structure will be investigated at these study sites. As microbes have a rapid lifecycle they may be the most appropriate organisms to show latitudinal gradient differences.

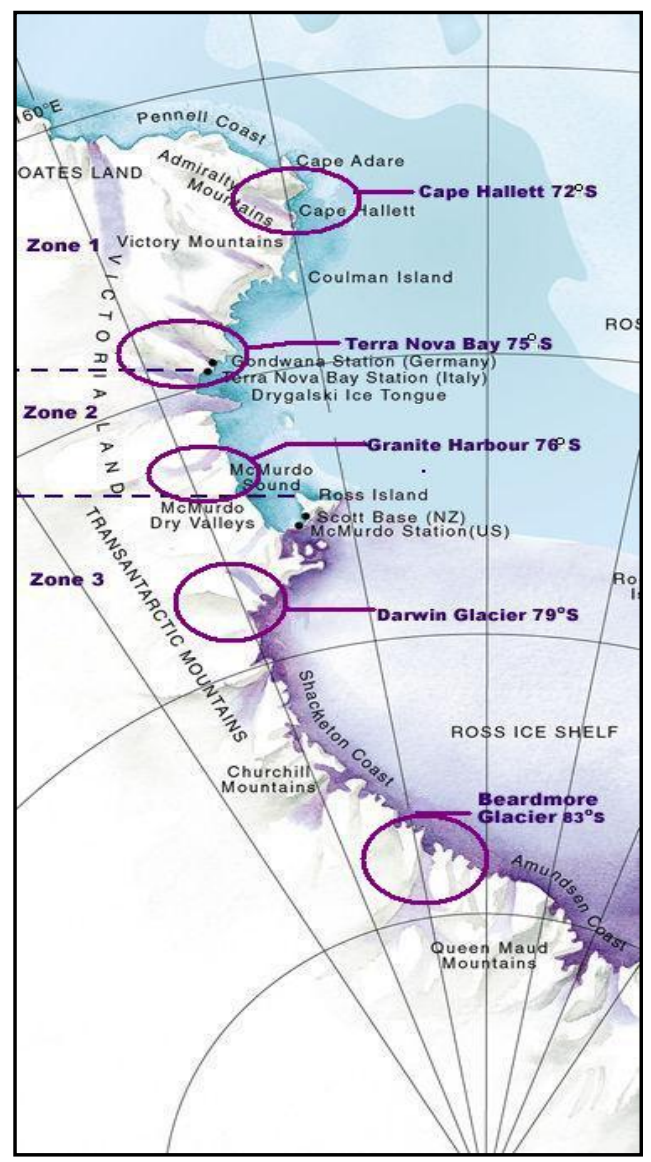

Figure 1.3 Map showing the five sites of the Latitudinal gradient along the Victoria Land coastline.

\subsection{Thesis Structure}

Studies of sea ice microbiology, particularly bacteriology are still in their infancy. Further research on the Southern Ocean sea-ice system is required, not only to further our basic understanding of the ecology, but also to provide ecosystem managers with the information necessary for the development of strategies in response to short- and medium-term environmental changes in Antarctica. This requires a good understanding of ecosystem structure and function and how it relates to environmental 
drivers. Microbes are known to reside in Antarctic sea ice but little is known about the identity, diversity, abundance, physiology and ecology of many of these microbes as well as the processes they perform in the environment. Recent advances in molecular biology have allowed a considerable advancement in microbial ecology. Thus, the aims of this study were to:

1. Investigate the relationships between Antarctic sea ice bacterial community structure and the environment using DNA and RNA fingerprinting techniques.

2. Use methylumbelliferyl enzyme substrates and quantitative PCR to understand bacterial functions and their role in Antarctic biogeochemical cycles.

3. Apply novel sequencing and culture techniques to determine bacterial and archaeal diversity.

In chapter 2, I developed the molecular methods used in the subsequent chapters in this thesis. RNA collection methods, nucleic acid extraction methods, PCR and qPCR protocols, fingerprinting techniques and enzyme substrate assays were optimised to obtain high quantity and quality of samples.

In Chapter 3, I investigated microbial community structure using T-RFLP. There have been no studies investigating Antarctic sea ice community structure or how it may change with spatial, temporal and environmental changes. Community richness and evenness was also compared. The latitudinal gradient was used as a proxy for climate change to determine if it has an influence on the bacterial community or whether changes are due to more local variables. Understanding microbial community change in relation to environmental variables will allow for predictions to be made about ecosystem function and response in the face of climate change. A modified version of chapter 3 is currently in preparation for publication:

Cowie ROM, Maas EW, Williams GJ, Lee CK, Voyles VM and Ryan KG (In prep). Changes in sea ice bacterial communities may be linked to environmental conditions. To be submitted to Applied and Environmental Microbiology.

The role of bacteria in sea ice biogeochemical cycles is largely unknown. Chapter 4 investigated the heterotrophic and photoheterotrophic activity of bacteria. This is the 
first study in Antarctic sea ice to quantify the abundance of certain functional genes present in the metabolically active population of bacteria. This chapter is in preparation for publication:

Cowie ROM, Maas EW, and Ryan KG (In prep). Role of bacteria in the Antarctic sea ice ecosystem. To be submitted to Applied and Environmental Microbiology.

The study of Antarctic prokaryotic diversity in Antarctic sea ice is still in its infancy. Archaea have not previously been described in Antarctic sea ice. In Chapter 5, archaeal diversity is explored using clone libraries and sequencing. This is the first account of archaeal diversity in Antarctic sea ice. Chapter 5 has been published as:

Cowie ROM, Maas EM, and Ryan KG (2011) Archaeal Diversity Revealed in Antarctic Sea Ice. Antarctic Science. doi:10.1017/S0954102011000368

Prokaryotic diversity was further investigated using culture based methods and deep sequencing. Chapter 6 is the first study to deeply sequence the bacterial sea ice community using 454 technologies. This chapter is in preparation for publication as:

Cowie ROM, Maas EW, and Ryan KG (In prep). Bacterial diversity in Antarctic sea ice. To be submitted to ISME Journal.

Lastly, Chapter 7 provides a summary of the preceding chapters and discusses the links between bacterial community structure, function and diversity in Antarctic sea ice. This chapter also outlines directions for future research. 


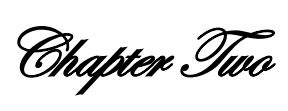

Method development

\subsection{INTRODUCTION}

The study of microbial ecology has been revolutionised by the development of molecular techniques. Prior to this, cultivation methods were the main tool for characterisation of the microbial community but were hindered by the un-cultivability of many bacteria with only $1-15 \%$ of the bacterial community being typically cultivable (Ward et al. 1990). Many applications have been developed for the analysis of microbial communities such as hybridisation of probes to extracted DNA (Lee and Fuhrman 1990), fingerprinting methods (Muyzer et al. 1993; Lui et al. 1997; Moeseneder et al. 2001) and polymerase chain reaction (PCR) approaches to amplify target gene sequences to generate clone libraries. DNA-based methods can serve as an indicator for total biodiversity or genetic potential of the community. To investigate the metabolically active community or bacterial gene expression in a sample, the mRNA may be targeted using mRNA probes, northern blotting and reverse transcription -PCR techniques.

Nucleic acids must be extracted from the cells in order to conduct many of these methods. However, the amount of nucleic acids extracted from a sample varies depending on the lysis method and the extraction protocol used (Zhou et al. 1996; Harry et al. 1999; Roose-Amsaleg et al. 2001). To optimise the quantity and quality of nucleic acids from an environmental sample, an appropriate extraction method that suits the sample profile is required. DNA has been extracted from the environment since Torsvik (1980) and there are now a variety of different methods to extract DNA from marine environments. In comparison, RNA extractions from environmental samples have not been used to the same degree and as a result are not so well established. As messenger RNA (mRNA) has a short half-life and RNases are in high 
abundance, the recovery of RNA is still challenging. There are typically three phases that can be optimised to extract high quality and concentration of nucleic acids from the environment; 1) cell recovery, 2) cell lysis and 3) nucleic acid recovery.

Bacterial cells are generally recovered from the marine environment by concentration onto Sterivex or polycarbonate $0.2 \mu \mathrm{m}$ filters followed by storage at $-80{ }^{\circ} \mathrm{C}$ or at -20 ${ }^{\circ} \mathrm{C}$ in a nucleic acid preservative. RNA is an unstable molecule which must be quickly collected from the environment and preserved in order to retain its integrity. RNAlater ${ }^{\mathrm{TM}}$ (Ambion) is an aqueous, non-toxic tissue storage medium that immediately stabilises RNA and protects it from degradation.

Cells are lysed by enzymatic degradation (i.e. Böstrom et al. 2004) and / or mechanical disruption (i.e Lloyd et al. 2009; Urakawa et al. 2010). Enzymatic lysis is relatively gentle and therefore often discriminates against cell types such as Gram positive bacteria. However, there is limited shearing of DNA. Mechanical disruption such as bead beating has been found to yield higher amounts of DNA than enzymatic lysis methods, but it tends to shear DNA (Smalla et al. 1993). Often a combination of minimal mechanical disruption in an enzymatic lysis buffer is used. Nucleic acids are recovered with ethanol or isopropanol precipitation, although there is no difference in precipitation efficiency between the two (Bostrom et al. 2004). However, the concentration of DNA and RNA can be increased by using a co-precipitant to enhance recovery or tRNA as a carrier. Commercial kits have reduced the time taken to extract nucleic acids, avoid phenol chloroform and reduce PCR-inhibiting substances (Webster et al. 2003). However, they may be limited in the recovery of a sufficient amount of DNA/ RNA from small samples.

Once the nucleic acids are extracted from the environmental sample, analyses can then be done to investigate bacterial community structure and diversity. Among the various molecular methods available to investigate community structure, fingerprinting methods enable a large number of samples to be compared via fast, reliable and inexpensive methods. Fingerprinting tools such as denaturing gradient gel electrophoresis (DGGE), single stranded conformation polymorphism (SSCP), terminal restriction fragment length polymorphism (T-RFLP) and automated ribosomal intergenic spacer analysis (ARISA) have been frequently utilised in 
microbial ecology (e.g. Muyzer et al. 1993; Lui et al. 1997; Brown et al. 2005). They will detect only the most abundant taxa in a sample and provide information on variability in community structure both spatially and temporally. DGGE separates DNA/ cDNA fragments on a denaturing gradient gel depending on their melting behaviour. A partially melted DNA molecule will migrate further than a more helical form of the molecule. A pattern of bands is produced where variability is determined by sequence discrepancy. A GC clamp is added so that the molecule will not melt completely. DGGE has been applied to soil (Smalla et al. 2007; Enwall et al. 2007), biofilms (Muyzer et al. 1993), seawater (Diez et al. 2001; Sanchez et al. 2007) and sea ice (Gast et al. 2004) samples. In contrast, T-RFLP is an automated approach that utilises fluorescently labelled primers to generate labelled DNA from a mixed sample of bacteria. The DNA is subsequently digested by overnight incubation with restriction enzymes (RE) producing variable fragments lengths that are detected by capillary electrophoresis. T-RFLP has been used to study microbial communities from soil (Dunbar et al. 2001; Smalla et al. 2007; Enwall et al. 2008), microbial mats (Moyer et al. 1994) and seawater (Moeseneder et al. 2005; Danovaro et al. 2006). Differences in communities can immediately be seen using DGGE, where the presence and absence of bands on the gel are easily visualised. However, bands may be difficult to compare due to gel artefacts (i.e "smiles") and gel-gel variation. TRFLP is an automated method which is run with an internal standard to prevent gelgel variation. Due to the automatisation, high throughputs of large amounts of samples are done rapidly and with high sensitivity. However, knowledge of suitable analysis algorithms is required to determine individual peaks and discriminate between peaks and noise. Fingerprinting methods are generally based on the bacterial $16 \mathrm{~S}$ rRNA gene as this is the primary gene used to identify and name species via phenotypic comparisons (Woese et al. 1990). T-RFLP can amplify the whole 16S rRNA gene in comparison to only a small part of this gene (200 - $500 \mathrm{bp})$ that is amplified using DGGE. The longer sequences may enable more accurate identification. However, short sequence fragments from regions such as variable region 3 (V3) and 6 (V6) of the 16S rRNA gene can provide substantial phylogenic resolution of bacteria to genus level or below (Sogin et al. 2006; Liu et al. 2007; Huse et al. 2008). 
Fingerprinting methods have recently been applied to functional genes to understand the role of microbial communities in certain biogeochemical cycles (Horz et al. 2005; Yeager et al. 2005; Belila et al. 2009). However, fingerprinting methods are unable to give accurate quantitative information about the abundance of particular bacterial groups in a community. Quantitative PCR (qPCR) enables the abundance of genes to be estimated in a certain volume of environmental sample. qPCR is based on the incorporation of a fluorescent dye that binds to double stranded DNA as it is amplified. It is critical that the primers are optimised in order to obtain accurate quantification of genes and parameters such as primer specificity, length of target sequence and \% GC content are taken into account. Primers have been optimised to identify bacteria involved in biogeochemical cycles such as nitrogen fixation (Moisanader et al. 2008; Reimann et al. 2010), denitrification (Braker et al. 1998; Henry et al. 2004; Mosier and Francis 2010), ammonia oxidisation (Nicol et al. 2008), carbon cycling (Giri et al. 2004), chitin hydrolysis (Cottrell et al. 2000) and light energy utilisation (Schwalbach et al. 2005; Cottrell and Kirchman 2009). The majority of studies using qPCR have investigated bacteria from soils (Braker et al. 1998; Nicol et al. 2008; Henry et al. 2004) with some studies on marine environments (Cottrell et al. 2000; Giri et al. 2004; Schwalbach and Fuhrman 2005; Reimann et al. 2010; Mosier and Francis 2010). Few studies have investigated the functional potential of polar bacterial communities (Cottrell and Kirchman 2009; Yergeau et al. 2007) with none exploring bacteria in Antarctic sea ice.

The investigation of bacterial enzymatic activity can also give insight into the role of bacterial communities in biogeochemical cycles (i.e. Hoppe 2002; Bergamasco et al. 2003; Yu et al. 2009). Bacteria release enzymes into the environment that break down large polymers into monomers that can then be taken up by the bacteria and utilised (Hoppe 1983). The activity of bacterial enzymes can be measured using fluorescently labelled synthetic substrates (methylumbelliferyl (MUF) substrates or methylcoumarin (MCA) substrates), a sensitive technique pioneered by Hoppe (1983). If the bacterial enzyme of interest is present, the synthetic substrate will be cleaved producing fluorescence that can then be measured. In Arctic sea ice, bacterial enzymes degrade large macromolecules such as proteins, cellulose, lignin, and lipids into soluble monomer molecules such as amino acids, glucose, fatty acids, and glycerol. This technique has not been applied to Antarctic sea ice microbes so far. 
The aims of this chapter were to 1) investigate various DNA and RNA extraction methods; 2) develop a method to collect intact RNA from sea ice; 3) compare two widely used fingerprinting techniques to determine which best describes sea ice community structure; 4) develop a method to quantify gene expression in sea ice and 5) develop a collection method to investigate bacterial activity using methylumbelliferyl (MUF) substrate analysis.

\subsection{MethodS}

\subsubsection{Nucleic acid extraction}

One L of Wellington Harbour water was filtered through a $47 \mathrm{~mm} 0.2 \mu \mathrm{m}$ polycarbonate filter (Whatman Plc, USA) using a diaphragm vacuum pump and either stored in $2 \mathrm{~mL}$ of extraction buffer (Appendix A) or RNAlater ${ }^{\mathrm{TM}}$. Secondly, $2.6 \mathrm{~L}$ of Wellington Harbour water was filtered through a $3 \mu \mathrm{m}$ pre-filter followed by concentration of microbes onto a $0.22 \mu \mathrm{m}$ Sterivex cartridge (Millipore) using a peristaltic pump.

\subsubsection{Simultaneous DNA / RNA extraction}

Extraction methods that could isolate the DNA and RNA simultaneously were trialled. Four different DNA / RNA extraction kits were tested on filters that had been stored in $2 \mathrm{~mL}$ RNAlater ${ }^{\mathrm{TM}}$ at $-20^{\circ} \mathrm{C}$ (Table 2.1).

Table 2.1 DNA / RNA extraction kits trialled.

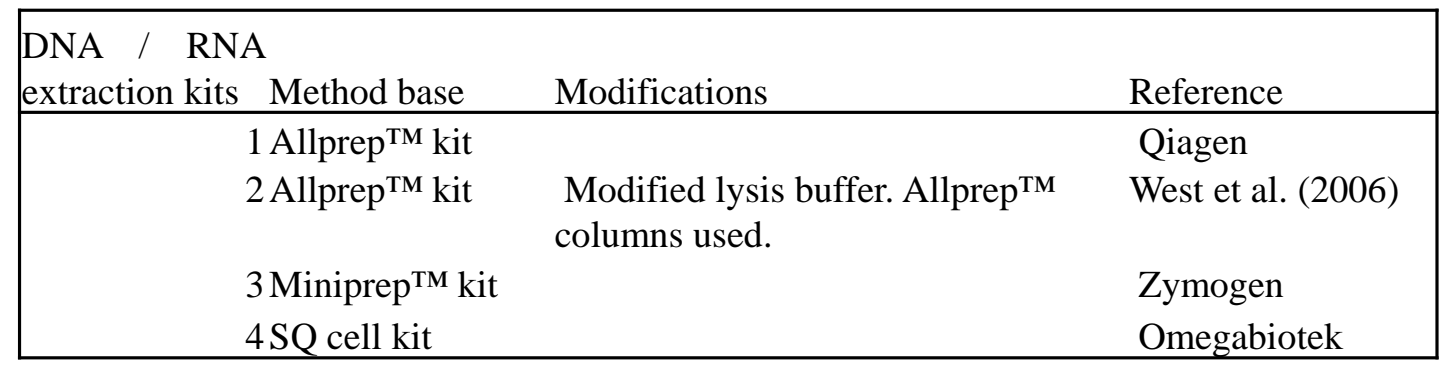


Filters were cut into pieces aseptically and cells were disrupted by vortexing with 0.2 $\mathrm{g}$ of $0.1 \mathrm{~mm}$ glass beads in $600 \mu \mathrm{L}$ buffer RTL containing $6 \mu \mathrm{L}$ of $\beta$-mercaptoethanol. The sample was transferred to an AllPrep DNA spin column and centrifuged. The DNA remained within the column while the RNA was extracted into the flowthrough. To the RNA flow-through, 1 volume of $70 \%$ ethanol was added and mixed by pipetting. The flow-through was transferred to an RNeasy spin column and was centrifuged for $15 \mathrm{~s}$ at $10,000 \mathrm{x}$. The flow-through was discarded and $700 \mu \mathrm{L}$ Buffer RW1 was added to the RNeasy spin column and again centrifuged. The RNA was washed by adding $500 \mu \mathrm{L}$ Buffer RPE to the spin column and again centrifuging. This step was repeated. The RNeasy spin column was placed in a new collection tube and the RNA was eluted into RNase-free water through centrifugation for $1 \mathrm{~min}$ at 10,000 $\mathrm{x}$ g. The DNA was washed by adding $500 \mu \mathrm{L}$ Buffer AW1 to the AllPrep DNA spin column and centrifugation for $15 \mathrm{~s}$ at $10,000 \mathrm{x}$. This step was repeated and the AllPrep DNA spin column was placed in a new collection tube. Buffer EB warmed to $37{ }^{\circ} \mathrm{C}$ was added directly to the spin column membrane and incubated at room temperature for $1 \mathrm{~min}$. The AllPrep spin column was centrifuged for $1 \mathrm{~min}$ at 8,000 $\mathrm{x}$ $\mathrm{g}$ to elute the DNA.

\section{DNA/RNA method 2- Allprep kit (Qiagen) with modifications}

The filter was added to $840 \mu \mathrm{L}$ of lysis buffer (40 mM EDTA, $50 \mathrm{mM}$ Tris- $\mathrm{HCl}(\mathrm{pH}$ 7.4), $0.75 \mathrm{M}$ sucrose and $15 \%$ Tween 80) and incubated with $50 \mu \mathrm{L}$ lysozyme (20 $\mathrm{mg} / \mathrm{mL}$ ) at $37{ }^{\circ} \mathrm{C}$ for $45 \mathrm{~min}$. The sample was then incubated at $55{ }^{\circ} \mathrm{C}$ for $30 \mathrm{~min}$ with sodium dodecyl sulfate (SDS, final concentration 1\% (wt. / vol)) and proteinase $\mathrm{K}$ (final concentration $0.5 \mathrm{mg} / \mathrm{mL}$ ). The lysate was split into $2 \times 600 \mu \mathrm{L}$ fractions with one fraction following the Allprep DNA protocol to isolate DNA and the other the Allprep RNA protocol to isolate RNA as previously described in the DNA/RNA method 1 extraction method but using Polyinosinic acid as a carrier (Invitrogen). 
To the filter, $400 \mu \mathrm{L}$ DNA/RNA Lysis Buffer 1 was added and the sample was homogenised with $0.2 \mathrm{~g}$ of $0.1 \mathrm{~mm}$ glass beads in a Ribolyser (Hybaid) at setting 4.0 for 2 x 30 s. The sample was then placed in a Zymo-Spin ${ }^{\mathrm{TM}}$ IIIC Column and centrifuged at $\geq 12,000 \mathrm{x}$ g for $1 \mathrm{~min}$. The flow-through contained RNA where as the column contained the DNA. To the RNA-containing flow-through, $0.8 \mathrm{x}$ volume ethanol (99\%) was added and mixed by pipetting. The sample was transferred into a Zymo-Spin ${ }^{\mathrm{TM}}$ IIC Column and centrifuged at $\geq 12,000 \mathrm{x}$ g for $1 \mathrm{~min}$. To the column, $400 \mu \mathrm{L}$ of RNA Prep Buffer was added and the column was again centrifuged. The RNA was washed by adding $700 \mu \mathrm{L}$ RNA Wash Buffer to the column followed by centrifugation. The wash step was repeated followed by centrifugation of the ZymoSpin ${ }^{\mathrm{TM}}$ IIC Column in an empty collection tube for 2 min to remove any excess buffer. To the column matrix $25 \mu \mathrm{L}$ of RNase-free water were added and incubated for $1 \mathrm{~min}$ at room temperature. The RNA was eluted through centrifugation at 10,000 $\mathrm{x} g$ for $30 \mathrm{~s}$. To the DNA-containing column, $200 \mu \mathrm{L}$ of DNA Prep Buffer were added and centrifuged at $13,000 \mathrm{rpm}$ for $30 \mathrm{~s}$. The DNA was washed by adding 500 $\mu \mathrm{L}$ DNA Wash Buffer to the column and centrifugation. Any excess buffer was removed by centrifuging the Zymo-Spin ${ }^{\mathrm{TM}}$ IIIC Column in an emptied collection tube for $2 \mathrm{~min}$. To the column matrix, $50 \mu \mathrm{L}$ RNase-free water were added and incubated for $5 \mathrm{~min}$ at room temperature The DNA was eluted by centrifugation at maximum speed for $30 \mathrm{~s}$.

\section{DNA/RNA method 4- SQ DNA/RNA cell kit (Omegabiotek)}

To the filter, $300 \mu \mathrm{L}$ of SQ1 cell lysis buffer was added and the sample was homogenised with $0.2 \mathrm{~g}$ of glass beads in a Ribolyser on setting 4.0 for 2 x $30 \mathrm{~s}$. To the sample, $100 \mu \mathrm{L}$ of SQ2 buffer was added and vortexed for $30 \mathrm{~s}$. The sample was incubated on ice for $10 \mathrm{~min}$ followed by centrifugation for $10 \mathrm{~min}$. The supernatant was removed and placed in a fresh Eppendorf tube to which isopropanol was added to precipitate the DNA and RNA. After the centrifugation to collect RNA pellet, the supernatant was mixed with Buffer SQ3 to precipitate DNA. The DNA and RNA pellets were dissolved with RNase-free water. 
Table 2.2 Overview of DNA extraction methods

\begin{tabular}{|c|c|c|c|}
\hline DNA extraction method & Method base & Modifications & Reference \\
\hline 1 & Phenol:chloroform & $\begin{array}{l}\text { Modified lysis buffer. Incubated at } 37^{\circ} \mathrm{C} \\
\text { overnight. DNA precipitated using linear } \\
\text { acrylamide. }\end{array}$ & Moeseneder et al. (2001) \\
\hline 2 & Phenol:chloroform & $\begin{array}{l}\text { No lysis buffer, phenol and chloroform added } \\
\text { separately. Stored in extraction buffer. }\end{array}$ & Moeseneder et al. (2001) \\
\hline 3 & DNAeasy kit & $\begin{array}{l}\text { Lysis buffer and lyzozyme added and incubated } \\
\text { at } 37^{\circ} \mathrm{C} \text { for } 1 \mathrm{hr} \text {. Proteinase } \mathrm{K} \text { and buffer } \mathrm{AL} \\
\text { added and incubated at } 56^{\circ} \mathrm{C} \text { for } 2 \mathrm{~h} \text {. }\end{array}$ & Qiagen \\
\hline 4 & DNAeasy kit & $\begin{array}{l}\text { Stored in RNAlater. Above modifications } \\
\text { followed. }\end{array}$ & \\
\hline 5 & $\begin{array}{l}\text { Phenol:chloroform } \\
\text { with Sterivex } \\
\text { Cartridge }\end{array}$ & $\begin{array}{l}\text { Modified lysis buffer. Incubated at } 37^{\circ} \mathrm{C} \\
\text { overnight. DNA precipitated using linear } \\
\text { acrylamide. }\end{array}$ & Moeseneder et al. (2001) \\
\hline
\end{tabular}




\subsubsection{DNA extraction methods}

Five different DNA extraction methods were trialled on Wellington Harbour water to determine the best method for DNA quantity and quality from environmental samples (Table 2.2). DNA quantity was assessed using the sensitive fluorescent nucleic acid stain Quant-iT ${ }^{\mathrm{TM}}$ PicoGreen ${ }^{\circledR}$ dsDNA reagent as described later in this chapter. The ability for the $16 \mathrm{~S}$ rRNA gene to be amplified and the quality of the band was checked by electrophoresis. If the DNA has been degraded or inhibitors have been coextracted, the amplification of the 16S rRNA gene will be compromised showing few or no bands on an agarose gel.

\section{DNA method 1- phenol:chloroform}

The DNA was extracted using a modified version of the phenol: chloroform method (Moeseneder et al. 2001). Filters were stored in enzymatic lysis buffer (40 mM EDTA, $50 \mathrm{mM}$ Tris- $\mathrm{HCl}$ (pH 7.4), $0.75 \mathrm{M}$ sucrose and $15 \%$ Tween 80) at $-20{ }^{\circ} \mathrm{C}$ until processing. Filters were cut into pieces aseptically and put into $1 \mathrm{~mL}$ of enzymatic lysis buffer and incubated with lysozyme (final concentration $2 \mathrm{mg} / \mathrm{mL}$ ) at $37{ }^{\circ} \mathrm{C}$ overnight. The sample was then incubated at $55^{\circ} \mathrm{C}$ for $2 \mathrm{~h}$ with sodium dodecyl sulfate (SDS, final concentration 1\% (wt. /vol)) and proteinase $\mathrm{K}$ (final concentration $0.5 \mathrm{mg} / \mathrm{mL}$ ). DNA was extracted using an equal volume of phenol-chloroformisoamyl alcohol (25:24:1) followed by chloroform-isoamyl alcohol (24:1). DNA was precipitated at $-20{ }^{\circ} \mathrm{C}$ overnight using $5 \mu \mathrm{g} / \mathrm{mL}$ linear acrylamide (Ambion Inc, USA), in 0.25 volume $5 \mathrm{M}$ ammonium acetate and 1 volume $100 \%$ isopropanol. The DNA was pelleted by centrifugation at $\geq 12,000 \mathrm{x}$ g for $20 \mathrm{~min}$ at $4{ }^{\circ} \mathrm{C}$. The pellet was washed using $70 \%$ ethanol (Sigma) then left to air dry. The pellet was resuspended in $20 \mu \mathrm{L}$ DEPC-water and DNases were inactivated by incubation at $65{ }^{\circ} \mathrm{C}$ for $10 \mathrm{~min}$.

\section{DNA method 2- phenol:chloroform}

Filters were stored in enzymatic lysis buffer at $-20{ }^{\circ} \mathrm{C}$. They were cut into pieces aseptically and suspended in $1 \mathrm{~mL}$ TE buffer in a $2 \mathrm{~mL}$ Eppendorf tube. The sample was incubated overnight at $37^{\circ} \mathrm{C}$ with lysozyme (final concentration $2 \mathrm{mg} / \mathrm{mL}$ ). 
Sodium dodecyl sulphate (SDS, final concentration 1\% (wt. /vol)) and proteinase K (final concentration $0.2 \mathrm{mg} / \mathrm{mL}$ ) were added and incubated at $65{ }^{\circ} \mathrm{C}$ for $1 \mathrm{~h}$. DNA was extracted using an equal volume of TE buffered phenol, the sample was centrifuged for $10 \mathrm{~min}$ at $\geq 12,000 \mathrm{x} \mathrm{g}$ and the aqueous layer removed to a new Eppendorf tube. An equal volume of chloroform was added to the aqueous layer and then the samples were centrifuged. DNA was precipitated from the aqueous layer at $20{ }^{\circ} \mathrm{C}$ overnight using $5 \mu \mathrm{g} / \mathrm{mL}$ linear acrylamide as described previously.

\section{DNA method 3,4- DNeasy ${ }^{\mathrm{TM}}$ kit (Qiagen)}

Filters were stored in either i) enzymatic lysis buffer or ii) RNAlater at $-20{ }^{\circ} \mathrm{C}$ until they were processed. Filters were cut into pieces aseptically and suspended in $550 \mu \mathrm{L}$ enzymatic lysis buffer with lysozyme (final concentration $2 \mathrm{mg} / \mathrm{mL}$ ). The sample was incubated for $1 \mathrm{~h}$ shaking at $100 \mathrm{rpm}$. Proteinase K (final concentration $0.2 \mathrm{mg} /$ $\mathrm{mL}$ ) and $1 \mathrm{x}$ volume $\mathrm{AL}$ buffer (DNeasy ${ }^{\mathrm{TM}}$ kit, with no ethanol added) were added and incubated at $56^{\circ} \mathrm{C}$ for $2 \mathrm{~h}$ shaking at $100 \mathrm{rpm}$. The supernatant was removed to a sterile tube and $1 / 2 \times$ volume $99 \%$ ethanol was added and vortexed to mix. The entire volume was transferred onto a DNeasy ${ }^{\mathrm{TM}}$ mini spin column and centrifuged at $\geq 6,000$ $\mathrm{x} g$ for $1 \mathrm{~min}$. The DNA was washed by adding $500 \mu \mathrm{L}$ Buffer AW1 to the spin column followed by centrifugation. This step was repeated using $500 \mu \mathrm{L}$ Buffer AW2 followed by centrifugation at maximum speed for $3 \mathrm{~min}$. To the column matrix, buffer $\mathrm{AE}$ was added and the column was incubated at room temperature for 1 min before centrifugation at $\geq 12,000 \mathrm{x} g$ for $1 \mathrm{~min}$.

\section{DNA method 5- Sterivex cartridge}

The cartridge was stored in extraction buffer and frozen until analysis. The cartridge was thawed on ice and $40 \mu \mathrm{L}$ of lysozyme $(50 \mathrm{mg} / \mathrm{mL})$ was added to each unit. The cartridges were incubated at $37{ }^{\circ} \mathrm{C}$ overnight in a shaking incubator at $100 \mathrm{rpm}$. To each cartridge, $100 \mu \mathrm{L}$ proteinase $\mathrm{K}(10 \mathrm{mg} / \mathrm{mL})$ and $100 \mu \mathrm{L} 20 \%$ SDS were added and incubated at $55^{\circ} \mathrm{C}$ for $2 \mathrm{~h}$. The lysate was drawn from the cartridge using a sterile syringe and put into $2 \times 2 \mathrm{~mL}$ Eppendorf tubes. DNA was extracted using an equal volume of phenol-chloroform-isoamyl alcohol (25:24:1), followed by 
chloroform-isoamyl alcohol (24:1). DNA was precipitated at $-20{ }^{\circ} \mathrm{C}$ overnight using 5 $\mu \mathrm{g} / \mathrm{mL}$ linear acrylamide as described previously.

\subsubsection{RNA extraction methods}

Four RNA extraction methods were trialled on Wellington Harbour water to determine the best method for RNA quantitification and 16S rRNA gene amplification from bacterial samples. Filters were stored in 2 mL RNAlater ${ }^{\mathrm{TM}}$ at -20 ${ }^{\circ} \mathrm{C}$ until they were processed (Table 2.3).

Table 2.3 Overview of RNA extraction methods

\begin{tabular}{|c|c|c|c|}
\hline $\begin{array}{l}\text { RNA } \\
\text { extraction } \\
\text { method }\end{array}$ & Method base & Modifications & Reference \\
\hline 1 & $\begin{array}{l}\text { Guanidinium } \\
\text { thiocynate }\end{array}$ & & $\begin{array}{l}\text { Chomczynski and } \\
\text { Sacchi (1987) }\end{array}$ \\
\hline 2 & TRIzol® & & Invitrogen \\
\hline 3 & RNeasy $^{\mathrm{TM}}$ kit & $\begin{array}{l}\text { Sample homogenised using } 0.1 \mathrm{~mm} \\
\text { beads and a Ribolyser (Hybaid). }\end{array}$ & Qiagen \\
\hline 4 & RNeasy $^{\mathrm{TM}}$ kit & $\begin{array}{l}\text { Sample homogenised as above with } \\
\text { also } 0.1 \mathrm{~g} \text { of } 2 \mathrm{~mm} \text { glass beads }\end{array}$ & \\
\hline 5 & RNeasy $^{\mathrm{TM}}$ kit & $\begin{array}{l}\text { Decreased homogenisation time to } \\
2 \times 20 \mathrm{~s}\end{array}$ & \\
\hline
\end{tabular}

\section{RNA method 1- guanidinium thiocynate}

$1 \mathrm{~mL}$ of denaturing solution was added (4M guanidinium thiocynate, $100 \mathrm{mM} \beta$ mercaptoethanol) to the filter with $0.2 \mathrm{~g}$ of acid washed and sterilised $0.1 \mathrm{~mm}$ glass beads (Syntech Distributors, New Zealand). Samples were homogenised in a Ribolyser (Hybaid) at a setting of 4.0 for $30 \mathrm{~s}$ and incubated at $55{ }^{\circ} \mathrm{C}$ for $1 \mathrm{~h}$. An equal volume of phenol-chloroform-isoamyl alcohol (25:24:1) was added and vortexed for $1 \mathrm{~min}$ followed by incubation on ice for $15 \mathrm{~min}$. The samples were centrifuged at $\geq 12000 \mathrm{x}$ g at $4{ }^{\circ} \mathrm{C}$ to separate the phases and the aqueous phase was removed to a fresh tube. To each sample, 1/10 volume of sodium acetate (3M) was 
added and vortexed. Chloroform-isoamyl alcohol (24:1) was added at $1 \mathrm{x}$ volume. The samples were vortexed for $1 \mathrm{~min}$ and incubated on ice for $15 \mathrm{~min}$. The samples were centrifuged, the aqueous phase removed and the RNA was precipitated at $-20{ }^{\circ} \mathrm{C}$ overnight using $5 \mu \mathrm{g} / \mathrm{mL}$ linear acrylamide (Ambion) in 0.25 volume $5 \mathrm{M}$ ammonium acetate and 1 volume $100 \%$ isopropanol. The RNA pellet was washed using $70 \%$ ethanol (Sigma) then left to air dry. The pellet was suspended in $20 \mu \mathrm{L}$ DEPC- water.

\section{RNA method 2- TRIzol®}

To each sample, $0.75 \mathrm{~mL}$ of TRIzol ${ }^{\circledR}$ and $0.2 \mathrm{~g}$ of acid washed and sterilised $0.1 \mathrm{~mm}$ glass beads were added. The samples were homogenised in a Ribolyser (Hybaid) for 2 x $20 \mathrm{~s}$ at setting 6.0. The samples were incubated on ice between homogenisation. Samples were incubated for $5 \mathrm{~min}$ at $30{ }^{\circ} \mathrm{C}$; $0.2 \mathrm{~mL}$ chloroform was added and incubated again at $30{ }^{\circ} \mathrm{C}$ for $10 \mathrm{~min}$. Samples were centrifuged at $\geq 12,000 \mathrm{x}$ g at $4{ }^{\circ} \mathrm{C}$ for 5 min to obtain a separation of phases. The aqueous phase was removed to a sterile Eppendorf tube and $0.5 \mathrm{~mL}$ isopropanol was added. The samples were incubated at $30{ }^{\circ} \mathrm{C}$ for $10 \mathrm{~min}$ before centrifugation to obtain a pellet. The RNA was precipitated at $-20{ }^{\circ} \mathrm{C}$ overnight using $5 \mu \mathrm{g} / \mathrm{mL}$ linear acrylamide (Ambion Inc, USA), in 0.25 volume $5 \mathrm{M}$ ammonium acetate and 1 volume $100 \%$ isopropanol. The RNA pellet was washed using $70 \%$ ethanol (Sigma) then left to air dry. The pellet was suspended in $20 \mu \mathrm{L}$ DEPC- water.

\section{RNA method 3, 4, 5- RNeasy ${ }^{\mathrm{TM}}$ kit}

The filter was cut into small pieces aseptically and $300 \mu \mathrm{L}$ of $0.1 \mathrm{~mm}$ beads (method 3) or $300 \mu \mathrm{l}$ of $0.1 \mathrm{~mm}$ beads $+0.1 \mathrm{~g} 2 \mathrm{~mm}$ glass beads (methods 4, 5) and $600 \mu \mathrm{L}$ RTL buffer (RNeasy ${ }^{\text {TM }}$ kit) with $\beta$-mercaptoethanol $(10 \mu \mathrm{L} / \mathrm{mL})$ was added. The samples were homogenised using a Ribolyser (Hybaid) as for methods 3 and 4 (Table 2.3) on setting 6.0 for $30 \mathrm{~s}$ followed by incubation on ice for $1.5 \mathrm{~min}$, then both steps were repeated two more times. For method 5 (Table 2.3), samples were homogenised on setting 4.0 for 20 s followed by incubation on ice for $1.5 \mathrm{~min}$ then both steps were repeated. To the homogenate, 1 volume of $70 \%$ ethanol was added and mixed by pipetting. The homogenate was transferred to an RNeasy spin column and was 
centrifuged for $15 \mathrm{~s}$ at $10,000 \mathrm{x}$ g. The flow-through was discarded and $700 \mu \mathrm{L}$ Buffer RW1 were added to the RNeasy spin column and again centrifuged. The RNA was washed by adding $500 \mu \mathrm{L}$ Buffer RPE to the spin column and again centrifuging. This step was repeated. The RNeasy spin column was placed in a new collection tube and the RNA was eluted into RNase-free water through centrifugation for $1 \mathrm{~min}$ at 10,000 $\mathrm{x}$ g. DNA was removed by adding $1 \mathrm{x}$ Reaction Buffer and 1 unit of Amplification Grade DNase I (Sigma-Aldrich) to the RNA. The RNA was incubated at room temperature for $15 \mathrm{~min}$ before adding stop solution (final concentration of $1 \%$ ). The samples were incubated at $70{ }^{\circ} \mathrm{C}$ for $10 \mathrm{~min}$ and then stored at $-20^{\circ} \mathrm{C}$.

\subsubsection{Quantity and quality check of DNA and RNA}

The quantity of the DNA and RNA extracted from each method was determined using the sensitive fluorescent nucleic acid stain Quant-iT ${ }^{\mathrm{TM}}$ PicoGreen ${ }^{\circledR}$ dsDNA reagent and Quant-iT ${ }^{\mathrm{TM}}$ RicoGreen ${ }^{\circledR}$ (Molecular Probes Ltd). RNA was converted to cDNA using SuperScript ${ }^{\mathrm{TM}}$ III First-Strand Synthesis SuperMix using random hexamers as primers following the manufactures protocol (Invitrogen, Carlsbad, USA). To determine if inhibitors were present effecting the amplification of the 16S rRNA gene, the 16S rRNA gene was amplified from the DNA and cDNA using the bacterial specific primer pair F27m (5-AGRGTTTGATCCTGGCTCAg-3) and R1391 (5GACGGGCGGTGWGTRCA-3). To each $25 \mu \mathrm{L}$ reaction, $10 \mathrm{ng}$ of DNA and $1 \mathrm{ng}$ of cDNA were added and denatured at $95{ }^{\circ} \mathrm{C}$ prior to amplification with 30 cycles consisting of denaturation at $95{ }^{\circ} \mathrm{C}$ for $45 \mathrm{~s}$, primer annealing at $50{ }^{\circ} \mathrm{C}$ for $60 \mathrm{~s}$, and elongation at $72{ }^{\circ} \mathrm{C}$ for $60 \mathrm{~s}$. The final elongation step was at $72{ }^{\circ} \mathrm{C}$ for $7 \mathrm{~min}$ in an Applied Biosystems 2700 PCR Machine (Applied Biosystems, Ltd). The amplification ability of the 16S rRNA gene was investigated by visualisation of the $16 \mathrm{~S}$ rRNA band on a $1 \%$ agarose gel and the amplified PCR products quantified using Quant-iTTM PicoGreen ${ }^{\circledR}$.

\subsubsection{Collection of RNA from sea ice}

Seven methods were trialled to investigate the best method for obtaining a high yield of RNA from Antarctic sea ice collected in September/October 2008 (Table 2.4). The methods were i) sea ice was scraped from the sea ice core into a $5 \mathrm{~mL}$ cryovial and 
stored at $-80^{\circ} \mathrm{C}$; ii) the sea ice core was melted rapidly in $0.22 \mu \mathrm{m}$ filtered autoclaved seawater using a warm water bath (30-60 min), and the bacteria were collected onto a $0.2 \mu \mathrm{m}$ polycarbonate filter and stored in $2 \mathrm{~mL}$ of RNAlater ${ }^{\mathrm{TM}}$; iii-vii) different concentrations of sea ice : RNAlater ${ }^{\mathrm{TM}}$ were trialled where $5 \mathrm{~mL}$ of sea ice were added to iii) $3.3 \mathrm{x}$, iv) $5 \mathrm{x}$ and v) $10 \mathrm{x}$ RNAlater ${ }^{\mathrm{TM}}$ and $10 \mathrm{~mL}$ of sea ice added to vi) $3.3 \times$ and vii) $5 \times$ RNAlater ${ }^{\mathrm{TM}}$ (Table 2.4). The RNA was extracted using the RNA/DNA Allprep ${ }^{\mathrm{TM}}$ method (Qiagen) and quantified using Quant-iT ${ }^{\mathrm{TM}}$ RicoGreen®.

Table 2.4 RNA collection methods from Antarctic sea ice.

\begin{tabular}{|c|c|c|c|}
\hline Method & Sea Ice core & RNAlater ${ }^{\mathrm{TM}}$ & Stored \\
\hline 1 & $2 \mathrm{~mL}$ ice & none & $-80^{\circ} \mathrm{C}$ \\
\hline 2 & $\sim 500 \mathrm{~mL}$ melted onto $0.22 \mu \mathrm{M}$ filter & $2 \mathrm{~mL}$ & $-20^{\circ} \mathrm{C}$ \\
\hline 3 & $5 \mathrm{~mL}$ ice & $10 \mathrm{~mL}$ & $-20^{\circ} \mathrm{C}$ \\
\hline 4 & $5 \mathrm{~mL}$ ice & $20 \mathrm{~mL}$ & $-20^{\circ} \mathrm{C}$ \\
\hline 5 & $5 \mathrm{~mL}$ ice & $45 \mathrm{~mL}$ & $-20^{\circ} \mathrm{C}$ \\
\hline 6 & $10 \mathrm{~mL}$ ice & $20 \mathrm{~mL}$ & $-20^{\circ} \mathrm{C}$ \\
\hline 7 & $10 \mathrm{~mL}$ ice & $40 \mathrm{~mL}$ & $-20^{\circ} \mathrm{C}$ \\
\hline
\end{tabular}

RNA was converted to cDNA using SuperScript ${ }^{\mathrm{TM}}$ III First-Strand Synthesis SuperMix as described previously. The 16S rRNA gene was amplified using the primer pair F27m and R1391. To each $25 \mu \mathrm{L}$ reaction, $5 \mu \mathrm{L}$ of cDNA were added and denatured at $95{ }^{\circ} \mathrm{C}$ prior to amplification over 30 cycles of denaturation at $95{ }^{\circ} \mathrm{C}$ for $45 \mathrm{~s}$, primer annealing at $50{ }^{\circ} \mathrm{C}$ for $60 \mathrm{~s}$, and elongation at $72{ }^{\circ} \mathrm{C}$ for $60 \mathrm{~s}$. The final elongation step was at $72{ }^{\circ} \mathrm{C}$ for $7 \mathrm{~min}$. The quality of the RNA was investigated by visualisation of the 16S rRNA band by gel electrophoresis.

\subsubsection{Comparison of fingerprinting techniques}

Pilot studies were performed on samples previously gathered from Antarctic sea ice in 2004 - 2007 by members of the K043 team. Samples from Cape Hallet in 2004 were collected by Aimee Simpson; those from Gondwana Station were collected by Libby Liggins in 2006 and Eileen Koh in 2007. Samples were filtered onto $0.2 \mu \mathrm{m}$ filters (Millipore, USA) and stored at $-80^{\circ} \mathrm{C}$. RNA analysis was not conducted on these 
previously collected samples as they were not stored in an appropriate preservative. Even though the samples were kept at $-80^{\circ} \mathrm{C}$, RNA is prone to degradation even at low storage temperatures.

Filters were cut into pieces aseptically and suspended in $1 \mathrm{~mL}$ TE buffer in a $2 \mathrm{~mL}$ Eppendorf tube. The sample was incubated overnight at $37{ }^{\circ} \mathrm{C}$ with lysozyme (final concentration $2 \mathrm{mg} / \mathrm{mL}$ ). Sodium dodecyl sulphate (SDS, final concentration $1 \%$ (wt. /vol)) and proteinase $\mathrm{K}$ (final concentration $0.2 \mathrm{mg} / \mathrm{mL}$ ) were added and incubated at $65{ }^{\circ} \mathrm{C}$ for $1 \mathrm{~h}$. DNA was extracted using the phenol:choloroform method as previously described with subsequent precipitation of the DNA using linear acrylamide.

\subsubsection{Denaturing gradient gel electrophoresis (DGGE)}

Two sets of primers for DGGE were trialled i) a standard primer pair for the V3 region F357 (5'-CCT ACG GGA GGC AGC AG-3') and R518 (5'-ATT ACC GCG GCT GCT GG-3'; Yu and Morrison 2004) and ii) a primer pair for the V6 region F967 (5'- CAACGCGAAAAACCTTACC-3') and R1046 (5'CGACAGCCATGCANCACCT-3'; Huber et al. 2007). Primers were made by Invitrogen with a GC clamp on the forward primer. Duplicate DGGE PCRs contained $10 \mathrm{ng}$ of DNA and $0.2 \mathrm{mM}$ of each primer, and made up to $25 \mu \mathrm{L}$ with DEPC-water in Illustra Ready-To-Go ${ }^{\mathrm{TM}}$ PCR Beads (GE Healthcare). The samples were denatured at $95{ }^{\circ} \mathrm{C}$ prior to amplification with 30 cycles of denaturation at $95{ }^{\circ} \mathrm{C}$ for $45 \mathrm{~s}$, primer annealing at $50{ }^{\circ} \mathrm{C}$ for $60 \mathrm{~s}$, and elongation at $72{ }^{\circ} \mathrm{C}$ for $60 \mathrm{~s}$. The reactions were combined, visualized on $1 \%$ agarose gels stained with ethidium bromide, and quantified using Quant-iT ${ }^{\mathrm{TM}}$ PicoGreen ${ }^{\circledR}$. DGGE was performed on an acrylamide gel with a gradient of 35 to 55\% urea using the DCode ${ }^{\mathrm{TM}}$ Universal Mutation Detection System (Bio-Rad Laboratories, München, Germany). To each lane, 500 ng of PCR product were added with $10 \mu \mathrm{L}$ of 10x loading dye. The DGGE gels were run in $1 \%$ TAE buffer (Bio-Rad) at $60{ }^{\circ} \mathrm{C}$ at $130 \mathrm{~V}$ for $4.5 \mathrm{~h}$. The gel was then stained with SYBR green and visualised under UV light. 


\subsubsection{Terminal restriction fragment length polymorphism (TRFLP)}

\section{PCR optimisation}

PCR for T-RFLP analysis was optimised using bacterial samples from Antarctic Ross Sea sediments (supplied by Els Maas, NIWA NZ). Four different DNA concentrations were investigated: $20 \mathrm{ng} / 25 \mu \mathrm{L}, 15 \mathrm{ng} / 25 \mu \mathrm{L}$ and $10 \mathrm{ng} / 25 \mu \mathrm{L}$ against a negative control with no DNA. Fluorescent primers and non-fluorescent primers were mixed at different ratios to determine the influence of primer concentration on overall PCR product yield. It has been previously found that T-RFLP PCR product yield can be increased by adding a small amount of non-fluorescent primers to the PCR (pers. comm. Els Maas).

\section{Taq polymerase optimising}

Several taq polymerases were investigated: Proof $^{\mathrm{TM}}$ High-Fidelity Master Mix (BioRad), PCR SuperMix (Invitrogen), AmpliTaq Gold® PCR Master Mix (AppliedBiosystems), Taq polymerase (Bioline), FastStart Master Mix (Roche) and Illustra Ready-To-Go ${ }^{\text {TM }}$ PCR Beads (GE Healthcare).

\section{PCR conditions and T-RFLP}

Each sample was amplified using the eubacterial specific primer pair $F 27 \mathrm{~m}$ and R1391. The forward primer was labelled at the 5' end with phosphoramidite fluorochrome 5- carboxy-fluorescein (5, 6-FAM, blue). The reverse primer was labelled with phosphoramidite fluorochrome 6-hexachlorofluorescein (5' 6-HEX, green). Two $50 \mu \mathrm{L}$ PCR reactions were carried out for each DNA sample separately. To each reaction, $20 \mathrm{ng}$ of DNA, $0.18 \mathrm{mM}$ of each fluorescent primer and $0.02 \mathrm{mM}$ of non-fluorescent primer were added and denatured at $95{ }^{\circ} \mathrm{C}$ prior to amplification with 30 cycles consisting of denaturation at $95{ }^{\circ} \mathrm{C}$ for $45 \mathrm{~s}$, primer annealing at $50{ }^{\circ} \mathrm{C}$ for $60 \mathrm{~s}$, and elongation at $72{ }^{\circ} \mathrm{C}$ for $60 \mathrm{~s}$. The final elongation step was at $72{ }^{\circ} \mathrm{C}$ for 7 min in an Applied Biosystems 2700 PCR Machine. The 16S rRNA band was visualized by gel electrophoresis on a $1 \%$ agarose gel. Samples with a positive $16 \mathrm{~S}$ rRNA bands were pooled, column purified following the spin column protocol 
(Zymogen) and quantified using Quant-iT ${ }^{\mathrm{TM}}$ PicoGreen ${ }^{\circledR}$ dsDNA reagent (Molecular Probes Ltd). The digestions were carried out in a total volume of $15 \mu \mathrm{L}$ containing 400 ng of PCR product and 10 units (U) of the restriction endonuclease $A l u$ I overnight at $37{ }^{\circ} \mathrm{C}$. This restriction enzyme was used as previous studies have shown it to be highly efficient in assessing bacterial diversity in aquatic assemblages (Osborn et al. 2000). The sample was re-quantified and a concentration of $10 \mathrm{ng} \mu \mathrm{L}^{-1}$ was sent for analysis on the ABI prism 3730 capillary sequencer run under GeneScan mode at the Allan Wilson Centre (Massey University, New Zealand). The size of the fluorescently labelled fragments was determined by comparison with the ROX 500 internal standard (Applied Biosystems).

\section{T-RFLP reproducibility}

The T-RFLP accuracy was checked by sending 5 individual PCR digestions taken from the same bottom sea ice sample at McMurdo Station in 2008. The electropheroGrams were compared to determine discrepancies that may arise from the capillary electrophoresis.

\subsubsection{Statistical analyses}

DGGE and T-RFLP DNA profiles were analyzed using BioNumerics ${ }^{\mathrm{TM}}$ (Applied Maths, Ghent, Belgium). DendroGrams were based upon the presence or absence of bands at each position and generated using the un-weighted pair group method with averages (UPGMA) cluster analysis parameter in BioNumerics ${ }^{\mathrm{TM}}$.

\subsubsection{Quantitative PCR}

\subsubsection{Primer optimisation}

Quantitative PCR (qPCR) of functional genes were optimised using DNA samples from bottom sea ice at McMurdo Station, Cape Roberts in 2008, seawater samples taken from New Zealand oceanic waters and genomic DNA from Lake Kinneret in Israel supplied by Eileen Koh (VUW, NZ). Functional genes have not previously been identified from Antarctic sea ice therefore these genes may or may not be present. To 
get a positive result, seawater and lake samples were also used to optimise qPCR. For example, as cyanobacteria have not been found in Antarctic sea ice (Koh, 2011) it is likely that the RuBisCo gene (cbbL) will not be found in Antarctic sea ice samples. Therefore oceanic water samples were used to optimise the qPCR for RuBisCo (Giri et al. 2004) in order to get a definite positive result.

A total of 16 primer pairs were investigated to target genes involved in dominant biogeochemical cycles (Appendix B). Each PCR reaction was carried out using $10 \mu \mathrm{L}$ of iProof $^{\mathrm{TM}}$ High-Fidelity Master Mix (BioRad), $10 \mathrm{ng}$ of DNA, $0.2 \mathrm{mM}$ of each primer and made up to $20 \mu \mathrm{L}$ with DEPC-water. To optimise the annealing temperature for each primer set, a PCR cycle with an initial denaturation step of $95^{\circ} \mathrm{C}$ was carried out for 5 min followed by 40 cycles of $95{ }^{\circ} \mathrm{C}$ for $30 \mathrm{~s}$, annealing at a temperature gradient between $46-60{ }^{\circ} \mathrm{C}$, and elongation at $72{ }^{\circ} \mathrm{C}$ for $1 \mathrm{~min}$. A final elongation step of $72{ }^{\circ} \mathrm{C}$ for 7 min was then carried out in a CFX96 ${ }^{\mathrm{TM}}$ real-time PCR detection system (BioRad). The correct size band and the optimal temperature for PCR were checked by gel electrophoresis.

\subsubsection{Sequence analysis}

Samples with the correct band size and high product yield were mixed with $5 \mu \mathrm{L}$ of 3 $\mathrm{x}$ dye and run on a $1 \%$ agarose gel. Each band was cut out with a sterile scalpel using a UV trans-illuminator and put into a fresh Eppendorf tube. The PCR amplicons were extracted using an Illustra GFX PCR and Gel purification kit (GE Healthcare). Briefly, $10 \mu \mathrm{L}$ of capture buffer type 2 were added to each $10 \mathrm{mg}$ of gel slice and incubated at $60{ }^{\circ} \mathrm{C}$ until dissolved. The sample was transferred to a GFX MicroSpin column, centrifuged and washed with wash buffer. The DNA was eluted using DNase / RNase free water and $7 \mu \mathrm{L}$ of the purified product was A-tailed. In each PCR reaction, 1 x FastStart ${ }^{\mathrm{TM}}$ Taq DNA Polymerase Reaction Buffer with $\mathrm{MgCl}_{2}$ (Roche), $0.2 \mathrm{mM}$ of dATP, $5 \mathrm{U}$ of FastStart ${ }^{\mathrm{TM}}$ Taq DNA Polymerase (Roche) and DEPC- $\mathrm{H}_{2} \mathrm{O}$ were added to make a final volume of $10 \mu \mathrm{L}$. Samples were incubated at $72{ }^{\circ} \mathrm{C}$ for 20 min. The products were immediately cloned into pGEM-T Easy vector (Promega, Maddison, Wis.) at a 3:1 ratio of insert: vector. Each reaction contained $25 \mathrm{ng}$ of pGEM®-T vector, 1 x ligation buffer, 1.5 Weiss units T4 DNA Ligase, $1.5 \mu \mathrm{L}$ of DNA and DEPC-water to make up to the final volume of $5 \mu \mathrm{L}$. The ligation reactions 
were incubated overnight at $4{ }^{\circ} \mathrm{C}$. The products were transformed into DH5- $\alpha$ (Invitrogen, Carlsbad, USA) chemically competent cells by adding $2 \mu \mathrm{L}$ of the ligation mix to $25 \mu \mathrm{L}$ of cells, incubating on ice for $30 \mathrm{~min}$, heat shocking at $42{ }^{\circ} \mathrm{C}$ for $45 \mathrm{~s}$ and then incubating on ice for $2 \mathrm{~min}$. To this mix, $150 \mu \mathrm{L}$ of LB broth were added and then incubated at $37^{\circ} \mathrm{C}$ for $60 \mathrm{~min}$ at $100 \mathrm{rpm}$. The cells were spread onto two LB plates supplemented with IPTG, X-Gal and Ampicillin (Appendix A). Two plates were used to give two different concentrations of colonies, where one plate was spread with $95 \mu \mathrm{L}$ of cells and the other with $25 \mu \mathrm{L}$ of cells. The plates were incubated at $37{ }^{\circ} \mathrm{C}$ overnight. As blue/white screening was used, the transformed cells developed colonies with distinct colouration after incubation. The white colonies were picked into $50 \mu \mathrm{L}$ of PCR grade water (Ambion) and stored at $-80{ }^{\circ} \mathrm{C}$. Individual colonies were amplified in blue PCR SuperMix (Invitrogen) with $0.2 \mathrm{mM}$ of the primers M13F and M13R. Clones containing the correct insert were detected by gel electrophoresis and purified using a column clean up kit following the manufacturer's instructions (Zymogen, Orange, CA). All samples were sequenced using the ABI 3730 DNA Analyzer (Applied Biosystem, USA) at the Allan Wilson Centre Genome Service centre at Massey University (Palmerston North, New Zealand). Sequences were identified using the BLAST search function (www.ncbi.nlm.nih.gov/BLAST).

\subsubsection{Methylumbelliferyl (MUF) Substrate Assays}

Water samples were collected on board the $R V$ Tangaroa using 6 different methods. For the first method, $2 \mathrm{~mL}$ of seawater were collected and frozen at $-20{ }^{\circ} \mathrm{C}$. For the following 3 methods, $2 \mathrm{~mL}$ of seawater was added to increasing volumes of RNAlater $^{\mathrm{TM}}(1: 1,1: 3,1: 5)$. The last two methods involved $200 \mathrm{~mL}$ of seawater filtered through a $0.2 \mu \mathrm{M}$ polycarbonate filter; either frozen at $-20{ }^{\circ} \mathrm{C}$ to be later suspended in PBS, or stored in $2 \mathrm{~mL}$ RNAlater ${ }^{\mathrm{TM}}$ and frozen at $-20^{\circ} \mathrm{C}$. In Antarctica, cores were collected from the top, middle and bottom $10 \mathrm{~cm}$ sections of the sea ice. The total community was collected from each section by taking i) an ice sample (15 x $15 \times 20 \mathrm{~mm}$ ) and storing it at $-20^{\circ} \mathrm{C}$, or fast melting each section following the protocol previously described and filtering the sample through a $0.2 \mu \mathrm{m}$ filter and both the ii) filter and iii) filtrate were collected and frozen at $-20{ }^{\circ} \mathrm{C}$. The filter was resuspended in $3.5 \mathrm{~mL}$ of PBS and vortexed. Four synthetic substrates were used to test for bacterial enzyme activity and analysed on one 96 well plate (Figure 2.1). 
MUF- $\beta$-D-glucoside detected the presence of enzymes that are used for degrading cellulose and hemicelluloses. MUF-phosphate detected inorganic phosphate recycling, where phosphate groups are removed from large compounds i.e. nucleic acids, MUF-N- $\beta$-D-acetyl-glucosaminide detected the degradation of chitins and MUF- oleate identified lipid utilisation. To $200 \mu \mathrm{L}$ of melted sea ice sample, $5 \mu \mathrm{L}$ of each synthetic substrate were added in triplicate. Negative controls containing no substrate, positive controls and the MUF fluorogenic standard were also included in duplicate. The positive controls used were glucosidase from almonds (Sigma), alkaline phosphatase (Roche) chitinase from Streptomyces griseus (Sigma) and lipase from wheat germ (Sigma). The samples were analysed for fluorescence every $5 \mathrm{~min}$ for $4 \mathrm{~h}$ using a Modulus ${ }^{\mathrm{TM}}$ microplate reader (Turner Biosystems).

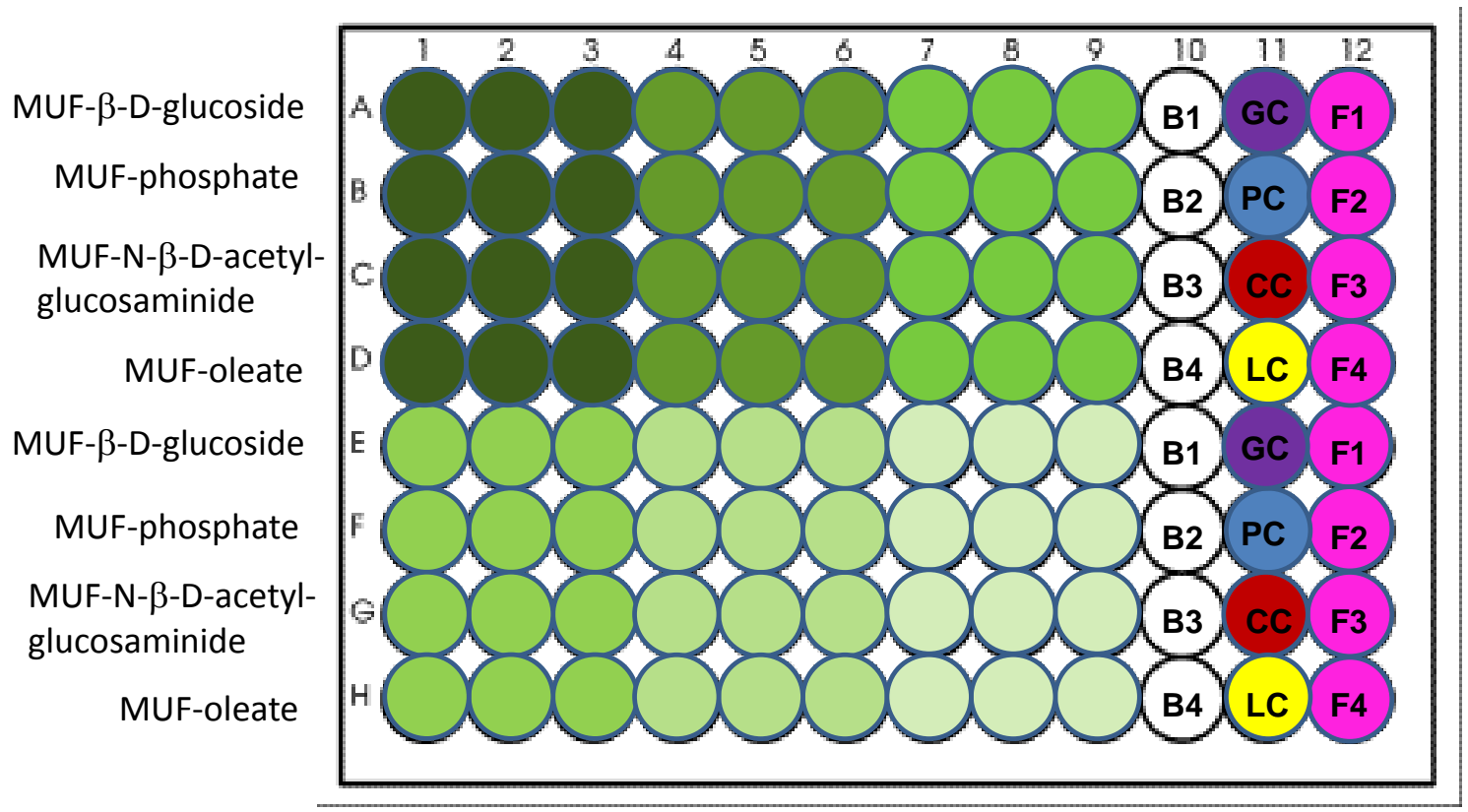

Figure 2.1 Diagram showing the set up of the 96 well plate to measure MUF fluorescence from Antarctic sea ice samples. Six samples (shown in shades of green) are analysed for MUF-b-Dglucoside, MUF-phosphate, MUF-N-b-D-acetyl-glucosaminide and MUF- oleate in triplicate. Blank samples contained substrate and PBS (B1-B4); the positive controls glucosidase (GC), alkaline phosphatase (PC), chitinase (CC), lipase (LC) and the MUF fluorescence standard curve (F1-F4) were added in duplicate. 


\subsection{Results}

\subsubsection{Nucleic acid extraction}

The DNA / RNA simultaneous extraction kits all failed to extract sufficient amounts of DNA for PCR amplification. Low yields of RNA were also extracted from all methods apart from the Allprep ${ }^{\text {TM }}$ kit (Table 2.5).

Table 2.5 DNA and RNA yields from the different simultaneous extraction kits in $n g \mathrm{~L}^{-1} \pm$ standard error, $n=4$. Total yield $\left(n \mathrm{~L}^{-1}\right)$ was calculated by multiplying the amount in $n g \mathrm{~L}^{-1}$ by the final volume the nucleic acids were extracted in.

The DNA extraction methods all obtained high yields of DNA which was visualised by an appropriate band when run on an agarose gel (data not shown). The highest yield of DNA was extracted using the phenol: chloroform DNA extraction method 1 which had longer incubation times for enzymatic lysis than the other methods (Table 2.6). RNAlater ${ }^{\mathrm{TM}}$ did not hinder DNA extraction as both methods using the DNeasy $^{\mathrm{TM}}$ kit gave similar yields.

Table 2.6 DNA quantity from the different simultaneous extraction kits in $n g \mathrm{~L}^{-1}$ and total yield $\mathrm{L}^{-1} \pm$ standard error, $n=4$. The total yield $\left(\mathrm{ng} \mathrm{L}^{-1}\right)$ was calculated by taking into account the volume filtered and the final volume the nucleic acids were extracted in.

\begin{tabular}{llrr} 
& DNA extraction method & ng $\mu \mathrm{L}^{-1}$ & total $\mathrm{ng} \mathrm{L}^{-1}$ \\
\hline 1 & Phenol:Chloro 1 & $34.05 \pm 2.29$ & $10,896 \pm 458$ \\
2 & Phenol:Chloro 2 & $21.04 \pm 2.06$ & $6,733 \pm 412$ \\
3 & DNeasy ${ }^{\mathrm{TM}}$ kit & $17.63 \pm 2.42$ & $5,643 \pm 484$ \\
4 & DNeasy & kit (RNAlater \\
$\mathrm{TM})$ & $17.03 \pm 1.86$ & $5,449 \pm 372$ \\
5 & Sterivex Phe:Chloro $^{\mathrm{TM}}$ & $106.50 \pm 0.35$ & $3,289 \pm 182$ \\
\hline
\end{tabular}


Although the Sterivex cartridge extracted the most DNA, when standardised to the number of litres filtered it had the least total yield. No RNA bands were present when viewed on an agarose gel. RNA was not extracted using the TRIzol® method. The guanidinium thiocynate and the RNeasy ${ }^{\mathrm{TM}}$ methods both extracted RNA. RNA yield could be increased from the RNeasy ${ }^{\mathrm{TM}}$ kit by adding $0.2 \mathrm{~mm}$ beads to the fine beads and homogenising the sample for a shorter period of time (Table 2.7).

Table 2.7 RNA from the different simultaneous extraction kits in $n g \mathrm{~L}^{-1}$ and total yield $\mathrm{L}^{-1} \pm$ standard error, $n=4$. The total yield $\left(\mathrm{ng} \mathrm{L}^{-1}\right.$ ) was calculated by taking into account the volume filtered and the final volume the nucleic acids were extracted in.

\begin{tabular}{|c|c|c|c|}
\hline & RNA extraction method & $\mathrm{ng} / \mu \mathrm{L}$ & total ng/ L \\
\hline 1 & TRIzol® & 0 & 0 \\
\hline 2 & Guanidinium thiocynate & $19.46 \pm 0.82$ & $3113.6 \pm 147.6$ \\
\hline 3 & RNeasy $^{\mathrm{TM}}$ kit & $2.95 \pm 0.64$ & $354.5 \pm 76.2$ \\
\hline 4 & RNeasy $^{\mathrm{TM}}$ kit & $28.28 \pm 3.06$ & $3393.4 \pm 367.8$ \\
\hline 5 & RNeasy $^{\mathrm{TM}}$ kit & $25.07 \pm 2.26$ & $3008.1 \pm 267.9$ \\
\hline
\end{tabular}

The 16S rRNA gene amplification ability from the DNA was checked by visualisation on an agarose gel. All samples produced a definite and appropriately sized band at approximately $1500 \mathrm{bp}$ with little smearing suggesting minimal shearing had occurred (Figure 2.2).

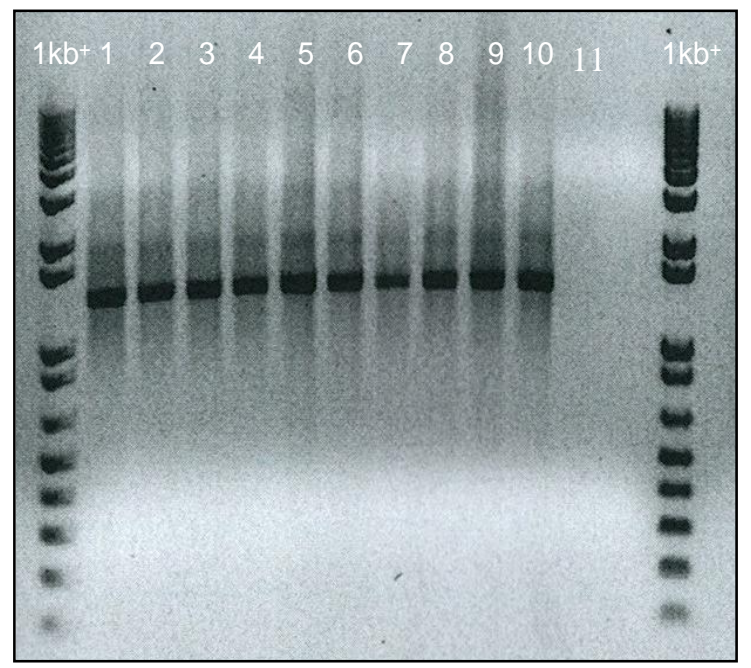

Figure 2.2 Agarose gel showing the 16S rRNA gene amplified from DNA from the phenol:chloroform extraction method 1 (lane 5, 6); method 2 (lane 1, 2); DNeasy 3 (lane 2, 3); DNeasy ${ }^{\mathrm{TM}}$ method 4 (lane 9, 10) and Sterivex method 5 (lane 7,8 ) against a blank control (lane 11) and $1 \mathrm{~kb}^{+}$ladder (Invitrogen). 


\subsubsection{Collection of RNA from Sea ice}

Only very small concentrations $(<1 \mathrm{ng} / \mu \mathrm{L})$ of RNA were extracted from Antarctic sea ice samples using the RNeasy ${ }^{\mathrm{TM}}$ method. Despite this, the samples were run through reverse transcription and 16S rRNA gene amplification.

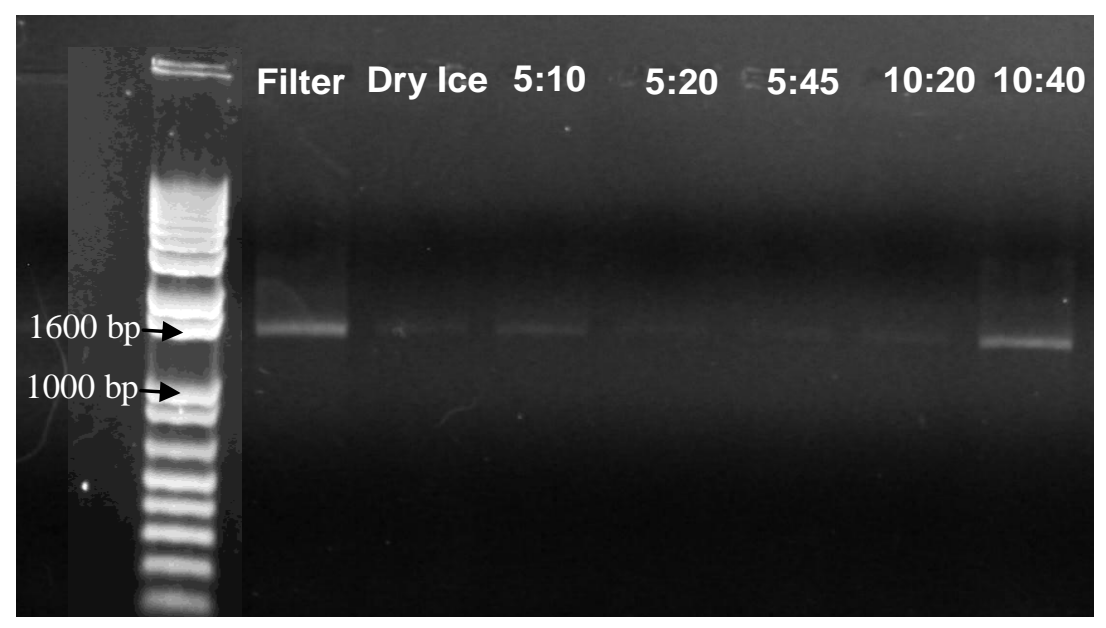

Figure 2.3 Gel showing the 16S rRNA gene from Antarctic sea ice taken from the 7 different extraction methods against a $1 \mathrm{~kb}+$ ladder.

The 16S rRNA gene was amplified from all samples (Figure 2.3) but the most product was obtained from two methods; where 1) the filter was stored in RNAlater ${ }^{\mathrm{TM}}$, and when 2) $10 \mathrm{~mL}$ of sea ice sample was stored in $5 \mathrm{x}$ volume of RNAlater ${ }^{\mathrm{TM}}$.

\subsubsection{Comparisons between fingerprinting methods}

\subsubsection{Denaturing gradient gel electrophoresis (DGGE)}

A denaturing gradient of $30-55 \%$ showed the best discrimination between bands (Figure 2.4). The V3 and the V6 primer sets both produced $\sim 15-20$ bands per sample (Figure 2.5). Each band refers to an individual operational taxonomic unit or OTU. There was a similar community pattern seen between sites where many of the OTUs were shared across sites (Figure 2.6). Bands with greater intensity suggested that these OTUs were potentially more abundant than bands that were faint. Many of these abundant OTUs were also found across many of the sites. 


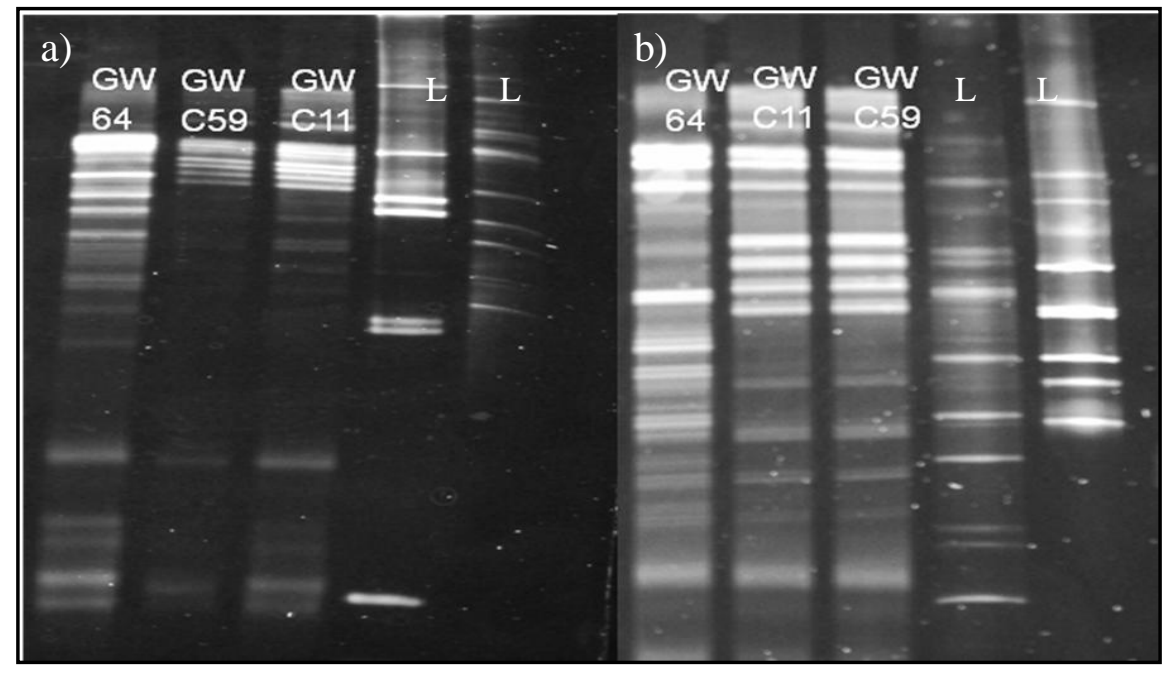

Figure 2.4 DGGE gels of three samples taken from Gondwana Station (GW) in 2007 against two ladders (L). Gel a) is a gradient of $20-80 \%$ whereas gel b) is a gradient of $30-55 \%$.

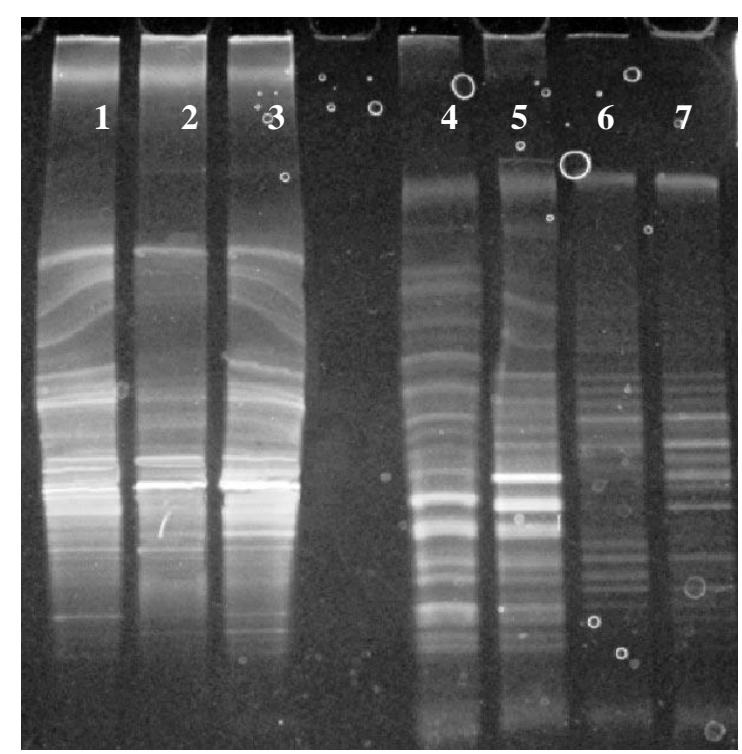

Figure 2.5 DGGE gel showing the profiles for the V3 (lanes 1 -3) and V6 (lanes 4 - 7) regions from samples taken from Cape Hallet $(\mathrm{CH})$ in 2006. Gel "smiling" seen in the upper left. 


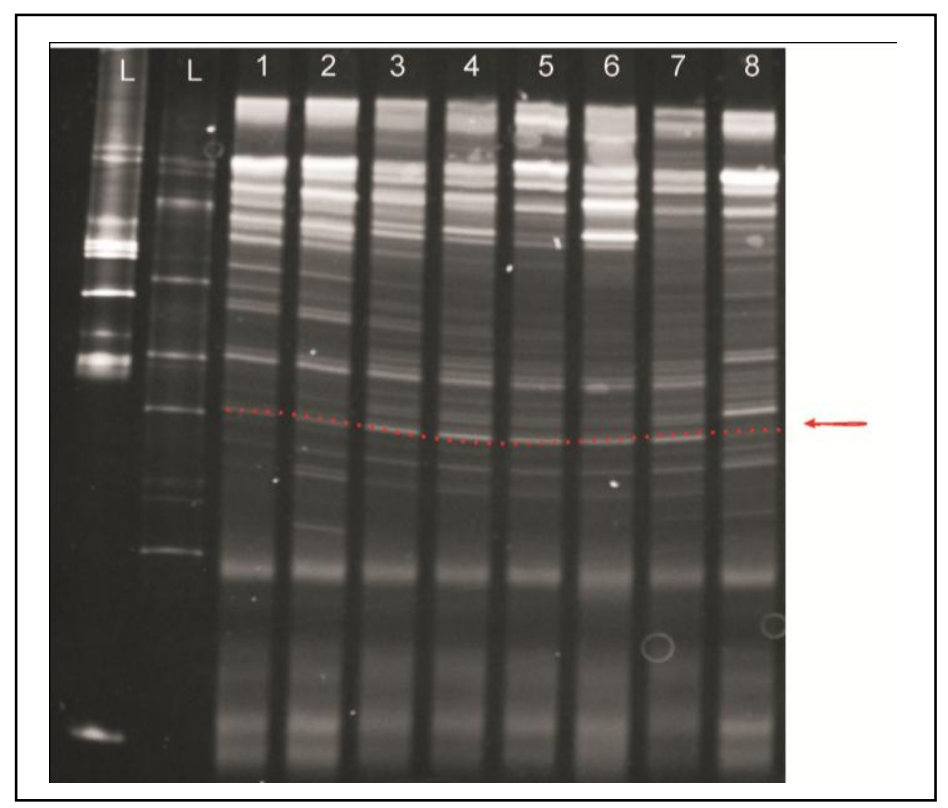

Figure 2.6 An example of a DGGE gel where each lane is a different bacterial community collected from the top (1) to the bottom (8) of the sea ice core at Gondwana Station in 2006 run against two ladders (L). An artefact, gel "smiling" can be seen, the curvature marked by the red line.

\subsubsection{Terminal restriction fragment length polymorphism (TRFLP)}

\section{PCR optimisation}

The concentration of DNA added to each PCR did not have a large effect on the amount of PCR product obtained. The greatest yield was obtained when only nonfluorescent primers were added to the PCR and the least when only fluorescent primers were added. However, increasing the primer concentration led to an increase in yield. Adding $0.1 \mu \mathrm{L}$ of non- fluorescent primer to $0.9 \mu \mathrm{L}$ of fluorescent primer gave the highest yield at 15 and 10 ng of DNA (Table 2.8). 
Table 2.8 DNA yield (ng $\mu \mathrm{L}^{-1}$ ) when amplified with different concentrations of DNA and fluorescent (F) and non- fluorescent (nF) primers.

\begin{tabular}{|l|l|l|l|l|}
\hline & \multicolumn{4}{|c|}{ DNA concentration (ng/ 25 $\mu$ reaction ) } \\
\hline $\begin{array}{l}\text { Primers }(\mu \mathrm{L} / 25 \mu \mathrm{L} \\
\text { reaction) }\end{array}$ & 20 & 15 & 10 & 0 \\
\hline $0.5 \mu \mathrm{LF}$ & 37.1 & 44.2 & 40.2 & 1.2 \\
\hline $0.45 \mu \mathrm{LF}+0.05 \mu \mathrm{L} \mathrm{nF}$ & 27.4 & 28.1 & 28.2 & 0.4 \\
\hline $0.4 \mu \mathrm{LF}+0.1 \mu \mathrm{LF}$ & 22.2 & 19.7 & 23.4 & 0.7 \\
\hline $0.2 \mu \mathrm{LF}+0.05 \mu \mathrm{LnF}$ & 16.2 & 15.3 & 13.3 & 0.5 \\
\hline $0.22 \mu \mathrm{LF}+0.03 \mu \mathrm{L} n \mathrm{~F}$ & 14.2 & 15.5 & 13.5 & 0.3 \\
\hline $0.68 \mu \mathrm{LF}+0.07 \mu \mathrm{L} \mathrm{nF}$ & 27.7 & 31.0 & 29.9 & 0 \\
\hline $0.9 \mu \mathrm{LF}+0.1 \mu \mathrm{LF}$ & 27.5 & 36.9 & 32.2 & 0 \\
\hline $0.5 \mu \mathrm{LF}$ & 32.1 & 27.2 & 31.3 & 0.8 \\
\hline $0.25 \mu \mathrm{LF}$ & 10.1 & 12.2 & 7.3 & 0.9 \\
\hline
\end{tabular}

\section{Taq polymerase optimisation}

The majority of the taq polymerases tested produced small PCR product yield after 16S rRNA amplification. The Ready-To-Go ${ }^{\text {TM }}$ RT-PCR Beads produced a high yield, but this was not enough after PCR clean up. However, they provide an inexpensive means to check each sample first for sufficient 16S rRNA amplification without fluorescent primers before proceeding to fluorescent PCR. The iProof ${ }^{\mathrm{TM}}$ High-Fidelity Master Mix produced enough PCR product from two reactions for digestion (Table 2.9).

Table 2.9 DNA yield of PCR products after amplification with various taq polymerases. The total yield is per reaction prior to PCR clean up.

\begin{tabular}{|c|c|c|}
\hline & $\mathrm{ng} \mu \mathrm{L}^{-1}$ & total \\
\hline PCR SuperMix & 3.67 & 73.4 \\
\hline FastStart Master Mix & 4.01 & 80.2 \\
\hline Platinum supermix & 4.11 & 82.2 \\
\hline AmpliTaq Gold® PCR Master Mix & 1.29 & 25.8 \\
\hline iProof $^{\mathrm{TM}}$ High-Fidelity Master Mix & 35 & 1750 \\
\hline Taq polymerase (Bioline) & 1.68 & 33.6 \\
\hline Ready-To-Go ${ }^{\text {TM }}$ RT-PCR Beads & 11 & 550 \\
\hline
\end{tabular}


T-RFLP was found to be reproducible, where the number, size and heights of peaks were comparable across the replicated samples (Figure 2.7). The Antarctic sea ice TRFLP profiles were characterised by some high peaks indicating that some dominant bacterial groups were found across sites. T-RFLP profiles produced 30-50 different restriction fragment lengths (RFLs) from both the forward and reverse primers.

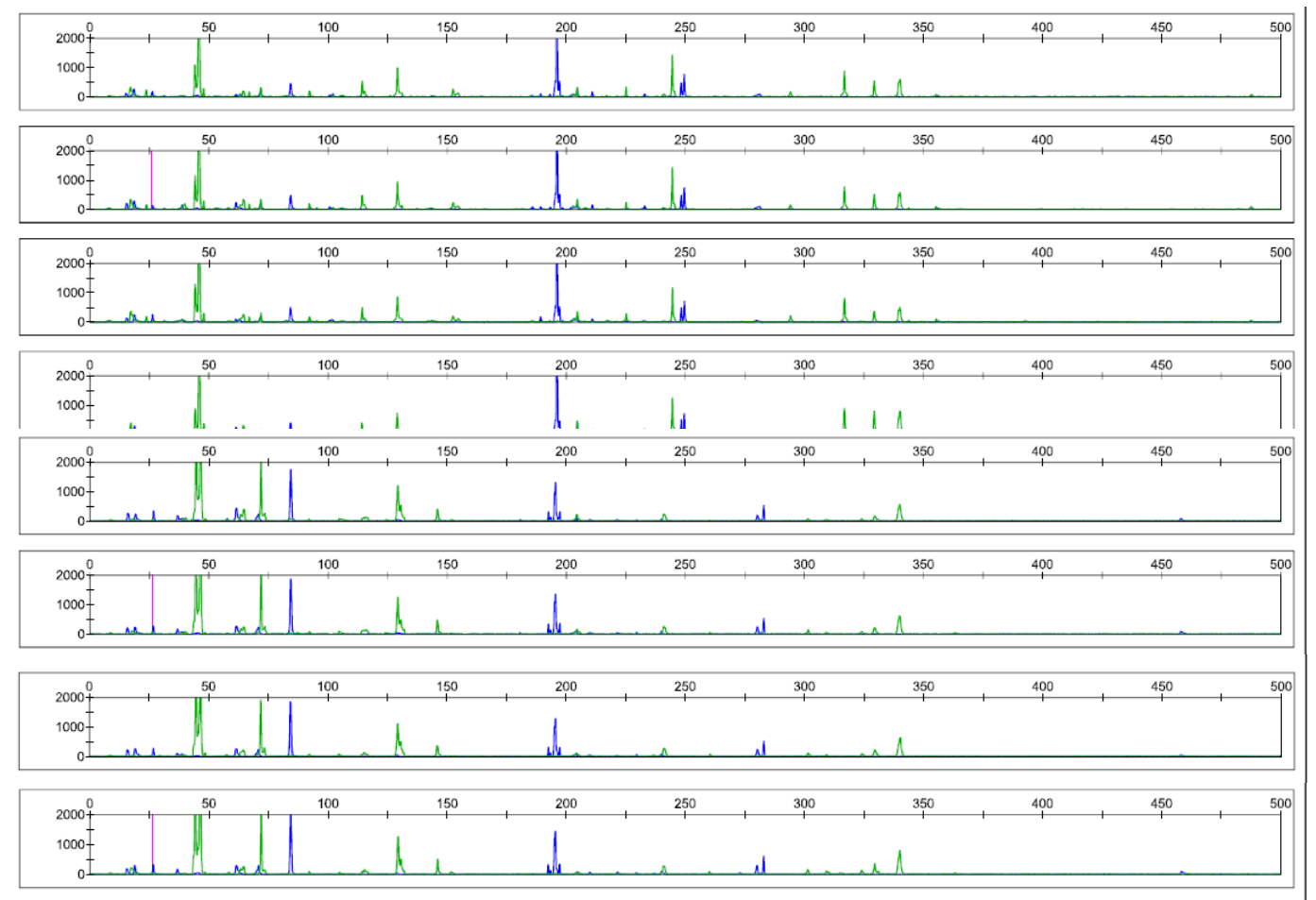

Figure 2.7 ElectropheroGrams taken from bottom sea ice at two sites at McMurdo Station in 2008. The $\mathrm{x}$ axis defines the size of the T-RFLP fragment in base pairs. The $\mathrm{y}$ axis shows fluorescence intensity. The forward (blue dye) and reverse (green dye) fragments are both shown.

\subsubsection{DGGE vs. T-RFLP}

UPGMA analysis revealed differences in the percentage similarity between samples and clustering between the DGGE and T-RFLP methods (Figure 2.8). The DGGE samples showed greater similarity between samples where all were at least $50 \%$ similar to one another. T-RFLP showed a similarity of only $25 \%$ between Gondwana Station in 2006 (GW 2006) and in 2007 (GW 2007). The DGGE and T-RFLP profiles both failed to group each site separately. GW 2006 grouped better with T-RFLP with 
the majority of the samples clustering together into one group and only one sample not clustering. There were three separate groups for GW 2006 in the DGGE UPGMA. CH 2004 and GW 2007 also showed better clustering based on site in the T-RFLP profiles than profiles from the DGGE.
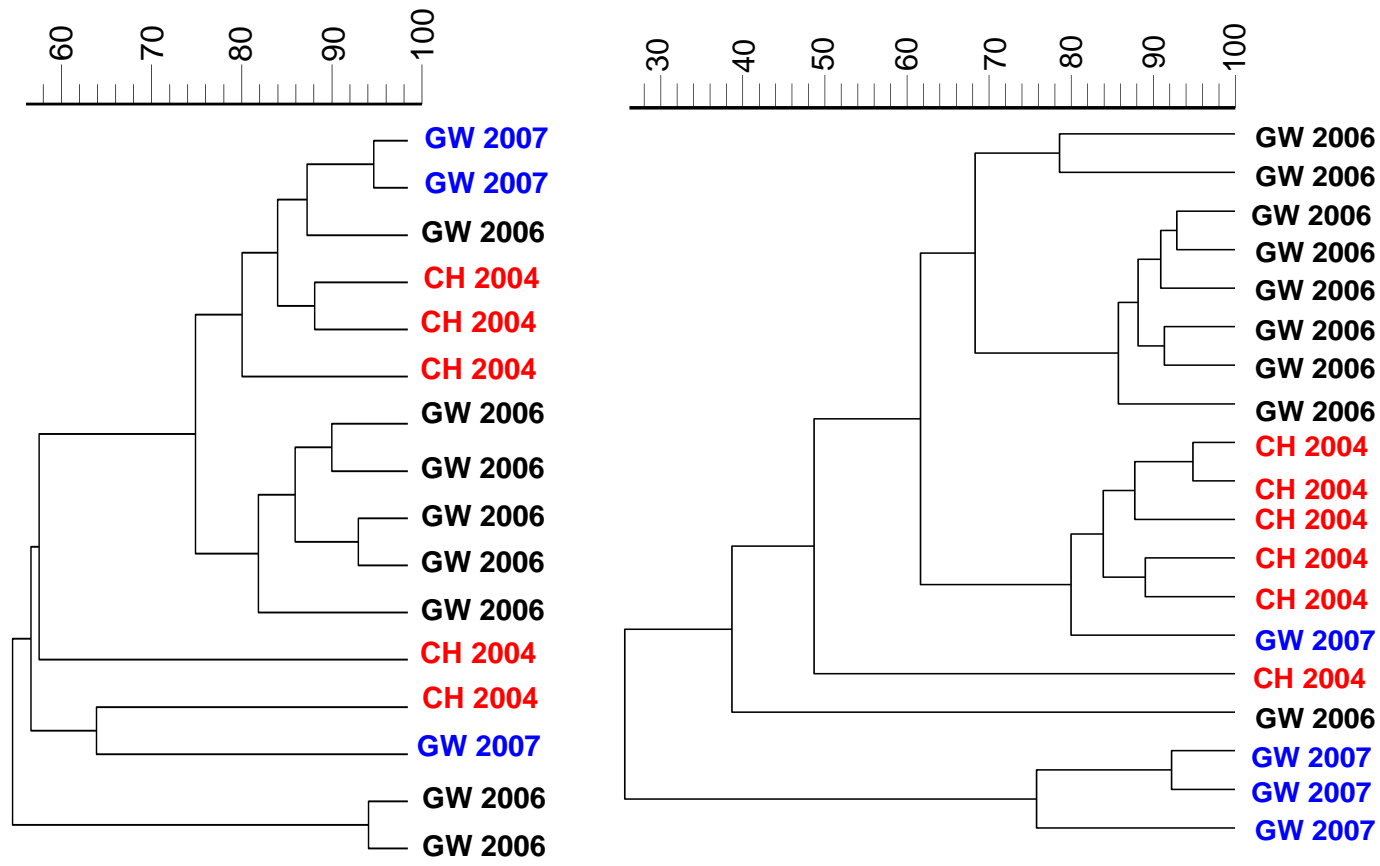

Figure 2.8 DendroGram of DGGE (a) and T-RFLP (b) profiles of bacterial communities from GW = Gondwana Station, $\mathrm{CH}=$ Cape Hallett. The cluster analysis was based on Pearson's correlation index and the unweighted pair-group method with arithmetic averages.

\subsubsection{Quantitative PCR}

Gel electrophoresis showed the correct sized bands for the functional genes nirK, amoA-1, amoA-2, nifH-1, nifH-2, PR-1, pufM-1, pufM-2 and chitA2 (Figure 2.9, 2.10). The functional genes nirS, RuBisCo, PR-2 and chitAl did not produce the correct sized band when visualised by electrophoresis (Figure 2.9, 2.10). In these cases, the correct gene was not amplified and these genes were dropped from further analysis. The archaeal 16S rRNA gene did not give any positive band after amplification, therefore archaeal clones were amplified from previously sequenced archaea $16 \mathrm{~S}$ rRNA genes (see Chapter 5). After clone library construction and sequencing, only the nirK, archaeal 16S rRNA, bacterial 16S rRNA, pufM and PR genes were 
positively identified using BLAST (Table 2.11). The presence and abundance of these five functional genes were investigated in Chapter 4.

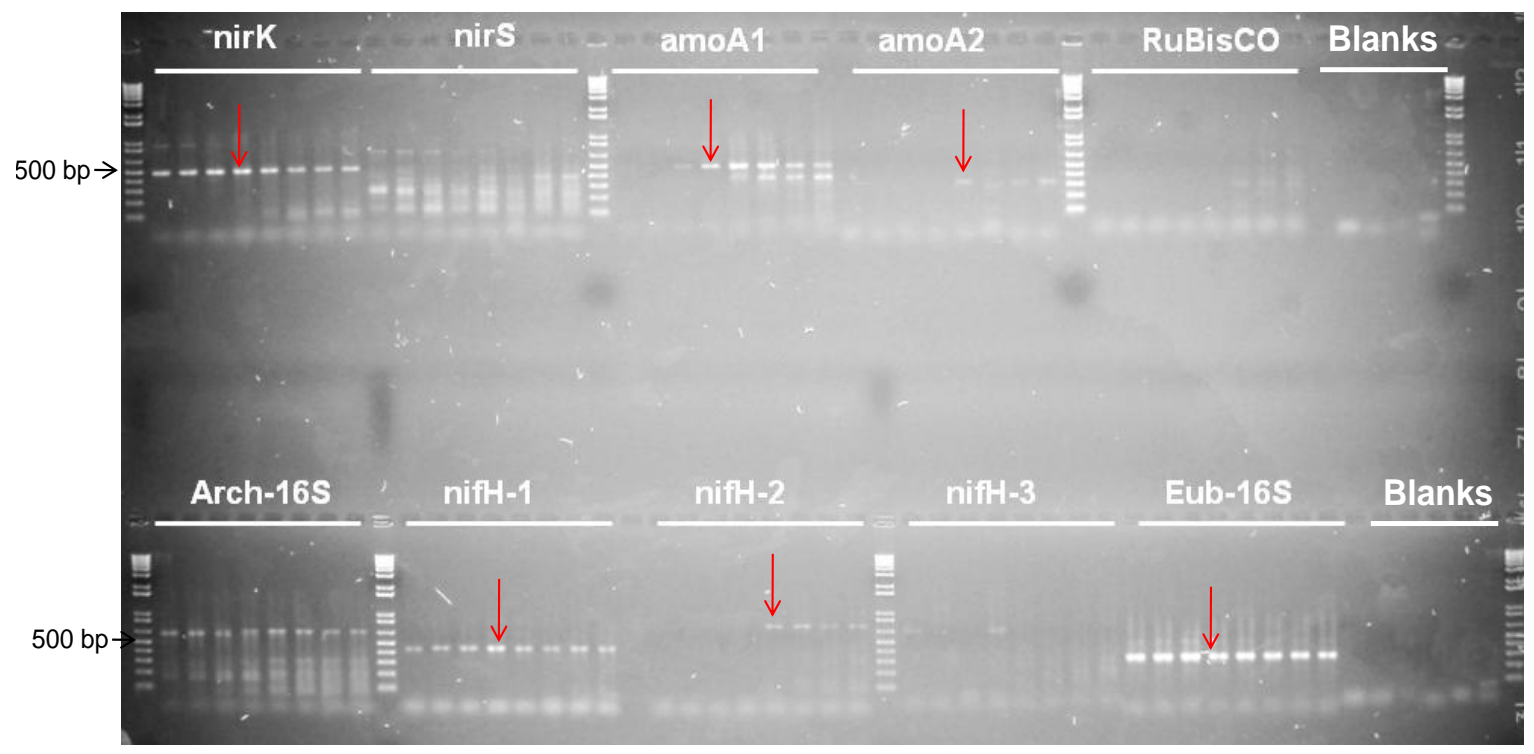

Figure 2.9 Temperature gradient of 8 increments from $62-48{ }^{\circ} \mathrm{C}$ for each of the 10 functional genes. Red arrows show the samples that were re-run on an agarose gel, excised and cleaned with a gel clean up kit.

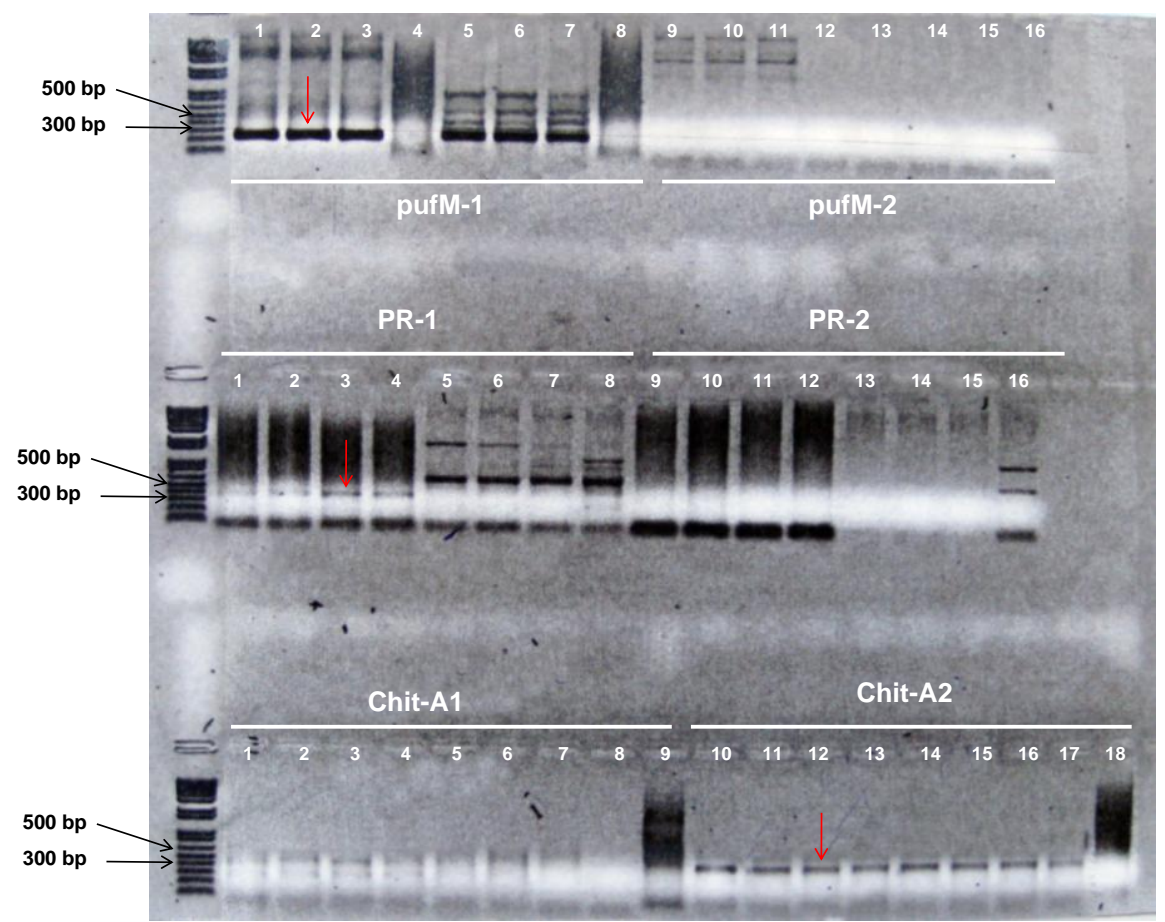

Figure 2.10 Agarose gel showing the $p u f M$, PR and Chit genes amplified by two primer sets. Red arrows show the samples that were re-run on an agarose gel, excised and cleaned with a gel clean up kit. 
Table 2.10 The expected band sizes of functional genes, whether they were amplified and the closest sequence after BLAST.

\begin{tabular}{|c|c|c|c|c|}
\hline Gene & Target & Band size (bp) & Correct sized band? & Closest sequence \\
\hline nirk & copper & 450 & Yes & nirK; GQ454135 \\
\hline nirS & cytochrome cd1 & 650 & No & NA \\
\hline amoA1 & $\beta$-Proteobacteria & 500 & Yes & 16S; FM206290 \\
\hline amoA2 & $\gamma$-Proteobacteria & 250 & Yes & 16S; AM706905 \\
\hline RuBisCO & & 650 & No & NA \\
\hline $\mathrm{NifH}-1$ & -Proteobacteria & 450 & Yes & 16S; AM706605 \\
\hline $\mathrm{NifH}-2$ & $\beta$-Proteobacteria & 650 & Yes & 16S; AB497925 \\
\hline $\mathrm{NifH}-3$ & cluster III & 450 & No & NA \\
\hline PR-1 & & 300 & Yes & PR; AY210910 \\
\hline PR-2 & & 300 & No & NA \\
\hline pufM-1 & & 300 & Yes & pufM; HQ142840 \\
\hline pufM-2 & & 300 & Yes & NA \\
\hline chit-A1 & & 300 & No & NA \\
\hline chit-A2 & & 300 & Yes & 16S; FN666225 \\
\hline 16S rRNA & Archaea & 300 & Yes & Arch; GU234243 \\
\hline 16S rRNA & Bacteria & 300 & Yes & 16S; GQ849228 \\
\hline
\end{tabular}

Table 2.11 The five genes targeted for qPCR showing the optimised annealing temperature.

\begin{tabular}{|lllc|}
\hline Function & Gene & Primer name & $\begin{array}{c}\text { Annealing } \\
\text { temperature }\left({ }^{\circ} \mathrm{C}\right)\end{array}$ \\
\hline Nitrogen reduction & Nitrite reductase & $\begin{array}{l}\text { nirK-q-F } \\
\text { nirK-1040 }\end{array}$ & 53 \\
\hline Bacteriochlorophyll & Proteorhodopsin & $\begin{array}{l}\text { RYIDWF } \\
\text { GWAIYPR }\end{array}$ & 50.1 \\
& pufM & $\begin{array}{l}\text { pufM.557F } \\
\text { pufM.750R }\end{array}$ & 53 \\
& & ARCH1017F & \\
Archaea & ARCH1392R & 57 \\
\hline Bacteria & 16S rRNA & BAC518F & \\
& & BAC800R & 57 \\
\hline
\end{tabular}

\subsubsection{MUF substrate assays}

The most activity was seen in the seawater samples which were collected and frozen or filtered and re-suspended in PBS. The filter stored in RNAlater ${ }^{\mathrm{TM}}$ had no activity (data not shown). In Antarctic sea ice, phosphatase and lipase activity were highest in 
the total ice sample. The filter had higher amounts of lipase activity and the filtrate had higher amounts of phosphatase activity (Figure 2.11).

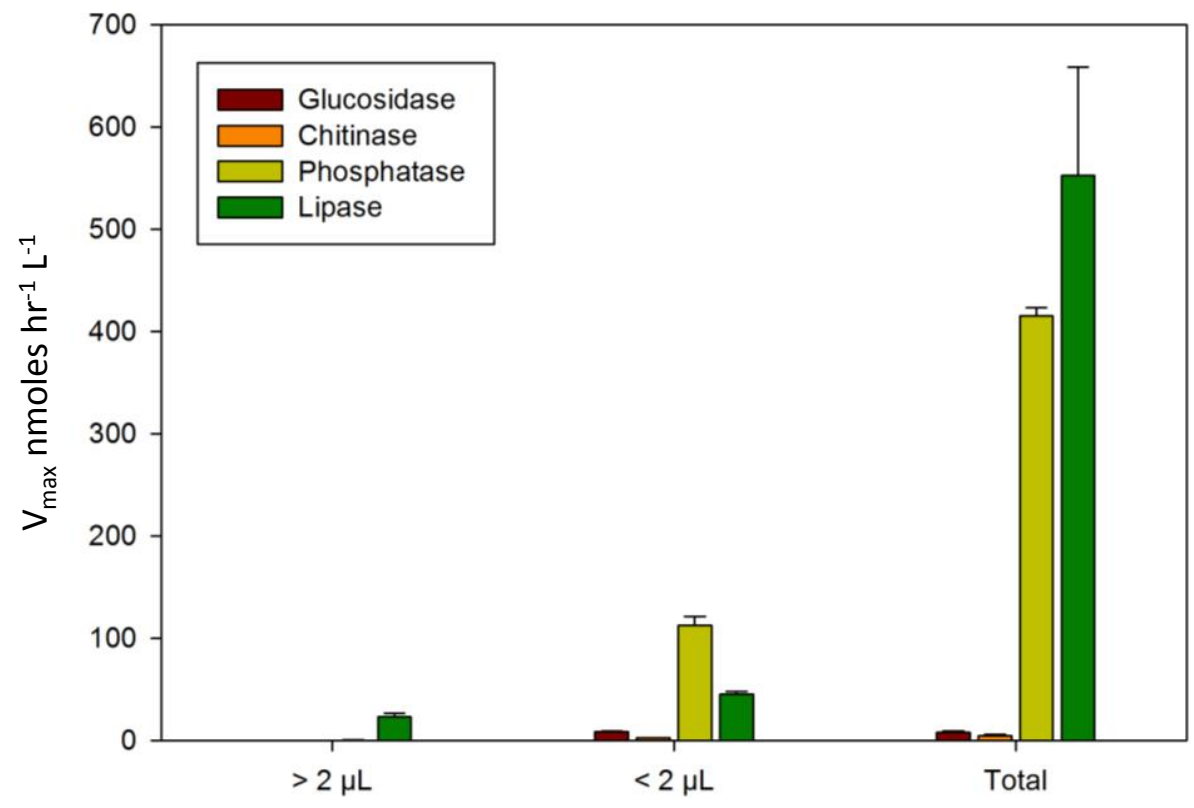

Figure 2.11 Metabolic activity of bacteria in the top and middle of ice core at Gondwana Station using methylumbelliferyl substrates. Data shows mean $+\mathrm{SE}(\mathrm{n}=3)$.

\subsection{Discussion}

To gain comparative data from both DNA and RNA extraction methods it is preferable to use a technique that extracts both nucleic acids simultaneously from the same sample. Kits that do this were investigated but they failed to extract high yields of DNA and RNA. Some RNA was obtained using the Allprep kit, but despite the long time spent optimising this kit, it failed to extract DNA. DNA and RNA extraction methods were then investigated separately. The DNA extraction method that gave the best yield was the phenol: chloroform method with increased enzymatic lysis in lysozyme overnight. An overnight incubation at $37^{\circ} \mathrm{C}$ perhaps increased the amount of bacterial cells that were lysed and therefore increased the DNA concentration. The RNA method that gave the best yield was the guanidinium thiocynate method. Both these methods are laborious and involve harmful chemicals including phenol and chloroform. Also, extra care had to be taken to not lose the DNA or RNA pellet that was precipitated. 
To decrease time and effort, kits to extract DNA and RNA were investigated. To give some comparability between the methods, the filter was cut in half, one following the DNeasy ${ }^{\mathrm{TM}}$ and the other following the RNeasy ${ }^{\mathrm{TM}}$ protocols, a process that has been employed by other studies (West et al. 2008). The DNeasy ${ }^{\mathrm{TM}}$ kit was modified to include a lysosyme incubation followed by a proteinase $\mathrm{K}$ incubation which was found to increase yield in the phenol: chloroform methods. The RNeasy ${ }^{\mathrm{TM}}$ method was modified to include bead beating. RNA yield was increased by adding larger beads to the lysing matrix. The RNA yield was not affected by decreasing the homogenising step which may decrease shearing of the RNA. Both DNeasy ${ }^{\mathrm{TM}}$ and RNeasy ${ }^{\mathrm{TM}}$ kits gave a good yield of both DNA and RNA with high reproducibility.

Antarctic sea ice was collected by various methods to determine which was best in obtaining and preserving RNA. Low concentrations of RNA were extracted from all samples. The samples were collected during spring when the days are short and the sea ice is still forming. During this time, there were fewer bacterial cells in the ice, and the cells may also be less active or dormant, waiting for the phytoplankton bloom which happens later in the year. The samples were reverse transcribed into cDNA and the 16S rRNA gene was amplified. All samples had some degree of amplification which was more prominent in the filter and the 10:40 ice to RNAlater ${ }^{\mathrm{TM}}$ samples. In terms of method utilisation, it was easier to collect RNA by scraping sea ice into a sterile vial and then adding RNAlater ${ }^{\mathrm{TM}}$. Also, this method enabled the RNA to be stabilised directly from the environment which meant there was less time for RNases to degrade the material. However, a large amount of RNAlater ${ }^{\mathrm{TM}}$ was required (40 $\mathrm{mL}$ / sample) and once in the laboratory the method proved to be more laborious. Each sample was pipetted into $25 \times 2 \mathrm{~mL}$ Eppendorf tubes, centrifuged at 16,000 rpm to form a pellet and most of the supernatant was removed. The collected cells were then re-suspended and then combined. The filtration method was easier to manipulate in the laboratory as the filter was cut aseptically and used directly. These samples were collected from bottom ice which has a high number of bacteria compared to within the sea ice core (Martin, 2010). The filtration method enables a greater amount of bacteria to be collected than just sea ice samples, especially from the middle of the ice core where they are in less abundance. However, for this method, the sea ice core must be initially melted in order to collect the bacteria through filtration. The sample was melted in filter sterilised and autoclaved seawater to prevent osmotic shock and 
in a warm water bath to decrease the melting time to under an h. Previously, ice cores were melted overnight without a water bath. The samples were then filtered as soon as the ice completely melted so the temperature of the sample remained at $-1.8{ }^{\circ} \mathrm{C}$ preventing heat shock. DNA / RNA was therefore collected using this last filtration method in subsequent field collections as it is imperative to increase cell numbers to maximize DNA / RNA content, especially from within-core samples. Although some RNA molecules may be degraded in the process of filtration, as long as the same method is applied across all samples then comparisons can be made for bacterial communities and functions.

DGGE and T-RFLP produced complex banding patterns which formed characteristic fingerprints for each site. The PCR products used in DGGE were amplified using two sets of primers: those that targeted the V3 hypervariable region of the small subunit rRNA gene and those that targeted the V6 hypervariable region of the small subunit rRNA gene. The V3 region was shown to provide the best resolution between DGGE profiles compared to the V1 and V9 regions ( $\mathrm{Yu}$ and Morrison 2004). However, longer reads would be more phylogenetically informative. The V6 region has only previously been used to describe bacterial communities using 454 pyrosequencing (Sogin et al. 2006; Huber et al. 2007), but is accurate in resolving bacterial diversity to genus level (Huse et al. 2008) and reproduces the same results obtained from full length 16 S sequences using the UniFrac clustering tool (Liu et al. 2007). I found that the number of ribotypes detected by the V6 primers was similar to that found with the V3 primer set. The UPGMA clusters based on Pearson's correlation gave some clustering of bacterial communities by site in both DGGE and T-RFLP. T-RFLP was more sensitive than DGGE with sites clustering better together. However, 'site' may not be a variable that influences community changes. Other environmental variables were not taken into account during these analyses, and microenvironments may have a large effect on some communities. This may explain why some of the sites clustered separately from the main group. There was a higher number of OTUs identified by $\mathrm{T}$ RFLP over DGGE and DGGE had many bands that were present across all sites. This may suggest that T-RFLP can identify more rare OTUs in the environment that are not picked up by DGGE. As a result the greater dissimilarity seen between T-RFLP groups may be due to the inclusion of the rare OTUs. T-RFLP is semi-quantitative and accurate between gels as an internal standard can be run. TRFLP is suitable for 
the analysis of large sample numbers due to its reproducibility and potential for automatisation. The inability to load all samples on the same gel and the potential of gel-to-gel variation have been discussed as major drawbacks influencing DGGE analysis (Nunan et al. 2005). Therefore T-RFLP was chosen for all further analyses in this thesis.

A wide range of functional genes were amplified by various primer sets. Out of the 16 primer sets, only 10 produced the correct size band when run on an agarose gel. Of these 10, half amplified the gene of interest. The nirK primers amplified the right product from McMurdo Station bottom sea ice. The products sequenced from the subsequent clone library were closely related to the nitrite reductase genes. The nirS primers were not specific, and its amplification produced many bands. Consequently, the nirS gene was deleted from further examination. The amoA-1 and $a m o A-2$ primers both produced bands that were the appropriate size; however sequencing showed that parts of the 16S rRNA gene had been amplified instead. These primers were re-tested on the seawater samples taken from New Zealand oceanic waters. An appropriate sized band was produced from the amoA-1 primer set (data not shown) but sequencing showed that the ammonia monooxygenase gene had again not been targeted. Primers for the RuBisCO gene did not produce a band of the appropriate size from McMurdo Station samples. RuBisCo is a gene that is predominant in cyanobacteria, but not in heterotrophic bacteria. Cyanobacteria have not been found in Antarctic sea ice (Koh, 2011) which may confirm the negative result given. A positive RuBisCo band was obtained from the New Zealand oceanic waters, but the sequences were not readable. Archaea targeted primers did not produce an appropriate band from McMurdo Station samples, which may be due to their low abundance in sea ice (Cowie et al. 2011). A 16S rRNA archaeal clone which had been previously sequenced (see Chapter 5) was used as the control and re-checked to confirm an archaeal 16S rRNA gene. The nifH-1, nifH-2 and chitA-2 primer sets also produced a band of the appropriate size, but failed to target the right gene. One each of the primers targeting the pufM and PR genes gave a band of the right size and sequencing revealed that the right product had also been targeted. Functional genes of Antarctic sea ice bacteria have not previously been studied, and very few studies have come from polar environments. The functional potential of permafrost affected Arctic soils (Yergeau et al. 2010) and the presence of ammonia oxidising archaea in Antarctic 
waters (Kalanetra et al. 2009) have been investigated. Many of the primers that were used in our study have been optimised on soil (i.e. Braker et al. 1998) and temperate marine (Mosier and Francis 2010) environments. Antarctic sea ice communities may be different in terms of the genetic make-up of their functional genes which may result in these primers failing to isolate these genes. Further research into primer design and optimisation is required to isolate these genes from Antarctic bacterial communities.

Antarctic sea ice bacteria appear to be enzymatically active, predominantly degrading phosphates and lipids. The filter stored in RNAlater ${ }^{\mathrm{TM}}$ had no activity; this therefore confirmed that RNAlater ${ }^{\mathrm{TM}}$ inhibits bacterial activity. The higher concentration of bacterial lipase activity on the filter in comparison to the filtrate suggests that it is associated with cells larger than $2 \mu \mathrm{M}$. Therefore lipase may be an intracellular enzyme or perhaps an ectoenzyme where it remains attached to the cell surface. Phosphatase, on the other hand is higher in the filtrate which may suggest that this enzyme is released completely from the cell. However, both intracellular and extracellular lipases and phosphatases have been found (Ertugrul et al. 2007). To investigate both intra- and extra- cellular enzymatic activity, the whole sample would need to be directly analysed.

In conclusion, Antarctic sea ice cores will be collected, melted and concentrated onto $0.2 \mu \mathrm{M}$ filters and stored in RNAlater ${ }^{\mathrm{TM}}$ at $-20^{\circ} \mathrm{C}$. DNA and RNA will be extracted from Antarctic sea ice samples using the DNAeasy ${ }^{\mathrm{TM}}$ and RNAeasy ${ }^{\mathrm{TM}}$ kits respectively and community structure will be analysed using the optimised T-RFLP method. Bacterial activity will be investigated by either MUF enzyme analysis on frozen sea ice samples or qPCR on the RNA extracted community. The functional genes investigated will determine nitrite reductase, proteorhodopsin and bacteriochloropyll activity using the bacterial 16S rRNA gene as a housekeeping gene. These genes will be amplified from the RNA community therefore giving insight, for the first time in Antarctic sea ice, into the abundance and metabolic potential of prokaryotes. 


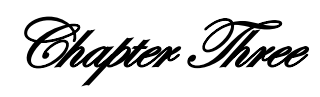

\section{Bacterial community structure and relationships with the environment}

\subsection{Abstract}

Bacterial communities inhabiting Antarctic sea-ice were investigated using terminal restriction fragment length polymorphism (T-RFLP). DNA and RNA were extracted and the 16S rRNA gene was investigated to understand bacterial community structure from both the active population (RNA) and the total community (DNA). T-RFLP data revealed that bacterial communities collected from within the same site in the same year were more similar than those collected from different geographical locations and from separate years. Bacterial community structure also varied with vertical position in sea ice cores. The bacterial community compositions were correlated with sea ice thickness and inorganic nutrients. This was more evident in the metabolically active rRNA communities as they may more readily reflect changes in the environment. Ice thickness and the concentrations of nitrite and phosphate explained an average of 39\% of the variation seen among communities, which suggests that sea-ice structure and nutrient availability play an important role in the development of sea-ice bacterial communities.

\subsection{INTRODUCTION}

The Ross Sea pack ice is an extreme environment, where steep gradients of salinity, light, temperature and nutrient concentrations are found (Arrigo and Sullivan 1992). During the early stages of ice formation, planktonic microbes are scavenged from the surrounding Ross Sea water column and are incorporated into the semi-solid matrix (Mock and 
Thomas 2005). At the bottom $10 \mathrm{~cm}$ of ice, a complex microbial community develops as the environment is stable and favourable for growth. Here, the salinity is $35 \%$, the temperature is $-1.8{ }^{\circ} \mathrm{C}$ and there is a constant flux of nutrients from the water below (Arrigo and Sullivan 1992, Arrigo and Thomas 2004; Mock and Thomas 2005). However, further away from the sea ice / water interface (and closer to the surface), salinity and irradiance increases dramatically and temperature and nutrient concentrations decrease (McMinn et al. 1999; Thomas and Dieckman 2002). This sea ice microbial community (SIMCO) not only survives in these harsh conditions, but may be one of the more productive microbial habitats globally (Martin et al. 2008), producing a large amount of energy to the Southern Ocean's food webs (Arrigo and Thomas 2004). For example, the amount of chlorophyll- $a$ (Chl- $a$ ) produced from the sea ice can be 10 times greater than that of the water beneath (Sullivan and Palmisano 1984). Although most of this is produced by the eukaryotic community, bacteria may have their own important role in secondary mineralisation of organic matter (Azam et al. 1991).

The term 'microbial loop' was first coined by Azam et al. (1983; Fig 3.1). This review paper suggested that the classic view of marine plankton communities was rudimentary in assuming that DOM from phytoplankton flowed directly to higher trophic groups or was lost to the environment. Instead, DOM is initially cycled through the 'microbial loop' which consists of phytoplankton, bacteria and phagotrophic Protozoa (McKenna et al. 2006; Azam \& Malfatti 2007). Microbes are central in food chains, are critical to ecosystem functioning and play a key role in biogeochemical cycles.

In Antarctic sea ice, relationships between bacterial communities and algae have been investigated in detail (Grossi et al. 1984; Kottmeier and Sullivan 1987; Stewart and Fritzen 2004; Martin et al. 2011). The presence of the microbial loop (Azam et al. 1983) has been inferred by regression analysis and correlation between algae (or proxies such as Chl- $a$ ) and estimates of bacterial abundance or production (Stewart and Fritsen 2004). In turn, bacteria may provide remineralised inorganic nutrients necessary for algal growth. Sea ice algae and bacterial biomass have been shown to be positively correlated during the spring and summer (Grossi et al. 1984; Kottmeier and Sullivan 1987), but this coupling is not seen during the 
winter (Kottmeier and Sullivan, 1987). However, these interactions are still not well understood (Azam and Malfatti 2007; Martin et al. 2008). Studies that identify relationships between bacterial abundance and phytoplankton Chl- $a$ may overlook the direct influence that inorganic nutrients have on growth (Sullivan and Palmisano 1984; Stewart and Fritzen 2004).

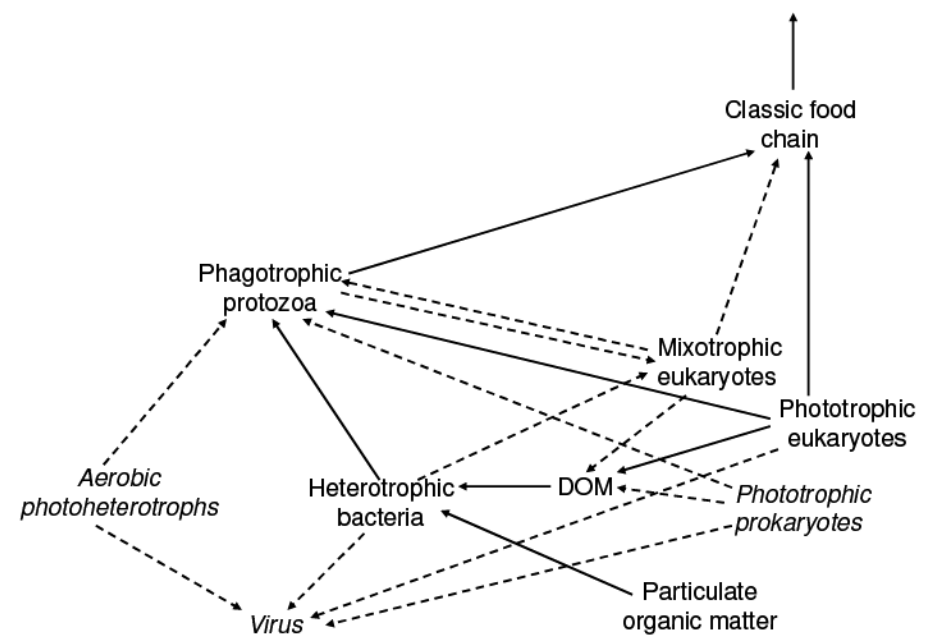

Figure 3.1. The 'microbial loop' as described in Azam et al (1983) and modified by Fenchel (2008). Components linked by solid arrows are from Azam; dotted arrows refer to later additions by other authors. $\mathrm{DOM}=$ dissolved organic matter.

Inorganic nutrient concentrations may play a central role in the widely observed phenomenon of algal-bacterial coupling (Wheeler and Kirchman 1986; Currie 1990). Nitrogen limitation has been found to lead to uncoupling along phosphate gradients (Le et al. 1994). There is also evidence to suggest that there are more complex interactions between inorganic nutrient supply and community composition (Keinanen et al. 2002). Nutrient manipulation experiments have shown that bacterial phylogenetic groups respond differently to additions of inorganic nutrients (Teira et al. 2010).

Bacterial communities are influenced by many abiotic and biotic environmental factors (Figure 3.2). Most research is based on a "bottom up" approach, which assumes that resources and abiotic variables drive microbial structure and function. These include, but are not limited to, regulation by nutrients, Chl- $a$, temperature, site and irradiance. 'Top 
down' regulation also occurs from grazers and lytic viruses and these put strong selection pressure on microbes. Selection pressures may affect certain groups of bacteria over others leading to changes in species abundances and distributions. Therefore, a community perspective is required to understand microbial diversity and function in Antarctic sea ice.

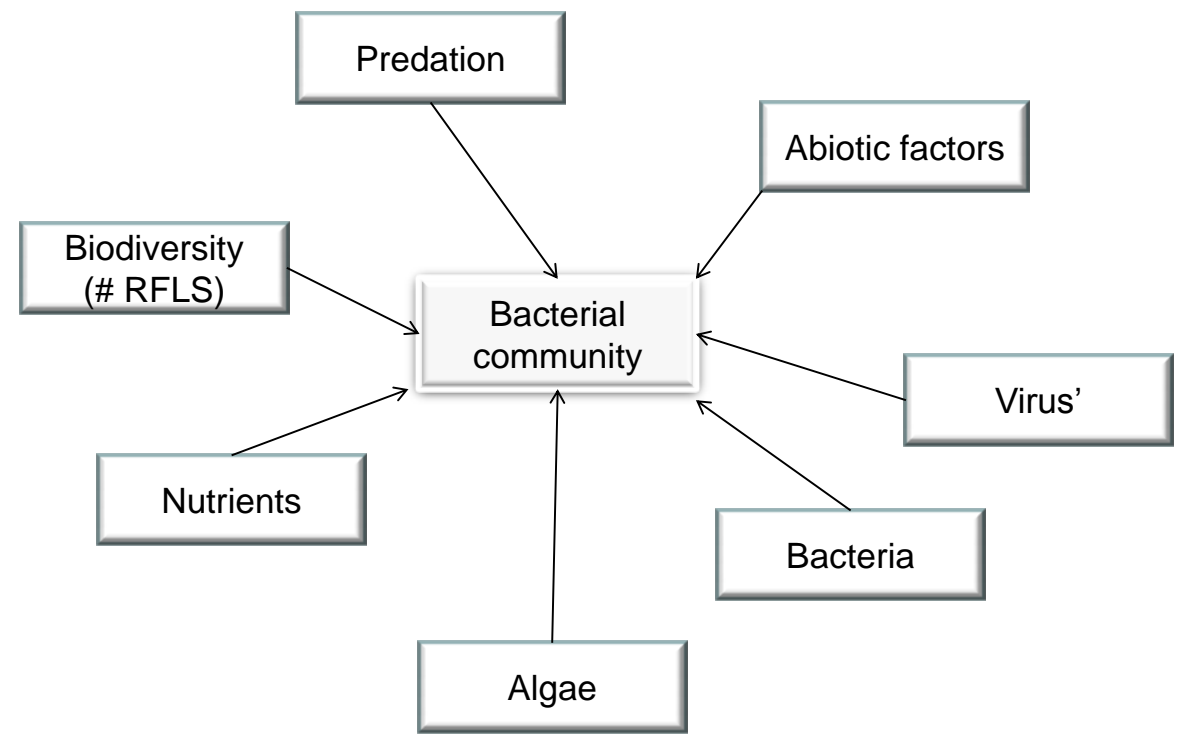

Figure 3.2 A simplified diagram of factors that may control bacterial community structure in Antarctic sea ice. This diagram includes some, but not all, of the factors that influence bacterial community structure. The number of restriction fragment lengths (\# RFLs) gives an estimate of community biodiversity.

Bacterial community structure and diversity has been investigated using a number of different approaches. Terminal restriction fragment length polymorphism (T-RFLP) is one method that is particularity useful in the analysis of multiple complex communities as it is highly sensitive and reproducible and allows for high throughput analysis of samples (Liu et al. 1997; Moeseneder et al. 2001; Smalla et al. 2007). PCR products amplified from environmental samples are digested using restriction enzymes to produce many fragments that vary in length (Figure 3.3) depending on the sequence. The fragments are separated using an automated capillary electrophoresis based genetic analyser producing an electropherogram where each peak is potentially derived from a unique bacterial species, giving an estimate of species diversity and the fluorescence 
intensity gives an estimate of species abundance. However, as each peak may be derived from more than one species the term restriction fragment length (RFL) is used, instead of operational taxonomic unit (OTU) or species.

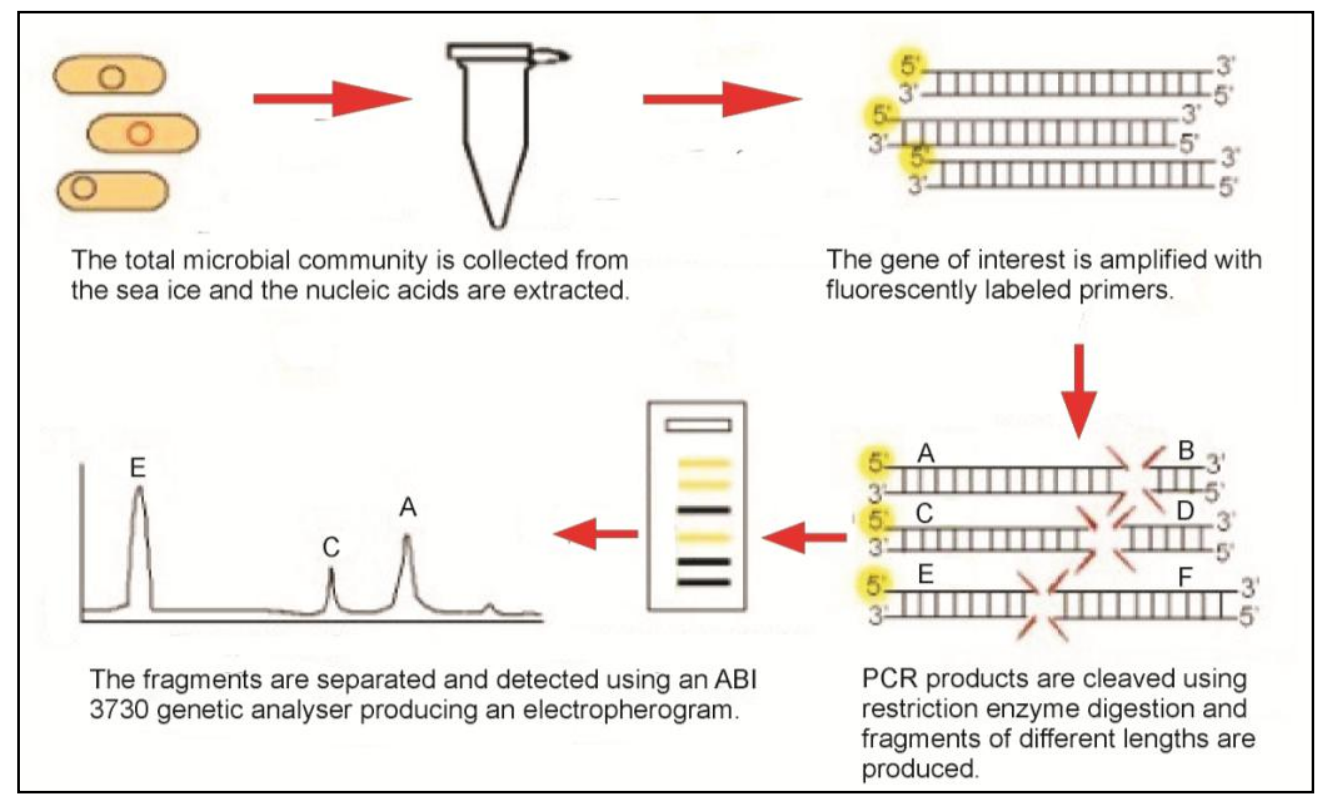

Figure 3.3 Overview of the T-RFLP method.

Most studies examining species diversity in environmental samples investigate the $16 \mathrm{~S}$ rRNA gene and have utilized DNA-based analyses. Studies comparing both rDNA and rRNA simultaneously are rare (Fuhrman et al. 1994; Nogales et al. 2001; Moeseneder et al. 2005; Gentile et al. 2006; West et al. 2008). The combination of both components is important to an understanding of the total community diversity and function (Moeseneder et al. 2001; Gentile et al. 2006). As DNA resides in the cell and in the environment after death (Dell'Anno and Danovaro 2005), DNA-based studies reveal information about the active population as well as the dormant and dead cells, and may be more biased towards bacteria with a higher number of operons (Klappenbach et al. 2000). In contrast, rRNA is less stable than rDNA and does not persist as long in the environment. Although rRNA has a more complex secondary structure, it has been used as an indicator of metabolically active populations (Mills et al. 2004; 2005). Cellular concentrations of rRNA are more 
closely correlated with metabolic activity and therefore may be used to link community composition with the environment (Felske et al. 1997; Miskin et al. 1999). In Antarctic sea ice, bacteria appear to be highly metabolically active (Brinkmeyer et al. 2003; Martin et al. 2008), which suggests that they may play a dominant ecological role in the sea-ice microbial loop and may be able to actively respond to changes in the environment.

With changes in environmental conditions, bacteria are expected to respond by i) migration into a more favourable area, ii) adaptation by a shift in phenotype, iii) extinction of certain species and/or iv) changes in patterns of dormancy/activity. Therefore bacteria may respond to changing environmental conditions with changes in bacterial numbers or changes in the community diversity. Community diversity can be defined by two parameters: species richness (the number of species in a community) and species evenness (the size of species populations in a community), where either or both may be affected by the environment.

The poles are particularly sensitive to small increases in temperature. Ice melting reduces reflection and allows more heat transfer from the ocean to the surface, which accelerates the warming effect (Murray and Gryzmski 2007). As a result, sea ice is likely to decrease in thickness and extent due to global warming (Clarke and Harris 2003). Latitudinal gradients provide a natural system to investigate the relationships between changing environmental conditions and sea ice communities. Animals and plants show a latitudinal gradient of diversity, where greater diversity is found at the lower latitudes in comparison to the poles (Mittelbach et al. 2007). However, these patterns have been reported as weak or absent in microbial communities (Hillebrand 2004), perhaps due to their ubiquity and ability to disperse easily (Fenchel and Finlay 2004). The spatial and temporal biogeographical patterns of microbial communities have long been of interest in temporal oceans, but are largely unknown in polar environments (Murray et al. 1998) particularly in sea ice (Collins et al. 2010). Several studies have explored the structure of marine bacterial communities but few have examined changes in structure over time and linked these changes to the environment (Fuhrman et al. 2006; Pommier et al. 2007). Bacterial communities have been found to vary greatly with larger spatial (Hewson et al. 2006) and 
temporal (Lee and Fuhrman 1990) scales, and behave predictably to a wide range of abiotic and biotic factors (Fuhrman et al. 2006).

The Latitudinal Gradient Project (LGP) is a multi-national and multi-disciplinary research program studying marine and terrestrial ecosystems along the Victoria Land coastline, Antarctica (Howard-Williams et al. 2006). The aim of the LGP is to understand the ecosystems that reside along this coastline and the effects that environmental change may have on these ecosystems. As part of the LGP, I investigated both bacterial community structure and its relationship to abiotic and biotic variables. I proposed that i) DNA and RNA extraction methods will reveal different bacterial community structures; ii) bacterial diversity will decrease with increasing latitude; iii) bacterial communities will show greater differences at larger spatial and temporal scales; iv) particular restriction fragment lengths (RFLs) affiliated with psychrophilic bacteria will persist in the sea ice environment and v) bacterial abundance and community structure will be influenced by environmental factors.

\subsection{MATERIALS AND METHODS}

\subsubsection{Core collection}

A total of 46 cores were collected from 5 sites in annual sea ice along the Ross Sea coast, Antarctica during the austral summers of 2008 and 2009. I collected cores in 2008 from Cape Evans (CE08 $77^{\circ} 39^{\prime} \mathrm{S}, 1^{166^{\circ}} 19^{\prime} \mathrm{E}$,) on the 13.11.2008, Granite Harbour on 18.11.2008 (GH08a) and 25.11.2008 (GH08b 77 0'S, $162^{\circ} 54 ' \mathrm{E}$ ), Cape Roberts on the 22.11.2008 (CR08 $77^{\circ} 1^{\prime} \mathrm{S}, 163^{\circ} 10^{\prime} \mathrm{E}$ ), Terra Nova Bay on the 24.11.2008 (TNB08

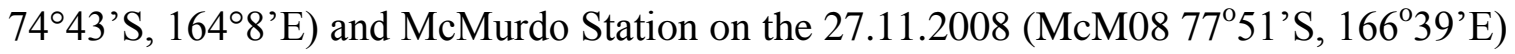
to investigate spatial changes in sea ice bacteria (Figure 3.4). In 2009, cores were collected again at Cape Evans (CE09) on the 12.11.2009 and at Granite Harbour on the 18.11.2009 (GH09a), 21.11.2009 (GH09b), 24.11.2009 (GH09c), 27.11.2009 (GH09d)

and 29.11.2009 (GH09e) to examine temporal changes in the bacterial community structure. The cores were collected using a Kovaks (USA) ice coring drill and the bottom, middle and top $10 \mathrm{~cm}$ from each ice core was removed. To minimise contamination from 
human-borne microbes, an $8 \times 8 \times 10 \mathrm{~cm}$ block was cut from within the section. This ice block was melted in autoclaved $0.2 \mu \mathrm{m}$ filtered seawater and the microbes concentrated by filtration onto a $0.22 \mu \mathrm{m}$ polycarbonate filter (Millipore Ltd). The filter was stored in RNAlater ${ }^{\mathrm{TM}}$ (Ambion) at $-20{ }^{\circ} \mathrm{C}$ until processed. Seawater samples were taken each day the cores were collected from the underlying water column on 19, 21, 24, 27, 28, 29, 30 of November 2009. Two L of seawater were filtered through a $0.22 \mu \mathrm{m}$ sterivex cartridge (Millipore Ltd) using a peristaltic pump. A volume of $2 \mathrm{ml}$ of RNAlater ${ }^{\mathrm{TM}}$ (Ambion) was injected into the cartridge using a sterile syringe and the sample was stored at $-20{ }^{\circ} \mathrm{C}$ until processed.

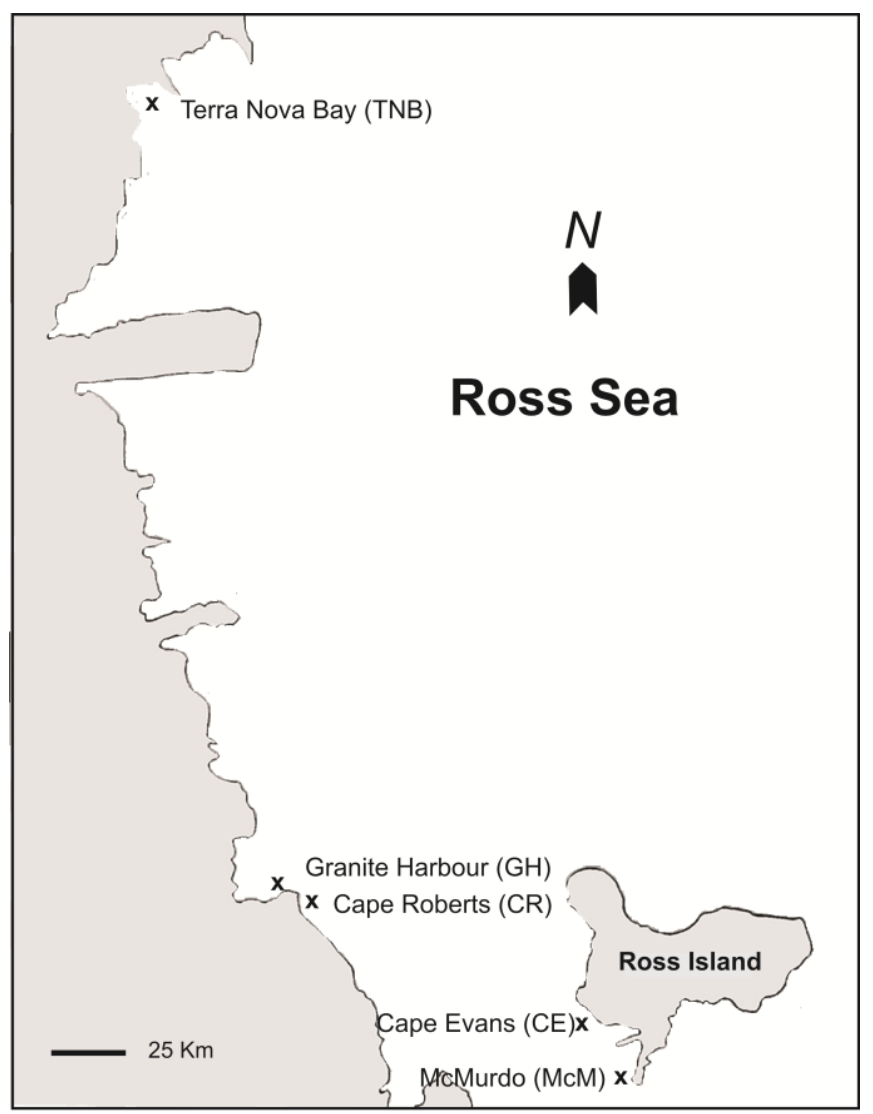

Figure 3.4 Map of the Ross Sea region, Antarctica, showing the locations of Terra Nova Bay (TNB), Granite Harbour (GH), Cape Roberts (CR) Cape Evans (CE) and McMurdo Station (McM) sampling sites. 


\subsubsection{Environmental parameters}

Ice thickness was measured and used as a proxy for irradiance (Odate et al. 2004).

Chl- $a$ was measured on site where $100 \mathrm{~mL}$ of the melted sea ice sample was filtered onto a $47 \mathrm{~mm} \mathrm{GF} / \mathrm{F}$ filter and extracted in $10 \mathrm{~mL}$ of methanol over $12 \mathrm{~h}$ in the dark at $4{ }^{\circ} \mathrm{C}$. The extracted Chl- $a$ was subsequently measured on a digital fluorometer (10AU Turner Designs, USA.) using the acidification protocol of Evans et al. (1987).

Sea ice was collected directly from the sea ice core in sterile tubes and stored at $-20{ }^{\circ} \mathrm{C}$ until analysis for nutrient levels. Samples were melted overnight in the dark and filtered through $70 \mu \mathrm{m}$ gauze just prior to nutrient analyses. Nitrate, nitrite, phosphate, ammonia and silicate were analyzed using flow injection analysis on a Skalar $\mathrm{San}^{++}$Automated Ion Analyser (Skalar Co., The Netherlands) in triplicate. For each analysis, a six-point calibration curve was created from which sample concentrations were internally calculated using the $\mathrm{San}^{++}$Flow Access software for Windows. Every ten samples, a mid-range standard and blank were run to account for instrument drift. As sample concentrations were calculated while the analysis was in progress, if a sample was found to be greater than the highest standard it was diluted and added to the end of the run.

Bacterial abundance was analysed on a Becton Dickinson LSRII flow cytometer (BD Biosciences). Samples were fixed in glutaraldehyde and frozen until processed. The samples were thawed and $1 \mathrm{~mL}$ of each sample was stained in the dark for 10 minutes with Hoechst (final concentration $5 \mu \mathrm{g} \mathrm{mL}^{-1}$ ). Samples were run at a medium flow rate for $1 \mathrm{~min}$ in duplicate and the volume analysed was measured to give number of bacterial cells $\mathrm{mL}^{-1}$. Bacterial cell populations were identified from bivariate plots of blue fluorescence (FL4) vs. SSC (Side Scatter). TruCOUNT ${ }^{\mathrm{TM}}$ controls (BD Biosciences, San Jose, CA) were used as an internal standard in all measurements. 


\subsubsection{Nucleic acid extraction and T-RFLP}

Nucleic acid extraction was carried out as outlined in Chapter 2. Briefly, filters were cut in half and DNA was extracted from one half following the DNeasy ${ }^{\mathrm{TM}}$ protocol (Qiagen DNeasy blood and tissue handbook, 07/2006) starting from step number 4 in the handbook. RNA was extracted from the other half filter using the RNeasy ${ }^{\mathrm{TM}}$ protocol from step 2 (RNeasy minikit handbook 04/2006) with subsequent DNAse I (SigmaAldrich) digestion. The DNA and RNA were quantified using the sensitive fluorescent nucleic acid stains Quant-IT PicoGreen and RiboGreen respectively (See Chapter 2 for full methods). RNA was converted to cDNA using SuperScript ${ }^{\mathrm{TM}}$ III First-Strand Synthesis SuperMix and random hexamers as primers (Invitrogen, Carlsbad, USA). Some samples without reverse transcriptase were also included to rule out DNA contamination. PCR amplification was carried out as described previously, and the PCR products were digested with $A l u \mathrm{I}$ overnight to generate gene fragments of varying length. A total of 10 $\mathrm{ng} / \mu \mathrm{L}$ of digestion was sent for analysis on the ABI prism 3730 capillary sequencer run under GeneScan mode (Applied Biosystems, Allan Wilson Centre, Palmerston North, NZ). The size of the fluorescently labelled fragments was determined by comparison with the ROX 500 internal standard (Applied Biosystems).

\subsubsection{Clone libraries}

The dominant members of the community were investigated by clone library construction. The 16S rRNA gene amplicons were cloned using TOPO TA (Invitrogen, Carlsbad, USA) and pGEM-T (Promega, Maddison, Wis.) cloning vectors and transformed into DH5- $\alpha$ (Invitrogen, Carlsbad, USA) chemically competent cells with a 3:1 insert:vector molar ratio. Individual colonies were amplified using the vector specific M13F and M13R primers. Clones containing the correct insert were detected by gel electrophoresis and column purified (Zymogen, Orange, CA). A total of 100 M13 amplicons were digested following the protocol above and 36 unique RFLP patterns were detected by gel electrophoresis. Clones with unique RFLP patterns were analysed for TRFLP using the above protocol. Clones whose T-RFLP profiles matched the dominant 
peaks in the bacterial community profiles were then sequenced using an ABI Prism 3100 genetic analyzer. The clones were aligned in ARB (http://www.arb-home.de, Ludwig et al. 2004) using evolutionary-conserved primary sequence and secondary structure (Lane 1991). Calculation of the phylogenetic trees was performed using the maximumparsimony algorithm in ARB to determine the closest relative to the clones.

\subsubsection{Statistical analyses}

The relationships between environmental variables were calculated using regression analysis in SigmaPlot v10. A number of diversity indices were calculated to investigate species richness and species evenness: the Shannon-Wiener index (H'), the Simpson's index $\left(1-\lambda^{\prime}\right)$, and the modified Hill's ratio (N21'). The Shannon-Wiener index ( $\left.\mathrm{H}^{\prime}\right)$ was calculated to investigate the influences of the rarer species on community diversity (Clarke and Warwick 2001) whereas the Simpson's index $\left(1-\lambda^{\prime}\right)$ is more sensitive to the dominant members of the community. The modified Hill's ratio was used as a measure of equitability (spread between taxa) as it has an advantage over traditional measures of evenness by its non-dependency on the number of species (Rogers et al. 1999). Tests for significance between data sets were performed using ANOVA using the general linear model on data that were checked for normality. Individual pairwise tests were performed using the TUKEY post hoc test with Bonferroni correction for type 1 errors. Where the data did not fit a normal distribution, the Kruskal-Wallace (K-W) non-parametric test was performed with subsequent Dunn's pairwise comparisons.

The raw T-RFLP data were filtered and binned using an algorithm from Abdo et al. (2006) to model the distribution of noise as binomial rather than normal. The standard deviation of each of the T-RFLP profiles from each sample was determined and those with peak areas less than three standard deviations from the mean fluorescence were considered as noise. Absolute peak heights were transformed into percentage values to normalise the total fluorescence among samples. 
Analyses were based on a Bray-Curtis index of similarity which is superior to others as it takes into consideration the value of zero, where two samples have no species in common (Rees et al. 2004). A $\log (\mathrm{X}+1)$ transformation of T-RFLP abundance data was used to reduce the weighting of the abundant RFLs, allowing both the mid range and rarer RFLs to exert some influence on the calculation of similarity (Clarke and Warwick 2001). A permutational multivariate analysis of variance (PERMANOVA) (McArdle and Anderson 2001) with 9999 random permutations was used to test the effect of each factor, their interactions and all pair-wise comparisons. Significant patterns in multivariate space were then visualised using canonical analyses of principle components (CAP) (Anderson and Willis 2003).

To investigate the association between the bacterial community, function and the environment I used a distance-based multivariate multiple regression technique (DISTLM) (McArdle and Anderson 2001). DISTLM carries out a partitioning of variation in a data set described by a resemblance matrix according to a regression (or multiple regression) model. Predictor variables included can be both discrete and continuous, and the technique makes no prior assumptions about the nature of the response variable(s), thus normality does not have to be satisfied (Anderson et al. 2008). All predictors were included in the model selection process as the highest intercorrelation value equaled 0.38. All predictors were then normalised and fitted conditionally in a step-wise manner, with tests based on 9999 permutations of the residuals under a reduced model (Anderson 2001). To balance between statistical performance and model parsimony, model selection was based on Akaike's information criterion (Akaike 1973) with a second-order bias correction applied (AICc) to account for the relatively low number of response observations relative to the number of predictors included during selection (Hurvich and Tsai 1989; Burnham and Anderson 2004). Each year of data (2008 and 2009) was modelled separately to evaluate consistencies in the model outputs and validate conclusions drawn over time. 


\subsection{RESULtS}

\subsubsection{Environmental conditions}

In 2008 there was minimal snow cover at TNB, GH and CE. At CR snow cover was $\sim 5$ $\mathrm{cm}$ and thicker still at McM. At GH and CE in 2009 snow cover was between $10-20$ $\mathrm{cm}$. The sea ice thickness was $0.65 \mathrm{~m}$ at TNB, $2.4 \mathrm{~m}$ at GH and $\mathrm{CR}$, and $1.9 \mathrm{~m}$ at $\mathrm{CE}$ and $\mathrm{McM}$ in 2008, and $2.9 \mathrm{~m}$ at $\mathrm{CE}$ and $3.1 \mathrm{~m}$ at $\mathrm{GH}$ in 2009. Linear regression analysis was performed on a number of parameters and the results are illustrated in figure 3.4. Bacterial abundance ranged from $1.9 \times 10^{3}-1.4 \times 10^{5}$ cells $/ \mathrm{mL}$. There was no correlation between bacterial cell numbers and depth of the sea ice core or with Chl- $a$ (Figure 3.5a, b). There was no significant effect of nutrients on bacterial cell abundance.

Chl- $a$ concentrations were positively correlated with nitrate ((linear regression, $\mathrm{F}_{1,94}=$ 26.4029, $P<0.0001$, Figure 3.5d), phosphate (linear regression, $\mathrm{F}_{1,96}=137.5362, P<$ 0.0001, Figure 3.4f) and silicate (linear regression, $\mathrm{F}_{1,95}=31.9892, P<0.0001$, Figure 3.5 e). Nitrate and nitrite (linear regression $\mathrm{F}_{1,97}=16.18, P<0.0001$, Figure 3.5c), and nitrate and phosphate concentrations were also positively correlated (linear regression, $\mathrm{F}_{1}$, $97=39.9219, P<0.0001$, Figure $3.5 \mathrm{~g})$. 

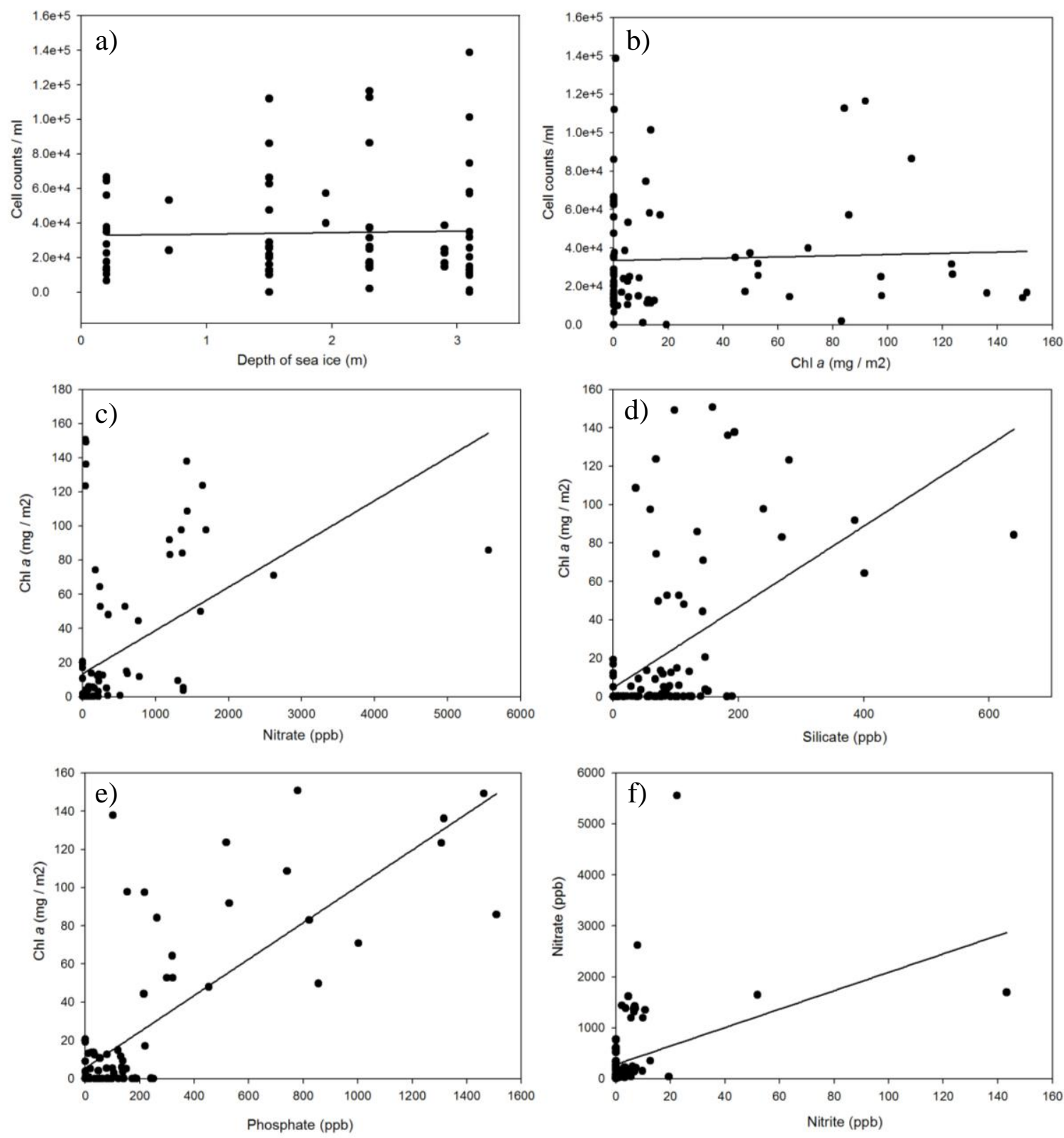

Figure 3.5 Linear regression of bacterial cell counts against (a) depth of sea ice $\left(\mathrm{R}^{2}=0.001\right)$ where $0 \mathrm{~m}$ is at the water-ice interface and $3 \mathrm{~m}$ is at the top of the core and (b) Chl- $a$ concentration $\left(\mathrm{R}^{2}=0.0019\right)$. Chl- $a$ concentrations against (c) nitrate $\left(R^{2}=0.2211\right)(d)$ silicate $\left(R^{2}=0.2539\right)$ and (e) phosphate $\left(R^{2}=0.5940\right)$, and (f) Nitrate concentration against nitrite concentration $\left(R^{2}=0.1443\right)$. 


\subsubsection{Bottom ice community: differences between sites}

Nutrient concentrations in the bottom of the sea ice core were investigated along the latitudinal gradient. Nitrate, nitrite and silicate were not correlated with latitude (data not shown; linear regression, $P>0.05)$. Phosphate and Chl- $a$ were significantly lower at TNB which led to a correlation between these nutrients when plotted against the latitudinal gradient (linear regression, $\mathrm{F}_{1,19}=17.27, P<0.001 ; \mathrm{F}_{1,19}=4.6762, P=$ 0.0443, Figure 3.6).
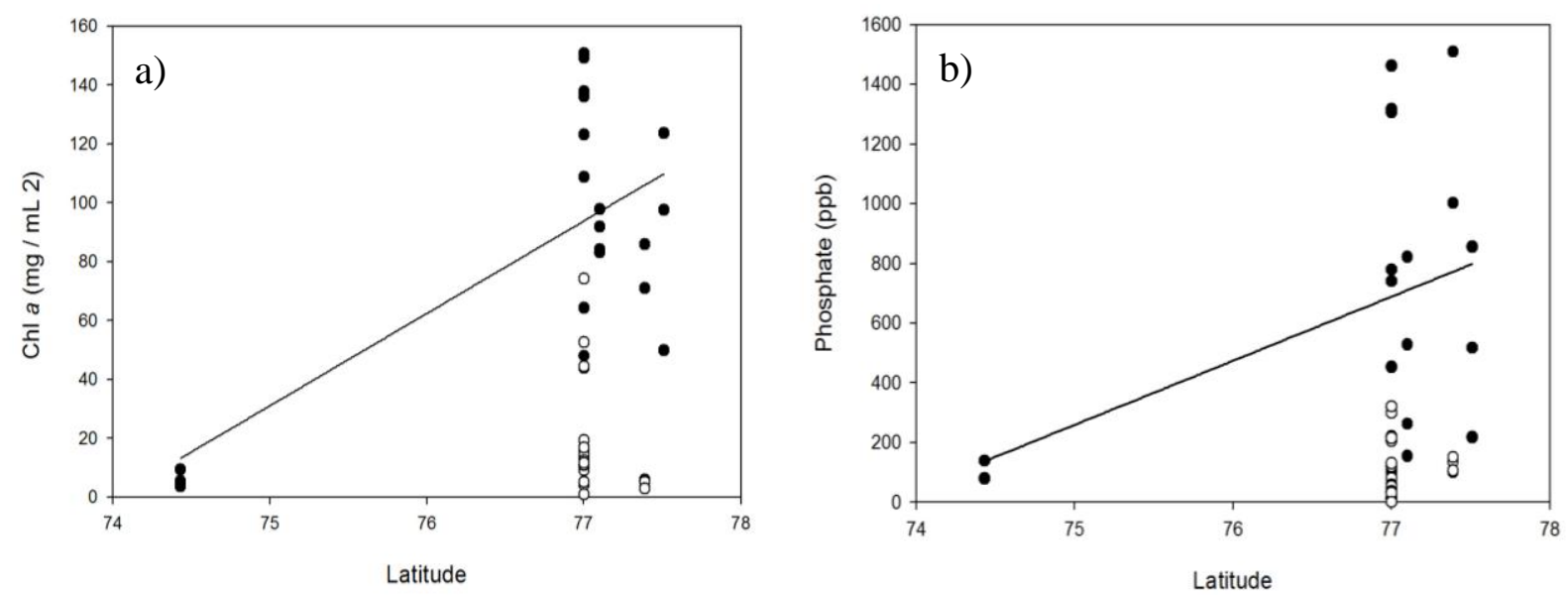

Figure 3.6 Significant relationships seen between (a) Chl- $a\left(\mathrm{R}^{2}=0.4897\right)$ and (b) phosphate $\left(\mathrm{R}^{2}=0.1018\right)$ concentrations with increased latitude in 2008 (dark circles). These nutrients are also plotted against latitude in 2009 (open circles). The line represents the linear regression between sites in 2008 only (dark circles). 

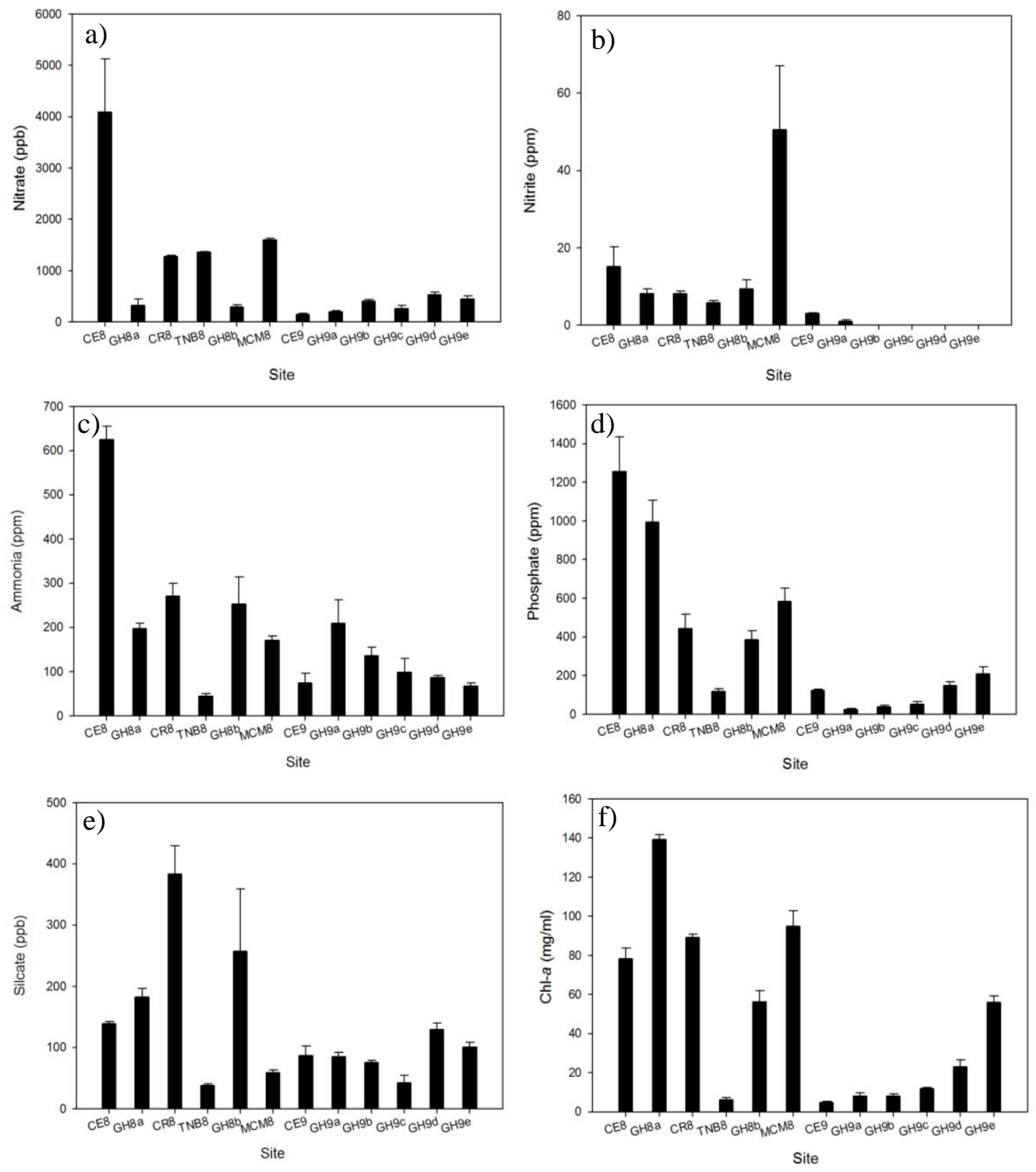

Figure 3.7 Nutrient concentrations (a) nitrate, (b) nitrite, (c) ammonia, (d) phosphate (e), silicate (ppb) and (f) Chl- $a\left(\mathrm{mg} / \mathrm{mL}^{2}\right)$ at the bottom of the sea ice core each site in 2008 and 2009. Nutrients were collected from Cape Evans (CE), Granite Harbour (GH), Cape Roberts (CR), Terra Nova Bay (TNB) and McMurdo Station $(\mathrm{McM})$. 
In 2008, nitrate, ammonia and phosphate concentrations were highest at CE08 (Figure 3.7a, c, d), whereas nitrite and silicate were highest at McM08 and CR08, respectively (Figure 3.7 b, e; Dunn's pairwise comparisons, $P<0.05$ for all comparisons). At Granite Harbour (GH09), nitrite and ammonia (Figure 3.7b, c) decreased over the time period whereas phosphate and Chl- $a$ concentrations increased (Figure 3.7d, f).

\subsubsection{Vertical profiles through the sea ice core}

Nutrient concentrations were compared between the top, middle and bottom of the sea ice core at Cape Evans on the $12^{\text {th }}$ of November 2009 and at Granite Harbour over a time period of 11 days in 2009 (Figure 3.8). Silicate concentration was high at Cape Evans, especially at the bottom of the sea ice core (Dunn's pairwise comparisons, $P<0.01$ for all comparisons). Silicate decreased at the top of the sea ice core at Granite Harbour over time, but increased with time in the middle and bottom of the ice core (Figure 3.8a). Nitrate concentrations were highest at the bottom of the ice core (Dunn's pairwise comparisons, $P<0.01$ for all comparisons) and increased over time at Granite Harbour (Figure 3.8b). Nitrite concentrations fell below the detection limits between the 18.11.09 to the 21.11.09 (Figure 3.8c) at $\mathrm{GH}$ and remained there for the rest of the study period. Ammonia levels also decreased in the bottom ice over a 9 day period, in the middle ice over a 3 day period and at the top of the ice core over an 8 day period. Ammonia concentrations were lower at the bottom of the sea ice core than the middle and top at $\mathrm{GH}$, and low throughout the core at Cape Evans (Figure 3.8d). Phosphate and Chl- $a$ were both in higher concentrations at the bottom of the ice core and increased over time at Granite Harbour (Figure 3.8e; Dunn's pairwise comparisons, $P<0.01$ for all comparisons). Chl- $a$ concentrations were very low in the top and middle of the sea ice cores (Figure 3.8f). 

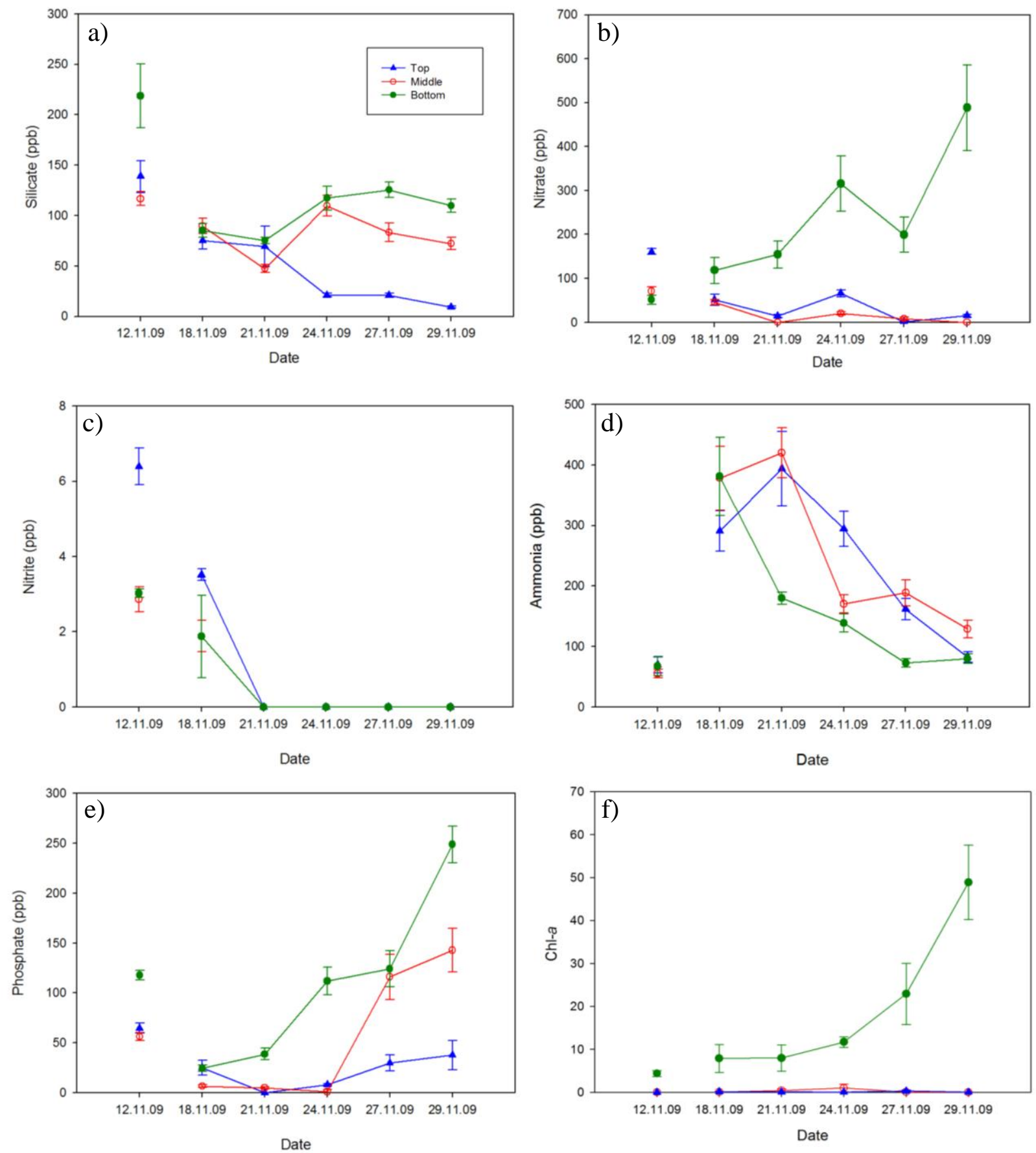

Figure 3.8 Nutrient concentrations (a) silicate, (b) nitrate, (c) nitrite, (d) ammonia, (e) phosphate (ppb) and (f) Chl- $a\left(\mathrm{mg} / \mathrm{mL}^{2}\right)$ at Cape Evans (12.11.09) and Granite Harbour (18.11.09 - 29.11.09) in the top, middle and bottom of the sea ice core. 


\subsubsection{Bacterial community diversity}

Each peak in the T-RFLP electropherogram was considered as a unique restriction fragment length (RFL) and the relative fluorescence indicated its relative abundance within each sample. The total number of peaks in each profile ranged from 42 to 68 and were broadly used as a measure for 'species richness'. In 2008, the number of RFLs significantly decreased in the bottom ice with increasing latitude in the rRNA communities (Figure 3.9; $\mathrm{F}_{26}=11.805, \mathrm{P}=0.0021$ ). There was no significant influence of latitude on the number of RFLs in the rDNA bacterial community $(\mathrm{P}>0.05)$.

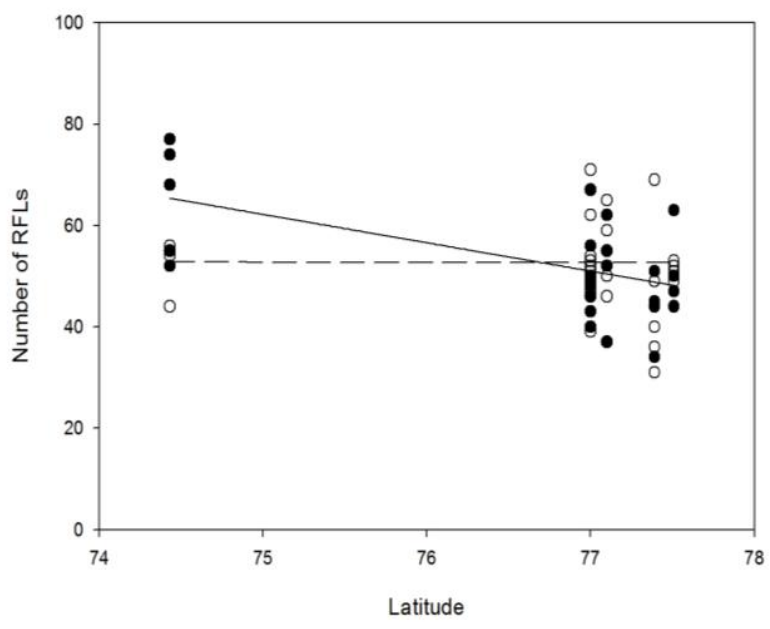

Figure 3.9 Number of RFLs (species richness) in DNA- (open circles, dotted line; $\left(\mathrm{R}^{2}=0.001\right)$ and RNAbased (closed circles; $\left(R^{2}=0.3207\right)$ communities at the bottom of the sea ice core with latitude. The lines show the linear regression fit to the data.

In 2009, there was an apparent decrease in RFLs with depth at Cape Evans in the rDNA community but no change in the RFLs at Granite Harbour. In the rRNA community, there was an increase in RFLs with depth at both Cape Evans and Granite Harbour. However, none of these correlations were significant (Figure 3.10; $\mathrm{P}>0.05$ for all comparisons). 

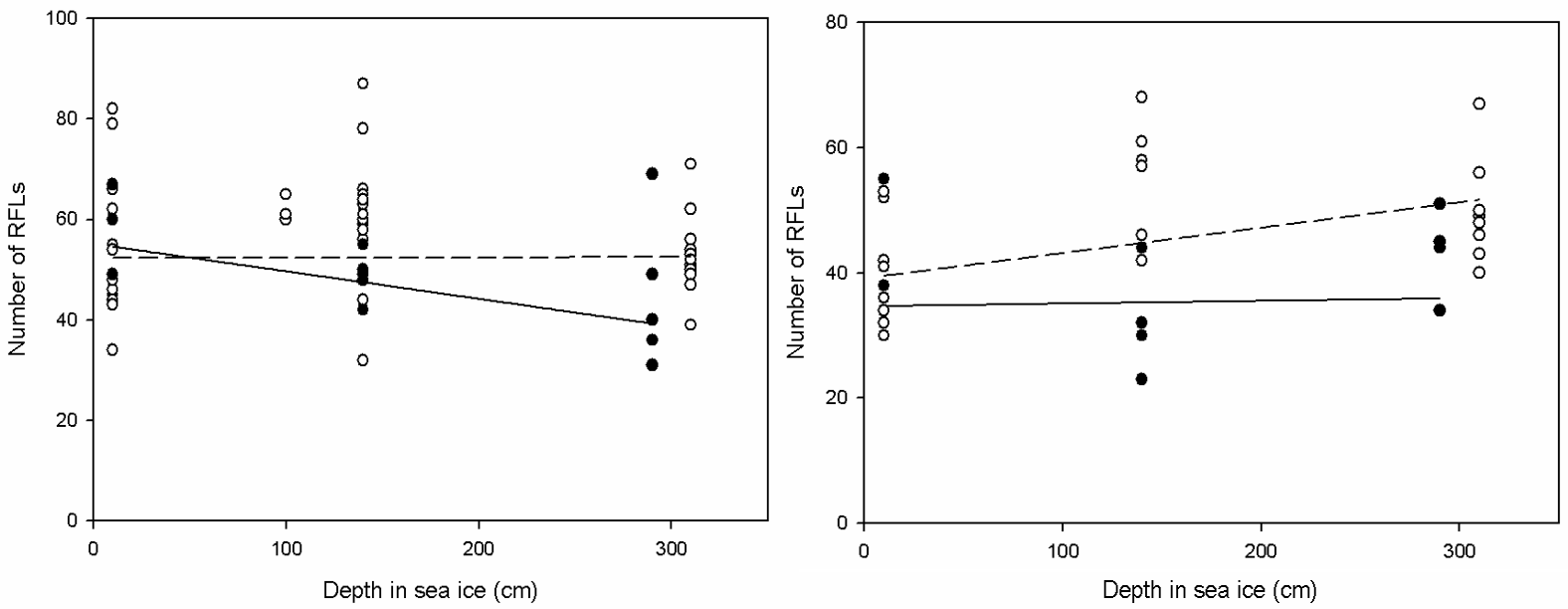

Figure 3.10 Number of RFLs (species richness) with depth down the sea ice core in the (a) rDNA communities at Granite Harbour (GH, open circles, dotted line; $\left(\mathrm{R}^{2}=0.0001\right)$ and Cape Evans $(\mathrm{CE}$, closed circles, solid line; $\left.R^{2}=0.3207\right)$ and (b) rRNA populations at $G H\left(R^{2}=0.0775\right)$ and $C E\left(R^{2}=0.2132\right)$. The lines show the linear regression fit to the data.

Bacterial diversity was estimated using the Shannon-Wiener index (H') the Simpson's index (1- $\left.\lambda^{\prime}\right)$ and the modified Hill's ratio (N21', Figure 3.11). At the bottom of the ice core in 2008, there was no significant difference between the rDNA and rRNA communities (ANOVA $F_{1}=0.18, P=0.626$, Figure 3.11a). There was a significant difference seen in $\mathrm{H}^{\prime}$ across sites in the rDNA (ANOVA $\mathrm{F}_{64}=3.49, \mathrm{P}=0.031$ ) where the richness at CE08 was significantly higher than at GH09b (Tukey's, $\mathrm{P}=0.0237$ ), and the richness at GH08a was significantly higher than at GH09b and GH09d (Tukey's, P < 0.01 , Figure 3.11a). There were no differences seen across the rRNA (ANOVA $F_{51}=$ $0.92, \mathrm{P}=0.534)$ communities.

Simpson's index $\left(1-\lambda^{\prime}\right)$ was also lower for the rRNA community at TNB08 and GH08a (Figure 3.11c). There was no significant difference seen between the rDNA and rRNA communities in $2008\left(\mathrm{~K}-\mathrm{W}, \mathrm{H}_{1}=1.81, \mathrm{P}=0.179\right)$. Simpson's index was significantly higher for the rRNA community at GH09a-d than for the rDNA community (Dunn's pairwise comparisons, $\mathrm{P}<0.05$ ). Across sites in the rDNA community, GH08a, b, CE08 and CR08 were significantly higher than GH09 a, b, d and McM08 had higher diversity 
than GH09 a,b (Tukey's test, $\mathrm{P}<0.01$ ). There was no significant difference across the rRNA communities $\left(\mathrm{K}-\mathrm{W}, \mathrm{H}_{11}=18.68, \mathrm{P}=0.067\right)$.

Community evenness (N21') was lower at the bottom of the ice core for the rRNA community at GH08a but again similar at the other sites (Figure 3.11e). N21' was significantly higher for the rRNA community at GH09a and $b$ than for the rDNA community (Tukey's test $\mathrm{P}<0.05$ ). There was a significant difference seen across sites in the rDNA (ANOVA F F2 $=10.03, \mathrm{P}<0.0001$ ) where GH09a, b and d had significantly lower N21' than did GH08a, b and CE08. TNB08 and CR08 also had higher diversity than GHa and $\mathrm{b}$ (Tukey's test $\mathrm{P}<0.05$, Figure 3.11e). There was a significant difference between the rRNA communities (ANOVA F $49=4.7, \mathrm{P}<0.0001$ ) where CE08 had higher evenness than did TNB08 and GH09a, and N21' was significantly lower for GH09a than GH09 b and c (Tukey's test $\mathrm{P}<0.05$, Figure 3.11e).

There was no significant difference in richness ( $\left.\mathrm{H}^{\prime}, 1-\lambda^{\prime}\right)$ or evenness (N21') through the sea ice core at Granite Harbour 2009 between the rDNA or rRNA communities (Figure 3.11b, d, f). 

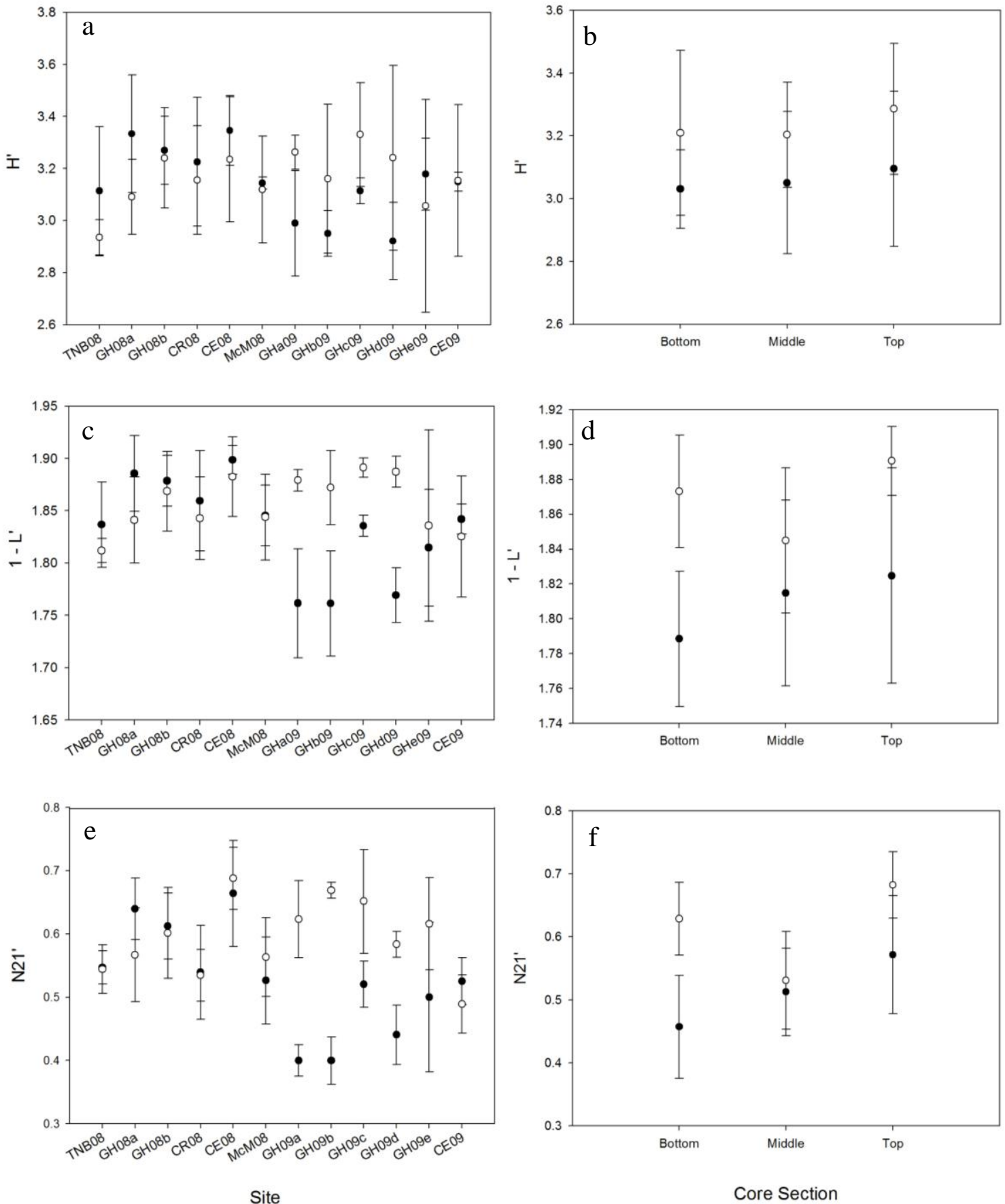

Figure 3.11 Diversity index H' (Shannon - Wiener index) at a) the bottom of the sea ice core between sites and b) through the sea ice core at GH09. Diversity index $1-$ L (Simpson's index) at c) the bottom of the sea ice core between sites and d) through the sea ice core at GH09. Diversity index N21' (Modified Hill's ratio) at e) the bottom of the sea ice core between sites and f) through the sea ice core at GH09. Sites were Cape Evans (CE), Granite Harbour (GH), Cape Roberts (CR), Terra Nova Bay (TNB) and McMurdo Station (McM). rDNA (black circles) and rRNA (open circles) bacterial communities are displayed with mean \pm standard deviation. 


\subsubsection{Bacterial community structure}

\subsubsection{Bottom ice community: differences between sites}

The raw electropherogram's were compared between the bottom ice samples across sites in 2008 and 2009. Each peak indicated a different RFL from either the forward (f, blue electropherogram's) or reverse (r, green electropherogram's) sequences and the height of each peak gives some indication to the quantity of that RFL in the community. It is apparent that some RFLs, representing specific bacterial phylotypes, are present at all sites in either the rDNA (for example, RFL81r, Figure 3.12) or the rRNA profiles (for example, RFL71f, Figure 3.13). Other phylotypes only appear in some samples, for example RFL198f (in DNA profiles, Figure 3.12) does not appear at Granite Harbour and RFL245f (rRNA profile) does not appear at McMurdo Station. RFL455f appears at TNB, $\mathrm{GH}$ and $\mathrm{McM}$ in the DNA community, whereas only at TNB in the rRNA portion. Some phylotypes appear in both the rDNA and rRNA profiles, such as RFL340r (Figure 3.12, $3.13)$. 


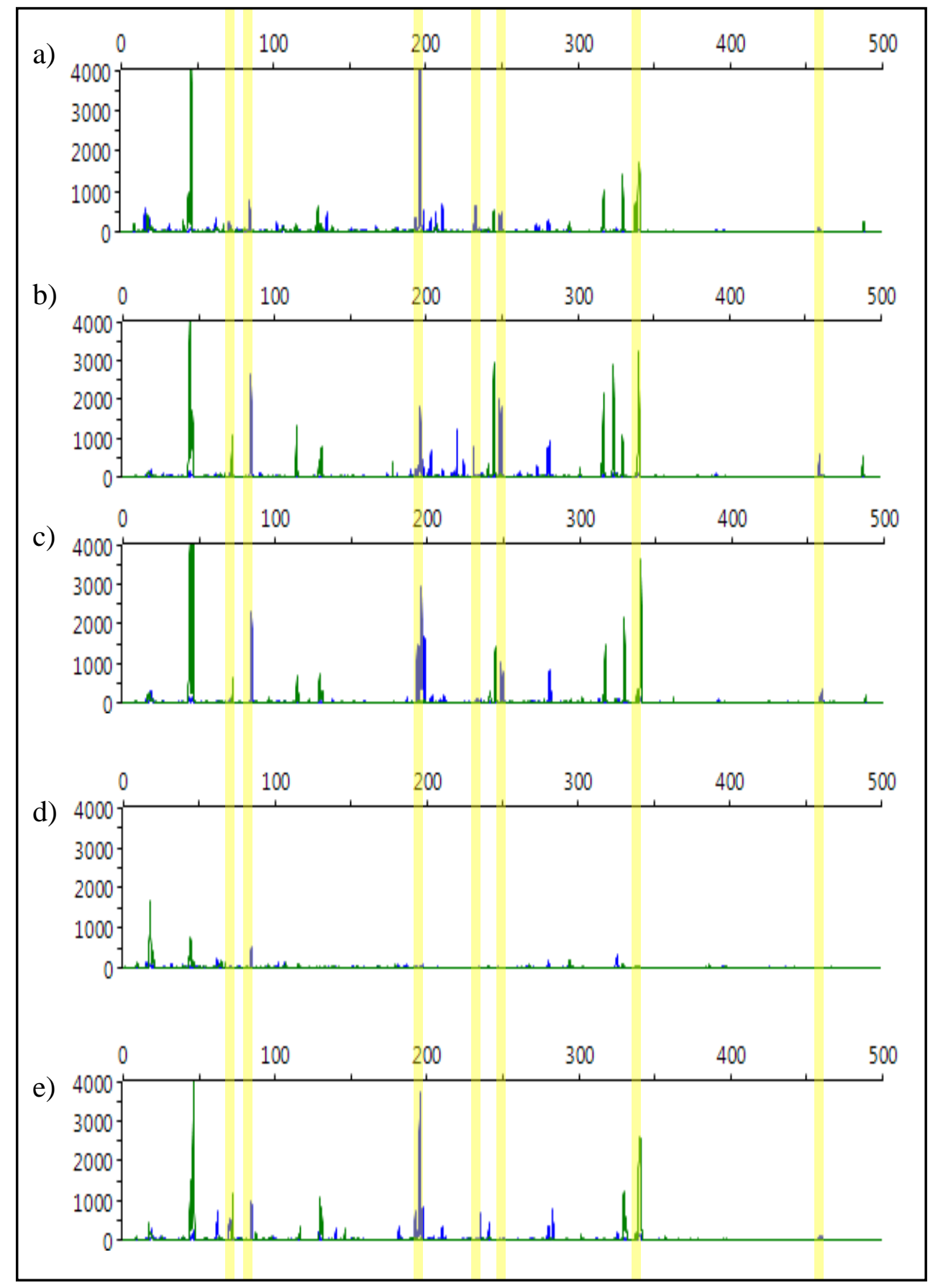

Figure 3.12 Raw T-RFLP profiles from selected bottom-ice samples investigating peak differences and similarities between selected rDNA communities. The samples were taken from sites (a) Terra Nova Bay (TNB08), (b) Granite Harbour, (c) Cape Roberts (d) Cape Evans (CE08) and (e) McMurdo Station (McM08) and plotted against fragment size in base pairs (bp). The forward (blue dye) and reverse (green dye) T-RFLP fragments are both shown. Some T-RFLs of interest are highlighted in yellow. 


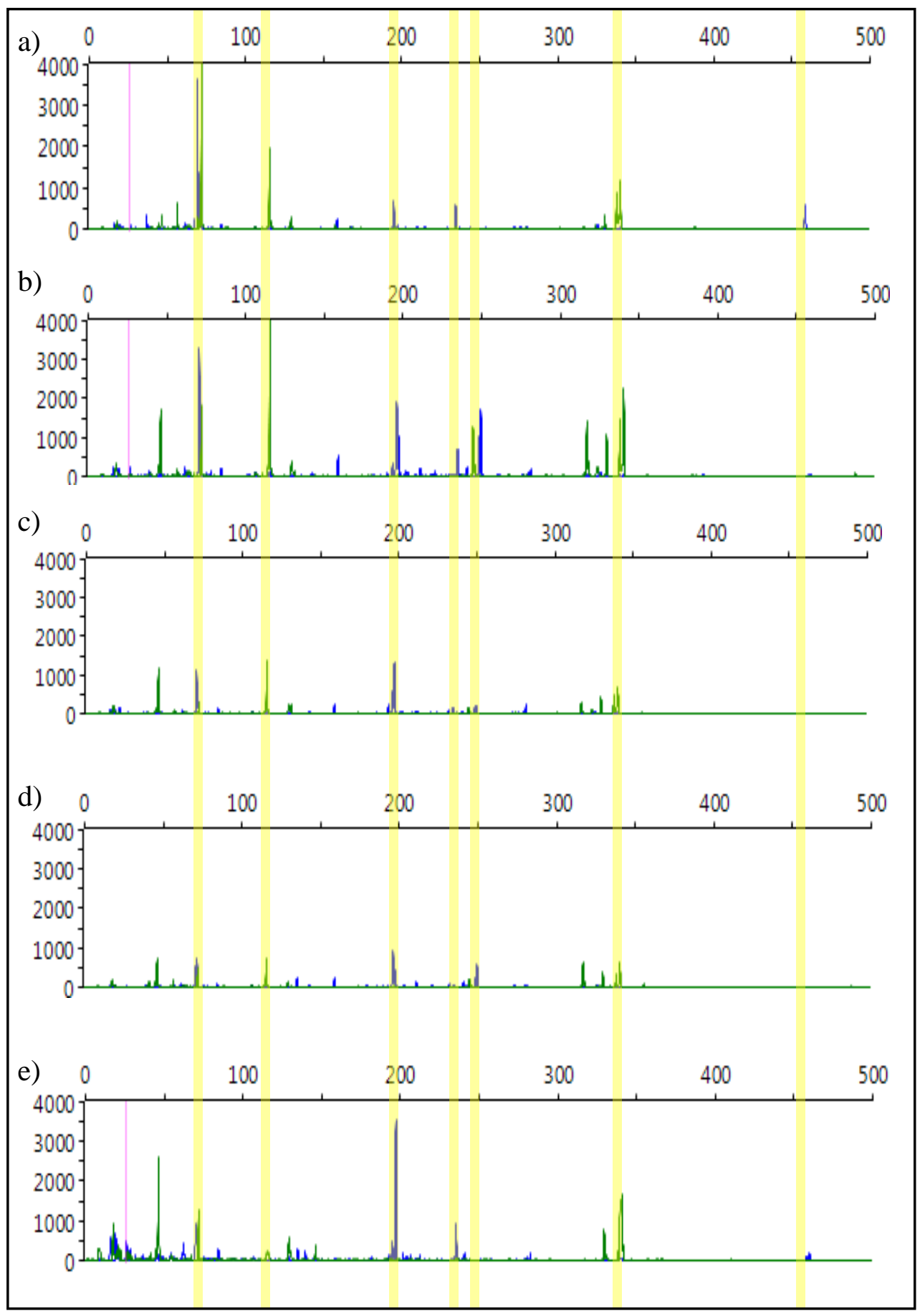

Figure 3.13 Raw T-RFLP profiles from selected bottom-ice samples investigating peak differences and similarities between selected rRNA communities. The samples were taken from sites (a) Terra Nova Bay (TNB08), (b) Granite Harbour, (c) Cape Roberts (d) Cape Evans (CE08) and (e) McMurdo Station (McM08) and plotted against fragment size in base pairs (bp). The forward (blue dye) and reverse (green dye) T-RFLP fragments are both shown. Some T-RFLs of interest are highlighted in yellow. 
I used a PERMANOVA to test for differences in the bacterial communities at the bottom of the sea ice core between years 2008 and 2009, among the different sites, and between the rDNA and rRNA communities. Significant interactions occurred between all three factors (Year, Site and the rDNA versus rRNA method, Appendix B), therefore the data were analysed in sections in order to unravel these complexities.

Firstly, I tested the hypothesis that bacterial communities from the bottom of the sea ice core would differ between the active (rRNA) and the total (rDNA) samples (Table 3.1).

Table 3.1 Summary results of a permutational multivariate analysis of variance (PERMANOVA) of comparing DNA and rRNA bacterial communities at each site. Significant differences are shown as $*=p$ $<0.05, * *=p<0.01$, and no significance $=$ ns.

\begin{tabular}{lc} 
Site & DNA vs. rRNA \\
\hline TNB08 & ns \\
GH08a & $* *$ \\
GH08b & ns \\
CR08 & ns \\
CE08 & ns \\
MCM08 & $* *$ \\
CE09 & $*$ \\
GH09a & $*$ \\
GH09b & $* *$ \\
GH09c & $*$ \\
GH09d & $*$ \\
GH09e & ns \\
SW09 & ns
\end{tabular}

Pairwise comparisons between the rDNA and the rRNA sea ice communities revealed significant differences at GH08a and MCM08 but not at the other sites in 2008. In the sea ice at Granite Harbour 2009 (GH09), the rDNA and rRNA profiles were significantly different (Table 3.1), apart from at GH09e. The rDNA and rRNA profiles were not significantly different from each other in the seawater column (SW09).

Secondly, the hypothesis that bacterial communities would show greater differences with greater spatial and temporal scales was supported. In both the rDNA and rRNA profiles 
from 2008, bacterial communities collected from bottom ice from the same site were more similar than those collected from more distant sites. TNB08 and McM08 communities were more distinct relative to the communities at GH08, CE08 and CR08 in both the rDNA and rRNA profiles (Figure 3.14a, b; Table 3.2).
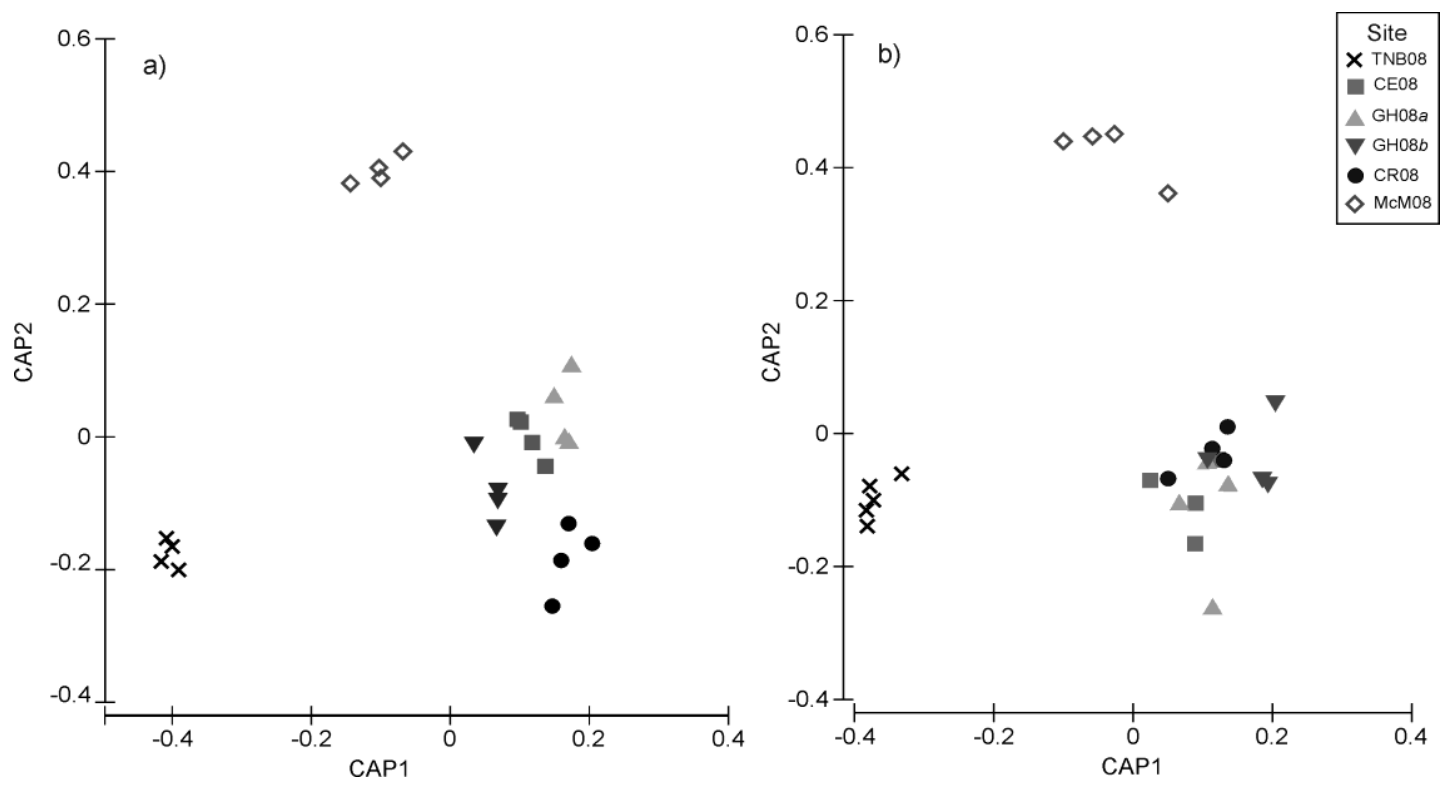

Fig 3.14 Canonical analysis of principle components plots showing the PERMANOVA data of DNA (a) and rRNA (b) communities from bottom ice samples taken in 2008. Samples were collected from sites Terra Nova Bay (TNB), Cape Evans (CE), Granite Harbour (GH), Cape Roberts (CR) and McMurdo Station (McM).

Table 3.2 Summary results of a permutational multivariate analysis of variance (PERMANOVA) of bacterial communities from bottom ice cores in 2008. Pairwise comparisons among sites were investigated in DNA (white boxes) and rRNA (grey boxes) populations separately. Significant differences are shown as $*=p<0.05, * *=p<0.01$ and no-significance $=$ ns.

\begin{tabular}{|l|cccccc|}
\hline & TNB08 & GH08a & GH08b & CR08 & CE08 & MCM08 \\
\hline TNB08 & & $* *$ & $* *$ & $* *$ & $* *$ & $* *$ \\
GH08a & $*$ & & ns & ns & $*$ & $*$ \\
GH08b & $*$ & ns & & ns & ns & $*$ \\
CR08 & $*$ & $*$ & $*$ & & $*$ & $*$ \\
CE08 & $*$ & ns & ns & $*$ & & $* *$ \\
MCM08 & $*$ & $*$ & $*$ & $*$ & $*$ & \\
\hline
\end{tabular}


The rDNA and rRNA profiles were then compared at Cape Evans and Granite Harbour between two years, 2008 and 2009. The rDNA and rRNA profiles both showed temporal variations where communities collected from $\mathrm{CE}$ and $\mathrm{GH}$ in 2009 were different to those found at the same sites in 2008 (Figure 3.15a, b; Table 3.3).
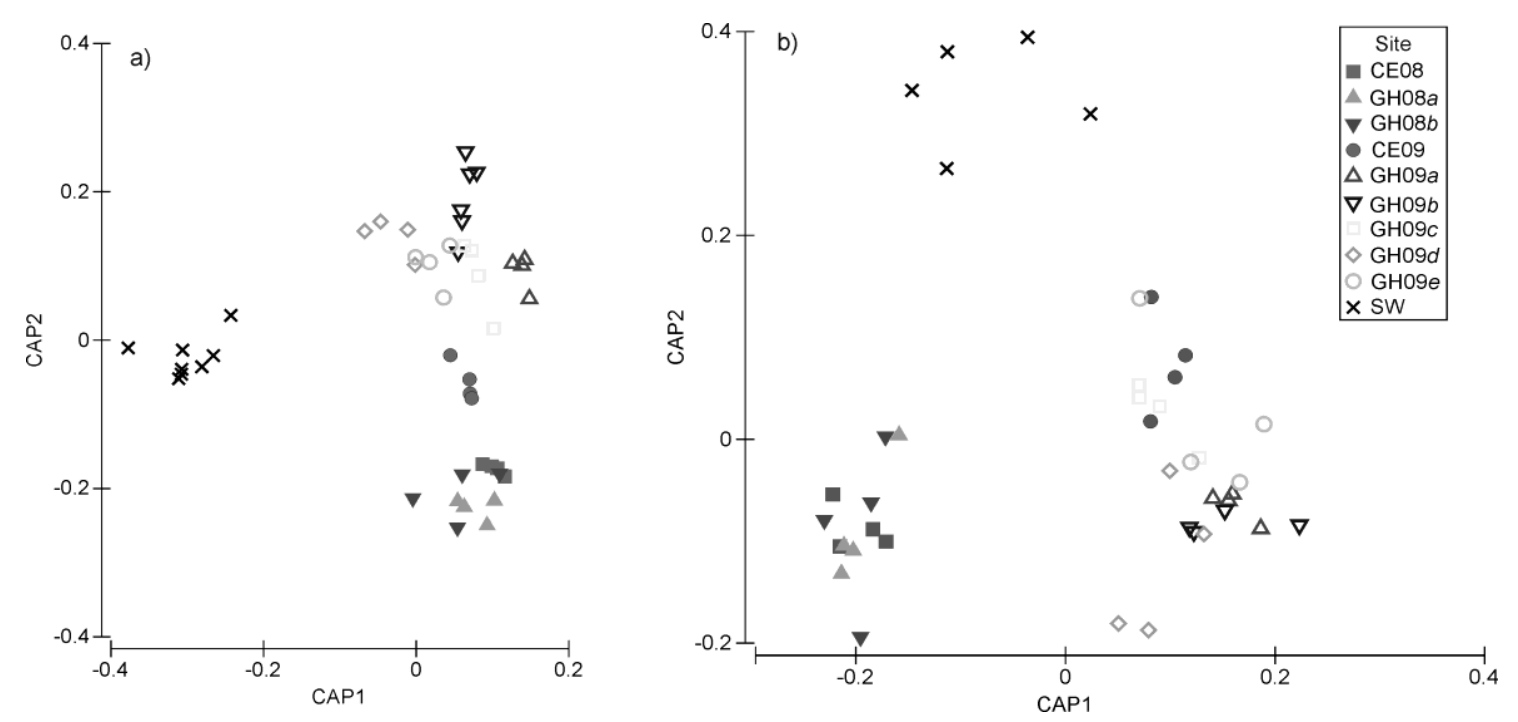

Fig 3.15 Canonical analysis of principle components plots showing the PERMANOVA data of DNA (a) and rRNA (b) bottom ice communities comparing changes in community structure from Cape Evans (CE) and Granite Harbour (GH) across the two year period of 2008 to 2009.

However, over a shorter temporal scale of two weeks at GH09, there was little or no change in the bacterial communities (Table 3.3). The rDNA and rRNA profiles collected from the underlying seawater at Granite Harbour in 2009 were significantly different from the profiles collected from the sea ice (Table 3.3). 
Table 3.3 Summary results of a permutational multivariate analysis of variance (PERMANOVA) of bacterial communities at CE and GH 2008 and 2009. Pairwise comparisons among sites were investigated in DNA (white boxes) and rRNA (grey boxes) populations separately. Significant differences are shown as $*=p<0.05, * *=p<0.01$ and no-significance $=\mathrm{ns}$.

\begin{tabular}{|l|cccccccccc|}
\hline & CE08 & GH08a & GH08b & CE09 & GH09a & GH09b & GH09c & GH09d & GH09e & SW09 \\
\hline CE08 & & $*$ & ns & $* *$ & $* *$ & $* *$ & $* *$ & $* *$ & $* *$ & $* *$ \\
GH08a & ns & & ns & $*$ & $*$ & $*$ & $*$ & $*$ & $*$ & $* *$ \\
GH08b & ns & ns & & $*$ & $*$ & $*$ & $*$ & $*$ & $*$ & $* *$ \\
CE09 & $*$ & $*$ & $*$ & & $*$ & $*$ & $*$ & $*$ & $\mathrm{~ns}$ & $*$ \\
GH09a & $*$ & $*$ & $*$ & $*$ & & ns & ns & ns & ns & $* *$ \\
GH09b & $* *$ & $* *$ & $* *$ & $* *$ & $* *$ & & ns & ns & ns & $* *$ \\
GH09c & $*$ & $*$ & $*$ & $*$ & ns & ns & & ns & ns & $* *$ \\
GH09d & $*$ & $*$ & $*$ & $*$ & $*$ & ns & $*$ & & ns & $* *$ \\
GH09e & ns & $*$ & $*$ & $*$ & $*$ & ns & ns & ns & & $*$ \\
SW09 & $* *$ & $* *$ & $* *$ & $* *$ & $* *$ & $* *$ & $* *$ & $* *$ & $*$ & \\
\hline
\end{tabular}

\subsubsection{Communities throughout the sea ice core and seawater}

The raw electropherograms from the rDNA and rRNA were compared between the top, middle and bottom of the sea ice core at Cape Evans and Granite Harbour in 2009 (Figures 3.16 - 3.19). Some RFLs were dominant in the majority of the rRNA and rDNA profiles (for example, RFL109r and RFL345r). Other phylotypes only appeared in some samples, for example RFL390r only appeared in the rRNA profiles at Granite Harbour in 2009 (Figure 3.19), but was not seen in the rDNA profiles nor did it appear at Cape Evans. RFL128r appeared at Cape Evans (Figure 3.16, 3.17) but was absent at Granite Harbour. Some of the RFLs were present in the top, middle and bottom of the sea ice core, such as RFL71r and RFL109r at Granite Harbour, and RFL128r at Cape Evans. RFL260r occurred only in the rDNA and rRNA bottom ice samples at GH (Figures 3.18, 3.19) but was present in the top and middle of the sea ice core at CE. RFL71f at Cape Evans was only found further towards the top of the sea ice core in both the rDNA and rRNA communities (Figures 3.16, 3.17). There were many peaks below $50 \mathrm{bp}$ at the top of the sea ice core in the rRNA profiles. These peaks are likely to be primer dimers and were removed prior to further analysis. 


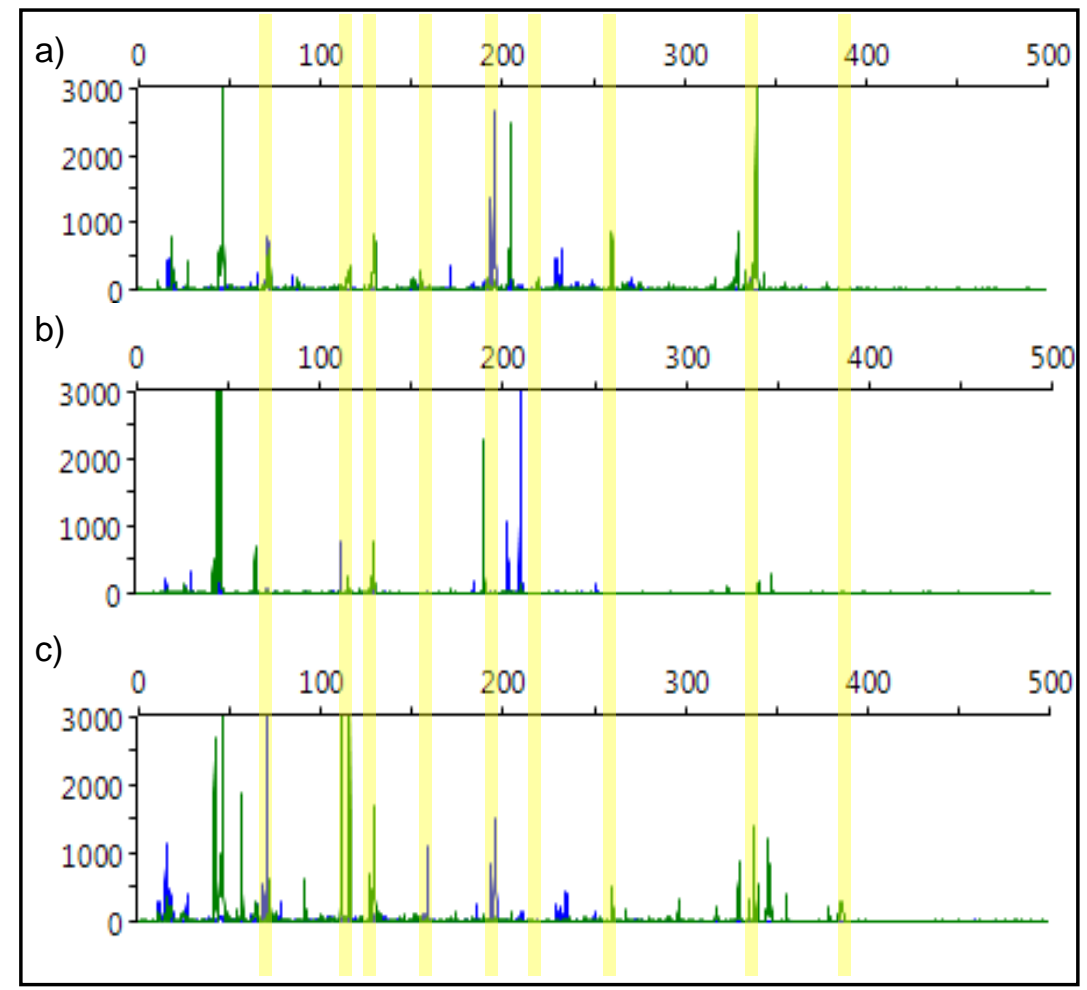

Figure 3.16 Raw T-RFLP profiles from the rDNA communities at the (a) top, (b) middle and (c) bottom of the sea ice core at Cape Evans 2009. The forward (blue) and reverse (green) T-RFLP fragments are both shown. Some T-RFLs of interest are highlighted.

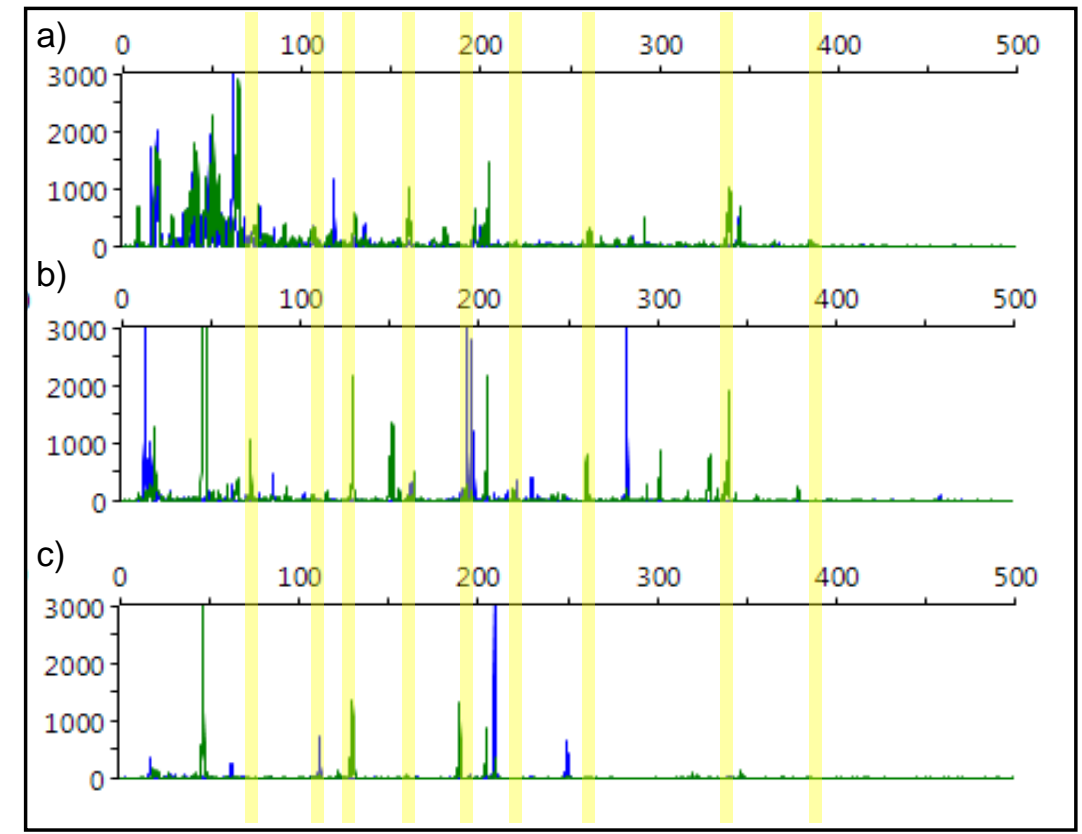

Figure 3.17 Raw rRNA T-RFLP profiles from the (a) top, (b) middle and (c) bottom of the sea ice core at Cape Evans 2009. The forward (blue) and reverse (green) T-RFLP fragments are both shown. Some TRFLs of interest are highlighted. 


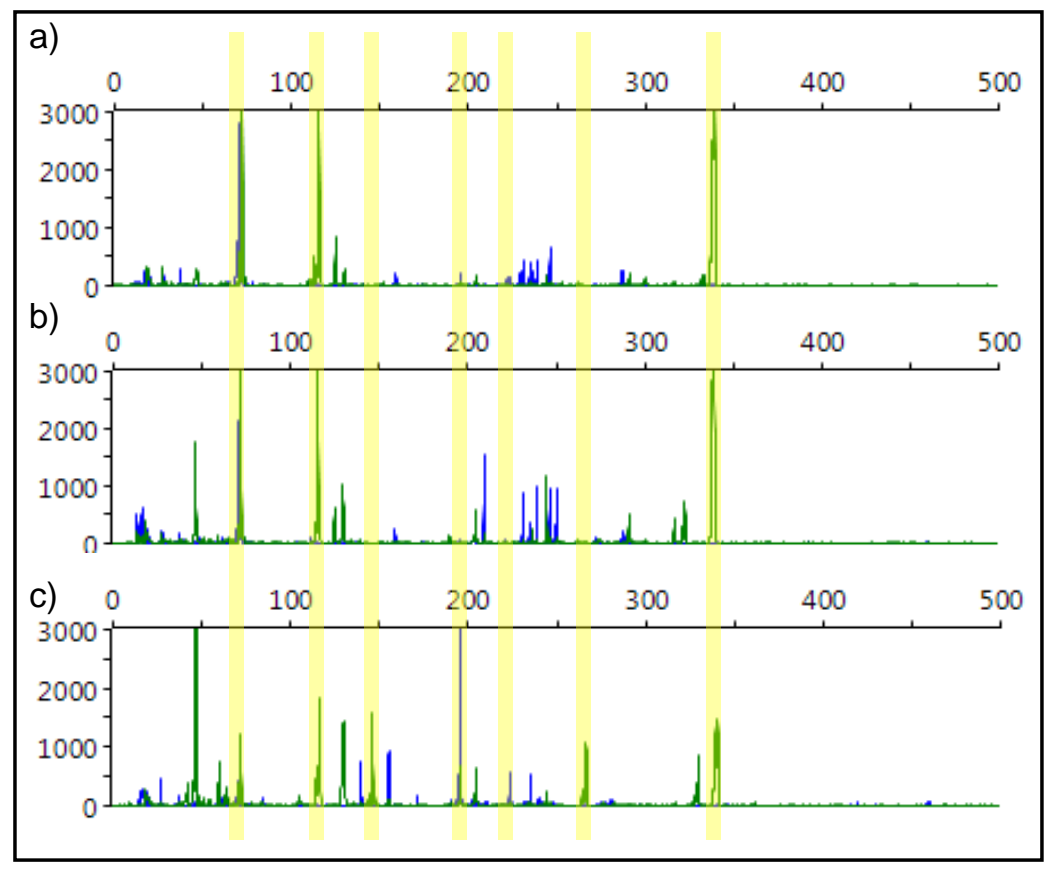

Figure 3.18 Raw rDNA T-RFLP profiles from the (a) top, (b) middle and (c) bottom of the sea ice core at Granite Harbour 2009 (GH09e). The forward (blue) and reverse (green) T-RFLP fragments are both shown. Some T-RFLs of interest are highlighted.

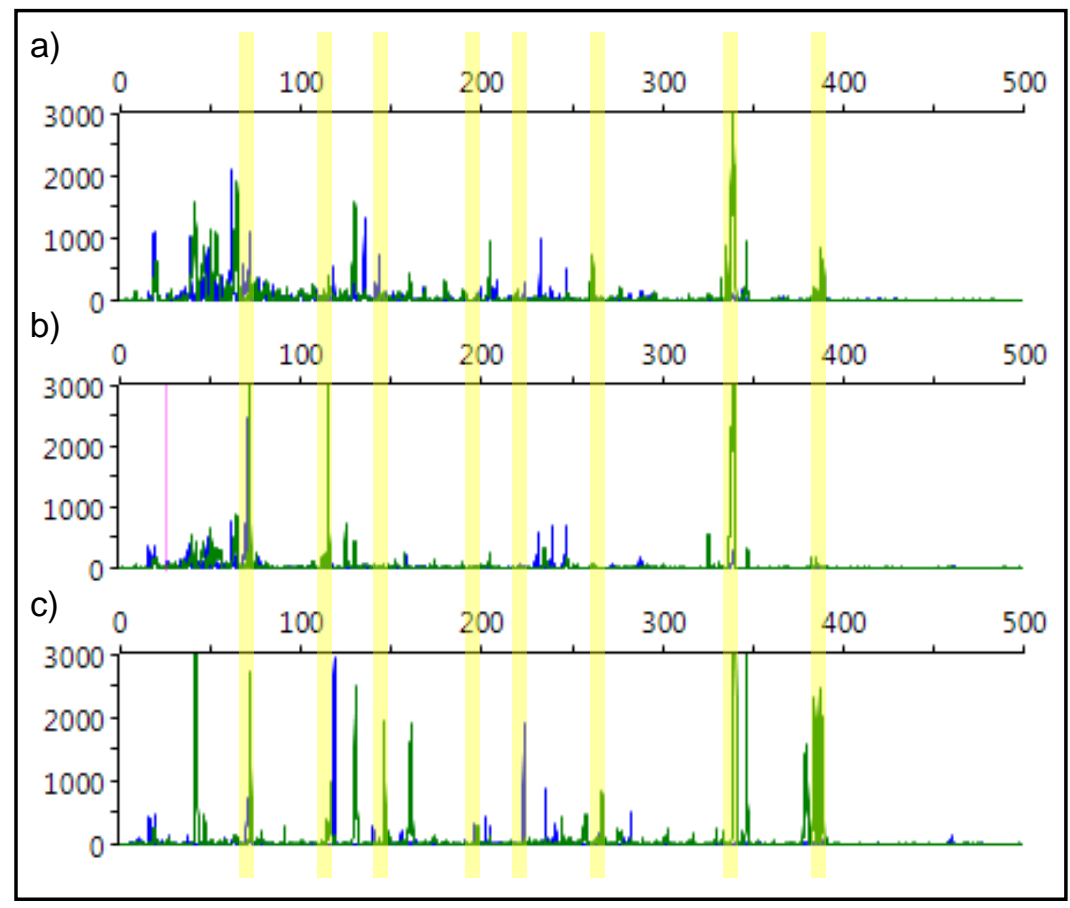

Figure 3.19 Raw rRNA T-RFLP profiles from the (a) top, (b) middle and (c) bottom of the sea ice core at Granite Harbour 2009 (GH09e). The forward (blue) and reverse (green) T-RFLP fragments are both shown. Some T-RFLs of interest are highlighted. 


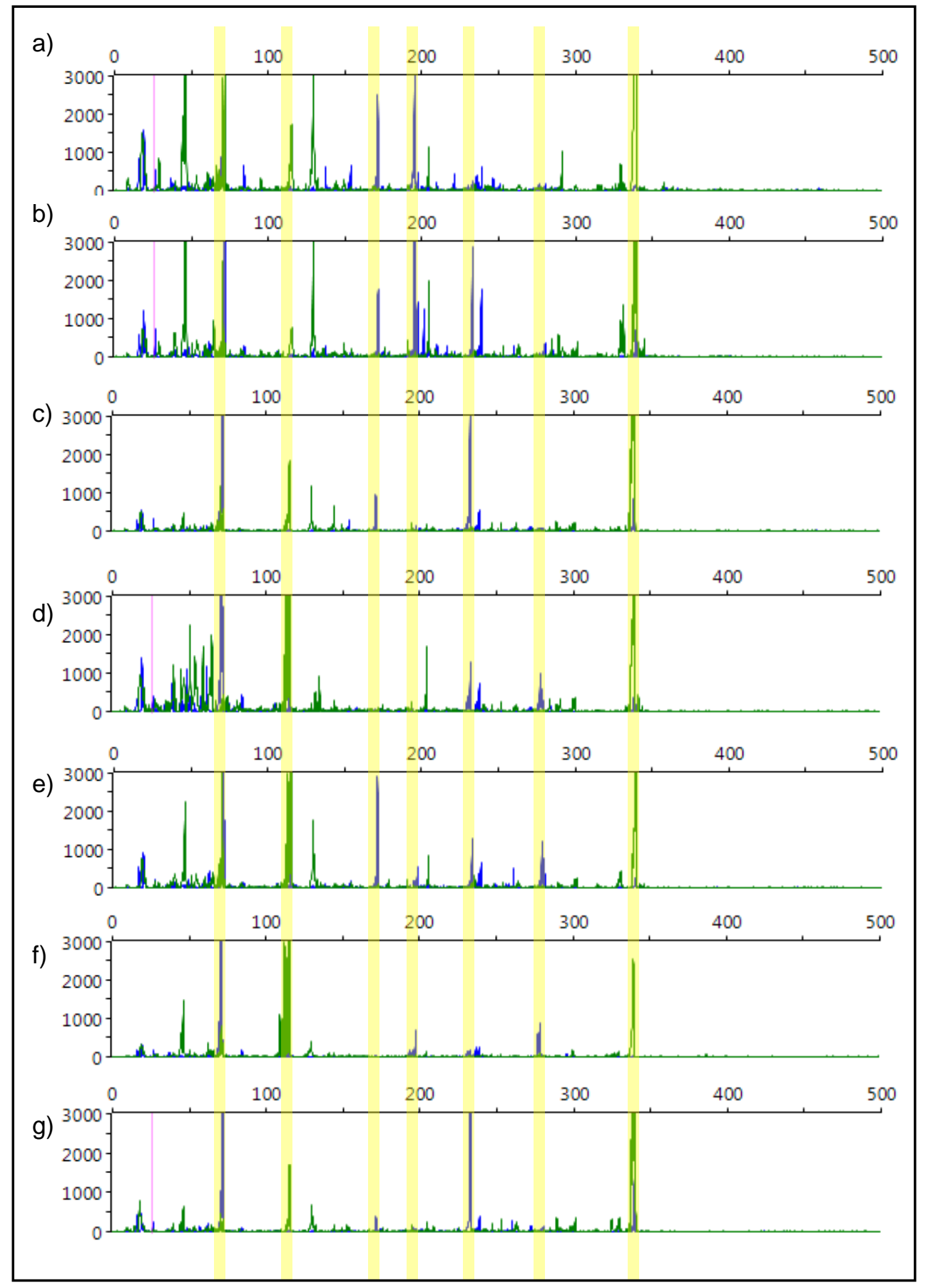

Figure 3.20 Raw rDNA T-RFLP profiles from the sea water beneath the sea ice core at Granite Harbour in 2009. Samples were collected on the (a) 19.11 .09 , (b) 21.11 .09 , (c) 24.11 .09 , (d) 27.11 .09 , (e) 28.11 .09 , (f) 29.11.09 and (g) 30.11.09. The forward (blue) and reverse (green) T-RFLP fragments are both shown. TRFLs of interest are highlighted. 


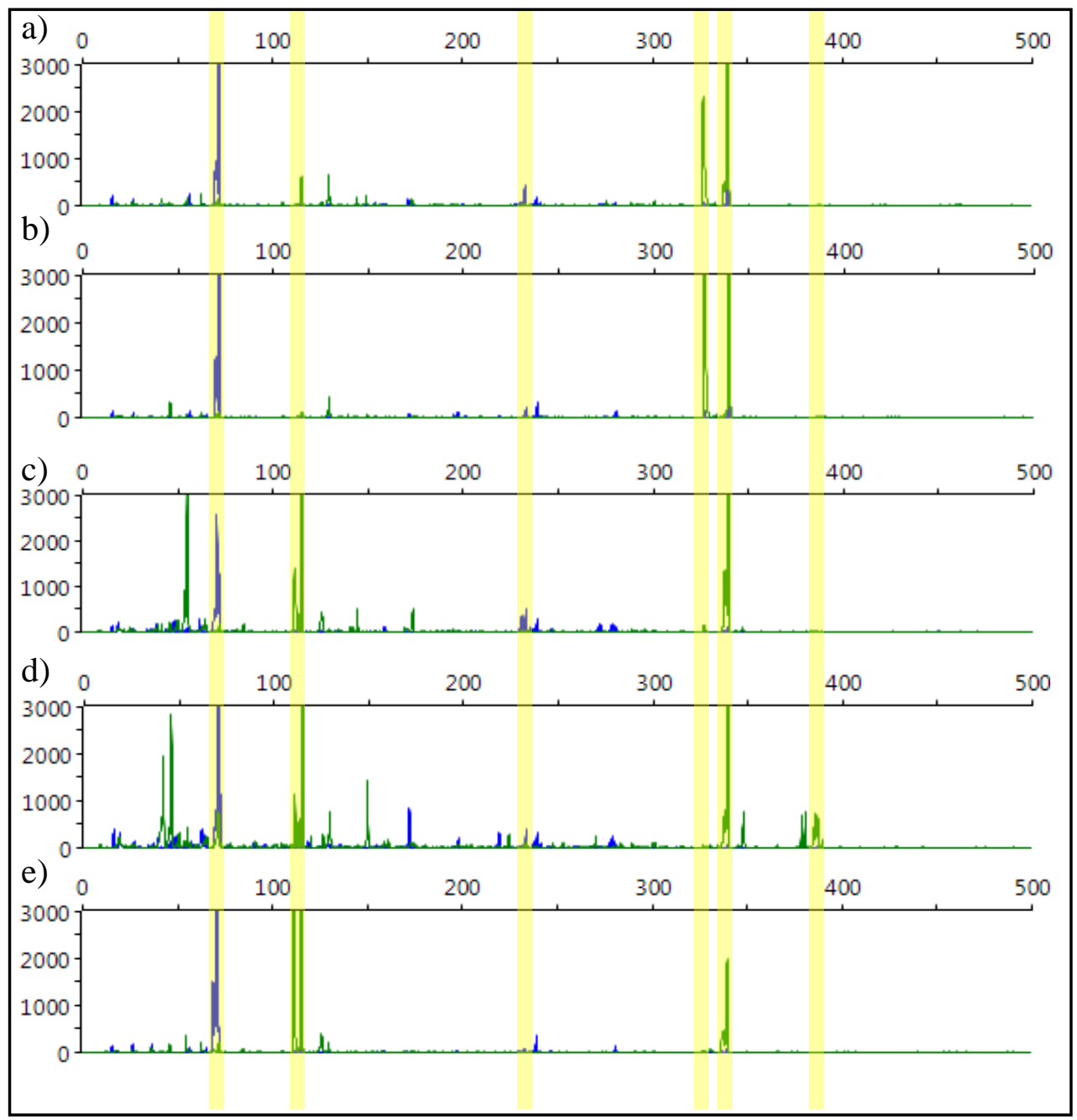

Figure 3.20 Raw rRNA T-RFLP profiles from the sea water beneath the sea ice core at Granite Harbour in 2009. Samples were collected on the (a) 21.11.09, (b) 24.11.09, (c) 27.11.09, (d) 28.11.09, and (e) 29.11.09. The forward (blue) and reverse (green) T-RFLP fragments are both shown. T-RFLs of interest are highlighted.

The seawater rDNA and rRNA communities shared some similar RFLs throughout the sampling period of 10 days. RFLs 71f, 109r, 231f, and 340r were generally all present in both the rDNA and rRNA profiles over time (Figure 3.20, 3.21). RFL194f was dominant in the rDNA profiles early in the sampling time frame, but then disappeared (Figure 3.20). It was not seen in the rRNA community. RFL330r was dominant in the earlier rRNA profiles but also disappeared with time (Figure 3.21). 
A PERMANOVA was used to test for differences in the bacterial communities through the sea ice core, between sites and between the rDNA and rRNA communities. Again, significant interactions occurred between all three factors (site, core section and the DNA versus rRNA method, Appendix B), therefore the data were analysed in sections in order to unravel these complexities. Samples were collected from the top, middle and bottom of the sea ice core for rDNA and rRNA analysis. There was a significant difference between the rDNA and rRNA communities through the sea ice core apart from at 'GH09e bottom', 'CE09 middle' and between the seawater populations (Table 3.4).

Table 3.4 Summary results of a permutational multivariate analysis of variance (PERMANOVA) of comparing rDNA and rRNA bacterial communities at each site. Significant differences between DNA and RNA bacterial communities are shown as $*=p<0.05, * *=p<0.01$, and no significance $=$ ns. Blank boxes $=$ no analyses was done.

\begin{tabular}{cccc} 
Site & Bottom & Middle & Top \\
\hline GH09a & $*$ & $*$ & $*$ \\
GH09b & $* *$ & & \\
GH09c & $*$ & & \\
GH09d & $*$ & & \\
GH09e & $\mathrm{ns}$ & $*$ & $*$ \\
CE09 & $* *$ & $\mathrm{~ns}$ & $*$ \\
\hline $\mathrm{SW}$ & $\mathrm{ns}$ & & \\
\hline
\end{tabular}

The seawater (SW) samples collected from 2009 were comprised of a different community to that found at the bottom of the sea ice core at GH09a-e (Figure 3.22a, b). 

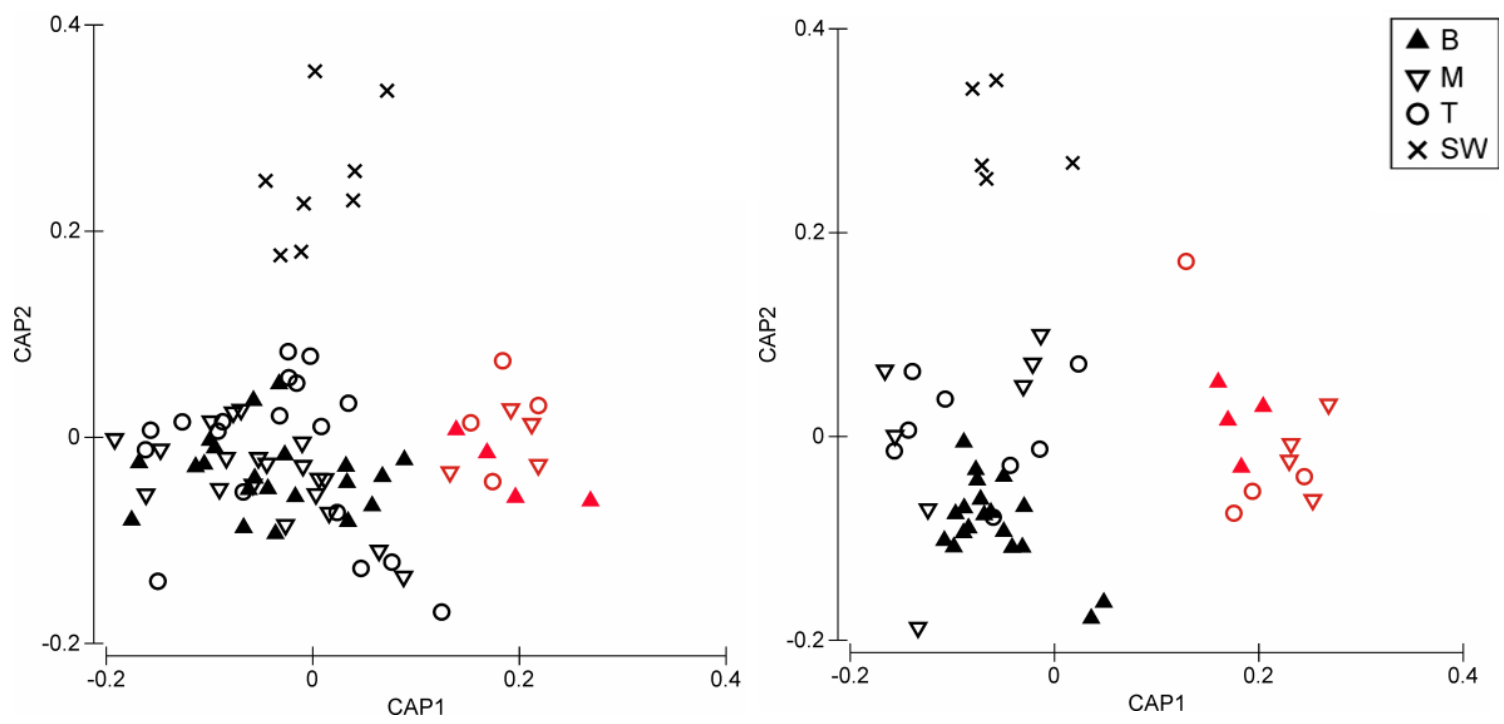

Fig 3.22 Canonical analysis of principle components plots showing the PERMANOVA data of DNA (a) and rRNA (b) communities comparing changes in community structure through the sea ice core at Granite Harbour (black) and Cape Evans (red) in 2009. Bacterial communities came from the top (T), middle (M) and bottom (B) of the sea ice core and the underlying seawater (SW).

Comparing the rDNA communities at GH (Figure 3.22a), the PERMANOVA showed that there were significant differences between the bottom and middle, and bottom and top profiles. However, there was no difference between the middle and top rDNA communities. There was a significant difference in bacterial communities through the sea ice core at Cape Evans (Table 3.5). The bacterial communities found at Cape Evans were significantly different from the communities found at Granite Harbour (Table 3.5).

Comparing the rRNA communities (Figure 3.21b), the PERMANOVA showed that there were significant differences between the bottom and middle, and bottom and top rRNA communities (Table 3.5). There were no significant differences between the middle and top sea ice communities at Granite Harbour or at Cape Evans (Table 3.5). 
Table 3.5 Summary results of a permutational multivariate analysis of variance (PERMANOVA) of bacterial communities from bottom, middle and top of the sea ice cores in 2009. Pairwise comparisons among sites were investigated in rDNA (white boxes) and rRNA (grey boxes) populations separately. Significant differences are shown as $*=p<0.05, * *=p<0.01$ and no significance $=\mathrm{ns}$. Boxes with no entries indicate the data were not analysed.

\begin{tabular}{|c|c|c|c|c|c|c|c|}
\hline GH09a & $\mathrm{B}$ & M & $\mathrm{T}$ & $\mathrm{GH} 09 b$ & B & $\mathrm{M}$ & $\mathrm{T}$ \\
\hline B & & * & * & B & & & \\
\hline M & * & & ns & M & ** & & \\
\hline $\mathrm{T}$ & * & ns & & $\mathrm{T}$ & * & * & \\
\hline $\mathrm{GH} 0 \mathrm{ge}_{e}$ & $\mathrm{~B}$ & $M$ & $\mathrm{~T}$ & $\mathrm{GH} 09 c$ & B & $M$ & $\mathrm{~T}$ \\
\hline B & & * & * & B & & & \\
\hline M & ns & . & ns & M & * & & \\
\hline $\mathrm{T}$ & ns & ns & & $\mathrm{T}$ & * & ns & \\
\hline CE09 & B & $M$ & $\mathrm{~T}$ & GH09d & B & $M$ & $\mathrm{~T}$ \\
\hline B & & * & * & B & & & \\
\hline M & * & & ns & M & * & & \\
\hline $\mathrm{T}$ & * & * & & $\mathrm{T}$ & * & ns & \\
\hline
\end{tabular}

There was the small drift in the rDNA community structure from the $19^{\text {th }}$ of November 2009 to $30^{\text {th }}$ of November 2009 (Table 3.6). At the bottom of the ice core, GH09a was significantly different from GH09d and e. GH09c was also significantly different from GH09d. In the middle of the sea ice core, GH09a and b were significantly different from GH09e. GH09b also was a significantly different community from GH09d. At the top of the ice core, the rDNA community did not change apart from GH09b being significantly different from GH09d (Table 3.6).

There was no shift in the rRNA community at the bottom of the sea ice core over time at GH09. However, there was a shift between GH09a and GH09e in both the top and middle of the ice core. The rRNA community at the top and middle of the sea ice core at GH09a was not significantly different from CE09 (Table 3.6). 
Table 3.6 Summary results of a permutational multivariate analysis of variance (PERMANOVA) of bacterial communities at CE and GH 2009 at the bottom, middle and top of the ice core and from GH 2009 seawater (SW). Pairwise comparisons among sites were investigated in DNA (white boxes) and rRNA (grey boxes) populations separately. Significant differences are shown as $*=p<0.05, * *=p<0.01$ and no-significance $=$ ns. Boxes with no entry were not analysed.

\begin{tabular}{|c|c|c|c|c|c|c|c|c|}
\hline Core & Site & GH09a & $\mathrm{GH} 09 b$ & $\mathrm{GH} 09 c$ & $\mathrm{GH} 09 d$ & GH09e & CE09 & SW \\
\hline \multirow[t]{7}{*}{ Bottom } & GH09a & & ns & ns & ns & ns & * & $\star * *$ \\
\hline & $\mathrm{GH} 09 b$ & ** & & ns & ns & ns & * & $* * *$ \\
\hline & $\mathrm{GH} 09 c$ & ns & ns & & ns & ns & * & $* \star \star$ \\
\hline & GH09d & * & ns & * & & ns & * & $\star \star * \star$ \\
\hline & GH09e & * & ns & ns & ns & & ns & $* * *$ \\
\hline & CE09 & * & $* * *$ & * & * & * & & $\star * *$ \\
\hline & SW & $* * *$ & $* * *$ & $* * *$ & $* * *$ & $* * *$ & $* * *$ & 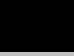 \\
\hline \multirow[t]{7}{*}{ Middle } & GH09a & & & & & * & ns & $\star \star \star \star$ \\
\hline & $\mathrm{GH} 09 b$ & ns & & & & & & \\
\hline & $\mathrm{GH} 09 c$ & ns & ns & & & & & \\
\hline & $\mathrm{GH} 09 d$ & ns & * & ns & & & & \\
\hline & $\mathrm{GH} 09 e$ & * & * & ns & ns & & * & $* * *$ \\
\hline & CE09 & * & * & * & ns & ** & & $\star * *$ \\
\hline & SW & $\star \star \star$ & $* * *$ & $\star \star \star ~$ & $* * *$ & $* * *$ & $* * *$ & \\
\hline \multirow[t]{7}{*}{ Top } & GH09a & & & & & * & ns & $* * *$ \\
\hline & $\mathrm{GH} 09 b$ & ns & & & & & & \\
\hline & $\mathrm{GH} 09 c$ & ns & ns & & & & & \\
\hline & $\mathrm{GH} 09 d$ & ns & * & ns & & & & \\
\hline & $\mathrm{GH} 09 e$ & ns & ns & ns & ns & 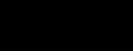 & * & $* * *$ \\
\hline & CE09 & * & * & * & ns & * & & $* * *$ \\
\hline & SW & $\star * *$ & *** & $\star \star *$ & *** & $* * *$ & $* * *$ & \\
\hline
\end{tabular}

The seawater samples were then investigated separately as they were collected on different days over the same time frame. The MDS plot confirmed the results found by the electropherogram data indicating that the rDNA and rRNA bacterial community compositions shift over time (Figure 3.23). In particular, the RNA plot indicates that the populations become more and more distinct with time (arrows, Figure 3.22). There was significant difference between the rDNA and rRNA communities (ANOSIM r $=0.063, \mathrm{P}$ $=0.274)$ perhaps due to the large variation in the seawater community structure. 


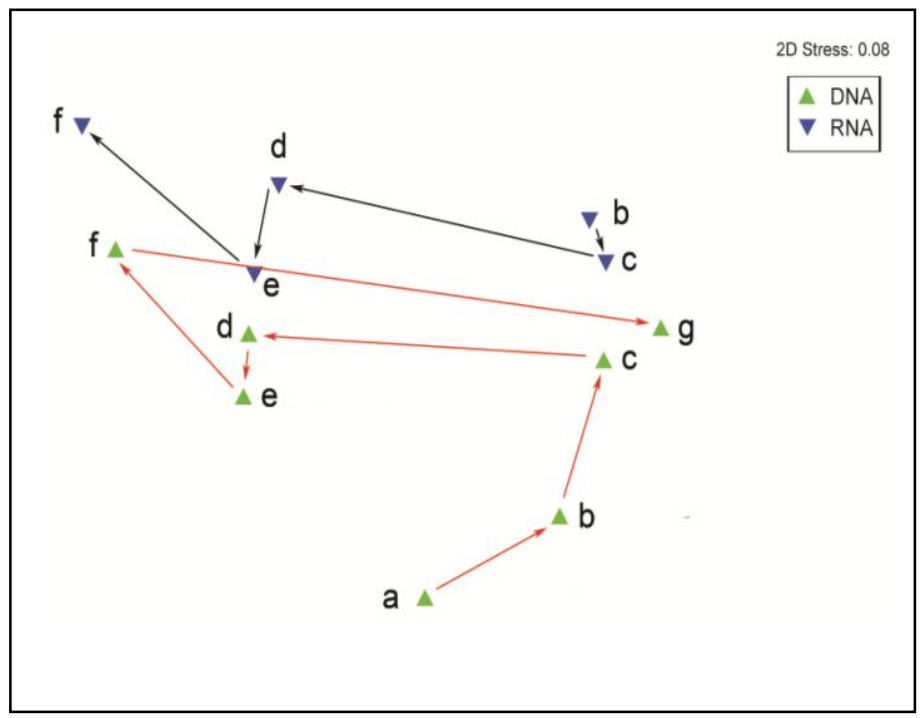

Fig 3.23 MDS plot on the T-RFLP profiles of rDNA and rRNA seawater communities. The Bray-Curtis similarity matrix was used on $\log (\mathrm{x}+1)$ transformed data. The arrows show the shift of the communities in multivariate space. The seawater samples were collected on (a) 19.11 .09 , (b) 21.11 .09 , (c) 24.11 .09 , (d) 27.11.09, (e) 28.11.09, (f) 29.11.09 and (g) 30.11.09. Samples for rRNA were not collected on (a) 19.11.09 or $(\mathrm{g}) 30.11 .09$.

\subsubsection{Relationships between the community and the environment.}

\subsubsection{The bottom ice community and the environment}

Variations in the rDNA and rRNA communities could be explained to some degree by the environmental factors I investigated. Overall, silicate was the optimal predictor for explaining variations in the rDNA bacterial community structure in 2008, explaining 15.1 $\%$ of the total variation across sites. In 2009, nitrite explained $28.2 \%$ of the rDNA variation (Table 3.7). A greater amount of the variation in community structure was explained in the rRNA community where sea ice thickness was the strongest predictor explaining $21.42 \%$ and $34.4 \%$ of the total variation in 2008 and 2009, respectively (Table 3.7). Nitrite also explained a significant proportion (11.9\%) of the variation seen between communities in 2008 whereas in 2009 phosphate explained $12.8 \%$ of the variation (Table 3.7). 
Table 3.7 Summary of results showing the associations between bottom ice bacterial communities against environmental variables using a distance-based permutational multiple regression analysis (DISTLM). Model selection was based on Akaike's Information Criterion with a second-order bias correction applied (AICc), with the total variation explained $\left(\mathrm{r}^{2}\right)$ by each best-fit model shown (\% total). Analyses based on 9999 random permutations of the raw data.

\begin{tabular}{|c|c|c|c|c|c|c|}
\hline T-RFLP community & Predictor & $\mathrm{AICc}$ & Pseudo-F & $P$ value & $\begin{array}{r}\% \\
\text { variability } \\
\end{array}$ & $\%$ total \\
\hline 16S rDNA 2008 & Silicate & 153.62 & 4.1666 & 0.001 & 18.8 & 18.8 \\
\hline \multirow[t]{2}{*}{ 16S rRNA 2008} & Ice thickness & 145.83 & 4.9073 & 0.003 & 21.42 & \\
\hline & Nitrite & 148.97 & 3.0248 & 0.0116 & 11.87 & 33.29 \\
\hline 16S rDNA 2009 & Nitrite & 183.55 & 9.0382 & 0.0002 & 28.2 & 28.2 \\
\hline \multirow[t]{2}{*}{ 16S rRNA 2009} & Nitrite & 189.59 & 6.5899 & 0.0019 & 22.27 & \\
\hline & Phosphate & 186.17 & 5.983 & 0.0003 & 16.62 & 38.89 \\
\hline
\end{tabular}

\subsubsection{Community structure through the sea ice core and environment}

The relationships between the environmental variables through the sea ice core at Cape Evans and Granite Harbour in 2009 was then investigated. Again, ice thickness was the optimal predictor for explaining variations in the rDNA and rRNA bacterial communities, explaining 11.36 and $21.65 \%$ of the total variation seen down the ice core, respectively. In the rDNA communities, nitrite and ammonia explained an additional 8.94 and $2.86 \%$ variation respectively (Table 3.8), contributing to a total of $26.56 \%$ of the variation through the sea ice core being explained. In the rRNA communities, nitrite concentrations also explained an additional $4.91 \%$ of the variation seen between communities. The average proportion of variability in bacterial rDNA and rRNA community structure that could be explained was $28.2 \%$. 
Table 3.8 Summary of results showing the associations between bacterial communities in the top, middle and bottom of the ice core against environmental variables using a distance-based permutational multiple regression analysis (DISTLM). Model selection was based on Akaike's Information Criterion with a second-order bias correction applied (AICc), with the total variation explained (r2) by each best-fit model shown (\% total). Analyses based on 9999 random permutations of the raw data.

\begin{tabular}{llrrrrr} 
& & & & & $\%$ \\
T-RFLP community & Predictor & AICc & Pseudo-F & P value & variability & $\%$ total \\
\hline 16S rDNA 2009 & Depth & 529.33 & 8.588 & 0.0001 & 11.36 & \\
& Nitrite & 524.18 & 7.4044 & 0.0001 & 8.94 & \\
& Ammonia & 523.92 & 2.4174 & 0.0088 & 2.86 & 26.56 \\
16S rRNA 2009 & Depth & 353.05 & 12.16 & 0.0001 & 21.65 & \\
& Nitrite & 352.36 & 2.87 & 0.0011 & 4.91 & 23.16 \\
\hline
\end{tabular}

\subsubsection{Inferring phylogeny from T-RFLP profiles}

\subsubsection{Between sites: bottom ice community}

There were several dominant RFLs that were present in sea-ice communities found at all sites. These were RFL71f, RFL128r, RFL194f and RFL305r (Figures 3.16-3.19). These RFLs were tentatively identified predominantly as psychrophilic bacteria by clone library analysis and were closely related to Polaribacter dokdonensis (RFL71f), uncultured Erythrobacter sp., and Pseudomonas fluorescens (RFL128r) Polaribacter irgensii, Psychrobacter spp., and Sphingobacteria spp. (RFL194f) and an unknown bacteria (RFL305; Table 3.10). The dominant RFLs in the seawater (SW) at Granite Harbour (Figures 3.20, 3.21) were RFL71f, RFL86f, RFL280f and RFL305r which were identified as being related to Polaribacter dokdonensis (RFL71f), Psychrobacter glacincola and Micrococcus antarcticus (RFL86f), and uncultured Shigella sp. (RFL280f).

Several RFLs, identified using Pearson's correlation, were identified as driving the separation between the different bottom ice sites with respect to both the rDNA and rRNA communities from 2008 and 2009 (Figures 3.24, 3.25; Table 3.10). In 2008, concentrations of silicate explained some of the variation (18.8\%) seen in rDNA community. Silicate concentrations were lowest at TNB08, which was characterised by Polaribacter dokdonensis (RFL71f) and Lewinella persicus and Polaribacter sp. 
(RFL458r), and highest at CR8 and GH8a, b which were negatively correlated with uncultured Erythrobacter sp. and Pseudomonas fluorescens (RFL128r), Planococcus psychrotoleratus (RFLs 140f) and Lewinella persicus and Polaribacter sp. (RFL458r; Figure 3.24a). In the rRNA community, nitrite and ice thickness were the strongest predictors of community variability. The sea-ice was the thinnest and nitrite was lowest at Terra Nova Bay (TNB08), and the bacterial community there was characterised by unidentified RFLs 102f and 277f (Figure 3.24b). Nitrite was highest at McMurdo Station (McM08) and the community always included RFL140f, which was tentatively identified as Planococcus psychrotoleratus. In 2009, nitrite explained $28.2 \%$ of the rDNA variation (Table 3.8) and was highest at Cape Evans.
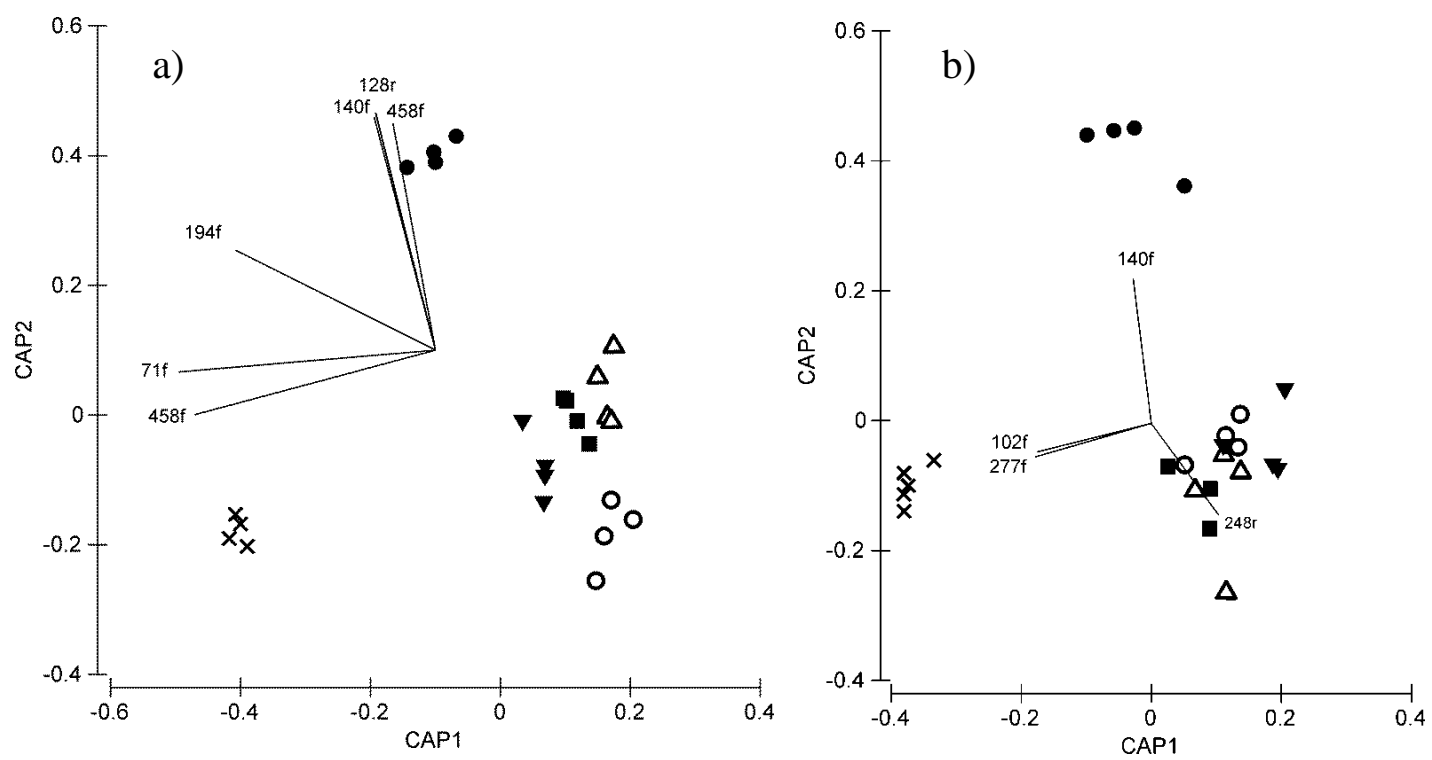

Figure 3.24 Canonical analysis of principle components plots of bacterial community structure determined by T-RFLP profiles of DNA (a) and RNA (b) communities from samples taken in 2008. Sites were Cape Evans (CE), Granite Harbour (GH), Cape Roberts (CR), Terra Nova Bay (TNB) and McMurdo Station $(\mathrm{McM})$. Overlaid onto the CAP are vectors of the subset of RFLs identified by Pearson's correlation, indicating the association of RFLs with particular sites. The directions of the environmental vector lines indicate the relationship of each RFL to the site groupings in multivariate space. The length of each vector line is proportional to the strength of the variance explained by the RFL.

In 2009, there were several RFLs that drove separation between bottom ice communities at $\mathrm{CE}$ and $\mathrm{GH}$. The rDNA CE bacterial community was characterised by high abundances of RFL102r, uncultured Erythrobacter sp., Pseudomonas fluorescens (RFL128r), 
uncultured Sphingobacteria sp. (RFL150f), Psychrobacter glacialis, Glaciecola pallidula, Bacillus sp., and Paracoccus sp. (RFL159f), uncultured Polaribacter sp. (RFL231f) and RFL294 which was unidentified (Figure 3.25a). Nitrite and phosphate explained 22.3 and $16.6 \%$ respectively of the variation in the rRNA community. Phosphate was lowest at CE09 and increased at GH09 over time. CE09 was characterised by Rhodococcus sp., Bacillus sp., and Glaciecola pallidula (RFL116f), uncultured Sphingobacteria sp. (RFL150f), Psychrobacter glacialis, Glaciecola pallidula, Bacillus sp., and Paracoccus sp. (RFL159f). GH09 was characterised by Williamsia serinedens (RFL118r) and Psychrobacter glacialis, uncultured Janibacter sp., and Rhodococcus sp. (RFL340f; Figure 3.25b, Table 3.10).
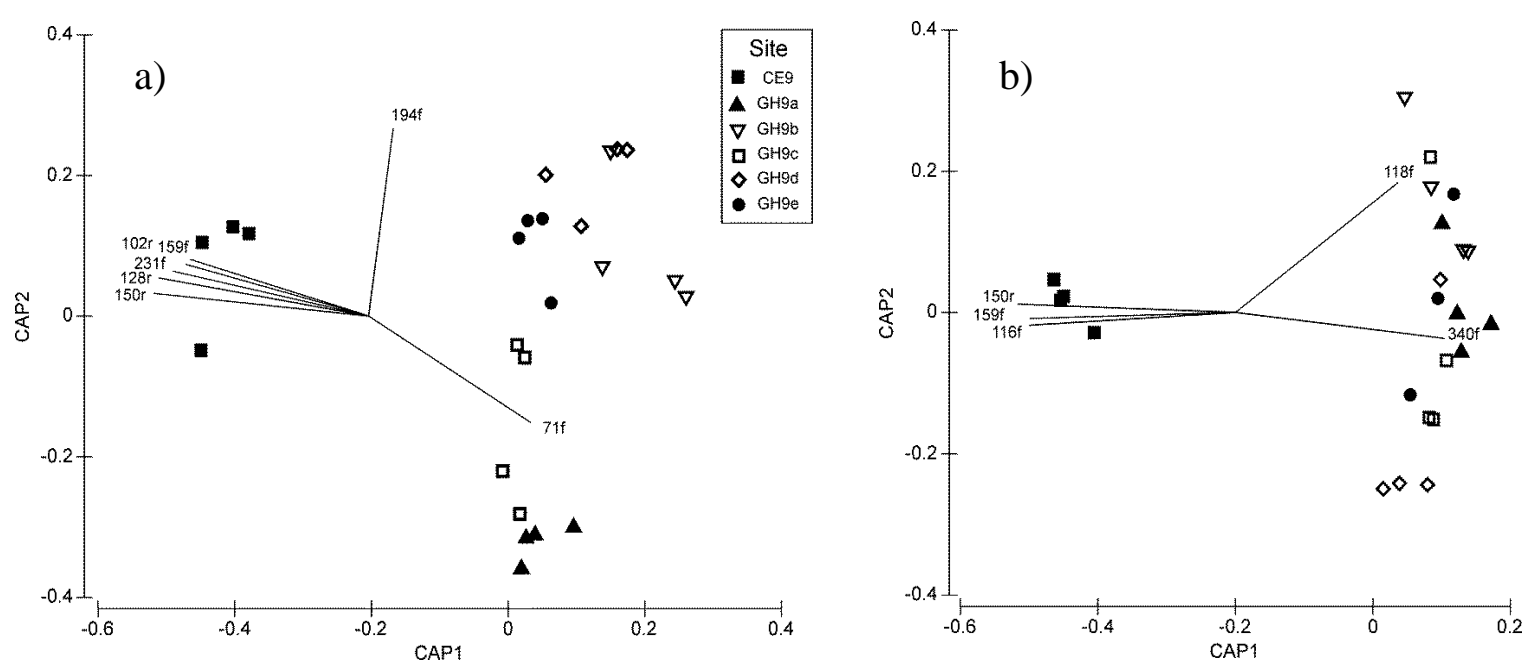

Fig 3.25 Canonical analysis of principle components plots of bacterial community structure determined by T-RFLP profiles of rDNA (a) and rRNA (b) communities from samples taken from Cape Evans (CE) and Granite Harbour (GH) in 2009. Overlaid onto the CAP are vectors of the subset of RFLs identified by Pearson's correlation, indicating the association of RFLs with particular sites. The directions of the environmental vector lines indicate the relationship of each RFL to the site groupings in multivariate space. The length of each vector line is proportional to the strength of the variance explained by the RFL. 


\subsubsection{Bacterial communities through the sea ice core and seawater}

Several RFLs were identified as driving separation between the sea ice bacterial community from the water column and into the sea ice core at GH (Figure 3.26). In the rRNA profiles, the sea water community was characterized by a high abundance of RFLs 241f, 340f and 125r. RFL340f was also found characterising the rDNA seawater community. Additional RFLs were found to characterise the bottom and within-ice community, but there was no overlap in the RFLs between the rDNA and rRNA profiles.
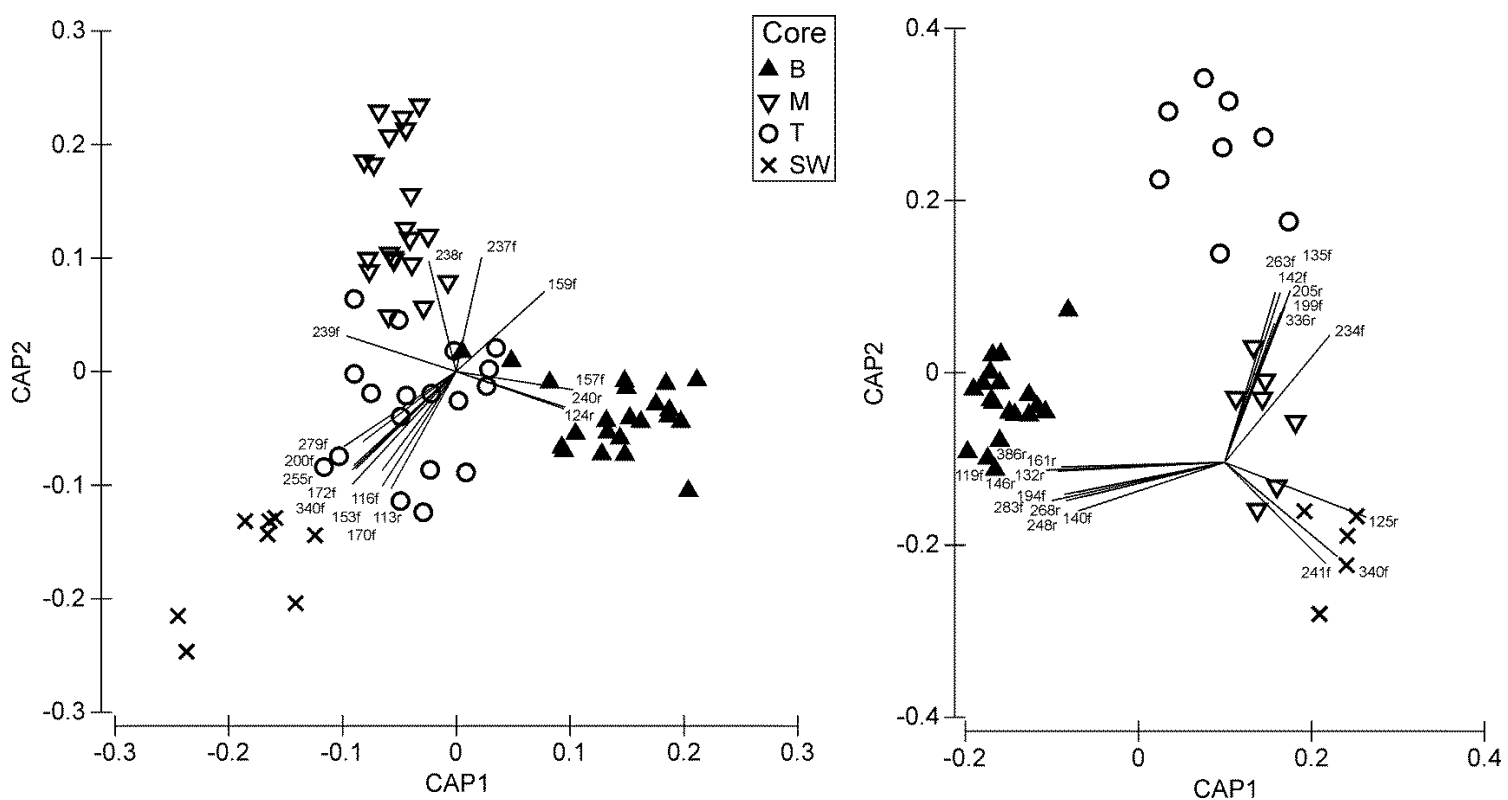

Figure 3.26 Canonical analyses of principle components plots of bacterial community structure determined by T-RFLP profiles of rDNA (a) and rRNA (b) communities from top (T), middle (M), bottom (B) and seawater (SW) samples taken in 2009. Overlaid onto the CAP are vectors of the subset of RFLs identified by Pearson's correlation, indicating the association of RFLs with particular sites. The directions of the environmental vector lines indicate the relationship of each RFL to the site groupings in multivariate space. The length of each vector line is proportional to the strength of the variance explained by the RFL.

The rDNA seawater community was characterised by a high abundance of RFLs that were identified as Psychrobacter glacialis, Bacillus sp., Erythrobacter sp., Micrococcus sp., Glaciocola pallidula and Rhodococcus sp., which were also found characterising communities within the sea ice. The rRNA seawater community was characterised by a 
high abundance Psychrobacter glacialis, Rhodococcus sp., uncultured Janibacter sp., and Planococcus psychrotoleratus. However, there was a shift to RFLs identified as Flavobacterium degerlachei, Arthrobacter sp., Psychroflexus torquis., Polaribacter dokdonensis., Erythrobacter sp., and Antarctic sea ice bacterium characterising the sea ice communities (Table 3.9).

Table 3.9 RFLS identified by clone library analysis found to characterise the groups defined by the CAP plot through the ice core and seawater at GH (Figure 3.25). Bacterial species were found to characterise either the DNA (grey), RNA (lined), both (hashed) or no (white) communities.

\begin{tabular}{|c|c|c|c|}
\hline & Seawater & Bottom ice & Within-ice \\
\hline \multicolumn{4}{|l|}{ Psychrobacter glacialis (AJ539102) } \\
\hline \multicolumn{4}{|l|}{ Bacillus sp. (AF414443) } \\
\hline \multicolumn{4}{|l|}{ Uncultured Sphingobacteria (FN433448.2) } \\
\hline \multicolumn{4}{|l|}{ Erythrobacter sp. (EF512713) } \\
\hline \multicolumn{4}{|l|}{ Micrococcus sp. (EU394442) } \\
\hline \multicolumn{4}{|l|}{ Glaciecola pallidula (FR746107) } \\
\hline \multicolumn{4}{|l|}{ Polaribacter dokdonensis (DQ481463) } \\
\hline \multicolumn{4}{|l|}{ Rhodococcus sp. (FN397657) } \\
\hline \multicolumn{4}{|l|}{ Brevundimonas mediterranea (AJ244706) } \\
\hline \multicolumn{4}{|l|}{ Uncultured Janibacter sp. (FN582323) } \\
\hline \multicolumn{4}{|l|}{ Pseudomonas fluorescens (GU198126) } \\
\hline \multicolumn{4}{|l|}{ Paracoccus sp. (AM275338) } \\
\hline \multicolumn{4}{|l|}{ Planococcus psychrotoleratus (AY771711) } \\
\hline \multicolumn{4}{|l|}{ Pelagiocola litoralis (AY165584) } \\
\hline \multicolumn{4}{|l|}{ Flavobacterium degerlachei (AJ557886) } \\
\hline \multicolumn{4}{|l|}{ Arthrobacter sp. (DQ341426) } \\
\hline \multicolumn{4}{|l|}{ Uncultured bacterium clone (GU196023) } \\
\hline \multicolumn{4}{|l|}{ Psychroflexus torquis (AY167320) } \\
\hline Antarctic sea ice bacterium (FJ998358) & & & \\
\hline
\end{tabular}


Table 3.10 T-RFLP RFLs (bp) tentatively identified by their closest BLAST relative (s).

\begin{tabular}{|c|c|c|c|}
\hline RFL & Closest relative (BLAST accession no.) & RFL & Closest relative (BLAST accession no.) \\
\hline \multirow[t]{2}{*}{$71 f$} & Polaribacter dokdonensis (DQ481463) & $113 r$ & Glaciecola pallidula (FR746107) \\
\hline & (FN433448) & & Psychrobacter glacialis (AJ539102) \\
\hline \multirow[t]{2}{*}{$86 f$} & Psychrobacter glacialis (AJ539102) & & Brevundimonas mediterranea (AJ244706) \\
\hline & Micrococcus antarcticus (FJ907955) & $118 r$ & Williamsia serinedens (FN673550) \\
\hline \multirow[t]{3}{*}{$116 f$} & Rhodococcus sp. (FN397657) & $124 r$ & Erythrobacter sp. (EF512713) \\
\hline & Bacillus sp. (AF414443) & & Paracoccus sp. (AM275338) \\
\hline & Glaciecola pallidula (FR746107) & & Planococcus psychrotoleratus (AY771711) \\
\hline \multirow[t]{2}{*}{$119 f$} & Rhodococcus sp. (FN397657) & & Pseudomonas fluorescens (GU198126) \\
\hline & Antarctic sea ice bacterium (FJ998358) & $125 r$ & Rhodococcus sp. (FN397657) \\
\hline $140 f$ & Planococcus psychrotoleratus (AY771711) & $128 r$ & uncultured Erythrobacter sp. (AY646157) \\
\hline \multirow[t]{2}{*}{$142 f$} & Bacillus sp. (AF414443) & & Pseudomonas fluorescens (GU198126) \\
\hline & Planococcus psychrotoleratus (AY771711) & $132 r$ & Arthrobacter sp. (DQ341426) \\
\hline $150 f$ & $\begin{array}{l}\text { uncultured Sphingobacteria bacterium } \\
\text { (FN433448) }\end{array}$ & & Paracoccus sp. (AM275338) \\
\hline \multirow[t]{2}{*}{$153 f$} & Polaribacter dokdonensis (DQ481463) & $146 r$ & Psychrobacter glacialis (AJ539102) \\
\hline & Erythrobacter sp. (EF512713) & $161 \mathrm{r}$ & Paracoccus sp. (AM275338) \\
\hline $157 f$ & Bacillus sp. (AF414443) & $205 r$ & Polaribacter dokdonensis (DQ481463) \\
\hline \multirow[t]{4}{*}{$159 f$} & Psychrobacter glacialis (AJ539102) & & Erythrobacter sp. (EF512713) \\
\hline & Glaciecola pallidula (FR746107) & $240 r$ & Psychrobacter glacialis (AJ539102) \\
\hline & Bacillus sp. (AF414443) & & Uncultured Sphingobacteria (FN433448) \\
\hline & Paracoccus sp. (AM275338) & & Pelagiocola litoralis AY165584.1 \\
\hline $170 f$ & Uncultured Janibacter sp. (FN582323) & $248 r$ & Erythrobacter sp. (EF512713) \\
\hline $172 f$ & Psychrobacter glacialis (AJ539102) & & Micrococcus sp. (EU394442) \\
\hline \multirow[t]{3}{*}{$194 f$} & Psychrobacter glacialis (AJ539102) & & Uncultured bacterium clone (GU196023) \\
\hline & Flavobacterium degerlachei (AJ557886) & & Polaribacter dokdonensis (DQ481463) \\
\hline & Paracoccus sp. (AM275338) & & Pelagiocola litoralis (AY165584) \\
\hline \multirow[t]{2}{*}{$199 f$} & Polaribacter dokdonensis (DQ481463) & & Antarctic sea ice bacterium (FJ998358) \\
\hline & Uncultured Sphingobacteria (FN433448) & $255 r$ & Brevundimonas mediterranea (AJ244706) \\
\hline \multirow[t]{3}{*}{$200 f$} & Uncultured Sphingobacteria (FN433448) & $268 r$ & Arthrobacter sp. (DQ341426) \\
\hline & Psychrobacter glacialis (AJ539102) & $336 r$ & Erythrobacter sp. (EF512713) \\
\hline & Micrococcus sp. (EU394442) & $458 r$ & Lewinella persicus (EU371935) \\
\hline \multirow[t]{2}{*}{$234 f$} & Psychroflexus torquis (AY167320) & & Polaribacter dokdonensis (DQ481463) \\
\hline & Polaribacter dokdonensis (DQ481463) & & \\
\hline \multirow[t]{4}{*}{$237 f$} & Micrococcus sp. (EU394442) & & \\
\hline & Paracoccus sp. (AM275338) & & \\
\hline & Rhodococcus sp. (FN397657) & & \\
\hline & Sphingobacteria (FN433448.2) & & \\
\hline $239 f$ & Paracoccus sp. (AM275338) & & \\
\hline \multirow[t]{2}{*}{$241 f$} & Rhodococcus sp. (FN397657) & & \\
\hline & Planococcus psychrotoleratus (AY771711) & & \\
\hline $280 f$ & uncultured Shigella sp. (GU968176) & & \\
\hline $283 f$ & Rhodococcus sp. (FN397657) & & \\
\hline \multirow[t]{3}{*}{$340 f$} & Psychrobacter glacialis (AJ539102) & & \\
\hline & Uncultured Janibacter sp. (FN582323) & & \\
\hline & Rhodococcus sp. (FN397657) & & \\
\hline
\end{tabular}




\subsection{Discussion}

To my knowledge, this is the first study of the bacterial community structure at different sites in Antarctic sea ice using T- RFLP analysis to compare the metabolically active proportion (rRNA) and the total community (rDNA). T-RFLP is a fast and reliable fingerprinting technique that has been utilised to study microbial communities from soil (Dunbar et al. 2001; Smalla et al. 2007), microbial mats (Moyer et al. 1994), seawater (Moeseneder et al. 2005; Danovaro et al. 2006) and sea ice (Collins et al. 2010). In the present study, bacterial diversity was estimated from the total number of RFLs in each sample. All estimates of diversity need to be interpreted with care due to biases that arise from nucleic acid extraction and PCR amplification. As a result, true diversity is likely underestimated as rare members of the population will often not be detected by T-RFLP (Lui et al. 1997) and the same RFLs can be generated from multiple phylotypes that are not related (Blackwood et al. 2007).

The number of bacterial RFLs in this study was positively correlated with a decrease in latitude in the rRNA community only. The rRNA community is an indicator of the metabolically active population (Mills et al. 2004; 2005) and is perhaps a more reliable marker to use when investigating associations between communities and the environment. We found that RFL richness in the bottom ice community was highest at Terra Nova Bay (TNB08) and decreased with increasing latitude. However, when investigating bacterial richness and evenness using diversity indices ( $\mathrm{H}^{\prime}, 1-\lambda$ ' and $\mathrm{N} 21^{\prime}$ ') in the rRNA and rDNA bottom ice community, the latitudinal trends were not clear. Animal and plant diversity have been shown to increase towards the tropics as i) the increased productivity is able to support a greater number of organisms and ii) increased temperature speeds up biological processes such as metabolism and reproduction leading to increased speciation (see Furhman et al. 2008 and references within). More recently a latitudinal gradient has also been associated with planktonic bacteria (Fuhrman et al. 2006). Terra Nova Bay had the thinnest sea ice and the increased number of RFLs at this site may have been an effect of increased irradiance rather than the latitudinal gradient. Fuhrman et al. (2006) also reported a correlation of marine bacterial diversity with 
latitude and temperature and questioned whether the latitudinal gradient was merely a proxy for the effect of solar irradiance on seawater temperature. At the bottom of the sea ice however, the temperature is $-1.8{ }^{\circ} \mathrm{C}$ regardless of latitude as it is partly a function of salinity. Therefore the number of RFLs will not be related to temperature but may instead be related to ice thickness and therefore indirectly to irradiance. Martin et al. (2009) found that the percentage of metabolically active bacteria increased when incubated at higher irradiances for $48 \mathrm{hrs}$. Bacterial metabolism is influenced by the production of photosynthetic exudates from microalgae (Martin et al. 2009) and changes in irradiance may indirectly drive diversification in sea ice bacteria. The thin sea ice at TNB, in comparison to other sites, increases irradiance into the sea ice core which in turn may drive DOM production and bacterial metabolism. Therefore the higher number of RFLs at TNB may be site specific rather than due to latitudinal differences.

There was no correlation between bacterial abundance and Chl- $a$, which suggests an uncoupling of the microbial loop. However, algal-bacterial coupling may not be primarily based on algal exudates, but may also be due to different inorganic nutrient levels of $\mathrm{N}$ and $\mathrm{P}$ (Le et al. 1994). There were also no relationships seen between bacterial numbers and nutrient concentrations which is surprising as increases in bacterial abundance can be stimulated by the addition of inorganic nitrogen and phosphorus (Caron et al. 2000). Bacterial growth can also be limited by nutrient deficiency suggesting that sea ice bacteria may be $\mathrm{N}$ or $\mathrm{P}$ limited. Le et al. (1994) showed that algal-bacterial coupling depends upon the ratio of N/P where a high N/P ratio (> 40) is required for coupling between bacteria and algae, and $\mathrm{N}$ limitation leads to uncoupling with the growth of bacteria and algae dependent on $\mathrm{P}$ concentrations. Antarctic sea ice had low N/P ratios which may explain the lack of algal-bacterial coupling in sea ice. However, the strength of algal-bacterial coupling is variable in Antarctic sea ice (Kottmeier and Sullivan 1987; Cota et al. 1990; Bird and Karl 1999; Martin et al. 2009) and a weak relationship may be due to low temperatures which limit assimilation of organic substrates (Pomeroy and Wiebe 2001), predation (Vaqué et al. 2002) or viral lysis (Guixa-Boixereu et al. 2002). Although sea-ice temperatures are low $<-1.8^{\circ} \mathrm{C}$ (Mock and Thomas, 2005), positive correlations between bacterial abundance and Chl- $a$ are sometimes seen in sea-ice 
(Stewart and Fritzen, 2004; Martin et al. 2009), which suggests that temperature may not be a factor in controlling the microbial loop. Viral lysis and grazing were outside the scope of this thesis, however several studies have shown that heterotrophic bacterial numbers are controlled via nanoflagellate grazing (del Giorgio et al. 1996) and bacterivorous protists (Jezbera et al. 2005) and that viruses may also regulate the bacterial community (Kepner et al. 1998; Suttle 2007). Therefore, perhaps bacterial cell numbers were not increasing as they were being kept under control by grazing. Bacteria also have a significant lag in their response time to available growth substrates (Martin et al. 2011) of about 15 - 30 days (Billen and Becquevort 1990), which may suggest that the bacterial community had not responded to the sea ice algal bloom. Future studies might use other proxies besides Chl- $a$ and bacterial abundance to look for bacterial-algal coupling. For example, bacterial productivity, measured by the incorporation of radiolabelled leucine or thymidine by bacteria (Tibbles and Harris 1996), might increase with Chl- $a$, with no change in bacterial abundance. Also, using dry weight of the algae instead of Chl- $a$ might be used as a more accurate proxy for algal biomass if the algae was accidently exposed to sunlight resulting in light-shock.

Relationships between bacterial communities and the environment were investigated using multivariate statistical analysis of T-RFLP profiles. Typically, bacterial communities are analysed using relative abundance data or are reduced to a presence/absence matrix (i.e. Collins et al. 2010; Edwards et al. 2010). Relative abundance provides more information due to its semi-quantitative nature but larger common peaks dominate the degree of similarity between communities. Transformation of the data to presence/absence corrects for this problem but reduces resolution; under this scheme, a peak that is very abundant in one community is given the same weight as a peak that is of low abundance in another community. To circumvent these problems I used relative abundance data with a $\log (x+1)$ transformation to reduce the influence of larger common peaks.

The rDNA and rRNA bacterial communities were investigated to determine whether the active (rRNA) population was different from the total (rDNA) community. In 2008, the 
rDNA and rRNA communities were not significantly different from each other. Therefore, in 2009 the DNA was extracted from all the samples. RNA was extracted from all the bottom ice samples as well as through the sea ice core at Cape Evans. RNA was extracted from only two sites at Granite Harbour to look for changes between these time periods but also to reduce laboratory costs. In 2009 however, the rDNA and rRNA communities were significantly different from each other at the top and middle of the ice core, but were similar in bottom sections and in the seawater. It is unlikely that the difference between bacterial communities was due to the extraction of rDNA and rRNA through two separate methods. The similarities seen between the rDNA and rRNA profiles and the multivariate patterns, especially in 2008, suggest that both methods extracted an equivalent bacterial community from the environment. This is because the dominant peaks detected in the rDNA community were also detected in the rRNA community.

The similarity between the 2008 rDNA and rRNA bottom ice profiles is interesting, considering that growth rates of bacterial cells are related to cellular RNA content and a proportion of the bacteria is assumed to be either dormant, damaged or dead (del Giorgio and Gasol 2008). This similarity suggests that the most active microbes are the most abundant ones (as T-RFLP only targets the most abundant organisms). In temperate environments, metabolically active bacteria make up only a small fraction (1-10\%) of the total community, but are more abundant in sea ice (Junge et al. 2002; Brinkmeyer et al. 2003; Martin et al. 2008). Algae release DOM rich in carbon and nutrients such as nitrogen and phosphorus which stimulates bacterial productivity (Castillo et al. 2003). Jones and Lennon (2010) showed that the proportion of active bacteria was high in productive microbial ecosystems and this may be the case in the bottom of the sea ice community particularly in 2008 when nutrients and algal concentrations are high. If this explanation is correct, then in 2009 when there were lower Chl- $a$ and algal concentrations, then there were likely fewer metabolically active bacteria at the bottom of the ice core. 
In 2009, the rDNA and rRNA communities at the top, middle and bottom of the ice core were different. The difference between the rDNA and rRNA communities in 2009 might suggest an abundance of dead/dormant bacteria in the DNA derived community. Alternatively, the difference between these communities may also be due to a shift in the metabolically active cells to those better adapted. Whether the difference between profiles is due to more dead cells or species better able to adapt might be determined by investigating the proportion of RNA RFLs to DNA RFLs (RNA: DNA). At the bottom of the sea ice core there was no change in RNA: DNA RFLs between 2008 and 2009. This suggests that the proportion of dead cells is the same between the two years. Furthermore, this observation suggests that there may have been a shift in the RNA in 2009 to better adapted species. Sea ice in 2009 was $1 \mathrm{~m}$ thicker and nitrate, phosphate and Chl-a concentrations were significantly lower than in 2008. The bacteria incorporated into the bottom of the sea ice core in 2009 may be better adapted to lower light levels and nutrients. However, through the sea ice core there was a decrease in RNA: DNA RFLs. At the bottom of the sea ice cores the RNA: DNA was equal, but decreased to 0.67:1 at the top of the ice core. This suggests that there are more dead cells at the top of the sea ice core and supports data obtained by Martin et al. (2008) that metabolically active cells decrease towards the top of the sea ice core.

In both assemblages, the PERMANOVA analysis showed that samples collected from within the same site clustered closer together than those collected from further away. However, as these samples were collected on different days, the changes seen between bacterial communities at each site could have also been due to temporal variations. Therefore changes in bacterial community structures were investigated in 2009 over a period of two weeks. There was no change in the rRNA community and little change in the rDNA community over the two week time period, suggesting that the differences we found among the bacterial communities in 2008 were due to spatial rather than temporal differences.

Bacterial community structure was also investigated over a larger temporal scale by comparing bottom ice samples at two sites (Cape Evans and Granite Harbour) in 2008 
and 2009. Over this greater time frame, there was a shift in both the rDNA and rRNA community structure. If bacterial species were ubiquitous and ecologically redundant, I would expect to find no patterns in the distribution of communities. However, it is becoming more evident that the biogeography of bacterial communities is affected by environmental heterogeneity and dispersal limitation. Bacterioplankton communities are influenced by environmental variables such as latitude (Fuhrman et al. 2008), salinity (Crump et al. 2004) and depth (Reimann et al. 1999) and dispersal limitation (Whitaker et al. 2003) or combinations of both (Martiny et al. 2006; Oakley et al. 2010). There were significant differences in the sea ice communities found between geographical locations and over larger temporal scales. These differences could be due to the sea ice freezing at different times at the different locations and thus incorporating different planktonic communities that reflect the seawater microbial composition at that time. Alternatively, if bacteria are abundant and widely dispersed in the Ross Sea, the same heterogeneous community could initially be trapped in the sea ice matrix, which then adapts to the sea ice microenvironment at each site. The spatial and temporal patterns of bacterial diversity have been shown to be influenced by environmental processes (e.g. Pommier et al. 2007; Fuhrman 2009; Edwards et al. 2010) and it is likely that Antarctic sea ice communities are influenced by both abiotic and biotic factors. Whether the sea ice bacterial community forms from different or similar seawater communities at each site is unclear but there is subsequent selection for particular bacteria due to the environment.

Variations in the bacterial sea ice community structure could be explained by environmental conditions. The thickness of the sea ice explained $21.4 \%$ of the variation between sites in the rRNA communities at the bottom of the ice core in 2008. Sea-ice thickness determines the amount of solar and UV radiation that reaches the bottom SIMCO (Odate et al. 2004), which influences algal physiological responses. An increase in light causing increases in algal photosynthesis (Martin et al. 2011) or algal mortality (Davidson and van der Heijden 2000) has been shown to increase bacterial growth and metabolism. There was no change in the RNA: DNA RFLs among sites in 2008 showing that there was no variation in bacterial activity across sites. Sea-ice thickness determines the amount of solar and UV radiation that reaches the bottom SIMCO (Odate et al. 2004), 
which influences algal physiological responses. Irradiance has been found to induce chemical transformations of DOM which may result in changes in bacterial community structure (Perez and Sommaruga 2006). Therefore variations in solar radiation may influence the composition of DOM which will result in the selection of bacterial groups that are better adapted to the conditions. However, $71.8 \%$ of the variation seen between bacterial communities was not explained. My study concentrated on the effects of bottom-up (resources) on bacterial communities; however top-down (predation) factors such as nanoflagellate grazing (del Giorgio et al. 1996) and bacterivorous protists (Jezbera et al. 2005) and viruses (Kepner et al. 1998; Suttle 2007) also regulate bacterial populations.

Sea-ice was the thinnest at Terra Nova Bay (TNB08) but despite the high irradiance, Chl$a$ concentrations were low. This community was characterised by $P$. dokdonensis and $L$. persicus and Polaribacter sp. Sea ice bacterial communities are dominated by psychrophilic bacteria as they are better adapted for growth at suboptimal temperatures (Bowman et al. 1997; Nichols et al. 1999). However, P. dokdonensis and L. persicus are psychrotolerant and can grow at temperatures from $<0{ }^{\circ} \mathrm{C}$ to above $20^{\circ} \mathrm{C}$ (Yoon et al. 2006; Sly et al. 1998). At the bottom of the sea ice core the temperatures are warmer than at the middle and top of the core and therefore true psychrophiles may not necessarily be selected for. P. dokdonensis and L. persicus have been isolated from marine waters (Yoon et al. 2006; Sly et al. 2008). Here, they would be exposed to higher irradiances and more oligotrophic conditions than at the bottom of the sea ice core. It is likely that the characteristic bacteria of TNB have traits, such as a wider tolerance range to temperate (psychrotolerance), that enable them to be better adapted to the high irradiance but low nutrient conditions at this site.

Nitrite and phosphate levels were also associated with changes in sea ice bacterial communities between sites. Nitrite explained $11.9 \%$ of the variation between rRNA bottom ice communities and $4.9 \%$ of the variation through the sea ice core. Nitrite concentration was highest at McMurdo Station and was characterised by a specific but unknown RFL. Nitrite is typically a short-lived intermediate in the nitrogen cycle 
pathway formed during nitrification of ammonia to nitrate but may accumulate when it is released from light-limited phytoplankton or during decoupling of the oxidative and reductive cycles of nitrification (Lomas and Lipshultz, 2006). We found a positive correlation between nitrate and nitrite, and ammonia and nitrate, which suggests that both nitrification and denitrification processes are occurring in sea ice. Therefore, the accumulation of nitrite in McM sea ice may have been due to its production from lightlimited algae. There was greater snow cover at McM than the other sites in 2008 which may have limited the amount of light available to the underlying algae resulting in increased nitrite concentrations. Variations between bacterial communities are thus partially due to adaptation to nitrite concentrations released by algae.

The thickness of the sea ice explained $21.7 \%$ of the variation between bacterial communities through the sea ice core. Towards the top of the sea ice core, temperature decreases, and salinity and irradiance increase. Temperature was not measured directly but is $-1.8^{\circ} \mathrm{C}$ in the water column and decreases up through the ice core. Martin (2010) measured temperature and salinity from $15^{\text {th }}$ of November to $3^{\text {rd }}$ December 2006 in this region and found temperature to range from $-1.8^{\circ} \mathrm{C}$ in the water column, to $-4.4^{\circ} \mathrm{C}$ in the middle of the ice core and $-6.8^{\circ} \mathrm{C}$ at the top. Salinity also increased from $36 \%$ in the water, to $74 \%$ in the middle to $108 \%$ at the top of the ice core. Correlations between RFLs and multivariate axes suggested that different vertical positions in sea ice were characterised by high densities of certain RFLs. The bottom of the sea ice core was characterised by $W$. serinedens, A. parietes and P. dokdonensis. The middle of the sea ice core was characterised by $P$. dokdonensis and an uncultured Spingobacterium sp. The top ice community was characterised by an uncultured Spingobacterium sp. and Polaribacter sp. These bacterial groups are known for survival in sea ice; for example they produce lipids to increase membrane viscosity and can grow at high salinities of $100-150 \%$, which are required for survival at low temperatures as salinity has an inverse relationship with temperature (Bowman 2008). As explained earlier in the discussion, there was a decrease in the RNA: DNA RFLs towards the top of the sea ice core showing that a lower proportion of cells were active in the community. Therefore the change in community 
composition is likely due to the death of bacteria that are not able to survive in these conditions and survival and growth of psychrophilic species.

Phosphate explained $16.6 \%$ of the variation seen between bottom ice bacterial communities at Cape Evans (CE09) and Granite Harbour (GH09). Phosphate was low at CE09 and increased at GH09 over time. Over the time period at GH09, Chl- $a$ also increased. The low concentrations of phosphate at CE09 may have been associated with a low rate of photosynthesis and low Chl-a. The availability of DOM for bacteria would have been low which may have led to slow growth rates. At GH09, the high phosphate concentration may have stimulated algal production and therefore increased bacterial growth rates, which may have led to changes in the bacterial community structure. Phosphate is a limiting nutrient that can inhibit photosynthesis, nitrogen uptake and heterotrophic bacterial production (Moutin and Rainbault 2002). CE09 was characterised by $G$. antarcticus, uncultured Shigella sp, uncultured Sphingobacteria sp., P. torquis, $P$. fluorescens and B. idriensis which may be better adapted to living in more nutrient and carbon poor environments. GH09 was characterised by $W$. serinedens and $O$. antarcticus which may require higher nutrient concentrations and algal productivity for growth.

In total, $40.2 \%$ of the variation between rRNA bacterial communities could be explained by ice thickness and nutrient concentrations. Bacteria do respond directly to a change in temperature (Martin et al. 2009), but it appears that their responses to other changes in the environment are modulated by algae. Ice thickness and nutrient concentrations affect algal photosynthesis and growth, which have a direct influence on the composition and distribution of the DOM. Bacteria respond to changes in DOM through adaptation and extinction. An average of $59.8 \%$ of the variation between bacteria communities remained unexplained in the models suggesting that there are other factors at play such as top down control. Additional research including more variables, such as oxygen concentrations, $\mathrm{pH}$, and top down effects such as viral lysis and grazing should be investigated.

Many of the abundant RFLs were identified using clone libraries. The rRNA and rDNA profiles across sites shared many of the same RFLs which were also in high abundance 
(shown by high fluorescent intensity). These organisms may be more abundant and widespread than the rarer bacterial OTUs as they may be able to a) grow on a wider range of resources and b) are better able to survive and disperse (Sloan et al. 2006). The dominant RFLs were identified either as psychrotolerant bacteria such as $P$. dokdonensis that would survive a range of temperatures (Yoon et al. 2006), or as gram positive bacteria such as Micrococcus sp. and Bacilli sp. Many of the latter have gas vacuoles or spores (Gosink et al. 1998), which enhance survival and dispersal rates.

In 2009, abundant RFLs were identified as driving the separation between rDNA and rRNA communities. Many RFLs that characterised the rDNA seawater communities were also found to be abundant through the sea ice core. These RFLS were tentatively identified as psychrotolerant genera Bacillus, Erythrobacter, Psychrobacter, Polaribacter, Micrococcus, Rhodococcus, and unidentified Sphingobacterium. This is not surprising considering that the bacterial community is incorporated into the ice matrix from the water column. As these peaks were present in the rDNA community, their abundance may be due to the persistence of DNA in dormant or dead bacteria and may not reflect those that are active. In the rRNA communities, certain RFLS that were identified as $P$. dokdonensis and Planococcus psychrotoleratus were found to characterise the seawater and sea ice communities. The presence of RFLs through the sea ice core and seawater in the rRNA community shows the ability to survive incorporation from the water into the harsh ice matrix. Another RFL corresponded to W. serinedens, a bacterium that has previously not been described in Antarctic sea ice. This genus has been found in deep sea sediments (Pathom-Aree et al. 2006). A clone isolated from snow above Tibetan plateau glaciers (Liu et al. 2009) was found to be closely related to $W$. serinedens, suggesting that this organism can survive in extreme conditions.

Many of the abundant RFLs of the rDNA seawater community were not abundant in the rRNA seawater community suggesting that many of the abundant RFLs in seawater are dormant, or dead. However, the genera Bacillus, Erythrobacter, Sphingobacteria, and Polaribacter characterised the rRNA communities within the ice core which suggest that dormant bacteria in sea water may become active and dominate within the ice core. In the 
active community, there was a more apparent shift in the bacterial community from more psychrotrophic groups such as Psychrobacter glacialis, Rhodococcus sp., and uncultured Janibacter sp. in the seawater to more psychrophilic species such as Psychroflexus torquis, Erythrobacter sp., and Bacillus sp. in the ice core. Other studies have suggested a similar shift towards more psychrophilic species in sea ice from the water column (Brown and Bowman 2001). That this shift was more apparent in the rRNA community highlights the importance of investigating the active community. P. torquis is a common psychrophile that has been described from Antarctic sea ice and contains many adaptations to survive life in extreme conditions (Bowman et al. 1998; Brown and Bowman 2001). Erythrobacter sp., B. idriensis are also known to survive in snow and ice (Staley and Gosink 1999). Bacillus may have increased ability for survival due to endospore production and the presence of a thick Gram positive cell wall, which helps it to survive in extreme conditions. A shift in bacterial community structure also supports my earlier conclusions that community changes are due to adaptation to the sea ice environment.

T-RFLP is useful for comparative analyses but will not identify all of the bacteria in a community. Clone libraries from the sample environment can be used in order to find the most likely identification of the RFLs in T-RFLP profiles but as multiple taxa can have the same length of fragment, multiple taxa may be identified for a single RFL. Many of the abundant RFLs may have been represented by more than one bacterial taxon and therefore we can only speculate about their identification. However, the dominant RFLs belonged to psychrophilic or psychrotolerant groups, which gives us some insight into the key players that may reside in these communities. Further investigations using full clone libraries would need to be pursued in order to fully understand the bacterial diversity and population dynamics in sea-ice.

I did not find evidence for bacterial and algal coupling using cell counts and Chl- $a$. This suggests that there is an uncoupling between bacteria and algae or that these parameters are not sensitive enough to show microbial loop dynamics. The nutrients phosphate and nitrite explained some of the variation seen in the bacterial community composition. 
Phosphate and nitrite may be produced by algae during photosynthesis or under photolimited conditions, which may in turn stimulate bacterial growth and diversity. These relationships seen between bacteria and nutrient concentrations may suggest that bacteria do play a role in the microbial loop. The relationships between bacterial communities and the environment were stronger in the rRNA community. Therefore the metabolically active community should be investigated to gain a better understanding of community relationships with the environment.

One of the overarching aims of the LGP is to determine the effects of environmental change on the ecosystems residing along the Victoria Land coast. Antarctica is sensitive to climate change and it is projected that sea ice is likely to decrease in thickness and extent by $33 \%$ over the $21^{\text {st }}$ century (Bracegirdle et al. 2008). This is the first study to provide important information about baseline bacterial communities and their relationships with the environment. Bacterial communities are indeed influenced by the environment, particularly ice thickness and nutrient concentrations. The thickness of sea ice determines the amount of light that reaches the algal community and directly affects its physiology. Thus, bacterial community structure is influenced by the concentration and distribution of algal primary production. 


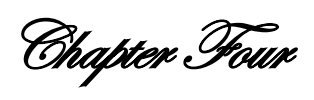

\section{Bacterial Community Function}

\subsection{Abstract}

Bacteria are involved in global biogeochemical cycles but little is known about the role(s) they may play in Antarctic sea ice. They have been shown to be positively correlated with algal biomass, which suggests that they are involved in the microbial loop where they assimilate dissolved organic matter (DOM) produced by algae and pass it to higher trophic levels in the Antarctic ecosystem. It has been thought that sea ice bacteria were entirely heterotrophic, but recently light-utilising bacteria have been described from Antarctic sea ice. However, their abundance in sea ice and their role in the microbial loop is unknown. Here, I present the first report quantifying functional genes involved in denitrification and photoheterotrophy from the RNA bacterial community in sea ice. These genes are active in Antarctic sea ice, but appear to be in low abundance suggesting that these processes may not be the most important in sea ice. Sea ice bacteria were also capable of synthesising proteases, $\beta$-galactosidases, phosphatises, lipases and chitinases. Bacterial activity was positively correlated with nutrient concentrations and also influenced bacterial community structure. Changes in environmental conditions may cause a shift in the bacterial community to favour those that are better able to utilise the nutrients, and this will in turn increase the expression of the enzymes required for the uptake and assimilation of energy.

\subsection{INTRODUCTION}

Bacteria mediate global biogeochemical cycles where they play fundamental roles in the assimilation of carbon and nutrients such as phosphate and nitrogen. In Antarctic terrestrial habitats, biogeochemical cycles are almost exclusively driven by microbes (Smith 1994), but little is known of such cycles in sea ice. However, it appears that 
Antarctic sea ice bacteria may play a role in the sea ice microbial loop where they assimilate dissolved organic matter (DOM) from algae, and transfer it to higher trophic levels via grazing by protists (Martin et al. 2011). The coupling of bacterial abundances with algal primary productivity (Stewart and Fritsen 2004; Martin et al. 2009) suggests that sea ice bacteria are heterotrophic, relying on organic matter for energy. Photosynthetic prokaryotes such as cyanobacteria play a dominant role as primary producers in many oceanic waters (Kolber et al. 2000; Rudi et al. 2000). However, cyanobacteria have not been found in Antarctic sea ice (Koh 2011). Some bacterial groups, although unable to photosynthesise as in higher plants, contain genes that enable them to generate ATP from light energy (Kolber et al. 2000). Recently, light energy utilising bacteria have been described from Antarctic sea ice (Koh et al. 2010).

The microbial loop may be more complex in Antarctic sea ice than originally thought due to the presence of these light harvesting bacteria. Some microbes are able to supplement their metabolism either from harvesting light (phototrophy), assimilation of organic or inorganic compounds (chemotrophy), or mixtures of both. For example, purple nonsulfur bacteria (anoxygenic photosynthetic bacteria) are able to shift between metabolic modes depending on the environmental conditions (Yurkov and Beatty 1998). Photoheterotrophy, the ability to assimilate organic matter and to also harvest light energy, occurs in a range of microbes (Eilers et al. 2000) including bacteria. Photoheterotrophic microbes include aerobic anoxygenic phototrophic (AAnP) bacteria which contain the pigment bacteriochlorophyll $a$ (BChla), and proteorhodopsin (PR)-containing bacteria. Both of these groups have been described in Antarctic sea ice (Koh et al. 2010, Koh 2011) but their role in the microbial loop is uncertain.

AAnP bacteria have been described by targeting the pufM gene which encodes a pigment-binding protein subunit of the reaction centre complex (Alberti et al. 1995). Representatives of the AAnP bacteria are diverse; in marine environments pufM sequences have been found that are related to those from Roseobacter and Rhodobacter, the Betaproteobacteria and Gammaaproteobacteria (Venter et al. 2004; Delong et al. 2006). The PR gene encodes for a light-driven proton pump that is present in three classes of bacteria: the Alphaproteobacteria, gammaproteobacteria, 
and the Flavobacteria, while variants of this gene also exist in Actinobacteria and Archaea. PR bacteria are very abundant in marine surface waters suggesting they play a dominant role in light harvesting (Venter et al. 2004; Campbell et al. 2008).

The nitrogen cycle is an important biogeochemical process that was purely driven by microbes (Figure 4.1) before increased agriculture and industry and the burning of fossil fuels (Galloway et al. 2008) dramatically modified the process in land based ecosystems. Nitrification and denitrification are key processes in the nitrogen cycle that may counteract natural and anthropogenic eutrophication by eliminating the nutrients $\mathrm{NO}_{3}^{-}$and $\mathrm{NH}_{3}$. Denitrification is performed by a wide range of microorganisms where nitrate is reduced via nitrite, nitric oxide and nitrous oxide to nitrogen gas (Knowles 1982). Denitrification rates in bacteria are controlled by the supply of $\mathrm{NO}_{3}{ }^{-}$and carbon (Tiedje et al. 1982); therefore it is likely that increased primary production (and DOM) leads to increased denitrification rates.

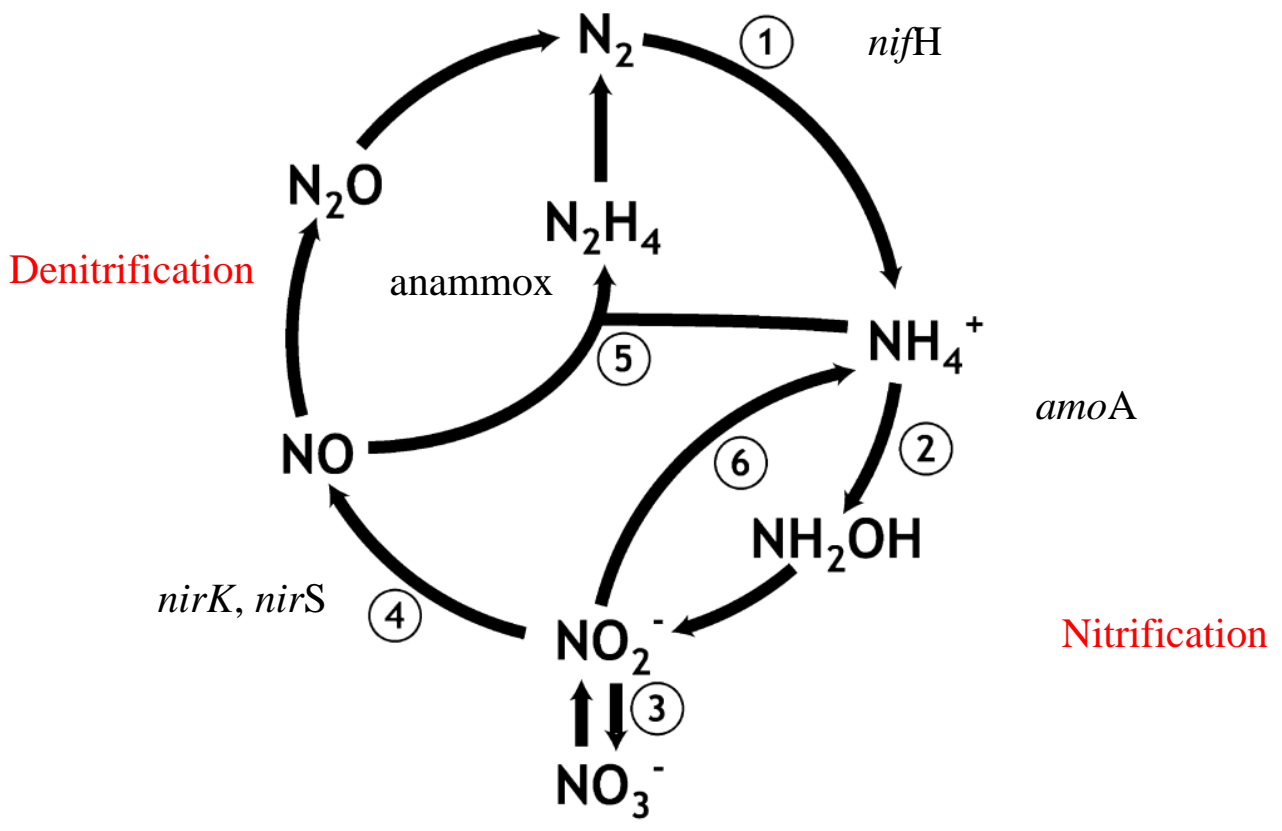

Figure 4.1 Reactions of the microbial nitrogen cycle and examples of genes that are involved in these reactions. (1) Dinitrogen gas fixation, (nifH gene) (2) aerobic ammonium oxidation by bacteria and archaea, (amoA gene) (3) aerobic nitrite oxidation; (4) denitrification (nirK, nirS genes); (5) anaerobic ammonium oxidation (anammox, 16S rRNA gene); and (6) dissimilatory nitrate and nitrite reduction to ammonium. Nitrification is the oxidation of reduced $\mathrm{N}$ in the form of $\mathrm{NH}_{4}{ }^{+}$to $\mathrm{NO}_{3}{ }^{-}$. Denitrification transforms nitrate $\mathrm{NO}_{3}{ }^{-}$into $\mathrm{N}_{2}$ gas. 
The denitrification process is catalysed by the enzyme nitrite reductase (nir), which originates from two genes. One enzyme contains copper (nirK) and the other cytochrome cd1 (nirS). Studies investigating denitrification have focused on communities from soils and coastal and oceanic shelf sediments (Braker et al. 1998; Nogales et al. 2002; Liu et al. 2003; Mosier and Francis 2010). In marine sediments, denitrification may account for up to half of the return of fixed $\mathrm{N}$ to the atmosphere (Seitzinger 1990; Devol 1991; Devol and Christensen 1997). There have been few studies investigating denitrification in the water column, and these studies have been restricted to suboxic and anoxic zones (Oakley et al. 2007). The nitrogen cycle in Antarctic sea ice is poorly understood but studies have shown that nitrogen may be the main limiting nutrient particularly at high latitudes. As Antarctica has little human influence, inorganic $\mathrm{N}$ is only produced by bacteria which algae rely upon. The production of inorganic $\mathrm{N}$ by bacteria and its subsequent uptake by algae is also influenced by the low temperatures and light conditions (Mataloni et al. 2000). A study of Baltic Sea ice has revealed populations of anoxygenic phototrophic purple sulphur bacteria (Petri and Imhoff 2001). Since these organisms are exclusively anaerobic, this suggests that there are anoxic zones in sea ice. The action of aerobic heterotrophic respiration removes oxygen from microsites, producing anoxic areas that are surrounded by fully aerobic conditions (Tiedje et al. 1982). Anaerobic conditions may also occur during ice melt due to the release of oxygen depleted melt water (Glud et al. 2002). Other studies have shown active denitrifying bacteria in Arctic sea ice (Rysgaard and Glud 2004; Rysgaard et al. 2008). Denitrifying bacteria have also been identified in Antarctic sea ice (Staley and Gosink 1999) and they may play a role in important biogeochemical cycles.

While photoheterotrophs and denitrifiers have been described from Antarctic sea ice, their abundance and contribution to biogeochemical cycles is unknown. The use of quantitative PCR (qPCR) combined with reverse transcription (RT) enables gene expression to be quantified; the relative abundance of particular bacteria can be related to metabolic activity and ecological function. qPCR is similar to PCR in that the gene of interest is targeted by specific primers. However gene abundance is quantified using either the dye SYBR green, which fluoresces when bound to double stranded DNA (Wittwer et al. 1997), or by adding fluorescently labelled primers. An increase in fluorescence corresponds to increased product formation which can be 
measured in real time. This strategy is more accurate than end-point PCR where amplification bias increases with PCR cycles. With qPCR, the quantification of gene copy numbers occurs in the early exponential phase where copy numbers are proportional to starting template concentration. When SYBR green binds to double stranded (ds) DNA, care must be taken to design highly specific primers. SYBR green is not gene specific, and it will therefore bind to any ds DNA producing nonspecific products that may contribute to the fluorescent signal. This problem can be circumvented using fluorescent primers and the TaqMan ${ }^{\mathrm{TM}}$ probe system in which fluorescence will only occur when the primers bind to the sequence of interest. However, this method is more expensive requires the presence of an additional conserved site within the short amplicon sequence to be present (see Smith and Osborn 2009 and references within). A reference or housekeeping gene that is representative of the DNA concentration in a sample is used to normalise data. Many studies normalise copy numbers of the target gene to the numbers of the 16S rRNA gene (Neretin et al. 2003; Treusch et al. 2005; Kandeler et al. 2006).

qPCR has its drawbacks, like all molecular methods. It has biases that arise during nucleic acid extraction from the environment, where some species are more readily extracted than others. However, if nucleic acids are extracted from different samples using the same methods then the abundance of genes in each sample can be compared. It also has biases during PCR amplification that may cause the abundance and distribution of genes to be skewed. These biases can be reduced by analysing all samples to be compared on one 96 well plate against the same standard curve and with the same amplification efficiency. Despite these biases, qPCR is a robust, highly reproducible and sensitive method to investigate gene abundance in environmental samples.

Fluorescently labelled synthetic substrates (methylumbelliferyl (MUF) or methylcoumarin (MCA)) are sensitive tools to measure the metabolic activity of bacteria using fluorogenic substrate analogues (Hoppe 1983). The substrates are added directly to the microbial community to measure their enzymatic activity, circumventing biases that may occur during culture isolation, nucleic acid extraction and PCR amplification (discussed in Chapter 6). These substrates are synthetic and, 
when cleaved by the enzyme of interest, release a highly fluorescent product, which can be quantified using fluorometry.

Most of the organic matter in the marine environment consists of high molecular weight compounds such as proteins, lipids, nucleic acids, and polysaccharides (Poremba 1995). These polymers are important sources of carbon, nitrogen and energy for bacteria but they are too large to be directly transported across the cell membrane (Hoppe 1983; Chróst et al. 1989). As a result, many heterotrophic bacteria produce extracellular hydrolytic enzymes that degrade these large polymers, thus enabling them to take up and utilise them. These enzymes are located either on the bacterial cell surface, in the periplasmic space (cell-attached extracellular enzymes), or are released from the bacterium into the environment (cell-free extracellular enzymes) where they may act in solution or be adsorbed to surfaces. The action of bacterial enzymes drives microbial growth and therefore they are directly related to bacterial productivity and biomass. It is useful therefore to measure bacterial enzyme activity in the environment in order to understand the composition of DOM and what role bacteria have in the microbial loop.

The enzymatic functions of Antarctic sea ice bacteria have not been investigated but Arctic bacteria have cold-adapted hydrolytic enzymes that degrade lipids (lipase) and polysaccharides ( $\beta$-galactosidase, Groudieva et al. 2004; Yu et al. 2009). Antarctic planktonic bacteria have high lipase, $\beta$-galactosidase and phosphatase activity (Bergamasco et al. 2003). Not all bacteria are able to produce every enzyme, however. A study by Yu et al. (2009) on 338 isolates from Arctic sea ice found that protease, lipase, chitinase, $\beta$-galactosidase and amylase activity occurred in 65.7, 71.6, 16.9, 31.6 and $38.5 \%$ of the isolates, respectively. Enzymatic activity has also been associated with changes in environmental conditions. One study showed that enzyme activities increased after a diatom bloom and that different enzymes peaked at different times during this bloom (Smith et al. 1995). Changes in enzymatic activity may have been due to regulation of phenotypes in response to the available organic substrates. Alternatively, changes in enzymatic activity may have occurred from community succession where bacteria with appropriate enzymatic capabilities are dominant at the different stages of the algal bloom (Reimann et al. 2000). 
Phosphatase activity is widespread in marine bacteria and can play an important role in supplying phosphorus to heterotrophic and autotrophic organisms in the community (Hoppe 2002). Phosphatase activity has been shown in many species of marine bacteria, primarily from the genera Pseudomonas, Chromobacterium, Bacillus and Flavobacteria (Martinez et al. 1996) and has also been found in psychrophilic Arthrobacter isolates (Prada and Brenchley 1997).

$\beta$-galactosidases are produced by Pseudoalteromonas, Marinomonas, Colwellia and Shewanella. Flavobacterium degerlachei isolated from Arctic sea ice was also found to produce these enzymes ( $\mathrm{Yu}$ et al. 2009). Many bacteria are capable of producing proteases. Protease enzymes will cleave proteins into peptides and amino acids (Ainsworth and Goulder 2000).Yu et al. (2009) found members of Colwellia with protease activity.

Marine environments also have high levels of lipase activity in which triglycerides are broken down into glycerol and fatty acids (Boetius 1995). Many psychrophilic bacteria, such as Colwellia hornerae, C. psychroerythraea, Marinomonas primoryensis, Shewanella livingstonensis and Psychroflexus torques, degrade lipids (Yu et al. 2009).

Chitin is an abundant polysaccharide found in the marine environment. It is a component of the exoskeleton of zooplankton and invertebrates and is also found in the cell walls of some diatoms (Durkin et al. 2009). The key step in the mineralisation of chitin is its hydrolysis by microbes (Gooday 1990). The ability to degrade chitin is widespread among prokaryotes including Photobacterium spp., Actinomycetes, Bacilli, Clostridia and archaea (Tsujibo et al. 1991; Hiraga et al. 1999; Cottrell et al. 1999). The species Pseudoalteromonas tetraodonis, Pseudoalteromonas elyakovii, Bacillus firmus and Janibacter melonis isolated from Arctic sea ice have been shown to degrade chitin (Yu et al. 2009).

The aim of this chapter was to investigate bacterial community function in sea ice using molecular dependent and molecular independent approaches. Functional genes of interest were targeted using primers optimised by previous studies and quantified using qPCR. The relative abundance of these genes were calculated as a percentage of 
the bacterial or prokaryotic community. I hypothesised that pufM, PR and nirK genes would be present and active in sea ice habitats. Bacterial enzymatic activity was also investigated using synthetic substrates that are added directly to the sea ice sample. Bacterial enzymatic activity was compared between communities at the bottom of the sea ice core and through the sea ice core in 2008 and 2009. Furthermore, relationships among bacterial activity, bacterial community data and nutrient concentrations were investigated using results obtained from Chapter 3. I hypothesised that enzymatic activity would vary between samples and be related to bacterial community structure.

\subsection{Methods}

\subsubsection{Quantitative PCR}

Sea ice cores and seawater samples were collected from Antarctic sea ice in 2008 and 2009 as described previously in Chapter 3. Brine was also collected from Granite Harbour in 2009. Brine was collected by drilling a $1 \mathrm{~m}$ deep hole using a Jiffy drill and leaving the hole covered for $30 \mathrm{~min}$. During this time the brine drained from the surrounding ice into the bottom of the hole. The brine was removed using a sterile syringe, and transported back to the field laboratory where the microbes were concentrated onto a $0.22 \mu \mathrm{m}$ polycarbonate filter and stored at $-20^{\circ} \mathrm{C}$ in RNAlater ${ }^{\mathrm{TM}}$. The RNA was extracted from the samples and stored at $-80{ }^{\circ} \mathrm{C}$. RNA was converted into cDNA following the protocol outlines in Chapter 2 and incubated with DNase (Sigma) to remove DNA. The samples were pooled together to estimate the total potential functional activity for the bacteria at that site at the top, middle and bottom of the sea ice core. A total of 24 RNA samples were chosen for analysis (Table 4.1) and five genes were targeted for qPCR. The genes were nirK, PR, pufM and the 16S rRNA genes of archaea and bacteria (Table 4.1). The annealing temperatures were optimised during PCR optimisation as described in Chapter 2. Quantitative PCR reactions were performed on the CFX96 ${ }^{\mathrm{TM}}$ Real Time PCR System (Bio-Rad, CA, USA). Amplifications were carried out in triplicate in 1 x SsoFast $^{\mathrm{TM}}$ Eva Green SuperMix (SYBR based system, Bio-Rad), containing specific primers $(0.1 \mathrm{mM})$ and a total concentration of $2 \mathrm{ng}$ cDNA. PCR cycling conditions were $95{ }^{\circ} \mathrm{C}$ for $3 \mathrm{~min}$, followed by 40 cycles of $95{ }^{\circ} \mathrm{C}$ for $10 \mathrm{~s}, 20 \mathrm{~s}$ at the optimal annealing temperature and 
$72{ }^{\circ} \mathrm{C}$ for $30 \mathrm{~s}$. Melt curves profiles were analyzed for both $16 \mathrm{~S}$ rRNA genes. A standard curve, based on a dilution series ranging from $10^{1}$ to $10^{7}$ gene copies $\mu \mathrm{L}^{-1}$ was run in triplicate with the samples. The standard curves were constructed from plasmids from environmental samples. The concentration of the plasmid was measured using Picogreen fluorescence. With the molecular weight of the plasmid and insert known, it was possible to calculate the copy number of each gene standard as follows (Whelan et al. 2003):

Weight in daltons $\left(\mathrm{g} \mathrm{mol}^{-1}\right)=(\mathrm{bp}$ size of double stranded product $) \times(660 \mathrm{Da})$ Hence: $\left(\mathrm{g} \mathrm{mol}^{-1}\right) /$ Avogadro's number $=\mathrm{g}$ molecule $^{-1}=$ copy number

The percentage of the plasmid that contributes to the final PCR product must first be calculated. The size of the target gene is divided by the total size of the recombinant plasmid to get the proportion of the insert DNA:

Insert DNA $(\%)=\quad$ insert (bp) $\quad$ x 100

recombinant plasmid (vector + insert)

The concentration of the insert DNA is then calculated:

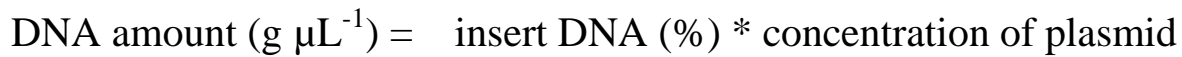

Therefore, the number of gene copies of the standard can be calculated:

Gene copy number $=\quad \underline{\text { Avogadro's number } \times \text { DNA amount }\left(g \mu \mathrm{L}^{-1}\right)}$

DNA length (of insert, bp) $\times 660 \mathrm{Da}$

A standard curve was drawn by plotting the natural log of the threshold cycle $\left(\mathrm{C}_{\mathrm{T}}\right)$ against the natural $\log$ of the number of molecules. The $\mathrm{C}_{\mathrm{T}}$ was defined as the cycle at which a statistically significant increase in the magnitude of the signal generated by the PCR reaction was first detected. $\mathrm{C}_{\mathrm{T}}$ was calculated under default settings for the real-time sequence detection software (Applied Biosystems). From the slope of each 
standard curve, PCR amplification efficiency (E) was calculated according to the equation (Pfaffl, 2001):

$$
\mathrm{E}=10(-1 / \text { slope })-1
$$

High amplification efficiencies of 95-104\% were obtained for all genes, with $\mathrm{R}^{2}$ values between 0.990 and 0.997 . The number of gene copies $\mu \mathrm{L}^{-1}$ of template DNA were converted to gene copies $\mathrm{mL}^{-1}$ of melted sea ice core by taking into account the volume filtered, and the final volume of DNA extracted, and by assuming that $100 \%$ of the DNA had been extracted from each sample. qPCR was carried out in 96 well plates which enabled 24 samples in triplicate, a seven point standard curve and a notemplate control also in triplicate all to be run on the same plate. This eliminated the bias that may occur between separate runs in which amplification efficiencies and $\mathrm{R}^{2}$ values may vary causing error when comparing samples. The 24 samples and plate layout are shown in Figure 4.2.

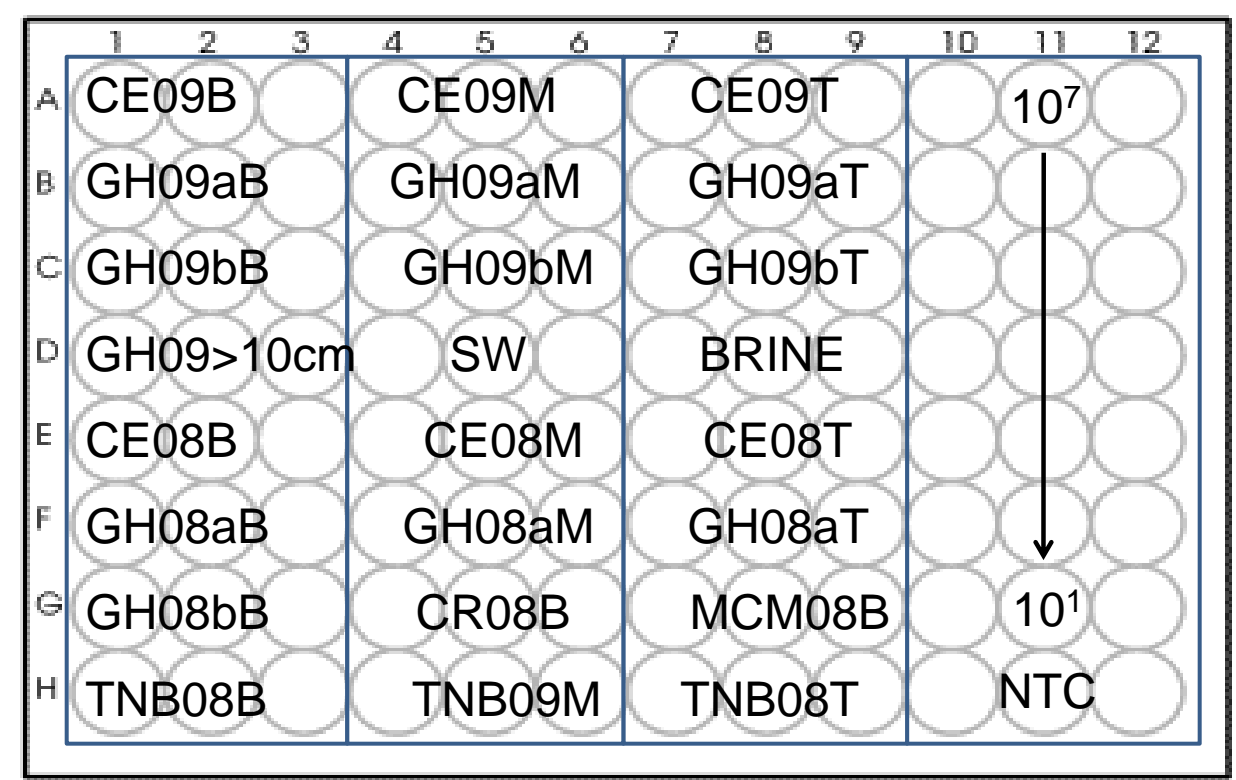

Figure 4.2 Plate layout showing 24 cDNA samples from Cape Evans (CE), Granite Harbour (GH), seawater (SW), brine (BRINE), Cape Roberts (CR), McMurdo Station (McM), Terra Nova Bay (TNB) and no template control (NTC). Samples are taken from the bottom (B), middle (M) and top (T) of the sea ice core each run in triplicate. The standard curve was based on a dilution series of $10^{7}$ to $10^{1}$ gene copies $\mu \mathrm{L}^{-1}$. 
Table 4.1 Primers used in this study to target the five different genes and their optimal annealing temperatures $\left({ }^{\circ} \mathrm{C}\right)$.

\begin{tabular}{|c|c|c|c|c|c|}
\hline $\begin{array}{l}\text { Function / } \\
\text { organism }\end{array}$ & Gene & Primer name & Primer sequence $\left(5^{\prime}-3^{\prime}\right)$ & $\begin{array}{l}\text { Annealing } \\
\text { temperature }{ }^{\circ} \mathrm{C}\end{array}$ & Reference \\
\hline $\begin{array}{l}\text { Nitrogen } \\
\text { reduction }\end{array}$ & nitrite reductase & $\begin{array}{l}\operatorname{nir} K-\mathrm{q}-\mathrm{F} \\
\operatorname{nir} K-1040 \\
\end{array}$ & $\begin{array}{l}\text { TCATGGTGCTGCCGCGYGA } \\
\text { GCCTCGATCCGRTTRTGGTT }\end{array}$ & 59 & Braker et al. 1998 \\
\hline $\begin{array}{l}\text { Bacterio- } \\
\text { chlorophyll }\end{array}$ & $\begin{array}{l}\text { Proteorhodopsin } \\
\text { pufM }\end{array}$ & $\begin{array}{l}\text { RYIDWF } \\
\text { GWAIYPR } \\
\text { pufM.557F } \\
\text { pufM.750R } \\
\end{array}$ & $\begin{array}{l}\text { MGNTAYATHGAYTGG } \\
\text { GGNTGGGCNATHTAYCCN } \\
\text { CGCACCTGGACTGGAC } \\
\text { CCCATGGTCCAGCGCCAGAA }\end{array}$ & $\begin{array}{l}50.1 \\
53\end{array}$ & $\begin{array}{l}\text { Atamna-Ismaeel et al. } 2008 \\
\text { Achenbach et al. } 2001\end{array}$ \\
\hline Archaea & 16S rRNA & $\begin{array}{l}\text { Arch1017F } \\
\text { Arch1392R } \\
\end{array}$ & $\begin{array}{l}\text { GAGAGGWGGTGCATGGCC } \\
\text { TGACGGGCGGTGTGTGCTTG }\end{array}$ & 57 & Suzuki et al. 2000 \\
\hline Bacteria & 16S rRNA & $\begin{array}{l}\text { Bac518F } \\
\text { Bac800R }\end{array}$ & $\begin{array}{l}\text { CCAGCAGCCGCGGTAATACG } \\
\text { TACCAGGGTATCTAATCC }\end{array}$ & 57 & Universal \\
\hline
\end{tabular}




\subsubsection{Methylumbelliferyl substrate assays}

Sea ice samples were collected and stored at $-20{ }^{\circ} \mathrm{C}$ until processed. Lipase, chitinase, $\beta$-galactosidase, phosphatase and protease enzyme activities were investigated. To each thawed sample, the following synthetic substrates were added to test for bacterial enzyme activity; lipase, 4-Methylumbelliferyl oleate; chitinase, 4-Methylumbelliferyl $\mathrm{N}$-acetyl- $\beta$-D-glucosaminide; $\quad \beta$-galactosidase, $\quad 4$-Methylumbelliferyl $\quad \beta$-Dglucopyranoside; phosphatase, 4-Methylumbelliferyl phosphate and protease, LLeucine-7-amido-4-methylcoumarin hydrochloride. Each sample was run in triplicate against the positive controls; lipase from wheat germ, chitinase from Streptomyces griseus, glucosidase from almonds (Sigma), alkaline phosphatase and proteinase-K (Roche). A standard curve was constructed from the fluorogenic substrates 4Methylumbelliferone (MUF) or 7-Amino-4-methylcoumarin (MCA). Enzyme activities measured by means of fluorogenic substrates were expressed in terms of the rate of MUF or MCA production. The samples were analysed for fluorescence every 5 min for $4 \mathrm{~h}$ on a Modulus microplate reader (Biosystems) at $10{ }^{\circ} \mathrm{C}$. Determination of the enzymatic $\mathrm{V}_{\max }$ and the Michaelis-Menten constant was performed following Chrost and Velimirov (1991).

\subsubsection{Statistical analyses}

A similarity profile test (SIMPROF) was used to calculate similarities in MUF activity between bacterial communities. The test was based on a Bray-Curtis similarity matrix and groupings examined at the $5 \%$ significance level $(<0.05)$ using a maximum of 1000 random permutations of the raw data. Correlations between MUF activity and nutrient concentrations were investigated using regression analyses in SigmaPlot v 10. To investigate the association between the bacterial community (TRFLP data from Chapter 3) and MUF activity, I used a distance-based multivariate multiple regression technique (DISTLM) (McArdle and Anderson 2001) as previously explained in Chapter 3. Once the optimal (best-fit) model was identified, a distance-based redundancy analysis (dbRDA) (McArdle and Anderson 2001) was 
used to visualize the correlation between the bacterial enzymatic activity and community composition differences across sites.

\subsection{Results}

\subsubsection{Quantitative PCR}

\subsubsection{Bacteria}

Bacterial 16S rRNA gene copy numbers were in high abundance throughout the sea ice core and at all sites collected from 2008 and 2009 (Figure 4.3). Bacterial numbers were generally highest in the middle of the sea ice core, and were lowest at the top of the ice core. However, at Terra Nova Bay in 2008, bacterial numbers at the top of the ice core were an order of magnitude more abundant than at the top of the ice in other sites. At the bottom of the ice core, bacterial numbers were higher in Granite Harbour than in Cape Evans in 2009. In 2008, they were highest at McMurdo station, then Terra Nova Bay and lowest at Granite Harbour (GH08b). The highest bacterial gene copy numbers of all samples were recorded in the brine community from the mid region of the ice from Granite Harbour in 2009 (Fig 4.3b) and lowest at CE08 at the top of the ice core (Figure 4.3a). 

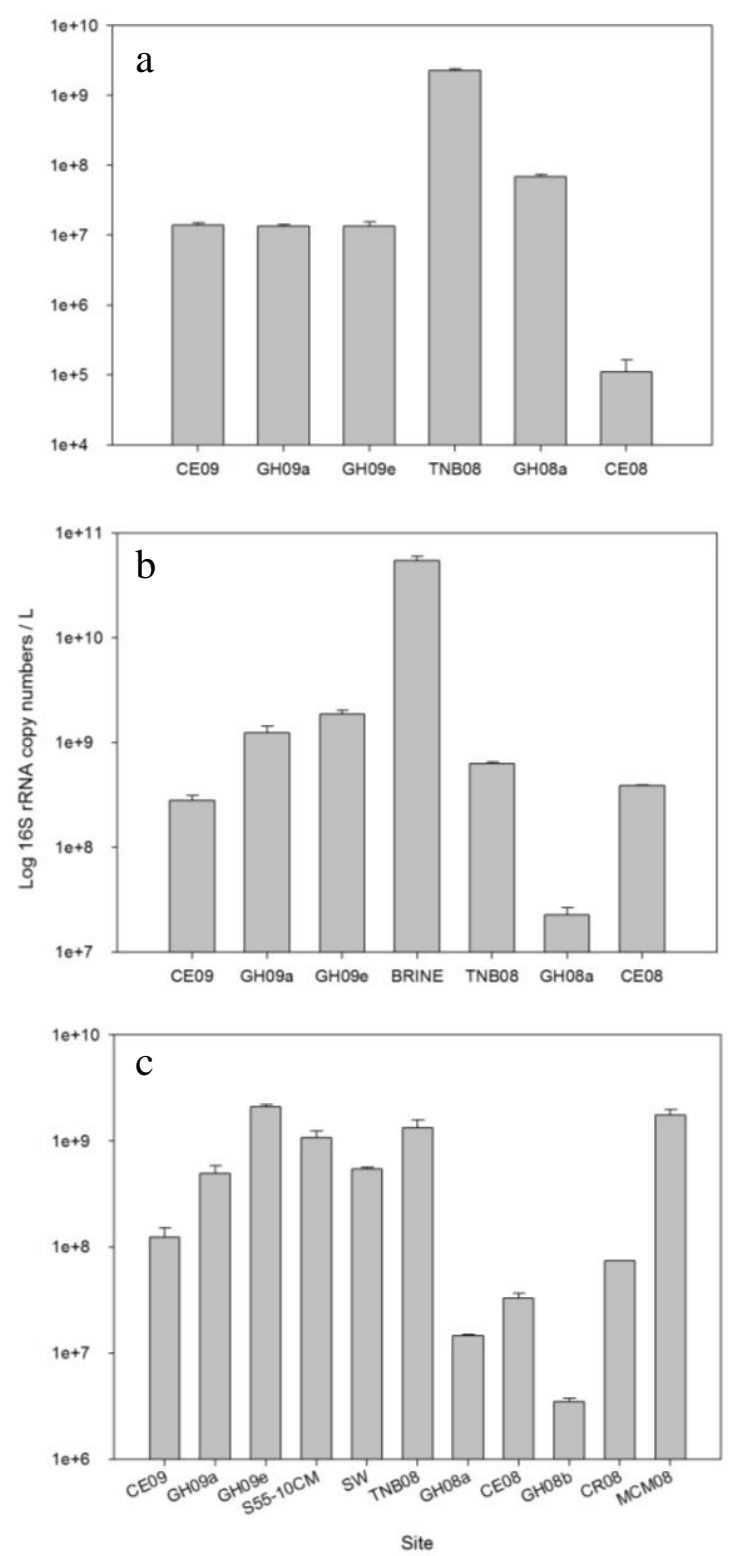

Figure 4.3 Bacterial 16S rRNA gene copy number $\mathrm{L}^{-1}$ at the (a) top, (b) middle and (c) bottom of the sea ice core in 2008 and 2009. The mean \pm 1 standard error calculated from the samples $(n=3)$ are shown.

\subsubsection{Archaea}

Archaeal 16S rRNA genes were present throughout the sea ice core and at all sites collected from 2008 and 2009 (Figure 4.4). Archaeal abundance reflected that found for the bacteria, in that it was highest in the middle of the sea ice core (Figure 4.4c) and lowest at the top of the ice core (Figure 4.4a). At the bottom of the ice core in 2009, archaea were in greater numbers at Granite Harbour compared to Cape Evans (Figure 4.4e). In 2008, they were highest at McMurdo station and lowest at Granite 
Harbour (GH08a, Figure 4.4e). Archaeal numbers ranged from $2.2 \times 10^{5}-1.4 \times 10^{8}$ $\mathrm{L}^{-1}$ at the bottom of the ice core (Figure 4.4e), $1.1 \times 10^{5}-4.0 \times 10^{8} \mathrm{~L}^{-1}$ in the middle of the sea ice core (Figure 4.4c) and were lowest $\left(5.1 \times 10^{5}-6.8 \times 10^{6} \mathrm{~L}^{-1}\right)$ at the top of the ice core (Figure 4.4a).
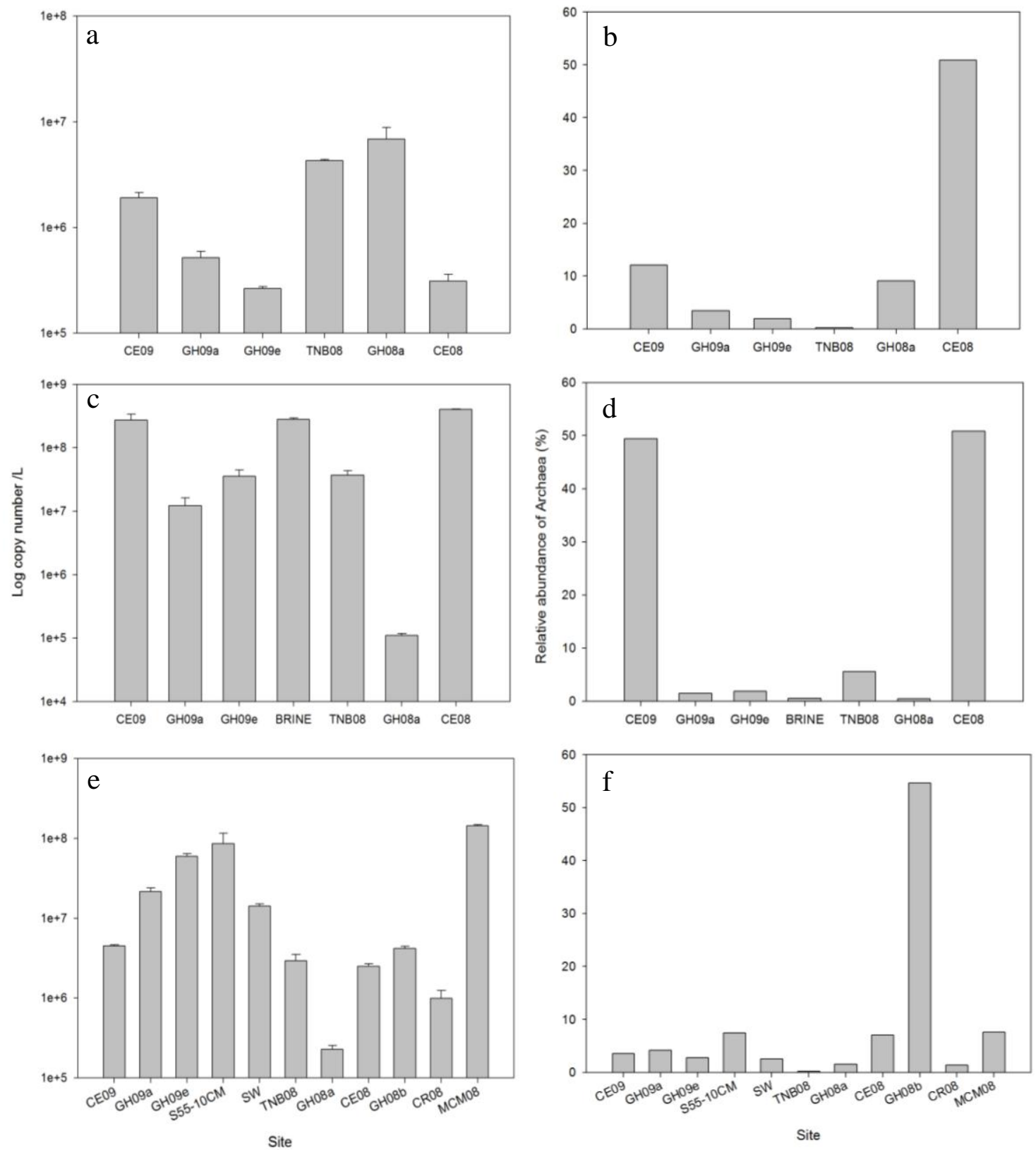

Figure 4.4 Archaea copy number of the 16S rRNA gene $\mathrm{L}^{-1}$ (left column) and relative abundance (\%, right column) of the prokaryotic community. The $(\mathrm{a}, \mathrm{b})$ top, $(\mathrm{c}, \mathrm{d})$ middle and $(\mathrm{e}, \mathrm{f})$ bottom of the sea ice core in 2008 and 2009 are shown. The mean \pm 1 standard error $(n=3)$ is shown. 
Prokaryotes were defined as the sum of bacterial and archaeal 16S rRNA genes. The relative abundance of archaea was calculated as a percentage of the total number of prokaryotes and these values are illustrated in Figure 4.4b, d, e. Through the sea ice core, archaea generally made up $<10 \%$ of the prokaryotic community. Archaea were rare throughout the ice core at Terra Nova Bay (Figure 4.4b, d, e). However, at Granite Harbour (GH08b), archaea contributed significantly to the prokaryote community comprising $54 \%$ of the prokaryotic abundance (Figure $4.4 \mathrm{e}$ ). Similarly, high abundances of archaea were also seen at Cape Evans in 2008 and 2009 in the middle and top sea ice communities (Figure 4.4b, d).

\subsubsection{Functional genes}

NirK gene abundances were found in greatest numbers at the bottom of the sea ice core where gene copies ranged from $1.1 \times 10^{3}-5.3 \times 10^{6} \mathrm{~L}^{-1}$ (Figure 4.5c). They decreased in the middle and top of the sea ice core where they ranged from $6.9 \times 10^{2}-$ $1.5 \times 10^{4} \mathrm{~L}^{-1}$ (Figure 4.5b) and $4.4 \times 10^{2}-2.2 \times 10^{4} \mathrm{~L}^{-1}$ respectively (Figure 4.5a). 

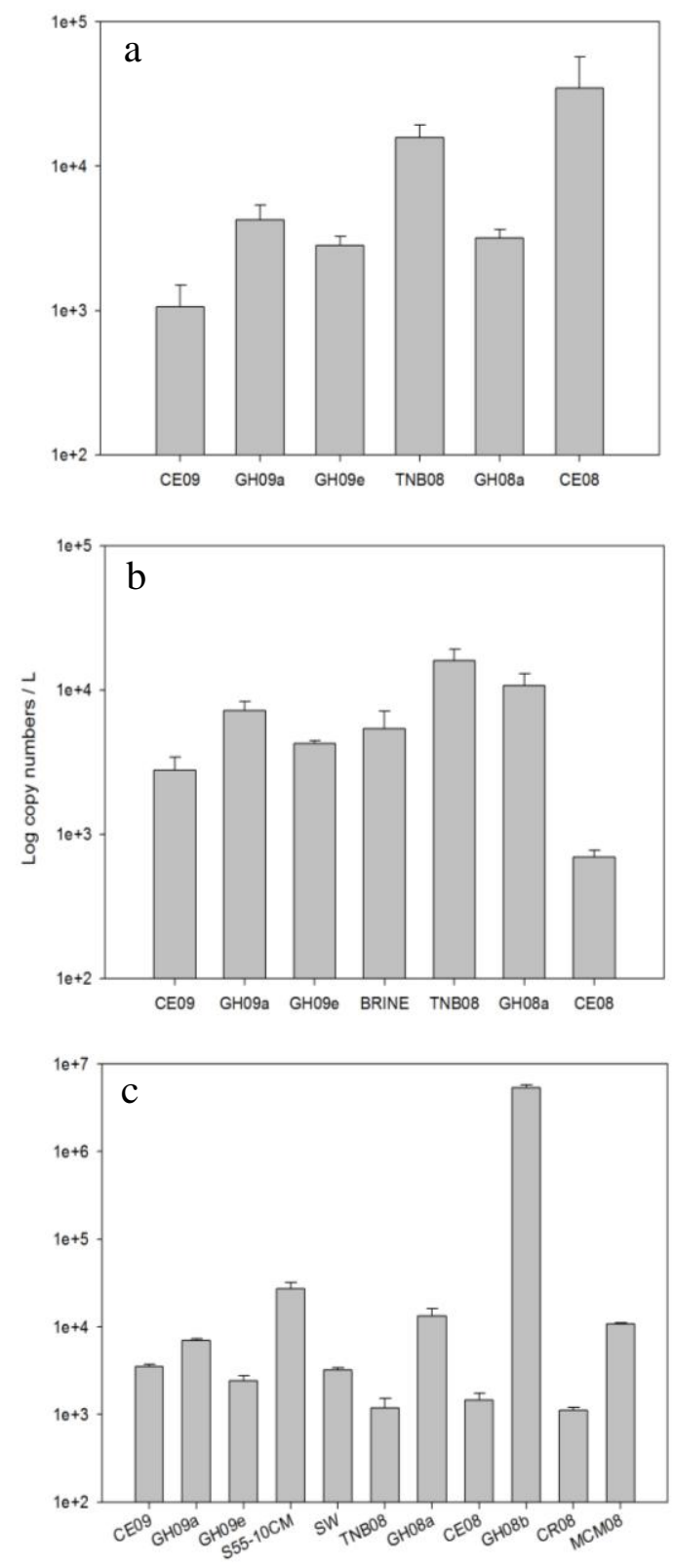

Site

Figure 4.5 Copy number $\mathrm{L}^{-1}$ nirK at the top (a), middle (b) and bottom (including sea water) (c) of the ice core. The mean \pm 1 standard error $(n=3)$ is shown.

PufM gene abundances ranged from $5.0 \times 10^{4}-4.1 \times 10^{5} \mathrm{~L}^{-1}$ at the bottom of the ice core (Figure 4.6c) and were highest at GH08a. In the middle of the ice core $p u f M$ gene copies ranged from $7.7 \times 10^{3} \mathrm{~L}^{-1}$ at GH09e $-2.8 \times 10^{4} \mathrm{~L}^{-1}$ in the brine at GH09 (Figure 4.6b). At the top of the ice core pufM gene copy numbers were lowest at GH09e $\left(3.9 \times 10^{3} \mathrm{~L}^{-1}\right)$ and highest at GH08a $\left(1.1 \times 10^{4} \mathrm{~L}^{-1}\right.$, figure $\left.4.6 \mathrm{a}\right)$. 

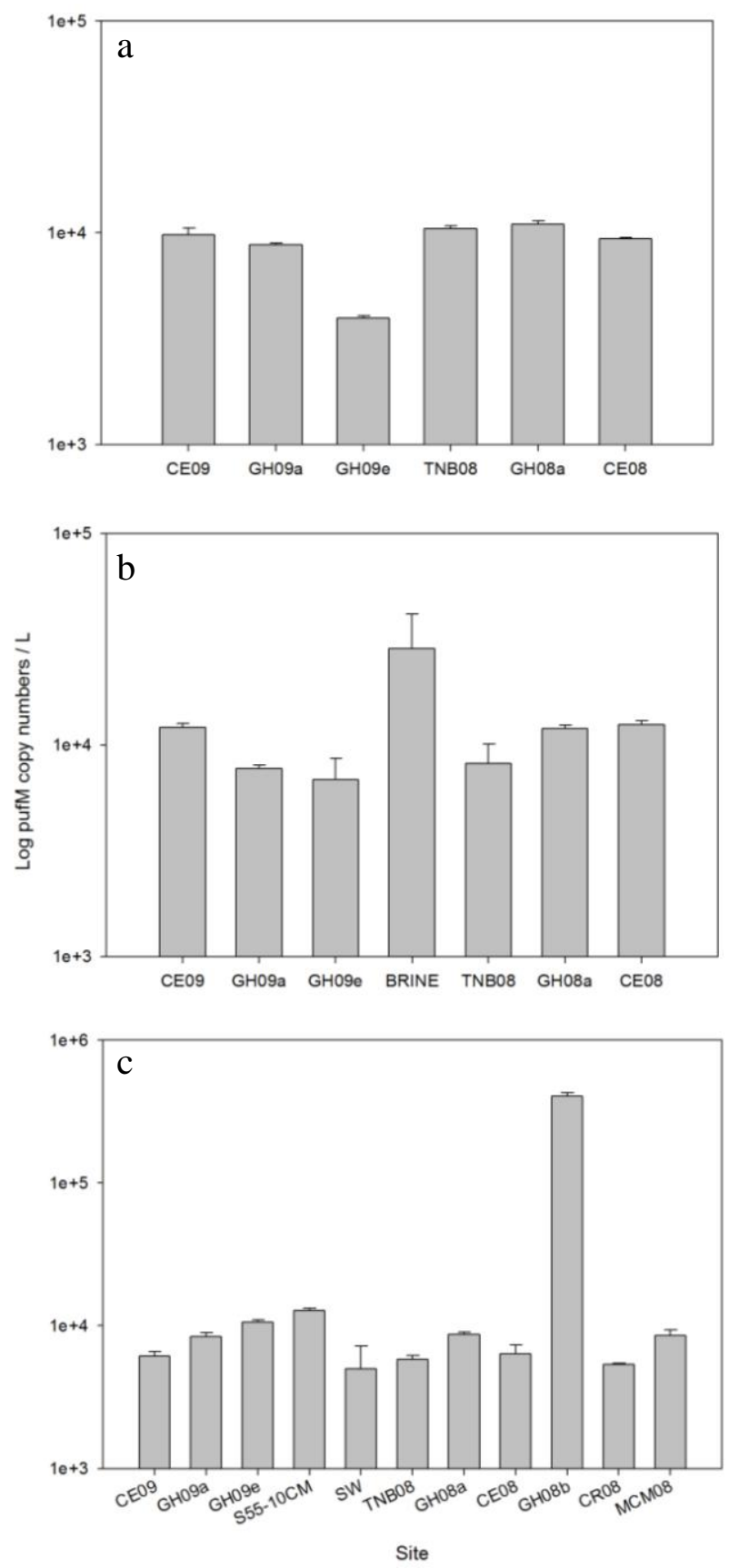

Figure 4.6 Copy number $\mathrm{L}^{-1}$ pufM at the top (a), middle (b) and bottom (including sea water) (c) of the ice core. The mean \pm 1 standard error $(n=3)$ is shown.

The PR gene was not detected at the bottom of the sea ice core, apart from at Cape Evans in $2009\left(1.0 \times 10^{5} \mathrm{~L}^{-1}\right)$. It was present in higher numbers in the brine community at $3.2 \times 10^{6}$ copies $\mathrm{L}^{-1}$ and also found in the middle of the core (Figure 4.7 b) at Cape Evans in $2008\left(3.4 \times 10^{4} \mathrm{~L}^{-1}\right)$. At the top of the sea ice core it was detected at more sites and ranged in abundance from 0 to $3.2 \times 10^{4}-1.1 \times 10^{5} \mathrm{~L}^{-1}$. The PR gene was not found within the ice core at Cape Evans in 2009 (Figure 4.7). 

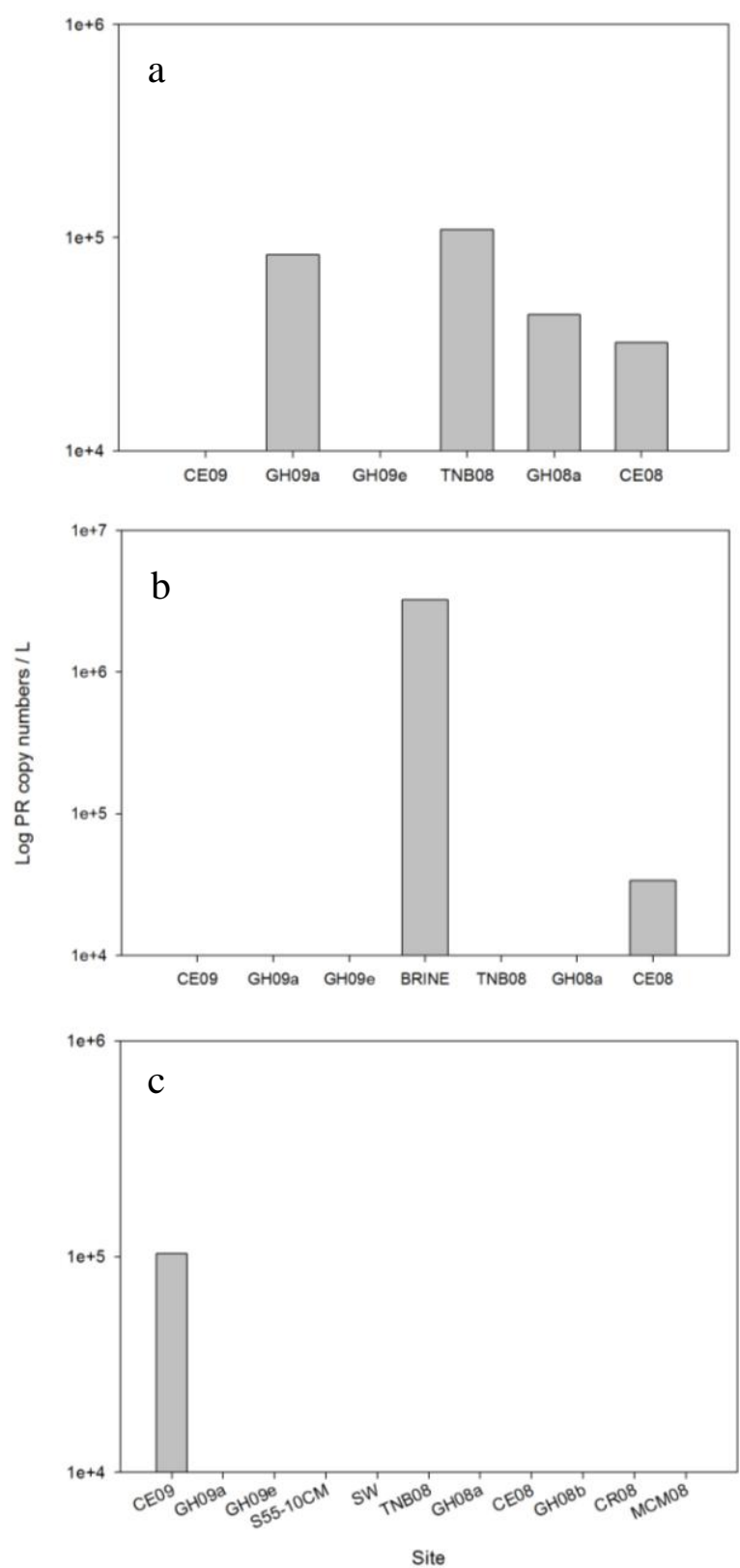

Figure 4.7 Copy number $L^{-1} \mathrm{PR}$ at the top (a), middle (b) and bottom (including sea water) (c) of the ice core. The mean \pm 1 standard error calculated from the samples $(n=3)$ are shown.

\subsubsection{Relative abundance of nirK, pufM and PR}

The genes nirK, pufM and PR were only found in a tiny proportion of bacteria in Antarctic sea ice, under $0.01 \%$ of the total bacterial community at the bottom of the ice core (Figure 4.8). 

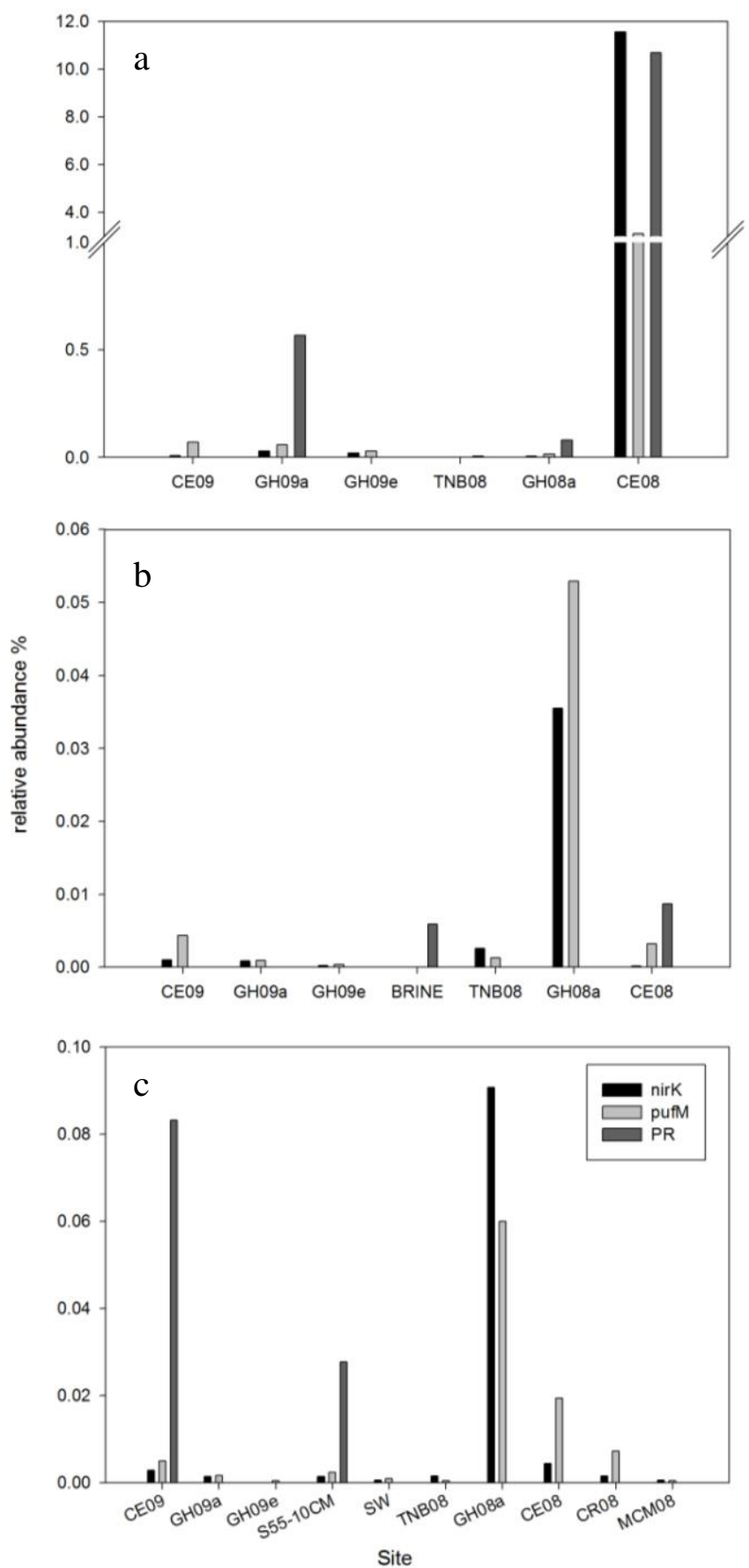

Figure 4.8 Relative abundance (\%) of nirK, pufM and PR genes in the top (a), middle (b) and bottom (c) of the sea ice core. The mean \pm 1 standard error calculated from the samples in triplicate are shown.

In the middle of the core, they were in even lower relative abundance, less than 0.01 $\%$ of the total bacterial community apart from at Granite Harbour (GH08a) where nirK and pufM were in higher abundance (Figure 4.8b). Only at the top of the sea ice core at Cape Evans in 2008 did nirK, pufM and PR contribute to a greater amount of the community (Figure 4.8a). nirK genes comprised $11.6 \%$ of the bacterial 
community, followed by PR which comprised a further $10.7 \%$ and pufM which were found at $3.1 \%$ relative abundance (Figure $4.8 \mathrm{a}$ ).

\subsubsection{Methylumbelliferyl substrate assays}

Antarctic sea ice bacteria were able to degrade polysaccharides, chitins, lipids and proteins at the bottom (Figure 4.9) and through the sea ice core (Figure 4.10). Bacteria were predominantly involved in phosphate recycling (Figure 4.9, 4.10). Firstly, enzymatic activity was compared between sites at the bottom of the ice core (Figure 4.8). There was greater enzymatic activity from samples taken in 2008 than in 2009. The average phosphatase activity in bottom sea ice in 2008 was $7.4 \pm 1.0 \mathrm{mmol} \mathrm{hr}^{-1} \mathrm{~L}^{-}$ 1. The highest activity was found at Granite Harbour (GH08a) where it reached $14.0 \pm$ $3.3 \mathrm{mmol} \mathrm{hr}^{-1} \mathrm{~L}^{-1}$. Phosphatase activity at Granite Harbour (GH09a-e) was much lower at the bottom of the ice core in 2009 , but was still more actively synthesised than the other enzymes, where it ranged from $43-912 \mathrm{nmol} \mathrm{hr}^{-1} \mathrm{~L}^{-1}$. There was no phosphatase activity at Cape Evans (CE09).

$\beta$ - galactosidase was actively synthesised in 2008 where activity ranged from $78 \mathrm{nmol}$ $\mathrm{hr}^{-1} \mathrm{~L}^{-1}$ at Terra Nova Bay (TNB08) to $1154 \mathrm{nmol} \mathrm{hr}^{-1} \mathrm{~L}^{-1}$ at McMurdo Station (McM08, Figure 4.9). In $2009 \beta$-galactosidase was less actively synthesised with an average value under $28 \mathrm{nmol} \mathrm{hr}^{-1} \mathrm{~L}^{-1}$ at all sites apart from $154 \mathrm{nmol} \mathrm{hr}^{-1} \mathrm{~L}^{-1}$ at Granite Harbour (GH09e). Protease activity was higher at Granite Harbour (GH08a) and McMurdo Station (McM08) at 886 and $762 \mathrm{nmol} \mathrm{hr}^{-1} \mathrm{~L}^{-1}$ respectively, but was low at Cape Evans (CE08) at $3 \mathrm{nmol} \mathrm{hr}^{-1} \mathrm{~L}^{-1}$. In 2009 protease activity ranged from $6-205$ $\mathrm{nmol} \mathrm{hr}{ }^{-1} \mathrm{~L}^{-1}$. Lipase activity was higher in 2008 ranging from $126-451 \mathrm{nmol} \mathrm{hr}^{-1} \mathrm{~L}^{-1}$ than 2009. At Granite Harbour (GH09c, d) there was no lipase activity. Chitinase was synthesised least actively across the bottom ice samples from 2008 and 2009. Activity ranged from $29-110 \mathrm{nmol} \mathrm{hr}^{-1} \mathrm{~L}^{-1}$ in 2008 and $2-62 \mathrm{nmol} \mathrm{hr}^{-1} \mathrm{~L}^{-1}$ in 2009 with the most activity seen at McMurdo Station in 2008 where chitinase activity was 1316 nmol hr-1 $\mathrm{L}^{-1}$ (Figure 4.9). 


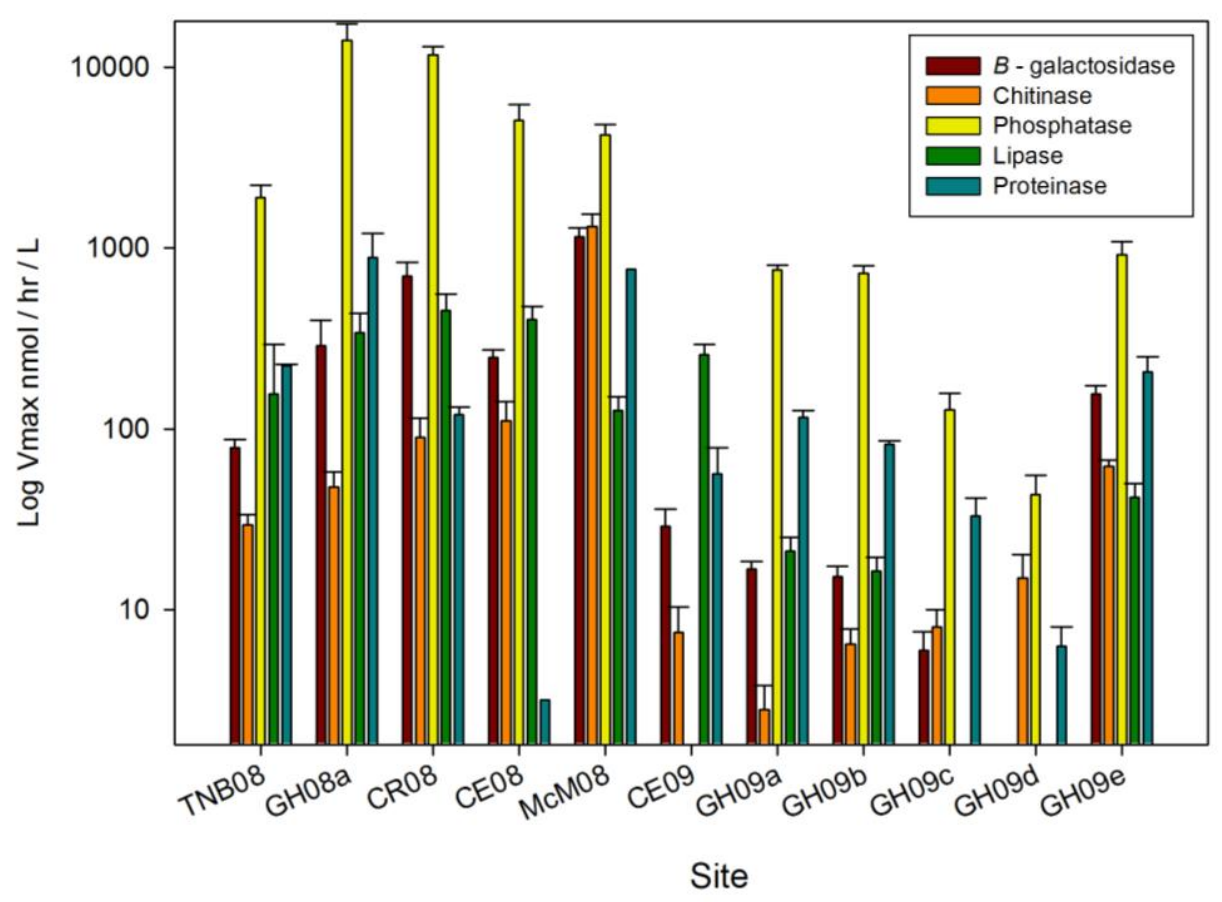

Figure 4.9 Bacterial enzymatic activity in bottom sea ice from different sites in 2008 and 2009. Each bar shows mean \pm 1 standard error.

Secondly, enzymatic activity was measured through the sea ice core at Cape Evans and Granite Harbour in 2009 (Figure 4.10). Phosphatase was again the most actively synthesised enzyme through the sea ice core where the greatest activity was seen in the middle of the ice core at CE09, GH09c, e (Figure 4.10b). Here, activity ranged from $6-2436 \mathrm{nmol} \mathrm{hr}{ }^{-1} \mathrm{~L}^{-1}$ which was higher than the activity found in the top of the core (928 nmol hr $\mathrm{n} \mathrm{L}^{-1}$ at Cape Evans and 0-185 $\mathrm{nmol} \mathrm{hr}^{-1} \mathrm{~L}^{-1}$ at Granite Harbour). $\beta$ galactosidase was less actively synthesised through the ice core than at the bottom of the sea ice core in 2009. In the middle and top of the ice core, $\beta$-galactosidase activity was highest at Cape Evans but was less than $22 \mathrm{nmol} \mathrm{hr}^{-1} \mathrm{~L}^{-1}$ at all sites (Figure 4.10a, b). Protease activity was again highest at the bottom of the ice core (Figure 4.10c). Activity ranged between $0-84 \mathrm{nmol} \mathrm{hr}^{-1} \mathrm{~L}^{-1}$ in the middle and top of the core (Figure 4.10a, b) but was highest at Granite Harbour (GH09c) at the top of the ice core (123 nmol hr${ }^{-1} \mathrm{~L}^{-1}$, Figure 4.10a). At Granite Harbour (GH09c, d) there was no lipase activity through the sea ice core. The highest lipase activity was at Cape Evans where it ranged from $132 \mathrm{nmol} \mathrm{hr}^{-1} \mathrm{~L}^{-1}$ at the top to $256 \mathrm{nmol} \mathrm{hr}^{-1} \mathrm{~L}^{-1}$ at the bottom of the core. Chitinase activity was low throughout the sea ice core where activity was less 
than $14 \mathrm{nmol} \mathrm{hr}^{-1} \mathrm{~L}^{-1}$ at all sites apart from at Granite Harbour (GH09c) where activity was $60 \mathrm{nmol} \mathrm{hr}^{-1} \mathrm{~L}^{-1}$ (Figure 4.10a, b, c).
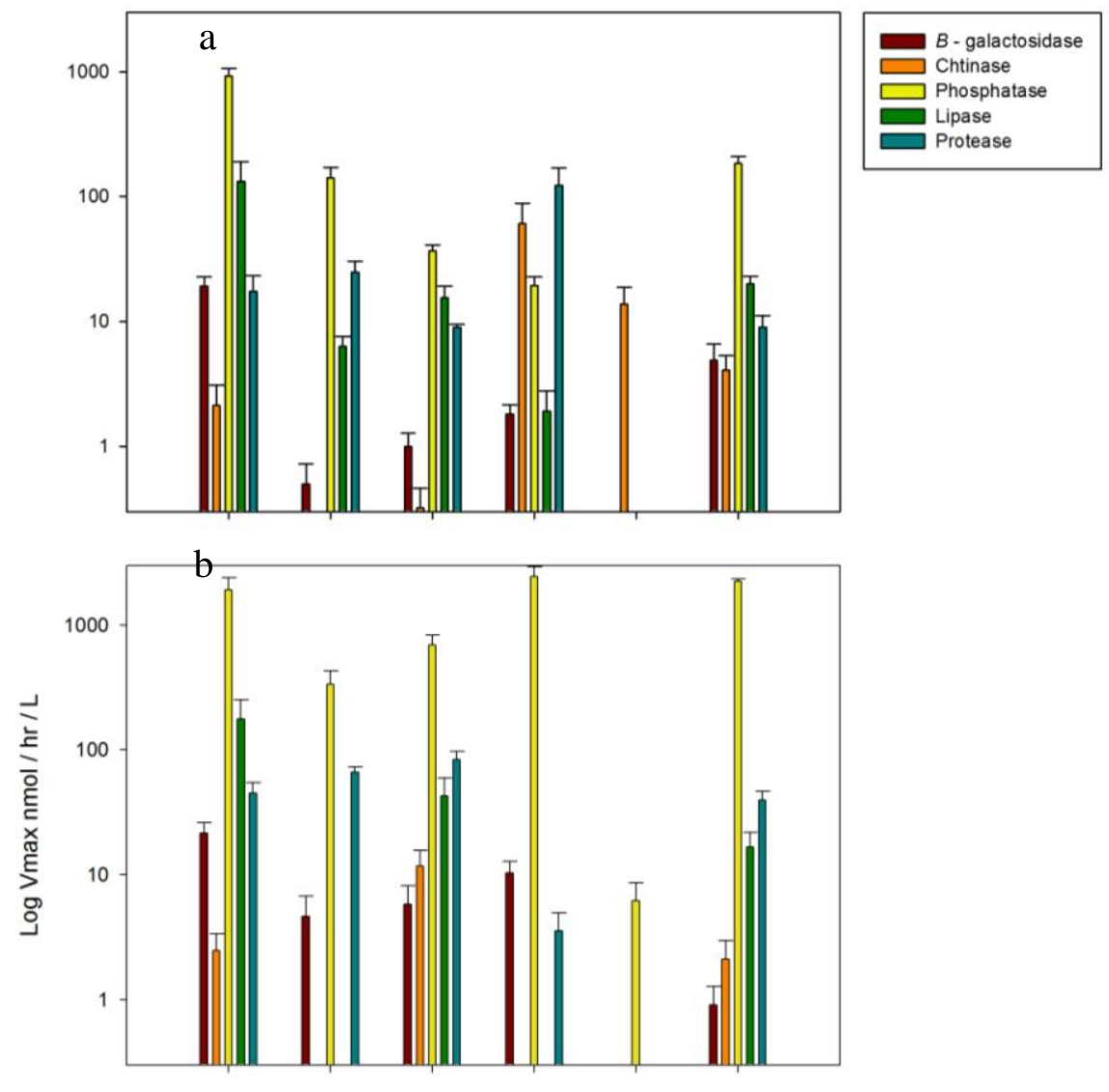

$\mathrm{c}$

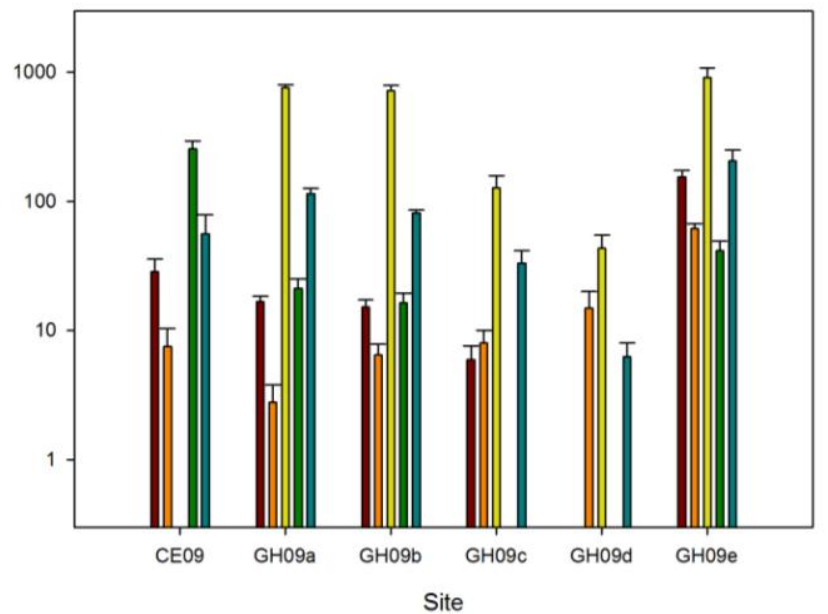

Figure 4.10 Bacterial enzymatic activity at the (a) top, (b) middle and (c) bottom of the sea ice core at Cape Evans (CE) and Granite Harbour (GH09a-e) in 2009. Each bar shows mean \pm 1 standard error. 


\subsubsection{Similarities between bacterial community enzymatic activity}

A dendrogram based on the 35 bacterial communities taken from the top, middle and bottom of the sea ice core is shown in figure 4.11. The samples clustered into groups depending on their similarities in MUF enzyme activity. Some communities grouped depending on which site they came from or whether they came from the top, middle or bottom of the sea ice core. Bacterial activity from Cape Evans showed some similarities and clustered together in groups 1 and 2. Enzymatic activity from Granite Harbour clustered together in group 4 from the top of the ice core and clustered in group 5 from the middle of the core. Two bottom ice cores from Cape Evans had similar activity and fell into group 6.

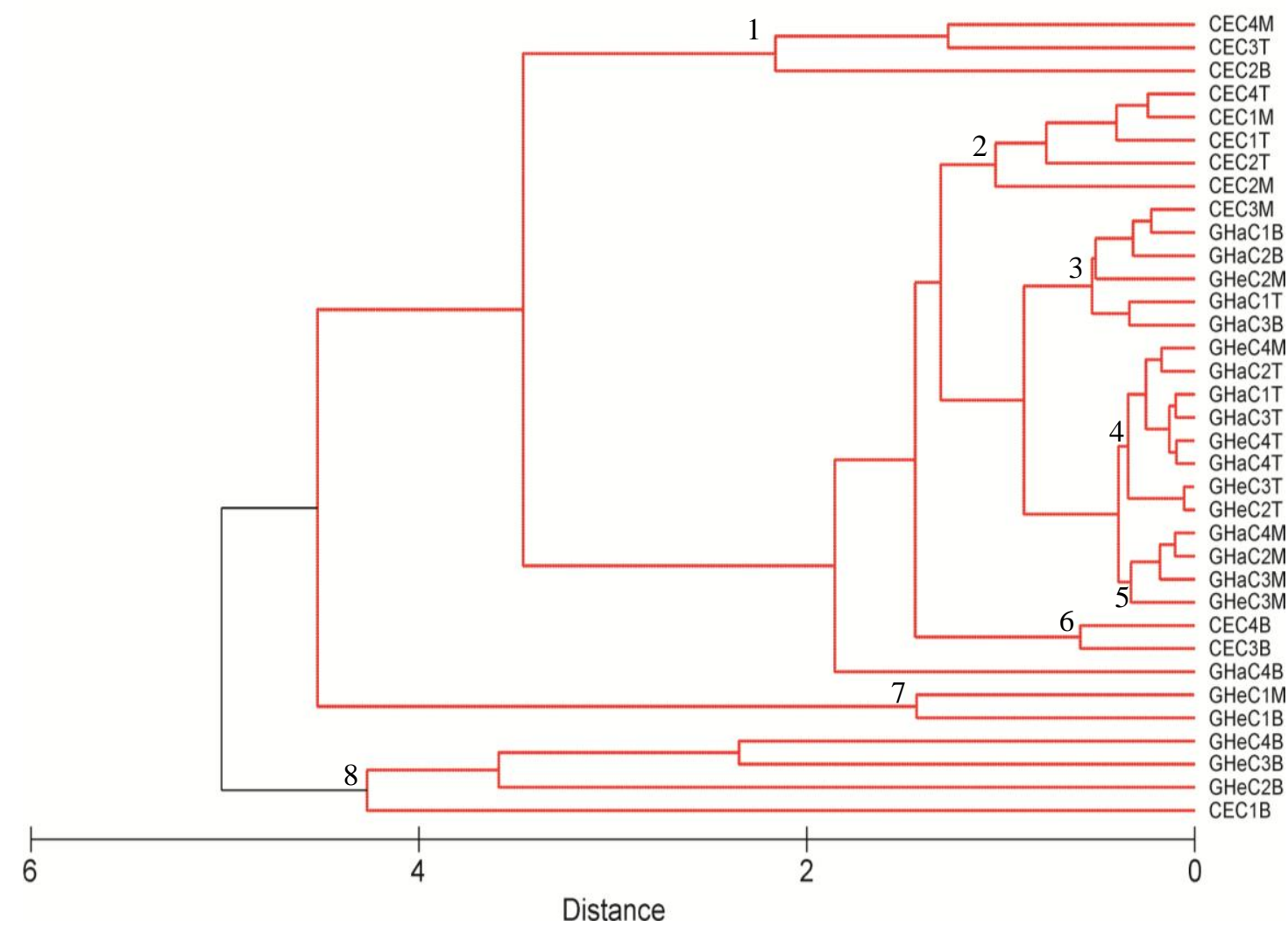

Figure 4.11 Dendrogram showing similarities in MUF activity between different bacterial communities. The distance bar shows the $\%$ of dissimilarity between communities. The Bray-Curtis similarity was calculated from $\log (\mathrm{x}+1)$ transformed MUF activity data. 
Groups 3 and 7 contained a mixture of samples. Group 8 contained bacterial communities with similar activity from the bottom of the sea ice core at both Cape Evans and Granite Harbour. The samples clustered into 2 significantly different clusters as determined by the SIMPROF-test $(\mathrm{P}<0.5)$. The first cluster was defined by Group 8 in Figure 4.11, and contained bacterial communities from the bottom of the ice core at Granite Harbour and Cape Evans. The second cluster was defined by all 7 other groups in Figure 4.11.

\subsubsection{Relationships between the environment and MUF activity}

There were positive relationships between nutrient concentrations in the environment and bacterial activity (Figure 4.12). Phosphate concentrations (ppb) were positively correlated with chitinase (linear regression, $F_{1,63}=12.01, p<0.001$, Figure 4.12a), $\beta$ galactosidase (linear regression, $F_{1,63}=24.4049, p<0.0001$, Figure 4.12b), proteinase activity (linear regression, $F_{1,63}=9.0513, p=0.004$, Figure $4.12 \mathrm{c}$ ) and phosphatase (linear regression, $F_{1,63}=11.75, p<0.001$, Figure 4.12d). Nitrate concentrations in sea ice were positively correlated with $\beta$ - galactosidase (linear regression, $\mathrm{F}_{1,63}=6.7037$, $\mathrm{p}=0.012$, Figure 4.12e) and protease (linear regression, $\mathrm{F}_{1,63}=9.6927, \mathrm{p}=0.002$, Figure 4.12f) activity. Nitrite was positively correlated with phosphotase activity (linear regression, $F_{1,63}=6.7047, p<0.01$, Figure $4.12 \mathrm{~g}$ ). There were no relationships between ammonia or silicate concentrations and bacterial activity $(\mathrm{p}>0.5)$. 

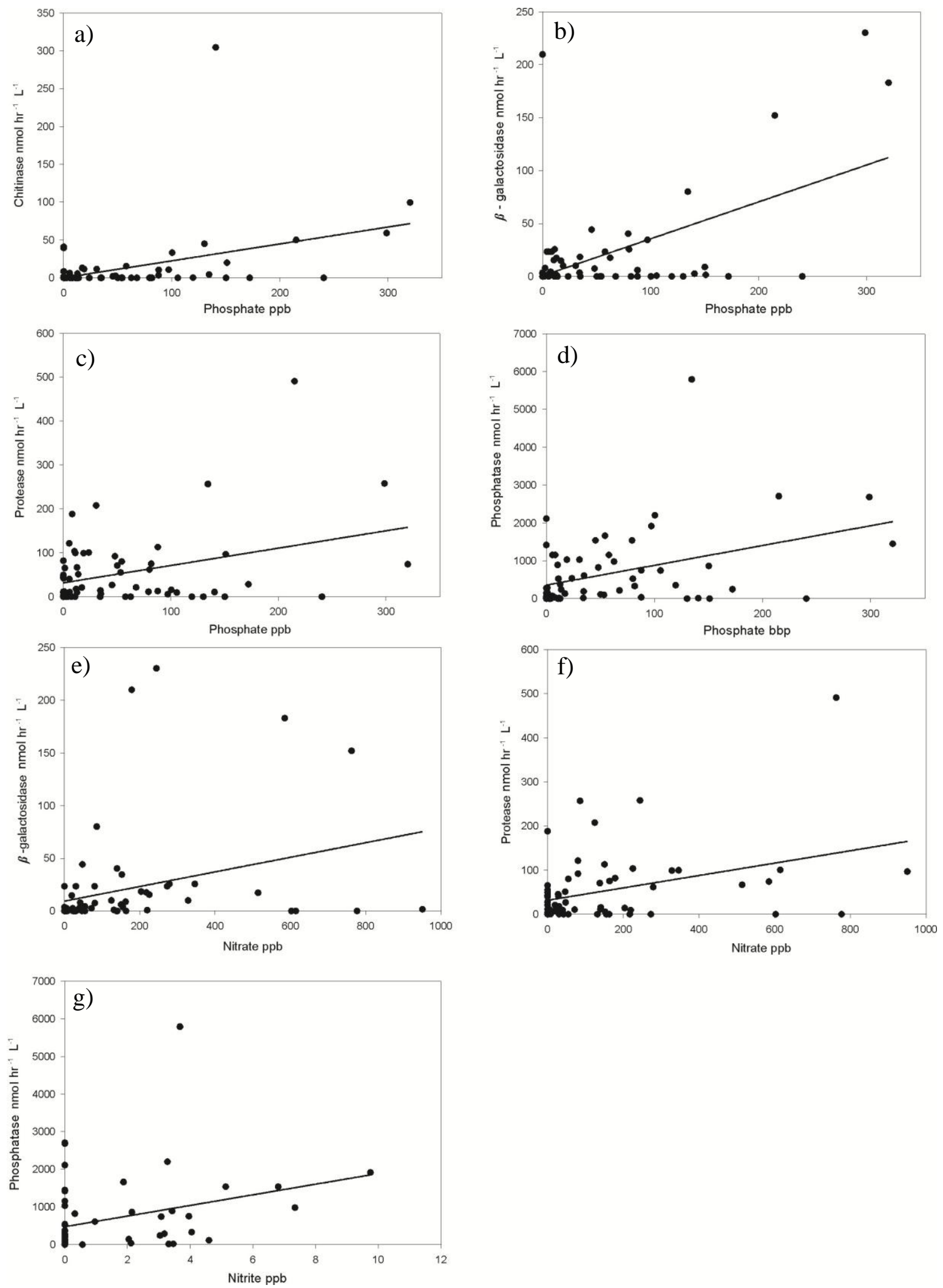

Figure 4.12 Significant relationships between nutrient concentrations in the environment and MUF bacterial activity. Phosphate (ppb) vs. (a) chitinase $\left(\mathrm{R}^{2}=0.1589\right)$, (b) $\beta$ - galactosidase $\left(\mathrm{R}^{2}=0.2854\right)$, (c) proteinase $\left(\mathrm{R}^{2}=0.1274\right)$ and $(\mathrm{d})$ phosphatise activity $\left(\mathrm{R}^{2}=0.1594\right)$. Nitrate $(\mathrm{ppb})$ vs. (e) $\beta$ galactosidase $\left(R^{2}=0.0962\right)$ and $(f)$ protease $\left(R^{2}=0.1365\right)$. Nitrite vs. $(g)$ phosphate activity $\left(R^{2}=\right.$ 0.0976). 


\subsubsection{Relationships between bacterial community structure and MUF activity}

Bacterial community structure was investigated using T-RFLP in Chapter 3. To investigate whether bacterial MUF activity could give an indication about the environment and its influence on bacterial community structure, relationships between activity and the bacterial community were examined using DISTLM (Table 4.2). Due to the replication required, relationships between bacterial communities and activity from the top, middle and bottom were investigated from CE09 and GH09a and e only. Lipase and protease activity explained 11.8 and $10.1 \%$ of the variation, respectively, between rRNA communities in 2009. Phosphatase could explain an additional $6.6 \%$. The total variation explained was $28.5 \%$.

Table 4.2 Summary of results showing the associations between bacterial communities against enzyme activity using a distance-based permutational multiple regression analysis (DISTLM). Model selection was based on Akaike's Information Criterion with a second-order bias correction applied (AICc), with the total variation explained $\left(r^{2}\right)$ by each best-fit model shown (\% total). Analyses based on 9999 random permutations of the raw data.

\begin{tabular}{lrrrrr} 
Predictor & AICc & Pseudo-F & P value & $\%$ variability & $\%$ total \\
\hline Lipase & 275.2 & 4.403 & $<0.001$ & 11.8 & \\
Protease & 283.34 & 4.191 & $<0.001$ & 10.1 & \\
Phosphatase & 272.83 & 2.845 & $<0.01$ & 6.6 & 28.5 \\
& & & & & \\
\hline
\end{tabular}

The dbRDA plots in Figure 4.13 visually depict the effects of the MUF enzyme activity on bacterial community structure shown by the DISTLM. Protease concentration drove the separation between bacterial communities at the top, middle and bottom of the sea ice core, particularly at Granite Harbour (Figure 4.13). Phosphatase and lipase activity drove the separation between the top, middle and bottom of the sea ice core bacterial communities at Cape Evans. These two variables also explained the bacterial community variation between cores at the middle and bottom of the ice core at Granite Harbour (Figure 4.13). 


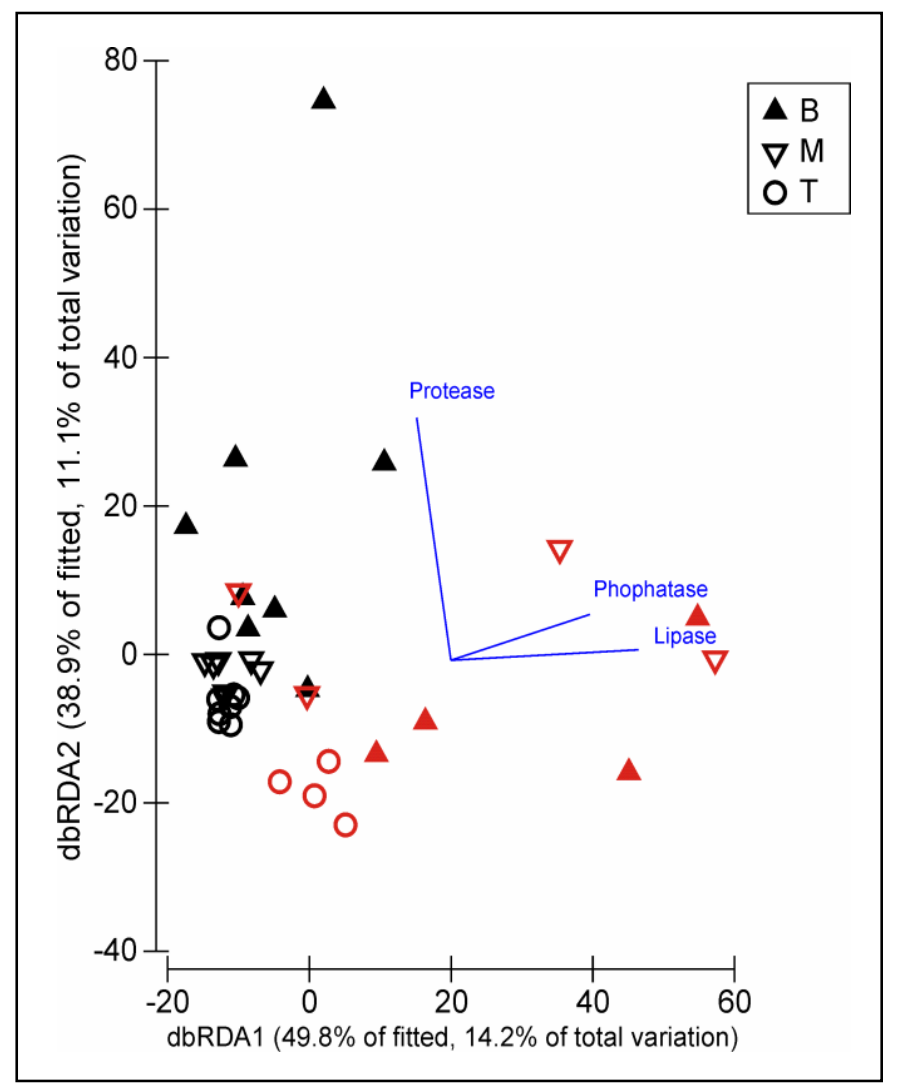

Figure 4.13 Distance based redundancy (dbRDA) plot visualising the fitted models from the DISTLM. The model displayed is the optimal model identified by the DISTLM analysis as presented in Table 4.2 and explains $28.5 \%$ of the variation in bacterial community structure between sites. dbRDA1 explains $14.2 \%$ of the total variation, dbRDA2 explains $11.1 \%$. The top $(\mathrm{T})$, middle $(\mathrm{M})$ and bottom (B) were investigated from CE09 (red) and GH09a and e (black) only. The directions of the environmental vector lines indicate the relationship of each variable to the site groupings in multivariate space. The length of each vector line is proportional to the strength of the variance explained by that variable.

\subsection{Discussion}

The sea ice prokaryotic community was investigated for bacterial, archaeal, denitrifier and photoheterotroph abundance using quantitative PCR. Archaea and denitrifying bacteria have previously been identified using the 16S rDNA gene (Cowie et al. 2011; Staley and Gosink 1999), however these sequences were extracted from DNA samples, which does not give information on the activity of these groups in sea ice. The pufM (Koh 2011) and PR genes (Koh et al. 2010) have also been isolated from Antarctic sea ice and sequences were described from both cDNA and DNA. While those results show that these genes are actively expressed in sea ice, there is no information on their abundance in the sea ice environment or whether they play an 
important role in sea ice biogeochemical cycles. The analysis of RNA from environmental samples with $\mathrm{qPCR}$ allows estimates to be made of the relative abundance and therefore the ecological importance of the community. In this study, RNA was extracted from samples from the top, middle and bottom of the sea ice as well as from the brine and water samples and the community function was investigated.

The abundance of cDNA Bacterial 16S rRNA gene copies was highly variable where bacterial numbers at some sites were more than four orders of magnitude higher than at others. Klappenbach et al. (2000) showed that rapidly growing soil bacteria had a higher copy number of rRNA operons (averaging 5.5 copies) than slowly growing colonies (averaging 1.4 operons). Therefore the number of bacterial cells could have been overestimated by at least 5 times. The communities with high copy numbers (for example TNB08 and McM08 with $\sim 10^{9}$ cells $\mathrm{L}^{-1}$ ) may be highly active which may explain why these numbers are over three orders of magnitude higher than those for GH08b. GH08b may have the same bacterial cell numbers but consisted of slower growing communities. However, the numbers of $16 \mathrm{~S}$ rRNA copies $\mathrm{L}^{-1}$ were similar to those found using flow cytometry in similar samples (Chapter $3 ; 10^{7}$ to $10^{9}$ cells $\mathrm{L}^{-1}$ ). Flow cytometry gives an estimate of total bacterial numbers including those that are dead, dormant and metabolically active. Bacteria in sea ice are highly active where 18 - $86 \%$ of active bacterial cells were detected by an rRNA probe (Junge et al. 2004). Other studies have also shown that metabolically active bacteria measured by CTC analyses make up a third of the bacterial community (Junge et al. 2002; Brinkmeyer et al. 2003; Martin et al. 2008), which is significantly higher than the 2 to $10 \%$ level of activity typical for most marine systems (Gasol et al. 1995; del Giorgio et al. 1996; Sherr et al. 1999). I found bacterial cell abundance to range from $1.9 \times 10^{6}-1.4 \times 10^{8}$ (Chapter 3), therefore I would expect active cell numbers to be $\sim 0.57 \times 10^{6}-0.47 \mathrm{x}$ $10^{8}$ cells $\mathrm{L}^{-1}$, which is similar to the gene copy numbers found with qPCR. Bacterial $16 \mathrm{~S}$ rRNA copy numbers were higher in the brine samples, but this is due to the concentration of bacteria during brine channel drainage from the surrounding ice.

The numbers of metabolically active bacteria in Antarctic sea ice were similar to those found in Arctic (Junge et al. 2002) and Antarctic (Brinkmeyer et al. 2003) sea ice. Bacterial activity did not seem to decrease between the bottom and middle of the 
sea ice core, but there was a decrease in activity at the top of the ice core. This pattern may suggest that certain bacterial groups become nutrient limited once nutrients drop below a threshold concentration. Nutrients were highest at the bottom of the ice core (Chapter 3), decreased towards the middle but were lowest at the top of the ice core.

The number of archaeal 16S rRNA gene copies in Antarctic sea ice was similar to the numbers found by Kalanetra et al. (2009) in Antarctic coastal waters using qPCR (< $0.01 \times 10^{6}-241 \times 10^{6}$ gene copies $\mathrm{L}^{-1}$ ). They also found that archaea could contribute significantly to the Antarctic seawater prokaryotic community where abundances could be up to $25 \%$ of the prokaryotic community. As they only extracted DNA from the environment, the metabolically active proportion of archaea is unknown. In Arctic sea ice, archaeal abundances were between $0-3.4 \%$ of the total cells (Junge et al. 2004). The Arctic study however, investigated archaeal abundances in wintertime sea ice using FISH. The low abundance of archaea in their study may be due to the time of sample collection as wintertime microbial abundances are low due to lack of sunlight and prokaryotes can be dormant. With the onset of spring, bacterial abundances increase in response to increasing algal photosynthate availability (Stewart and Fritzen 2004) and it is reasonable to assume that archaea respond similarly. In the majority of my samples, archaeal abundance was between 0.2 and 9.1 $\%$ of the total prokaryotic community, which is similar to that found in Arctic sea ice (Junge et al. 2004). Archaea were sampled from summertime Antarctic sea ice which may explain the slightly higher abundances of archaea. However, at Granite Harbour in 2008 at the bottom of the ice core, Cape Evans 2008 and 2009 at the middle of the ice core, and Cape Evans 2008 at the top of the ice core, archaeal abundances made up half the prokaryotic community at these sites. Archaea have been shown to play significant roles in the oceanic carbon (Herndl et al. 2005) and nitrogen cycles (Kalanetra et al. 2009) and their RNA abundance suggests they may sometimes have an active role in the sea ice ecosystem. Some archaeal groups are heterotrophic or possibly mixotrophic (Ouverney and Fuhrman 2000; Teira et al. 2004; Herndl et al. 2005), where they play a major role in environmental ammonia-oxidation (Francis et al. 2007, Leininger et al. 2006, Wuchter et al. 2006, Herfort et al. 2007, Kalanetra et al. 2009) and may be able to exploit different organic resources than bacteria. For example, archaea are more active than bacteria in assimilating D-aspartic acid from DOM (Teira et al. 2006). However, their high abundance at particular Antarctic sites 
may be reflective of the archaeal abundance in the water column when they were incorporated into the sea ice. The abundance of archaea varied between sites which suggest that their distribution may be due to environmental variables, and archaeal abundances have been shown to be positively correlated with nutrient concentrations (Herfort et al. 2007). Ammonia-oxidising archaea are widespread and abundant in many habitats (Francis et al. 2007; Leininger et al. 2006; Wuchter et al. 2006; Herfort et al. 2007; Kalanetra et al. 2009) and the high abundance of archaea at certain Antarctic sea ice sites might suggest active ammonia-oxidisation at these sites. Archaeal distributions in Antarctic waters are seasonal, showing high abundances in winter and decreasing towards summer (Murray et al. 1998), suggesting the time of sea ice formation may also play a role in archaeal distributions in sea ice.

The pufM gene was targeted by specific primers for the purple bacteria lightharvesting reaction centre (Achenbach et al. 2001). These primers have previously been used to demonstrate the presence of AAnP from the alpha- and $\beta$-Proteobacteria in Antarctic sea ice and seawater samples (Koh 2011). Some of these clones were from the cDNA suggesting that they are metabolically active in sea ice. The present study confirms and extends those preliminary findings by showing that the highest numbers of pufM gene copy numbers were at the bottom of the sea ice core at GH08b and in the brine. Koh (2011) also found the pufM to be predominantly in the middle of the ice core, with none at the top of the sea ice core, and suggested that the puf operon of AAnP is repressed by high light intensity (Rathgeber et al. 2004; Yurkov and Csotonyi 2009). The relative abundance of pufM genes was low throughout the sea ice core and only made up a small fraction of the total bacterial community apart from at CE08 where they comprised $3.1 \%$ of the total bacterial community. Schwalbach et al. (2005) found that BChla-containing bacteria were in low abundance in marine waters. They comprised $0.68 \%$ of the bacterial community in surface waters, increased to $3.09 \%$ at $5 \mathrm{~m}$, decreased with depth, and were not found below $100 \mathrm{~m}$. A low abundance of pufM genes was also found by Venter et al. (2004), which suggests that Bchla-containing bacteria are not as abundant in all marine environments as is currently proposed (Koblizek et al. 2007; Salka et al. 2008). Their ability to use light energy may give them an advantage over heterotrophic bacteria, particularly in the low nutrient, extreme environment in upper sections of the sea ice core. At CE08 this 
may be the case, however at the bottom of the ice core this process appears minor in Antarctic sea ice.

PR gene copy numbers were highest at the middle of the ice core, and occurred in high abundance at more sites at the top of the sea ice core. PR-containing bacteria were in low relative abundance apart from at CE08 where they comprised $10.7 \%$ of the total bacterial community. Koh et al. (2010) found that the majority of PRcontaining clones were isolated from the bottom of the sea ice core, with only a few from the middle of the core. PR-bearing bacteria can be influenced by light and availability of nutrients (Gomez-Consarnau et al. 2007). Campbell et al. (2008) found a negative relationship between PR abundance in the DNA community (normalised to $16 \mathrm{~S}$ rRNA gene abundance) with nutrients and chlorophyll. Irradiance also appears to influence the growth of PR-bearing bacteria and to regulate PR mRNA synthesis (Lami et al. 2009). This may explain my findings of higher numbers at the middle and top of the ice core where nutrients and chlorophyll are lower but irradiance is increased. Lami et al. (2009) found that PR abundance was high in the photic zone at $1.94 \times 10^{8} \mathrm{~L}^{-1}, 2$ to 3, 000 times the number of PR copy numbers in Antarctic sea ice. PR-containing bacteria are also abundant in marine waters (Rusch et al. 2007) where they can account for $13 \%$ of the community in the Mediterranean Sea to $70 \%$ of the community in the Sargasso Sea (Venter et al. 2004; Rusch et al. 2007; Campbell et al. 2008). The low abundance of PR-containing bacteria may suggest that light-utilisation is not a dominant process in Antarctic sea ice.

Until now, studies estimating the abundance of light-utilising genes have only investigated environmental DNA (Venter et al. 2004; Rusch et al. 2007; Campbell et al. 2008; Lami et al. 2009) and the proportions of these genes that are metabolically active and involved in marine cycles have been unknown. This is the first study to investigate the abundance of these genes in the metabolically active community. However, as rRNA abundances of these genes were generally less than $0.1 \%$ of the bacterial community, I suggest that their importance in the microbial loop is minor. However, the functional genes nirK, pufM and PR are single-copy genes and were standardised to the multi-copy bacterial 16S rRNA gene for comparisons between sites. As bacteria may have variable copies of the 16S rRNA gene depending on their physiological state (as discussed earlier in this Chapter), it is likely that the relative 
abundance of these functional genes were under-estimated by up to 5 times. However, even after taking this into account, the rRNA abundances of these genes would still comprise a minor $(<1 \%)$ of the bacterial community.

The majority of studies investigating the abundance of denitrifiers in environmental samples have focused on soil (Braker et al. 1998; Throback et al. 2004) and marine sediments (Braker et al. 2000, Nogales et al. 2002 and Liu et al. 2003). The diversity, but not the abundance, of nirK genes in marine waters has also been investigated (Oakley et al. 2007). It appears that nirK abundance in marine aquatic systems is relatively unknown making it difficult to make comparisons. The gene copy numbers in sea ice are $1000 \mathrm{x}$ less than in an equivalent volume of soil (Mosier and Francis 2010), suggesting that nirK abundance is relatively low in sea ice. The nirK gene was active in Antarctic sea ice and the highest gene copy numbers were found at the bottom of the sea ice core at GH08b. The abundance of nirK genes has been shown to be negatively correlated with salinity and positively correlated with total organic carbon (Mosier and Francis 2010), which may explain the higher abundance of these genes at the bottom of the sea ice core. The presence of metabolically active nirK genes in Antarctic sea ice also suggests that there are anoxic conditions in Antarctic sea ice. Rysgaard and Glud (2004) found that the brine channels were appropriate sites for nitrate reduction due to high concentrations of $\mathrm{NO}_{3}{ }^{-}$and organic carbon. They also found that denitrification activity (measured as $n m o l ~ ~ N^{-1}$ sea ice day ${ }^{-1}$ ) was highest in the lower $25 \mathrm{~cm}$ of Arctic first year ice. However, the low abundance of these genes in Antarctic sea ice may suggest that there are limited anoxic conditions and denitrification is a minor process.

The extracellular enzymatic activity of prokaryotes plays a key role in the assimilation of DOM. Previous studies have indicated that sea ice bacteria are capable of producing cold-adapted and salt-tolerant proteases, $\beta$-galactosidases, phosphatases (Thomas and Dieckmann 2002), lipases (Groudieva et al. 2004) and chitinases (Yu et al. 2009). Therefore it is likely that Antarctic sea ice bacteria can contribute significantly to the 'microbial loop' through hydrolysis of the major organic constituents in sea ice, which are then utilised by the bacteria and surrounding microbes. DOM is produced as photosynthate from algae or by lysis and death of sea ice organisms (Thomas et al. 2001) and is made up of many compounds such as 
amino acids, nucleic acids, carbohydrates and lipids. Sea ice contains a large pool of organic matter, which is in particularly high concentrations at the bottom of the ice core due to the concentration of algae and other sea ice organisms in this stable environment. The production and activity of hydrolytic enzymes may be determined by the availability, concentration and distribution of organic substrates in the environment (Boetius 1995). The enzymatic activity of Antarctic sea ice is therefore expected to reflect the distribution of organic matter in sea ice. Bacterial enzymatic activity was variable throughout the sea ice core and between sites suggesting that organic substrates had a varied distribution in sea ice. The composition of algal produced DOM is influenced by temperature, nutrient availability and light (Langenheder et al. 2006). DOM also varies in quantity and composition seasonally and is dependent on the algal species and their physiological states. For example, lipids are stored by algae when nutrients are deficient which may become released through algal grazing. Thus, the quantity and quality of organic matter has a substantial effect on bacterial communities (Pinhassi et al. 2004).

Antarctic bacterial communities are involved in organic phosphate recycling throughout the sea ice core. Phosphatase activity was highest in bottom ice bacterial communities sampled from 2008, but in 2009 activity was highest at the middle of the sea ice core. Phosphatase activity is widespread in marine bacteria and is important in carbon and phosphate cycles (Hoppe 2003; Hoppe and Urlich 1999). Helmke and Weyland (1995) discovered that sea ice cores from the Weddell Sea had phosphate hydrolysis rates $90 \mathrm{x}$ higher than in the water beneath the ice. Bacterial phosphatase activity in Ross Sea shelf water was between 59 and $598 \mathrm{nmol} \mathrm{hr}^{-1} \mathrm{~L}^{-1}$ (Bergamasco et al. 2003). These values were $\sim 23$ times less than my measurements in Antarctic sea ice confirming that sea ice bacteria are indeed more actively involved in phosphate hydrolysis compared with thsoe in the water column. This is not surprising considering that the algal biomass at the bottom of the sea ice core is approximately two orders of magnitude more productive than the water below (Ryan et al. 2006).

Proteases are produced by many heterotrophic bacteria in marine environments (Martinez et al. 1996). They hydrolyse proteins into peptides and amino acids, which are involved in many pathways of metabolism in microbes. Many bacterial isolates from Antarctic sea ice have been shown to have protease activity (Groudieva et al. 
2004; Yu et al. 2009), and previous studies have shown protease activity to range between 1.4 and $63 \mathrm{nmol} \mathrm{hr} \mathrm{L}^{-1} \mathrm{~L}^{-1}$ in sea ice (Helmke and Weyland 1995). These values were similar to those found at the top and middle of the ice core in the present study. However, protease activity was up to $14 \mathrm{x}$ higher at the bottom of the ice core, suggesting that proteins in the environment or protease-containing bacteria were in higher abundance in my samples.

Lipolytic bacteria are predominant in aquatic environments and in marine beach sediments where 96 - $98 \%$ of bacterial strains had lipase activity (Mudryk and Podgorska 2006). They are also actively synthesised to a considerable extent in Antarctic sea ice isolates (Groudieva et al. 2004; Yu et al. 2009). Lipase activity in Ross Sea waters was on average $52.3 \pm 12.3 \mathrm{nmol} \mathrm{h}^{-1} \mathrm{~L}^{-1}$ (Bergamasco et al. 2003), which was similar to that found though the ice core in this study. Lipase activity was, however, $2.5-9 \mathrm{x}$ higher at the bottom of the sea ice core than in the water beneath. Lipid compounds are released from lysed diatoms (Nagata and Kirchman 1992), which are in greater abundance at the bottom of the ice core than the seawater (Ryan et al. 2006).

Chitin is the most abundant polymer in the oceans but only $16 \%$ of sea ice bacterial isolates were able to degrade chitin (Yu et al. 2009). Other studies have also found that chitinolytic bacteria did not dominate the sea ice bacterial community (Bowman et al. 1997; Junge et al. 2002). At the bottom of the ice core in 2008, chitinase activity was higher than of 2009, suggesting that there may have been an increased presence of euphausiid, amphipod and copepod detritus available for mineralisation. However, chitins are also produced by diatoms (Durkin et al. 2009) and algal biomass, shown in Chapter 3, was greater in 2008 than in 2009. The high concentrations of chitin present at these sites may have induced chitin-containing bacteria to proliferate.

$\beta$-galactosidase activity was investigated to determine if bacteria in the sea ice were utilising carbohydrates. Many bacterial isolates from Antarctic sea ice have $\beta$ galactosidase activity (Groudieva et al. 2004; Yu et al. 2009) and are cold adapted (Hoyoux et al. 2001). $\beta$-galactosidase activity was lower in Antarctic sea ice than for the other enzymes, suggesting that the presence of $\beta-1,4-\mathrm{D}$ galactosidic linkages which are hydrolysed by $\beta$-galactosidase are in low abundance or enzymes other than 
$\beta$-galactosidase are preferentially utilised by bacteria in sea ice. Bacterial communities at the bottom of the sea ice core in 2008 were the most capable at synthesising $\beta$-galactosidases than at the bottom of the sea ice in 2009 and through the sea ice core.

Bacterial enzymatic activity was significantly correlated with nutrient concentrations in Antarctic sea ice. High concentrations of phosphates in Antarctic sea ice were associated with high bacterial phosphatase, protease, chitinase and $\beta$-galactosidase activity. The increase in phosphates was also correlated with increased Chl- $a$ concentrations (Chapter 3), which may relate to increases in algal lysis and/ or the release of organic matter that can then be assimilated by the bacteria. Increases in nitrate and nitrite concentrations were also related to greater phosphatase activity. Bacterial activity may be increased due to up-regulation of certain enzymes, or a shift in bacterial communities to those that are better able to assimilate the DOM. Shackle et al. (2006) found that the addition of nutrients to bacterial communities up-regulated their enzymatic activity. However, Kirchman et al. (2004) found that enzymatic activity was increased in certain groups that had more active enzymes. There was a significant correlation between $\beta$-Proteobacterial abundance and phosphatase activity as $\beta$-Proteobacteria have more active phosphatases (Kirchman et al. 2004). Enzymatic activity has also been associated with a shift in community composition (Reimann et al. 2000). In Antarctic sea ice, high concentrations of nutrients such as phosphate, nitrate and nitrite may either induce enzymatic activity in bacterial communities, or lead to a shift in community structure to those that are more metabolically suitable.

The relationships between bacterial community structure and activity were therefore investigated. Lipase, protease and phosphatase enzyme activities were explained 28.5 $\%$ of the variation seen between bacterial communities in 2009. Lipase and phosphatase activity was highest at Cape Evans in 2009 which suggests that lipids and organic phosphorus compounds form the dominant component of DOM at this site. Protease activity was higher at Granite Harbour at the bottom of the sea ice core suggesting an increase in proteinaceous organic compounds at the bottom of the ice core. The shift in community accompanied by variations in enzymatic activity suggests that sea ice bacterial groups are selected that are better at hydrolysing the most abundant substrates. Changes in the composition of DOM can be accompanied 
by changes in bacterial abundance, productivity and enzyme activities (Smith et al. 1995; Reimann et al. 2000; Herndl et al. 2008). Reimann et al. (2000) found that the dominance of certain bacterial phylotypes in a seawater mesocosm was associated with changes in the potential enzymatic activities. Similarly, I found that enzymatic activity is influenced by the composition of the bacterial community (as estimated by the T-RFLP profiles). This may suggest that bacterial groups that express high levels of lipase, protease and phosphatase activity are selected for in the sea ice environment. In Antarctic sea ice, nutrient availability may drive variations in enzyme activities and consequently bacterial population successions.

In conclusion, bacteria appear to be involved in nitrogen and carbon cycles in Antarctic sea ice, as would be expected. They are involved in denitrification and light energy utilisation but these appear to be minor processes in Antarctic sea ice. This chapter also reveals that sea ice bacteria are actively involved in processes associated with the microbial loop. In sea ice, phytoplankton primary production stimulates prokaryotic heterotrophic activity directly through enzyme release, or indirectly via grazing by metazoans (Marañon 2005), enabling the transfer of carbon through the microbial loop to higher trophic levels. Bacterial activity was positively related to nutrient concentrations, particularly phosphates and nitrates, and the latter also influenced bacterial community structure. However, these relationships may be more complex as nutrient concentration also influences community structure. Changes in environmental conditions, such as algal exudate composition, may cause a shift in the bacterial community to favour those that are better able to utilise the nutrients which will in turn increase the enzymes required for the uptake and assimilation of energy. 


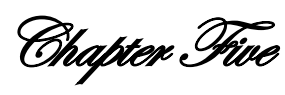

\section{Archaeal Diversity Revealed in Antarctic Sea Ice}

\subsection{ABStRACT}

Archaea, once thought to be extremophiles, are now known to be abundant in most environments. They can dominate in microbial communities and be significantly involved in many global biogeochemical cycles. However, Archaea have not been reported in Antarctic sea ice. Our understanding of the ecology of Antarctic sea ice prokaryotes is still in its infancy but this information is important if we are to understand their diversity, adaptations and biogeochemical roles in Antarctic systems. We detected Archaea in sea ice at two sampling sites taken from three subsequent years using conserved 16S rRNA gene archaeal primers and PCR. Archaeal abundance was measured using quantitative PCR and community diversity was investigated by sequencing cloned 16S rRNA gene PCR products. Archaea in Antarctic sea ice were found to be in low abundance conmprising $\leq 6.6 \%$ of the prokaryotic community. The majority $(90.8 \%)$ of sequences clustered with the recently described phylum Thaumarchaeota, with one group closely clustered with the ammonia-oxidising "Candidatus Nitrosopumilus maritimus". The remainder of the clones grouped with the Euryarchaeota.

\subsection{INTRODUCTION}

Archaea were once thought of as obligate extremophiles, inhabiting niches that were too stressful for other organisms. Until recently, the only archaea that had been successfully cultured were extremophiles, inhabiting salty brines, geothermal environments and anaerobic habitats (Stein and Simon 1996). But, as archaea are now known to be notoriously difficult to culture, this resulted in their misunderstanding and 
misrepresentation. As culture-independent methods have developed, based on the $16 \mathrm{~S}$ rRNA gene, it has become clear that archaea have a widespread occurrence and are abundant in diverse environments (Delong 1992; Karner et al. 2001; Leininger et al. 2006; Gillan and Danis 2008). However, archaea have not been described from Antarctic sea ice (Brown and Bowman 2001).

The sea ice environment is unique. It provides a stable platform for colonisation by a diverse range of microbes yet has extreme gradients of salinity, temperature, light and dissolved organic matter (DOM) (Arrigo and Thomas 2004; Mock and Thomas 2005). Despite these harsh conditions, microbial communities survive and thrive throughout the sea ice matrix (Brown and Bowman 2001; Brinkmeyer et al. 2003; Martin et al. 2008). The first study investigating the Antarctic sea ice microbial community (SIMCO) described sea ice diatoms (Hooker 1847). Since then, ciliates, flagellates, protists, bacteria and viruses in Antarctic pack-ice have been discovered (for reviews see Deming 2002; Mock and Thomas 2005; Murray and Gryzmski 2007). In comparison with other ecosystems, ecological information about Antarctic sea ice prokaryotes is still in its infancy. Antarctic sea ice research has predominantly focused on the community structure and physiology of eukaryotic communities (e.g. McMinn et al. 2007, Ryan et al. 2009), but this information from the prokaryotic population is still lacking (Mock and Thomas 2005; Martin et al. 2008; Murray and Gryzmski 2007).

Archaea were first identified in Antarctic ecosystems in 1988 (Franzmann et al. 1988) and have been found in Antarctic marine waters, frozen lakes and sediments (Delong et al. 1994; Murray et al. 1998; Murray et al. 1999; Bano et al. 2004; Karr et al. 2005; Gillan and Danis 2007). In Antarctic marine waters, archaea can be found in high abundances where they contribute up to $34 \%$ of the prokaryotic biomass (Delong et al. 1994; Murray et al. 1999; Kalanetra et al. 2009). Despite this abundance, archaea have not been described, nor have they been discovered in Antarctic sea ice (Brown and Bowman 2001). Recently, archaea have been detected in Arctic winter sea ice using fluorescence in situ hybridisation (FISH, Junge et al. 2004), although they were not detected using the same methods in Arctic summer sea ice (Brinkmeyer et al. 2003). 
FISH only provided limited resolution into the phylogenetic diversity of archaea using domain-level probes. However, it gave evidence that archaea in Arctic sea ice are in low abundance comprising $\leq 3.4 \%$ of total cells (Junge et al. 2004). Collins et al. (2010) have since described archaea in winter time Arctic sea ice using 16S rRNA techniques. The majority of archaea clustered within the phyla Thaumarchaeota and the rest within the Euryarchaeota.

The domain archaea consists of five distinct phyla: Crenarchaeota, Euryarchaeota (Woese et al. 1990), Nanoarchaeota (Huber et al. 2002), Korarchaeota (Elkins et al. 2008) and a recently proposed phylum the Thaumarchaeota, of which many are mesophilic and psychrophilic organisms (Brochier-Armanet et al. 2008). In marine environments, two groups are predominant: the Group I (GI) Crenarchaeota, now termed Thaumarchaeota, and the Group II (GII) Euryarchaeota. Thaumarchaeota are found in higher abundance in the oceans than the Euryarchaeota, particularly at depth (Karner et al. 2001; Church et al. 2003). Only two Thaumarchaeota have been well characterized: "Candidatus Nitrosopumilus maritimus" was the first Thaumarchaeota culture recently isolated from a marine aquarium (Konneke et al. 2005) and Cenarchaeum symbiosum, a psychrophile isolated from a marine sponge (Preston et al. 1996). It is likely that Thaumarchaeota may play an important role in the nitrogen cycle in many ecosystems (Leininger et al. 2006; Kalanetra et al. 2009). "Candidatus N. maritimus" is involved in nitrification, growing as a chemolithoautotroph by oxidizing ammonia to nitrite (Konneke et al. 2005).

This study seeks to gain more information about the organisms in sea ice environments. My aim was to detect and quantify archaeal abundance and describe the diversity of archaea using 16S rRNA gene molecular methods. This work forms a part of New Zealand's Latitudinal Gradient Project (LGP), a multi-nation and multidisciplinary research program studying marine and terrestrial ecosystems along the Victoria Land coastline, Antarctica (Howard-Williams et al. 2006). 


\subsection{Methods}

\subsubsection{Core collection}

A powered ice corer (Kovacs, USA) was used to collect sea ice cores from Antarctic fastice. The sea ice microbial community was collected from Gondwana Station, Terra Nova Bay (TNB, $74^{\circ} 43^{\prime}$ 'S, $164^{\circ} 8^{\prime} \mathrm{E}$ ) on the $6^{\text {th }}$ December 2007 by Eileen Koh. Cores were also collected from TNB on the $24^{\text {th }}$ November 2006 by Libby Liggins and at McMurdo Station (McM, $77^{\circ} 51^{\prime} \mathrm{S}, 166^{\circ} 39^{\prime} \mathrm{E}$ ) on the $30^{\text {th }}$ November 2008 by myself and K043. The bottom $10 \mathrm{~cm}$ of the core were removed for community analysis, and to avoid contamination from the underlying water and from human-borne prokaryotes, a 10x10x4 $\mathrm{cm}$ block was cut from within the bottom section of the sea ice core. This block was melted over a period of $12 \mathrm{~h}$ in three times the volume of autoclaved $0.22 \mu \mathrm{m}$ filtered seawater (following the procedure found in Ryan et al. 2004). This process of ice melt maintains the temperature at $-1.8{ }^{\circ} \mathrm{C}$ and reduces salinity shock. The microbes were concentrated onto $0.22 \mu \mathrm{m}$ mixed cellulose acetate filters (Pall Life Sciences, USA) using a diaphragm vacuum pump and stored at $-80{ }^{\circ} \mathrm{C}$ until processing.

\subsubsection{DNA extraction}

DNA was extracted using a modified version of the phenol: chloroform method (Moeseneder et al. 2001). Briefly, filters were cut into pieces, placed into $1 \mathrm{~mL}$ of lysis buffer (40 mM EDTA, $50 \mathrm{mM}$ Tris- $\mathrm{HCl}$ (pH 7.4), $0.75 \mathrm{M}$ sucrose and $15 \%$ Tween 80), and incubated with lysozyme at $37{ }^{\circ} \mathrm{C}$ overnight. The sample was then incubated at $55{ }^{\circ} \mathrm{C}$ for $2 \mathrm{~h}$ with $200 \mu \mathrm{L}$ of $10 \%$ SDS and $40 \mu \mathrm{L} 20 \mathrm{mg} / \mathrm{ml}$ proteinase K. DNA was extracted using an equal volume of phenol-chloroform-isoamyl alcohol (25:24:1) and chloroformisoamyl alcohol (24:1). DNA was precipitated at $-20^{\circ} \mathrm{C}$ overnight using $5 \mu \mathrm{g} / \mathrm{mL}$ linear acrylamide (Ambion Ltd, USA), 0.25 vol $5 \mathrm{M}$ sodium acetate and $1 \mathrm{x}$ volume isopropanol. 


\subsubsection{Quantitative PCR}

Quantitative PCR reactions were performed on the CFX96 ${ }^{\mathrm{TM}}$ Real Time PCR System (Bio-Rad, CA, USA). The archaeal 16S rRNA gene was amplified using the primers Arch-1017F (5'-GAGAGGWGGTGCATGGCC) and Arch-1392R (5'TGACGGGCGGTGTGTGCTTG, Barns et al. 1994). The bacterial 16S rRNA gene was amplified using the universal primers Bac-F518 (5'-CCAGCAGCCGCGGTAATACG) and Bac-R800 (5'-TACCAGGGTATCTAATCC). Amplifications were carried out in triplicate in 1 x SsoFast ${ }^{\mathrm{TM}}$ Eva Green SuperMix (SYBR based system, Bio-Rad), containing specific primers $(0.1 \mathrm{mM})$ and a final concentration of DNA at $1 \mathrm{ng} / \mu \mathrm{L}$. PCR cycling conditions were $95^{\circ} \mathrm{C}$ for $3 \mathrm{~min}$, followed by 40 cycles of $95^{\circ} \mathrm{C}$ for $10 \mathrm{~s}, 57^{\circ} \mathrm{C}$ for $20 \mathrm{~s}$ and $72{ }^{\circ} \mathrm{C}$ for $30 \mathrm{~s}$. Melt curve profiles were analyzed for both 16S rRNA genes. Standards for archaea and bacteria 16S rRNA genes were amplicons cloned from environmental samples. Standard curves were based on a dilution series ranging from $10^{1}$ to $10^{8}$ gene copies $\mu \mathrm{L}^{-1}$ and were run in triplicate. High amplification efficiencies of 95$104 \%$ were obtained from both genes, with $\mathrm{R}^{2}$ values between 0.990 and 0.997 . The gene copies $\mu \mathrm{l}^{-1}$ of template DNA was converted to gene copies $\mathrm{mL}^{-1}$ of melted sea ice core by taking into account the volume filtered, the final volume of DNA extracted and assuming that $100 \%$ of the DNA had been extracted from each sample.

\subsubsection{PCR conditions and clone library construction}

For clone library construction, the 16S rRNA gene was amplified with the primer pair Arch-21F and Arch-958R (Delong 1992) using illustra Ready-To-Go ${ }^{\text {TM }}$ PCR beads (GE healthcare, Piscataway, NJ). Each PCR reaction contained $10 \mathrm{ng}$ of DNA in two $25 \mu \mathrm{L}$ reactions and was denatured at $95{ }^{\circ} \mathrm{C}$ prior to amplification with 30 cycles consisting of denaturation at $95{ }^{\circ} \mathrm{C}$ for $45 \mathrm{~s}$, primer annealing at $50{ }^{\circ} \mathrm{C}$ for $60 \mathrm{~s}$, and elongation at $72^{\circ} \mathrm{C}$ for $60 \mathrm{~s}$. PCR products were checked using gel electrophoresis and a faint band was seen. This band was gel purified (GE Healthcare, Piscataway, NJ) and $5 \mu \mathrm{L}$ were added to a second PCR reaction under the same conditions as above. PCR products were again visualized using gel electrophoresis and quantified using the sensitive fluorescent nucleic acid stain PicoGreen (Molecular Probes, Oregon, USA). Amplicons were cloned using 
TOPO TA (Invitrogen, Carlsbad, USA) and pGEM-T (Promega, Maddison, Wis.) cloning vectors and transformed into DH5- $\alpha$ (Invitrogen, Carlsbad, USA) chemically competent cells with a 3:1 insert:vector molar ratio. Individual colonies were amplified using the vector-specific M13F and M13R primers. Clones containing the $16 \mathrm{~S}$ rRNA gene were detected by gel electrophoresis and column cleaned (Zymogen, Orange, CA).

\subsubsection{Sequence analysis}

The M13 PCR products were sequenced using an ABI Prism 3100 genetic analyzer. Chimera sequences were eliminated using Chimera-Check (Cole et al. 2003) and Pintail (Ashelford et al. 2005). The non-chimeric sequences have been submitted to Genbank (accession numbers, FN564099-FN564147). Sequences were aligned in ARB (http://www.arb-home.de, Ludwig et al. 2004) using evolutionary-conserved primary sequence and secondary structure (Lane 1991), and the total number of bases analysed was 804. Evolutionary distances were calculated from sequence pair dissimilarities using only unambiguously sequenced positions. The phylogenetic analyses were performed in PHYLIP (Felsenstein 1989) based on the majority rule consensus tree using the neighborjoining algorithm with Jukes-Cantor correction (Jukes and Cantor 1969). Trees were visualized using the program Dendroscope (Huson et al. 2007).

\subsection{Results}

The abundance of bacterial and archaeal 16S rRNA sequences were investigated using quantitative PCR. Prokaryotes were defined as the sum of bacterial and archaeal 16S rRNA genes. In the three Antarctic sea ice samples, archaeal 16S rRNA genes were in low abundance compared to bacterial numbers and made up $4.4-6.6 \%$ of the total prokaryotes (Table 5.1).

To investigate the community structure of the sea ice archaeal community I extensively sequenced one clone library which came from Antarctic sea ice at TNB in 2007. All 88 of these 16S rRNA sequences were identified as archaea and were associated with the 
Thaumarchaeota and the Euryarchaeota. To confirm this presence of archaea, 20 clones from two other sites, TNB in 2006 and McM in 2008 were also sequenced. All these sequences were identified as Thaumarchaeota. Phylogenetic analysis of the 16S rRNA sequences placed the majority (90.8\%) of the sequences within the Thaumarchaeota and the remaining clones (9.2\%) clustered with the GII Euryarchaeota (Figure 5.1).

\begin{tabular}{|c|cc|cc|}
\hline & \multicolumn{2}{|c|}{ Abundance $\left(10^{4}{\left.\text { copies } \mathrm{ml}^{-1}\right)}^{2}\right.$} & \multicolumn{2}{|c|}{ Proportion $\%$} \\
\cline { 2 - 5 } Site & Archaea & Bacteria & Archaea & Bacteria \\
TNB06 & 0.016 & 0.35 & 4.4 & 95.6 \\
TNB07 & 1.7 & 24 & 6.6 & 93.4 \\
McM08 & 0.28 & 4.3 & 6.1 & 93.9 \\
\hline
\end{tabular}

Table 5.1 Archaeal and bacterial 16S rRNA gene copy numbers and relative proportions in Antarctic sea ice samples as determined by qPCR.

The most abundant OTUs grouped within the Thaumarchaeota and the majority of these were closely related to the cultured marine ammonia-oxidizing "Candidatus $N$. maritimus" or archaeal clones that have been described from Antarctic and Arctic waters (Figure 5.1). One group that was identified was more distantly related to Antarctic and Arctic OTUs and more identical to clones from temperate waters such as the North Pacific and Gulf of Mexico (Figure 5.1). One OTU, FN564104, was $99 \%$ identical to an Antarctic coastal water clone (Kalanetra et al. 2009) and occurred in almost a quarter of the sequences obtained from the clone libraries. This OTU shared $92 \%$ phylogenetic similarity with "Candidatus N. maritimus". 

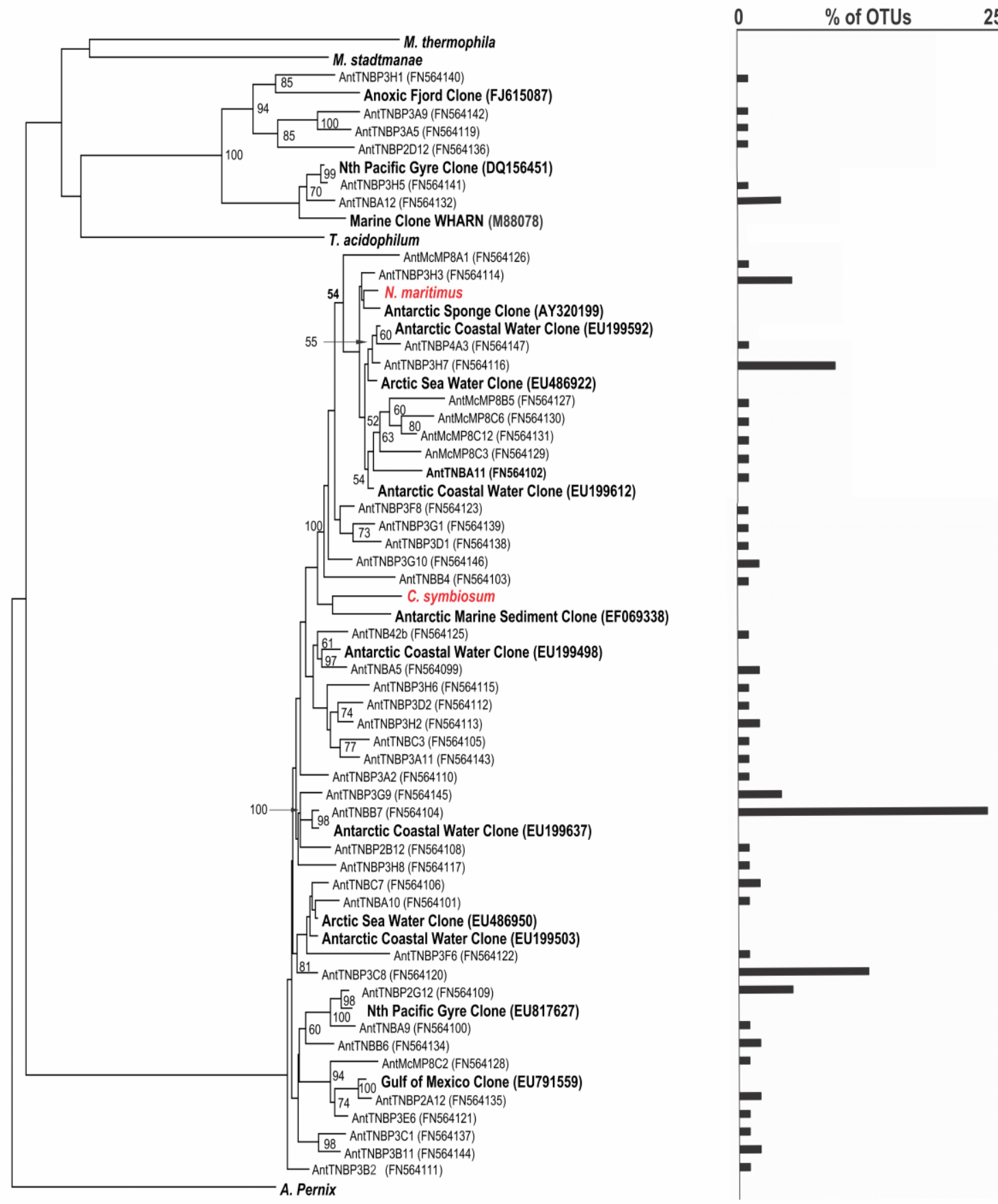

Substitutions per base pair : $\longmapsto 0.01$

Figure 5.1 Dendrogram showing the phylogenetic relationships between Archaeal 16S rRNA gene sequences from Antarctic sea ice. Bootstrap values greater than 50\% are shown and 804 bases were analysed. One sequence represented a group of sequences with similarity $>98.5 \%$ with the abundance of each sequence graphed on the right. Aeropyrum pernix was used as an out group. 


\subsection{Discussion}

Archaeal abundance in Antarctic sea ice was low comparable to bacterial numbers. Archaea can contribute significantly to Antarctic picoplankton communities where in late winter they comprise 21 - $34 \%$ of the total prokaryotic rRNA (Delong et al. 1994). However with the onset of spring, this high abundance of archaea disappears resulting in low abundances in Antarctic summer waters (Murray et al. 1998). Murray et al. (1999) extended their research of archaea in Antarctic waters to include the Ross Sea area. Here at McMurdo Station, archaea were also in low abundance in surface waters, but numbers increased to almost $10 \%$ of the total picoplankton rRNA at depth. Archaeal abundance is comparable to numbers found in winter Arctic sea ice (Junge et al. 2004) and in Arctic surface waters during autumn (Wells and Deming 2003). The low abundance of archaea in Antarctic summer sea ice may reflect the numbers that are found in summer surface waters (Murray et al. 1998; 1999). However, Collins et al. (2010) found a high degree of similarity between prokaryotic sea ice and sea water communities in the Arctic during winter suggesting that the extreme change in environmental conditions from sea water to sea ice does not exert any negative effects on the community. In contrast, the Antarctic sea ice bacterial community was found to differ from the underlying water column in the spring and summer seasons (Delille 1992; Bowman et al. 1997).

The majority of Antarctic sea ice archaeal sequences were identified as Thaumarchaeota with one group clustering with the ammonia-oxidising "Candidatus N. maritimus". These results reflect those of Collins et al. (2010) who found the majority (91\%) of Arctic sea ice Archaea was Thaumarchaeota with a small group within the Euryarchaeota. Archaeal sequences isolated from Arctic sea water (Collins et al. 2010) were also closely related with my Thaumarchaeota sequences. Prokaryotic phylotypes appear to be similar between the Arctic and Antarctic poles. Bacteria share many 16S rRNA phylotypes in sea ice (Brinkmeyer et al. 2003) and Thaumarchaeota show similar diversity in Arctic and Antarctic waters (Bano et al. 2004; Kalanetra et al. 2009). Thaumarchaeota are ubiquitous and abundant, found in global cold waters (Karner et al. 2001) and it is likely that adaptation and diversification has led to its survival in polar environments. 
The observed Euryarchaeota OTUs were found in low abundance, consistent with numbers found in Antarctic waters (Murray et al. 1998; 1999). The Euryarchaeota clones had a high degree of variability, where many of the sequences had less than $94 \%$ sequence similarity. They were more diverse than the Thaumarchaeota sequences, which have also been reported for marine and Antarctic waters (Massana et al. 2000; Bano et al. 2004). Their closest relatives were clones identified from marine waters and shared $>85$ \% similarity with a marine archaeal sp., clone WHARN (M88078, Delong 1992). They were distantly related to the cultured aerobic moderate thermophile Thermoplasma acidophilum.

The predominance of Thaumarchaeota has been documented in Antarctic marine picoplankton, where they comprise $\sim 95 \%$ of the archaeal community. However, during the Antarctic summer months, Thaumarchaeota are in low abundance in the surface waters and at numbers similar to that of the Euryarchaeota. They are found in high abundance at depths below the photic zone but will migrate to the surface during winter (Church et al. 2003). The low numbers of Euryarchaeota in sea ice may be a reflection of the rarity of this group in Antarctic waters (Bano et al. 2004). The dominance of Thaumarchaeota over Euryarchaeota in Antarctic sea ice may be due to the growth of ice during winter months, when the Thaumarchaeota are dominant in surface waters, followed by their migration down the sea ice core. Or perhaps the low irradiance beneath the sea ice, typically only $1 \%$ of the incident irradiance at the surface (McMinn et al. 2007), enables Thaumarchaeota communities to persist in the surface seawater into the summer months. A large proportion of bacteria are active in sea ice (Brinkmeyer et al. 2003, Martin et al. 2008) and are dominated by psychrophiles compared to the underlying sea water (Delille 1992; Bowman et al. 1997). The Thaumarchaeota contains psychrophilic members (Brochier-Armanet et al. 2008) that may be able to survive and grow under harsh sea ice conditions. 
This phylogenetic information gives insight into community structure and may help predict archaeal function when compared to sequences for which the function is known. Due to the preference for ammonia over nitrate in Antarctic systems (Dortch 1990) denitrifying species of bacteria have been found in Antarctic sea ice (Priscu et al. 1990; Bowman et al., 1998) therefore nitrification may be an important process in the sea ice ecosystem. Although the metabolic capabilities of archaea are relatively unknown, their high abundance suggests that they have an important role in global geochemical cycles. The abundance of ammonia oxidization ( $\mathrm{amoA}$ ) genes in the environment (Leininger et al. 2006; Nicol et al. 2008) and in the Antarctic water column (Kalanetra et al. 2009) suggests archaea are heavily involved in the nitrogen cycle. As my Antarctic sequences are closely related to "Candidatus N. maritimus" and to these Antarctic water sequences this might suggest their involvement in ammonia oxidisation. This phylogenetic information provides the first step into understanding the ecology of archaeal communities in Antarctic sea ice. However, further investigations are required to shed light into their activity and role in Antarctic biogeochemical cycles. 


\section{Erapteon Chis}

\section{Bacterial Diversity using Culture and Molecular Techniques}

\subsection{ABStRACT}

A comprehensive study into the diversity of bacteria in Antarctic sea ice was undertaken using both culture dependent and independent methods. A range of different media were used to cultivate a number of different Antarctic bacteria. Many of these could be identified to genus level using biochemical methods and were similar to bacteria previously isolated from Antarctic sea ice. A total of 43 unique isolates were sequenced and identified as Alphaproteobacteria, Gammaproteobacteria, Bacteroidetes, Actinobacteria and Firmicutes after phylogenetic analysis. A total of $22,00016 \mathrm{~S}$ rRNA sequences were obtained from 454 pyrosequencing and were classified into 294 different genera. The sequences identified using culture-dependent and independent techniques were compared and there was found to be overlap in the bacteria isolated. The culture-based methods identified the isolates with better resolution than did the 454 sequencing. However, there were many more genera identified by the 454 sequencing, many of which were in low abundance. The majority of them fell into the main groups defined above, but sequences from the Betaproteobacteria and Gammaproteobacteria, archaea and Verrucomicrobia were also identified. Pyrosequencing may give some insight into the "rare biosphere" of Antarctic sea ice which may contain the majority of the genetic diversity in which individuals may become more dominant with favourable conditions. This was apparent when comparing the vertical distribution of the microbial community through the ice, where groups such as the Actinobacteria, Bacillales, Rhodobacterales and Acholeplasmatales that were rare at the bottom of the ice core became more dominant at the top of the sea ice core. The combined effort of both culture-based and culture-independent methods gives a better insight into Antarctic bacterial diversity than each separately. Pyrosequencing enabled a greater 
genetic diversity to be described; however, the culture-based approaches lead to a better understanding of bacterial physiology and ecology. Both methods discovered additional genera that have not previously been described from sea ice.

\subsection{INTRODUCTION}

Bacteria are ubiquitous, inhabiting environments from the temperate to the extreme. In the world's oceans, bacterial abundance is estimated at $3.6 \times 10^{29}$ bacterial cells (Whitman et al. 1998) with estimates of marine bacterial diversity ranging from a few thousand (Hagström et al. 2002) to as many as two million distinct taxa (Curtis et al. 2002). Prior to 1987, bacterial diversity was investigated using culture-based techniques and bacteria were classified into hierarchical groups by their phenotypic features (Brenner et al. 2001). However, classification of bacteria based on phenotypes gave limited information as there was little basis for comparing evolutionary relatedness. The pioneering efforts of Woese et al. (1994) led to the comparison of the phylogenetic diversity of all organisms using a sequence standard the small subunit of the ribosomal RNA. This led to Woese's description of the 'universal tree of life' which contained three domains, the bacteria, archaea and eukarya.

The numbers of bacterial cells that form colonies on agar media are less populous by orders of magnitude than those counted by microscopic examination. This inability to culture many organisms from the environment was coined 'the great plate count anomaly' by Staley and Konopka (1985). Studies soon found that $<1 \%$ of the bacterial community from certain environments were cultivated (Amann at al. 1995; Pace 1997) and that the number of colony forming units (CFUs) did not reflect the abundance of bacteria in the environment (Ward et al. 1990). Bacteria may not be cultivable due to either a) their state of growth, i.e. they may be dormant or viable but not reproducing or b) they are not adapted for growth on synthetic media and may need oligotrophic or other fastidious conditions to be successfully cultured. Attempts to cultivate the "un-cultivatable" have led to novel culture approaches such as high throughput culturing (HTC) using dilution-to-extinction, encapsulation of bacteria in gel microdroplets, cultivation with a diffusion growth chamber, and modified plating 
methods (see Giovannoni and Stingl 2007 and references therein). HTC led to the cultivation of elusive bacteria from marine waters such as the SAR11 clade (Rappé et al. 2002) and also the first isolation of a marine Thaumarchaeote, Candidatus Nitrosopumilus maritimus (Konneke et al. 2006). ZoBell's Marine Medium is widely used for culturing heterotrophic bacteria (Bowman et al. 1997; Brinkmeyer et al. 2003) but it has $170 \mathrm{x}$ more dissolved organic carbon than natural seawater. Using minimal media closer to that of a bacterium's natural environment i.e. with reduced nitrate and phosphate concentrations (Eilers et al. 2001), has led to the cultivation of other novel bacteria.

To gain a better understanding of the physiology and ecology of bacteria, their isolation in pure culture remains an essential step in microbial ecology. In order to classify a bacterium, information about its morphological, biochemical, physiological and genetic characteristics are required (Brenner et al. 2001). Approximately 11,000 species of prokaryotes have been formally described (www.bacterio.cict.fr/number.html) and most of the information about these organisms comes from the study of pure cultures.

Identification of medical bacteria was traditionally based on an array of biochemical tests and phylogenetic analysis. As more and more bacteria were reported from the environment, biochemical tests were further developed to include marine heterotrophic bacteria but these tests were slow and time-consuming (Oliver 1982; Fenical 1995), and despite all the laborious biochemical tests, the isolates were still sometimes misidentified. As a result, a simple method to identify fifteen Gram negative (Figure 6.1) and six Gram positive (Figure 6.2) marine bacteria was proposed by Das et al (2007) based on minimal tests enabling marine heterotrophic bacteria to be identified to genus level based on key characteristics. 


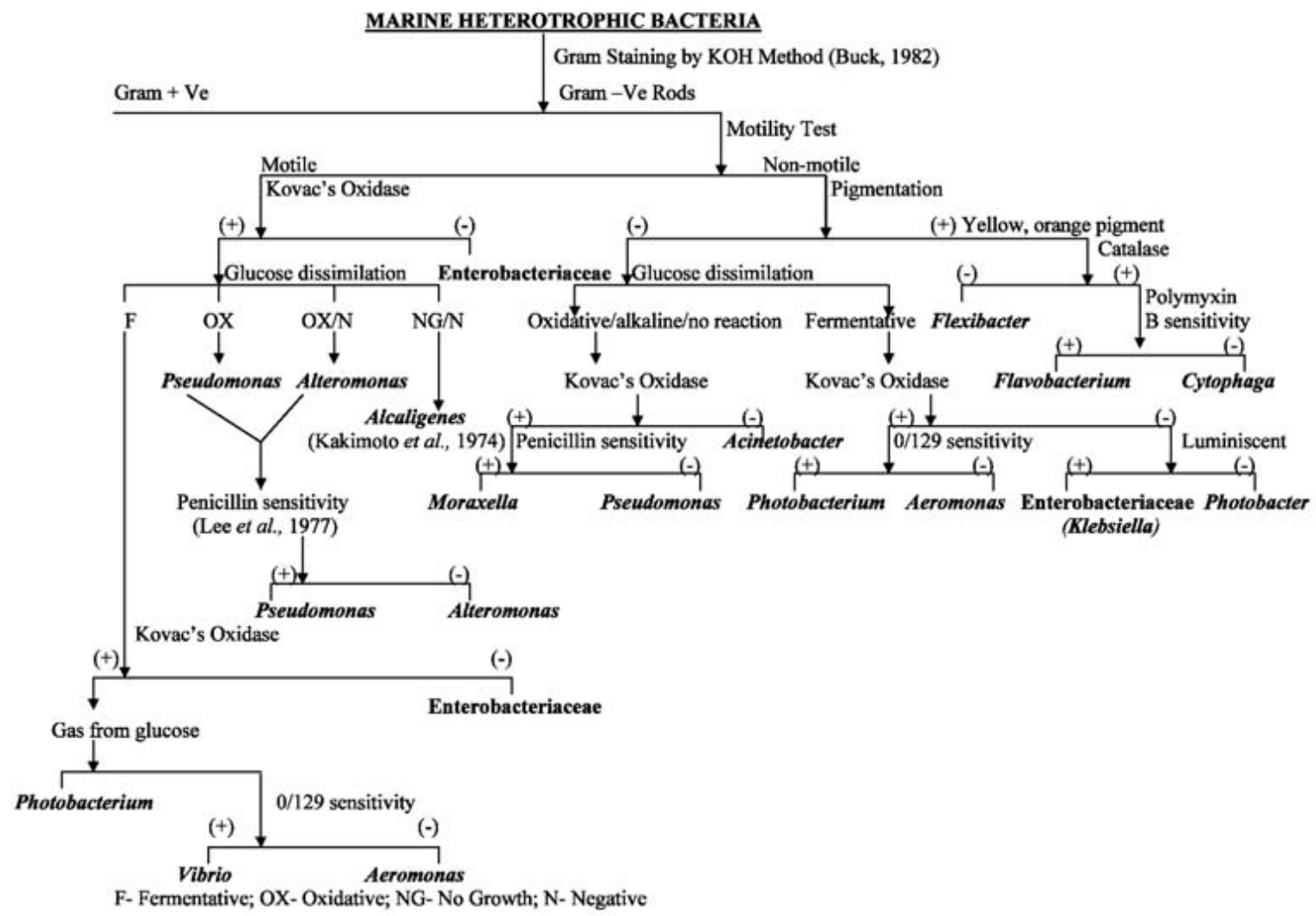

Figure 6.1 Biochemical tests used to identify Gram negative bacterial groups from the marine environment. Taken from Das et al. (2007)

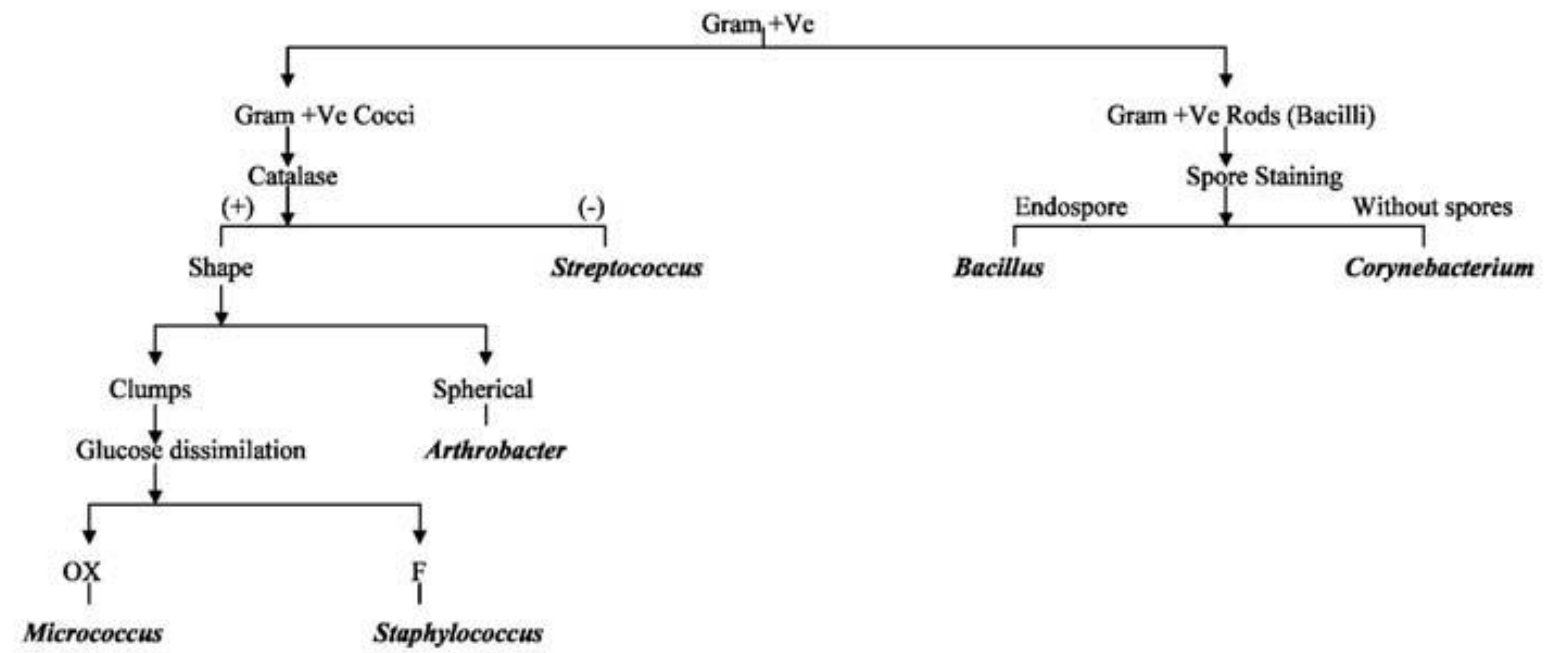

OX-Oxidative; F- Fermentative

Figure 6.2 Biochemical tests used to identify Gram positive bacterial groups from the marine environment. Taken from Das et al. (2007) 
Molecular methods have been developed to circumvent culture-based approaches and instead extract nucleic acids directly from environmental samples. These methods have revealed a far greater microbial diversity on Earth than previously thought from pure culture techniques (Pace 1997). This "un-cultivable" community has been investigated particularly using cloning and sequencing. Cloning requires that a library is constructed from each environmental sample where each clone has its own sequence. The sequences are then analysed using Sanger sequencing (Sanger et al. 1977), in which long reads of $\sim 1000$ base pairs (bp) can be achieved resulting in high phylogenetic resolution. Sanger sequencing produced the earliest in-depth analysis of microbial communities (Zhou et al. 2004; Ley et al. 2006) leading to large databases of $16 \mathrm{~S}$ rRNA sequences (e.g. http://www.ncbi.nlm.nih.gov). However, the rarefraction curve rarely reached an asymptote in clone library studies, suggesting that the microbial diversity was not fully sampled.

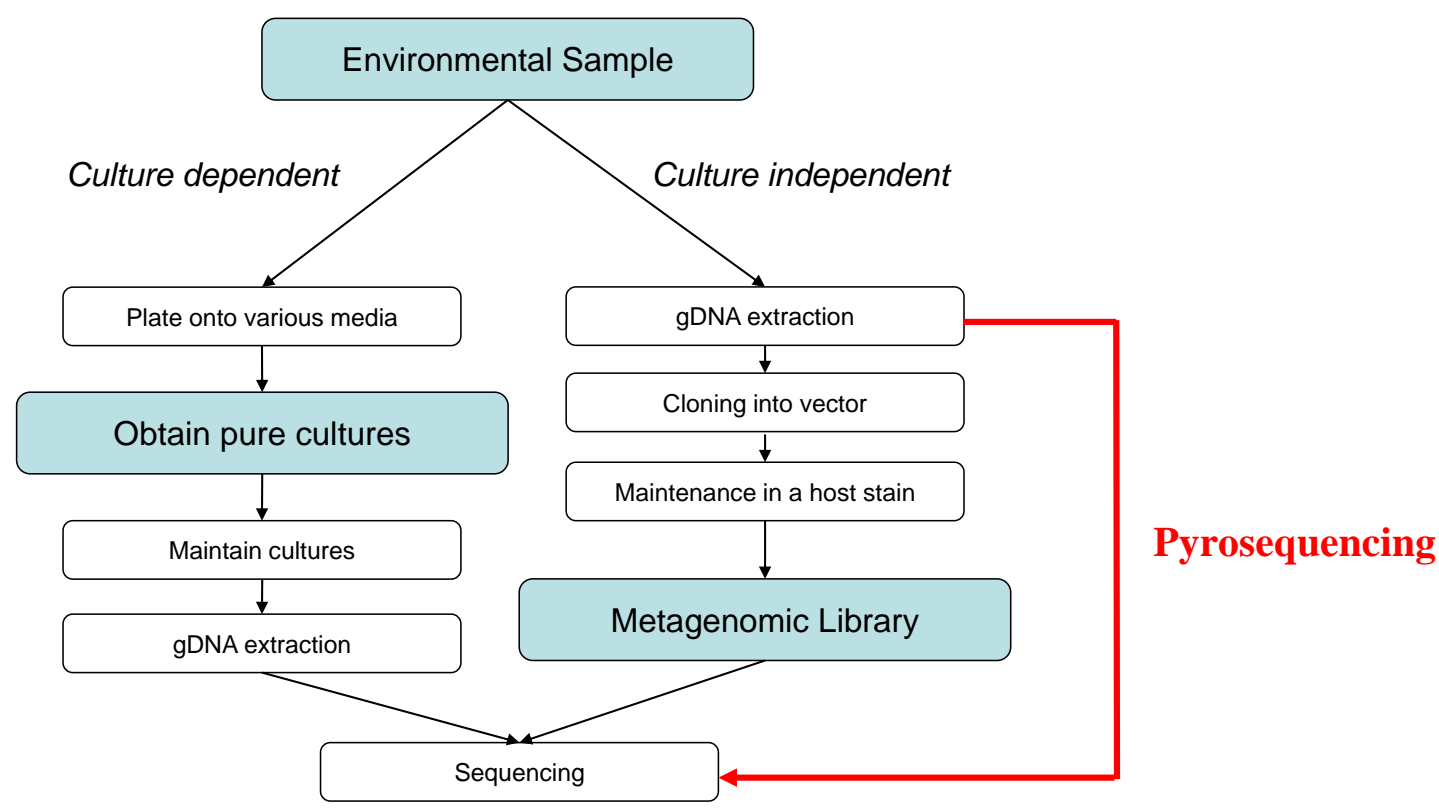

Figure 6.3 Culture dependent vs. Culture independent methods.

The development of pyrosequencing methods led to a reduction in cost per sequence, complexity (i.e evading clone libraries) and time (Figure 6.3) required to sequence large amounts of DNA as well as increased sensitivity and data production capacity. Pyrosequencing was first described in 1985 (Melamede and Wallace 1985), but the 
first massively parallel platform (GS20 454 Life Sciences) was detailed by Margulies et al. (2005). The 454 sequencing technology has been applied to an array of environments, including soil (Roesch et al. 2007; Jones et al. 2009), temperate (Sogin et al. 2006; Huber et al. 2007) and Arctic oceans (Kirchman et al. 2010), deep mines (Edwards et al. 2006) and the human gastrointestinal tract (Andersson et al. 2008). Pyrosequencing has eliminated cloning bias and has reduced chimera formation but comes at a cost of reduced sequence length. At the current time, pyrosequencing reads are only $\sim 400 \mathrm{bp}$ in length which may cause a decrease in the accuracy of the phylogenetic classification due to the reduced number of base pairs available for analysis. However, short sequences have been shown to provide accurate information on microbial communities (Liu et al. 2007) in which certain fragments of the $16 \mathrm{~S}$ rRNA gene can provide high phylogenetic resolution. Regions such as the variable region $3(\mathrm{~V} 3)$ and variable region 6 (V6) were compared to full length $16 \mathrm{~S}$ rRNA sequences, showing that the taxonomic assignments between the two methods were equivalent (Huse et al. 2008).

However, a major limitation is the constraint of amplification by the polymerase chain reaction (PCR). It is assumed that the relative abundance of $16 \mathrm{~S}$ rRNA amplicons generated during a fixed number of PCR cycles provides a measure of the $16 \mathrm{~S}$ rRNA gene proportions and abundance in the starting mixture. PCR bias can also result in sequence errors leading to mis-identification of members of the community, or it may skew the proportions of PCR products. Errors in sequences may be due to the misincorporation rate of Taq polymerase (Eckert and Kunkel 1991) and the formation of chimeric molecules during PCR (Wang and Wang 1997). Biases may also occur when bacteria contain heterogenic 16S rDNA sequences (von Wintzingerode et al. 1997). The distribution of PCR products may be biased by suboptimal reaction conditions, including lack of primer specificity or differences in the amplification efficiency of templates (Polz and Cananaugh 1998). Bacteria may have one copy or multiple copies of the 16S rRNA gene, in which base pair changes may exist among copies, resulting in sequence abundance and proportion inaccuracies (Acinas et al. 2004). Despite these difficulties, the precision of the Roche GS20 system has been calculated at $99.5 \%$ accuracy based on the V6 hyper-variable region (Huse et al. 2007). Due to the chemistry, base substitutions and chimeras are reduced but single base insertions are increased. Accuracy could be increased by the assembly of many overlapping reads 
(Huse et al. 2007), therefore, having many short reads that overlap may result in greater accuracy than having fewer reads that are longer in length.

Next-generation sequencing technology has revealed that microbial phylogenetic diversity is at least 100 times greater than estimates based on cultivation-dependent surveys alone. It has also been revealed that the number of abundant taxa in all environmental samples is low, and that thousands of low-abundance taxa account for most of the phylogenetic diversity (Sogin et al. 2006). The abundant taxa are "core" taxa which are well adapted to the particular environment. The rare or 'seed bank' taxa may become more abundant if the environment becomes more favourable, and these have recently been termed the 'rare biosphere' (Figure 6.4). This 'rare biosphere' is likely underexplored as it is under the detection limits of cloning techniques due to the small number of clones that most researchers can afford to analyse. However the 'rare biosphere' may sometimes be isolated through culture (Fuhrman 2009). For example, E. coli is rare in the gut community in most people but is exceptionally good at growing on a petri dish and therefore has been well characterised over other gut microbiota. Conversely, the abundant taxa within a community may be isolated using molecular methods, although they may not necessarily be picked up through cultivation.

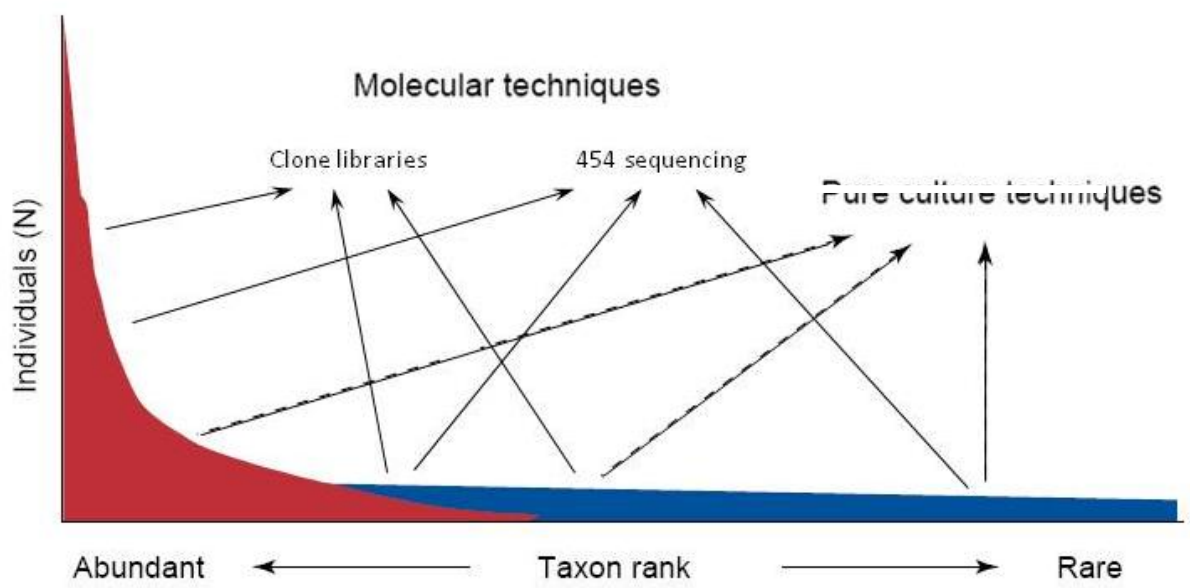

Figure 6.4 Rank-abundance curve plotting the number of individuals against their abundance. The red curve represents the abundant taxa whereas the blue represents the rare. The arrows indicate which portions of the diversity can be detected with the different methods. Modified from Pedros-Alio et al. (2006). 
Accurate classification of gene sequences to a particular genus or species requires analysis with a high-quality, comprehensive reference library. GenBank is a large, public database with 1,200,000 named 16S rDNA sequences, but its value is limited due to lack of administration, which can result in reference sequences of poor quality. Databases such as the Ribosomal Database Project (RDP, http://rdp.cme.msu.edu/), Greengenes project (http://greengenes.lbl.gov/) and Silva project (http://www.arbsilva.de) provide high quality partial or full $16 \mathrm{~S}$ rRNA gene sequences. The $16 \mathrm{~S}$ rRNA gene has become the most common approach to classify bacteria as it can determine evolutionary relationships due to lack of lateral gene transfer (Olsen et al. 1986) and has 8 conserved and 9 variable regions (Appendix B) that have evolved at different rates. The acceptable degree of difference between two sequences for classification to genus or species is variable, depending on the gene target and microorganism, and is the subject of ongoing debate. Stackebrandt and Goebel (1994) found that strains that had more than 3\% 16S rRNA sequence divergence were nearly always members of different species, as determined by DNA-DNA hybridization. Strains that had greater than $97 \%$ sequence similarity may or may not have been members of the same species. A cut off of $3 \%$ divergence was therefore recommended as a conservative measure for distinguishing between species. However, interpretation must be handled with care as many well defined species have $>97 \%$ similarity (Fox et al. 1992). For example, Bacillus cereus and Bacillus anthracis have identical 16S rDNA sequences and, in fact, cannot be separated reliably at the molecular level by their genomic DNA, because their pathogenic differentiation may be due to differences in plasmid DNA (Hoffmaster et al. 2004). As it is difficult to determine the phylogenetic relationship of bacteria, especially when limited to short fragments of the 16S rRNA gene, the term operational taxonomic unit (OTU) has been used. When the definition of the OTU is kept constant in a study, the diversity of microbial communities may be compared (Hughes et al. 2001). The best solution to determine bacterial species is to adopt a polyphasic approach to integrate all the available data using improved cultivation methods and molecular approaches.

The Antarctic sea ice bacterial community has been investigated using culture-based methods (Delille 1992; Staley and Gosink 1994; Bowman at al. 1997) and molecular methods (since Bowman et al. 1997). Limited phenotypic and chemotaxonomic 
surveys of sea ice bacteria indicate that sea ice bacteria are predominantly Gramnegative, non-fermentative rods or filaments, which are often pigmented (Delille 1992; Bowman at al. 1997; Brinkmeyer et al. 2003). They are also psychrophilic or psychrotolerant, heterotrophic, halotolerant (Brown and Bowman 2001; Junge et al. 2002) and some form gas vesicles (Staley and Gosink 1999). The CytophagaFlavobacterium-Bacteroidetes (CFB) comprises $\sim 70 \%$ of the bacterial community and other dominant bacterial groups are the Alphaproteobacteria and Gammaproteobacteria, the Gram-positive bacteria, and the orders Chlamydiales and Verrucomicrobiales (Brown and Bowman 2001). A substantial proportion of the sea ice bacterial community also harbours plasmids (Kobori et al. 1984). Bacteria have developed many attributes to survive such an extreme environment such as a lipid membrane that functions at low temperature by increasing the concentration of polyunsaturated fatty acids (PUFAs), antifreeze proteins that inhibit ice crystal formation (Gilbert et al. 2004), and extracellular polymeric substances (EPS) that provide a structure to grow on, protection from grazers and a buffer against salinity and pH (Thomas et al. 2001). Bacteria are also exposed to high salinities in brine channels during ice formation and near freshwater salinities during ice melt. Therefore they have salt tolerant enzymes that function over a range of salinities (Pomeroy and Weibe 2000).

Generally, studies investigating microbial communities employ either culture dependent or culture independent techniques, with few studies comparing both (Brinkmeyer et al. 2003; Donachie et al. 2007). Culture and molecular methods have been shown to identify two different microbial communities with some (0-30\%) degree of overlap (Donachie et al. 2004; Donachie et al. 2007). Therefore, the use of both culture-dependent and -independent methods may complement each other and enable a greater proportion of the microbial diversity to be explored. This chapter investigates Antarctic sea ice microbial diversity using both techniques. The cultivable diversity was investigated through isolation of pure cultures and identified using a series of biochemical tests and sequencing of the 16S rRNA gene. Diversity was further explored using 454 sequencing, a method that has previously not been conducted on Antarctic sea ice microbes. The RNA and DNA were both extracted from the sea ice bacterial community to understand the active proportion (RNA) of the total bacterial community (DNA). This approach was introduced in Chapter 3. The 
aims of this chapter were thus to 1) determine if sea ice bacterial isolates can be identified using biochemical methods; 2) investigate the RNA and DNA diversity of bacteria in sea ice and 3) understand the cultivatable and non-cultivatable proportions and the degree of overlap.

\subsection{Methods}

\subsubsection{Sample collection}

In 2008, sea ice cores were collected from Cape Evans (CE08), Granite Harbour (GH08a, b), Cape Roberts (CR08), Terra Nova Bay (TNB08) and McMurdo Station (McM08). In 2009, additional ice cores were also collected from Granite Harbour (GH09) and Cape Evans (CE09). The cores were collected using a Kovaks (USA) ice coring drill, then the bottom, middle and top $10 \mathrm{~cm}$ of each ice core were removed and the cores were processed following the procedure found in Chapter 2. This ice block was either 1) frozen for future culture work, 2) melted in autoclaved $0.22 \mu \mathrm{m}$ filtered seawater and spread onto agar plates in the field or 3) rapidly melted in autoclaved $0.22 \mu \mathrm{m}$ filtered seawater and concentrated by filtration onto a $0.2 \mu \mathrm{m}$ polycarbonate filter (Millipore Ltd) for further nucleic extraction and pyrosequencing. The filter was stored in RNAlater (Ambion) at $-20{ }^{\circ} \mathrm{C}$ until processed.

\subsubsection{Culture methods}

\subsubsection{Culture growth on media}

In 2008, samples for culture work were obtained by collecting sea ice directly into 2 $\mathrm{mL}$ cryovials and storing them in liquid nitrogen. Samples were collected from the top, middle and bottom of the ice cores from all sites. Samples were thawed on ice and $100 \mu \mathrm{l}$ of each sample were spread onto marine agar 2216 or marine agar 2216 1:10 dilution plates (Appendix A) and incubated in the dark at $15^{\circ} \mathrm{C}$. During the melting process, some bacteria may have experienced osmotic shock or ruptured due to high temperatures. Therefore, in 2009, sea ice core sections were melted into three times the volume of $0.22 \mu \mathrm{m}$ filtered and autoclaved seawater and then plated directly 
onto the agar plates in the field laboratory. Marine agar 2216 was again used as a cultivating medium. However, an extra seven different agar treatments were also prepared, some of minimal media (Table 4.1) using Antarctic filter-sterilized and autoclaved seawater (for full media methods see Appendix A).

Table 6.1 Agars prepared for growth of Antarctic sea ice bacteria

\begin{tabular}{|ll|}
\hline \multicolumn{2}{|c|}{ Culture media } \\
\hline 1 & Marine agar 2216 \\
2 & Marine agar 2216 1:10 dilution \\
3 & Marine agar 2216 + 1\% yeast extract \\
4 & M5 \\
5 & Seawater complete \\
6 & R2A \\
7 & R2A 1:10 dilution $+1 \%$ yeast extract \\
8 & R2A 1:10 dilution without yeast extract \\
9 & Sterile Antarctic sea water + nobel agar \\
\hline
\end{tabular}

Approximately $30 \mathrm{~mL}$ of each agar was poured under aseptic conditions into individual Petri dishes and left to cool. In 2009, the plates were then left in one of three conditions; 1) at $\sim 4{ }^{\circ} \mathrm{C}$ in the dark, 2) $\sim 15{ }^{\circ} \mathrm{C}$ in the dark and 3$) \sim 15{ }^{\circ} \mathrm{C}$ in the light. Temperature was measured using a thermometer. The samples incubated at $4{ }^{\circ} \mathrm{C}$ in the dark were placed in a cool box and placed outside the field laboratory tent. Those at $\sim 15{ }^{\circ} \mathrm{C}$ were left inside on the laboratory bench and those under dark conditions wrapped in tin foil. Samples were not incubated at $4{ }^{\circ} \mathrm{C}$ under light conditions as the light and temperature varied and was uncontrollable. However, the aim of incubation under these different conditions was to grow a range of different bacteria from sea ice.

\subsubsection{Maintenance and storage of cultures}

Individual cultures were re-streaked onto sterile agar that was the same as their isolation medium to gain a pure culture. Pure cultures were determined by the growth of one type of organism and the presence of only one type of cell by Gram stain. Each 
pure culture was grown in broth corresponding to the isolation agar it was originally grown in until $\log$ phase. A $1 \mathrm{~mL}$ aliquot of the culture was centrifuged at $\geq 12,000 \mathrm{x} \mathrm{g}$ for 15 minutes and the supernatant was removed. The pellet was re-suspended in 1 $\mathrm{mL}$ of broth glycerol (Appendix B) and stored at $-80^{\circ} \mathrm{C}$.

\subsubsection{Gram stain and colony morphology}

A single colony was picked onto a microscope slide with $10 \mu \mathrm{L}$ of $\mathrm{ddH}_{2} 0$. The sample was fixed to the slide by heating the sample over a Bunsen burner. The sample was then stained using the carboxy-fluorescein stain (Appendix B). Colony and cell morphologies were analysed by standard microbiological identification protocols.

\subsubsection{Motility}

A small drop of water was put on a slide with a central depression. Using a sterile tip, a single bacterial culture was added to the water. A coverslip was placed onto the slide and the sample examined microscopically $(\mathrm{x} 400)$ for motile organisms.

\subsubsection{Spore stain}

A pure culture was picked onto a microscope slide with $10 \mu \mathrm{L}$ of $\mathrm{ddH}_{2} 0$. The sample was fixed to the slide by heating the sample over a Bunsen burner. The sample was stained with malachite green. The stain was washed off with $\mathrm{ddH}_{2} \mathrm{O}$ and counterstained with safranin for 5 min (Schaeffer and Fulton 1993).

\subsubsection{Oxidase reaction}

A sterile tip was used to smear fresh culture onto Oxidase filter paper (Oxoid). A positive reaction occurred when the paper turned dark purple in colour within $10 \mathrm{~s}$ (Cowan and Steel 1970). 


\subsubsection{Catalase reaction}

To each freshly grown isolate, $2 \mu \mathrm{L}$ of $3 \%$ hydrogen peroxide were pipetted on top. A positive reaction was characterized by the formation of bubbles on the colony.

\subsubsection{Glucose oxidation and fermentation}

The medium used for the glucose oxidation and fermentation test was $1 \%$ glucose in Tryptone water (Appendix A). Two bijoux bottles containing $10 \mathrm{~mL}$ of medium were inoculated with each isolate. One of the bottles was covered in sterile liquid paraffin to produce an anoxic environment, while the other had a Durham tube added to monitor gas production. The bottles were incubated at the temperatures preferred by the isolates and monitored for changes in both colour and gas production over a period of a week.

\subsubsection{Growth at different temperatures}

The bacterial isolates were inoculated onto duplicate agar plates and incubated at $4{ }^{\circ} \mathrm{C}$ and $25{ }^{\circ} \mathrm{C}$ in both light and dark conditions. The plates were monitored over a two week period for growth.

\subsubsection{Sole carbon source testing}

The following carbon sources were prepared to a final concentration of $10 \% \mathrm{w} / \mathrm{v}$ in distilled water and filter sterilized: glycogen, tween 80, D-fructose, D-mannose, Larginine, glucose-6-phosphate (G-6-P, $5 \%$ w/v), D-raffinose (5\% w/v), sucrose, Dtrehalose and glucose. Each carbon source was added aseptically to the Carbon Source Testing Medium (Appendix B) to give a final concentration of $1 \% \mathrm{w} / \mathrm{v}$. Agar plates were then poured of each carbon source media as well as a negative control with no added substrate and left to cool. The agar plates were inoculated with the Antarctic sea-ice bacterial isolates and examined for growth over a 14 day period. 


\subsubsection{Growth of cultures: Mean generation time}

The unique bacterial isolates were grown in $200 \mu \mathrm{L}$ of TSB broth (BD Sciences, Appendix B) at $13{ }^{\circ} \mathrm{C}$, shaking at $100 \mathrm{rpm}$. TSB broth was chosen as it is a nutritious medium which supports the growth of a wide variety of microorganisms, including common aerobic, facultative and anaerobic bacteria. The cultures were grown in triplicate in a 96 well plate under shaking conditions as this has been found to promote cell growth (Mass 1992). The optical density (OD) of the cultures was measured using a spectrophotometer at $560 \mathrm{~nm}$. Mean generation times (MGTs) and lag phase were calculated from the OD graphs.

\subsubsection{DNA extraction and PCR conditions}

Each isolate was picked into $500 \mu \mathrm{L}$ of lysis buffer $(10 \mathrm{mM}$ Tris- $\mathrm{HCl} \mathrm{pH} 8.0,50 \mathrm{mM}$ $\mathrm{NaCl}, 10 \mathrm{mM}$ EDTA) and lysozyme (final conc. $2 \mathrm{mg} / \mathrm{mL}$ ). DNA was extracted using the phenol: chloroform method outlined in Chapter 2 with increased incubations for enzymatic lysis of cells. The DNA was quantified using PicoGreen fluorescence. The 16S rRNA gene was amplified using the forward primer Bac-27Fm (5AgRgTTTgATCCTggCTCAg-3) and the reverse primer Bac-1492R (5GACGGGCGGTGWGTRCA-3). Each PCR reaction contained 10 ng of DNA, Bac27m and Bac-1492 (final conc. $2 \mathrm{mM}$ ) and PCR blue supermix (Invitrogen). The samples were denatured at $95^{\circ} \mathrm{C}$ prior to amplification with 30 cycles consisting of denaturation at $95^{\circ} \mathrm{C}$ for $45 \mathrm{~s}$, primer annealing at $50^{\circ} \mathrm{C}$ for $60 \mathrm{~s}$ and elongation at $72^{\circ} \mathrm{C}$ for $2 \mathrm{~min}$. The final elongation step was at $72{ }^{\circ} \mathrm{C}$ for $7 \mathrm{~min}$ in an Applied Biosystems 2700 PCR Machine (Applied Biosystems, Ltd). PCR products were visualized using gel electrophoresis. PCR products for RFLP digestion were cleaned and concentrated using the DNA clean and concentrator ${ }^{\mathrm{TM}}$ (Zymo Research Corp., USA) following the manufacturer's protocol.

\subsubsection{RFLP analysis and identification by sequencing}

The digestions were carried out in a total volume of $15 \mu \mathrm{L}$ containing $400 \mathrm{ng}$ of PCR product and $10 \mathrm{U}$ of the restriction endonuclease $A l u \mathrm{I}$ overnight at $37{ }^{\circ} \mathrm{C}$. Digests were loaded onto a $1.5 \%$ agarose gel and run at $90 \mathrm{~V}$ for $1-1.5 \mathrm{~h}$. RFLP profiles were 
visualised using a UV illuminator. Cultures that had a unique RFLP profile were sent for sequencing on a Prism 3710 genetic analyzer (Applied Biosystems) using the primers Bac- F513 and Bac-R800. Chimera sequences were eliminated if detected using Chimera-Check (Cole et al. 2003) and Pintail (Ashelford et al. 2005). The sequences were then aligned in $\mathrm{ARB}$ and phylogenetic analyses were performed as described previously (in chapter's 3 and 5).

\subsubsection{4 pyrosequencing}

\subsubsection{DNA extraction}

Each filter was cut in half and the genomic DNA and RNA were extracted from each following the DNeasy and RNeasy protocols (Qiagen) as previously described in Chapter 2. The RNA was digested with DNase I (Sigma-Aldrich) to remove unwanted DNA. Briefly, to $8 \mu 1$ of RNA, $1 \mu 1$ of $10 \mathrm{x}$ reaction buffer and $1 \mu 1$ of amplification grade DNase I $(1 \mathrm{U} / \mu \mathrm{L})$ were added and incubated for $15 \mathrm{~min}$ at room temperature. Stop solution $(1 \mu \mathrm{L})$ was added and the sample was incubated at $70^{\circ} \mathrm{C}$ for $10 \mathrm{~min}$.

\subsubsection{2. cDNA synthesis}

RNA was converted to cDNA using SuperScript ${ }^{\mathrm{TM}}$ III First-Strand Synthesis SuperMix and random hexamers as primers (Invitrogen, Carlsbad, USA). Some samples without reverse transcriptase were also included to rule out DNA contamination. The cDNA synthesis reaction was checked for end-process integrity using gel electrophoresis on a $1 \%$ agarose gel.

\subsubsection{PCR conditions}

The V5-V7 region of the $16 \mathrm{~S}$ rRNA gene was targeted using the primers 784F (5'AGGATTAGATACCCTGGTA) and 1061R (5'-CRRCACGAGCTGACGAC, Andersson et al. 2009). There were a total of 22 samples run, each of which had a unique barcode attached to the forward primer sequence only (Appendix B). The barcodes for each sample were unique to facilitate sorting of sequences from a single pyrosequencing run (Hamaday et al. 2008). For each sample, two $50 \mu \mathrm{L}$ PCR mixes 
were prepared containing Pfu taq supermix (Roche), $0.5 \mu \mathrm{M}$ of each primer and $10 \mathrm{ng}$ of DNA or cDNA. The PCR conditions were $95^{\circ} \mathrm{C}$ for $5 \mathrm{~min}, 30$ cycles of $95^{\circ} \mathrm{C}$ for $40 \mathrm{~s}, 55^{\circ} \mathrm{C}$ for $40 \mathrm{~s}$ and $72{ }^{\circ} \mathrm{C}$ for $1 \mathrm{~min}$, followed by $72{ }^{\circ} \mathrm{C}$ for $7 \mathrm{~min}$ against a nontemplate control.

\subsubsection{Agarose gel electrophoresis}

All PCR products were run through a $1 \% \mathrm{w} / \mathrm{v}$ agarose gel run against a $1 \mathrm{~Kb}$ Plus DNA Ladder (Invitrogen Corp, USA) at 110 volts in 1x Tris-Borate EDTA buffer. After completion of electrophoresis, the gel was visualized on a UV trans-illuminator and a digital photograph of the gel was taken.

\subsubsection{Gel purification and quantification}

The $\sim 300$ bp product band was cut out with a sterile scalpel using a UV transilluminator and put into a fresh Eppendorf tube. The DNA from the PCR product was extracted using the QIAquick gel extraction kit (Qiagen). Briefly, 1 volume of diffusion buffer was added to 1 volume of gel slice and incubated at $50{ }^{\circ} \mathrm{C}$ until dissolved. To each sample, 3 x volume of buffer QG was added and the sample was transferred to a QIAquick spin column, centrifuged and washed with $0.75 \mathrm{~mL}$ buffer PE. The DNA was eluted using DNase/RNase free water and stored at $-20{ }^{\circ} \mathrm{C}$. The concentration was analysed using a nanodrop and $20 \mathrm{ng}$ of each of the 22 samples were pooled together.

\subsubsection{Amplicon Sequencing}

A 454 Life Sciences A adapter sequence was ligated onto the sequences and subsequently amplified in PCR mixture-in-oil emulsions on a Genome Sequencer FLX machine. The initial stage of 454 pyrosequencing requires the addition of DNA capture beads that attach to one single strand of DNA template. The DNA on each bead is amplified to 10 million copies for each template using emulsion PCR (emPCR), where no contamination between sequences or sequence competition can occur. The beads are then pipetted out onto a PicoTitrePlate ${ }^{\mathrm{TM}}$ which contains 1.6 million wells, just big enough for one bead plus additional polymerase, ATP 
sulphurylase and luciferase. The sequence of the template is determined by a chargecoupled (CCD) camera that detects the light produced when a nucleotide is added (Figure 6.5). This nucleic acid polymerisation reaction starts when an inorganic pyrophosphate (PPi) is released with nucleotide attachment. The PPi is converted to ATP by ATP sulfurylase and provides energy to luciferase to oxidise luciferin and produce light.
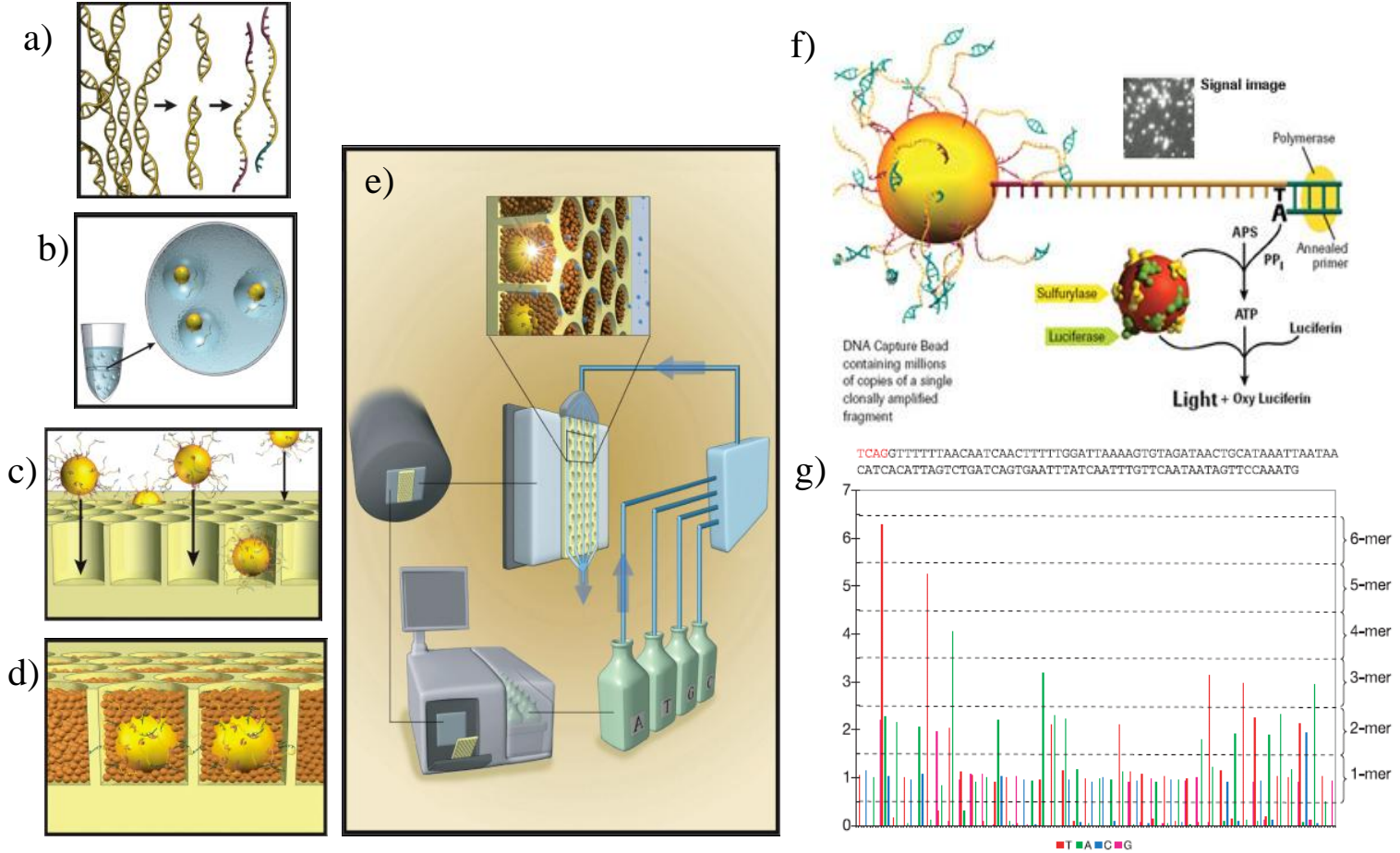

Figure 6.5 An overview of the 454 sequencing technology. (a) The gene of interest is isolated, ligated to adaptors and separated into single strands. (b) Each sequence is bounds to beads under conditions that favour one fragment per bead and PCR amplification occurs in each droplet of oil emulsion. (c) The beads are deposited into the wells of a fibre optic slide. (d) Smaller beads containing the enzymes required for the sequencing reaction are also put into each well. (e) The 454 instrument where nucleotides flow across the fibre optic slide which is viewed by a CCD camera-based imaging system and computer. (f) The pyrosequencing process whereby incorporation of the " $\mathrm{A}$ " base generates inorganic pyrophosphate (PPi) and continues a process that produces light. (g) The light intensities are picked up by the CCD computer and transcribed into a flowGram. Modified from Margulies et al. (2005).

There are two factors that limit community composition analysis: each run is expensive, and splitting the picotitre plate across multiple runs is difficult. This was solved by adding a unique tag or 'barcode' to each primer before PCR amplification. The barcodes were based on error-correcting codes (Hamady et al. 2008) that enabled 
22 different sea ice bacterial communities to be run simultaneously on one microtitre plate. Hamady et al. (2008) used Hamming codes, a formal mathematical technique to define barcodes in such a way that errors can be detected and corrected. These errorcorrecting tags were successfully used to track bacterial 16S rRNA gene sequences from 286 environmental samples and corrected $92 \%$ of sample assignment errors.

\subsubsection{Sequence analyses}

To determine the total diversity of bacteria in Antarctic sea ice, the raw 454 FLX data ( 100,000 sequences) was aligned using the NAST tool provided on the GreenGenes website and clustered by the complete-linkage clustering (or farthest neighbour) method available in Mothur (Schloss et al. 2009). Sequences that did not contain the 16S rRNA forward or reverse primers and had low-quality sequences where the number of ambiguous sequences $(\mathrm{N})>0$, or had a quality score (determined by the FLX software) of $<20$ and sequence length $<150 \mathrm{bp}$, were removed. A total of 75,504 high-quality sequences of $\sim 300 \mathrm{bp}$ were obtained. Rarefaction curves of the total bacterial diversity were calculated at $0,3,5$ and $10 \%$ sequence dissimilarity. The bacterial diversity in the DNA and RNA - based populations at the different sites as defined by the barcode sequence was then determined. Only the forward sequences contained barcodes, therefore half of the sequences were lost. Approximately 40,000 forward sequences were sorted in Geneious pro $^{\mathrm{TM}}$ (Biomatters Ltd, Auckland) by their barcode into each of the 22 sites and those without matching barcodes were removed. The phylogenetic affiliation of each 16S rRNA gene sequence was then analysed using the Ribosomal Database Project (RDP) Classifier algorithm with OTUs defined as having $95 \%$ (genera level) similarity. This algorithm assigns $16 \mathrm{~S}$ rRNA gene sequences to a phylogenetically consistent higher-order bacterial taxonomy hierarchy using a naïve Bayesian classifier (Wang et al. 2007). Once taxonomic status is assigned to a sequence, the numbers of sequences representing each taxon in each sample is determined, followed by identification of individual taxonomic ranks using ANOVA. Thus, each OTU can be compared to another OTU within the sample. A large number of these were identified as chloroplast DNA and were removed. In addition, sequences that occurred only once across all 22 samples were also removed. A total of $\sim 22,000$ sequences were then analysed to determine bacterial diversity in sea ice. Unique 16S rRNA gene sequences were aligned in ARB 
as described previously in this chapter for comparisons to be made between 454 and culture-derived OTUs. Evolutionary distances were calculated from sequence pair dissimilarities using only unambiguously sequenced positions. The phylogenetic analyses were performed as described previously.

\subsubsection{Statistical analyses}

A similarity profile test (SIMPROF) was used to examine for inherent structure in the data set. SIMPROF calculates similarities between a priori unstructured samples, orders them from highest to lowest and plots them against their rank to create a similarity profile. This profile is tested against a profile expected under the null hypothesis of no meaningful structure. For a full explanation of the technique, see Clarke et al. (2008). The test was based on a Bray-Curtis similarity matrix and groupings were examined at the $5 \%$ significance level $(<0.05)$ using a maximum of 1000 random permutations of the raw data. A range of diversity indices were calculated for the bacterial communities determined by pyrosequencing: total number of species (S), total number of individuals $(\mathrm{N})$, Shannon-Wiener index $\left(\mathrm{H}^{\prime}\right)$, Simpson's index (1- $\lambda)$, Hill numbers N1 and N2 and modified Hill's ratio (N21'). Shannon / N1 and Simpson's / N2 indices were calculated to assess the influence of rare and dominant species, respectively, on community diversity. The modified Hill's ratio was used as a measure of equitability (spread between taxa) as it has an advantage over traditional measures of evenness by its non-dependency on the number of species (Rogers et al. 1999).

\subsection{Results}

\subsubsection{Culture-dependent bacterial diversity}

\subsubsection{Growth on different media and colony morphology}

The 2008 and 2009 samples were spread onto Marine Agar 2216 (MA) or Marine Agar 2216 diluted 1:10 (MA10). In 2009, sea ice samples were also spread onto R2A, R2A 1:10 dilution without yeast extract, R2A 1:10 dilution with yeast extract, M5 and 
seawater complete agar (Appendix B). In 2008, $90.3 \%$ of the cultures were red in colour, lobate and globular. $9.1 \%$ of the cultures were grown from the top of the ice core, while the majority came from the middle $(49.6 \%)$ and bottom $(41.3 \%)$ of the ice core (Table 6.2). In 2009, only $50.3 \%$ of the cultures were red and globular, while an additional $40.2 \%$ were white, round and entire. The remainder were orange, yellow or pink (Appendix B). Two thirds of the cultures grew from the middle of the ice core; a further $19.7 \%$ came from the bottom of the ice core with the smallest proportion (13.4\%) grown from the top of the ice core (Table 6.3).

Table 6.2 Number of bacteria of different coloured pigments grown on Marine agar 2216 (MA) or marine agar 1/10 diluted (MA10) from the different sites McMurdo Station (McM), Cape Evans (CE), Granite Harbour (GH), Cape Roberts (CR) and Terra Nova Bay (TNB) in 2008.

\begin{tabular}{|c|c|c|c|c|c|c|c|}
\hline \multirow{2}{*}{\begin{tabular}{|l|} 
\\
Top
\end{tabular}} & \multirow[b]{3}{*}{$\mathrm{McM}$} & \multicolumn{3}{|c|}{ MA } & & \multirow{2}{*}{$\begin{array}{r}\text { MA10 } \\
\text { white }\end{array}$} & \multirow{2}{*}{ total } \\
\hline & & white & yellow & red & orange & & \\
\hline & & 0 & 0 & 0 & 0 & 0 & 0 \\
\hline & $\mathrm{CE}$ & 0 & 0 & 0 & 0 & 2 & 2 \\
\hline & $\mathrm{GH}$ & 0 & 0 & 0 & 0 & 0 & 0 \\
\hline & CR & 0 & 0 & 5 & 0 & 3 & 8 \\
\hline & TNB & 1 & 0 & 19 & 0 & 1 & 21 \\
\hline & total & 1 & 0 & 24 & 0 & 6 & 31 \\
\hline \multicolumn{8}{|l|}{ Middle } \\
\hline & $\mathrm{McM}$ & 2 & 1 & 0 & 0 & 0 & 3 \\
\hline & $\mathrm{CE}$ & 1 & 0 & 0 & 0 & 3 & 4 \\
\hline & GH & 0 & 0 & 0 & 0 & 0 & 0 \\
\hline & CR & 3 & 1 & 17 & 1 & 1 & 23 \\
\hline & TNB & 3 & 0 & 136 & 0 & 0 & 139 \\
\hline & total & 9 & 2 & 153 & 1 & 4 & 169 \\
\hline \multicolumn{8}{|l|}{ Bottom } \\
\hline & $\mathrm{McM}$ & 0 & 0 & 0 & 0 & 0 & 0 \\
\hline & $\mathrm{CE}$ & 0 & 0 & 92 & 0 & 3 & 95 \\
\hline & $\mathrm{GH}$ & 1 & 1 & 0 & 0 & 0 & 2 \\
\hline & CR & 4 & 0 & 32 & 0 & 1 & 37 \\
\hline & TNB & 0 & 0 & 7 & 0 & 0 & 7 \\
\hline & total & 5 & 1 & 131 & 0 & 4 & 141 \\
\hline & & & & & & & 341 \\
\hline
\end{tabular}


Bacteria collected from the middle of the sea ice core grew under light and dark conditions at 4 and $15{ }^{\circ} \mathrm{C}$. In the bottom ice samples, fewer cultures grew at $15^{\circ} \mathrm{C}$ in the dark whereas there was greater number of cultures grown from top core samples under light conditions (Table 6.3).

Table 6.3 Number of bacteria grown on Marine agar 2216 (MA), R2A, R2A 1: 10 dilution with yeast extract added (+) or without (-), M5 and Sea water complete (SWC) at $4{ }^{\circ} \mathrm{C}$ and $15{ }^{\circ} \mathrm{C}$ in the dark and $15^{\circ} \mathrm{C}$ in light conditions in 2009 . The samples were taken from the top, middle and bottom of the sea ice core at Granite Harbour 24.11.2009.

\begin{tabular}{|llrrrr|}
\hline & Media & $4^{\circ} \mathrm{C}$ dark & $15^{\circ} \mathrm{C}$ dark & $15^{\circ} \mathrm{C}$ light & total \\
\hline Top & MA & 4 & 1 & 23 & \\
& R2A & 8 & 1 & 8 & \\
& R2A 1:10 - & & & 1 & \\
R2A 1:10+ & 2 & 6 & 5 & \\
M5 & & 1 & & \\
& SWC & & 1 & 3 & 64 \\
\hline total & 14 & 10 & 40 & \\
\hline Middle & MA & 25 & 4 & 21 & \\
& R2A & 25 & 19 & 14 & \\
& R2A 1:10- & 30 & 7 & 25 & \\
R2A 1:10+ & 36 & & 10 & \\
M5 & 49 & 25 & 18 & \\
SWC & 3 & 5 & 4 & \\
\hline total & 168 & 60 & 92 & 320 \\
\hline Bottom & 5 & 2 & 4 & \\
& R2A & 14 & & 15 & \\
R2A 1:10- & 1 & & 3 & \\
R2A 1:10+ & 11 & & 3 & \\
M5 & 1 & 1 & & \\
SWC & 9 & 1 & 24 & \\
\hline total & 41 & 4 & 49 & \\
\hline & & & & & \\
\hline
\end{tabular}

\subsubsection{Growth at different temperatures under light and dark}

A subset of the 839 isolates from both years was re-streaked to obtain pure isolates based on their colony morphology and Gram stain. A total of 35 isolates from 2008 and 62 cultures from 2009 were grown on their various media. Isolates were incubated at $4{ }^{\circ} \mathrm{C}$ and $25^{\circ} \mathrm{C}$ under light and dark conditions to fully investigate their growth under controlled temperatures (not possible in the field). Within the first few days, the only isolates that had grown were found at $25{ }^{\circ} \mathrm{C}$ regardless of light 
conditions. Within two weeks, the majority of these had also grown at $4{ }^{\circ} \mathrm{C}$. A proportion of cultures $(8.3 \%)$ were slow growing isolates that only grew at $4{ }^{\circ} \mathrm{C}$. These cultures were generally the bacterial isolates that were red and of globular consistency (Appendix B). One isolate, C8, only grew at $25^{\circ} \mathrm{C}$ under dark conditions. Cultures isolated from the top of the sea ice core grew best under light conditions.

\subsubsection{Gram stain and colony morphology}

The results for the Gram stain and colony morphology are found in Appendix B. The majority of isolates from both years were Gram negative rods with only $9.7 \%$ of isolates staining Gram positive. The Gram positive cells were generally coccoid in appearance. Gram positive cocci colonies were either spherical in shape or formed clumps. There were a few bacterial isolates that had coccoid and bacillus cell morphologies, and many of the bacilli were vacuolated.

\subsubsection{Motility}

It was very difficult to determine the motility of bacteria using this test due to Brownian motion. Many of the cultures showed no darting, tumbling or any other organised movement.

\subsubsection{Spore stain}

The spore stain was conducted on cultures that were $<24 \mathrm{~h}$ old. The majority of cultures from both years $(89.9 \%)$ did not contain spores. The cultures that had positive spore stains were rod shaped and spores could be seen.

\subsubsection{Oxidase and catalase reaction}

A total of $65.3 \%$ of isolates were oxidase positive, and $78.9 \%$ were catalase positive. A total of $57.9 \%$ of the bacterial isolates were both oxidase and catalase positive. 


\subsubsection{Glucose Oxidation and Fermentation}

Many bacterial isolates were able to utilise glucose either by oxidation $(28.4 \%)$ or fermentation (29.5\%) under the test conditions (Fig 6.6). A few isolates (9.5\%) were able to produce gas under aerobic conditions (Appendix B). A total of $48.4 \%$ of the isolates were not able to utilise glucose.

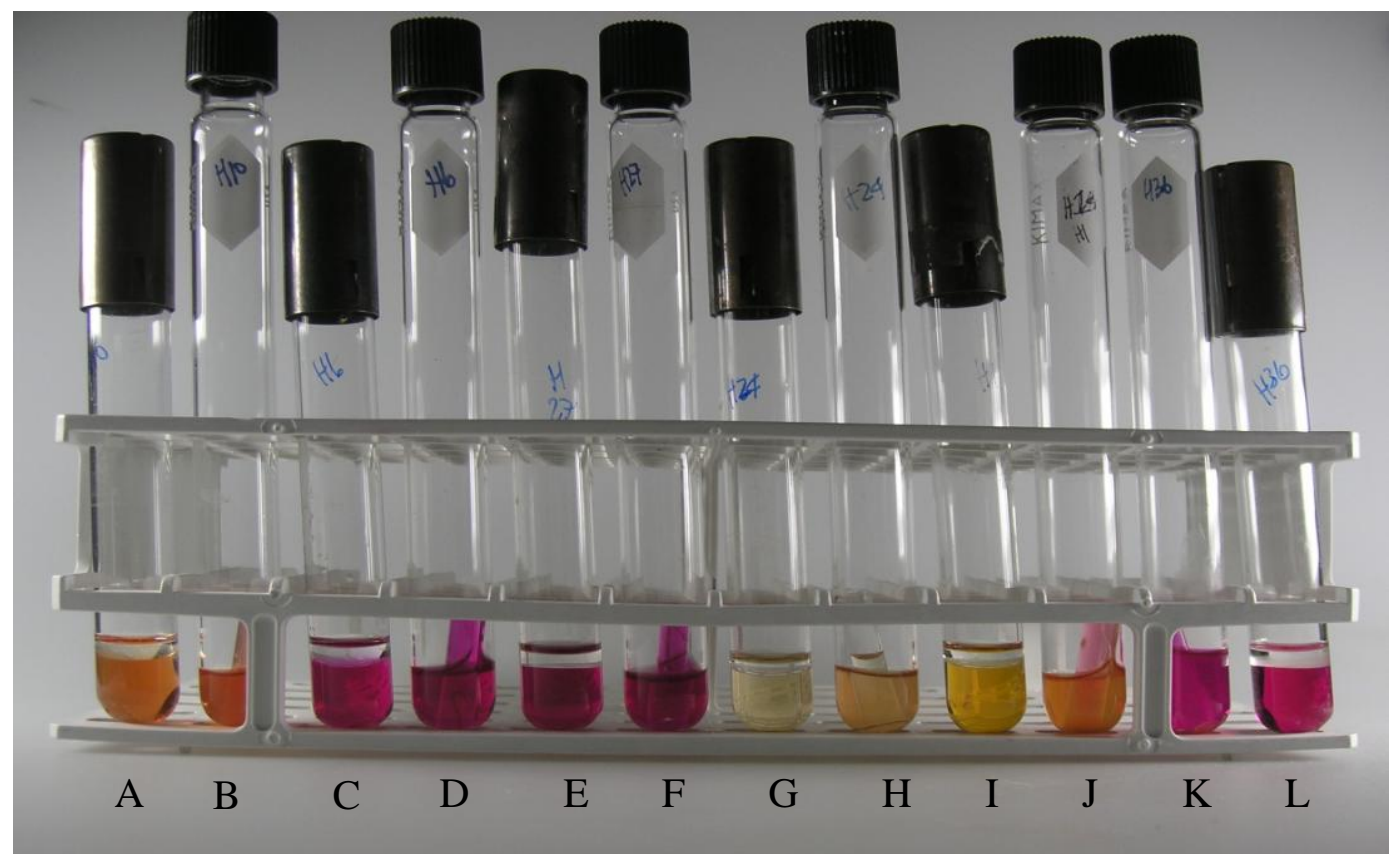

Figure 6.6 An example of the glucose oxidation and fermentation test. Vials with paraffin (A, C, E, G, I, L) were grown under anaerobic conditions whereas those with the Durham tubes were aerobic. Vials that are purple contained bacteria that were unable to utilise glucose. Gas was produced in vial $\mathrm{H}$.

\subsubsection{Sole carbon source testing}

The bacterial isolates were tested for sole carbon source utilization.

Table 6.4 (Following page) Growth of isolates on 11 different sole carbon sources. Isolate growth was measured as $-=$ no growth, $\mathrm{x}-\mathrm{xxx}=$ describes a range of growth rates from low to high. 


\begin{tabular}{|c|c|c|c|c|c|c|c|c|c|c|c|}
\hline Culture & $d$-fructose & sucrose & glucose & starch & G6P & d-raffinose & Tween 80 & arginine & d-mannose & glycogen & d-trehalose \\
\hline CA2 & $x x x$ & $x$ & $x x x$ & $x x$ & $x$ & $x$ & $x x x$ & $x x$ & $x x$ & $x x$ & $x x x$ \\
\hline CA3 & $x x$ & - & - & $x x$ & $x$ & - & $x x x$ & - & $x x$ & $x x$ & - \\
\hline CA5 & - & - & - & - & - & - & - & $x$ & - & - & - \\
\hline CA6 & - & - & - & - & - & - & $x$ & - & - & - & - \\
\hline CA7 & $x$ & $x x$ & $x$ & $x x$ & - & $x$ & $x x$ & $x$ & $x x$ & $x x$ & $x x$ \\
\hline CA8 & $x$ & $x$ & $x$ & - & - & $x$ & $x$ & $x$ & - & - & $x$ \\
\hline CA11 & $x$ & $x x$ & $x$ & $x x$ & - & - & $x$ & $x$ & $x$ & $x x x$ & $x$ \\
\hline CA13 & $x x$ & $x x$ & $x x$ & $x x$ & - & $x$ & $x x x$ & $x x x$ & $x x$ & $x$ & $x x$ \\
\hline CA14 & $x$ & $x$ & $x$ & $x$ & - & $x x$ & $x$ & $x x$ & - & $x x x$ & $x$ \\
\hline CA21 & - & - & - & - & - & - & - & - & - & - & - \\
\hline CA23 & $x x x$ & $x x x$ & $x x x$ & $x$ & - & $x$ & - & $x x x$ & $x x$ & $x$ & $x x x$ \\
\hline CA24 & - & $x$ & $x$ & $x x$ & $x$ & - & - & - & - & $x$ & - \\
\hline CA28 & $x$ & $x x$ & $x x$ & $x x x$ & - & $x x$ & - & $x$ & $x x$ & $x x x$ & $x$ \\
\hline CA29 & $x x x$ & $x x x$ & $x x x$ & $x x x$ & $x x$ & $x x x$ & $x x x$ & $x x x$ & $x x$ & $x x x$ & $x x x$ \\
\hline CA30 & $x x x$ & $x x x$ & $x x x$ & $x$ & $x$ & $x x$ & $x x x$ & $x x$ & $x x$ & $x x x$ & $x x x$ \\
\hline CA34 & - & - & - & - & - & - & - & - & - & - & - \\
\hline CA40 & - & $x$ & $x$ & $x$ & $x$ & - & - & $x$ & $x$ & $x x x$ & $x$ \\
\hline CA41 & - & - & - & $x$ & - & $x$ & $x$ & $x$ & $x$ & $x$ & $x$ \\
\hline CA42 & - & - & $x$ & $x$ & - & - & $x$ & - & $x$ & - & $x$ \\
\hline CA45 & $x$ & $x x$ & $x x$ & $x x$ & - & $x$ & $x$ & $x$ & $x$ & $x x$ & - \\
\hline CA48 & $x$ & $x x$ & $x$ & $x$ & - & $x$ & $x x x$ & $x x$ & $x$ & $x$ & $x$ \\
\hline CA49 & $x$ & $x$ & $x$ & - & - & - & $x$ & - & $x$ & $x$ & $x$ \\
\hline CA50 & $x$ & - & - & $x$ & - & - & $x x$ & $x$ & $x$ & $x$ & $x$ \\
\hline CA51 & - & $x$ & $x$ & - & $x$ & $x$ & - & - & $x$ & $x$ & $x$ \\
\hline CA52 & $x$ & $x$ & $x$ & $x x$ & - & - & $x$ & - & $x$ & $x$ & $x x$ \\
\hline CA54 & $x$ & - & - & - & $x x$ & $x x$ & $x$ & $x$ & - & $x x x$ & $x x$ \\
\hline CA55 & $x$ & $x x$ & $x x$ & $x x$ & $x$ & $x x$ & - & $x x$ & $x x$ & $x x x$ & $x x$ \\
\hline CA56 & $x x$ & $x x$ & $x x$ & $x x$ & $x$ & $x x$ & $x$ & $x$ & $x x$ & $x x$ & $x x$ \\
\hline CA58 & - & - & - & - & - & - & $x$ & - & - & - & - \\
\hline CA59 & $x$ & $x$ & $x x$ & $x$ & - & $x$ & $x$ & $x$ & $x x$ & - & $x x$ \\
\hline CA64 & $x x$ & $x$ & $x$ & $x$ & - & $x$ & $x x x$ & $x x x$ & $x$ & $x x x$ & - \\
\hline CA65 & $x x$ & $x$ & $x x$ & $x x$ & - & $x$ & $x x$ & $x$ & $x$ & $x x x$ & - \\
\hline
\end{tabular}




\begin{tabular}{|c|c|c|c|c|c|c|c|c|c|c|c|}
\hline CA67 & $x$ & - & $x$ & $x$ & - & $x$ & $x x x$ & $x$ & - & $x x x$ & $x$ \\
\hline CA69 & $x x x$ & $x x x$ & $x x$ & $x$ & $x$ & $x x$ & $x x$ & $x x$ & $x x$ & $x x$ & $x x x$ \\
\hline CA70 & $x x x$ & $x x x$ & $x x x$ & $x x x$ & $x$ & $x x$ & $x x x$ & $x x$ & $x x$ & $x x x$ & $x x x$ \\
\hline CA71 & $x x x$ & $x x x$ & $x x x$ & - & - & $x x x$ & $x$ & $x x x$ & $x x x$ & - & $x x$ \\
\hline CA72 & $x$ & - & $x$ & - & - & - & $x$ & - & - & $x$ & - \\
\hline CA73 & - & - & - & - & - & - & $x$ & - & - & - & - \\
\hline CA74 & - & $x$ & - & - & - & - & $x x$ & - & - & $x$ & - \\
\hline $\mathrm{H} 1$ & $x$ & $x$ & - & - & $x$ & $x$ & $x x x$ & $x x x$ & $x$ & $x$ & $x$ \\
\hline $\mathrm{H} 2$ & $x$ & $x$ & - & - & $x$ & $x$ & $x x x$ & $x x x$ & $x$ & $x$ & $x$ \\
\hline H3 & $x$ & $x x$ & $x$ & $x x$ & - & $x$ & $x x$ & $x$ & $x x$ & $x x$ & $x x$ \\
\hline $\mathrm{H} 4$ & $x$ & $x$ & - & $x$ & - & $x$ & $x x x$ & $x x x$ & $x$ & $x$ & $x$ \\
\hline $\mathrm{H} 5$ & $x$ & $x$ & - & - & $x$ & - & - & - & - & $x$ & $x$ \\
\hline $\mathrm{H} 6$ & $x x$ & $x$ & $x x x$ & $x$ & $x x$ & $x x x$ & $x x x$ & $x x x$ & $x x x$ & $x x$ & $x x$ \\
\hline $\mathrm{H} 7$ & $x x$ & $x$ & $x x x$ & $x$ & $x x$ & $x x x$ & $x x x$ & $x x x$ & $x x x$ & $x x$ & $x x$ \\
\hline $\mathrm{H} 10$ & $x$ & $x$ & $x$ & - & - & $x$ & $x x x$ & $x$ & $x$ & $x$ & - \\
\hline $\mathrm{H} 11$ & $x x$ & $x X X$ & $x x x$ & $x x$ & $x x$ & $x X X$ & $x x x$ & $x x$ & $x x x$ & $x x$ & - \\
\hline $\mathrm{H} 12$ & $x$ & $x$ & $x$ & $x x$ & $x$ & $x$ & $x x x$ & $x x x$ & $x$ & $x x$ & - \\
\hline $\mathrm{H} 20$ & $x$ & $x$ & $x$ & $x$ & $x$ & $x$ & $x x x$ & $x x x$ & $x x$ & $x$ & $x$ \\
\hline $\mathrm{H} 21$ & $x x$ & $x x$ & $x x x$ & $x x$ & $x x$ & $x$ & $x x x$ & $x x x$ & $x x$ & $x x$ & - \\
\hline H22 & $x$ & $x$ & $x x$ & $x$ & $x x$ & $x x$ & $x x x$ & $x x x$ & $x$ & $x$ & $x$ \\
\hline H23 & $x$ & $x$ & $x x$ & $x$ & - & $x x$ & $X X X$ & $x x x$ & $x$ & $x$ & $x$ \\
\hline $\mathrm{H} 24$ & $x x$ & $x$ & $x x$ & $x x$ & $x x$ & $x x$ & $x x x$ & $x x x$ & $x x$ & $x x$ & - \\
\hline $\mathrm{H} 26$ & $x$ & $x$ & $x$ & $x$ & - & $x$ & $x x x$ & $x x x$ & $x$ & $x x$ & $x$ \\
\hline H31 & $x$ & $x$ & $x$ & $x$ & - & $x$ & $x x x$ & $x x x$ & $x$ & $x$ & - \\
\hline H36 & $x$ & $x$ & $x$ & $x$ & $x$ & $x$ & $X X X$ & $x x x$ & $x$ & $x x$ & - \\
\hline H37 & - & $x$ & $x$ & - & $x$ & $x$ & - & - & - & $x$ & - \\
\hline H38 & $x$ & $x$ & - & - & - & - & $x$ & - & - & - & - \\
\hline
\end{tabular}


Two isolates, CA21 and CA34, did not utilise any of the carbon sources available whereas isolates CA2, CA29, CA30, CA56, CA69, CA70, H6, H7, H20 and H22 were able to utilise all sources. All the isolates were able to utilise at least one of the carbon sources. The majority $(81 \%)$ could utilise Tween 80 or glycogen as a sole carbon source but only $42 \%$ of isolates were able to utilise glucose-6-phosphate (G6-P, Table 6.4).

\subsubsection{Growth curves}

The bacterial isolates were all grown in TSB broth at a $\mathrm{pH}$ of 7.6 to determine their Mean Generation Time (MGT) and Lag Phase Time (Table 6.5). The longest lag phases occurred in isolates H7 and C42. C56 and C54 also had long lag phases. Stationary phase was reached by many of the isolates at $45 \mathrm{~h}$ (Figure 6.7).

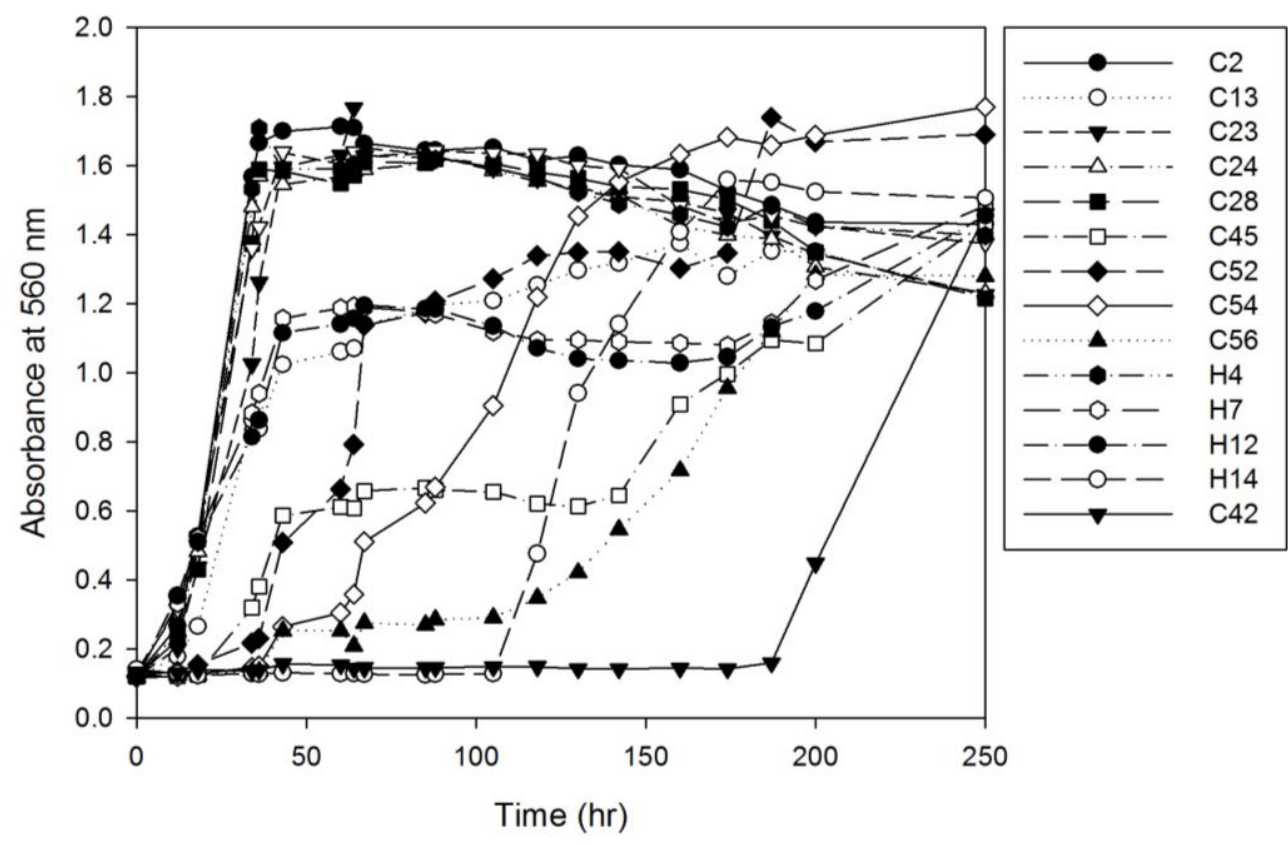

Figure 6.7 Growth curves of representative bacterial isolates. Isolates from 2009 are numbered C, whereas those from 2008 are numbered $\mathrm{H}$. 
Table 6.5 Lag phase and mean generation time (MGT) in hours from each representative isolate.

\begin{tabular}{|lcc|}
\hline & Lag phase $(\mathrm{h})$ & MGT $(\mathrm{h})$ \\
\hline C2 & - & 8.1 \\
C13 & - & 11.5 \\
C23 & - & 9.5 \\
C24 & - & 8.2 \\
C28 & - & 8.2 \\
C31 & 187 & 21.8 \\
C42 & 105 & 23.9 \\
C45 & 18 & 14 \\
C52 & 11 & 23 \\
C54 & 34 & 35.6 \\
C56 & 36 & 35.6 \\
H4 & - & 9.2 \\
H7 & - & 8.1 \\
H12 & 105 & 17.2 \\
H14 & - & 24.2 \\
\hline
\end{tabular}

\subsubsection{Identification of unique profiles by RFLP analysis}

The RFLP analysis revealed many unique profiles for the isolates showing the diversity of cultivable bacteria in sea ice, and that the initial characterisation by colony morphology and Gram stains adequately distinguished the different bacterial isolates. The RFLP profiles are shown in figure 6.8. Where identical profiles were observed (e.g. isolates C55 and C57), only one was sequenced. 


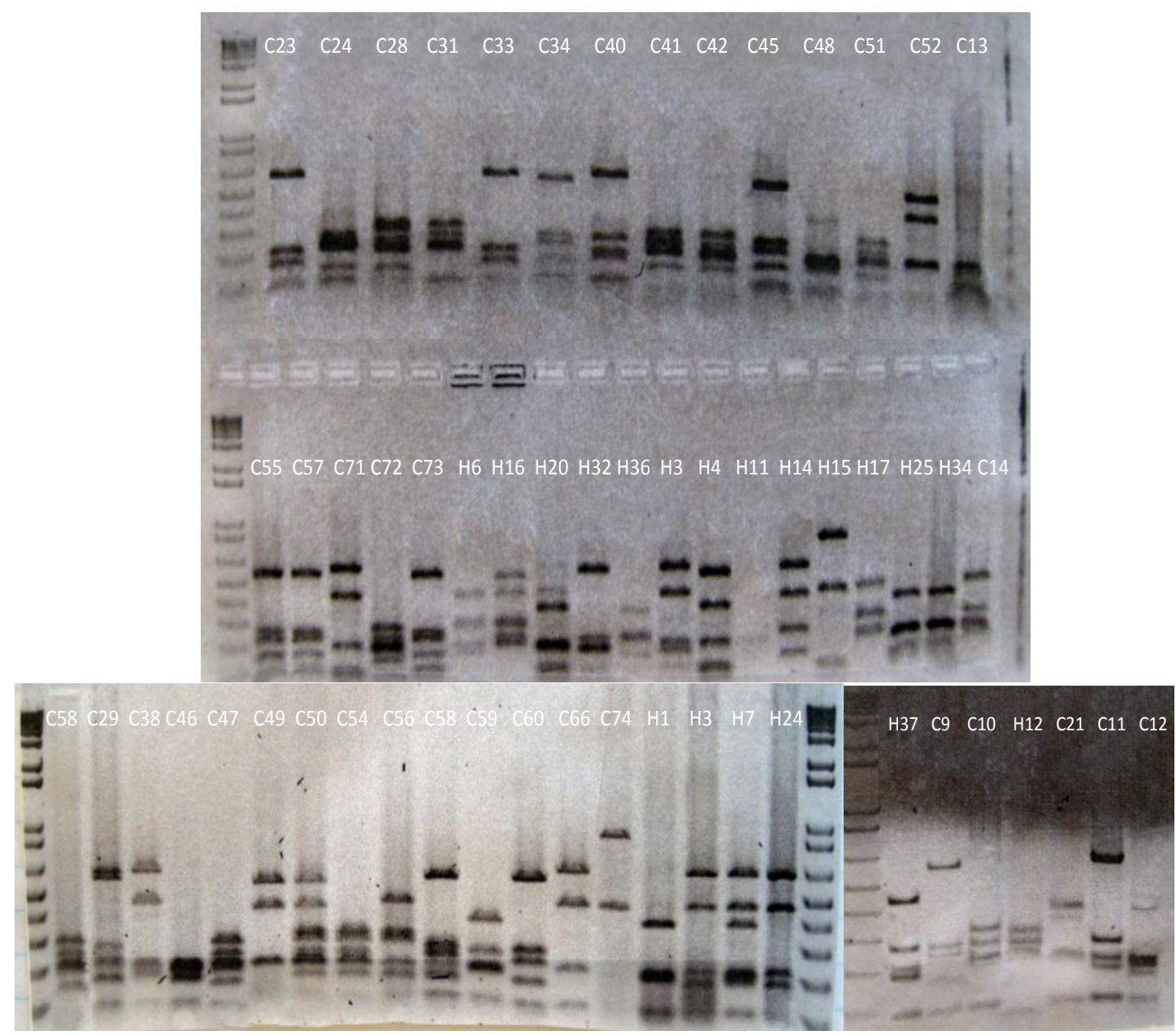

Figure 6.8 Representative RFLP profiles of the 16S rRNA gene extracted from pure bacterial isolates (not all data shown).

\subsubsection{Sequencing of cultures}

The 16S rRNA gene sequences clustered into five groups. Fourteen of the isolates clustered within class Gammaproteobacteria, six within class Alphaproteobacteria, ten within the phylum Bacteroidetes, six within the phylum Actinobacteria and seven within the phylum Firmicutes (Table 6.6). The isolates that clustered within the Gammaproteobacteria had between 85.8 - $100 \%$ sequence similarity. The isolate H12 was not closely related to the rest of the isolates and showed sequence homology of $<91 \%$ to all the other isolates. The rest of the isolates within the Gammaproteobacteria formed four groups that each had a number of identical isolates i) $\mathrm{C} 6$ and $\mathrm{C} 9$, ii) $\mathrm{C} 23$ and $\mathrm{C} 33$, iii) $\mathrm{H} 25, \mathrm{H} 34, \mathrm{H} 20$ and iv) $\mathrm{C} 13, \mathrm{C} 48, \mathrm{C} 12$ 
(Table 6.7a). Isolates that clustered within the Alphaproteobacteria had between 88.3 - $100 \%$ sequence similarity (Table 6.7b). Isolates that were identical to one another were $\mathrm{C} 51, \mathrm{C} 72$ and $\mathrm{C} 42$, with isolate $\mathrm{C} 21$ having a deviation in sequence similarity of $1 \%$ from these isolates. The isolates within the Bacteroidetes shared between 90.1 $100 \%$ sequence homology. The identical sequences were C3 and C24; C1, C34, C4 and $\mathrm{C} 73$; $\mathrm{C} 45, \mathrm{C} 5$ and $\mathrm{C} 55$. C52 and $\mathrm{H} 14$ were not related to the other isolates and only shared $\leq 88.3 \%$ and $89.9 \%$ sequence homology to the other Antarctic sea ice isolates. The closest relative of isolate C29 was an unknown Antarctic Bacteroidetes (AJ440998), sharing $94 \%$ sequence similarity. Therefore it's possible that this isolate may form a new genus within the Bacteroidetes (Table 6.7c). The isolates within the Actinobacteria were not closely related to each other. The isolate C50 shared only 93.8 \% homology with Micrococcus antarcticus suggesting this isolate may form a new genus within the Actinobacteria (Table 6.7d). The isolates C14, H32, C11, C40, and C2 within the Firmicutes shared $\geq 96.9 \%$ similarity with each and $\geq 98.1 \%$ similarity with Bacillus sp. This suggests that they all may be of the same genus but may be different species. C2 shared $100 \%$ sequence similarity with $\mathrm{C} 40$ and therefore they may be the same species (Table 6.7e). 
Table 6.6 16S rRNA sequence analysis showing the groups the isolates cluster within and the similarity with their nearest neighbour (\%). E. coli bases analysed were $95-1300$ and total number of bases analysed were 1129 using ARB (release 102).

\begin{tabular}{|c|c|c|c|}
\hline Culture & Group & Closest relative & Similarity \% \\
\hline $\mathrm{H} 12$ & Gammaproteobacteria & Rahnella aquatilis(AY253920) & 96 \\
\hline C6 & Gammaproteobacteria & Glaciecola pallidula (FR746107) & 100 \\
\hline C9 & Gammaproteobacteria & Glaciecola pallidula (FR746107) & 100 \\
\hline $\mathrm{C} 23$ & Gammaproteobacteria & Pseudomonas fluorescens (GU198126) & 99.9 \\
\hline C33 & Gammaproteobacteria & Pseudomonas fluorescens (GU198126) & 99.9 \\
\hline $\mathrm{H} 1$ & Gammaproteobacteria & Psychrobacter aquaticus (AJ830007) & 99.6 \\
\hline $\mathrm{H} 25$ & Gammaproteobacteria & Psychrobacter glacialis (AJ539102) & 99.4 \\
\hline H34 & Gammaproteobacteria & Psychrobacter glacialis (AJ539102) & 99.4 \\
\hline $\mathrm{H} 2 \mathrm{O}$ & Gammaproteobacteria & Psychrobacter glacialis (AJ539102) & 99.4 \\
\hline C46 & Gammaproteobacteria & Psychrobacter glacincola (FR691436) & 100 \\
\hline C13 & Gammaproteobacteria & Psychrobacter glacincola (FR691436) & 99.9 \\
\hline C48 & Gammaproteobacteria & Psychrobacter glacincola (FR691436) & 99.9 \\
\hline C12 & Gammaproteobacteria & Psychrobacter glacincola (FR691436) & 99.9 \\
\hline C59 & Gammaproteobacteria & Psychrobacter marincola (NR025458) & 99.6 \\
\hline C52 & Alphaproteobacteria & Brevundimonas mediterranea (AJ244706) & 100 \\
\hline $\mathrm{H} 14$ & Alphaproteobacteria & Paracoccus sp. (AM275338) & 99.2 \\
\hline C51 & Alphaproteobacteria & Uncultured Arctic sea ice bacteria (AF468357) & 98.0 \\
\hline $\mathrm{C} 72$ & Alphaproteobacteria & Uncultured Arctic sea ice bacteria (AF468357) & 98.0 \\
\hline C42 & Alphaproteobacteria & Uncultured Arctic sea ice bacteria (AF468357)) & 98.0 \\
\hline $\mathrm{C} 21$ & Alphaproteobacteria & Uncultured Arctic sea ice bacteria (AF468357) & 98.0 \\
\hline C29 & Bacteroidetes & Antarctic bacterium (AJ440998) & 94.4 \\
\hline C3 & Bacteroidetes & Polaribacter dokdonensis (DQ481463) & 98.5 \\
\hline C24 & Bacteroidetes & Polaribacter dokdonensis (DQ481463) & 98.5 \\
\hline C1 & Bacteroidetes & Psychroflexus torquis (AY167320) & 99.9 \\
\hline C34 & Bacteroidetes & Psychroflexus torquis (AY167320) & 99.9 \\
\hline C4 & Bacteroidetes & Psychroflexus torquis (AY167320) & 99.9 \\
\hline C58 & Bacteroidetes & Psychroflexus torquis (AY167320) & 99.9 \\
\hline $\mathrm{C} 73$ & Bacteroidetes & Psychroflexus torquis (AY167320) & 99.9 \\
\hline C45 & Bacteroidetes & Flavobacterium degerlachei (AJ557886) & 99.8 \\
\hline C5 & Bacteroidetes & Flavobacterium degerlachei (AJ557886) & 99.8 \\
\hline C55 & Bacteroidetes & Flavobacterium degerlachei (AJ557886) & 99.8 \\
\hline $\mathrm{C} 28$ & Actinobacteria & Arthrobacter sp. (DQ341426) & 99.9 \\
\hline C54 & Actinobacteria & Micrococcus sp. (EU394442) & 99.8 \\
\hline C50 & Actinobacteria & Micrococcus antarcticus (FJ907955) & 93.8 \\
\hline $\mathrm{C} 8$ & Actinobacteria & Micrococcus luteus (AJ536198) & 99.8 \\
\hline H36 & Actinobacteria & Rhodococcus sp. (FN397657) & 100 \\
\hline C56 & Actinobacteria & Uncultured Janibacter sp. (FN582323) & 100 \\
\hline C14 & Firmicutes & Bacillus sp. (FJ13320) & 99.7 \\
\hline H32 & Firmicutes & Bacillus sp. (FJ13320) & 98.1 \\
\hline C11 & Firmicutes & Bacillus sp. (FJ607061) & 99.6 \\
\hline C40 & Firmicutes & Bacillus sp. (AF414443) & 99.9 \\
\hline $\mathrm{C} 2$ & Firmicutes & Bacillus sp. (AF414443) & 99.9 \\
\hline $\mathrm{H} 7$ & Firmicutes & Planococcus psychrotoleratus (AY771711) & 97.5 \\
\hline $\mathrm{H} 24$ & Firmicutes & Planococcus psychrotoleratus (AY771711) & 100 \\
\hline
\end{tabular}


Table 6.7 16S rRNA gene sequences showing the \% similarity (top right section) and the \% divergence (bottom left section) between the bacterial isolates clustering within the (a) Gammaproteobacteria (b) Alphaproteobacteria (c) Bacteroidetes (d) Actinobacteria and (e) Firmicutes.

\begin{tabular}{|l|cccccccccccccc|}
\hline a) & C33 & C23 & C46 & C12 & C48 & C13 & C59 & H1 & H20 & H34 & H25 & C9 & C6 & H12 \\
\hline C33 & & 100.0 & 88.7 & 88.8 & 88.8 & 88.8 & 88.7 & 89.1 & 89.1 & 89.1 & 89.1 & 87.1 & 87.1 & 87.8 \\
C23 & 0.0 & & 88.7 & 88.8 & 88.8 & 88.8 & 88.7 & 89.1 & 89.1 & 89.1 & 89.1 & 87.1 & 87.1 & 87.8 \\
C46 & 11.3 & 11.3 & & 99.9 & 99.9 & 99.9 & 98.4 & 99.2 & 99.2 & 99.2 & 99.2 & 85.6 & 85.6 & 90.4 \\
C12 & 11.2 & 11.2 & 0.1 & & 100.0 & 100.0 & 98.3 & 99.3 & 99.3 & 99.3 & 99.3 & 85.7 & 85.7 & 90.5 \\
C48 & 11.2 & 11.2 & 0.1 & 0.0 & & 100.0 & 98.3 & 99.3 & 99.3 & 99.3 & 99.3 & 85.7 & 85.7 & 90.5 \\
C13 & 11.2 & 11.2 & 0.1 & 0.0 & 0.0 & & 98.3 & 99.3 & 99.3 & 99.3 & 99.3 & 85.7 & 85.7 & 90.5 \\
C59 & 11.3 & 11.3 & 1.6 & 1.7 & 1.7 & 1.7 & & 99.0 & 99.0 & 99.0 & 99.0 & 86.0 & 86.0 & 89.9 \\
H1 & 10.9 & 10.9 & 0.8 & 0.7 & 0.7 & 0.7 & 1.0 & & 100.0 & 100.0 & 100.0 & 86.1 & 86.1 & 90.7 \\
H20 & 10.9 & 10.9 & 0.8 & 0.7 & 0.7 & 0.7 & 1.0 & 0.0 & & 100.0 & 100.0 & 86.1 & 86.1 & 90.7 \\
H34 & 10.9 & 10.9 & 0.8 & 0.7 & 0.7 & 0.7 & 1.0 & 0.0 & 0.0 & & 100.0 & 86.1 & 86.1 & 90.7 \\
H25 & 10.9 & 10.9 & 0.8 & 0.7 & 0.7 & 0.7 & 1.0 & 0.0 & 0.0 & 0.0 & & 86.1 & 86.1 & 90.7 \\
C9 & 12.9 & 12.9 & 14.4 & 14.3 & 14.3 & 14.3 & 14.0 & 13.9 & 13.9 & 13.9 & 13.9 & & 100.0 & 88.8 \\
C6 & 12.9 & 12.9 & 14.4 & 14.3 & 14.3 & 14.3 & 14.0 & 13.9 & 13.9 & 13.9 & 13.9 & 0.0 & \\
H12 & 12.2 & 12.2 & 9.6 & 9.5 & 9.5 & 9.5 & 10.1 & 9.3 & 9.3 & 9.3 & 9.3 & 11.2 & 11.2 \\
\hline
\end{tabular}

\begin{tabular}{|l|cccccc|}
\hline b) & C52 & H14 & C51 & C72 & C42 & C21 \\
\hline C52 & & 88.3 & 88.3 & 88.3 & 88.3 & 87.9 \\
H14 & 11.7 & & 89.6 & 89.6 & 89.6 & 89.9 \\
C51 & 11.7 & 10.4 & & 100.0 & 100 & 99.0 \\
C72 & 11.7 & 10.4 & 0.0 & & 100 & 99.0 \\
C42 & 11.7 & 10.4 & 0.0 & 0.0 & & 99.0 \\
C21 & 12.1 & 10.1 & 1.0 & 1.0 & 1.0 & \\
\hline
\end{tabular}

\begin{tabular}{|l|ccccccccccc|}
\hline C) & C3 & C24 & C1 & C34 & C4 & C73 & C45 & C5 & C55 & C29 & C58 \\
\hline C3 & & 100 & 90.4 & 90.4 & 90.4 & 90.4 & 90.5 & 90.5 & 90.5 & 84.6 & 87.8 \\
C24 & 0.0 & & 90.4 & 90.4 & 90.4 & 90.4 & 90.5 & 90.5 & 90.5 & 84.6 & 87.8 \\
C1 & 9.6 & 9.6 & & 100 & 100 & 100 & 90.1 & 90.1 & 90.1 & 84.3 & 98.6 \\
C34 & 9.6 & 9.6 & 0.0 & & 100 & 100 & 90.1 & 90.1 & 90.1 & 84.3 & 98.6 \\
C4 & 9.6 & 9.6 & 0.0 & 0.0 & & 100 & 90.1 & 90.1 & 90.1 & 84.3 & 98.6 \\
C73 & 9.6 & 9.6 & 0.0 & 0.0 & 0.0 & & 90.1 & 90.1 & 90.1 & 84.3 & 98.6 \\
C45 & 9.5 & 9.5 & 9.9 & 9.9 & 9.9 & 9.9 & & 100 & 100 & 91.4 & 88.0 \\
C5 & 9.5 & 9.5 & 9.9 & 9.9 & 9.9 & 9.9 & 0.0 & & 100 & 91.4 & 88.0 \\
C55 & 9.5 & 9.5 & 9.9 & 9.9 & 9.9 & 9.9 & 0.0 & 0.0 & & 91.4 & 88.0 \\
C29 & 15.4 & 15.4 & 15.7 & 15.7 & 15.7 & 15.7 & 8.6 & 8.6 & 8.6 & & 83.6 \\
C58 & 12.2 & 12.2 & 1.4 & 1.4 & 1.4 & 1.4 & 12.0 & 12.0 & 12.0 & 16.4 & \\
\hline
\end{tabular}


Table 6.7. Continued.

\begin{tabular}{|l|cccccc|}
\hline d) & C28 & C8 & H36 & CA50 & CA54 & CA56 \\
\hline C28 & & 96.3 & 90.1 & 89.9 & 96.9 & 93.8 \\
C8 & 3.7 & & 89.8 & 93.8 & 97.8 & 93.8 \\
H36 & 9.9 & 10.2 & & 83 & 86.7 & 89.4 \\
CA50 & 10.1 & 6.2 & 17 & & 93 & 88.5 \\
CA54 & 3.1 & 2.2 & 13.3 & 7 & & 92.5 \\
CA56 & 6.2 & 6.1 & 10.6 & 11.5 & 6.5 & \\
\hline
\end{tabular}

\begin{tabular}{|l|ccccccc|}
\hline $\mathrm{e})$ & $\mathrm{H} 24$ & $\mathrm{H} 7$ & $\mathrm{CA} 14$ & $\mathrm{H} 32$ & $\mathrm{CA} 11$ & $\mathrm{CA} 40$ & $\mathrm{CA} 2$ \\
\hline $\mathrm{H} 24$ & & 97.5 & 97.7 & 96.3 & 96.3 & 96.3 & 96.5 \\
$\mathrm{H} 7$ & 2.5 & & 95.3 & 94.2 & 94.2 & 94.2 & 94.3 \\
$\mathrm{CA} 14$ & 2.3 & 4.7 & & 97.0 & 97.0 & 97.0 & 96.9 \\
H32 & 3.7 & 5.8 & 3.0 & & 96.7 & 96.7 & 96.6 \\
CA11 & 3.7 & 5.8 & 3.0 & 3.3 & & 100 & 97.9 \\
CA40 & 3.7 & 5.8 & 3.0 & 3.3 & 0 & & 97.9 \\
CA2 & 3.5 & 5.7 & 3.1 & 3.4 & 2.1 & 2.1 & \\
\hline
\end{tabular}




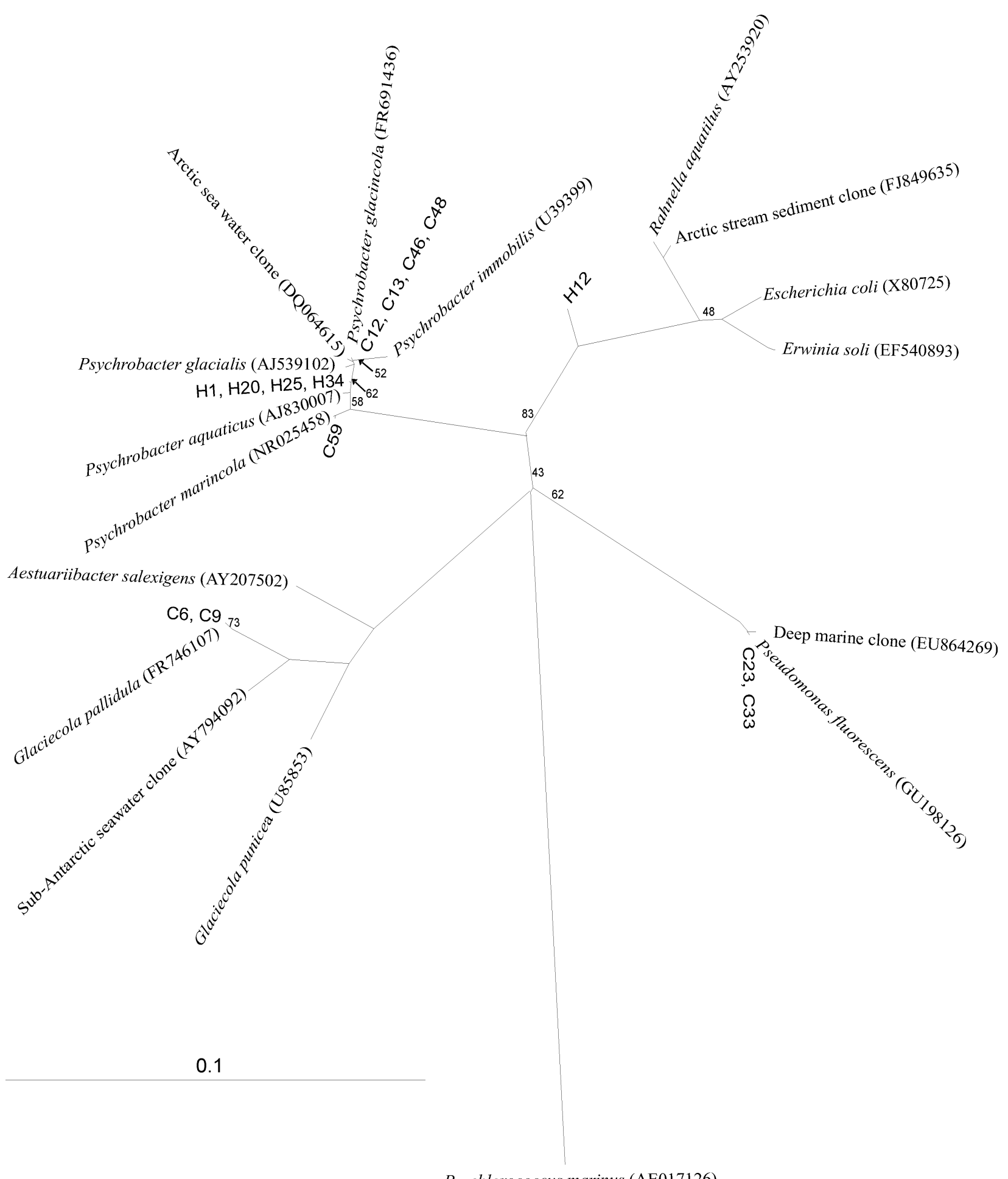

Prochlorococcus marinus (AE017126)

Figure 6.9 Dendrogram showing the estimated phylogenetic relationships between 16S rRNA gene sequences from Gammaproteobacteria isolated from Antarctic sea ice using 1308 bases from E.coli positions 35-1450. Bootstrap values that are less than $90 \%$ are shown. 


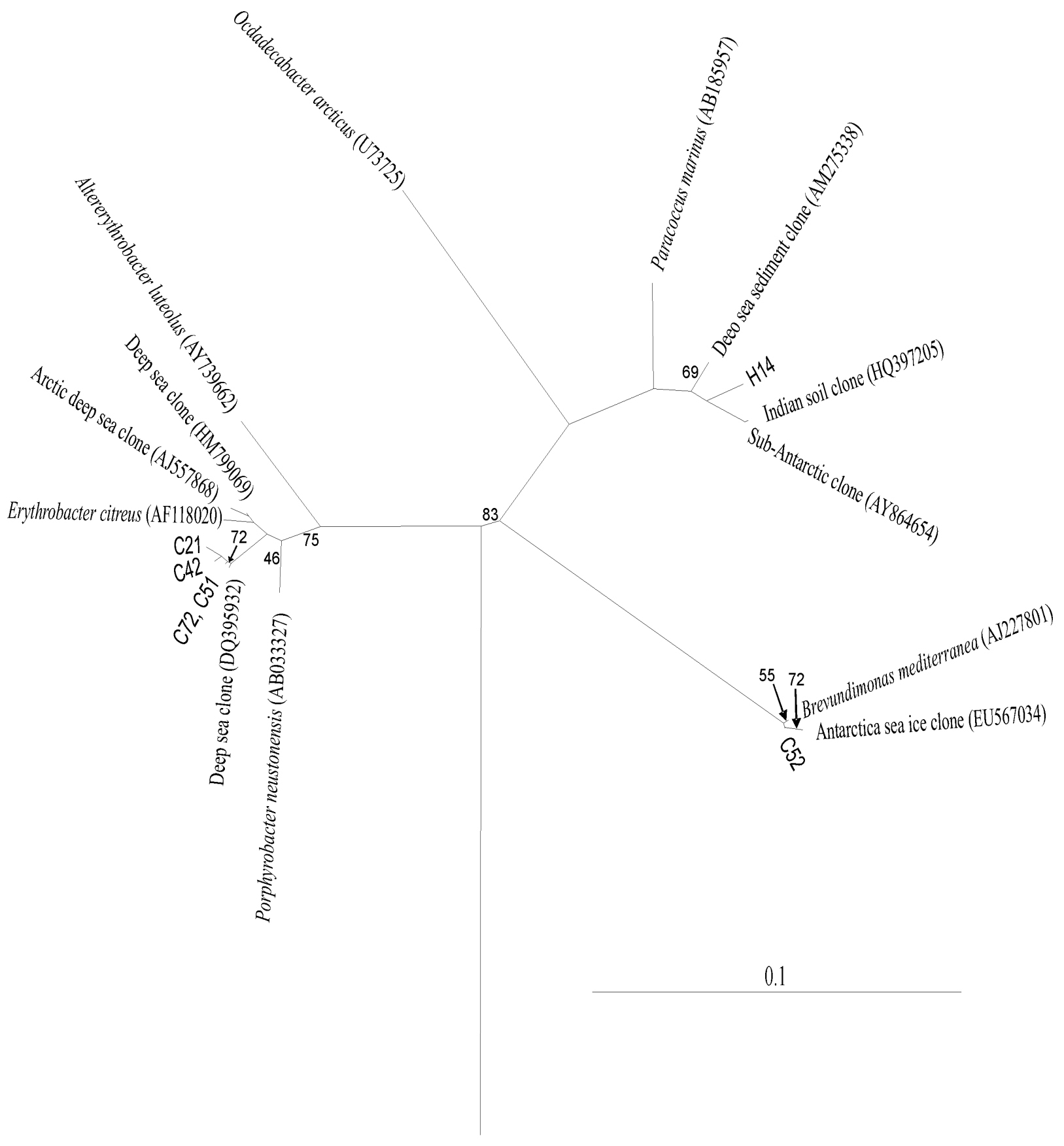

Escherichia coli (X80725)

Figure 6.10 Dendrogram showing the estimated phylogenetic relationships between 16S rRNA gene sequences from Alphaproteobacteria isolated from Antarctic sea ice using 1308 bases from E.coli positions 35-1450. Bootstrap values that are less than $90 \%$ are shown. 


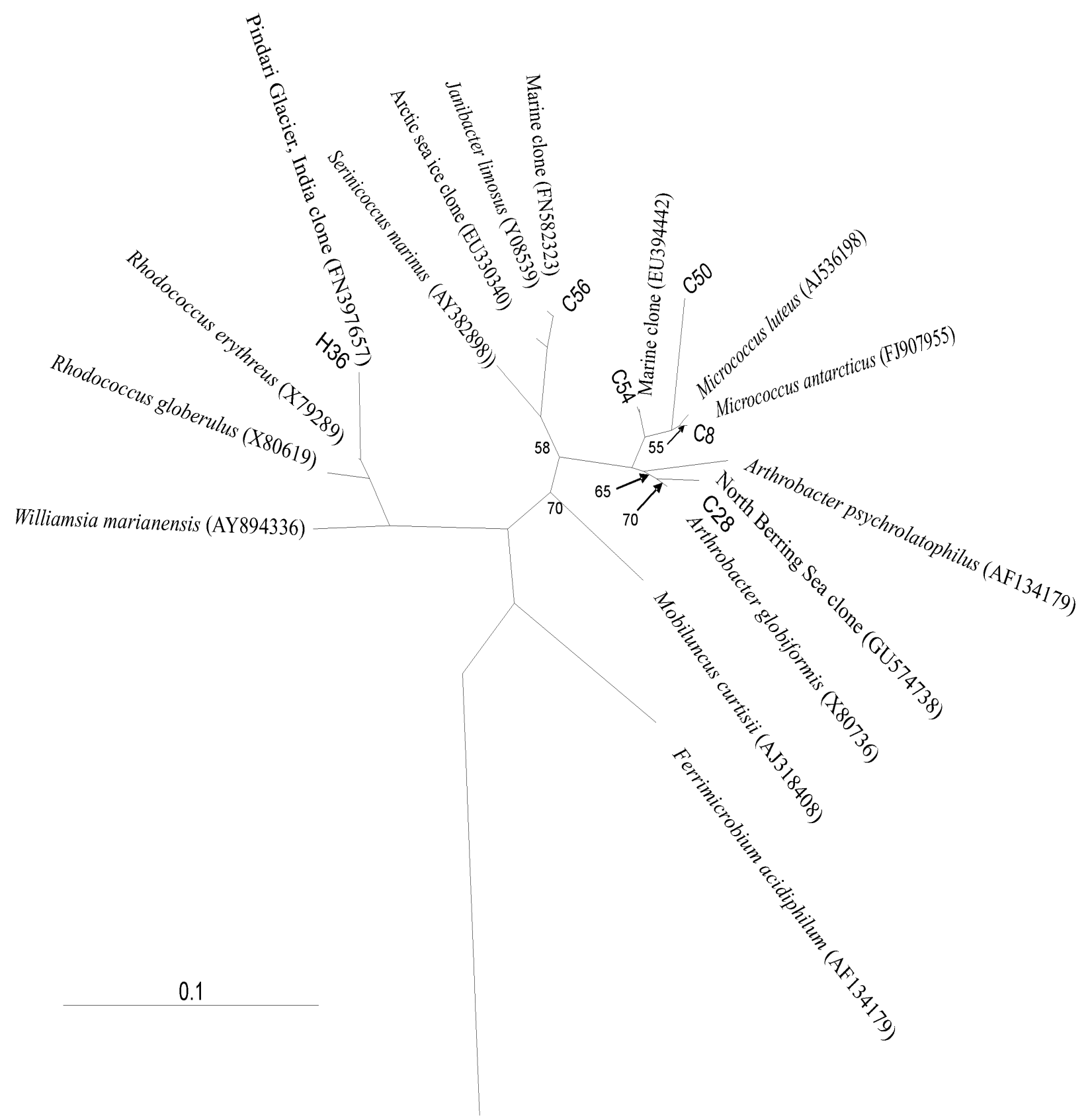

Escherichia coli (X80725)

Figure 6.11 Dendrogram showing the estimated phylogenetic relationships between 16S rRNA gene sequences from Actinobacteria isolated from Antarctic sea ice using 782 bases from E.coli positions 495-1300. Bootstrap values that are less than $90 \%$ are shown. 


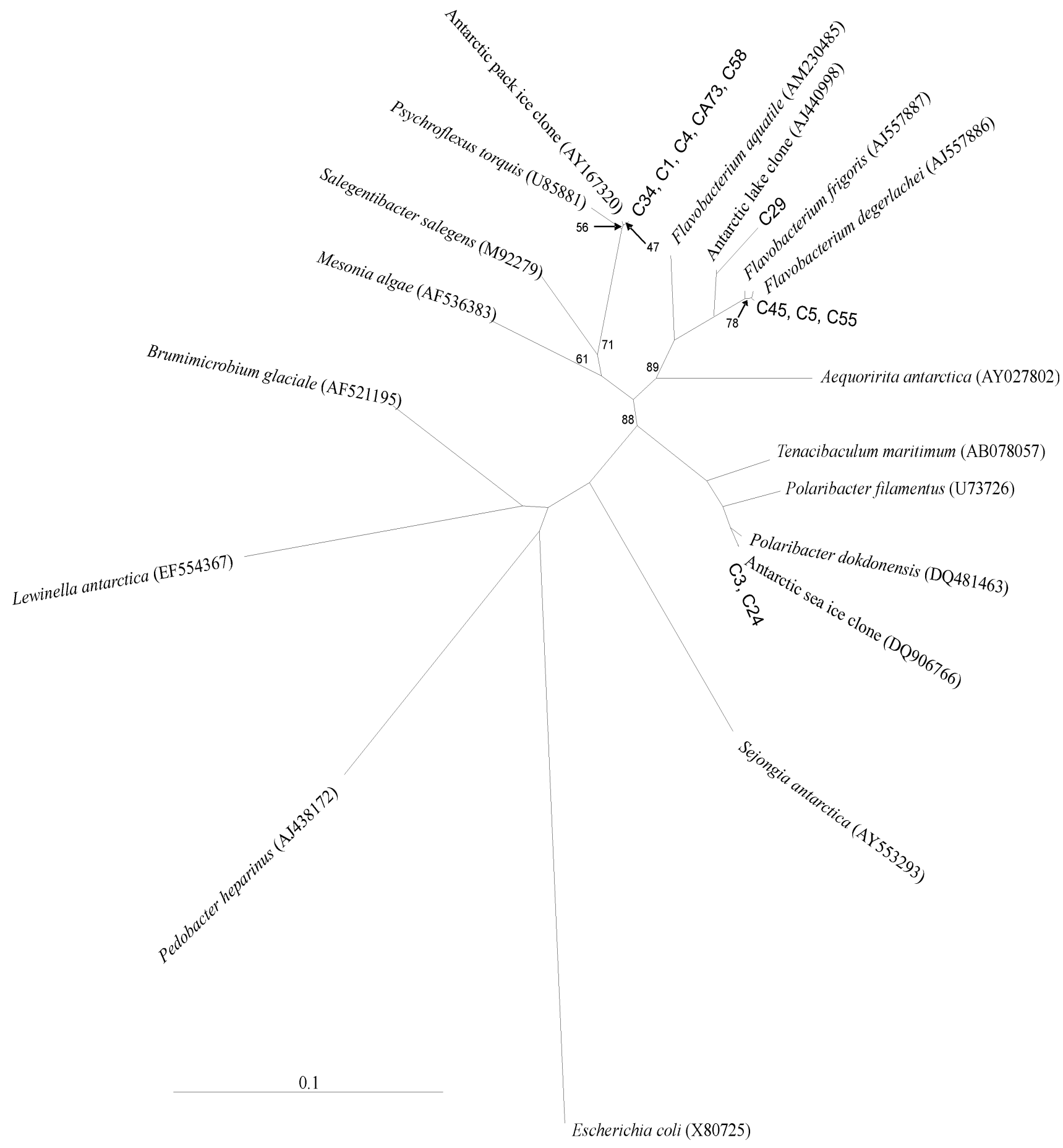

Figure 6.12 Dendrogram showing the estimated phylogenetic relationships between 16S rRNA gene sequences from Bacteroidetes isolated from Antarctic sea ice using 1247 bases from E.coli positions 73-1247. Bootstrap values that are less than $90 \%$ are shown. 


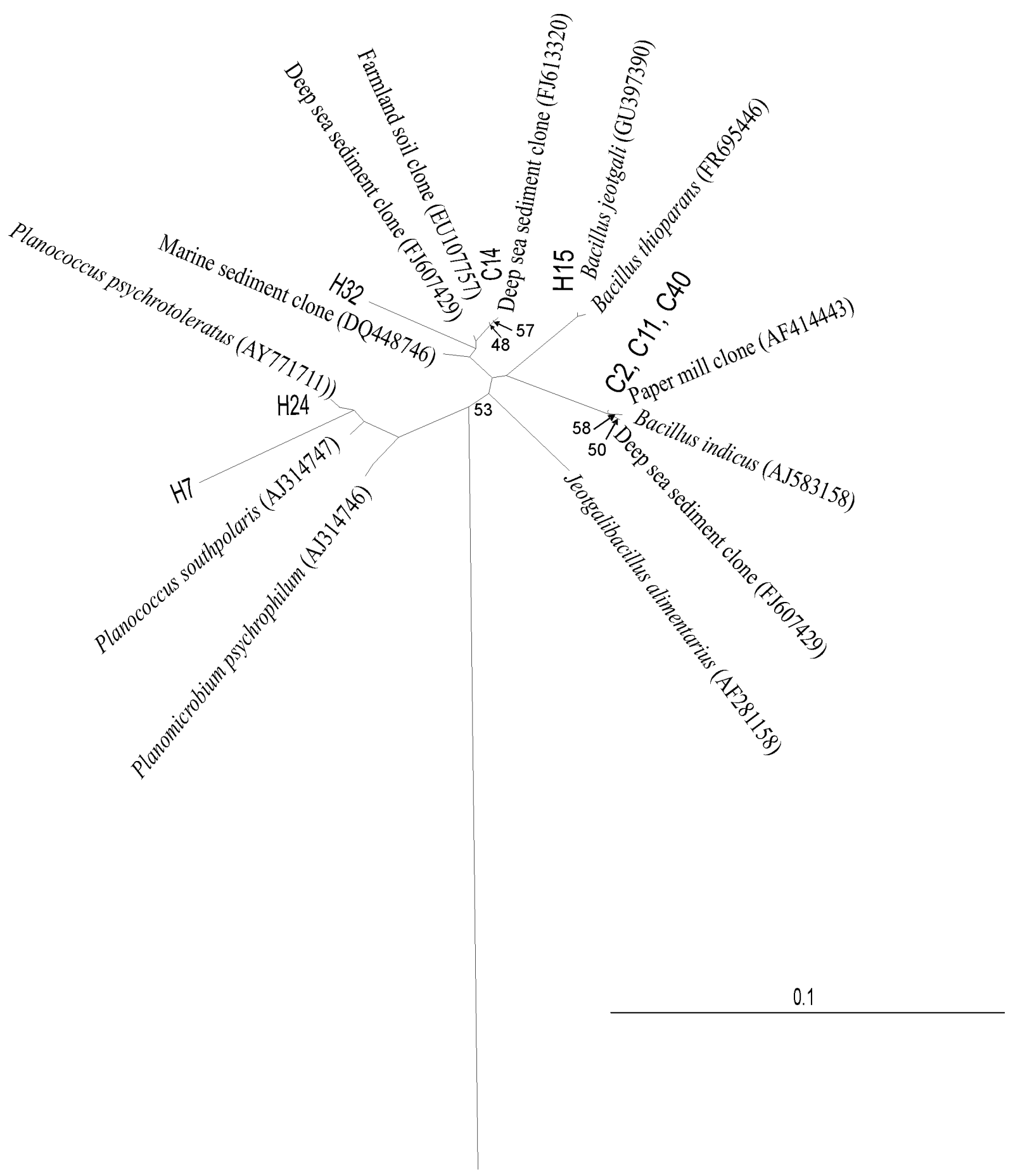

Escherichia coli (X80725)

Figure 6.13 Dendrogram showing the estimated phylogenetic relationships between 16S rRNA gene sequences from Firmicutes isolated from Antarctic sea ice using 856 bases from E.coli positions 4951360. Bootstrap values that are less than $90 \%$ are shown. 


\subsubsection{Culture independent bacterial diversity}

\subsubsection{Total bacterial diversity in Antarctic sea ice}

To determine rarefaction curves, operational taxonomic units (OTUs) were identified at genetic distances of $0,3,5$, and $10 \%$ sequence dissimilarity. At $3 \%$ sequence divergence the rarefaction curves reached saturation at $~ 3,000$ (Fig 6.14), indicating that the 22,000 sequences obtained in this study will have covered almost the full extent of taxonomic diversity in Antarctic sea ice at the species level.

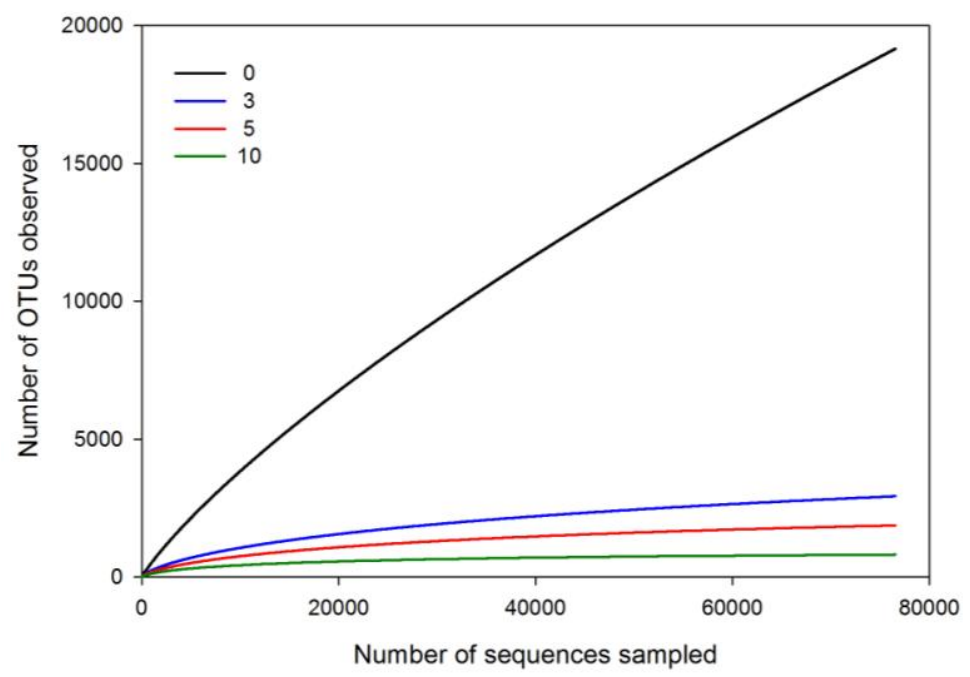

Figure 6.14 Rarefaction curves at 0,3,5 and $10 \%$ sequence dissimilarity.

The total bacterial 16S rRNA diversity in Antarctic sea ice was investigated using 454 sequencing to class level (Figure 6.15). The dominant groups were the Gram positive Actinobacteria, the Alphaproteobacteria, Betaproteobacteria and Gammaproteobacteria, the Flavobacteria and Sphingobacteria within the phylum Bacteroidetes, the Firmicutes, and the archaea. The Flavobacteria were the most dominant group, comprising $46.9 \%$ of all OTUs identified from Antarctic sea ice. The Gammaproteobacteria was the second most dominant group, comprising $24.9 \%$ of the diversity found from 454 sequencing. The other groups were found in lower abundance of $<10 \%$ of the total number of OTUs identified. 


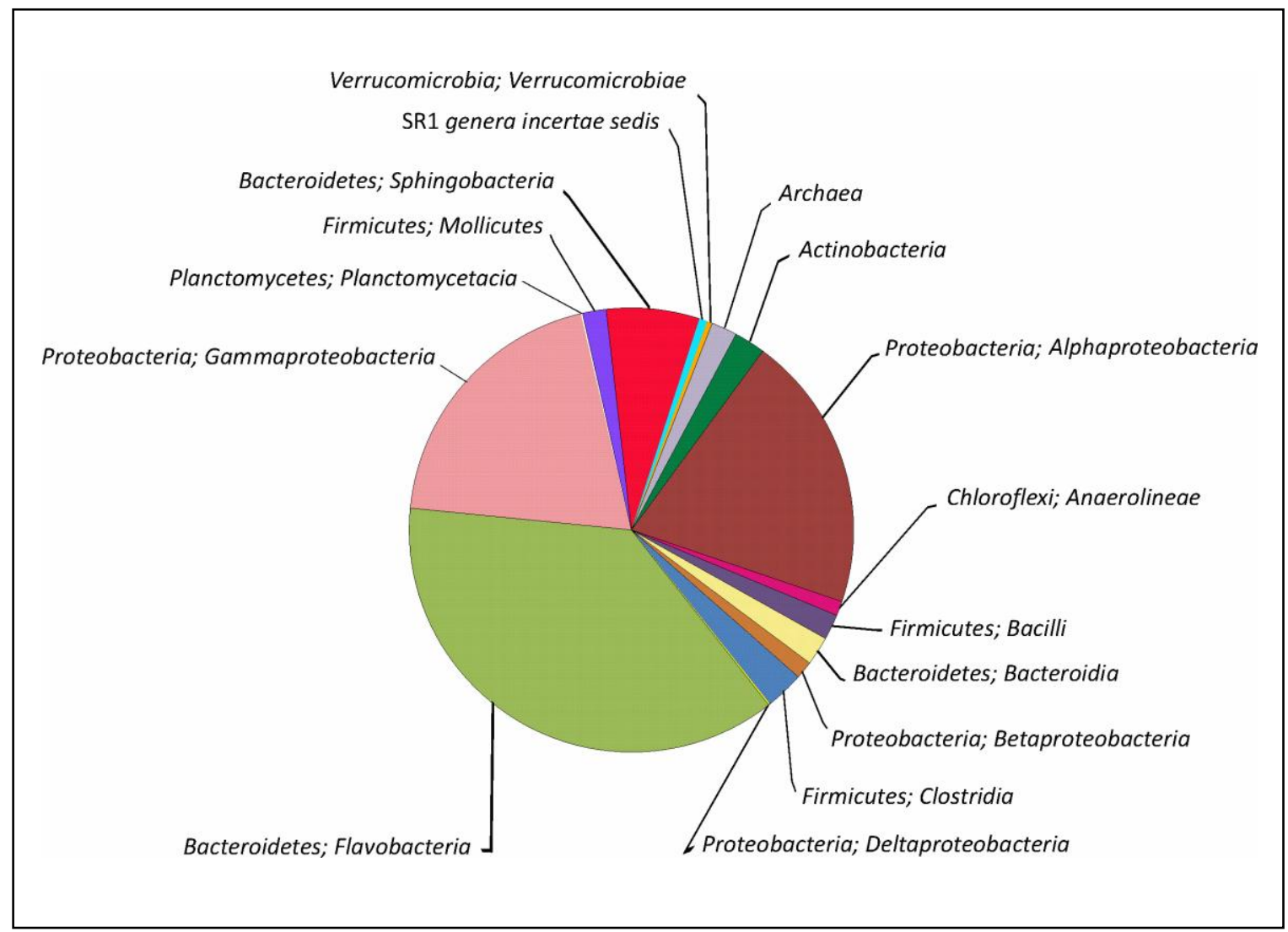

Figure 6.15 The main groups found in Antarctic sea ice using 454 sequencing (DNA and RNA).

These dominant groups were then investigated separately to genus level. Within the Actinobacteria, the majority of the OTUs were Actinomycetales (85.5\%) (Fig 6.16). The most abundant OTUs were identified to the genera Williamsia (16\%) and Rothia $(13 \%)$. 


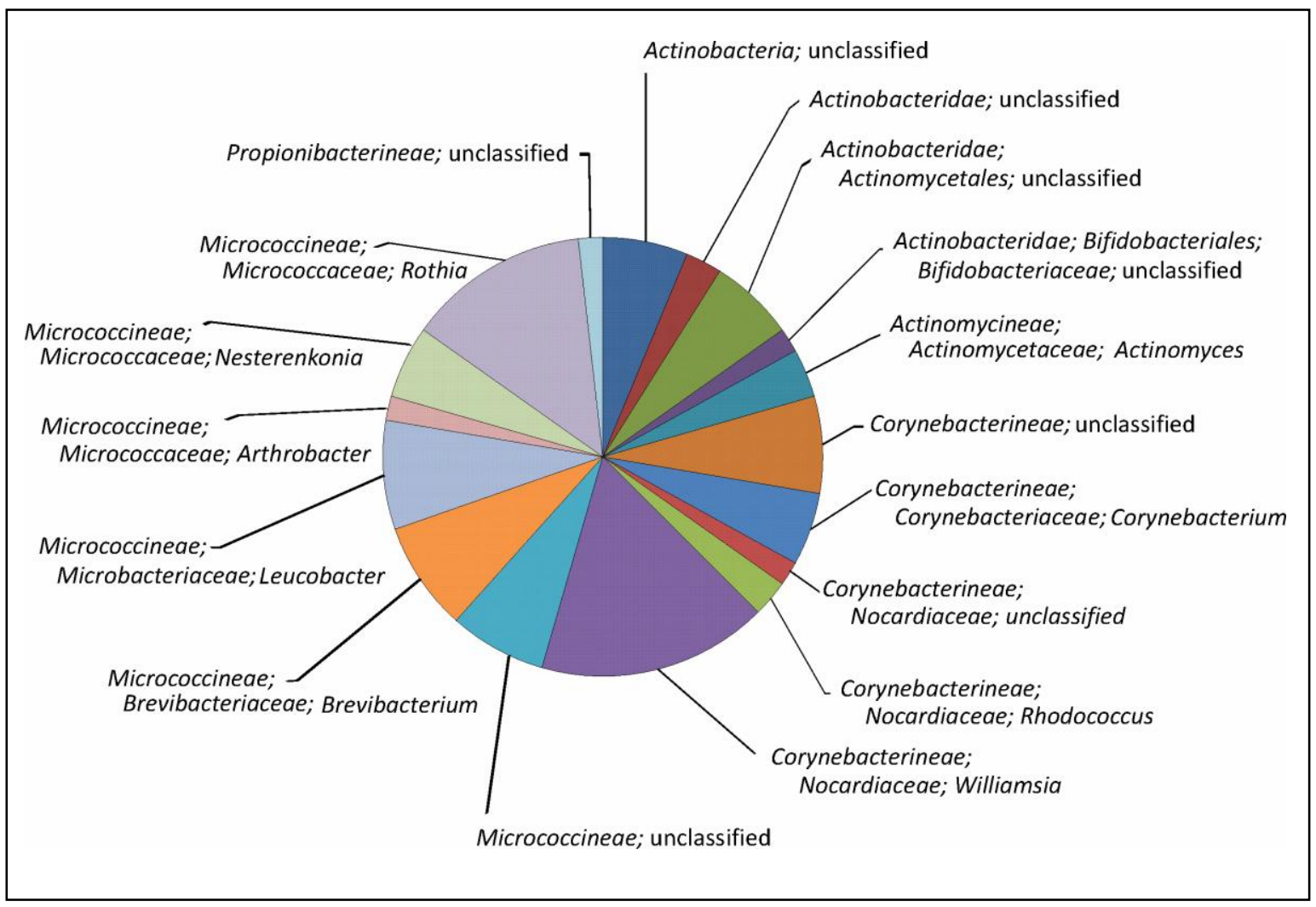

Figure 6.16 Identification of OTUs (genera level) within the Actinobacteria (DNA and RNA).

The majority of the Alphaproteobacterial OTUs (94\%) identified belonged to the order Rhodobacterales (Figure 6.17). The genera Octadecabacter and Thalassobacter comprised $38.8 \%$ and $38.3 \%$ of the OTUs within the Actinobacteria. Rare OTUs were identified as belonging to Paracoccus, Rhodobacter, Roseovarius, Rubellimicrobium, Ruegeria and Seohaeicola. OTUs from the orders Rhizobiales, Rickettsiales and Sphingomonadales were also in low abundance. The majority (64 $\%$ ) of the OTUs belonging to the class Betaproteobacteria were not identified further. A small percentage (20\%) of OTUs was classified as belonging to the order Burkholderiales, with $4 \%$ of the OTUs identified as Comamonas. There were two predominant genera belonging to the Gammaproteobacteria, Glaciecola $(30.9 \%)$ and Psychrobacter (29.7\%). Other abundant genera were Granulosicoccus (7.4\%), Neptunomonas (5.8\%), Psychromonas (5.1\%) and Colwellia (4.1\%) (Figure 6.18). 


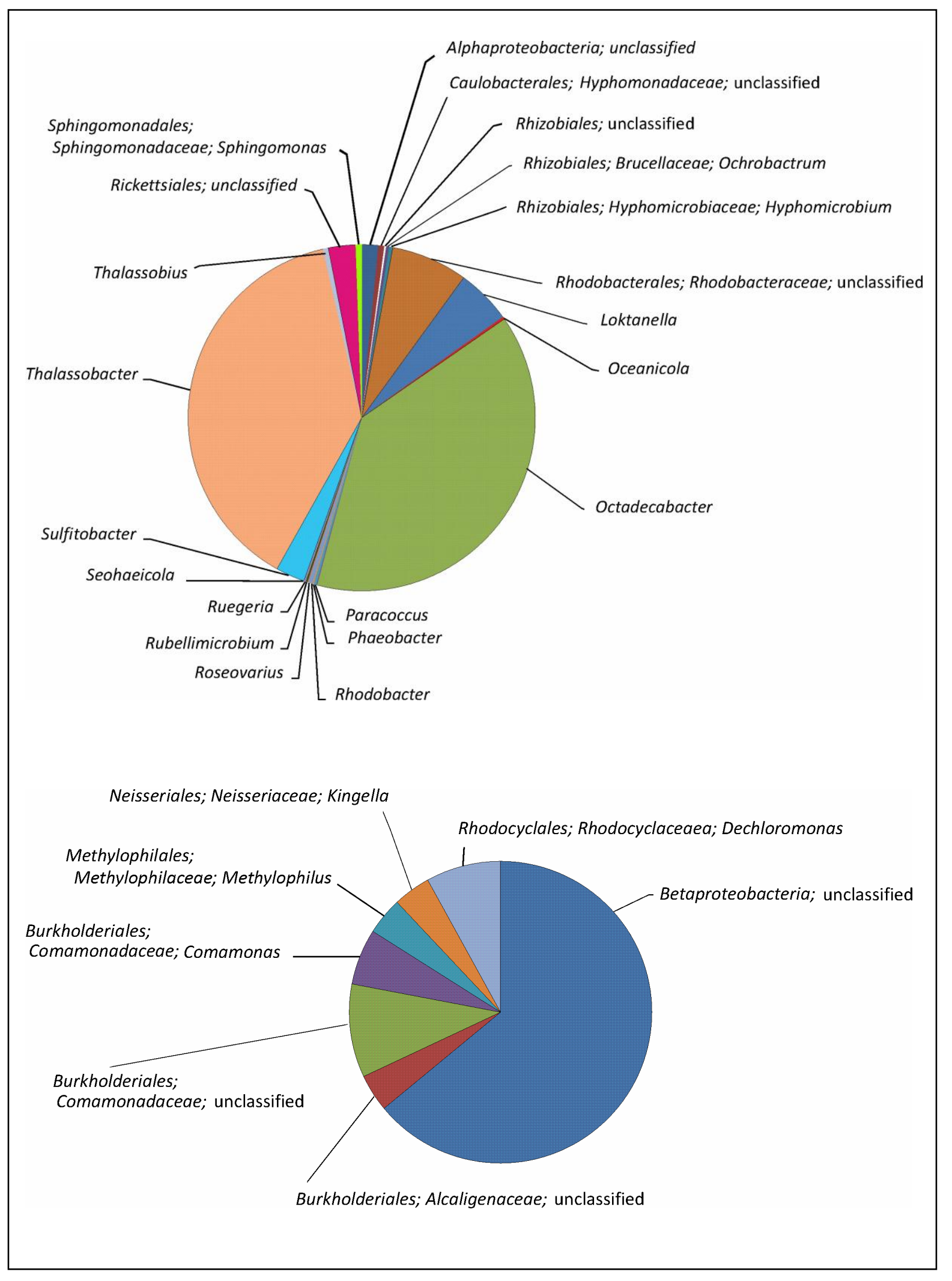

Figure 6.17 Identification of OTUs within the Alphaproteobacteria and Betaproteobacteria (DNA and RNA). 


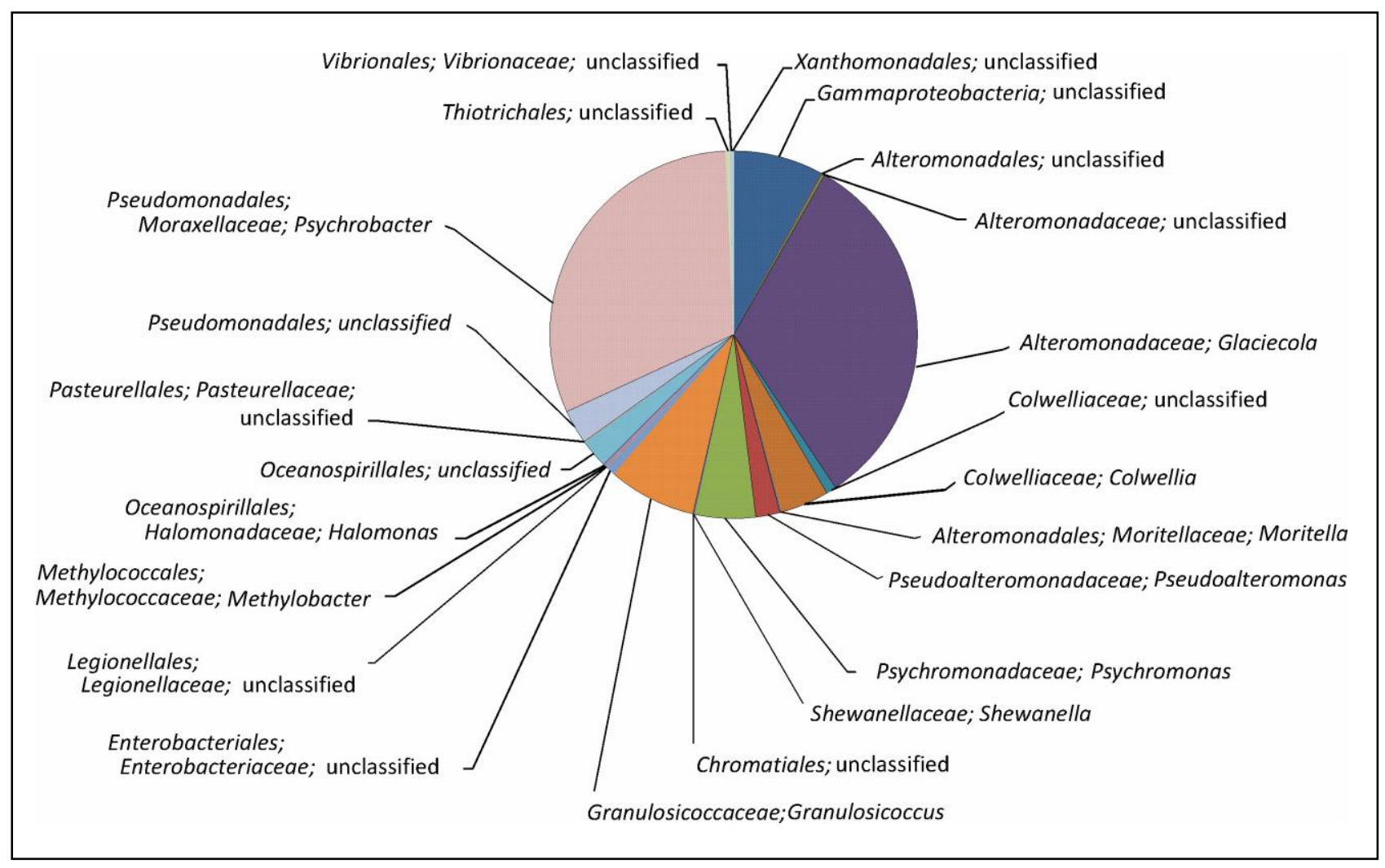

Figure 6.18 Identification of OTUs to genera within the Gammaproteobacteria (DNA and RNA).

The OTUs identified as belonging to the Firmicutes were further classified as Bacilli or Clostridia. A total of $41.4 \%$ of the OTUs were classified as Streptococcus, within the Bacilli. The genus Halobacteroides, within the Clostridia contained $38.2 \%$ of the OTUs. The rest of the OTUs classified as Bacilli or Clostridia were in low abundance (Figure 6.19). 


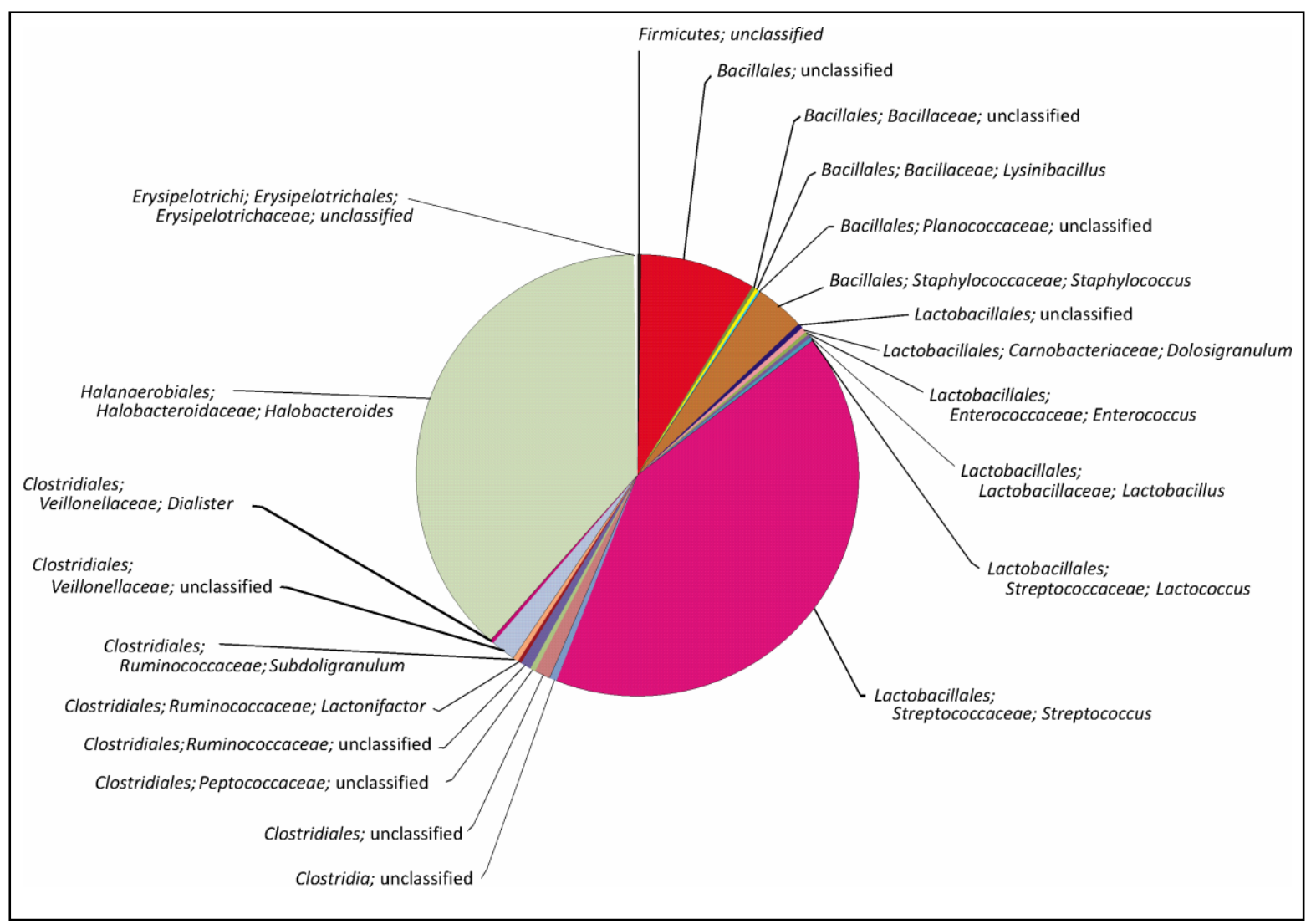

Figure 6.19 Identification of OTUs to genera within the Bacilli (right) and Clostridia (left) of the Firmicutes (DNA and RNA).

A total of $88.6 \%$ of the OTUs identified as Flavobacteria were classified as Polaribacter spp. A further $5.8 \%$ of the OTUs were identified as Winogradskyella spp., but the rest were in low abundance. The Sphingobacteria were comprised of three dominant genera identified as Lewinella (39.2\% of OTUs), Haliscomenobacter (28.8\%) and Aureispira (18.2\%) (Figure 6.20). 


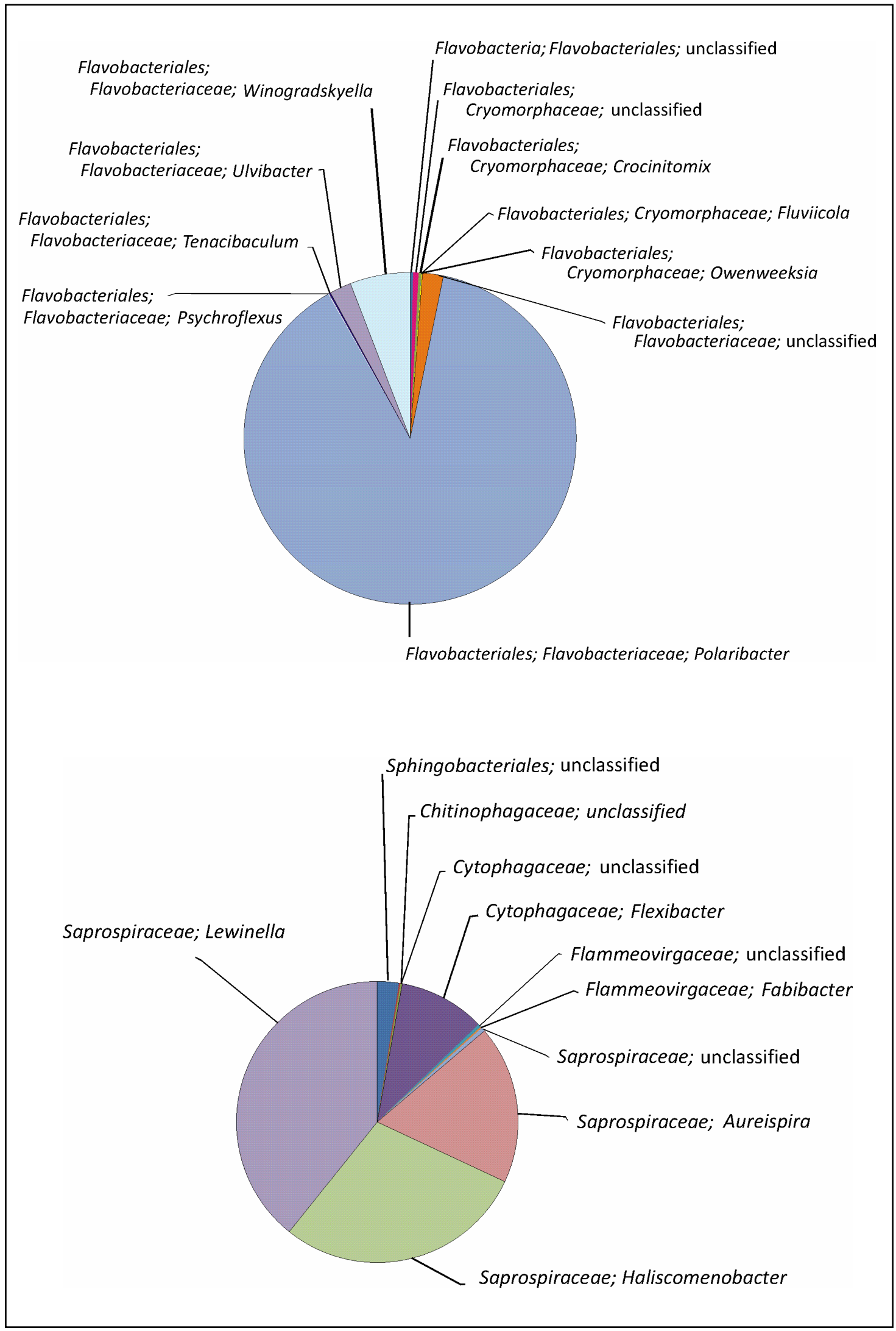

Figure 6.20 Identification of OTUs to genera within the classes Flavobacteria and order Spingobacteriales; Sphingobacteria of the Bacteroidetes (DNA and RNA). 
Lastly, the OTUs within the archaea were investigated. The majority of the archaea fell into the Euryarchaeota (46. 7 \%) or Crenarchaeota (42.4\%) with the remainder as unclassified archaea (10.9\%). Pyrobaculum comprised $38.6 \%$ of the archaeal community (Figure 6.21).

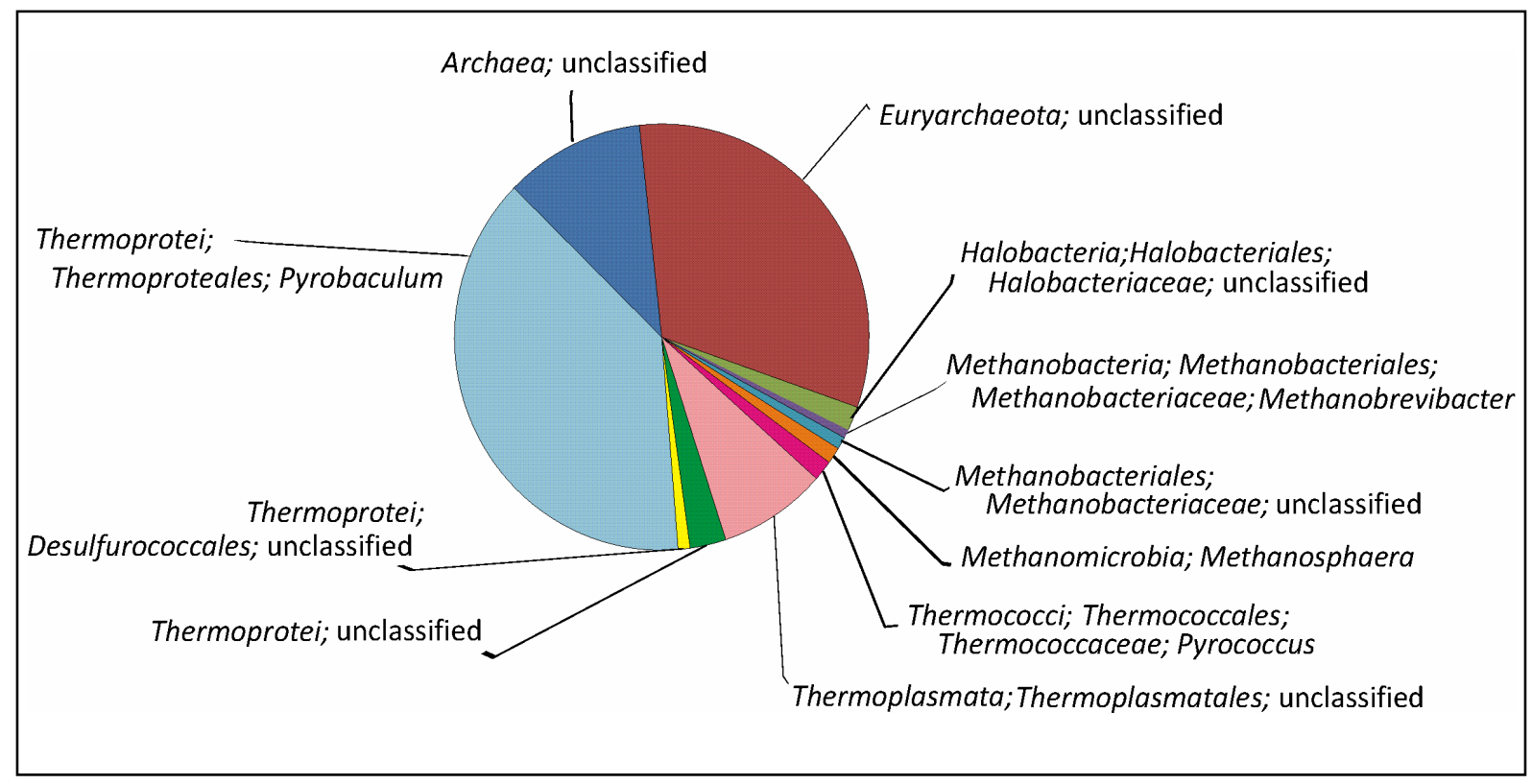

Figure 6.21 Identification of OTUs to genera within the Euryarchaeota (right of graph) and Crenarchaeota (left of graph) of the archaea (DNA and RNA).

\subsubsection{Bacterial diversity between sites}

A total of 174 OTUs were identified from the 22 sea ice bacterial communities from Terra Nova Bay (TNB), Granite Harbour (GH), Cape Evans (CE) and McMurdo Station (McM). Bacterial communities clustered into 5 significantly different groups determined by the SIMPROF test. The first two groups contained samples from Cape Evans. The 3rd group consisted of Granite Harbour samples with one from Cape Evans. The $4^{\text {th }}$ group contained bacterial communities from McMurdo Station, whereas the last group contained communities from both McMurdo Station and Terra Nova Bay. Groups 2 and 3 were separated at the $55 \%$ similarity level and shared $~ 40$ $\%$ community similarity with groups 1 and 4 from CE08 and McM08 respectively. Groups 1-4 shared < $40 \%$ similarity with Group 5. 


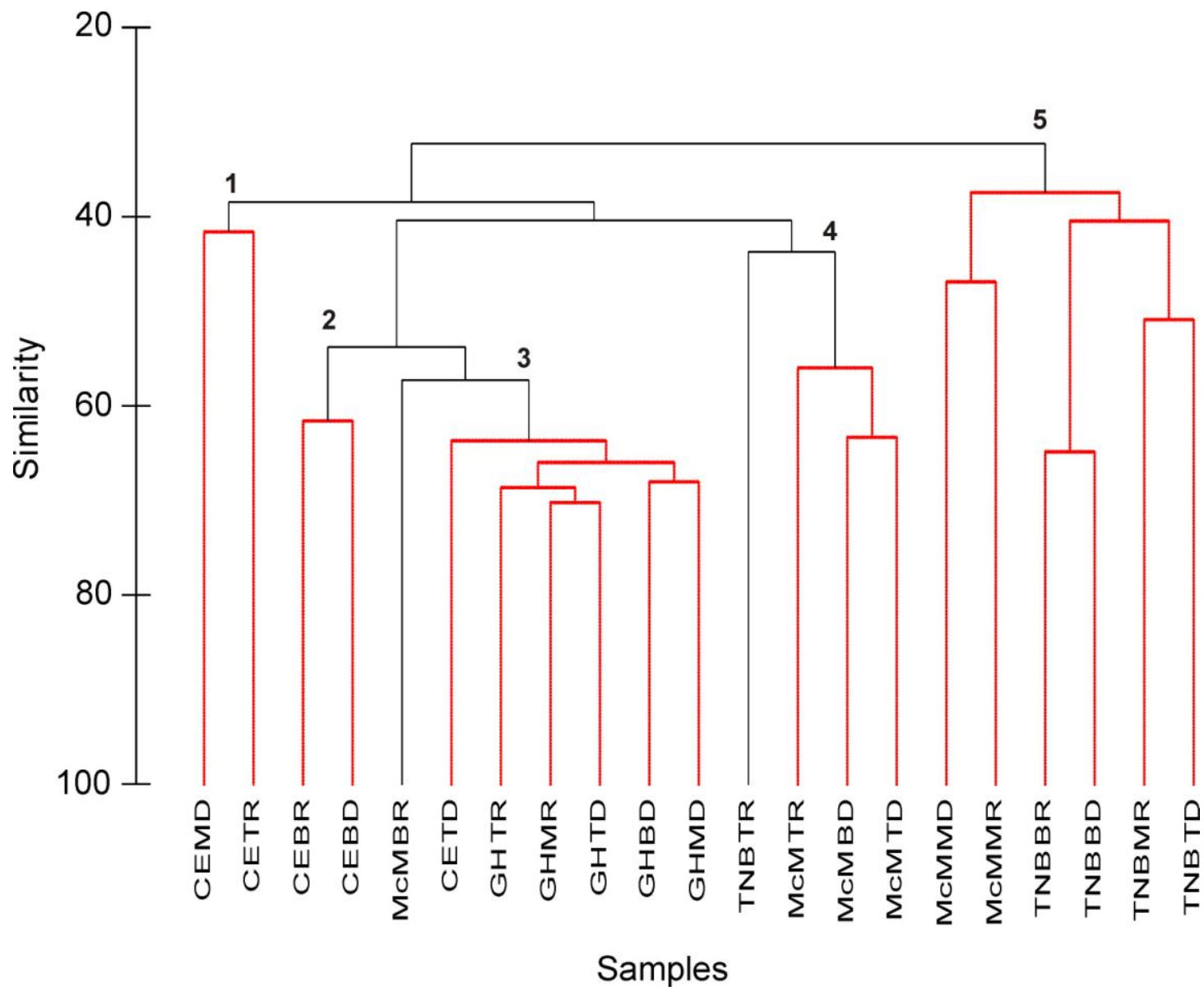

Figure 6.22 Cluster analysis based on the OTU diversity determined from each site by 454 sequencing showing the five distinct groups. Similarities were calculated using the Bray-Curtis measure and the red lines indicate clusters which pass the SIMPROF test.

Of the 174 OTUs, only $28.8 \%$ were found at TNB and $31.4 \%$ at GH (Figure 6.23). Approximately half of the OTUs were found at CE (52.9\%). The highest number of OTUs $(62.4 \%)$ occurred at McMurdo Station. A small proportion, $11.3 \%$ of the OTUs, occurred at all four sites. Over half of the OTUs (52.6\%) were found at one site only. Those found across all four sites were generally in higher abundance. Those found at only one site were generally rare occurring in $<0.1 \%$ of the community. The most abundant OTUs belonged to the Flavobacteria and Gammaproteobacteria. Terra Nova Bay was dominated by Polaribacter (62.7\% of the community; Table 6.8) whereas the other sites had more of a spread of OTUs (Figure 6.23). 


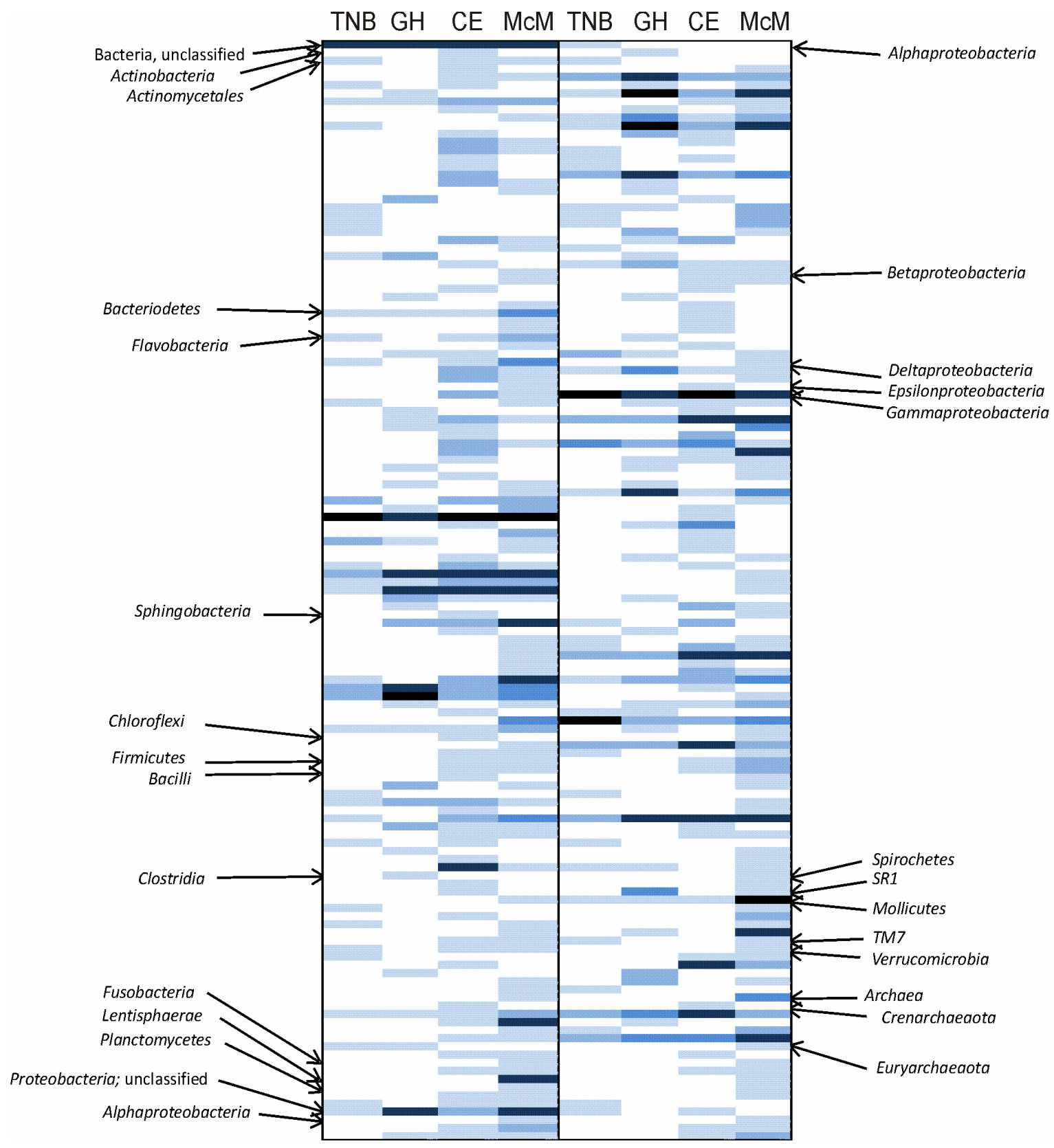

Figure 6.23 Heat map comparing the relative abundance (RA \%) of OTUs from 454 pyrosequencing across TNB, GH, CE and McM. Bacterial Phyla shown are Actinobacteria, Bacteroidetes, Chloroflexi, Firmicutes, Fusobacteria, Lentisphaerae, Planctomycetes Proteobacteria, Spirochetes, Mollicutes, Verrucomicrobia, Crenarchaeota and Euryarchaeota with further divisions to Class. Bacterial OTUs (at $95 \%$ genera level) fall under their designated Class but are not specified. OTUs that were not found at a particular site are coloured in white $=0 \%$ with increasing increments of lightest blue $=0-0.1 \%$, lighter blue $=0.1-0.5 \%$, blue $=0.5-1 \%$, darker blue $=1-10 \%$ and the most abundant OTUs in black $=10-50 \%$. 
Table 6.8 The 10 most abundant groups to genus level, as determined by their relative abundance (RA $\%$ ) from 454 pyrosequencing, from Terra Nova Bay (TNB), Granite Harbour (GH), Cape Evans (CE) and McMurdo Station (McM).

\begin{tabular}{|c|c|}
\hline & RA \%TNB \\
\hline Flavobacteria; Flavobacteriales; Flavobacteriaceae; Polaribacter & 62.65 \\
\hline Gammaproteobacteria; Pseudomonadales; Moraxellaceae; Psychrobacter & 20.06 \\
\hline Gammaproteobacteria; Alteromonadales; Alteromonadaceae; Glaciecola & 10.53 \\
\hline Bacteria; unclassified & 1.05 \\
\hline \multicolumn{2}{|l|}{ Gammaproteobacteria; Alteromonadales; Pseudoalteromonadaceae; } \\
\hline Pseudoalteromonas & 0.89 \\
\hline Alphaproteobacteria; Rhodobacterales; Rhodobacteraceae; Loktanella & 0.35 \\
\hline Betaproteobacteria; unclassified & 0.34 \\
\hline Gammaproteobacteria; Oceanospirillales; Oceanospirillaceae; Neptunomonas & 0.34 \\
\hline Gammaproteobacteria; Pseudomonadales; Pseudomonadaceae; Pseudomonas & 0.33 \\
\hline \multirow[t]{2}{*}{ Sphingobacteria; Sphingobacteriales; Saprospiraceae; Lewinella } & 0.30 \\
\hline & $\mathrm{RA} \% \mathrm{GH}$ \\
\hline Alphaproteobacteria; Rhodobacterales; Rhodobacteraceae; Thalassobacter & 15.54 \\
\hline Alphaproteobacteria; Rhodobacterales; Rhodobacteraceae; Octadecabacter & 11.89 \\
\hline Sphingobacteria; Sphingobacteriales; Saprospiraceae; Lewinella & 10.45 \\
\hline Bacteria; unclassified & 9.93 \\
\hline Flavobacteria; Flavobacteriales; Flavobacteriaceae; Polaribacter & 9.88 \\
\hline Gammaproteobacteria; Chromatiales; Granulosicoccaceae; Granulosicoccus & 9.50 \\
\hline Sphingobacteria; Sphingobacteriales; Saprospiraceae; Haliscomenobacter & 7.27 \\
\hline Flavobacteria; Flavobacteriales; Flavobacteriaceae; Winogradskyella & 5.22 \\
\hline Alphaproteobacteria; Rhodobacterales; Rhodobacteraceae; unclassified & 2.26 \\
\hline \multirow[t]{2}{*}{ Proteobacteria; unclassified } & 2.10 \\
\hline & $\mathrm{RA} \% \mathrm{CE}$ \\
\hline Flavobacteria; Flavobacteriales; Flavobacteriaceae; Polaribacter & 41.46 \\
\hline Gammaproteobacteria; Alteromonadales; Alteromonadaceae; Glaciecola & 12.58 \\
\hline Bacteria; unclassified & 9.79 \\
\hline Bacilli; Lactobacillales; Streptococcaceae; Streptococcus & 7.46 \\
\hline Gammaproteobacteria; Oceanospirillales; Oceanospirillaceae; Neptunomonas & 3.31 \\
\hline Gammaproteobacteria; unclassified & 3.19 \\
\hline Gammaproteobacteria; Alteromonadales; Colwelliaceae; Colwellia & 2.04 \\
\hline Flavobacteria; Flavobacteriales; Flavobacteriaceae; Winogradskyella & 1.67 \\
\hline Crenarchaeota; Thermoprotei; Thermoproteales; Thermoproteaceae; Pyrobaculum & 1.64 \\
\hline \multirow[t]{2}{*}{ Gammaproteobacteria; Pseudomonadales; Pseudomonadaceae; Pseudomonas } & 1.60 \\
\hline & RA \% McM \\
\hline Flavobacteria; Flavobacteriales; Flavobacteriaceae; Polaribacter & 16.73 \\
\hline Mollicutes; Acholeplasmatales; Acholeplasmataceae; Acholeplasma & 11.73 \\
\hline Clostridia; Halanaerobiales; Halobacteroidaceae; Halobacteroides & 6.21 \\
\hline Gammaproteobacteria; Alteromonadales; Psychromonadaceae; Psychromonas & 5.53 \\
\hline Alphaproteobacteria; Rhodobacterales; Rhodobacteraceae; Octadecabacter & 5.32 \\
\hline Flavobacteria; Flavobacteriales; Flavobacteriaceae; Winogradskyella & 4.89 \\
\hline Gammaproteobacteria; Alteromonadales; Alteromonadaceae; Glaciecola & 4.77 \\
\hline Bacteria; unclassified & 4.21 \\
\hline Sphingobacteria; Sphingobacteriales; Saprospiraceae; Aureispira & 4.19 \\
\hline Gammaproteobacteria; Oceanospirillales; Oceanospirillaceae; Neptunom & 2.58 \\
\hline
\end{tabular}




\subsubsection{Bacterial diversity between the rRNA and rDNA communities}

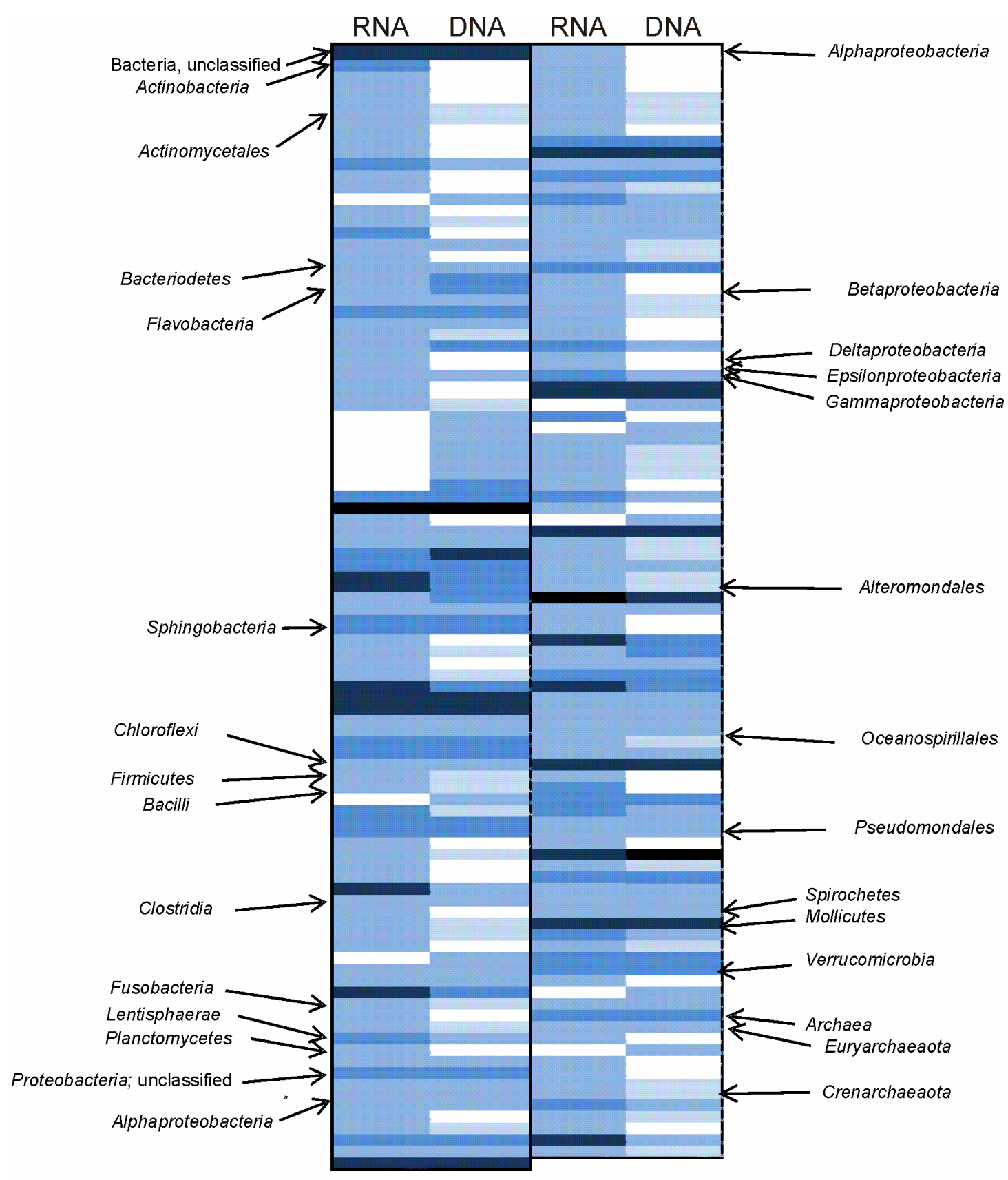

Figure 6.24 Heat map showing the relative abundance (RA \%) of genera from 454 pyrosequencing in the RNA and DNA populations. Bacterial Phyla shown are Actinobacteria, Bacteroidetes, Chloroflexi, Firmicutes, Fusobacteria, Lentisphaerae, Planctomycetes Proteobacteria, Spirochetes, Mollicutes, Verrucomicrobia, Crenarchaeota and Euryarchaeota with further divisions to Class. Bacterial OTUs (at $95 \%$ genera level) fall under their designated Class but are not specified. OTUs that were not found at a particular site are coloured in white $=0 \%$ with increasing increments of lightest blue $=0-0.1 \%$, lighter blue $=0.1-0.5 \%$, blue $=0.5-1 \%$, darker blue $=1-10 \%$ and the most abundant OTUs in black $=10-50 \%$. 
Table 6.9 The 10 most abundant groups to genus level as determined by their relative abundance (RA $\%$ ) from 454 pyrosequencing in the RNA and DNA populations.

\begin{tabular}{|l|r|}
\hline & RNA \\
\hline Flavobacteria; Flavobacteriales; Flavobacteriaceae; Polaribacter & 31.30 \\
Gammaproteobacteria; Alteromonadales; Alteromonadaceae; Glaciecola & 15.14 \\
Bacteria; unclassified & 6.79 \\
Flavobacteria; Flavobacteriales; Flavobacteriaceae; Winogradskyella & 4.28 \\
Mollicutes; Acholeplasmatales; Acholeplasmataceae; Acholeplasma & 4.00 \\
Alphaproteobacteria; Rhodobacterales; Rhodobacteraceae; Octadecabacter & 3.23 \\
Bacilli; Lactobacillales; Streptococcaceae; Streptococcus & 3.22 \\
Gammaproteobacteria; Pseudomonadales; Moraxellaceae; Psychrobacter & 2.14 \\
Clostridia; Halanaerobiales; Halobacteroidaceae; Halobacteroides & 2.02 \\
Alphaproteobacteria; Rhodobacterales; Rhodobacteraceae; Thalassobacter & 1.91 \\
\hline
\end{tabular}

\begin{tabular}{|l|r|}
\hline & DNA \\
\hline Flavobacteria; Flavobacteriales; Flavobacteriaceae; Polaribacter & 46.98 \\
Gammaproteobacteria; Pseudomonadales; Moraxellaceae; Psychrobacter & 13.30 \\
Alphaproteobacteria; Rhodobacterales; Rhodobacteraceae; Thalassobacter & 4.53 \\
Bacteria; unclassified & 4.42 \\
Alphaproteobacteria; Rhodobacterales; Rhodobacteraceae; Octadecabacter & 3.44 \\
Sphingobacteria; Sphingobacteriales; Saprospiraceae; Lewinella & 2.42 \\
Gammaproteobacteria; Chromatiales; Granulosicoccaceae; Granulosicoccus & 2.40 \\
Sphingobacteria; Sphingobacteriales; Saprospiraceae; Haliscomenobacter & 1.84 \\
Gammaproteobacteria; Alteromonadales; Alteromonadaceae; Glaciecola & 1.65 \\
Mollicutes; Acholeplasmatales; Acholeplasmataceae; Acholeplasma & 1.44 \\
\hline
\end{tabular}

A total of $67.3 \%$ of the OTUs were found in both the RNA and DNA populations. Another $24.4 \%$ were found just in the active (RNA) population only and the remaining $(8.3 \%)$ only in the DNA portion (Figure 6.23). Polaribacter was the most abundant OTU found in both the RNA and DNA communities, comprising $31.3 \%$ and $47 \%$ of the RNA and DNA populations, respectively (Table 6.9). Psychrobacter, Thalassobacter, Acholeplasma, Glaciecola, Octadecabacter, and unclassified bacteria were found in both communities. Abundant OTUs in the DNA population that were not abundant in the RNA population were Lewinella, Granulosicoccus and Haliscomenobacter. OTUs that were in the active community (RNA) and not in the total (DNA) community were related to Winogradskyella, Halobacteroides and Streptococcus (Table 6.9). 


\subsubsection{Bacterial diversity through the sea ice core}

The bacterial community structure shifted through the sea ice core. At the bottom of the sea ice, the community was dominated by the orders Flavobacteriales, Rhodobacteriales, Sphingobacteriales, Oceanospiralles and Alteromonadales in both the DNA and RNA communities (Table 6.10). In the middle of the ice core, many of these bacterial groups were found in both the DNA and RNA populations. However there was an addition of orders such as the Bacteroidales, Actinobacteriales, Caulobacteriales and Pseudomonadales in both communities. The abundance of Flavobacteriales decreased in both communities and Archaea also decreased in the RNA population. At the top of the sea ice core, both the rDNA and rRNA community were dominated by the orders Lactobacillales, Flavobacteriales, Sphingobacteriales, Bacillales, Oceanospirillales and Pseudomonadales. In the active community, organisms related to Acholeplasmatales, Rhodobacterales and Planctomycetales became more abundant (Table 6.10). 
Table 6.10 The most abundant groups (> 1\% of relative abundance RA) in the rDNA and rRNA communities from 454 pyrosequencing in the bottom, middle and top of the sea ice core.

\begin{tabular}{|l|rrr|rrr|}
\hline & \multicolumn{3}{|c|}{ DNA } & \multicolumn{3}{c|}{ RNA } \\
\hline & Bottom & Middle & Top & Bottom & Middle & \multicolumn{1}{c|}{ Top } \\
\hline Acholeplasmatales & 2.48 & & & & & 5.19 \\
Actinobacteria & & 4.05 & 2.76 & & 4.45 & 21.74 \\
Alteromonadales & 2.07 & 13.58 & & 21.9 & 10.95 & \\
Bacillales & & & 11.77 & & & 8.15 \\
Bacteroidales & & 6.78 & & & 5.42 & \\
Burkholderiales & & & 2.66 & & & 1.2 \\
Caulobacterales & & 3.38 & & & 1.15 & 1.44 \\
Chromatiales & 3.22 & & & & 5.46 & \\
Clostridiales & & 1.31 & & & & \\
$\begin{array}{l}\text { Enterobacteriales } \\
\text { Flavobacteriales }\end{array}$ & 56.88 & 19.96 & 17.81 & 46.39 & 30.33 & 21.1 \\
Halanaerobiales & 1.46 & 2.73 & & & & \\
Lactobacillales & & 1.81 & 20.46 & & & 9.48 \\
Oceanospirilales & 2.69 & 3.2 & 9.12 & 2.12 & 5.84 & 1.76 \\
Planctomycetales & & & & & & 1.53 \\
Pseudomonadales & & 2.17 & 4.43 & & 1.01 & 4.54 \\
Rhodobacterales & 14.9 & 27.8 & 4.86 & 14.32 & 20.57 & 3.89 \\
Sphingobacteriales & 4.44 & 6.04 & 12.89 & 1.57 & 9.06 & 11.01 \\
\hline
\end{tabular}

Both the rDNA and rRNA communities were dominated by abundant genera. Polaribacter was the most abundant OTU at the bottom of the ice core making up 53.8 and $36 \%$ of the rDNA and rRNA communities, respectively (Table 6.10). Polaribacter was abundant throughout the sea ice core, but decreased in both communities towards the top of the ice core. In the rRNA communities, Glaciecola was the second most abundant OTU at the bottom of the ice core but was below the detection limit ( $<1 \%$ of the community) in the rDNA community. At the middle of the sea ice core there was a shift to the OTUs Psychromonas, Colwellia and Psychrobacter in both the rDNA and rRNA communities. Neptunomonas spp. were only found at the bottom of the ice core whereas Haliscomenobacter spp. were rare in the bottom and middle of the sea ice core, but abundant at the top of the ice core. Glaciecola was only found in the rRNA community where it was in abundance at the bottom of the sea ice core but decreased up through the core. 
Table 6.11 The most abundant genera ( $>1 \%$ of relative abundance RA) in the rDNA and rRNA communities from 454 pyrosequencing in the bottom, middle and top of the sea ice core.

\begin{tabular}{|c|c|c|c|c|c|c|}
\hline & \multicolumn{3}{|c|}{ DNA } & \multicolumn{3}{|c|}{ RNA } \\
\hline Most abundant (> 1\%) Genera & Bottom & Middle & Top & Bottom & Middle & Top \\
\hline Acholeplasmataceae; Acholeplasma & 2.48 & & & & & 5.19 \\
\hline Alteromonadaceae; Glaciecola & & 1.96 & & 21.37 & 4.48 & 1.34 \\
\hline Colwelliaceae; Colwellia & 1.09 & 10.82 & 20.23 & & 6.47 & \\
\hline Cytophagaceae; Flexibacter & & & 1.06 & & & \\
\hline Flavobacteriaceae; Aquimarina & & 1.57 & & & & \\
\hline Flavobacteriaceae; Polaribacter & 53.75 & 14.66 & 3.83 & 36.04 & 29.59 & 10.41 \\
\hline Flavobacteriaceae; Tenacibaculum & & 1.62 & 2.63 & 8.99 & 5.46 & 2.67 \\
\hline Flavobacteriaceae; Ulvibacter & 1.32 & 2.73 & & 1.15 & & \\
\hline Francisellaceae; Francisella & & & 1.09 & & & \\
\hline Granulosicoccaceae; Granulosicoccus & 3.22 & 1.86 & 1.72 & & 3.77 & 2.70 \\
\hline Halobacteroidaceae; Halobacteroides & 1.46 & & 4.20 & & & 2.42 \\
\hline Micrococcaceae; Arthrobacter & & & & & & 1.44 \\
\hline Moraxellaceae; Psychrobacter & & 3.20 & & & 5.84 & 18.25 \\
\hline Oceanospirillaceae; Neptunomonas & 2.01 & & 1.05 & 1.83 & & \\
\hline $\begin{array}{l}\text { Pseudoalteromonadaceae; } \\
\text { Pseudoalteromonas }\end{array}$ & & 1.71 & & & & 1.53 \\
\hline Pseudomonadaceae; Pseudomonas & & 1.09 & & & & 2.28 \\
\hline Psychromonadaceae; Psychromonas & & 21.44 & & & 15.92 & \\
\hline Rhodobacteraceae; Octadecabacter & 4.86 & 2.96 & 2.07 & 8.69 & 2.08 & 3.29 \\
\hline Rhodobacteraceae; Thalassobacter & 7.42 & 2.74 & 2.23 & 4.01 & 2.31 & 2.84 \\
\hline Saprospiraceae; Aureispira & & & 4.15 & & & \\
\hline Saprospiraceae; Haliscomenobacter & 1.07 & 2.30 & 2.87 & & 3.42 & 3.55 \\
\hline Saprospiraceae; Lewinella & 1.57 & 2.65 & 3.91 & & 5.07 & 5.33 \\
\hline
\end{tabular}

Streptococcaceae and Acholeplasma were not found at the bottom or middle of the ice core in abundance, but were dominant at the top of the ice core in the rRNA community only (Table 6.11). At the top of the ice core, the genus Lewinella was dominant in both communities. The rRNA community was also rich in the genera Psychrobacter, Polaribacter and Acholeplasma, whereas the rDNA community contained the genera Colwellia and Halobacteroides (Table 6.11). In the rDNA community, the genera Colwellia increased towards the top of the ice core, but were not a dominant genus in the rRNA community suggesting this OTU is dormant or dead and may reflect the community of the seawater column during ice formation. In the rRNA community, Psychrobacter became a predominant OTU at the top of the ice 
core. Increases were also seen in Arthrobacter, Halobacteroides and Pseudomonas towards the top of the ice core.

\subsubsection{Similarities among bacterial communities}

The bacterial community diversity from pyrosequencing was investigated by analysing species richness (N1, N2) and evenness (N21'). There was no significant difference in the diversity seen between the rDNA and rRNA communities using any of the indices (T-test $p \geq 0.05$ ) or through the sea ice core (ANOVA $p \geq 0.05$ ). There was a significant difference in both diversity indices and evenness between sites (ANOVA $\mathrm{p}<0.05$ ) and the communities with the highest diversity were found at Cape Evans at the top and middle of the ice core, and at McMurdo Station at the top of the sea ice core (Table 6.12). Tukey's pairwise comparisons revealed that TNB had a significantly lower diversity than the other sites (Pairwise comparisons; $\mathrm{P}<0.001$ ).

Table 6.12 Diversity indices, N1 and N2 (Hill numbers) and N21' (modified Hill's ratio) at each site CE (Cape Evans), McM (McMurdo Station), TNB (Terra Nova Bay) and GH (Granite Harbour) in 2008. The bottom (B), middle (M) and top (T) of the sea ice cores was compared between the RNA (R) and DNA (D) communities.

\begin{tabular}{cccc|cccc}
\hline RNA & N1 & N2 & N21' & DNA & N1 & N2 & N21' \\
\hline TNBBR & 1.58 & 1.28 & 0.48 & TNBBD & 1.38 & 1.11 & 0.3 \\
TNBMR & 2.28 & 1.71 & 0.56 & TNBTD & 1.74 & 1.28 & 0.38 \\
TNBTR & 5.88 & 2.6 & 0.33 & GHBD & 9.61 & 6.36 & 0.62 \\
GHMR & 13.54 & 9.71 & 0.69 & GHMD & 19.12 & 12.98 & 0.66 \\
GHTR & 13.29 & 8.93 & 0.65 & GHTD & 12.82 & 9.8 & 0.74 \\
CEBR & 7.87 & 5.06 & 0.59 & CEBD & 2.95 & 1.62 & 0.32 \\
CETR & 12.79 & 5.05 & 0.34 & CEMD & 16.39 & 9.87 & 0.58 \\
McMBR & 7.94 & 5.6 & 0.66 & CETD & 16.48 & 12.36 & 0.73 \\
McMMR & 6.3 & 3.55 & 0.48 & McMBD & 14 & 6.08 & 0.39 \\
McMTR & 15.86 & 9.37 & 0.56 & McMMD & 3.99 & 2.28 & 0.43 \\
& & & & McMTD & 16.07 & 9.07 & 0.54
\end{tabular}




\subsubsection{Comparisons between culture and pyrosequeng}

The majority of bacterial isolates that were identified from culture were also detected by pyrosequencing techniques. The culture method had higher resolution and isolates could be identified to species level. However, this was not the case with the pyrosequencing data. Many of the sequences when analysed against the RDP database could be identified to the family or genus level, but only rarely to the species level. The culture technique isolated organisms from the following genera: Rahnella, Brevundimonas, Flavobacterium, Micrococcus and Rhodococcus that were not identified using the 454 sequencing. The lower resolution of pyrosequencing is likely due to the small sequence fragments (Table 6.13).

Table 6.13 A comparison between the bacterial groups identified by culture dependent methods with those found through pyrosequencing.

\begin{tabular}{|lc|}
\hline Genus identified in culture & Taxon identified using 454 sequencing? \\
\hline Rahnella sp.(AY253920) & Family Enterobacteriaceae \\
Glaciecola sp. (FR746107) & $\mathrm{V}$ \\
Pseudomonas sp. (GU198126) & $\mathrm{V}$ \\
Psychrobacter sp. (AJ539102) & $\mathrm{V}$ \\
Psychrobacter sp. (FR691436) & $\mathrm{V}$ \\
Brevundimonas sp. (AJ244706) & Order Caulobacteraceae \\
Paracoccus sp. (AM275338) & $\mathrm{V}$ \\
uncultured marine Sphingomonadales (GU474922) & $\mathrm{V}$ \\
Polaribacter sp. (DQ481463) & $\mathrm{V}$ \\
Psychroflexus sp. (AY167320) & $\mathrm{V}$ \\
Flavobacterium sp. (AJ557886) & $\mathrm{V}$ \\
Arthrobacter sp. (DQ341426) & $\mathrm{V}$ \\
Micrococcus sp. (AJ536198) & Family Micrococcaceae \\
Janibacter sp. (FN582323) & Suborder Micrococcineae \\
Rhodococcus sp. (FN397657) & $\mathrm{V}$ \\
Bacillus sp. (FJ13320) & $\mathrm{V}$ \\
\hline
\end{tabular}

Many of the genera that were identified through culture were also found in low abundance in Antarctic sea ice using molecular methods. However, very abundant bacteria obtained through pyrosequencing such as Polaribacter spp., Glaciecola spp., Psychrobacter spp. and Pseudomonas spp. were also detected through culture. Many 
groups that were detected by pyrosequencing were not detected with culture-based methods.

\subsection{Discussion}

Antarctic sea ice bacterial diversity was investigated using culture dependent and independent techniques. Bacterial isolates were identified to genus level using a series of biochemical tests. Unique RFLP profiles were then sequenced to confirm their identification using the complete $16 \mathrm{~S}$ rRNA gene. The "uncultivable" community diversity was also investigated in Antarctic sea ice using in-depth sequencing. This is the first time that 454 sequencing has been applied to Antarctic sea ice communities and it has revealed groups that have not previously been identified in sea ice.

The biochemical properties of Antarctic sea ice bacterial isolates were examined to allow identification and to give insight into their diversity. Many of the bacterial isolates were chromogenic and of these the majority of colonies were red, lobate and globular. The majority of the isolates were rod shaped Gram negative bacteria. These results are similar to those of Bowman et al. (1997).

The isolates were grown at either $4{ }^{\circ} \mathrm{C}$ or at room temperature $\left(\sim 25^{\circ} \mathrm{C}\right)$ under dark and light conditions. Only a small proportion of the isolates did not grow at $25^{\circ} \mathrm{C}$. These bacteria are likely to be psychrophiles with an optimal growth temperature of < $15{ }^{\circ} \mathrm{C}$ (Bowman et al. 1997). Isolates that were purely psychrophiles were red pigmented and of globular consistency and many of these grew under light and dark conditions at $4{ }^{\circ} \mathrm{C}$. The majority of the isolates grew at both temperatures under both light conditions and are likely to be psychrotrophs: organisms that grow well at low temperatures but can also grow at 20 to $25^{\circ} \mathrm{C}$.

Fewer isolates grew from samples taken from the top of the sea ice core, with the most isolates obtained from the middle and bottom of the ice core. This may suggest that fewer active bacteria are present at the top of the ice core in comparison to the middle and bottom of the core. In Chapter 3 I found no correlation between total bacterial cell numbers and depth of ice but it was unknown how many of these 
bacteria were active. Martin (2010) found bacteria to be highly active in sea ice, especially those concentrated at the bottom of the ice core. The low abundance of bacteria isolated from the top of the ice core may also be due to their incapacity to grow in the harsh environmental conditions such as low temperatures, low nutrient concentrations and high irradiance. The cultivable proportion of bacteria from some environments can be $<1 \%$ of the total community (Amann et al. 1995; Cottrell and Kirchman 2000) but up to $62 \%$ of sea ice bacteria have been cultured (Junge et al. 2002, Brinkmeyer et al. 2003). A total of 26 different isolates were identified through various biochemical tests and confirmed by $16 \mathrm{~S}$ rRNA sequencing. The majority of the isolates that were identified were very closely related to known bacteria from Antarctic sea ice (Brown and Bowman 2001; Brinkmeyer et al. 2003).

Following the biochemical tests outlined in Das et al. (2007) the yellow or orange isolates that were Gram negative rods were subjected to the catalase test. Isolates that tested negative were classified as Flexibacter and those that were positive as Flavobacterium (Das et al. 2007). None of the yellow pigmented isolates were catalase negative, but isolates C5, C44, C45, C55, C60 and H16 were catalase positive and therefore classified as Flavobacterium. Of these, C5, C45 and C55 were sequenced and confirmed as Flavobacterium degerlachei. F. degerlachei is a Gram negative psychrophilic bacterium that was previously isolated from saline Antarctic lakes, is catalase and oxidase positive, and has yellow colonies (Van Trappen et al. 2004). Isolates had similar phenotypic traits to those of $F$. degerlachei, supporting the fact that these isolates are closely related to this bacterium.

Bacterial isolates that were non-pigmented Gram negative rods were tested using glucose dissimilation and Kovac's oxidase. Glucose dissimilation results were read as: yellow (anaerobic and aerobic) $=$ fermentative; yellow $($ aerobic $)=$ oxidative; and purple/no change $=$ no reaction based on the Das classification (Das et al. 2007) . Isolates that were non-fermenters were expected to fall into the genera Alteromonas, Pseudomonas and Moraxella. Those that were oxidase positive were classified as Pseudomonas or Moraxella. Bacterial isolates C23 and C33 were oxidase positive, had identical RFLP profiles, and both were sequenced and confirmed as Pseudomonas fluorescens. P. fluorescens is a common psychrotolerant Gram negative bacterium. It is oxidase positive and aerobic and has been identified in sea ice (Romanenko et al. 
2008). The sequencing of the 16S rRNA gene revealed that isolates C23 and C33 had $100 \%$ sequence similarity to each other and $99.9 \%$ similarity to $P$. fluorescens.

Isolates that were Gram positive rods were identified as Bacilli with a positive spore test. There were ten isolates in this group of which five were sequenced. All $16 \mathrm{~S}$ rRNA sequences were confirmed as Bacillus sp. Bacilli are Gram positive organisms, they are spore formers and are catalase positive.

The isolates that were Gram positive cocci and tested positive for catalase production were further investigated. Those that formed clumps (C8, C50 and C54) were classified as Micrococcus and those that did not (C28 and C56) were classified as Arthrobacter. C28 was a yellow pigmented isolate which shared $99.9 \% 16 \mathrm{~S}$ rRNA gene similarity with an Arthrobacter sp. (DQ341426). C56 was not pigmented and shared $100 \%$ sequence similarity with an uncultured Janibacter sp. Janibacter spp. group within the suborder Micrococcaceae, which contains Arthrobacter and Micrococcus. All of the species of the genus Arthrobacter are Gram positive, catalase positive and aerobic (Schleifer and Kandler 1972), whereas Micrococcus are oxidase positive bacteria which can be pigmented. C8, C50 and C58 were all bright yellow isolates. C8 was closely related to M. luteus, but C50 had no close relationships with any other known bacterium. C50 shared $93.8 \%$ sequence similarity to M. antarcticus. M. antarcticus has been described as coccoid, non-motile, Gram-positive, aerobic and with no spores. The colonies are yellow with entire margins. The catalase and oxidase tests were positive and were able to utilize starch and tween 80 (Liu et al. 2000). Isolate C50 is identical to M. antarcticus in terms of its morphology and biochemistry and therefore this is likely to class it within the same genus but perhaps a different species.

One other isolate had $>3 \%$ sequence divergence from any known organism. H12 shared $96 \%$ 16S rRNA sequence similarity with Rahnella aquatilis. Rahnella aquatilis has been described as a cold-adapted, glucose-fermentative Gram-negative bacterium. It is catalase positive and oxidase negative and able to utilise a wide range of carbon sources including D-trehalose (Vyas et al. 2010). The isolate H12 also had these attributes although $\mathrm{H} 12$ was oxidase positive and did not utilize D-trehalose. 
Therefore H12 may delineate from the genus Rahnella. Further work is needed to confirm the taxonomic position of $\mathrm{H} 12$ and C50.

The biochemical tests utilised in this study were able to identify the isolates belonging to the genera Flavobacterium, Pseudomonas, Bacillus and Micrococcus. However, many of the sea ice isolates could not be identified in this way. Although the tests were developed to identify marine heterotrophic bacteria, they have not been optimized for the psychrophilic or psychrotolerant groups that are typically found in Antarctic sea ice. Nevertheless, these tests at least give insight into the phenotypic characteristics of these sea ice isolates and point to the groups to which they may belong.

Some isolates that had similar colony morphologies and cell shapes differed when they were tested biochemically. For example, isolates that were red pigmented, viscous, Gram negative rods differed in their oxidase and catalase production and ability to utilise glucose. However, their RFLP profiles were identical and they were all found to be closely related to Psychroflexus torquis after 16S rRNA gene identification. P. torquis is a pigmented bacterium, elastic in consistency, circular and convex in shape with slightly spreading edges. It is catalase and oxidase positive, and hydrolyses Tween 80 (Bowman et al. 1998). The difference in the phenotypic characteristics between isolates may suggest that they are either different strains or species. In order to separate them genetically, further analysis would need to be done using DNA-DNA hybridization or alternative gene targets that can provide better separation of closely related species (Cohan et al. 2002). For example, the $r p o B$ gene that encodes the $\beta$-subunit of the bacterial RNA polymerase can be used when the $16 \mathrm{~S}$ rRNA gene cannot discriminate among taxa (La Scola et al. 2006). Culture-based methods however have identified the phenotypic differences among $P$. torquis isolates, which would not have been identified using culture-independent methods.

The isolates that grouped within the Alpharoteobacteria were closely related to Brevundimonas mediterranea, Paracoccus sp. or an uncultured sphingomonad. $B$. mediterranea was a Gram-negative, rod-shaped, non-spore-forming bacterium, traits that were also seen in isolate C52. H14 was a Gram negative rod that was catalase and oxidase positive and did not utilize glucose. Paracoccus sp. was a Gram negative 
carotenoid-producing species (Harker et al. 1998). Based on the colouring of H12 it is likely to be a Paracoccus sp.

Isolates C21, C42, C51 and C72 were dark red in colour and were Gram negative rods. They were catalase and oxidase positive and were unable to metabolise glucose. They shared $>99 \%$ similarity to each other and $99.8 \%$ similarity to an uncultured member of Sphingomonadales. They clustered in the same group as Erythrobacter citreus and shared similar attributes to Erythrobacter spp. which are red/ orangepigmented Gram negative rods and are aerobic, anoxygenic phototrophs (Yurkov and Beatty 1998).

Glaciecola pallidula was isolated from Antarctic sea ice and described by Bowman et al. (1998). G. pallidula is an aerobic Gram negative rod that forms pink colonies and is catalase and oxidase positive (Bowman et al. 1998). The isolates C6 and C9 shared $100 \%$ homology with G. pallidula and shared the phenotypic identification (apart from that both isolates were catalase negative). Isolates $\mathrm{C} 6$ and $\mathrm{C} 9$ may be a different strain to that found by Bowman et al. (1998).

The genus Psychrobacter comprises Gram negative rods that are non-motile, aerobic, catalase positive and cold adapted (Bowman 2006). The isolates H25, H34, H20, C12, $\mathrm{C} 13$ and $\mathrm{C} 48$ were all cold adapted, only growing at $4^{\circ} \mathrm{C}$. They were all Gram negative rods, white or cream coloured, and catalase positive supporting that they group within the Psychrobacter.

Polaribacter dokdonensis is a Gram-negative rod / bacillus, non-motile, non-sporeforming bacterium. It is oxidase and catalase positive and a dull yellow in colour (Yoon et al. 2006). Isolates C3 and C24 were similar both genetically and phenotypically to $P$. dokdonensis.

Culture studies on Antarctic sea ice bacteria have found the majority of isolates to be in the Alphaproteobacteria, Gammaproteobacteria, Flexibacter-CytophagaBacteroides group or Gram-positive groups (Bowman et al. 1997; Brinkmeyer et al. 2003). The majority of my isolates also fell into these groups. Brinkmeyer et al. (2003) identified isolates of Colwellia, Marinobacter, Roseobacter and 
Octadecabacter in low abundance. I did not isolate these from Antarctic sea ice. Although they did use Marine agar 2216 as a medium for growing cultures, they also obtained isolates on chitin agar and a nutrient-poor agar containing yeast extract and potassium nitrate. The lack of these bacterial groups in my isolates may be due to the different medium that was used for culture. However, I was able to cultivate isolates that were related to Rhodococcus and Bacillus that have not been previously cultivated from Antarctic sea ice. Bacillus firmus has been isolated from Arctic sea ice (Yu et al. 2009).

The 16S rRNA gene is important for inferring phylogeny, but does not have sufficient resolution to discriminate between bacterial species or strains. At one end of the scale, bacterial strains can have identical 16S rRNA sequences yet be different species, whereas at the other end the same species may have $2.5 \%$ 16S rRNA sequence difference (Stackebrandt and Goebel 1994). Therefore a polyphasic approach using $16 \mathrm{~S}$ rRNA sequencing and phylogenetic and biochemical characteristics can provide more information about the phylogeny of bacteria.

The "unculturable" bacterial diversity was investigated using 454 sequencing. PCR biases are well known to lead to errors in identifying bacterial groups and their distribution. Reeder and Knight (2009) suggested that the majority of OTUs that make up the "rare biosphere" represents the accumulation of small sequencing errors and that these may artificially inflate diversity estimates by two orders of magnitude (Kunin et al. 2010). Therefore the Antarctic sea ice "rare biosphere" may not be as large as expected. Kunin et al. (2010) suggested that clustering thresholds no greater than $97 \%$ identity should be used to avoid overestimates of the rare biosphere. In my study, the error rate was reduced by removing low quality sequences and those with errors in the barcode or primer sequences. OTUs were clustered at $95 \%$ sequence similarity. Antarctic bacterial sequences that only occurred once in 22,000 reads were also discarded as errors and did not contribute to the "rare biosphere". It was assumed that each bacterium contained one $16 \mathrm{~S}$ rRNA gene and that bacterial groups were amplified with the same efficiency in order to quantitatively compare OTU abundances between sites. The accuracy of pyrosequencing has been described as 99.5\% (Huse et al. 2007) during the amplification process. The taxonomic assignment accuracy using the RDP Classifier tool was calculated at $83.2 \%$ at genus 
level for 200 base pairs (Wang et al. 2007). My reads were slightly longer, which may increase the accuracy of classification. Taxonomic assignment is therefore satisfactory at the genus level but has limited resolving power at the species level, thus OTUs were discriminated at the genus level. The sequences were taxonomically classified by deducing the $16 \mathrm{~S}$ rRNA sequence similarities by comparison with full length sequences in the RDP database. When highly similar sequences are present in the database this approach works well. However, if communities are less well characterized, such as sea ice bacterial communities, many reads may lack close matches and will be classified to higher phylogenetic levels. Sequences that were not identified to OTU level were classified at family or phylum level (i.e. Bacteria; unclassified). These OTUs are likely to be a miscellaneous assemblage of many taxa, rather than a single group of similar sequences. The inability for the RDP to classify Antarctic microbes at the OTU level perhaps reflects the small number of studies conducted on Antarctic sea ice communities in comparison to other microbial communities. 454 sequencing has not been done on Antarctic sea ice bacterial communities before, and therefore there may be a lack of sequences in the public databases leading to the loss of resolution in the identification of sequences.

The main OTUs found in Antarctic sea ice grouped in the Alphaproteobacteria and Betaproteobacteria, Bacteroidetes, Actinobacteria, Firmicutes, Verrucomicrobia and archaea which is consistent with the groups previously found in Antarctic sea ice using clone library techniques (Brown and Bowman 2001; Brinkmeyer et al. 2003; Cowie et al. 2011). Polaribacter was the most dominant OTU in Antarctic sea ice comprising $\sim 37 \%$ of the total diversity in sea ice. Furthermore, approximately $65 \%$ of the species richness in sea ice was derived from only eight genera. The rarefaction curves also suggested that the Antarctic sea ice community had been fully sampled, with the number of sequences at $97 \%$ similarity (species level) being approximately 3000. This diversity is not considered to be exceptionally high compared to other environments such as soil and sediment. However, the rarefaction curve only looks at diversity within my library, and not in the sample per se, so bacteria could have been missed due to extraction failure. Brown and Bowman (2001) found that bacterial diversity in sea ice is low, so perhaps my results are reflective of sea ice diversity. The remaining $35 \%$ of the diversity was made up of many rare taxa which may give us some insight into the 'rare biosphere' in Antarctic sea ice. This 'rare biosphere' may 
consist of the majority of diversity found in sea ice, and these OTUs have the potential to proliferate when the environment becomes more favourable. This was apparent when comparing the vertical distribution of the microbial community through the ice, where groups such as the Actinobacteria, Bacillales, Rhodobacterales and Planctomycetales that were rare at the bottom of the ice core became more dominant at the top of the sea ice core. The diversity of OTUs was compared between sites and the dominant OTUs were generally abundant and cosmopolitan. The rarer OTUs were observed sporadically, although they perhaps were present at all sites but under the detection level of 454 sequencing.

The SIMPROF test revealed that bacterial communities that were similar in community composition grouped with communities from similar sites. Communities from CE08 and GH08 shared greater bacterial community similarity than with those from McM and TNB. Bacterial communities from TNB had the least similarity in community composition with the other sites. These trends mirror the results found by the T-RFLP in Chapter 3 therefore adding value to the concept that sea ice bacterial communities show patterns and are influenced by environmental and biogeographical processes. A quarter of the OTUs were observed only in McMurdo Station sea ice samples. This site was different from the others as the sea ice was collected from within a $2 \mathrm{~km}$ proximity to the American Station and may have had anthropogenic influences. These bacterial OTUs may have been introduced via run-off or windblown from the base or brought in via transport vectors as this site is traversed by vehicles and is also close to the aviation field. The site at Terra Nova Bay (TNB) is also within relatively close proximity to the Italian Station $(7 \mathrm{~km})$ and may also be influenced by anthropogenic factors. However, the bacterial OTU richness and diversity there was low. TNB has a polynya, controlled by katabatic winds, that is responsible for both the formation of the sea ice and its continuous removal (Budillon and Spezie 2000). Therefore the thin nature of the sea ice is due to its late formation compared to the other sites. There was lower algal biomass (measured as Chl- $a$ concentration) at this site (Chapter 3), therefore perhaps algae were unable to develop in this shorter period of time, and may not have been a productive environment for bacterial growth and development. 
The Flavobacteriales were abundant throughout the sea ice core, although more so at the bottom in both the active and total communities. There was a shift up through the ice core to more Gram positive groups: the Actinobacteria and Bacilli and groups without a peptidoglycan cell wall, the Acholeplasmatales and Planctomycetales, became more common closer to the surface of the sea ice. Actinobacteria and Bacilli have been described in Antarctic sea ice along with other members of Gram positive bacteria such as Planococcus and Arthrobacter (Bowman et al. 1997). The genus Bacillus produces endospores that are resistant to extreme temperatures and desiccation and may enable increased survival in the sea ice environment. The complex nature of Gram positive cell walls may explain their resistance and ability to survive in this environment. The Acholeplasmatales and Planctomycetales have not previously been described in Antarctic sea ice and the Planctomycetales were generally in low abundance. However, there was an increase in members of the genus Acholeplasma towards the top of the ice core and was found to be one of the most abundant genera in the rRNA community. The abundance of this OTU in the rRNA community suggests that it is highly active and able to adapt and grow in this environment.

Previous studies using clone libraries would have isolated the more abundant members of a community and the rarer organisms would not be detected. Bowman et al. (1997) found many obligate and facultative psychrophilic Proteobacteria including Colwellia, Pseudoalteromonas, Octadecabacter, Pseudomonas, Alteromonas, Sphingomonas and Shewanella of which many contain gas vacuoles. Polaribacter (Gosink et al. 1998) and Psychroflexus (Bowman et al. 1998) have also been described in Antarctic sea ice. I also found these groups throughout the sea ice core. The similarity between these groups and those already identified suggests that these bacteria contain characteristics that are resistant to freezing and extend survival under frozen conditions. The adaptation to cold environments does appear to be evolutionarily necessary as $80 \%$ of Earth has temperatures below $5^{\circ} \mathrm{C}$. In addition to these groups, the Rickettsiales and Burkholderiales were found in Antarctic sea ice in abundance but have not previously been described in this environment. Granulosicoccus was also present in abundance in Antarctic sea ice but has only been characterised from Antarctic seawater (Lee et al. 2007). 
Previous studies of bacteria in Antarctic sea ice have only investigated the microbial community using genomic DNA. Although this gives insight into the total bacterial community it does not identify those bacteria that are metabolically active and contributing to the sea ice ecosystem. This is the first molecular study to investigate the diversity of Antarctic sea ice microbes from RNA extracted from the associated communities. The metabolically active population (RNA-based) and the total community (DNA-based) were comprised of similar abundant groups which suggests that a large proportion of bacteria are active in sea ice. Diversity indices also confirmed this as shown by the insignificance between the rDNA and rRNA communities. This may explain why a high proportion of bacteria in sea ice are cultivable (Junge et al. 2002; Brinkmeyer et al. 2003), as more cells are viable. A high proportion of the OTUs were found in both DNA and RNA fractions. However, additional OTUs were found in only the DNA or the RNA fractions where a quarter of the OTUS were found only in the RNA community. This highlights the importance of extracting both the DNA and RNA from a community to gauge the total bacterial diversity. The diversity indices also revealed that the bacterial communities with the highest diversity were generally from the rRNA community at the top of the sea ice core. The top of the sea ice core is characterised by low nutrient concentrations, temperatures and high irradiance in which bacteria must respond in order to survive and thrive. The highest diversity was in the rRNA population as these bacteria are better able to respond to the environment, with subsequent diversification through migration, extinction and growth of bacterial groups that are best adapted.

Culture-based methods to identify bacteria are important as not only do they provide information about their taxonomic relationships, but they also give insight into their physiology and biochemical characteristics, which may lead to identification of different bacterial strains and provide clues about their function. Culture methods fail to describe the total diversity as many bacteria are un-cultivable, but those that are described can be determined to species or strain level. Culture methods are also able to detect bacteria that are both abundant and rare in the environment and therefore may identify rare bacteria that are under the detection limits of molecular methods. The development of 454 pyrosequencing has enabled the un-cultivable population to be investigated and perhaps dip into this "rare biosphere" that is missed by clone library methods. There was some overlap in diversity when comparing bacterial 
isolates and OTUs obtained from the 454 sequencing. Genera such as Glaciecola, Pseudomonas, Psychrobacter, Paracoccus, Arthrobacter and Bacillus were identified using both techniques. Identification to species level was obtained for bacterial isolates, but due to the shorter sequences obtained from 454 sequencing, the resolution here was only to genus.

There were several genera that were identified using culture methods but were not found in the pyrosequencing. These genera included Rahnella, Brevundimonas, Janibacter and Micrococcus. Culture methods may detect rare bacteria if the medium favours their growth. The absence of these genera in the pyrosequencing data suggests that they are either under the detection limit or were not extracted from the sea ice samples. The genera Janibacter and Micrococcus belong to the Actinobacteria and perhaps the nucleic acid extraction methods failed to break open their tough cell walls. The presence of genera only detected by culture-based methods shows that although many of the rare taxa in Antarctic sea ice can be targeted using 454 sequencing, there is still a subset of this seed bank that is not detected.

There were many bacterial groups identified using 454 sequencing that were not isolated using culture techniques. The groups archaea, Oceanospirillales and Sphingobacteriales were present in the rRNA population and therefore they are presumably metabolically active, but the culture media were unfavourable for their growth. These groups were abundant in the sequencing data which confirms that even abundant bacteria in the environment are not necessarily able to be cultured.

The use of single-method approaches does not give a full understanding of the extent of microbial diversity within a community (Donachie et al. 2007). My results showed overlap between the two methods, but greater resolution of lower taxonomic levels was revealed using culture, whereas higher resolution was given into the diversity of bacterial groups was provided by pyrosequencing. Therefore parallel culture libraries should be used to complement metagenomic techniques in order to understand the diversity of a community. 


\section{Enapter Clacen}

\section{Discussion}

\subsection{General OVERVIEW}

In this thesis, I investigated prokaryotic community structure and diversity in Antarctic sea ice. I also investigated the role that bacteria have in the functioning of the sea ice ecosystem. The functioning of the Antarctic sea ice system was investigated indirectly by examining relationships between bacterial community structure and the environment, and directly through analysis of functional genes and enzymatic activity. The prokaryotic diversity was measured using both culture dependent and independent techniques. Culture - based methods gave insight into the physiology and biochemistry of the cultivatable fraction of bacteria, whereas 454 sequencing enabled me to the measure the un-cultivatable community and sample the "rare biosphere". This is the first study on Antarctic sea ice that has i) used fingerprinting methods to understand changes in the bacterial community structure and their interactions with the environment; ii) employed $\mathrm{qPCR}$ to measure the abundance of functional genes to find out the role of bacteria in sea ice biogeochemical cycles; iii) discovered Archaea in sea ice and described their diversity and iv) used 454 pyrosequencing to gain a deeper understanding of prokaryotic diversity in sea ice. It provides baseline data about the bacterial community structure and how it is influenced by the environment. This baseline study will be able to be built on and will allow predictions to be made about sea ice ecosystem function and response in the face of climate change. 


\subsection{OUTLINE OF RESEARCH FINDINGS}

The main findings from each of the four data chapters is summarised below.

\section{Chapter 3}

Bacterial community structure was investigated using T-RFLP analysis of 16S rRNA genes, which were amplified from RNA and DNA extracted from environmental samples. RNA is synthesised by metabolically active bacteria and is degraded quickly in the environment, while DNA resides in the cells of active, dormant and dead bacteria. The analyses of both types of nucleic acids enabled the active proportion (RNA) of the total (DNA) bacterial community to be investigated and compared. Many of the sea ice bacterial communities were not significantly different in terms of their rRNA and rDNA profiles, suggesting that bacteria are highly active in sea ice. Bacterial communities that were closer together spatially were more similar than communities further apart. This relationship appeared to be driven by environmental variables rather than biogeography, and this was particularly with their vertical position in sea ice as well as concentrations of the nutrients nitrite and phosphate. A greater amount of the variation between communities could be explained in the rRNA population as the metabolically active subset of the community is better able to respond to the environment.

\section{Chapter 4}

The functional role of bacteria in sea ice was investigated using qPCR and enzyme assays on the community as a whole. The low abundance of the light energy utilising and denitrification genes suggest that these processes are minor in Antarctic sea ice. Archaea were active in sea ice and highly abundant at some sites. Their high abundance at these particular sites may be due to their ability to utilise components of DOM or nutrients that are inaccessible to bacteria. Alternatively, when the sea ice formed at these sites perhaps there was greater abundance of Archaea in the water column. The reason for the high abundance of archaea at only a couple of sites is uncertain and more work is needed to understand their distribution. Bacteria were actively involved in the hydrolysis of lipids, chitins, phosphates, proteins and sugars. 
Enzyme activity varied between sites, suggesting that enzyme regulation was dependent upon the composition of the DOM. Activity was generally highest at the bottom of the ice core, but bacteria were active throughout. Variations between bacterial communities could be explained by lipase, phosphatase and protease activity. Therefore the presence of these polymers in the environment selects for bacteria that are able to produce the enzymes required to hydrolyse these substrates. Chitinase and $\beta$ - galactosidase activity did not explain community changes, suggesting either that chitin and sugar hydrolysis is a minor process in sea ice or that these enzymes are found in most sea ice bacteria.

\section{Chapter 5}

Sea ice communities were investigated further using clone libraries and sequencing. Archaea have not been previously described from Antarctic sea ice, therefore the aim of this chapter was to detect their presence and investigate their diversity by sequencing the 16S rRNA gene. Archaea were found in Antarctic sea ice in low abundance, comprising $<6.6 \%$ of the prokaryotic DNA community. The majority of sequences clustered within the recently described phylum Thaumarchaeota and the rest within the Euryarchaeota. Many of the sequences were similar to those found in Antarctic waters or from Arctic sea ice and water environments.

\section{Chapter 6}

This is the first comprehensive study into the diversity of bacteria in Antarctic sea ice using both culture-based and deep sequencing methods. Culture-based methods are only able to detect the cultivable proportion of the community. In Antarctic sea ice this cultivable diversity can be up to $62 \%$ of the total bacterial diversity (Junge et al. 2002; Brinkmeyer et al. 2003). Culture studies provide information not only about the genetics of a bacterium, but also its physiological and biochemical properties. The majority of bacterial isolates were cold adapted red globular colonies which were identified as Psychroflexus torquis. In contrast, P. torquis was rare in the 454 sequencing data set. Furthermore, culture-based methods also identified other groups that were not found using deep sequencing techniques. These bacterial isolates may not have been found among the 454 sequences as they were rare and under the 
detection limit or they were not extracted from the environment using the nucleic acid extraction methods. This shows that a proportion of the bacterial diversity was not detected using 454 sequencing and emphasises the importance of using both approaches. Both methods isolated bacteria from the Alphaproteobacteria and Gammaproteobacteria and the Gram-positive bacteria. Additional groups from the archaea, Betaproteobacteria and Deltaproteobacteria were identified using 454 sequencing. Approximately $65 \%$ of the bacteria in Antarctic sea ice identified by 454 sequencing were derived from only eight OTUs. The majority of these were found in both the rDNA and rRNA communities throughout the sea ice core. However, some of the OTUs were found only in the rDNA or the rRNA populations. Those found only in the rDNA assemblages are likely not metabolically active. Those only in the rRNA community are likely active bacteria. Therefore they may be under the detection limits of 454 sequencing in the rDNA community, but in high abundance in the rRNA community. There was a shift in the bacterial community through the sea ice core, and this was particularly seen in the rRNA community. At the bottom of the ice core, the bacterial groups Bacteroidetes, Gammaproteobacteria and Actinobacteria were abundant, but this pattern shifted to greater abundance of the groups Bacilli, Mollicutes and Planctomycetes at the top of the ice core.

\subsection{THE OVERALL PICTURE}

The main concept in ecology is to understand community diversity, structure and function and its relationships with the environment. In order to understand this concept, an integrated approach must be used based on: cultivation studies, to gain information about sequences and phenotypic traits; metagenomics, to understand natural variation and population genetics and functions; and environmental data, to understand spatial and temporal patterns and microbial activities such as through enzyme assays. This thesis engaged all three aspects in order to shed some light on the following overarching questions:

1. Are sea ice bacterial communities influenced by environmental variables and can the latitudinal gradient act as a proxy for climate change?

2. What roles do bacteria play in the sea ice ecosystem and the "microbial loop"? 
3. Do bacteria show biogeographical patterns and/or is "everything everywhere"?

4. Can sea ice microbial diversity be described adequately with current techniques?

\section{Question 1: Are sea ice bacterial communities influenced by environmental variables and can the latitudinal gradient act as a proxy for climate change?}

Polar environments are sensitive to global warming where minimal changes in temperature have large effects on sea ice thickness and extent (Smetacek and Nicol 2005). Microorganisms have a rapid life cycle where bacterial doubling times average on the order of a few days (Ducklow 2000). It was proposed in this thesis that bacteria may be used as sensitive indicators of environmental change. A latitudinal gradient spanning $14^{\circ}$ of latitude exists down the Victoria Land coastline and may be used as a proxy for climate change (Howard-Williams 2000). Along this gradient, environmental factors such as solar radiation, temperature and sea ice cover vary.

I found that there was a significant effect of sea ice thickness on bacterial community structure (Chapter 3). Sea ice thickness is unlikely to affect the bacterial communities directly, but will instead influence algal photosynthesis leading to variations in DOM and nutrient concentrations. Increases in irradiance have been shown to increase algal productivity (Martin et al. 2011) or algal mortality (Davidson and van der Heijden 2000), and both of these increase bacterial growth and metabolism through the supply of additional algal-derived DOM. To support this, I found that bacterial enzymatic activity was highest at the bottom of the sea ice core especially in 2008 where Chl- $a$ concentrations were higher (Chapter 4). An increase in bacterial activity will stimulate their migration into more favourable areas where the nutrient composition in the environment will select for bacteria that can utilise these substrates. I found that the nutrients nitrite and phosphate also influenced bacterial community structure (Chapter 3). Nitrite can accumulate when algae are light-limited and phosphate has long been considered to limit planktonic productivity (Atkins 1923). Again this shows that bacteria are modulated by the environment produced by the algal community.

Furthermore, I found that bacterial enzymatic activity influenced community change. The availability, concentration and distribution of organic substrates in the 
environment influences the production and activity of bacterial hydrolytic enzymes (Boetius 1995). The variability of enzymatic synthesis in Antarctic sea ice suggests that DOM is heterogeneously distributed and the environment selects for bacteria with the enzymes required.

Overall, there was no discernable effect of latitude on the bacterial community richness and diversity indices but as samples were only collected spanning $\sim 3^{\circ}$ of latitude, this range may not have been large enough. While there was an increase in the number of RFLs from the rRNA community with latitude (Chapter 3), this relationship was driven by the high number of RFLs at TNB. When these were removed from the analysis, there was no effect of latitude. OTU richness has been related to latitudinal gradients (Pommier et al. 2007; Fuhrman et al. 2008) but these studies found that latitude was correlated with temperature which influenced bacterial metabolism. This may be the case in Antarctic sea ice as temperature at the bottom of the ice core is constant and OTU richness did not change with the latitudinal gradient. I would therefore expect a decrease in richness up through the sea ice core where temperature decreases rapidly, but such a decrease was not observed in the T-RFLP studies (Chapter 3). However there was a decrease in the RNA: DNA RFL ratio suggesting that there were more dead and/ or dormant cells at the top of the ice core. Therefore I show that there is an effect of vertical position on bacterial activity, but whether this is due to temperature, irradiance or salinity remains unclear.

In conclusion, there was no effect of latitude on bacterial communities but there was an influence of the environment. To understand the effects of climate change on ecosystems it is ultimately important to collect samples from a range of sites that have differing environmental variables. A latitudinal gradient may provide these parameters, but did not appear to do so in this study.

\section{Question 2. What roles do bacteria play in the sea ice ecosystem and the 'microbial loop'?}

Until recently the 'microbial loop' was thought to contain only phytoplankton, heterotrophic bacteria and protists (Azam et al. 1983). Now we must also include phototrophic bacteria (Fenchel 2008; Fuhrman et al. 2008). The presence of light- 
utilising bacteria has recently been documented in sea ice (Koh et al. 2010; Koh 2011). Phototrophs would have an advantage under nutrient-depleted conditions in the presence of light (Gomez-Consarnau et al. 2010), conditions that are likely to occur at the top of the sea ice core. I found more phototrophs higher in the sea ice core in comparison to the bottom of the ice core. However, these bacterial groups were in low abundance based on quantitative PCR (Chapter 4) and therefore I conclude that lightutilising processes in sea ice are minor.

There was no relationship between bacterial numbers and chl- $a$ concentration, suggesting there was an uncoupling of the microbial loop. This may be because bacterial numbers have reached an equilibrium with the environment. They have reached maximum growth due to saturation with the amount of DOM present in the environment but are also being kept at these numbers due to viral and grazing constraints. As a result, the relationship between bacterial numbers and chl- $a$ should not be used as a proxy for microbial loop dynamics. When investigating enzymatic activity however, I confirm that sea ice bacteria are predominantly heterotrophic organisms and are highly involved in hydrolysing particular components of DOM.

\section{Do bacteria show biogeographical patterns and/or is 'everything everywhere'?}

Bass-Becking stated 'everything is everywhere, but the environment selects' (see O'Malley, 2007 and citations within), which is one of the more contentious areas in contemporary microbiology. It suggests that bacteria are cosmopolitan and any biogeographical patterns are weak or absent. The development of deep sequencing methods have enabled the 'rare biosphere' to be sampled, which revealed a large biodiversity of bacterial OTUs in sea ice (Chapter 4). This 'rare biosphere' may provide a global seed bank that is similar in composition and, perhaps 'everything is everywhere'.

A total of $11.3 \%$ of the bacterial OTUs were found at all the sites. The majority of these were abundant in sea ice, each contributing to over $1 \%$ of the community. These abundant bacteria were identified as members of the Gammaproteobacteria, Actinobacteria, Bacteroidetes and Bacillus that are perhaps able to grow in a diverse range of environments and contain traits such as spores or vacuoles to survive 
dispersion. The most abundant OTUs were related to the genera Polaribacter, Glaciecola, and Psychrobacter, all of which could grow at $25^{\circ} \mathrm{C}$ in culture suggesting that they are more generalist. These genera have also been identified in Arctic environments (Junge et al. 2002; Brinkmeyer et al. 2003), implying that the same selection methods occur in both the Arctic and Antarctic. This also implies that biogeographical barriers are permeable and that these bacterial species are indeed cosmopolitan.

However, $52.5 \%$ of the OTUs were surveyed sporadically. Many of these were rare, comprising $<0.1 \%$ of the community. These rare bacteria are perhaps more specialist where they only grow under particular environmental conditions. Perhaps the rare OTUs are part of a global seed bank and are present at all sites, but 454 sequencing is not sensitive enough to detect them or they were not extracted from the environment. I did show that by comparing the culture-based and molecular-based sequences, there was a proportion of the bacterial community that was not detected using 454 sequencing. The discrimination between the culture and 454 sequencing databases is likely due to the nucleic acid extraction failing to rupture the bacterial walls of Gram positive cells (Chapter 6). It is unlikely that the extraction methods would have a large influence, as if a certain group is not being extracted then it would be absent from the whole database rather than just one site. Also, the rank abundance curve reached an asymptote at 3000 OTUs suggesting that OTU diversity had been fully sampled. So perhaps at certain sites these rare taxa are in such low abundance that they are not amplified or are lost in the analyses. However, studies have shown that bacteria can be endemic, driven by biogeography (Cho and Tiedje 2000; Oda et al. 2003; Whitaker et al. 2003) or environmental variables (Horner-Devine et al. 2004). A study based on data from Genbank found that $<10 \%$ of bacterioplankton 16S rRNA sequences were ubiquitous (Pommier et al. 2005). Therefore perhaps these sea ice bacteria are not ubiquitous and do show biogeographical patterns.

In Antarctic sea ice, bacterial communities showed taxa-area relationships where groups located close together were more similar in composition than communities located farther away (Chapter 3). The sites Granite Harbour (GH) and Cape Roberts (CR) which were closer in geography had greater bacterial similarity than at Terra Nova Bay (TNB) and McMurdo Station (McM). Terra Nova Bay (TNB) was the 
furthest site and the sea ice bacterial communities were $<40 \%$ similar to the communities collected from the other sites. However, the bacterial community structure at TNB was more similar to the McMurdo Station sea ice community, which was further away from TNB than those at Granite Harbour and Cape Evans. So perhaps this relationship is driven primarily by environmental heterogeneity rather than geographical distance.

The existence of microbial biogeography has been recently called into question by Bland Finlay who wrote "there is no biogeography for anything smaller than 1 millimeter" (Finlay 2002). If this is the case, bacteria would be ubiquitous due to their unlimited capacity for long distance dispersal, ecologically redundant and thus will not show any distribution patterns. Sea ice bacteria are dispersal limited and showed taxa-area relationships therefore I oppose the view that 'everything is everywhere'. However, sea ice bacterial communities are influenced by the environment and it is likely that both the environment as well as geography play a role in shaping community structure.

\section{Can sea ice microbial diversity be described adequately with current techniques?}

There is no single technique today that can describe the entire diversity of a bacterial community due to the biases that are introduced at each step. Only through a combined approach such as using culturing and PCR-based methods can we begin to gain sufficient information. I found that there was some degree of overlap between the cultivatable bacteria and the PCR-detected bacteria, which has also been documented by Brown and Bowman (2001) and Brinkmeyer et al. (2003). This strongly contrasts to other marine environments where there is little overlap between culture dependent and independent methods (Amann et al. 1995). Nonetheless, the use of both methods enables a greater proportion of the bacterial diversity in a sample to be detected. Also, I have shown the importance of extracting both the RNA and DNA from environmental samples in order to sample a greater diversity of bacteria. The 454 sequencing revealed that the rDNA and rRNA communities shared many of the same OTUs. However, the rRNA and rDNA both contributed a proportion of OTUs that were only found in one or the other community. 
T-RFLP may have caused biases in the measurement of OTU richness using RFLs as T-RFLP only targets the abundant species in a sample. RFL richness at TNB was higher than at the other sites (Chapter 3). However, analysis of the number of OTUs at this site using 454 sequencing revealed that the OTU diversity and evenness was low compared to the other sites (Chapter 6). TNB only contained a quarter of the number of OTUs that were found at all sites and was dominated by few abundant OTUs. The other sites had more of a spread of OTUs and more rare bacteria. This confirms that T-RFLP does indeed target the more abundant species in a community and as a result causes biases when investigating species richness. Communities that are depicted as having higher RFL richness may actually have less species but they are in higher abundance and therefore detected using this method. Other communities that have more rare OTUs will not be detected using T-RFLP even though they may be more species rich. Many studies use RFL diversity as a measure for species richness (e.g. Danovaro et al. 2006; Orcutt et al. 2009; Edwards et al. 2010) but by itself this technique should be used with caution.

The determination of bacterial diversity in sea ice is challenging as the distinction between bacterial species is somewhat arbitrary. It is accepted that two strains must show a similarity $>97 \%$ to be considered part of the same species. However, the $16 \mathrm{~S}$ rRNA gene does not have enough resolution to delineate species. The species richness curve showed that OTU richness at $3 \%$ similarity (species level) in Antarctic sea ice levelled off at about $3 \times 10^{3}$. Therefore sea ice bacteria diversity is at the low end of the diversity estimate scale (Pedros-Alio 2006) and aligns closely to the $10^{3}-10^{4}$ proposed by Finlay (2002). Although Finlay (2002) referred to eukaryotic microbes, the idea that diversity is low due to a lack of geographical barriers and limitless dispersal was extrapolated to all microorganisms. However, I show that bacterial OTUs are influenced by geography and can be dispersal limited. Therefore, the low diversity may occur due to the challenging environmental conditions of Antarctic sea ice. It will support lower colonization rates leading to relatively few microbial taxa compared to environments that are more hospitable. The sea ice will be dominated by populations uniquely adapted to survive in the harsh environment (Atlas and Bartha 1986). 
Sea ice thickness and extent is expected to decrease over the next century. This study provides baseline data which give insight into how the SIMCO will respond to the changing environment. Sea ice bacteria follow classic ecological patterns showing taxa-area relationships and dispersal limitation. The bacterial community among sites contained many common OTUs which comprise a large percentage of the community, but also rare OTUs which were different across sites. Bacteria were also influenced by the environment which appeared to be directly related to algal productivity. Therefore the sea ice bacteria community composition may show repeatable patterns that are predictable from a variety of abiotic, biotic, nutrient, and ecosystem function variables. Further expansion of this work using multi-year monitoring will give better information about how climate change might alter the sea ice microbial community.

\subsection{FUTURE RESEARCH DIRECTIONS}

The focus of this thesis was on the prokaryotic communities in Antarctic sea ice. Bacterial communities were influenced by environmental variables, but there was still a percentage of the variation that was not explained using the parameters that were measured. One variable that was not measured was viral abundance. Viruses may have a huge impact on the bacterial community where they target the most abundant bacteria species and 'kill the winner' (Thingstad 2000). Studies of viruses in the sea ice are scarce and virtually nothing is known about the role of viruses in the SIMCO, if they drive changes in bacterial diversity, or if they are simply following the changes in bacterial abundance.

Although there was no relationships seen between Chl- $a$ and bacterial numbers or bacterial community structure, it would be interesting to see if there were any relationships between particular groups of algae and bacterial community structure. Changes in algal community structure may be measured using fingerprinting techniques such as T-RFLP and subsequent analysis to look for associations with the bacterial community structure. Future work may also benefit from investigating the relationships between particular bacterial groups and the environment. Bacterial diversity has been shown to increase with primary productivity (Horner-Devine et al. 2003), a trend that was not clear in sea ice. However, Horner-Devine et al. (2003) 
found a relationship between richness and productivity for Alphaproteobacteria but no discernable relationship for Betaproteobacteria. Therefore diversity may be related to primary productivity in sea ice but there may be more complex interactions where environmental influences may be highly dependent on the taxa in question (Reimann et al. 2000; Horner-Devine et al. 2003; Ganderton and Coker 2005).

T-RFLP was used to investigate 16S rRNA sequences in Antarctic sea ice. It may be interesting to target particular functional genes, such as those involved in nitrogen and carbon cycling, using T-RFLP. T-RFLP has been used for the analysis of functional genes such as those encoding ammonia oxidation (Horz et al. 2000), nitrogen fixation (Tan et al. 2003) and methane oxidation (Horz et al. 2001). This information would give insight into changes in functional gene patterns spatially and temporally and also may show relationships with these particular functions and the environment.

T-RFLP and 454 sequencing methods are semi-quantitative as they both have issues with PCR bias. In order to confirm the quantity of particular bacterial group a method such as Fluorescence in situ Hybridisation (FISH) analysis may be used. As FISH frequently results in a dim fluorescence signal, fluorescence can be increased using catalysed reporter deposition FISH (CARD-FISH) where oligonucleotide probes are labelled with a horseradish peroxidase (HRP, Pernthaler et al. 2002). CARD-FISH has also been combined with microautoradiography (MICRO-CARD-FISH) to determine the abundance of bacteria taking up aspartic acid in the North Atlantic (Teira et al. 2004). FISH is best used when a specific group or species is targeted, rather than aiming to determine total diversity, as there are limits to how many probes and/or primer sets can be used. 


\section{OBbliography}

Abdo Z, Shuette U, Bent SJ, Williams CJ, Forney LJ and Joyce P. (2006) Statistical methods for characterizing diversity of microbial communities by analysis of terminal restriction fragment length polymorphisms of 16S rRNA genes. Environ Microbiol 8(5): 929-938

Achenbach LA, Carey J and Madigan M.T. (2001) Photosynthetic and Phylogenetic Primers for Detection of Anoxygenic Phototrophs in Natural Environments. Appl Environ Microbiol 67 2922-2926

Acinas SG, Klepac-Ceraj V, Hunt DE, Pharino C, Ceraj I, Distel DL and Polz MF. (2004). Finescale phylogenetic architecture of a complex bacterial community. Nature 430 551-554

Ackley SF and Sullivan CW. (1994) Physical controls on the development and characteristics of Antarctic sea ice biological communities - a review and synthesis. Deep-Sea Res 41: 15831604

Ainsworth AM and Goulder R. (2000) The effect of sewageworks effluent on riverine extracellular aminopeptidase activity and microbial leucine assimilation. Wat Res 34: 2551

Akaike H. (1973) Information theory as an extension of the maximum likelihood principal. In: Petrov B.N Caski F. (Eds.) Proceedings of the Second International Symposium on Information Theory. Akademiai Kiado Budapest pp. 261-281

Alberti M, Burke DH and Hearst JE. (1995). Structure and sequence of the photosynthesis gene cluster. In Anoxygenic photosynthesis bacteria pp. 1083-1106. Edited by R. E. Blankenship MT Madigan and CE Bauer: Kluwer.

Amann RI, Ludwig W and Schleifer KH. (1995). Phylogenetic identification and in situ detection of individual microbial cells without cultivation. Microbiol Rev 59: 143-169

Anderson MJ and Willis TJ (2003) Canonical analysis of principal coordinates: a useful method of constrained ordination for ecology. Ecol 84: 511-524

Anderson MJ (2001). A new method for non-parametric multivariate analysis of variance. Austral Ecol 26(1): 32-46

Anderson MJ, Gorley RN and Clarke KR. (2008) PERMANOVA+ for PRIMER: Guide to software and statistical methods. PRIMER-E Ltd. Plymouth, United Kingdom

Andersson AF, Lindberg M, Jakobsson H, Backhed F, Nyren P et al. (2008) Comparative analysis of human gut microbiota by barcoded pyrosequencing. PLOS ONE 3: e2836

Arrigo KR and Thomas DN. (2004) Large scale importance of sea ice biology in the Southern Ocean. Antarct Sci 16:471-486

Arrigo KR and Sullivan CW. (1992) The influence of salinity and temperature covariation on the photophysiological characteristics of Antarctic sea ice microalgae. J Phycol 28:746-56

Ashelford KE, Chuzhanova N, Fry JC, Jones AJ and Weightman AJ. (2005). At least one in twenty 16S rRNA sequence records currently held in public repositories estimated to contain substantial anomalies. Appl Environ Microbiol 71: 7724-7736 
Atamna-Ismaeel N, Sabehi G, Sharon I et al. (2008). Widespread distribution of proteorhodopsins in freshwater and brackish ecosystems. ISME J 2: 656-662

Atkins WRG. (1923) The phosphate content of fresh and salt waters in its relationship to the growth of the algal plankton. J Mar Biol Ass UK 13: 119-150

Atlas RM and Bartha R. (1986) Structure of microbial communities. In: RM Atlas, R Bartha, (eds) Microbial ecology, fundamentals and applications, $2^{\text {nd }}$ ed., Benjamin/Cummings Publishing Company, Inc, Reading MA. Pp 79-83

Azam F and Malfatti F. (2007) Microbial structuring of marine ecosystems. Nature Rev Microbiol 5: 782-791

Azam F, Fenchel T, Field JG, Gray JS, Meyer-Reil LA and Thingstad F. (1983). The ecological role of water-column microbes in the sea. MEPS 10 257-263

Azam F and Worden AZ (2004) OCEANOGRAPHY: Microbes Molecules and Marine Ecosystems. Science 303: 1622-1624

Azam F, Smith DC and Hollibaugh JT. (1991). The role of the microbial loop in Antarctic pelagic ecosystems. Polar Res 10(1): 239-243

Bano N, Ruffin S, Ransom B and Hollibaugh JT. (2004). Phylogenetic composition of Arctic Ocean archaeal assemblages and comparison with Antarctic assemblages. Appl Environ Microbiol 70: 781-789

Barns SM, Fundyga RE, Jeffries MW and Pace NR. (1994) Remarkable archaeal diversity detected in a Yellowstone National Park hot spring environment. PNAS 91: 1609-1613

Beja O, Suzuki MT, Heidelberg JF, Nelson WC, Preston CM, Hamada T, Eisen JA, Fraser CM and DeLong EF. (2002). Unsuspected diversity among marine aerobic anoxygenic phototrophs. Nature 415 630-633

Belila A, Gtari M, Ghrabi A and Hassen A. (2009) Purple anoxygenic phototrophic bacteria distribution in Tunisian wastewater stabilisation plant exhibiting red water phenomenon. Ann Microbiol 59(3): 399-408

Bergamasco A, Defendi V, Del Negro P and Uman SF. (2003) Effects of the physical properties of water masses on microbial activity during an Ice Shelf Water overflow in the central Ross Sea. Antarct Sci 15(3): 405-411

Bird DF and Karl DM. (1999) Uncoupling of bacteria and phytoplankton during the austral spring bloom in Gerlache Strait Antarctic Peninsula. Aquat Microb Ecol 19: 13-27

Blackwood CB, Hudleston D, Zak DR and Buyer JS. (2007) Interpreting Ecological Diversity Indices Applied to Terminal Restriction Fragment Length Polymorphism Data: Insights from Simulated Microbial Communities. Appl Environ Microbiol 73(16): 5276-5283

Boetius A. (1995) Microbial hydrolytic enzyme activities in deep-sea sediments. Hel Meer 49: 177

Boone DR, Castenholz CW, George M, Garrity GM eds. (2001) Bergey's manual of systematic bacteriology. Vol. $12 \mathrm{~d}$ ed. New York Springer

Boström K, Hagström H, Riemann L and Simu K. (2004) Optimization of DNA extraction for quantitative marine bacterioplankton community analysis. Limnol Oceanogr 2: 365-378

Bowman JP, McCammon SA, Brown MV, Nichols DS and McMeekin TA. (1997). Diversity and association of psychrophilic bacteria in Antarctic sea ice. Appl Environ Microbiol 63: 3068-3078

Bowman JP, McCammon SA, Lewis T, Skerratt JH, Brown JL, Nichols DS et al. (1998). Psychroflexus torquis gen. nov sp. nov a psychrophilic species from Antarctic sea ice and 
reclassification of Flavobacterium gondwanense (Dobson.1993) as Psychroflexus gondwanense gen. nov comb. nov. Microbiol UK 144 1601-1609

Bowman JP. (2006) The Genus Psychrobacter. In: The Prokaryotes - Volume 6 Springer (Ed.) New York. pp. 920-930

Bowman JP. (2008) Genomic analysis of psychrophilic prokaryotes Psychrophiles: From Biodiversity to Biotechnology Springer NY Rosa Margesin Franz Schinner Jean-Claude Marx \& Charles Gerday (ed) New York USA pp. 265-284

Bracegirdle TJ, Connolley WM and Turner J. (2008) Antarctic climate change over the twenty first century. J Geophys Res 113 D03103 doi:10.1029/2007JD008933.

Braker G, Fesefeldt A and Witzel K. (1998) Development of PCR Primer Systems for Amplification of Nitrite Reductase Genes (nirK and nirS) To Detect Denitrifying Bacteria in Environmental Samples. Appl Environ Microbiol 64(10): 3769-3775

Brenner DJ, Staley JT and Krieg NR (2001) Classification of procaryotic organisms and the concept of bacterial speciation. In Bergey's manual of systematic bacteriology Boone D.R Castenholz R.W Garrity G.M 2nd edn. vol. 1 2001pp. 27-31. Eds. New York NY:Springer

Brinkmeyer R, Knittel K, Jürgens J, Weyland H, Amann R and Helmke E. (2003). Diversity and Structure of Bacterial Communities in Arctic versus Antarctic Pack Ice. Appl Environ Microbiol 69: 6610-6619

Brochier-Armanet C, Boussau B, Gribaldo S and Forterre P. (2008) Mesophilic crenarchaeota: proposal for a third archaeal phylum the Thaumarchaeota. Nat Rev Microbiol 6: 245-252.

Brown MV and Bowman JP. (2001). A molecular phylogenetic survey of sea ice microbial communities (SIMCO). FEMS Microbiology Ecology 35: 267-275

Brown MV, Schwalbach M,S Hewson I and Fuhrman J.A. (2005) Coupling 16S-ITS rDNA clone libraries and automated ribosomal intergenic spacer analysis to show marine microbial diversity: development and application to a time series. Environ Microbiol 7: 1466-1479

Budillon G and Spezie G. (2000). Thermohaline structure and variability in the Terra Nova Bay polynya Ross Sea. Ant Sci 12(4) 501-516

Burnham KP and Anderson DR. (2004) Multimodel inference - understanding AIC and BIC in model selection. Sociological Methods Res. 33 261-304

Caffrey JM, Bano N, Kalanetra K and Hollibaugh JT. (2007). Ammonia oxidation and ammonia oxidizing bacteria and archaea from estuaries with differing histories of hypoxia. ISME $J 1$ : $660-662$

Campbell BJ, Waidner LA, Cottrell MT and Kirchman D.L. (2008) Abundant proteorhodopsin genes in the North Atlantic Ocean. Environ Microbiol 10(1): 99-109

Caron DA, Lim EL, Sanders RW, Dennett MR and Berninger UG. (2000) Responses of bacterioplankton and phytoplankton to organic carbon and inorganic nutrient additions in contrasting oceanic ecosystems. Aquat Microbiol Ecol 22: 175-184

Castella E, Adalsteinsson H, Brittain JE, Gislason GM, Lehmann A, et al. (2001) Macrobenthic invertebrate richness and composition along a latitudinal gradient of European glacier-fed streams. Fresh Biol 46: 1811-1831

Castillo MM, Kling GW and Allan JD. (2003) Bottom-up controls on bacterial production in tropical lowland rivers. Limnol Oceanogr 48: 1466-1475

Chapin SF. (1974) Morphological and Physiological Mechanisms of Temperature Compensation in Phosphate Absorption along a Latitudinal Gradient. Ecol. 55(6): 1180-1198 
Cho JC and Tiedje JM. (2000). Biogeography and degree of endemicity of fluorescent Pseudomonas strains in soil. Appl Environ Microbiol 66: 5448-5456

Chomczynski P and Sacchi N. (1987) Single-step method of RNA isolation by acid guanidinium thiocyanate-phenol-chloroform extraction. Anal Biochem 162: 156-159.

Chrost RJ, Munster U, Rai H, Albrecht D, Witzel PK and Overbeck J. (1989) Photosynthetic production and exoenzymatic degradation of organic matter in the euphotic zone of a eutrophic lake. J Plankton Res 11:223-242

Chrost RJ and Velimirov B. (1991). Measurement of enzyme kinetics in water samples: effect of freezing and soluble stabilizer. MEPS 70: 93-100

Church MJ, DeLong EF, Ducklow HW, Karner MB, Preston CM and Karl DM. (2003). Abundance and distribution of planktonic Archaea and Bacteria in the waters west of the Antarctic Peninsula. Limnol Oceanogr 48: 1893-1902

Clarke A and Harris CM. (2003) Polar marine ecosystems: major threats and future change. Environ Conserv 30: 1-25

Clarke K, Somerfield P and Gorley R. (2008) Testing of null hypotheses in exploratory community analyses: similarity profiles and biota-environment linkage. J Exp Mar Biol Ecol 366: 56-69

Clarke KR and Warwick RM (2001) Change in marine communities: an approach to statistical analysis and interpretation. 2nd ed. PRIMER-E Ltd Plymouth United Kingdom.

Cohan FM. (2002) What are bacterial species? Annu Rev Microbiol 56: 457-87

Cole JR, Chai B, Marsh TL, Farris RJ, Wang Q, Kulam SA et al. (2003). The Ribosomal Database Project (RDPII): previewing a new autoaligner that allows regular updates and the new prokaryotic taxonomy. Nucleic Acids Res 31: 442-443

Collins RE, Rocap G and Deming JW. 2010. Persistence of bacterial and archaeal communities in sea ice through an Arctic Winter. Environ Microbiol 12(7) 1828-1841

Cota GF, Kottmeier ST, Robinson DH, Smith WO and Sullivan CW. (1990). Bacterioplankton in the marginal ice zone of the Weddell Sea: biomass production and metabolic activities during austral autumn. Deep-Sea Res 37 (7): 1145-1167

Cottrell MT and Kirchman DL. (2009) Photoheterotrophic Microbes in the Arctic Ocean in Summer and Winter. Appl Environ Microbiol 75(15): 4958-4966

Cottrell MT, Wood DN, Yu L and Kirchman D.L. (2000) Selected chitinase genes in cultured and uncultured marine bacteria in the $\alpha$ - and $\gamma$-Subclasses of the Proteobacteria. Appl Environ Microbiol 66(3): 1195-1201

Cottrell MT and Kirchman DL. (2000) Community composition of marine bacterioplankton determined by $16 \mathrm{~S}$ rRNA gene clone libraries and fluorescence in situ hybridization. Appl Environ Microbiol 66: 5116-5122

Cottrell MT, Moore JA and Kirchman D.L. (1999) Chitinases from Uncultured Marine Microorganisms. Appl Environ Microbiol 65: 2553-2557

Cowan SF and Steel KJ (1970). Manual for the Identification of the Medical Bacteria Cambridge: Cambridge University Press. pp. 7-122

Cowie ROM, Maas EW, Ryan KG (2011) Archaeal Diversity Revealed in Antarctic Sea Ice. Ant Sci doi:10.1017/S0954102011000368.

Crowley TJ. (1986) Paleoclimatic modeling. In: ME Schlesinger (ed) Physically-based modeling and simulation of climate and climatic change (Part 2). Kluwer Academic Pablishers, Norwell, MA, pp 883-950 
Currie DJ. (1990) Large scale variability and interactions among phytoplankton bacterioplankton and phosphorus. Limnol Oceanogr 35: 1437-1455

Curtis TP, Sloan WT and Scannell JW (2002) Estimating prokaryotic diversity and its limits. PNAS 99: 10494-10499

Danovaro R, Luna GM, Dell'Anno A and Pietrangeli B. (2006) Comparison of Two Fingerprinting Techniques Terminal Restriction Fragment Length Polymorphism and Automated Ribosomal Intergenic Spacer Analysis for Determination of Bacterial Diversity in Aquatic Environments. Appl Environ Microbiol 72: 5982-5989

Das S, Lyla PS and Ajmal K. (2007) A Simple Scheme for The Identification of Marine Heterotrophic Bacteria. Thalassas 23(2): 17-21

Davidson AT and van der Hiejden A (2000) Exposure of natural Antarctic marine microbial assemblages to ambient UV radiation: effects on bacterioplankton. Aquat Microb Ecol 21:257-264

del Giorgio PA and Gasol JM. (2008) Physiological structure and single cell activity in marine bacterioplankton. In: Microbial Ecology of the Oceans (ed. Kirchman DL). Wiley pp. 243298

del Giorgio PA, Gasol JM, Vaqué D, Mura P, Agustí S and Duarte CM (1996) Bacterioplankton community structure: protists control net production and the proportion of active bacteria in a coastal marine community. Limnol Oceanogr 41:1169-1179

Delille D. (1992) Marine bacterioplankton at the Weddell Sea ice edge distribution of psychrophilic and psychrotrophic populations. Polar Biol 12: 205-210.

Dell'Anno A and Danovaro R. (2005) Extracellular DNA plays a key role in deep-sea ecosystem functioning. Science 309: 2179

DeLong EF, Wu KY, Prezelin BB and Jovine RVM. (1994). High abundance of Archaea in Antarctic marine picoplankton. Nature 371: 69-697

DeLong EF. (1992) Archaea in coastal marine environments. PNAS 89: 5685-5689

DeLong E.F Preston C.M Mincer T Rich V Hallam S.J Frigaard N.U et al. (2006) Community genomics among stratified microbial assemblages in the ocean's interior. Science 311: 496503

Deming JW. (2002). Psychrophiles and polar regions. Curr Opin Microbiol 5: 301-309

Devol AH. (1991) Direct measurements of nitrogen gas fluxes from continental sediments. Nature 349: 319-321

Devol AH and Christensen JP. (1997) Benthic fluxes and nitrogen cycling in sediments of the continental margin of the eastern North Pacific. J Mar Res 51: 345-372

Diez B, Pedros-Alio C, Marsh TL and Massana R. (2001) Application of Denaturing Gradient Gel Electrophoresis (DGGE) To Study the Diversity of Marine Picoeukaryotic Assemblages and Comparison of DGGE with Other Molecular Techniques. Appl Environ Microbiol 67: 2942-2951

Donachie SP, Foster JS and Brown M.V. (2007) Culture clash: challenging the dogma of microbial diversity. ISME J 1 97-102

Donachie SP, Hou S, Lee KS, Riley CW, Pikina A et al. (2004) The Hawaiian Archipelago: a microbial diversity hotspot. Microb Ecol 48 509-520

Dortch Q. (1990). The interaction between ammonium and nitrate uptake in phytoplankton. Mar Ecol Prog Ser 61: 183-201 
Ducklow HW (2000) Bacterioplankton production and biomass in the oceans. In Microbial ecology of the oceans Kirchman D.L pp. 85-120. Eds. New York, NY:Wiley

Dunbar J, Ticknor LO and Kuske CR. (2001) Phylogenetic Specificity and Reproducibility and New Method for Analysis of Terminal Restriction Fragment Profiles of 16S rRNA Genes from Bacterial Communities. Appl Environ Microbiol 67(1): 190-197

Durkin CA, Mock T and Armbrust EV (2009) Chitin in Diatoms and Its Association with the Cell Wall. Euk Cell 8(7): 1038-1050

Eckert KA and Kunkel TA. (1991) DNA polymerase fidelity and the polymerase chain reaction. PCR Methods Appl 1: 17-24

Edwards A, Anesio AM, Rassner SM, Sattler B, Hubbard B, et al. (2010) Possible interactions between bacterial diversity microbial activity and supraglacial hydrology of cryoconite holes in Svalbard. ISME J. 5(1): 150-60

Edwards RA, Rodriguez BB, Wegley L, Haynes M, Breitbart M et al. (2006) Using pyrosequencing to shed light on deep mine microbial ecology. BMC Genomics 7: 57

Eilers H, Pernthaler J, Peplies J, Glocknes FO, Gerdts G and Amann R. (2001) Isolation of Novel Pelagic Bacteria from the German Bight and Their Seasonal Contributions to Surface Picoplankton. Appl Environ Microbiol 67(11): 5134-5142

Eilers H, Pernthaler J, Glockner FO and Amann R. (2000) Culturability and in situ abundance of pelagic bacteria from the North Sea. Appl Environ Microbiol 66:3044-3051

Elkins JG, Podarc M, Graham DE, Makarovae KS, Wolfe Y et al. (2008). A korarchaeal genome reveals insights into the evolution of the Archaea. PNAS 105(23): 8102-8107

Enwall K, Nyberga KL, Bertilssonb S, Cederlunda H, John Stenströma J and Hallin S. (2007) Long-term impact of fertilization on activity and composition of bacterial communities and metabolic guilds in agricultural soil. Soil Biol Biochem 39(1): 106-115

Ertugrul S, Donmez G and Takac S. (2007) Isolation of lipase producing Bacillus sp. from olive mill wastewater and improving its enzyme activity. Hazardous Materials 149: 720-724

Evans CA, O'Reilly JE and Thomas JP (1987) A handbook for the measurement of chlorophyll a and primary production. College StationTexas A\&M University $114 \mathrm{p}$.

Felsenstein J. (1989). PHYLIP- Phylogeny Inference Package (Version 3.2). Cladistics 5: 164166

Felske A, Rheims H, Wolterink A, Stackebrandt E and Akkermans A.D. (1997) Ribosome analysis reveals prominent activity of an uncultured member of the class Actinobacteria in grassland soils. Microbiol 143 (9): 2983- 2989

Fenchel T. (2005) Cosmopolitan microbes and their 'cryptic' species. Aquat Microb Ecol 41:4954

Fenchel T. (2008) ' The microbial loop - 25 years later '. J Exp Mar Biol Ecol 366: 99-103

Fenchel T. and Finlay B.J. (2004). The ubiquity of small species: Patterns of local and global diversity. Biosci 54 777-784

Finlay BJ. (2002) Global dispersal of free-living microbial eukaryote species. Science 2961061 1063

Fisher MM and Triplett EW. (1999) Automated approach for ribosomal intergenic spacer analysis of microbial diversity and its application to freshwater bacterial communities. Appl Environ Microbiol 65: 4630-4636 
Fox GE, Wisotzkey JD and Jurtshuk P. (1992) How Close Is Close - 16s Ribosomal-Rna Sequence Identity May Not Be Sufficient to Guarantee Species Identity. Int J Syst Bacteriol 42:166-170

Francis CA, Beman JM and Kuypers MMM. (2007) New processes and players in the nitrogen cycle: the microbial ecology of anaerobic and archaeal ammonia oxidation. ISME J 1: 19-27

Franzmann PD, Stackebrandt E, Sanderson K, Volkman JK, Cameron DE, Stevenson PL et al. (1988). Halobacterium lacusprofundi sp. nov a halophilic bacterium isolated from Deep Lake Antarctica. Syst Appl Microbiol 11: 207

Fuhrman JA, Sleeter TD, Carlson CA and Proctor LM. (1989) Dominance of bacterial biomass in the Sargasso Sea and its ecological implications. MEPS 57: 207-217

Fuhrman JA, Lee SH, Masuchi Y, Davis AA and Wilcox RM. (1994) Characterization of marine prokaryotic communities via DNA and RNA. Microb Ecol 28: 133-145

Fuhrman JA, Steele JA, Hewson I, Schwalbach MS, Brown MV, Green JL and Brown JH. (2008) A latitudinal diversity gradient in planktonic marine bacteria. PNAS 105(22): 77747778

Fuhrman JA. (2009) Microbial community structure and its functional implications. Nature 459: 193-199

Fuhrman JA, Hewson I, Schwalbach MS, Steele JA, Brown MV and Naeem S. (2006) Annually reoccurring bacterial communities are predictable from ocean conditions. PNAS 103: 1310413109

Galloway JN, Townsend AR, Erisman JW, Bekunda M, Cai Z et al. (2008) Transformation of the nitrogen cycle: Recent trends questions and potential solutions. Science 320: 889-892

Ganderton P and Coker P. (2005) Environmental Biogeography. Pearson Education, Essex, England.

Gasol JM, del Giorgio PA, Massana R and Duarte CM (1995) Active versus inactive bacteria: size-dependence in a coastal marine plankton community. MEPS 128:91-97

Gast RJ, Dennett MR and Caron DA. (2004) Characterization of Protistan Assemblages in the Ross Sea Antarctica by Denaturing Gradient Gel Electrophoresis. Appl Environ Microbiol 70(4): 2028-2037

Gentile G, Giuliano L, D'Auria G, Smedile F, Azzaro M, De Domenico M and Yakimov MM. (2006) Study of bacterial communities in Antarctic coastal waters by a combination of $16 \mathrm{~S}$ rRNA and 16S rDNA sequencing. Environ Microbiol 8: 2150-2161

Gilbert JA, Hill PJ, Dodd CER and Laybourn-Parry J (2004) Demonstration of antifreeze protein activity in Antarctic lake bacteria. Microbiol 150: 171-180

Gillan DC and Danis B. (2007). The archaebacterial com munities in Antarctic bathypelagic sediments. Deep Sea Res II 54: 1682-1690

Giovannoni SJ and Stingl U. (2007) The importance of culturing bacterioplankton in the 'omics' age. Nature Rev Microb 5:820-6

Giri BJ, Bano N and Hollibaugh JT. (2004) Distribution of RuBisCO Genotypes along a Redox Gradient in Mono Lake California. Appl Environ Microbiol 70(6): 3443-3448

Glud RN, Rysgaard S and Kuhl M. (2002) A laboratory study on $\mathrm{O}_{2}$ dynamics and photosynthesis in ice algal communities: Quantification by microsensors $\mathrm{O}_{2}$ exchange rates 14C incubations and PAM fluorometer. Aquat Microb Ecol 27: 301- 311 
Gomez-Consarnau L, Gonzalez JM, Coll-Llado M, Gourdon P, Parscher T, Neutze R, PedrosAlio C and Pinhassi J. (2007). Light stimulates growth of proteorhodopsin-containing marine Flavobacteria. Nature 445 210-213

Gooday GW. (1990) The ecology of chitin degradation. Adv Microb Ecol 11:38

Gosink J and Staley JT. (1995). Biodiversity of gas vacuolate bacteria from Antarctic sea ice and water. FEMS Microb Ecol 102: 8590

Gosink JJ, Woese CR. and Staley JT. (1998). Polaribacter gen. nov with three new species $P$. irgensii sp. nov $P$. franzmannii sp. nov. and $P$. filamentus sp. nov gas vacuolated polar marine bacteria of the Cytophaga-Flavobacterium-Bacteroides group and reclassification of 'Flectobacillus glomeratus' as Polaribacter glomeratus comb. nov. Int J Syst Bacteriol 48: 223-235

Gross L. (2005) As the Antarctic ice pack recedes a fragile ecosystem hangs in the balance. PLoS Biol. 3(4): e127 557-561

Grossi SM, Kottmeier ST and Sullivan CW. (1984) Sea Ice Microbial Communities III. Seasonal abundance of microalgae associated bacteria in McMurdo Sound Antarctica. Microb Ecol 10: 231-242

Groudieva T, Kambourova M, Yusef $\mathrm{H}$ et al. (2004) Diversity and cold active hydrolytic enzymes of culturable bacteria associated with Arctic sea ice Spitzbergen. Extremophiles 8: $475-488$

Guixa-Boixereu N, Vaqué D, Gasol JM, Sanchez-Cámara J and Pedrós-Alió C (2002) Viral distribution and activity in Antarctic waters. Deep-Sea Res II 49:827-845

Hagström A, Pommier T, Rohwer F, Simu K, Stolte W, Svensson D and Zweifel UL. (2002) Use of $16 \mathrm{~S}$ ribosomal DNA for delineation of marine bacterioplankton species. Appl Environ Microbiol 68: 3628-3633

Hamady M, Walker JJ, Harris J,K Gold NJ and Knight R (2008) Error-correcting barcoded primers for pyrosequencing hundreds of samples in multiplex. Nat Methods 5: 235-237.

Harker M, Hirschberg J and Oren A (1998). Paracoccus marcusii sp. nov. an orange Gramnegative coccus. Int J Syst Bacteriol 48: 543-548

Harry M, Gambier B, Bourezgui Y and Garnier-Sillam E. (1999) Evaluation of purification procedures for DNA extracted from organic rich samples: interference with humic substances. Analusis 27 439-442

Helmke E and Weyland H. (1995) Bacteria in sea ice and underlying water of the eastern Weddell Sea in midwinter. MEPS 117: 269-287

Henry S, Baudoin E, Lopez-Gutierrez JC, Martin- Laurent F, Baumann A and Philippot L. (2004) Quantification of denitrifying bacteria in soils by nirK gene targeted real-time PCR. $J$ Microbiol Methods 59: 327-335

Herfort L, Schouten S, Abbas B, Veldhuis MJW, Coolen .JL, Wuchter C et al. (2007) Variations in spatial and temporal distribution of Archaea in the North Sea in relation to environmental variables. FEMS Microbiol Ecol 62: 242-257

Herndl GJ, Agogué H, Baltar F, Reinthaler T, Sintes E and Varela MM (2008) Regulation of aquatic microbial processes: the 'microbial loop' of the sunlit surface waters and the dark ocean dissected. Appl Environ Microbiol 53:59-68

Herndl GJ, Reinthaler T, Teira E, van Aken H, Veth C, Pernthaler A et al. (2005). Contribution of Archaea to total prokaryotic production in the deep Atlantic Ocean. Appl Environ Microbiol 71: 2303-2309 
Hewson I, Capone DG, Steele JA and Fuhrman JA. (2006) Temporal and spatial scales of variation in bacterioplankton assemblages of oligotrophic surface waters. Mar Ecol Prog Ser 311: $67-77$

Hillebrand H (2004) On the generality of the latitudinal diversity gradient. Am Nat 163:192-211

Hiraga K, Shou L, Kitazawa M, Takahashi S, Shimada M, Sato R and Oda K. (1997) Isolation and characterization of chitinase from a lake-chitin degradation marine bacterium Aeromonas hydrophila H-2330. Biosci Biotechnol Biochem 61 174-176

Hoffmaster AR, Ravel J, Rasko DA, Chapman GD, Chute MD et al. (2004) Identification of anthrax toxin genes in a Bacillus cereus associated with an illness resembling inhalation anthrax. PNAS $1018449-8454$

Hooker JD. (1847) The Botany of the Antarctic Voyage of H.M. Discovery Ships Erebus and Terror in the Years 1838-1843. Part 1. Flora Antarctica. London UK: Reeve Brothers.

Hoppe H (1983). Significance of exoenzymatic activities in the ecology of brackish water: measurements by means of methylumbelliferyl-substrates. MEPS 11: 299-308

Hoppe HG. (2002) Phosphatase activity in the sea. Hydrobiologia 493: 187-200

Hoppe HG and Ullrich S. (1999) Profiles of ectoenzymes in the Indian Ocean: phenomena of phosphatase activity in the mesopelagic zone. Aquat Microb Ecol 19: 129-138

Horner-Devine MC, Leibold MA, Smith VH and Bohannan BJM. (2003) Bacterial diversity patterns along a gradient of primary productivity. Ecol Let 6: 613-622

Horner-Devine MC, Lage M, Hughes JB and Bohannan BJM. (2004). A taxa-area relationship for bacteria. Nature 432 750-753

Horz, HP, Rotthauwe JH, Lukow T and Liesack W. (2000). Identification of major subgroups of ammonia-oxidizing bacteria in environmental samples by t-RFLP analysis of amoA PCR products. J Microbiol Methods 39: 197-204

Horz HP, Yimga MT, Liesack W (2001) Detection of methanotroph diversity on roots of submerged rice plants by molecular retrieval of pmoA, mmoX, mxaF, and 16S rRNA and ribosomal DNA, including pmoA-based terminal restriction fragment length polymorphism profiling. Appl Environ Microbiol 67: 4177-4185

Horz HP, Rotthauwe JH, Lukow T and Liesack W. (2005) Identification of major subgroups of ammonia-oxidizing bacteria in environmental samples by T-RFLP analysis of amoA PCR products. J Microbiol Methods 39(3): 197-204

Howard-Williams C, Peterson D, Lyons WB, Cattaneo-Vietti R and Gordon S. (2006) Measuring ecosystem response in a rapidly changing environment: the Latitudinal Gradient Project. Ant Sci 18(4): 465-471

Hoyoux A, Jennes I, Dubois P, Genicot S, Dubail F, et al. (2001). Cold-Adapted bGalactosidase from the Antarctic Psychrophile Pseudoalteromonas haloplanktis. Appl Environ Microbiol 67 (4): 1529-1535

Huber H, Hohn MJ, Rachel R, Fuchs T, Wimmer VC and Stetter KO. (2002). A new phylum of Archaea represented by a nanosized hyperthermophilic symbiont. Nature 417: 63-67

Huber JA, Welch DBM, Morrison HG, Huse SM, Neal P, R Butterfield DA and Sogin ML. (2007) Microbial Population Structures in the Deep Marine Biosphere. Science 318: 97-100

Hugenholtz P and Huber T. (2003) Chimearic 16S rRNA sequences of diverse origin are accumulating in the public databases. Int J Syst Evol Microbiol 53: 289 - 293

Hurvich CM and Tsai CL. (1989) Regression and time-series model selection in small samples. Biometrika 76: 297-307 
Huse SM, Dethlefsen L, Huber JA, Welch DM, Relman D and Sogin ML. (2008) Exploring Microbial Diversity and Taxonomy Using SSU rRNA Hypervariable Tag Sequencing. PLoS Genet 4(11): e1000255

Huse SM, Huber JA, Morrison HG, Sogin ML and Welch DM. (2007) Accuracy and quality of massively parallel DNA pyrosequencing Genome Biol 8: R143

Huson DH, Richter DC, Rausch C, Dezulian T, Franz M and Rupp R. (2007). Dendroscope: An interactive viewer for large phylogenetic trees. BMC Bioinformatics 8(1): 460

Hughes JB, Hellmann JJ, Ricketts TH and Bohannan BJ (2001) Counting the Uncountable: Statistical Approaches to Estimating Microbial Diversity. Appl Environ Microbiol 67(10) 4399-4406

Jezbera J, Hornak K and Simek K. (2005) Food selection by bacterivorous protists: insight from the analysis of the food vacuole content by means of fluorescence in situ hybridization. FEMS Microbiol Ecol 52:351-363

Jones RT, Robeson MS, Lauber CL, Hamady M, Knight R and Fierer N. (2009). A comprehensive survey of soil acidobacterial diversity using pyrosequencing and clone library analyses. ISME J 3: 442-453

Jones SE and Lennon JT. (2010) Dormancy contributes to the maintenance of microbial diversity. PNAS 107(13): 5881-588

Jukes TH and Cantor CR. (1969). Evolution of protein molecules In: Munro H (ed.) Mammalian Protein Metabolism Academic Press New York. pp. 21-132

Junge K, Imhoff F, Staley T and Deming JW. (2002) Phylogenetic diversity of numerically important arctic sea-ice bacteria cultured at subzero temperature. Microb Ecol 43: 315-38.

Junge K, Eicken H and Deming JW. (2004). Bacterial activity at -2 to -20 degrees C in Arctic wintertime sea ice. Appl Environ Microbiol 70: 550-557

Kalanetra KM, Bano N and Hollibaugh JT. (2009). Ammonia oxidizing archaea in the Arctic Ocean and Antarctic coastal waters. Environ micro 11(9): 2434-2445

Kandeler E, Deiglmayr K, Tscherko D, Bru D and Philippot L (2006) Abundance of narG nirS nirK and nosZ genes of denitrifying bacteria during primary successions of a glacier foreland. Appl Environ Microb 72: 5957-5962

Karner MB, Delong EF and Karl DM. (2001). Archaeal dominance in the mesopelagic zone of the Pacific Ocean. Nature 409: 507-510

Karr EA, Ng JM, Belchik SM, Sattley WM, Madigan MT and Achenbach LA. (2006). Biodiversity of Methanogenic and Other Archaea in the Permanently Frozen Lake Fryxell Antarctica. Appl Environ Microbiol 72(2): 1663-1666

Keinänen MM, Korhonen LK, Lehtola MJ, Miettinen IT, Martikainen PJ et al. (2002) The microbial community structure of drinking water biofilms can be affected by phosphorus availability. Appl Environ Microbiol 68:434-439

Kepner RL and Pratt JR. (1994) Use of fluorochromes for direct enumeration of total bacteria in environmental samples: past and present. Microbiol Rev 58: 603-615

Kirchman DL Dittel AI Findlay SEG and Fischer D. (2004) Changes in bacterial activity and community structure in response to dissolved organic matter in the Hudson River New York. Aquat Microl Ecol 35: 243-25

Kirchman DL, Cottrell MT and Lovejoy C. (2010) The structure of bacterial communities in the western Arctic Ocean as revealed by pyrosequencing of $16 \mathrm{~S}$ rRNA genes. Environ Microbiol 12: $1132-1143$ 
Klappenbach JA, Saxman PR, Cole JR and Schmidt TM. (2001) rrndb: the ribosomal RNA operon copy number database. Nucleic Acids Res 29: 181-184

Knowles R. (1982) Denitrification. Microbiol Rev 46: 43-70

Kobližžek M, Mašín M, Ras ,J Poulton AJ and Prášil O. (2007) Rapid growth rates of aerobic anoxygenic phototrophs in the ocean. Environ Microbiol 9: 2401-2406

Kobori H, Sullivan CW and Shizuya H. (1984) Bacterial plasmids in Antarctic natural microbial assemblages. Appl Environ Microbiol 48: 515- 518

Koh EY, Atamna-Ismaee N, Martin AR, Cowie ROM, Beja O, Davy SK, Maas EW and Ryan KG. (2010) Proteorhodopsin-bearing bacteria in Antarctic sea ice. Appl Environ Microbiol 76 (17): 5918-5925

Koh EY. (2011) Phototrophic bacteria in Antarctic sea ice. Ph.D. Thesis, Victoria University of Wellington, NZ

Kolber ZS, van Dover CL, Niederman RA and Falkowski PG. (2000). Bacterial photosynthesis in surface waters of the open ocean. Nature 407: 177-179

Konneke M, Bernhard AE, de la Torre JR, Walker CB, Waterbury JB and Stahl DA. (2005). Isolation of an autotrophic ammonia oxidizing marine archaeon. Nature 437: 543-546

Kottmeier ST and Sullivan CW. (1987) Late winter primary production and bacterial production in sea ice and seawater west of the Antarctic Peninsula. MEPS 36: 287-298

Krembs C, Gradinger R and Spindler M. (2000) Implications of brine channel geometry and surface area for the interaction of sympagic organisms in Arctic sea ice. J Exp Mar Bio Ecol 243: $55-80$

Kunin V, Engelbrektson A, Ochman H and Hugenholtz P. (2010) Wrinkles in the rare biosphere: pyrosequencing errors lead to artificial inflation of diversity estimates. Environ Microbiol 12:118-123

La Scola B, Gundi VA, Khamis A and Raoult D. (2006) Sequencing of the rpoB gene and flanking spacers for molecular identification of Acinetobacter species. J Clin Microbiol 44:827-32

Lami RMT, Cottrell J, Ras O, Ulloa I, Obernosterer H et al. (2007) High abundances of aerobic anoxygenic photosynthetic bacteria in the South Pacific Ocean. Appl Environ Microbiol 73: 4198-4205

Lane DJ. (1991) 16S/23S rRNA Sequencing. In: Stackebrandt EaG M. (ed.) Nucleic Acid Techniques in Bacterial Systematics John Wiley \& Sons Ltd Chichester. pp. 115-175

Langenheder S, Sobek S, and Tranvik LJ. 2006. Changes in bacterial community composition along a solar radiation gradient in humic waters. Aquat Sci 68: 415-424

Le J, Wehr JD and Campbell L. (1994) Uncoupling of bacterioplankton and phytoplankton production in fresh waters is affected by inorganic nutrient limitation. Appl Environ Microbiol 60(6): 2086-209

Lee K, Lee HK, Choi TH, Kim KM and Cho JC. (2007) Granulosicoccaceae fam. nov to include Granulosicoccus antarcticus gen. nov sp. nov a non-phototrophic obligately aerobic chemoheterotroph in the order Chromatiales isolated from Antarctic seawater. J Microbiol Biotechnol 17(9):1483-90

Lee $S$ and Fuhrman JA. (1990) DNA hybridization to compare species compositions of natural bacterioplankton assemblages. Appl Environ Microbiol 56: 739-746

Leininger S, Urich T, Schloter M, Schwark L, Qi J, Nicol GW et al. (2006). Archaea predominate among ammonia oxidizing prokaryotes in soils. Nature 442: 807-809 
Ley RE, Turnbaugh PJ, Klein S and Gordon JI (2006) Microbial ecology: human gut microbes associated with obesity. Nature 444: 1022-1023

Liu H, Xu Y, Ma Y and Zhou P. (2000) Characterization of Micrococcus antarcticus sp. nov a psychrophilic bacterium from Antarctica. Int J Syst Evol Microbiol 50: 715-719

Liu XD, Tiquia SM, Holguin G, Wu LY, Nold SC, Devol AH et al. (2003) Molecular diversity of denitrifying genes in continental margin sediments within the oxygendeficient zone off the Pacific coast of Mexico. Appl Environ Microbiol 69: 3549-3560

Liu Y, Yao T, Jiao N, Kang S, Xu B, Zeng Y, Huang S and Liu X. (2009) Bacterial diversity in the snow over Tibetan Plateau Glaciers. Extremophiles 13(3): 411-423

Liu WT, Marsh TL, Cheng H and Forney LJ. (1997) Characterization of microbial diversity by determining terminal restriction fragment length polymorphisms of genes encoding $16 \mathrm{~S}$ rRNA. Appl Environ Microbiol 63: 4516-4522

Liu Z, Lozupone C, Hamady M, Bushman FD and Knight R. (2007) Short pyrosequencing reads suffice for accurate microbial community analysis. Nucl Acids Res 35: e120

Lizotte MP. (2003) The influence of sea ice on Ross Sea biogeochemical processes. Antarct Res Ser 78: 107-122

Lloyd KG, MacGregor BJ and Teske A. (2009) Quantitative PCR methods for RNA and DNA in marine sediments: maximizing yield while overcoming inhibition. FEMS Microbiol Ecol 72: 143-151

Lomas MW and Lipschultz F. (2006) Forming the primary nitrite maximum: Nitrifiers or phytoplankton? Limnol Oceanogr 51(5): 2453-2467

Ludwig W, Strunk O, Westram R, Richter L, Meier H et al. (2004). ARB: a software environment for sequence data. Nucleic Acids Res 32: 1363-1371

Maas EW (1992) The causative agent of toxic shellfish poisoning. Ph.D. Thesis. The University of Otago, Dunedin, New Zealand

Marañon E (2005) Phytoplankton growth rates in the Atlantic subtropical gyre. Limnol Oceanogr 50: $299-310$

Margulies M, Egholm M, Altman WE, Attiya S, Bader JS et al. (2005) Genome sequencing in microfabricated high-density picolitre reactors. Nature 441: 377-390

Martin A, Hall JA, O'Toole R, Davy SK and Ryan KG. (2008). High single cell metabolic activity in Antarctic sea ice bacteria. Aquat microb ecol 52: 25-31

Martin AR. (2010) Microbial loop dynamics in Antarctic sea-ice. Thesis (PhD). Victoria University of Wellington NZ.

Martin AR, Hall J and Ryan K.G. (2009) Low Salinity and High-Level UV-B Radiation Reduce Single-Cell Activity in Antarctic Sea Ice Bacteria. Appl Environ Microbiol 75(23): 75707573

Martin AR, Anderson MJ, Thorn C, Davy SK and Ryan KG (2011) Response of sea-ice microbial communities to environmental disturbance: an in situ transplant experiment in the Antarctic. MEPS 424:25-37

Martinez J, Smith DC, Steward GF and Azam F. (1996) Variability in ectohydrolytic enzyme activities of pelagic marine bacteria and its significance for substrate processing in the sea. Aquat Microb Ecol 10:223-230

Massana R, Delong EF and Pedros-Alio C. (2000). A few cosmopolitan phylotypes dominate planktonic archaeal assemblages in widely different oceanic provinces. Appl Environ Microbiol 66: 1777-1787 
Mataloni G, Tell G and Wynn-Williams DD. (2000). Structure and diversity of soil algal communities from Cierva Point (Antarctic Peninsula). Polar Biol 23: 205-211

Maykut GA. (1985) The ice environment p. 21-82. In R. A. Horner (ed.) Sea ice biota. CRC Press Inc Boca Raton Fla

McArdle BH and Anderson MJ (2001) Fitting multivariate models to community data: a comment on distance-based redundancy analysis. Ecol 82(1): 290-297

McKenna KC, Mooread DL, Roberts EC and Laybourn-Parry J (2006) Simulated patterns of carbon flow in the pelagic food web of Lake Fryxell Antarctica: little evidence of topdown control. Ecological Modelling 192: 457-472

McMinn A, Ashworth and C Ryan KG (1999) Growth and productivity of Antaractic sea ice algae under PAR and UV irradiances. Botanica Marina 42: 401-407

McMinn A, Ryan KG, Ralph PJ and Pankowshi A. (2007). Spring sea ice photosynthesis primary production and biomass distribution in eastern Antarctica 2002-2004. Mar Biol 151: 985-999

Meehl GA, Collins WD, Boville BA, Kiehl JT, Wigley TML and Arblaster JM. (2000) Response of the NCAR climate system model to increased $\mathrm{CO} 2$ and the role of physical processes. $J$ Climate 13: 1879-1898

Melamede RJ and Wallace SS (1985) A possible secondary role for thymine-containing DNA precursors. Basic Life Sci 31: 67-102

Middelboe M, Hagstrom A, Blackburn N, Sinn B, Fischer U, Borch NH et al. (2001). Effects of bacteriophages on the population dynamics of four strains of pelagic marine bacteria. Microb Ecol 42: 395-406

Mills HJ, Martinez RJ, Story S and Sobecky P.A. (2004) Identification of members of the metabolically active microbial populations associated with Beggiatoa species mat communities from Gulf of Mexico cold-seep sediments. Appl Environ Microbiol 70: 54475458

Mills HJ, Martinez RJ, Story S and Sobecky P.A. (2005) Characterization of microbial community structure in Gulf of Mexico gas hydrates: comparative analysis of DNA- and RNA-derived clone libraries. Appl Environ Microbiol 71: 3235-3247

Miskin IP, Farrimond P and Head IM. (1999) Identification of novel bacterial lineages as active members of microbial populations in a freshwater sediment using a rapid RNA extraction procedure and RT-PCR. Microbiol 145 (8): 1977-1987

Mittelbach GG, Schemske DW, Cornell HV, Allen AP, Brown JM et al. (2007) Evolution and the latitudinal diversity gradient: Speciation extinction and biogeography. Ecol Lett 10:315331

Mock T and Thomas DN. (2005) Recent advances in seaice microbiology. Environ Microbiol 7(5): 605-619

Moeseneder MM, Winter C, Arrieta JM and Herndl GJ. (2001) Terminal restriction fragment length polymorphism (TRFLP) screening of a marine archaeal library to determine the different phylotypes. J Microbiol Methods 44: 159-172

Moeseneder MM, Arrieta JM and Herndl GJ. (2005) A comparison of DNA- and RNA-based clone libraries from the same marine bacterioplankton community. FEMS Microbiol Ecol 51: 341-352 
Moisanader PH, Beinart RA, Voss M and Zehr JP. (2008) Diversity and abundance of diazotrophic microorganisms in the South China Sea during intermonsoon. ISME J 2: 954967

Mosier AC and Francis CA. (2010) Denitrifier abundance and activity across the San Francisco Bay estuary. Environ Microbiol Reports doi:10.1111/j.1758-2229.2010.00156

Moutin T and Rainbault P. (2002) Primary production carbon export and nutrient availability in western and eastern Mediterranean Sea in early summer 1996 (MINOS cruise). J Mar Systems 33-34 273- 288

Moyer C, Dobbs F and Karl D. (1994) Estimation of diversity and community structure through restriction fragment length polymorphism distribution analysis of bacterial 16S rRNA genes from a microbial mat at an active hydrothermal vent system Loihi Seamount Hawaii. Appl Environ Microbiol 60: 871-879.

Mudryk Z and Podgorska B. (2006) Enzymatic activity bacterial strains isolated from marine beach. Pol.J Environ Stud 15: 444-448

Murray AE and Grzymski JJ. (2007) Diversity and genomics of Antarctic marine microorganisms. Phil Trans R Soc B 362: 2259-2271

Murray AE, Preston CM, Massana R, Taylor LT, Blakis A, Wu K and DeLong EF. (1998) Seasonal and Spatial Variability of Bacterial and Archaeal Assemblages in the Coastal Waters near Anvers Island Antarctica. Appl Environ Microbiol 64: 2585-2595

Murray AE, Wu KY, Moyer CL, Karl DM and DeLong EF. (1999) Evidence for circumpolar distribution of planktonic Archaea in the Southern Ocean. Aquat Microb Ecol 18: 263-273

Muyzer G, de Waal EC and Uitterlinden AG. (1993) Profiling of complex microbial populations by denaturing gradient gel electrophoresis analysis of polymerase chain reaction-amplified genes coding for 16S rRNA. Appl Environ Microbiol 59: 695-700

Nagata T and Kirchman DL. (1992) Release of macromolecular organic complexes by heterotrophic marine flagellates. MEPS 83: 233-240

Neretin LN, Schippers A, Pernthaler A, Hamann K, Amann R and Jorgensen BB (2003) Quantification of dissimilatory (bi)sulphite reductase gene expression in Desulfobacterium autotrophicum using real time PCR. Environ Microbiol 5: 660-671

Nichols DS, Greenhill AR, Shadbolt CT, Ross T and McMeekin TA. (1999a) Physicochemical Parameters for Growth of the Sea Ice Bacteria Glaciecola punicea ACAM 611T and Gelidibacter sp. Strain IC158 Appl Environ Microbiol 65(8): 3757-3760

Nichols DS, Bowman J, Sanderson K, Nichols C, Lewis T, McMeekin TA and Nichols PD. (1999b). Developments with Antarctic microorganisms: culture collections, bioactivity screening, taxonomy, PUFA production and cold adapted enzymes. Curr Opin Biotech 10: 240-246

Nicol G, Leininger S, Schleper C and Prosser J. (2008) The influence of soil pH on the diversity abundance and transcriptional activity of ammonia oxidizing archaea and bacteria. Environ Microbiol 10 (11): 2966-2978

Nogales B, Moore ERB, Llobet-Brossa E, Rossello-Mora R, Amann R and Timmis KN. (2001) Combined Use of 16S Ribosomal DNA and 16S rRNA To Study the Bacterial Community of Polychlorinated Biphenyl-Polluted Soil. Appl Environ Microbiol 67: 1874-1884

Nogales B, Timmis KN, Nedwell DB and Osborn AM. (2002) Detection and diversity of expressed denitrification genes in estuarine sediments after reverse transcription- PCR amplification from mRNA. Appl Environ Microbiol 68: 5017-5025 
Nunan N, Daniell T, Singh B, Papert A, McNicol J and Prosser J. (2005) Links between plant and rhizoplane bacterial communities in grassland soils characterized using molecular techniques. Appl Environ Microb 71(11): 6784

Oakley BB, Francis CA, Roberts KJ, Fuchsman CA, Srinivasan S and Staley JT. (2007) Analysis of nitrite reductase (nirK and $n i r S$ ) genes and cultivation reveal depauperate community of denitrifying bacteria in the Black Sea suboxic zone. Environ Microbiol 9: 118-130

Oda Y, Star B, Huisman LA, Gottschal JC and Forney LJ. (2003). Biogeography of the purple nonsulfur bacterium Rhodopseudomonas palustris. Appl Environ Microbiol 69: 5186-5191

Odate T, Hirawake T and Fukuchi M. (2004): Empirical relationship between sea ice thickness and underwater light intensity based on observations near Syowa Station Antarctica in austral summer. Antarct Rec 48: 91-97

Olsen GJ, Lane DJ, Giovannoni SJ and Pace NR. (1986) Microbial ecology and evolution: a ribosomal RNA approach. Annu Rev Microbiol 40: 337-355.

O'Malley MA. (2007) The nineteenth century roots of 'everything is everywhere'. Nat Rev Microbiol 5: 647-651

Orcutt B, Bailey B, Staudigel H, Tebo BM, Edwards KJ (2009) An interlaboratory comparison of $16 \mathrm{~S}$ rRNA gene-based terminal restriction fragment length polymorphism and sequencing methods for assessing microbial diversity of seafloor basalts. Environ Microbiol 11: 17281735

Osborn AM, Moore ERB and Timmis KN. (2000) An evaluation of terminal-restriction fragment length polymorphism (T-RFLP) analysis for the study of microbial community structure and dynamics. Environ Microbiol 2: 39-50

Ouverney CC and Fuhrman JA. (2001) Marine planktonic Archaea take up amino acids. Appl Environ Microbiol 66: 4829-4833

Overpeck JT, Otto-Bliesner BL, Miller GH, Muhs DR, Alley RB and Kiehl JT. (2006). Paleoclimatic Evidence for Future Ice-Sheet Instability and Rapid Sea-Level Rise. Science 311(5768): 1747-1750

Pace NR. (1997). A molecular view of microbial diversity and the biosphere. Science 276: 734740

Pathom-Aree W, Stach JE, Ward AC, Horikoshi K, Bull T and Goodfellow M. (2006) Diversity of actinomycetes isolated from Challenger Deep sediment $(10898 \mathrm{~m})$ from the Mariana Trench. Extremophiles. 10(3): 181-189

Pedrós-Alió C. (2006) Marine microbial diversity: can it be determined? Trends Microbiol 14(6): 257-263

Pérez MT and Sommaruga R. (2006) Differential Effect of Algal- and Soil-Derived Dissolved Organic Matter on Alpine Lake Bacterial Community Composition and Activity. Limnol and Oceanogr 51 (6): 2527-2537

Pernthaler A, Pernthaler J and Amann R. (2002) Fluorescence in situ hybridization and catalyzed reporter deposition for the identification of marine bacteria. Appl Environ Microbiol 68(6): 3094-101

Petri R and Imhoff JF. (2001) Genetic analysis of sea-ice bacterial communities of the western Baltic Sea using an improved double gradient method. Polar Biol 24: 252-257

Pfaffl MW (2001) A new mathematical model for relative quantification in real-time RT-PCR Nuc Acid Res 29(9): 2002-2007 
Pinhassi J, Sala MM, Havskum H, Peters F, Guadayol Ò, Malits A, Marrasé C (2004) Changes in bacterioplankton composition under different phytoplankton regimens. Appl Environ Microbiol 70: 673-676

Polz MF and Cavanaugh CM. (1998) Bias in template-to-product ratios in multitemplate PCR. Appl Environ Microbiol 64: 3724-3730

Pomeroy LR and Wiebe WJ. (2001) Temperature and substrates as interactive limiting factors for marine heterotrophic bacteria. Aquat Microb Ecol 23: 187-204

Pommier T, Pinhassi J, Hagström ^ (2005) Biogeography analysis of ribosomal RNA clusters from marine bacterioplankton. Aquat Microb Ecol 41: 79-89

Pommier T, Canback B, Bostrom KH, Simu K, Lundbery P, Tunlid A and Hagstrom A. (2007) Global patterns of diversity and community structure in marine bacterioplankton. Mol Ecol 16: $867-880$

Poremba K. (1995) Hydrolytic enzymatic activity in deep-sea sediments. FEMS Microbiol Ecol 16: $213-221$

Prada P and Brenchley JE. (1997) Purification and characterization of two extracellular alkaline phosphatases from a psychrophilic arthrobacter isolate. Appl Environ Microbiol 63 (7): 2928-2931

Preston CM, Wu K, Molinski TF and Delong EF. (1996) A psychrophilic crenarchaeon inhabits a marine sponge: Cenarcheum symbiosum gen. nov sp. nov. PNAS 93 6241-6246

Ralph P, McMinn A and Ryan KG. (2005) Short-term effect of temperature on the photokinetics of microalgae from the surface layers of Antarctic pack ice. J Phycol 41: $763-769$

Rappé MS, Kemp PF and Giovannoni SJ. (1997) Phylogenetic diversity of marine coastal picoplankton 16S rRNA genes cloned from the continental shelf off Cape Hatteras North Carolina. Limnol Oceanogr 42: 811-826

Rappé MS, Connon SA, Vergin KL and Giovannoni SJ. (2002) Cultivation of the ubiquitous SAR11 marine bacterioplankton clade. Nature 418 630-633

Rathgeber C, Beatty JY and Yurkov V. (2004) Aerobic phototrophic bacteria: New evidence for the diversity ecological importance and applied potential of this previously overlooked group. Photosynth Res 81: 113-128

Reeder J and Knight R. (2009) The 'rare biosphere': a reality check. Nat Methods 6:636-637

Rees GN, Baldwin DS, Watson GO, Perryman S and Nielsen DL (2004) Ordination and significance testing of microbial community composition derived from terminal restriction fragment length polymorphisms: application of multivariate statistics. Antonie van Leeuwenhoek 86: 339-347

Reimann L, Steward GF and Azam F. (2000) Dynamics of bacterial community composition and activity during a mesocosm diatom bloom. Appl Environ Microbiol 66(2): 578-587

Roesch LF, Fulthorpe RR, Riva A, Casella G, Hadwin AK et al. (2007) Pyrosequencing enumerates and contrasts soil microbial diversity. ISME J 1: 283-290

Rogers SI, Clarke KR and Reynolds JD. (1999) The taxonomic distinctness of coastal bottomdwelling fish communities of the North-east Atlantic. J Animal Ecol 68: 769-782

Romanenko LA, Uchino M, Tebo BM, Tanaka N, Frolova GM and Mikhailov VV. (2008) Pseudomonas marincola $\mathrm{sp}$. nov isolated from marine environments. Int J Syst Evol Microbiol 58: 706-710

Roose-Amseleg CL, Garnier-Sillam E and Harry M. (2001) Extraction and purification of microbial DNA from soil and sediment samples. Appl Soil Ecol. 18:47-60. 
Rosenzweig ML. (1995) Species Diversity in Space and Time. Cambridge University Press Cambridge England.

Rudi K, Skulberg OM, Skulberg R and Jakobsen KS. (2000). Application of sequence-specific labeled 16S rRNA gene oligonucleotide probes for genetic profiling of cyanobacterial abundance and diversity by array hybridization. Appl Environ Microbiol 66: 4004-4011

Rusch DB, Halpern AL, Sutton G, Heidelberg KB, Williamson S et al. (2007) The Sorcerer II global ocean sampling expedition: Northwest Atlantic through Eastern Tropical Pacific. PLoS Biol 5: 398-431

Ryan KG, Hegseth E, Martin, A Davy S, O’Toole R et al. (2006) Abundance and distribution of the microalgal community within sea ice along a latitudinal gradient in the Ross Sea. Antarct Sci 18: 583-594

Ryan KG, Ralph P and McMinn A. (2004) Acclimation of Antarctic bottom-ice algal communities to lowered salinities during melting. Polar Biol 27: 679-686.

Ryan KG, Cowie ROM, Liggins L, McNaughtan D, Martin A and Davy SK. (2009) The Shortterm effect of irradiance on the photosynthetic properties of Antarctic fast-ice microalgae communities. J Phycol 45: $1290-1298$

Rysgaard S and Glud RN. (2004) Anaerobic N2 production in Arctic sea ice. Limnol Oceanogr 49(1): 86-94

Rysgaard S, Glud RN, Sejr MK, Blicher ME and Stahl HJ. (2008) Denitrification activity and oxygen dynamics in Arctic sea ice. Pol Biol 31(5): 527-537

Salka I, Moulisova V, Koblizek M, Jost G, Jurgens K and Labrenz M. (2008). Abundance depth distribution and composition of aerobic bacteriochlorophyll a-producing bacteria in four basins of the central baltic sea. Appl Environ Microbiol 74: 4398-4404

Sanchez O, Gasol JM, Massana R, Mas J and Pedros-Alio C. (2007) Comparison of Different Denaturing Gradient Gel Electrophoresis Primer Sets for the Study of Marine Bacterioplankton Communities. Appl Environ Microbiol 73(18): 5962-5967

Sanger F, Air GM, Barrell BG, Brown NL, Coulson AR et al. (1977) Nucleotide sequence of bacteriophage phi X174 DNA. Nature 265: 687-695

Schaeffer AB and Fulton M (1993) A simplified method of staining endospores. Science 77: 194

Schleifer KH and Kandler O. (1972) Peptidoglycan types of bacterial cell walls and their taxonomic implications. Bacteriol Rev 36: 407-472

Schloss PD, Westcott SL. Ryabin T. Hall JR, Hartmann M et al. (2009) Introducing mothur: Open-source platform-independent community-supported software for describing and comparing microbial communities. Appl Environ Microbiol 75(23):7537-41

Schwalbach MS, Brown M and Fuhrman JA. (2005) Impact of light on marine bacterioplankton community structure. Aquat Microb Ecol 39: 235-245

Seitzinger SP. (1990) Denitrification in aquatic sediments. In: Revsbech NP Ssrensen J (eds) Denitrification in soil and sediment. FEMS Symposium No 56. Plenum Press New York p 291-300

Shackle V, Freeman C and Reynolds B (2006) Exogenous enzyme supplements to promote treatment efficiency in constructed wetlands. Sci Tot Env 361: 18- 24

Sherr BF, Del Giorgio PA and Sherr EB (1999) Estimating the abundance and single-cell characteristics of respiring bacteria via the redox dye CTC. Aquat Microb Ecol 18: 117-131. 
Sigler WV, Crivii S and Zeyer J. (2002) Bacterial succession in glacial forefield soils characterized by community structure activity and opportunistic growth dynamics. Microb Ecol 44: 306-316

Sloan WT, Lunn M, Woodcock S, Head IM, Nee S and Curtis TP (2006) Quantifying the roles of immigration and chance in shaping prokaryote community structure. Environ Microbiol 8: $732-740$

Sly LI, Taghavit M and Fegan M. (1998) Phylogenetic heterogeneity within the genus Herpetosiphon: transfer of the marine species Herpetosiphon cohaerens, Herpetosiphon nigricans and Herpetosiphon persicus to the genus Lewinella gen. nov. in the FlexibacterBacteroides-Cytophaga phylum. Int J Syst Evol Microbiol 48: 731-737

Smalla K, Cresswell N, Mendonca-Hagler LC, Wolters A and Elsas JD. (1993) Rapid DNA extraction protocol from soil for polymerase chain reaction-mediated amplification. $J$ Appl Bacteriol 74: 78-85

Smalla K, Oros-Sichler M, Milling A, Heuer H, Baumgarte S, Becker R. et al. (2007) Bacterial diversity of soils assessed by DGGE T-RFLP and SSCP fingerprints of PCR-amplified 16S rRNA gene fragments: Do the different methods provide similar results? J Microbiol Methods 69: 470-479

Smetacek V and Nicol S. (2005) Polar ocean ecosystems in a changing world. Nature 437: 362368

Smith RIL. (1994). Species-diversity and resource relationships of South Georgian fungi. Ant Sci 6: 45-52

Smith D, Steward GF, Long RA and Azam F. (1995) Bacterial mediation of carbon fluxes during a diatom bloom in a mesocosm. Deep-Sea Res II 42: 75-97

Smith CJ and Osborn AM. (2009) Advantages and limitations of quantitative PCR (Q-PCR)based approaches in microbial ecology. FEMS Microbiol Ecol 67: 6-20

Sogin ML, Morrison HG, Huber JA, Welch DM, Huse SM et al. (2006) Microbial diversity in the deep sea and the underexplored 'rare biosphere'. PNAS 103: 12115-12120

Solomon S, Qin D, Manning M, Chen Z, Marquis M, Averyt KB, Tignor M, Miller HL (2007) Climate Change 2007: The Physical Science Basis (Cambridge Univ Press, Cambridge, UK).

Stackebrandt E and Goebel BM. (1994) Taxonomic note: a place for DNA:DNA reassociation and $16 \mathrm{~S}$ rRNA sequence analysis in the present species definition in bacteriology. Int $J$ Syst Bacteriol 44: 846-49

Stackebrandt E, Frederiksen W, Garrity GM, Grimont PAD, Kampfer P et al. (2002) Report of the ad hoc committee for the re-evaluation of the species definition in bacteriology. Int $J$ Syst Evol Microbiol 52: 1043-1047

Staley JT and Konopka A. (1985) Measurement of in situ activities of nonphotosynthetic microorganisms in aquatic and terrestrial habitats. Annu Rev Microbiol 39: 321-46

Staley JT and Gosink JJ. (1999) Poles apart: biodiversity and biogeography of sea ice bacteria. Annu Rev Microbiol 53: 189-215

Stein JL and Simon MI. (1996) Archaeal ubiquity. PNAS 93: 6228-6230

Stewart FJ and Fritsen CH. (2004) Bacteria-algae relationships in Antarctic sea ice. Ant Sci 16(2): 143-156

Stout LM, Blake RE, Greenwood JP, Martini AM and Rose EC. (2009) Microbial diversity of boron-rich volcanic hot springs of St. Lucia Lesser Antilles. FEMS Microbiol Ecol 70: 402412 
Sullivan CW and Palmisano AC. (1984) Sea Ice Microbial Communities: Distribution Abundance and Diversity of Ice Bacteria in McMurdo Sound Antarctica in 1980. Appl Environ Microbiol 47: 788-795

Suttle CA. (2007) Marine viruses - major players in the global ecosystem. Nat Rev Microbiol. 5: 801

Suzuki MT, Taylor LT and DeLong EF. (2000) Quantitative analysis of small-subunit rRNA genes in mixed microbial populations via 5'-nuclease assays. Appl Environ Microbiol 66: 4605-4614

Tan Z, Hurek T and Reinhold-Hurek B (2003) Effect of N-fertilization, plant genotype and environmental conditions on nifH gene pools in roots of rice. Environ Microbiol 5: 10091015

Teira E, Martínez-García S, Carreira C and Morán X. (2010) Changes in bacterioplankton and phytoplankton community composition in response to nutrient additions in coastal waters off the NW Iberian Peninsula. MEPS 426: 87-104

Teira E, Reinthaler T, Pernthaler A, Pernthaler J, and Herndl GJ. (2004) Combining catalyzed reporter depositionfluorescence in situ hybridization and microautoradiography to detect substrate utilization by Bacteria and Archaea in the deep ocean. Appl Environ Microbiol 70: $4411-4414$

Teira E, Van Aken HC, Veth and Herndl GJ. (2006) Archaeal uptake of enantiomeric amino acids in the meso- and bathypelagic waters of the North Atlantic. Limnol Oceanogr 51: 6069.

Thingstad TF (2000) Elements of a theory for the mechanisms controlling abundance, diversity, and biogeochemical role of lytic bacterial viruses in aquatic systems. Limnol Oceanogr 45:1320-1328

Thomas DN and Dieckmann GS. (2002) Antarctic Sea Ice - a Habitat for Extremophiles. Science 295: 641-644

Thomas DN, Kattner G, Engbrodt R, Giannelli V, Kennedy H et al. (2001) Dissolved organic matter in Antarctic sea ice. Annals of Glaciology 33: 297-302

Throback IN, Enwall K, Jarvis A and Hallin S. (2004). Reassessing PCR primers trageting nirS nirK and nosZ genes for community surveys of denitrifying bacteria with DGGE. FEMS Microbiol Ecol 49: 401-417

Tibbles BJ and Harris JM. (1996) Use of radiolabelled thymidine and leucine to estimate bacterial production in soils from continental Antarctica. Appl Environ Microbiol 62(2): 694701

Tiedje JM, Sexstone AJ, Myrold DD and Robinson JA. (1982) Denitrification: ecological niches competition and survival. Antonie Van Leeuwenhoek 48: 569-583

Torsvik VL. (1980) Isolation of bacterial DNA from soil. Soil Biol Biochem 12: 15-21

Treusch AH, Leininger S, Kletzin A, Schuster SC, Klenk HP and Schleper C (2005). Novel genes for nitrite reductase and Amorelated proteins indicate a role of uncultivated mesophilic crenarchaeota in nitrogen cycling. Environ Microbiol 7: 1985-1995

Tsujibo H, Yoshida Y, Imada C, Okami Y, Miyamoto K and Inamori Y. (1991) Isolation and characterization of a chitin degrading marine bacterium belong to the genus Alteromonas. Nippon Suisan Gakkaishi 57 2127-2131

Turchin P and Hanski I (1997) An Empirically Based Model for Latitudinal Gradient in Vole Population Dynamics. Am Nat 149(5): 842-874 
Urakawa H, Martens-Habbena W and Stahl DA. (2010) High Abundance of AmmoniaOxidizing Archaea in Coastal Waters Determined Using a Modified DNA Extraction Method. Appl Environ Microbiol 76(7): 2129-2135

Van Trappen S, Vandecandelaere I, Mergaert J and Swings J. (2004) Flavobacterium degerlachei sp. nov Flavobacterium frigoris sp. nov. and Flavobacterium micromati sp. nov novel psychrophilic bacteria isolated from microbial mats in Antarctic lakes. Int J Syst Evol Microbiol 54: 85-92

Vaqué D, Calderon-Paz JI, Guixa-Bioxereu N and Pedros-Alio C. (2002) Spatial distribution of microbial biomass and activity (bacterivory and bacterial production) in the northern Weddell Sea during the austral summer (January 1994). Aquat Microb Ecol 29: 107-121

Venter JC, Remington K, Heidelberg JF, Halpern L, Rusch D et al. (2004) Environmental genome shotgun sequencing of the Sargasso Sea. Science 304: 66-74

von Wintzingerode F, Gobel UB and E. Stackebrandt. (1997) Determination of microbial diversity in environmental samples: pitfalls of PCR-based rRNA analysis. FEMS Microbiol Rev 21: 213-229

Vyas P, Joshi R, Sharma K,C Rahi P, Gulati A and Gulati A. (2010) Cold-adapted and rhizosphere-competent strain of Rahnella sp. with broad-spectrum plant growth-promotion potential. J Microbiol Biotechnol 20(12): 1724-34

Wang GC and Wang Y. (1997) Frequency of formation of chimeric molecules as a consequence of PCR coamplification of $16 \mathrm{~S}$ rRNA genes from mixed bacterial genomes. Appl Environ Microbiol 63: 4645-4650

Wang Q, Garrity GM, Tiedje JM and Cole JR (2007) Naive Bayesian classifier for rapid assignment of rRNA sequences into the new bacterial taxonomy. Appl Environ Microbiol 73: 5261-5267.

Ward D, Weller MR and Bateson MM. (1990). 16S rRNA sequences reveal numerous uncultured microorganisms in a natural community. Nature 345: 63-65

Webster G, Newberry CJ, Fry JC and Weightman AJ. (2003) Assessment of bacterial community structure in the deep sub-seafloor biosphere by $16 \mathrm{~S}$ rDNAbased techniques: a cautionary tale. J Microbiol Methods 55: 155-164

Wells LE and Deming JW (2003) Abundance of Bacteria the Cytophaga- Flavobacterium cluster and Archaea in cold oligotrophic waters and nepheloid layers of the Northwest Passage Canadian Archipelago. Aquat Microb Ecol 31:19-31

West NJ, Obernosterer I, Zemb O and Lebaron P. (2008) Major differences of bacterial diversity and activity inside and outside of a natural iron-fertilized phytoplankton bloom in the Southern Ocean. Environ Microbiol 10(3): 738-756

Wheeler PA and Kirchman DL. (1986) Utilization of inorganic and organic nitrogen by Bacteria in marine systems. Limnol Oceanogr 31: 998-1009

Whelan JA Russel NB and Whelan M.A (2003) A method for the absolute quantification of cDNA using real time PCR. J Immunol Meth 278: 261-269

Whitaker RJ, Grogan DW and Taylor JW. (2003). Geographic barriers isolate endemic populations of hyperthermophilic archaea. Science 301: 976-978

Whitfield J. (2005) Biogeography: Is Everything Everywhere? Science 310: 960-961

Whitman WB, Coleman DC and Wiebe WJ. (1998) Prokaryotes: The unseen majority. PNAS 95: 6578-6583 
Wittwer CT, Herrmann MG, Moss AA and Rasmussen RP (1997) Continuous fluorescence monitoring of rapid cycle DNA amplification. BioTechniques 22: 130-138

Woese CR, Kandler O and Wheelis ML. (1990) Towards a natural system of organisms: Proposal for the domains Archaea Bacteria and Eucarya. PNAS 87: 4576-4579

Wuchter C, Abbas B, Coolen MJL, Herfort L, van Bleijswijk J, Timmers P et al. (2006) Archaeal nitrification in the ocean. PNAS 103: 12317- 12322

Yergeau E, Kang S, He Z, Zhou J and Kowalchuk GA. (2007) Functional microarray analysis of nitrogen and carbon cycling genes across an Antarctic latitudinal transect. ISME J 1: 163-179 doi:10.1038/ismej.2007.24

Yeager CM, Northup DE, Grow CC, Barns SM and Kuske CR (2005) Changes in nitrogenfixing and ammonia-oxidizing bacterial communities in soil of a mixed conifer forest after wildfire. Appl Environ Microbiol. 71(5): 2713-22

Yoon J, Kang S and Oh T. (2006) Polaribacter dokdonensis sp. nov isolated from seawater. Int J Syst Evol Microbiol 56: 1251-1255

Yu Y, Li H, Zeng Y and Chen B. (2009) Extracellular enzymes of cold-adapted bacteria from Arctic sea ice Canada Basin. Polar Biol 32: 1539-1547

$\mathrm{Yu} \mathrm{Z}$ and Morrison M. (2004) Comparisons of different hypervariable regions of rrs genes for use in fingerprinting of microbial communities by PCR-denaturing gradient gel electrophoresis. Appl Environ Microbiol 70(8): 4800-4806

Yurkov VV and Csotonyi JT (2008) New light on aerobic anoxygenic phototrophs. In: Hunter CN Daldal F Thurnauer MC Beatty JT (eds) Advances in photosynthesis and respiration volume 28. The purple phototrophic bacteria. Springer Berlin Heidelberg New York pp 3155

Yurkov VV and Beatty JT. (1998) Aerobic anoxygenic phototrophic bacteria. Microbiol Mol Biol Rev 62: 695-724

Zhou X, Bent SJ, Schneider MG, Davis CC, Islam MR et al. (2004) Characterization of vaginal microbial communities in adult healthy women using cultivation independent methods. Microbiol 150: 2565-2573

Zhou J, Bruns MA and Tiedje JM (1996) DNA recovery from soils of diverse composition. Appl Environ Microbiol 62: 316-322 


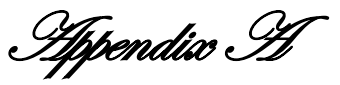

Media recipes

All reagents are from Sigma unless otherwise stated.

\section{Marine Agar 2216}

Marine agar 2216 (Difco) $37.5 \mathrm{~g}$

$\mathrm{dH}_{2} \mathrm{O}$

\section{Marine Broth Glycerol Mix}

$\begin{array}{lr}\text { Marine Broth } 2216 \text { (Difco) } & 3.75 \mathrm{~g} \\ \text { Glycerol } & 20.00 \mathrm{~g} \\ \mathrm{dH}_{2} \mathrm{O} & 100 \mathrm{ml}\end{array}$

The broth was autoclaved at $15 \mathrm{psi}$ at $121{ }^{\circ} \mathrm{C}$

\section{Seawater Complete Agar}

Peptone (Oxoid)

Yeast extract (Oxoid)

Glycerol

Sea water

Water

Agar

$$
\begin{gathered}
5 \mathrm{~g} \\
3 \mathrm{~g} \\
3 \mathrm{~mL} \\
750 \mathrm{~mL} \\
250 \mathrm{~mL} \\
15 \mathrm{~g}
\end{gathered}
$$

All the components were added and autoclaved at 15 psi at $121{ }^{\circ} \mathrm{C}$.

\section{R2A agar}

$\begin{array}{ll}\text { Yeast extract (Oxoid) } & 0.5 \mathrm{~g} \\ \text { Peptone (Oxoid) } & 0.5 \mathrm{~g} \\ \text { Casein (Oxoid) } & 0.5 \mathrm{~g} \\ \text { Glucose } & 0.5 \mathrm{~g} \\ \text { Starch } & 0.5 \mathrm{~g} \\ \text { Sodium pyruvate } & 0.3 \mathrm{~g} \\ \text { Sea water } & 750 \mathrm{~mL} \\ \text { Water } & 250 \mathrm{~mL} \\ \text { Agar } & 15 \mathrm{~g}\end{array}$


All ingredients were mixed and autoclaved at 15 psi at $121^{\circ} \mathrm{C}$.

1/10 R2A agar

$\begin{array}{ll}\text { Yeast extract (Oxoid) } & 0.05 \mathrm{~g} \\ \text { Peptone (Oxoid) } & 0.05 \mathrm{~g} \\ \text { Casein (Oxoid) } & 0.05 \mathrm{~g} \\ \text { Glucose } & 0.05 \mathrm{~g} \\ \text { Starch } & 0.05 \mathrm{~g} \\ \text { Sodium pyruvate } & 0.03 \mathrm{~g} \\ \text { Sea water } & 750 \mathrm{~mL} \\ \text { Water } & 250 \mathrm{~mL} \\ \text { Agar } & 15 \mathrm{~g}\end{array}$

All ingredients were mixed and autoclaved at 15 psi at $121^{\circ} \mathrm{C}$.

\section{1/10 R2A agar without yeast}

$\begin{array}{ll}\text { Yeast extract (Oxoid) } & 0.05 \mathrm{~g} \\ \text { Peptone (Oxoid) } & 0.05 \mathrm{~g} \\ \text { Casein (Oxoid) } & 0.05 \mathrm{~g} \\ \text { Starch } & 0.05 \mathrm{~g} \\ \text { Sodium pyruvate } & 0.03 \mathrm{~g} \\ \text { Sea water } & 750 \mathrm{~mL} \\ \text { Water } & 250 \mathrm{~mL} \\ \text { Agar } & 15 \mathrm{~g}\end{array}$

All ingredients were mixed and autoclaved at 15 psi at $121^{\circ} \mathrm{C}$.

\section{Sea water}

Sea water was collected from under the sea ice at Granite Harbour, Antarctica. The sea water was filtered through a $0.2 \mu \mathrm{M}$ filter before autoclaving to sterilize.

\section{M5}

Purified agar (Oxoid) $6 \mathrm{~g}$

Sea water $225 \mathrm{~mL}$

$\mathrm{dH}_{2} \mathrm{O} \quad 75 \mathrm{~mL}$

\section{2\% Bromocresol purple}

$\begin{array}{ll}\text { Bromocresol purple } & 0.4 \mathrm{~g} \\ 1 \mathrm{~N} \mathrm{NaOH} & 1.5 \mathrm{~mL} \\ \mathrm{dH}_{2} \mathrm{O} & 15 \mathrm{~mL} \\ \text { Ethanol Absolute } & 3.1 \mathrm{~mL}\end{array}$




\section{$1 \%$ Tryptone Water}

Bacto Tryptone (Difco) $10 \mathrm{~g}$

$\mathrm{NaCl} \quad 5 \mathrm{~g}$

$2 \%$ Bromocresol purple $2 \mathrm{~mL}$

The dry ingredients were dissolved in $1 \mathrm{~L} \mathrm{dH_{2 }} \mathrm{O}$. The $\mathrm{pH}$ was changed to 7.2 using $\mathrm{NaOH}$. The indicator (Bromocresol purple) was then added. The medium was dispensed into test tubes and then autoclaved to sterilize. The medium was cooled before filter sterilized glucose was added to a final concentration of $1 \%$. 


\section{MAppendiso $\mathscr{B}$}

\section{Supplementary material}

Chapter three - Permanova Results

Table B1 PERMANOVA table of results of bottom ice bacterial communities from years (YE) 2008 and 2009). Samples were taken from sites (Si) Granite Harbour, McMurdo Station, Cape Evans, Cape Roberts and Terra Nova Bay. Nucleic acids were extracted using DNA or RNA extraction methods (NA).

\begin{tabular}{|c|c|c|c|c|c|c|}
\hline Source & $\mathrm{df}$ & $\mathrm{SS}$ & $\mathrm{MS}$ & Pseudo-F & $\mathrm{P}$ & Unique perms \\
\hline $\mathrm{Ye}$ & 1 & 15219 & 15219 & 3.713 & 0.0712 & 2036 \\
\hline $\mathrm{Si}$ & 9 & 57021 & 6336 & 6.482 & 0.0001 & 9806 \\
\hline $\mathrm{NA}$ & 1 & 10806 & 10806 & 5.470 & 0.0033 & 9940 \\
\hline Ye x Si & 2 & 8202 & 4101 & 4.196 & 0.0001 & 9874 \\
\hline Ye x NA & 1 & 3908 & 3908 & 2.417 & 0.1802 & 9290 \\
\hline Si x NA & 9 & 18200 & 2022 & 2.069 & 0.0001 & 9749 \\
\hline Ye x Si x NA & 2 & 3235 & 1617 & 1.655 & 0.0073 & 9896 \\
\hline Res & 87 & 85037 & 977 & & & \\
\hline Total & 112 & $2.20 \mathrm{E}+05$ & & & & \\
\hline
\end{tabular}


Table B2 PERMANOVA table of results of top, middle and bottom bacterial communities (through the ice core (Co)) at sites Granite Harbour and Cape Evans in 2009 (Si). Nucleic acids were extracted using DNA or RNA extraction methods (NA).

\begin{tabular}{|c|c|c|c|c|c|c|}
\hline Source & $\mathrm{df}$ & $\mathrm{SS}$ & $\mathrm{MS}$ & Pseudo-F & $\mathrm{P}$ & Unique perms \\
\hline $\mathrm{Si}$ & 5 & 36856 & 7371.2 & 6.2234 & 0.0001 & 9838 \\
\hline $\mathrm{NA}$ & 1 & 24822 & 24822 & 5.613 & 0.0086 & 9946 \\
\hline $\mathrm{Co}$ & 2 & 36146 & 18073 & 5.1446 & 0.0001 & 9904 \\
\hline $\mathrm{Si} \times \mathrm{NA}$ & 5 & 16741 & 3348.2 & 2.8269 & 0.0001 & 9824 \\
\hline Si x Co & 10 & 42950 & 4295 & 3.6262 & 0.0001 & 9787 \\
\hline NA x Co & 2 & 12392 & 6195.8 & 3.198 & 0.0004 & 9916 \\
\hline Si x NA x Co & 5 & 9753.6 & 1950.7 & 1.647 & 0.0015 & 9848 \\
\hline Res & 101 & $1.20 \mathrm{E}+05$ & 1184.4 & & & \\
\hline Total & 133 & $3.48 \mathrm{E}+05$ & & & & \\
\hline
\end{tabular}

\section{ChaPter SiX - GROWTH OF CULTURE ON DIFFERENT MEDIA}

Table B3 The number of bacteria grown from Granite Harbour in 2009from the top, middle and bottom of the sea ice core. Colonies were grown on the media Marine agar 2216 (MA), R2A, R2A 1: 10 dilution with yeast extract added (+) or without (-), M5 and Sea water complete (SWC) at $15{ }^{\circ} \mathrm{C}$ in the light/ dark, or $4{ }^{\circ} \mathrm{C}$ in the light.

\begin{tabular}{|c|c|c|c|c|c|c|c|c|}
\hline Light / temp & Media & \multicolumn{7}{|c|}{ Colour of cultures } \\
\hline $15^{\circ} \mathrm{C}$ Light & & yellow & pink & red & white & red/orange & orange & cream \\
\hline \multirow[t]{6}{*}{ top } & MA & & & & 23 & & & \\
\hline & R2A & & 1 & & 6 & & 1 & \\
\hline & R2A- & & & & 1 & & & \\
\hline & R2At & & & & 1 & & & 4 \\
\hline & M5 & & & & & & & \\
\hline & SW & & & & 3 & & & \\
\hline \multirow[t]{6}{*}{ middle } & MA & & & & 21 & & & \\
\hline & R2A & & & 8 & 8 & & & \\
\hline & R2A- & 1 & & 15 & 7 & & & \\
\hline & R2At & 3 & & 2 & 1 & & 4 & \\
\hline & M5 & & & 8 & 10 & & & \\
\hline & SW & & & & 4 & & & \\
\hline \multirow[t]{6}{*}{ bottom } & MA & & & & 4 & & & \\
\hline & R2A & & & & 5 & & & \\
\hline & R2A- & & 1 & & 2 & & & \\
\hline & R2At & & & & 3 & & & \\
\hline & M5 & & & & & & & \\
\hline & sW & & & & 24 & & & \\
\hline
\end{tabular}


Table B3 Continued.

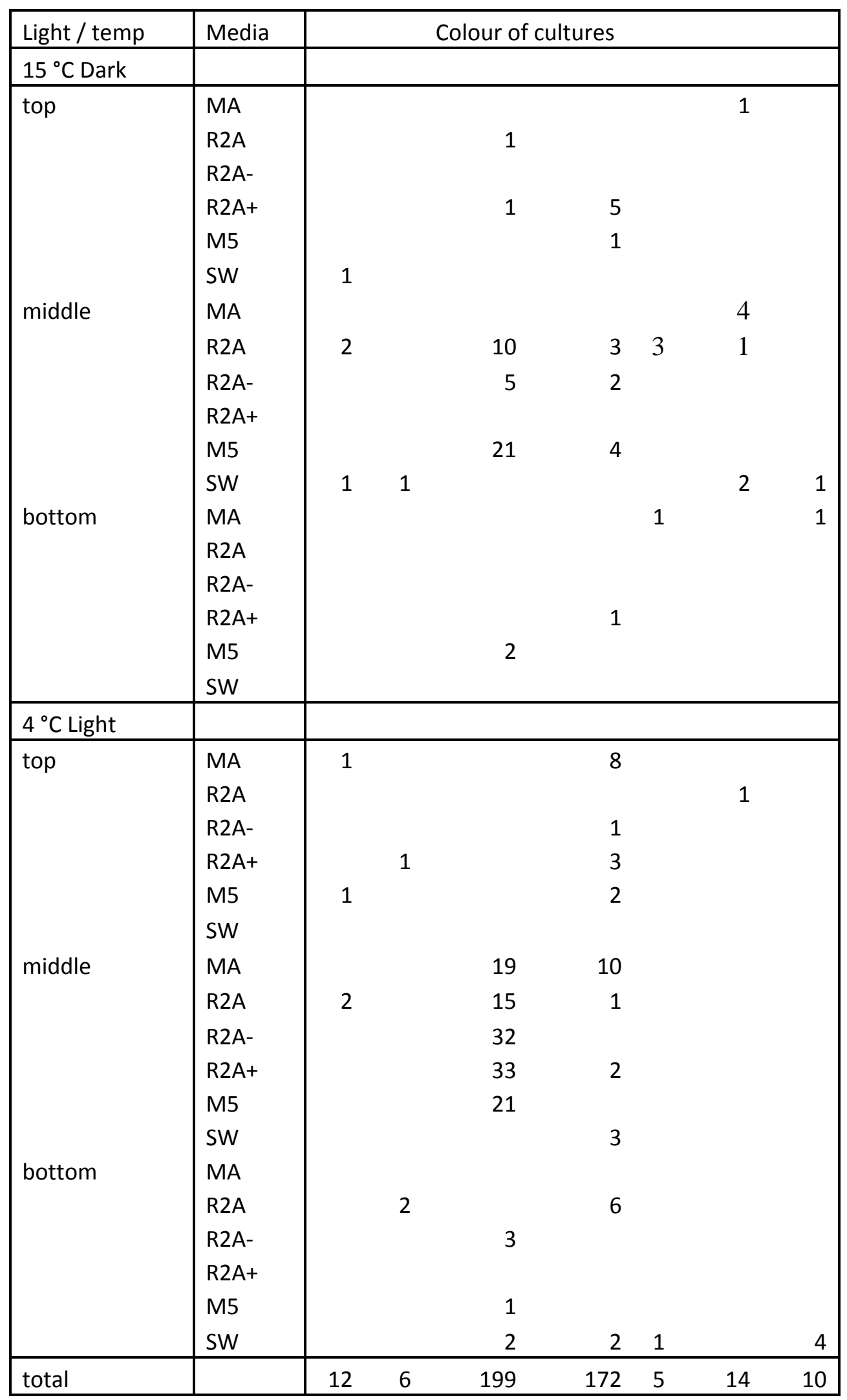




\section{GRAM STAIN AND COLONY MORPHOLOGY}

Table B4 Gram stain and colony morphology on Marine Agar 2216 plates

\begin{tabular}{|c|c|c|}
\hline Isolate & Colony morphology on MA plates & Gram reaction \\
\hline $\mathrm{C} 1$ & red circular and convex colony, mucoid consistency & negative medium rod \\
\hline $\mathrm{C} 2$ & white circular and convex colony & negative medium bacillus \\
\hline C3 & yellow, lobate & negative vacuole medium rod \\
\hline C4 & red circular and convex colony, mucoid consistency & negative medium rod \\
\hline C11 & pinky/cream, circular & negative large rod \\
\hline $\mathrm{C} 21$ & red circular and convex colony & negative rod \\
\hline $\mathrm{C} 22$ & red circular and convex colony, mucoid consistency & negative medium rod \\
\hline $\mathrm{C} 23$ & white circular colony, entire & negative medium rod \\
\hline $\mathrm{C} 24$ & dull yellow, lobate & negative vacuole medium rod \\
\hline C40 & white/ cream, waxy, undulate & negative vacuole medium rod \\
\hline C41 & red circular and convex colony, mucoid consistency & negative medium rod \\
\hline C42 & orange colony, undulate & negative large rod \\
\hline C43 & red orange colony, undulate & positive small bacillus \\
\hline $\mathrm{H} 1$ & white circular colony, entire & negative bacillus \\
\hline $\mathrm{H} 2$ & white circular colony, entire & negative bacillus \\
\hline H3 & small red circular colony, entire & negative cocci \\
\hline $\mathrm{H} 4$ & white circular colony, entire & negative bacillus \\
\hline H5 & small red circular colony, entire & negative bacillus \\
\hline $\mathrm{H} 6$ & yellow circular colony, entire & negative cocci \\
\hline $\mathrm{H} 10$ & white circular colony, entire & negative bacillus \\
\hline $\mathrm{H} 12$ & white circular colony, entire & negative rod \\
\hline $\mathrm{H} 14$ & small red circular colony, entire & negative rod \\
\hline $\mathrm{H} 16$ & yellow circular colony, entire & negative rod \\
\hline $\mathrm{H} 17$ & small red circular colony, entire & negative bacillus \\
\hline $\mathrm{H} 18$ & yellow colony, embedded, filamentous & actinomycete \\
\hline $\mathrm{H} 20$ & white circular colony, entire & negative cocci in tetrads \\
\hline $\mathrm{H} 21$ & small red circular colony, entire & negative bacillus \\
\hline $\mathrm{H} 22$ & white circular colony, entire & negative bacillus \\
\hline $\mathrm{H} 23$ & small red circular colony, entire & negative bacillus \\
\hline $\mathrm{H} 24$ & white circular colony, entire & positive cocci \\
\hline $\mathrm{H} 26$ & white circular colony, entire & negative bacillus \\
\hline $\mathrm{H} 27$ & small red circular colony, entire & negative rod \\
\hline $\mathrm{H} 28$ & small red circular colony, entire & negative rod \\
\hline $\mathrm{H} 30$ & small red circular colony, entire & negative rod \\
\hline H31 & white circular colony, entire & negative bacillus \\
\hline H32 & white circular colony, entire & negative rod \\
\hline H34 & small red circular colony, entire & negative rod \\
\hline H35 & Cream circular, entire & negative bacillus \\
\hline H36 & white circular colony, entire & negative rod \\
\hline H37 & small red circular colony, entire & negative rod vacuole \\
\hline
\end{tabular}


Table B5 Gram stain and colony morphology on R2A plates

\begin{tabular}{lll}
\hline Isolate & Colony morphology on R2A plates & Gram reaction \\
\hline C5 & yellow colony, undulate & negative small bacillus \\
C6 & pink colony, undulate & negative large rod \\
C9 & red circular and convex colony, mucoid consistency & negative small rod \\
C10 & small pink circular colony, entire & negative small bacillus \\
C12 & cream/pink circular smooth colony, entire & negative medium bacillus \\
C14 & orange colony, undulate & positive medium coccus \\
C28 & yellow round colony, entire & positive medium coccus \\
C29 & white colony, undulate & negative small bacillus \\
C30 & white colony, undulate & negative medium bacillus \\
C31 & pink colony, undulate & negative medium rod \\
C52 & white colony, undulate & negative small rod \\
C53 & red circular and convex colony, mucoid consistency & negative medium rod \\
C54 & bright yellow colony, convex, entire & negative medium coccus \\
C55 & bright yellow colony, undulate & negative small rod \\
C71 & white colony, undulate & negative large rod \\
C72 & small red circular colony, entire & negative small bacillus \\
C73 & red circular and convex colony, mucoid consistency & negative medium rod \\
C74 & yellow colony, undulate & negative large rod \\
\hline
\end{tabular}

Table B6 Gram stain and colony morphology on marine agar 2216 1:10 dilution plates

\begin{tabular}{lll}
\hline Isolate & Colony morphology on MA 1:10 plates & Gram reaction \\
\hline H7 & white circular colony, entire & negative bacillus \\
H8 & white circular colony, entire & negative bacillus \\
H9 & white circular colony, entire & negative bacillus \\
H1 & white circular colony, entire & negative bacillus \\
H13 & white circular colony, entire & negative bacillus \\
H15 & white circular colony, entire & negative bacillus \\
H19 & white circular colony, entire & negative bacillus \\
H25 & white circular colony, entire & negative bacillus \\
\hline
\end{tabular}


Table B7 Gram stain and colony morphology on seawater (SW) complete plates

\begin{tabular}{lll} 
Isolate & Colony morphology on SW complete plates & Gram reaction \\
\hline C7 & cream round colony, entire & negative medium rod \\
C8 & yellow round colony, convex, entire & negative bacillus/cocci \\
C13 & white cream round colony, undulate, convex & negative medium bacillus \\
C48 & white cream round colony, undulate, convex & negative medium bacillus \\
C49 & cream round colony, entire & negative small rod \\
C50 & bright yellow round colony, entire, convex & negative cocci \\
C51 & small pink colony, entire & negative large rod \\
\hline
\end{tabular}

Table B8 Gram stain and colony morphology on R2A 1:10 dilution without yeast extract.

\begin{tabular}{llc}
\hline Isolate & Colony morphology on R2A 1:10- plates & Gram reaction \\
\hline C32 & red circular and convex colony, mucoid consistency & negative medium rod \\
C33 & white colony, undulate & negative medium rod \\
C34 & red circular and convex colony, mucoid consistency & negative medium rod \\
C35 & red circular and convex colony, mucoid consistency & negative medium rod \\
C56 & white colony, undulate & negative medium bacillus \\
C57 & red circular and convex colony, mucoid consistency & negative medium rod \\
C58 & red circular and convex colony, mucoid consistency & negative medium rod \\
C59 & white colony not smooth outside & negative medium bacillus \\
C69 & white spreading colony & positive medium rod \\
C70 & white colony, undulate & negative small rod \\
\hline
\end{tabular}

Table B9 Gram stain and colony morphology on R2A 1:10 dilution with yeast extract.

\begin{tabular}{lll}
\hline Isolate & Colony morphology on R2A 1:10+ plates & Gram reaction \\
\hline C36 & yellow filamentous, embedded & positive medium bacillus \\
C37 & white filamentous, embedded & negative small rod \\
C38 & white colony, undulate & negative small rod \\
C39 & white colony, undulate & negative small rod \\
C44 & white colony, undulate & negative small bacillus \\
C45 & yellow filamentous, embedded & negative medium bacillus \\
C46 & white filamentous, embedded & negative small rods \\
C47 & red circular convex small colony & positive medium rod \\
C64 & white colony, undulate & negative medium bacillus \\
C65 & dull yellow colony, undulate & positive medium vacuole bacillus \\
C66 & white colony, undulate & positive large rod \\
C67 & white colony, undulate & negative medium bacillus \\
\hline
\end{tabular}


Table B10 Gram stain and colony morphology on M5 plates

\begin{tabular}{llc}
\hline Isolate & Colony morphology on M5 plates & Gram reaction \\
\hline C60 & white yellow, undulate & positive medium sized rods \\
C61 & white colony , undulate & negative rods
\end{tabular}

\section{SPORE AND BIOCHEMICAL TRAITS}

Table B11 Isolates grown from 2009 (C1 - C74) and 2008 (H1 - H37) on the media marine agar 2216 (MA), R2A, R2A 1: 10 dilution with yeast extract added (+) or without (-), M5 marine agar 2216 1:10 dilution and sea water complete (SWC). Isolates were from the top (T), middle (M) and bottom (B) of the sea ice core at sites McMurdo Station (McM), Cape Evans (CE), Granite Harbour (GH), Cape Roberts (CR) and Terra Nova Bay (TNB). Isolates were tested for spore production, oxidase, catalase, gas production, glucose oxidation (OX) and fermentation (FERM).

\begin{tabular}{|l|l|l|c|c|c|c|c|c|}
\hline$\#$ & media & Site & $\begin{array}{c}\text { spore } \\
\text { stain }\end{array}$ & oxidase & catalase & $\begin{array}{c}\text { gas } \\
\text { production }\end{array}$ & OX & FERM \\
\hline C1 & MA & GHB09 & - & ++ & ++ & - & - & + \\
C2 & MA & GHT09 & - & ++ & +++ & - & + & + \\
C3 & MA & GHT09 & - & - & + & - & + & - \\
C4 & MA & GHM09 & - & - & - & - & - & - \\
C5 & R2A & GHM09 & - & - & - & - & - & - \\
C6 & R2A & GHB09 & - & ++ & - & - & + & - \\
C7 & SW & GHM09 & - & - & - & - & - & - \\
C8 & SW & GHM09 & - & - & ++ & - & + & - \\
C9 & R2A & GHM09 & - & + & - & - & - & - \\
C10 & R2A & GHB09 & - & + & - & - & - & - \\
C11 & MA & GHT09 & + & - & ++ & - & - & - \\
C12 & R2A & GHT09 & - & ++ & ++ & - & - & - \\
C13 & SW & GHM09 & - & ++ & ++ & - & - & - \\
C14 & R2A & GHT09 & + & + & + & - & - & - \\
C21 & MA & GHB09 & - & + & ++ & - & - & - \\
C22 & MA & GHB09 & - & + & - & - & - & - \\
C23 & MA & GHM09 & - & ++ & +++ & + & - & + \\
C24 & MA & GHT09 & - & +++ & + & - & - & - \\
C28 & R2A & GHM09 & - & - & ++ & - & - & - \\
C29 & R2A & GHM09 & - & ++ & +++ & + & - & + \\
C30 & R2A & GHB09 & - & ++ & +++ & + & - & + \\
C31 & R2A & GHB09 & - & ++ & - & - & - & - \\
C32 & R2A 1:10 - & GHB09 & - & + & - & - & - & - \\
C33 & R2A 1:10 - & GHB09 & - & ++ & +++ & + & - & - \\
C34 & R2A 1:10 - & GHM09 & - & ++ & - & - & + & - \\
C35 & R2A 1:10 - & GHM09 & - & - & - & - & - & - \\
C36 & R2A 1.10 + & GHT09 & - & + & ++ & + & - & + \\
C37 & R2A 1.10 + & GHT09 & - & +++ & +++ & - & + & + \\
C38 & R2A 1.10 + & GHM09 & - & + & +++ & - & - & - \\
C39 & R2A 1.10 + & GHM09 & - & + & +++ & - & - & - \\
C40 & MA & GHT09 & + & - & +++ & - & - & + \\
\hline & & & & & & & & \\
& & & ++ & ++ \\
\end{tabular}


Table B11 Continued

\begin{tabular}{|l|l|l|c|c|c|c|c|c|}
\hline$\#$ & media & Site & $\begin{array}{c}\text { spore } \\
\text { stain }\end{array}$ & oxidase & catalase & $\begin{array}{c}\text { gas } \\
\text { production }\end{array}$ & OX & FERM \\
\hline C41 & MA & GHB09 & - & - & +++ & - & + & + \\
C42 & MA & GHM09 & - & ++ & ++ & - & - & - \\
C43 & MA & GHM09 & - & + & + & - & - & - \\
C45 & R2A 1.10 + & GHM09 & - & +++ & +++ & - & - & - \\
C46 & R2A 1.10 + & GHB09 & - & ++ & +++ & - & - & - \\
C47 & R2A 1.10 + & GHM09 & - & +++ & + & - & - & - \\
C48 & SW & GHM09 & - & +++ & +++ & - & - & - \\
C49 & SW & GHM09 & - & - & - & - & + & - \\
C50 & SW & GHM09 & - & + & +++ & - & - & + \\
C51 & SW & GHM09 & - & + & ++ & - & - & - \\
C52 & R2A & GHM09 & - & - & - & - & - & + \\
C53 & R2A & GHM09 & - & - & - & - & - & - \\
C54 & R2A & GHM09 & - & - & +++ & + & + & + \\
C55 & R2A & GHM09 & - & - & - & + & + & + \\
C56 & R2A 1:10 - & GHM09 & - & + & +++ & - & - & - \\
C57 & R2A 1:10 - & GHM09 & - & - & - & - & - & - \\
C58 & R2A 1:10 - & GHM09 & - & ++ & ++ & - & - & - \\
C59 & R2A 1:10 - & GHM09 & + & + & ++ & - & - & - \\
C60 & M5 & GHM09 & - & - & - & - & - & - \\
C61 & M5 & GHM09 & - & - & - & - & - & - \\
C64 & R2A 1.10 + & GHM09 & - & +++ & +++ & - & - & - \\
C65 & R2A 1.10 + & GHM09 & + & + & +++ & - & - & - \\
C66 & R2A 1.10 + & GHM09 & - & ++ & ++ & - & - & + \\
C67 & R2A 1.10 + & GHB09 & - & ++ & ++ & - & - & - \\
C69 & R2A 1:10 - & GHM09 & - & ++ & ++ & - & - & - \\
C70 & R2A 1:10 - & GHM09 & + & +++ & ++ & - & + & + \\
C71 & R2A & GHM09 & + & ++ & +++ & - & - & - \\
C72 & R2A & GHM09 & - & ++ & ++ & - & + & - \\
C73 & R2A & GHM09 & - & + & - & - & + & - \\
C74 & R2A & GHM09 & + & +++ & +++ & - & + & - \\
\hline
\end{tabular}


Table B11 Continued

\begin{tabular}{|l|l|l|c|c|c|c|c|c|}
\hline \# & media & Site & $\begin{array}{c}\text { spore } \\
\text { stain }\end{array}$ & oxidase & catalase & $\begin{array}{c}\text { gas } \\
\text { production }\end{array}$ & OX & FERM \\
\hline H1 & MA & CEM08 & - & +++ & ++ & - & + & + \\
H2 & MA & CRB08 & - & +++ & ++ & - & + & - \\
H3 & MA & CRM08 & - & + & +++ & - & + & + \\
H4 & MA & TNBB08 & - & +++ & +++ & - & + & + \\
H5 & MA & TNBT08 & - & - & + & - & - & - \\
H6 & MA & CRB08 & + & + & + & - & - & - \\
H7 & MA 1:10 & CEM08 & - & - & +++ & - & + & + \\
H8 & MA 1:10 & CEM08 & - & - & +++ & - & - & - \\
H9 & MA 1:10 & CEM08 & - & - & +++ & - & + & + \\
H10 & MA & CRT08 & - & +++ & +++ & - & - & - \\
H11 & MA 1:10 & CET08 & - & - & +++ & - & - & - \\
H12 & MA & TNBT08 & - & +++ & +++ & + & + & + \\
H13 & MA 1:10 & CEB08 & - & + & ++ & - & - & - \\
H14 & MA & CRB08 & - & ++ & ++ & - & - & - \\
H16 & MA & CRT08 & - & - & +++ & - & - & - \\
H17 & MA & CRM08 & - & - & + & - & + & - \\
H18 & MA & TNBM08 & - & - & + & - & + & - \\
H19 & MA 1:10 & CET08 & - & - & + & - & - & - \\
H20 & MA & GHB08 & - & +++ & +++ & - & + & + \\
H21 & MA & CRM08 & - & ++ & ++ & - & - & - \\
H22 & MA & McMM08 & - & +++ & +++ & - & + & + \\
H23 & MA & CEB08 & - & +++ & +++ & - & + & + \\
H24 & MA & CRM08 & - & + & +++ & + & + & + \\
H25 & MA 1:10 & CEB08 & - & - & + & - & - & - \\
H26 & MA & McMM08 & - & +++ & +++ & - & + & + \\
H27 & MA & TNBT09 & - & - & + & - & - & - \\
H28 & MA & TNBT09 & - & + & + & + & - & - \\
H30 & MA & CEB08 & - & - & + & - & - & - \\
H31 & MA & GHB08 & - & +++ & +++ & - & - & - \\
H32 & MA & CRM08 & + & ++ & +++ & - & + & + \\
H34 & MA & GHB08 & - & ++ & ++ & - & - & - \\
H35 & MA & TNBT08 & - & - & ++ & - & - & - \\
H36 & MA & GHB08 & - & - & +++ & - & - & - \\
H37 & MA & TNBT09 & + & + & ++ & - & + & - \\
\hline
\end{tabular}


Figure B12 Tags attached to sequences for 454 analysis to discriminate between sites

\begin{tabular}{cccc} 
Primer \# & MIDs & Primer $\#$ & MIDs \\
\hline 1 & ACGAGTGCGT & 12 & TGATACGTCT \\
2 & ACAGCACTAG & 13 & TACTGAGCTA \\
3 & ACGCTCGACA & 14 & TGTGTGCATA \\
4 & AGACGCACTC & 15 & TGTACCTATC \\
5 & AGCACTGTAG & 16 & CCAGCTGTT \\
6 & ATCAGACACG & 17 & TCTACCAATC \\
7 & ATATCGCGAG & 18 & CGCACTACGT \\
8 & CGTGCTTCTA & 19 & CGCATCTATA \\
9 & CTCGCGTGTC & 20 & TGTGCCTAGA \\
10 & TAGTATCAGC & 21 & TGTGCATCAC \\
11 & TCTCTATGCG & 22 & TGTACATTGT
\end{tabular}

KEY: totally conserved conserved variable highly variable $>75 \%$ variable variable regions priming sites

$\begin{array}{llllll}20 & 30 & 40 & 50 & 60\end{array}$

AAATTGAAGAGTTTGATCATGGCTCAGATTGAACGCTGGCGGCAGGCCTAACACATGCAAGTCGAACGGT

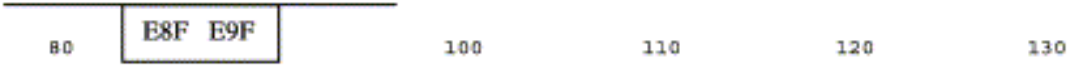

AACAGGAAGAAGCTTGCTTCTTTGCTGACGAGTGGCGGACGGGTGAGTAATGTCTGGGAAACTGCCTGAT
$150 \mathrm{VI} \quad 160$
170
180
190
200

GGAGGGGGATAACTACTGGAAACGGTAGCTAATACCGCATAACGTCGCAAGACCAAAGAGGGGGACCTTC

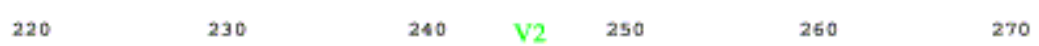

GGGCCTCTTGCCATCGGATGTGCCCAGATGGGATTAGCTAGTAGGTGGGGTAACGGCTCACCTAGGCGAC

$\begin{array}{llllll}290 & 300 & 310 & 320 & 330 & 340\end{array}$

GATCCCTAGCTGGTCTGAGAGGATGACCAGCCACACTGGAACTGAGACACGGTCCAGACTCCTACGGGAC

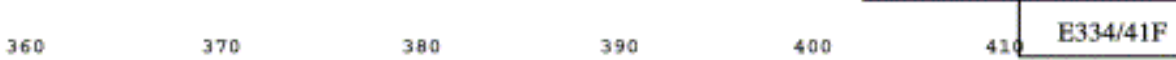

GCAGCAGTGGGGAATATTGCACAATGGGCGCAAGCCTGATGCAGCCATGCCGCGTGTATGAAGAAGGCCT

$430 \quad 440 \quad \$ 50 \quad 460 \quad 470 \quad 480$

TCGGGTTGTAAAGTACTTTCAGCGGGGAGGAAGGGAGTAAAGTTAATACCTTTGCTCATTGACGTTACCC

$500 \quad 510 \quad 520 \quad 530 \quad \mathrm{~V} 3 \quad 540 \quad 550$

GCAGAAGAAGCACCGGCTAACTCCGTGCCAGCAGCCGCGGTAATACGGAGGGTGCAAGCGTTAATCGGAA \begin{tabular}{|l|l|l|ll}
\hline U529/34/E533R & U515/519F & & 600
\end{tabular}$\quad 620$ TTACTGGGCGTAAAGCGCACGCAGGCGGTTTGTTAAGTCAGATGTGAAATCCCCGGGCTCAACCTGGGAA

$\begin{array}{lllllll}640 & 650 & 660 & 670 & 680 & \text { V4 } & 690\end{array}$

CTGCATCTGATACTGGCAAGCTTGAGTCTCGTAGAGGGGGGTAGAATTCCAGGTGTAGCGGTGAAATGCG

$\begin{array}{llllll}710 & 720 & 730 & 740 & 750 & 760\end{array}$


TAGAGATCTGGAGGAATACCGGTGGCGAAGGCGGCCCCCTGGACGAAGACTGACGCTCAGGTGCGAAAGC
780
790
800
810
820
830

GTGGGGAGCAAACAGGATTAGATACCCTGGTAGTCCACGCCGTAAACGATGTCGACTTGGAGGTTGTGCC

\begin{tabular}{|c|c|c|c|}
\hline 850 & E786F & 870 & 880 \\
\hline
\end{tabular}

CTTGAGGCGTGGCTTCCGGAGCTAACGCGTTAAGTCGACCGCCTGGGGAGTACGGCCGCAAGGTTAAAAC

$\begin{array}{lllll}920 & 930 & 940 & 950 & 960\end{array}$

TCAAATGAATTGACGGGGGCCCGCACAAGCGGTGGAGCATGTGGTTTAATTCGATGCAACGCGAAGAACC \begin{tabular}{l|llll}
\hline E926R/U926R/E939R & 1000 & 1010 & 1020 & 1030
\end{tabular}

TTACCTGGTCTTGACATCCACGGAAGTTTTCAGAGATGAGAATGTGCCTTCGGGAACCGTGAGACAGGTG

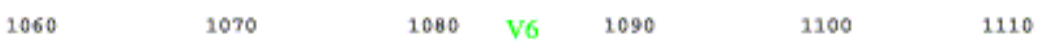

CTGCATGGCTGTCGTCAGCTCGTGTTGTGAAATGTTGGGTTAAGTCCCGCAACGAGCGCAACCCTTATCC

\begin{tabular}{|l|ll|l|l|}
\hline $\mathrm{U} 1053 \mathrm{~F}$ & 1130 & 2140 & U1115R/U1098F & 1180 \\
\hline
\end{tabular}

TTTGTTGCCAGCGGTCCGGCCGGGAACTCAAAGGAGACTGCCAGTGATAAACTGGAGGAAGGTGGGGATG

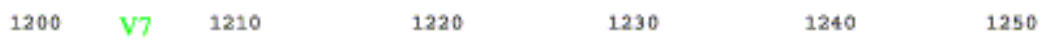

ACGTCAAGTCATCATGGCCCTTACGACCAGGGCTACACACGTGCTACAATGGCGCATACAAAGAGAAGCG

$\begin{array}{llllll}1270 & 1280 & 1290 & 1300 & 1310 & 1320\end{array}$

ACCTCGCGAGAGCAAGCGGACCTCATAAAGTGCGTCGTAGTCCGGATTGGAGTCTGCAACTCGACTCCAT

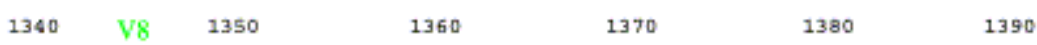

GAAGTCGGAATCGCTAGTAATCGTGGATCAGAATGCCACGGTGAATACGTTCCCGGGCCTTGTACACACC

1410

1420

1430

1440

1450

\begin{tabular}{l|l|l}
\hline 1460 & $\mathrm{U} 1406 / 15$ \\
\hline
\end{tabular}

GCCCGTCACACCATGGGAGTGGGTTGCAAAAGAAGTAGGTAGCTTAACCTTCGGGAGGGCGCTTACCACT

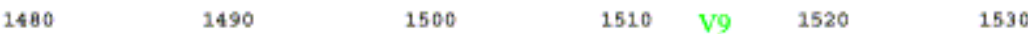

TTGTGATTCATGACTGGGGTGAAGTCGTAACAAGGTAACCGTAGGGGAACCTGCGGTTGGATCACCTCCT

\begin{tabular}{l|l|l|l|l}
\hline U1510R & & E1541R & \\
\hline
\end{tabular}

TA

Figure B1 $E$. coli $16 \mathrm{~S}$ rRNA gene sequence annotated with bacteria and "universal" priming sites and variable regions V1-V9. From Baker et al. (2003). 
Chapter 2, 4: Primers for Quantitative PCR

Table B12 Primers trailed for quantitative PCR targeting genes involved in nitrogen and carbon cycles, and light energy utilisation.

\begin{tabular}{|c|c|c|c|}
\hline Gene & $\begin{array}{l}\text { Primer } \\
\text { name }\end{array}$ & Primer sequence $\left(5^{\prime}-3^{\prime}\right)$ & Reference \\
\hline \multirow[t]{4}{*}{ Nitrite reductase } & nirk-q-F & TCATGGTGCTGCCGCGYGA & \multirow[t]{4}{*}{ Braker et al. 1998} \\
\hline & nirk-1040 & GCCTCGATCCGRTTRTGGTT & \\
\hline & nirS1F & $\operatorname{CCTA}(\mathrm{C} / \mathrm{T}) \mathrm{TGGCCGCC}(\mathrm{A} / \mathrm{G}) \mathrm{CA}(\mathrm{A} / \mathrm{G}) \mathrm{T}$ & \\
\hline & nirS-q-R & TCCMAGCCRCCRTCRTGCAG & \\
\hline $\begin{array}{l}\text { Ammonia } \\
\text { monooxygenase }\end{array}$ & amoA-1F & GGGGTTTCTACTGGTGGT & $\begin{array}{l}\text { Rotthauwe et al. } \\
1997\end{array}$ \\
\hline$\beta$-proteobacteria & amoA-2R & CCCCTCBGSAAAVCCTTCTTC & \multirow[t]{3}{*}{ Hornek et al. 2006} \\
\hline \multirow[t]{2}{*}{$\gamma$-proteobacteria } & amoA-3F & GGT GAG TGG GYT AAC MG & \\
\hline & amoB-4R & GCT AGC CAC TTT CTG G & \\
\hline $\begin{array}{l}\text { Nitrogenase } \\
\text { reductase }\end{array}$ & nifH-1F & CGGTAGAGGATCTTGAGCTTGAA & $\begin{array}{l}\text { Moisanader et al. } \\
2008\end{array}$ \\
\hline$\gamma$ - proteobacteria & nifH-2R & AAGTGCTTAAGGTTGGCTTTGGCGACA & \multirow{5}{*}{$\begin{array}{l}\text { Langlois et al. } \\
2008\end{array}$} \\
\hline \multirow[t]{2}{*}{$\beta$ proteobacteria } & $\mathrm{NifH}-3 \mathrm{~F}$ & ACCTCGATCAACATGCTCGAA, & \\
\hline & $\mathrm{NifH}-4 \mathrm{R}$ & GCAGACCACGTCACCCAGTAC & \\
\hline \multirow[t]{2}{*}{ Cluster III } & $\mathrm{NifH}-5 \mathrm{~F}$ & TCTGATCCTGAACTCCAAAGCA & \\
\hline & $\mathrm{NifH}-6 \mathrm{R}$ & ACCGTGCTGCACCTGGCCG & \\
\hline \multirow{2}{*}{ RuBisCO } & cbbl-595f & GACTTCACCAAAGACGACGA & \multirow{2}{*}{$\begin{array}{l}\text { Giri and } \\
\text { Hollibaugh } 2004\end{array}$} \\
\hline & cbbl-1387r & TCGAACTTGATTTCTTTCCA & \\
\hline \multirow[t]{4}{*}{$\begin{array}{l}\text { Proteorhodopsin } \\
\text { (PR) }\end{array}$} & RYIDWF & MGNTAYATHGAYTGG & \multirow[t]{4}{*}{$\begin{array}{l}\text { Atamna-Ismaeel } \\
\text { et al. } 2008\end{array}$} \\
\hline & GWAIYPR & GGNTGGGCNATHTAYCCN & \\
\hline & PR-Sar11F & ATGAAAAACTTAAACTGTTT & \\
\hline & PR-Sar11R & TGCAGCAGCCCAGATTACT & \\
\hline \multirow[t]{4}{*}{ pufM } & pufM.557F & CGCACCTGGACTGGAC & \multirow[t]{2}{*}{$\begin{array}{l}\text { Achenbach et al. } \\
2001\end{array}$} \\
\hline & pufM.750R & CCCATGGTCCAGCGCCAGAA & \\
\hline & pufM_uniF & GGNAAYYTNTWYTAYAAYCCNTTYCA & \multirow{2}{*}{ Yutin et al. 2005} \\
\hline & pufM_uniR & YCCATNGTCCANCKCCARAA & \\
\hline \multirow[t]{5}{*}{$\begin{array}{l}\text { Chitinase (family } \\
\text { 18) }\end{array}$} & ChiA-F1 & ACG GCG TGG ACA TCG AYT GGG ART & \multirow[t]{5}{*}{ Lian et al. 2007} \\
\hline & ChiA-R1 & CCC AGG CGC CGT AGA RRT CRT AYS & \\
\hline & ChiA-F2 & CGT GGA CAT CGA CTG GGA RTW YCC & \\
\hline & & CCC AGG CGC CGT AGA RRT CRT ARS & \\
\hline & ChiA-R2 & WCA & \\
\hline \multirow[t]{2}{*}{ 16S rRNA } & ARCH1017F & GAGAGGWGGTGCATGGCC & \multirow[b]{2}{*}{ Suzuki et al. 2000} \\
\hline & ARCH1392R & TGACGGGCGGTGTGTGCTTG & \\
\hline \multirow[t]{2}{*}{ 16S rRNA } & BAC518F & CCAGCAGCCGCGGTAATACG & \multirow[t]{2}{*}{ Universal } \\
\hline & BAC800R & TACCAGGGTATCTAATCC & \\
\hline
\end{tabular}




\section{A/ppendiso 8}

\section{Additional research}

During the course of this $\mathrm{PhD}$ research, I have also involved in a number of additional studies. In each of the papers I was actively involved in aspects of data collection, molecular laboratory data analyses, statistical analyses and writing manuscripts. These papers are:

Yiling EK, Atamna-Ismaee N, Martin AR, Cowie ROM, Beja O, Davy SK, Maas EW, Ryan KG (2010) Proteorhodopsin-bearing bacteria in Antarctic sea ice. Applied and Environmental Microbiology 76 (17): 5918-5925

Williams GJ, Aeby GS, Cowie ROM, Davy SK (2010) Explanatory models of coral disease occurrence within a reef system: a multivariate approach. Plos 1 5(2): e9264

Ryan KG, Cowie ROM, Liggins L, McNaughtan D, Martin A, Davy SK (2009) The Short-Term Effect of Irradiance on the Photosynthetic Properties of Antarctic Fast-Ice Microalgal Communities. J Phycol 45: 1290-1298

Stat M, Pochon X, Cowie ROM, Gates RD (2009) Symbiodinium community signatures from coral at Johnston Atoll using nuclear ITS2 and chloroplast 23S rDNA genes reveal similar patterns in host specificity. MEPS 386: 83-96 